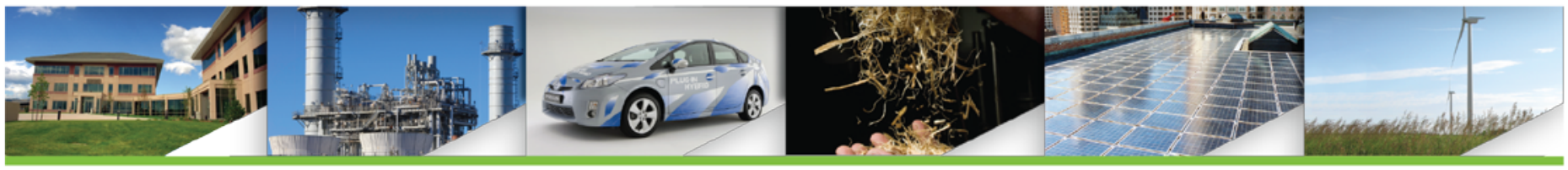

\title{
The Economic Potential of Two Nuclear-Renewable Hybrid Energy Systems
}

Mark Ruth, Dylan Cutler, Francisco Flores-Espino, Greg Stark, Thomas Jenkin, Travis Simpkins, and Jordan Macknick National Renewable Energy Laboratory

The Joint Institute for Strategic Energy Analysis is operated by the Alliance for Sustainable Energy, LLC, on behalf of the U.S. Department of Energy's National Renewable Energy Laboratory, the University of Colorado-Boulder, the Colorado School of Mines, the Colorado State University, the Massachusetts Institute of Technology, and Stanford University.

Technical Report

NREL/TP-6A50-66073

August 2016

Contract No. DE-AC36-08GO28308 


\title{
The Economic Potential of Two Nuclear-Renewable Hybrid Energy Systems
}

\author{
Mark Ruth, Dylan Cutler, \\ Francisco Flores-Espino, Greg Stark, \\ Thomas Jenkin, Travis Simpkins, \\ and Jordan Macknick \\ National Renewable Energy Laboratory
}

Prepared under Task No. SA15.1002

The Joint Institute for Strategic Energy Analysis 15013 Denver West Parkway Golden, CO 80401 303-275-3000 • www.jisea.org
The Joint Institute for Strategic Energy Analysis is operated by the Alliance for Sustainable Energy, LLC, on behalf of the U.S. Department of Energy's National Renewable Energy Laboratory, the University of Colorado-Boulder, the Colorado School of Mines, Colorado State University, the Massachusetts Institute of Technology, and Stanford University.

JISEA $^{\circledR}$ and all JISEA-based marks are trademarks or registered trademarks of the Alliance for Sustainable Energy, LLC.

\section{Technical Report}

NREL/TP-6A50-66073

August 2016

Contract No. DE-AC36-08GO28308 


\title{
NOTICE
}

This report was prepared as an account of work sponsored by an agency of the United States government. Neither the United States government nor any agency thereof, nor any of their employees, makes any warranty, express or implied, or assumes any legal liability or responsibility for the accuracy, completeness, or usefulness of any information, apparatus, product, or process disclosed, or represents that its use would not infringe privately owned rights. Reference herein to any specific commercial product, process, or service by trade name, trademark, manufacturer, or otherwise does not necessarily constitute or imply its endorsement, recommendation, or favoring by the United States government or any agency thereof. The views and opinions of authors expressed herein do not necessarily state or reflect those of the United States government or any agency thereof.

This report is available at no cost from the National Renewable Energy Laboratory (NREL) at www.nrel.gov/publications.

Available electronically at SciTech Connect http:/www.osti.gov/scitech

Available for a processing fee to U.S. Department of Energy and its contractors, in paper, from:

\author{
U.S. Department of Energy \\ Office of Scientific and Technical Information \\ P.O. Box 62 \\ Oak Ridge, TN 37831-0062 \\ OSTI http://www.osti.gov \\ Phone: 865.576.8401 \\ Fax: 865.576.5728 \\ Email: reports@osti.gov
}

Available for sale to the public, in paper, from:

\author{
U.S. Department of Commerce \\ National Technical Information Service \\ 5301 Shawnee Road \\ Alexandria, VA 22312 \\ NTIS http://www.ntis.gov \\ Phone: 800.553 .6847 or 703.605 .6000 \\ Fax: 703.605.6900 \\ Email: orders@ntis.gov
}

Cover Photos: (left to right) PIX 04135, iStock 22779761, PIX 16933., PIX 15648, PIX 08466, PIX 21205

NREL prints on paper that contains recycled content. 


\section{Preface}

Changes are occurring throughout the U.S. economy, especially in regards to how energy is generated and used in the electricity, buildings, industrial, and transportation sectors. These changes are being driven by environmental and energy security concerns and by economics. The electric-sector market share of natural gas and variable renewable generation, such as wind and solar photovoltaics (PV), continues to grow. The buildings sector is evolving to meet efficiency standards, the transportation sector is evolving to meet efficiency and renewable fuels standards, and the industrial sector is evolving to reduce emissions. Those changes are driving investment and utilization strategies for generation and other assets.

Nuclear and renewable energy sources are important to consider in the energy sector's evolution because both are considered to be clean and non-carbon emitting energy sources. The Idaho National Laboratory (INL) and National Renewable Energy Laboratory (NREL) are jointly investigating potential synergies between technologies exploiting nuclear and renewable energy sources. The two laboratories have held several joint workshops since 2011. Those workshops brought together experts in both areas to identify synergies and potential opportunities to work together. Workshop participants identified nuclear-renewable hybrid energy systems (N-R HESs) as one of the opportunities and recommended investigating whether N-R HESs could both generate dispatchable electricity without carbon emissions and provide clean energy to industrial processes. They also recommended analyzing the potential for N-R HESs to provide dispatchable capacity to a grid with high penetrations of non-dispatchable resources and to investigate whether real inertia provided by thermal power cycles within N-R HESs provides value to the grid.

This report is one of a series of reports INL and NREL are producing to investigate the technical and economic aspects of N-R HESs. It provides results of an analysis of two N-R HES scenarios. The first is a Texas-synthetic gasoline scenario that includes four subsystems including a nuclear reactor, thermal power cycle, wind power plant, and synthetic gasoline production technology. The second is an Arizona-desalination scenario with its four subsystems a nuclear reactor, thermal power cycle, PV, and a desalination plant. INL analyzed the technical performance of the same two N-R HESs in a previous report. Future analyses are planned for other N-R HES options. 


\section{Acknowledgments}

The authors thank the Office of Strategic Programs within the U.S. Department of Energy's (DOE's) office of Energy Efficiency and Renewable Energy (EERE) for their support of this analysis and report and Gian Porro for his management of NREL's work for EERE's Office of Strategic Programs. The authors also thank those who originated and developed the concept of nuclear-renewable hybrid energy systems: Charles Forsberg of the Massachusetts Institute of Technology (MIT); Richard Boardman, Shannon Bragg-Sitton, Humberto Garcia, and Bob Cherry of INL; and Owen Zinaman of NREL. And we acknowledge and thank the following individuals for their reviews and comments: Doug Arent of the Joint Institute for Strategic Energy Analysis (JISEA); Dave Mooney, Gian Porro, Ron Schoon, Bryan Pivovar, Keith Wipke, Mary Werner, and Robin Newmark of NREL; Steve Capanna and Paul Spitsen of EERE; Carl Sink of DOE's Office of Nuclear Energy (NE); Richard Boardman, Shannon Bragg-Sitton, Humberto Garcia, Michael McKeller, and Piyush Sabharwall of INL; Lou Qualls and colleagues at the Oak Ridge National Laboratory; Dan Ingersoll of NuScale Energy; Charles Forsberg of MIT; Marco Cometto of The Organization for Economic Cooperation and Development Nuclear Energy Agency; Willian D'Haeseleer of the University of Leuven; Sherry Bernhoft and Robin Bedilion of Electric Power Research Institute; and Pete Lyons, retired from NE.

This work was supported by DOE under Contract No. DE-AC36-08GO28308 with NREL. Funding was provided by EERE's Office of Strategic Programs. 


\section{Acronyms}

\begin{tabular}{|c|c|}
\hline $\mathrm{AEO}$ & Annual Energy Outlook \\
\hline bbl & barrel \\
\hline Btu & British thermal units \\
\hline capex & capital expenditure \\
\hline $\mathrm{CC}$ & natural gas combined cycle \\
\hline $\mathrm{CF}$ & capacity factor \\
\hline CT & combustion turbine \\
\hline $\mathrm{DOE}$ & U.S. Department of Energy \\
\hline EERE & DOE Office of Energy Efficiency and Renewable Energy \\
\hline EIA & U.S. Energy Information Agency \\
\hline EPA & U.S. Environmental Protection Agency \\
\hline FOM & figures of merit \\
\hline gal & gallon \\
\hline GHG & greenhouse gas \\
\hline GT & gas turbine \\
\hline $\mathrm{HHV}$ & higher heating value \\
\hline INL & Idaho National Laboratory \\
\hline IRR & internal rate of return \\
\hline $\mathrm{kW}$ & kilowatt \\
\hline kW-yr & kilowatt-year \\
\hline $\mathrm{LCOE}$ & levelized cost of energy \\
\hline LW-SMR & light-water small modular reactor \\
\hline MIT & Massachusetts Institute of Technology \\
\hline mmBtu & million British thermal units \\
\hline MWe & megawatt electrical \\
\hline MWh & megawatt-hour \\
\hline MWt & megawatt thermal \\
\hline NGCC & natural gas combined cycle \\
\hline NPV & net present value \\
\hline N-IP & nuclear reactor and industrial process \\
\hline N-R HES & nuclear-renewable hybrid energy system \\
\hline N-TPC & nuclear reactor and thermal power cycle \\
\hline NREL & National Renewable Energy Laboratory \\
\hline O\&M & operations and maintenance \\
\hline PV & photovoltaic \\
\hline $\mathrm{RE}$ & renewable energy subsystem \\
\hline REopt & Renewable Energy Optimization (planning platform) \\
\hline $\mathrm{RO}$ & reverse osmosis \\
\hline RPS & renewable portfolio standard \\
\hline RPS80 & An RPS scenario that results in $80 \%$ renewables by 2050 \\
\hline SMR & small modular reactor \\
\hline TCI & total capital investment \\
\hline VRE & variable renewable electricity \\
\hline WACC & weighted average cost of capital \\
\hline
\end{tabular}




\section{Executive Summary}

Changes are occurring throughout the U.S. economy, especially in regards to how energy is generated and used in the electricity, buildings, industrial, and transportation sectors. These changes are being driven by environmental and energy security concerns and by economics. The electric-sector market share of natural gas and variable renewable generation, such as wind and $\mathrm{PV}$, continues to grow. The buildings sector is evolving to meet efficiency standards, the transportation sector is evolving to meet efficiency and renewable fuels standards, and the industrial sector is evolving to reduce emissions. Those changes are driving investment and utilization strategies for generation and other assets. Policy and regulatory dynamics are also incentivizing generation portfolios with fewer greenhouse gas (GHG) emissions. With these motivations, analysts are working to understand implications of near-term goals and identify pathways that achieve deep decarbonization.

Tightly coupled N-R HESs are an option that can generate zero-carbon, dispatchable electricity and provide zero-carbon energy for industrial processes at a lower cost than alternatives. N-R HESs are defined as systems that are managed by a single entity and link a nuclear reactor that generates heat, a thermal power cycle for heat-to-electricity conversion, at least one renewable energy source, and an industrial process that uses thermal and/or electrical energy. They produce multiple products and can dynamically vary the amount of each produced. Because of that flexibility, N-R HESs are potentially advantageous over traditional technologies that produce a single product and use a minimal number of energy sources.

For example, an N-R HES can produce electricity at times when its value is higher than that of the industrial product and produce the industrial product when its value is higher than that of electricity. An N-R HES can also produce both electricity and the industrial product during hours when electricity services such as regulation or flexibility reserves are valuable but the value of electrical energy alone is lower than that of the industrial product. Potential benefits of N-R HESs include the ability to generate dispatchable, flexible, zero-carbon electricity that can support the grid's resource adequacy requirements; zero-carbon energy sources for industry; real inertia to support the grid; and alleviation of the impacts of price suppression. The costs and economic benefits of such N-R HESs have yet to be fully evaluated, and this report summarizes initial evaluations.

This report provides the results of an analysis of two N-R HES scenarios. The first is a Texassynthetic gasoline scenario that includes four subsystems: a nuclear reactor, a thermal power cycle, a wind power plant, and synthetic gasoline production technology. The second is an Arizona-desalination scenario with four subsystems a nuclear reactor, thermal power cycle, PV, and a desalination plant. The analysis focuses on the economics of the N-R HESs and how they compare to other options, including configurations without all the subsystems in each N-R HES and alternatives where the energy is provided by natural gas. This analysis builds upon a previous analysis performed by the Idaho National Laboratory (INL that focused on dynamic operability and performance of the same two N-R HES options and treated financial performance as a secondary objective. INL's team found that both N-R HESs can potentially meet operational requirements necessary to provide flexibility and that each is projected to be profitable. ${ }^{1}$ In this report, we assumed the configurations would be operable and focused on identifying the financially optimal configurations and operating schemes. 
We tested five hypotheses regarding the potential benefits of the N-R HES in each of the two scenarios:

1. The N-R HES configurations analyzed have the potential to be profitable to investors and are likely to be more profitable than uncoupled configurations.

2. Using nuclear-generated heat in an N-R HES can economically reduce GHG emissions from industry. If a cost of carbon is included in the economic analyses, the N-R HES will have a lower cost than competing uncoupled natural gas configurations.

3. N-R HESs can support resource adequacy for the electric grid while maximizing production of a more profitable industrial product if the market structures incentivize that option.

4. N-R HESs will be more profitable than uncoupled configurations because they can produce electricity when its price is high and the industrial product when the price of electricity is low.

5. The internal flexibility of N-R HESs makes them beneficial as a hedge against changing and uncertain future prices.

We used REopt, the NREL-developed energy planning platform, to optimize the design (i.e., identify the optimal subsystem configurations) and operation of each N-R HES. REopt's optimization was set to maximize the N-R HES's net present value (NPV) over the analysis period based on capital costs, operating costs, conversion efficiencies, product prices, and financial assumptions. Capital, fixed operating costs, and efficiencies for the nuclear reactor, thermal power cycle, renewable electricity generation, and the industrial process are from other published reports. We did not include a cost of carbon in the base case; however, we priced carbon in some sensitivity cases. We set the REopt inputs for the price of electrical energy and reserve products to marginal costs generated using the PLEXOS production cost model. PLEXOS performs a security-constrained, least-cost economic dispatch of generation assets to identify the least-cost option to serve the loads subject to operational constraints on a generation mix with a high penetration of variable renewable electricity (VRE) generation, as described in Section 2.3. We included a capacity payment for configurations selling electricity to the grid during the highest load hours. We estimated water and gasoline product prices based on a water supply curve developed from proposed projects and published gasoline price projections, respectively.

Our analysis partly supports hypothesis \#1. The full N-R HES configurations of both the Texassynthetic gasoline and Arizona-desalination scenarios are projected to be profitable under the base case parameters; however, the full N-R HES configurations are not projected to be as profitable as alternative configurations that produce the industrial product but not electricity. Table ES-1 shows that the Texas scenario's full N-R HES (the right column in the Texassynthetic gasoline section) is profitable; however, a reduced configuration with only a nuclear reactor and the synthetic gasoline subsystem (the left column in the Texas-synthetic gasoline section) is more profitable. In addition, the nuclear-industrial process configuration has a lower total capital investment (TCI). The combination results in an internal rate of return (IRR) of $25 \%$, which is higher than the $24 \%$ IRR of the full N-R HES configuration. The significance of the difference between those values is dependent upon the investor's profile; however, the reduced nuclear-industrial process configuration may to be more attractive to many investors due 
to the lower capital investment and higher net present value (NPV). We also provide the NPV/TCI ratio as an alternative method to assess profitability because it shows the impact of the size of capital investments instead of varying the discount rate for the different configurations. Adding electricity generation to the nuclear reactor-synthetic gasoline configuration does not increase the NPV unless the value of electricity is higher than the base case parameters. An electricity price multiplier of 1.25 is necessary for wind generation to increase the NPV and 1.3 for nuclear-generated electricity to increase it.

Table ES-1 also shows that the Arizona-desalination scenario's full N-R HES configuration (the right column in the Arizona-desalination section) is profitable but, like the Texas-synthetic gasoline scenario, a reduced configuration is more profitable. The reduced configuration also has a lower TCI. The combination makes both the IRR and the NPV/TCI ratio higher than the full NR HES so the reduced configuration is likely to be more attractive to investors. Unlike the Texassynthetic gasoline scenario, under a grid mix with a lower PV penetration or by including a cost of carbon for natural gas power generation, the most profitable configuration for the Arizonadesalination scenario includes all subsystems: the nuclear reactor, a thermal power cycle, a desalination unit, and PV generation. In those cases, co-management of the PV subsystem with flexible nuclear generation allows the PV subsystem to benefit from the increased value provided by water production.

Table ES-1. Financial Results of Two N-R HES Scenarios Compared to Alternative Configurations

\begin{tabular}{|c|c|c|c|c|}
\hline Scenario & Texas-Sy & tic Gasoline & Arizona & salination \\
\hline Configuration & $\begin{array}{l}\text { Nuclear } \\
\text { Reactor } \\
\text { (167 MWt) } \\
\quad+ \\
\text { Industrial } \\
\text { Process } \\
\text { (167 MWt) }\end{array}$ & 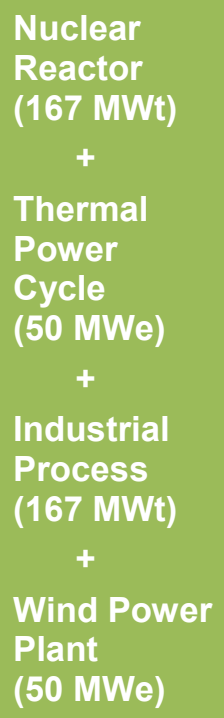 & $\begin{array}{c}\text { Nuclear } \\
\text { Reactor } \\
(167 \mathrm{MWt}) \\
\quad+ \\
\text { Thermal } \\
\text { Power } \\
\text { Cycle } \\
\text { (50 MWe) } \\
\quad+ \\
\text { Industrial } \\
\text { Process } \\
\text { (50 MWe) }\end{array}$ & $\begin{array}{c}\text { Nuclear } \\
\text { Reactor } \\
\text { (167 MWt) } \\
\quad+ \\
\text { Thermal } \\
\text { Power } \\
\text { Cycle } \\
\text { (50 MWe) } \\
\quad+ \\
\text { Industrial } \\
\text { Process } \\
\text { (50 MWe) } \\
\quad+ \\
\text { PV Plant } \\
\text { (50 MWe) }\end{array}$ \\
\hline NPV (\$ million) & $\$ 3,699$ & $\$ 3,631$ & $\$ 3,164$ & $\$ 3,151$ \\
\hline IRR & $25 \%$ & $24 \%$ & $48 \%$ & $46 \%$ \\
\hline TCI (\$ million) & $\$ 2,507$ & $\$ 2,657$ & $\$ 765$ & $\$ 820$ \\
\hline NPV/TCI Ratio & 1.48 & 1.37 & 4.14 & 3.84 \\
\hline
\end{tabular}

$\mathrm{MWt}=$ megawatt thermal

$\mathrm{MWe}=$ megawatt electrical 
Our analysis supports hypothesis \#2. The analysis shows that for both scenarios analyzed, industrial processes using nuclear-generated energy can be more profitable if a cost of carbon is included. The Texas-synthetic gasoline scenario's configuration with only the nuclear reactor and industrial process has an NPV of $\$ 3,699$ million, an IRR of $25 \%$, and an NPV/TCI ratio of 1.48. Replacing the nuclear reactor with a natural gas boiler reduces the NPV to $\$ 3,600$ million and does not change the IRR but it increases the NPV/TCI ratio to 1.55. Although the natural gas-heated system has less profit (lower NPV), it is likely to be more attractive to investors who are concerned about the uncertainty of recovering their capital investment due to the higher NPV/TCI ratio. The U.S. government provides four sets of social costs of carbon for analyses for regulatory analyses because the cost of climate-related impacts is uncertain. ${ }^{2}$ For most analyses, we used the 2035 value with a 3\% discount rate-\$61/metric ton $\mathrm{CO}_{2}$. The natural gas-heated synthetic gasoline configuration emits 281,000 metric tons of $\mathrm{CO}_{2}$ annually. If that configuration is assessed a $\$ 61 /$ metric ton $\mathrm{CO}_{2}$, its NPV is $\$ 3,520$ million and its NPV/TCI ratio is 1.45 ; thus, the nuclear-industrial process is both more profitable and may be more attractive to investors at that cost of carbon.

Using a natural gas combined cycle (NGCC) to produce the electric power for desalination results in emissions of 153,000 metric tons $\mathrm{CO}_{2}$ annually. Using the $\$ 61 /$ metric ton $\mathrm{CO}_{2}$ cost of carbon, the NPV for the nuclear-powered process is slightly higher than the NGCC-powered process - $\$ 3.16$ billion as compared to $\$ 3.08$ billion; however, at $48 \%$ the IRR for the nuclearpowered process is lower than that of the NGCC-powered process, which is $60 \%$. Thus, a high cost of carbon may be necessary to make the nuclear-desalination configuration more attractive than one powered by an NGCC.

Our analysis supports hypothesis \#3 in the Arizona-desalination scenario but not in the Texassynthetic gasoline scenario under the base case parameters and the capacity payments used in this analysis. The analysis of the Texas-synthetic gasoline N-R HES does not identify any condition where either a capacity payment or high electrical energy prices result in selling electricity to support electricity resource adequacy instead of maximizing production of synthetic gasoline. This is because synthetic gasoline is a more valuable product than electricity, and electricity generation requires a thermal power cycle, which is an additional investment. The capital cost for the thermal power cycle (and the opportunity costs of not generating gasoline during hours when the N-R HES generates electricity instead of producing gasoline) disincentivizes the nuclear-synthetic gasoline configuration from participating in the capacity markets.

The Arizona-desalination system is likely to optimally generate sufficient electricity to receive the capacity payment while maximizing production of water (a more profitable product) the majority of the year with a $\$ 50 /$ kilowatt-year $(\mathrm{kW}-\mathrm{yr})$ capacity payment, provided the water price is between $\$ 1.15 /$ thousand gallons (gal) and $\$ 3.50$ /thousand gal (i.e., high enough for the desalination unit to be profitable, but not so high that the opportunity cost of not producing water is greater than the value of electricity, including the capacity payment). At higher capacity payments, the Arizona-desalination scenario is likely to optimally generate electricity to receive the capacity payments. The key difference between the two scenarios is that the desalination scenario inherently includes a thermal power cycle, so electricity production requires no additional capital cost. 
Our analysis does not support hypothesis \#4. The analysis indicates that no configurations in the Texas-synthetic gasoline scenario realize sufficient value from the capacity payments to include the thermal power cycle necessary for a system capable of switching without decreasing its NPV; hence, the configuration with the maximum NPV is unlikely to select between products. The Arizona-desalination system only switches from water desalination to electricity production as necessary to receive capacity payments under the base-case parameters. Thus, the key value provided for electricity generation is the capacity payments. Without higher electricity prices, short periods of high-priced electricity are insufficient to incentivize N-R HESs to produce additional electricity because the opportunity cost of not producing the industrial product is too high.

Our analysis partially supports hypothesis \#5. N-R HESs have internal flexibility that make them beneficial as a partial hedge against uncertain product prices. However, the benefits of using a combined system are limited by the additional capital cost of a flexible configuration when compared to a configuration with fewer subsystems; the increase in fixed operating costs over a configuration with fewer subsystems; and the reduction in capacity factors because some subsystems in the flexible configuration are not operated at all times.

In summary, this analysis shows that N-R HES configurations in the two scenarios analyzed are profitable and the key driver for each is the industrial product. For electricity production to increase each N-R HES's value, the price of electricity needs to be higher than considered in this analysis. In addition, we found co-management of the nuclear and renewable assets to be beneficial only when the VRE subsystem generates some of the electricity necessary to receive capacity payments while minimizing the reduction in production of the industrial product, as it does in the Arizona-desalination scenario. Under the limitations of this analysis, we find that full hybridization does not improve the economics of these two scenarios; however, it may be beneficial under different market conditions or for other scenarios. Additional analysis of the potential for tightly coupled nuclear and renewable energy generators to provide thermal energy for industrial processes and both thermal and electrical energy for hydrogen production would be useful, because those options introduce more potential thermal loads. In addition, improving analyses of markets may identify opportunities for N-R HESs that were not identified in this analysis. 


\section{Table of Contents}

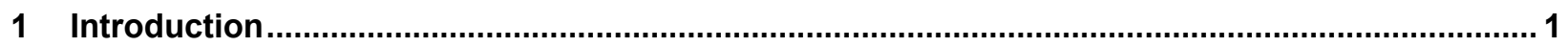

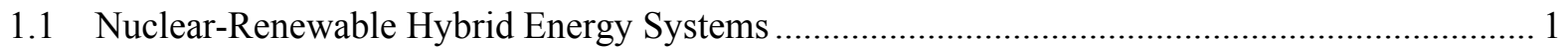

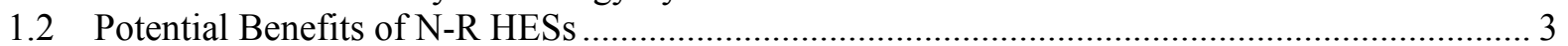

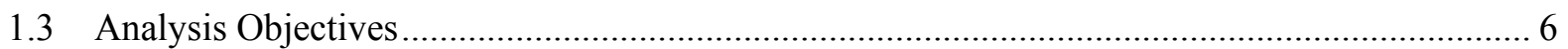

1.4 Nuclear-Renewable Hybrid Energy Systems Analyzed.................................................... 7

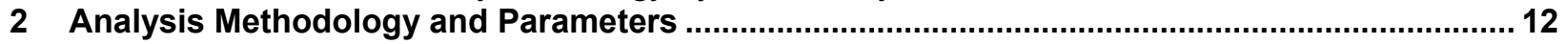

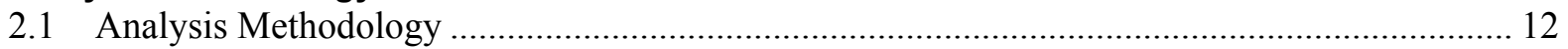

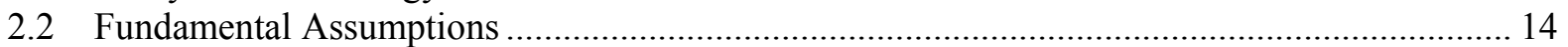

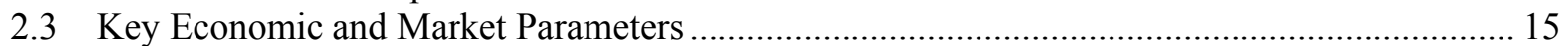

2.3.1 Methodology to Estimate Day-Ahead Electricity Prices ............................................ 15

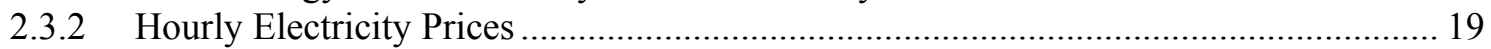

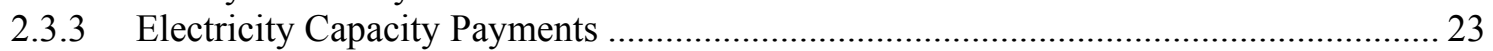

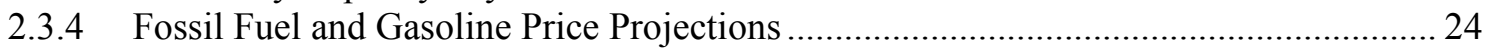

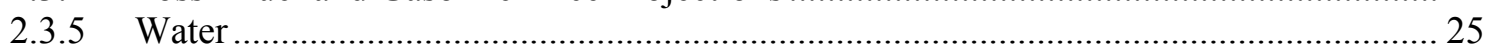

2.4 Other Financial and Performance Assumptions used in Optimization...................................... 25

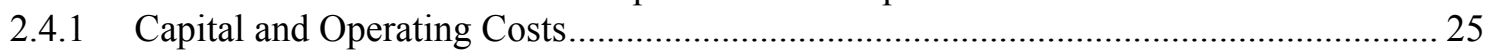

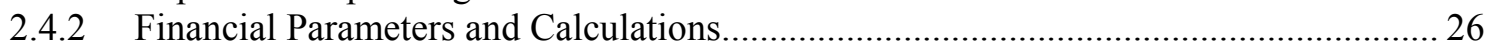

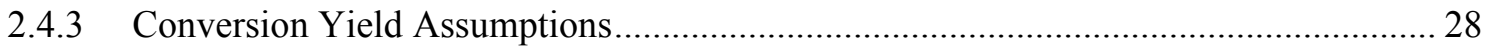

2.4.4 Levelized Cost of Energy (LCOE) Comparisons ........................................................... 28

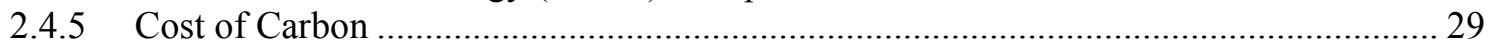

3 N-R HES Design on Operational Optimization Results ....................................................... 30

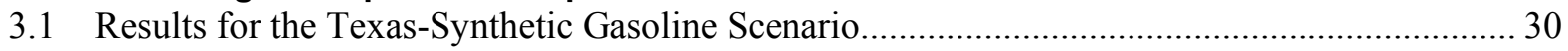

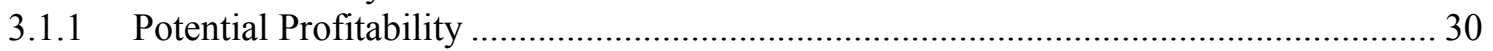

3.1.2 Potential to Reduce GHG Emissions and their Associated Costs ................................... 44

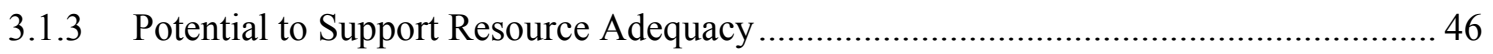

3.1.4 Potential for Flexibility to Increase Profitability ......................................................... 49

3.1.5 Potential Value of Product Flexibility to Hedge Against Uncertainty in Future Market

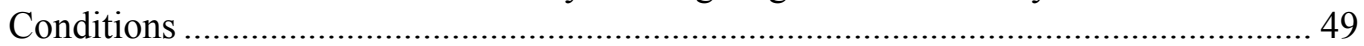

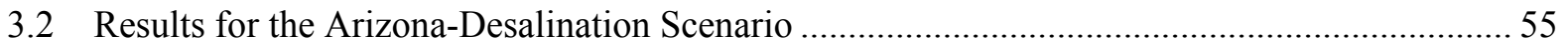

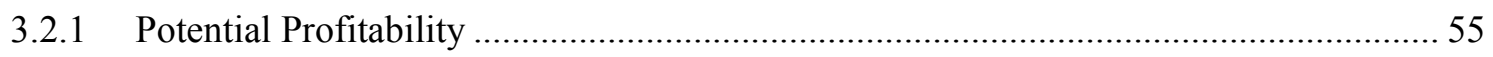

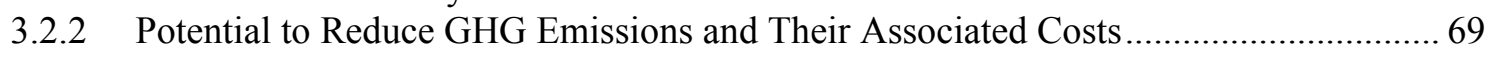

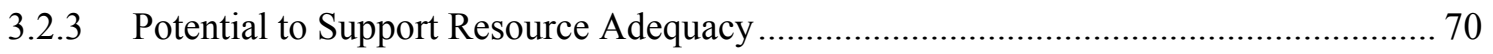

3.2.4 Potential for Flexibility to Increase Profitability ....................................................... 73

3.2.5 Potential for Flexibility to Hedge Against Uncertainty .............................................. 73

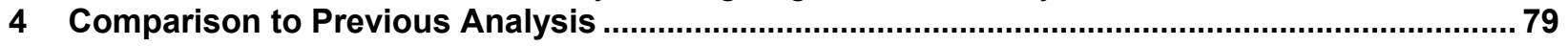

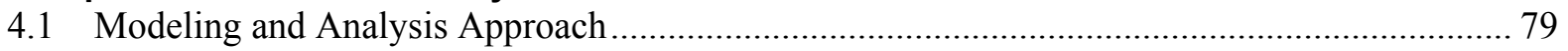

4.2 Comparison Between this Analysis and the Previous Analyses ......................................... 80

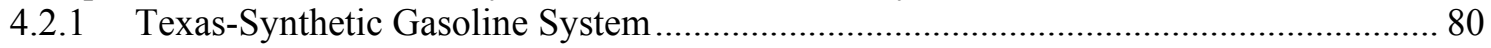

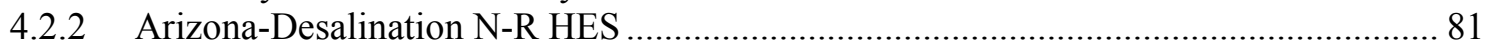

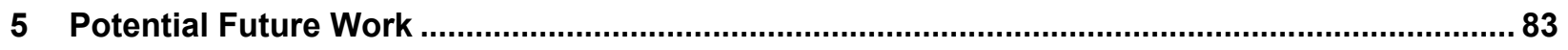

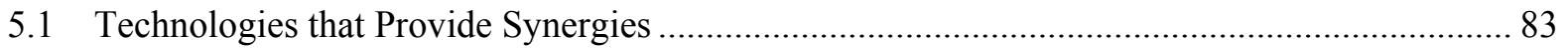

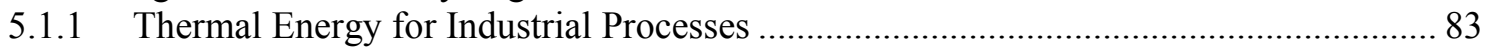

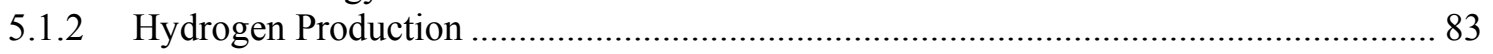

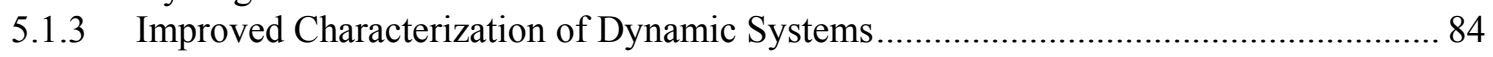

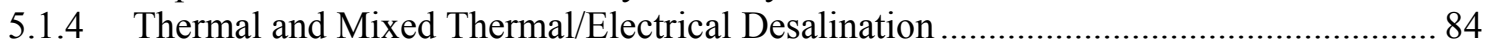

5.2 Improved Understanding Of Market Opportunities and Impacts ........................................... 86

5.2.1 Long-Run Marginal Cost Bids/Improved Electricity Pricing ................................... 86

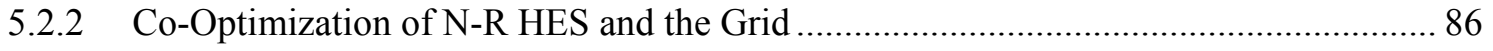

5.2.3 Identifying Deep Decarbonization Scenarios and Potential Synergies ......................... 87 


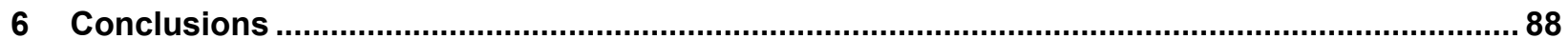

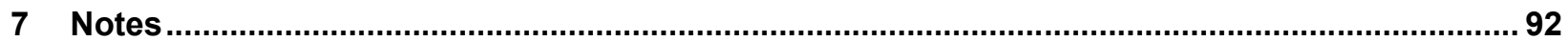

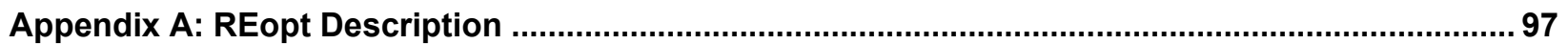

Appendix B: Additional Production Cost Modeling Details ......................................................... 100

Appendix C: Additional Information on Capacity Payments and Resource Price Estimates.........116

Appendix D: Additional Details on Fossil Fuel and Gasoline Price Projections .............................118

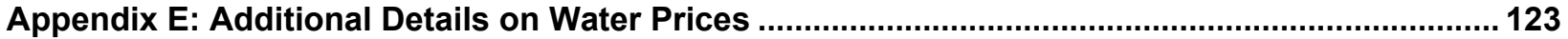

Appendix F: Additional Details on GHG Emissions ............................................................. 125

Appendix G: Additional Results from the Texas-Synthetic Gasoline Scenario ..............................126

Appendix H: Additional Results from the Arizona-Desalination Case ............................................189

Appendix I: Additional Information Comparing NREL's Analysis to INL's Analysis .......................252

\section{List of Figures and Tables}

Figure 1. Generalized N-R HES showing the system boundary and linkage to the grid ......................... 3 Figure 2. Variable renewable generation increases ramp rates and results in shorter peaks and lower turn-

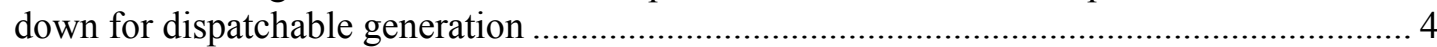

Figure 3. Price suppression impacts of several renewable generation technologies ................................. 6

Figure 4. N-R HES Scenario \#1-the synthetic fuel industrial process is expected to use thermal energy from the nuclear reactor and electricity from both the nuclear reactor and wind power plant 9

Figure 5. N-R HES Scenario \#2 - the RO desalination N-R HES is expected to use electricity from both the nuclear reactor and PV.....

Figure 6. Analysis methodology showing REopt as the central optimization engine, its inputs, and post-

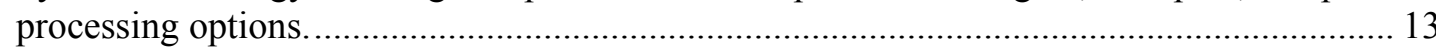

Figure 7. Generation mix by annual electrical energy production under the RPS80 scenarios for

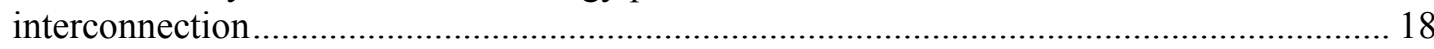

Figure 8. Generation mix by annual electrical energy production under the Current Law cases for

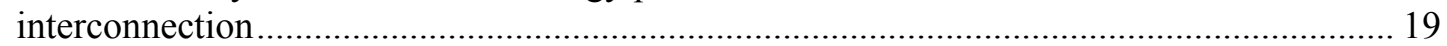

Figure 9. Texas-synthetic gasoline RPS80 scenario: electrical energy price duration curve.................... 21

Figure 10. Texas-synthetic gasoline RPS80 scenario: electrical energy price heat map .......................... 21

Figure 11. Arizona-desalination RPS80 scenario: electrical energy price duration curve..........................22

Figure 12. Arizona-desalination RPS80 scenario: electrical energy price heat map .............................. 23

Figure 13. Optimal configurations for the Texas-synthetic gasoline scenario at various gasoline prices and

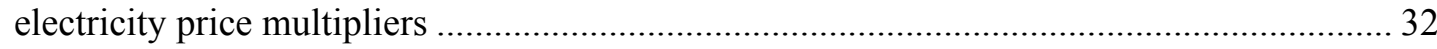

Figure 14. Optimal annual product generation at various gasoline prices and electricity price multipliers

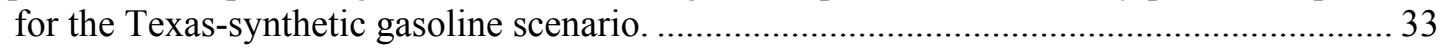

Figure 15. Texas-Synthetic Gasoline Scenario NPVs at various gasoline prices and electricity price multipliers - Electricity pricing based on AEO reference case and $\$ 50 / \mathrm{kW}$-yr capacity

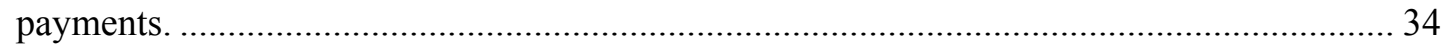

Figure 16. Optimal configurations for the Texas-synthetic gasoline scenario under the RPS80 generation mix (left) and Current Law generation mix (right) ....................................................... 40

Figure 17. Optimal configurations for the Texas-synthetic gasoline scenario AEO Reference Case Energy Prices (left) and the AEO Low-Oil Case Electricity Prices (right) ....................................... 41

Figure 18. Optimal configurations for the Texas-synthetic gasoline scenario AEO Reference Case Energy Prices (left) and prices including a cost of carbon (right) ................................................ 42

Figure 19. Optimal configurations for the Texas-synthetic gasoline scenario at a $10 \%$ nominal discount rate (left) and at an $8.15 \%$ nominal discount rate (right) ................................................... 43

Figure 20. Optimal configurations for the Texas-synthetic gasoline scenario with a 50-MWe maximum capacity of the nuclear reactor and thermal power cycle (left) and a 180-MWe maximum

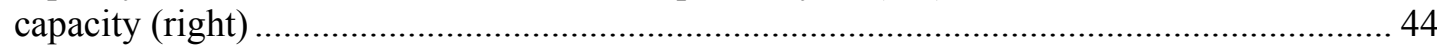


Figure 21. Optimal configurations for the Texas-synthetic gasoline scenario at various gasoline prices and electricity price multipliers at three levels of capacity payments.

Figure 22. Optimal annual electricity production for Texas-synthetic gasoline system at various gasoline prices and electricity price multipliers at three levels of capacity payments ........................ 48

Figure 23. Impacts of various combinations of futures on the discounted gross revenue minus feedstock costs of three configurations in the Texas-synthetic gasoline scenario..................................52

Figure 24. Impacts of various combinations of futures on the NPV of three configurations in the Texassynthetic gasoline scenario.

Figure 25. Impacts of various combinations of futures on the NPV/TCI ratio of three configurations in the Texas-synthetic gasoline scenario.

Figure 26. Optimal configurations for Arizona-desalination scenario at various water prices and electricity

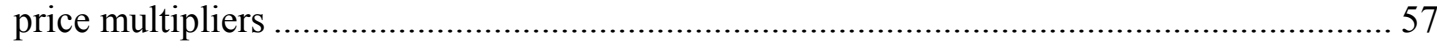

Figure 27. Optimal annual product generation at various water prices and electricity price multipliers for

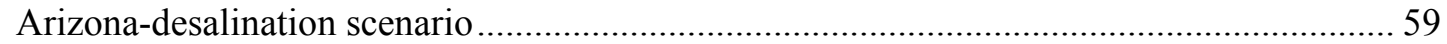

Figure 28. Arizona-Desalination NPVs at various water prices and electricity price multipliers Electricity pricing based on AEO reference case and $\$ 50 / \mathrm{kW}$-yr capacity payments.

Figure 29. Optimal configurations for the Arizona-desalination scenario under the RPS80 generation mix (left) and Current Law generation mix (right)

Figure 30. Optimal configurations for the Arizona-desalination scenario AEO Reference Case Energy Prices (left) and the AEO Low Oil Case Electricity Prices (right) 66

Figure 31. Optimal configurations for the Arizona-desalination scenario AEO Reference Case Energy Prices (left) and prices including a cost of carbon(right)

Figure 32. Optimal configurations for the Arizona-desalination scenario at a $10 \%$ nominal discount rate (left) and at an $8.15 \%$ nominal discount rate (right)

Figure 33. Optimal configurations for the Arizona-desalination scenario with a 50-MWe maximum capacity of the nuclear reactor and thermal power cycle (left) and a 180-MWe maximum capacity (right)

Figure 34. Optimal configurations for Arizona-desalination scenario at various water prices and electricity price multipliers at three levels of capacity payments.

Figure 35. Optimal annual electricity generation for Arizona-desalination scenario at various water prices and electricity multipliers at three levels of capacity payments............................................ 72

Figure 36. Impacts of various combinations of futures on the discounted gross revenue minus feedstock costs/electricity costs of three configurations in the Arizona scenario

Figure 37. Impacts of various combinations of futures on the NPV of three configurations in the Arizona water scenario

Figure 38. Impacts of various combinations of futures on the NPV/TCI ratio of three configurations in the

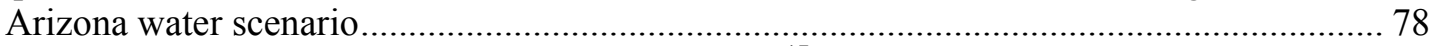

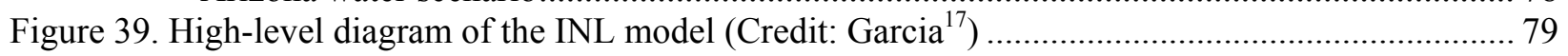

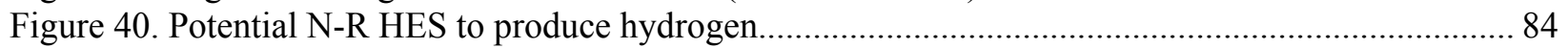

Figure 41. Schematic of desalination technologies that could be integrated with solar energy technologies

Figure 42. Diagram of membrane distillation treatment technology ................................................... 86

Table ES-1. Financial Results of Two N-R HES Scenarios Compared to Alternative Configurations.....viii

Table 1. EIA 2035 Energy Price Projections (2015 AEO - 2013\$) ........................................................2

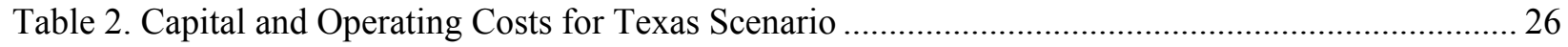

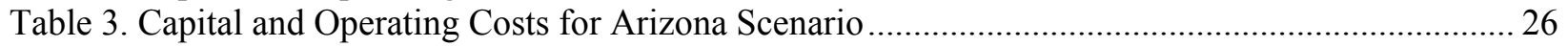

Table 4. Main Parameters Used in Our Financial Calculations ........................................................... 27

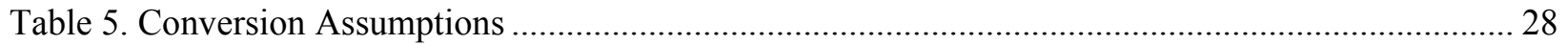

Table 6. LCOEs for Electric Power Generation Technologies (\$/MWh) ............................................... 29

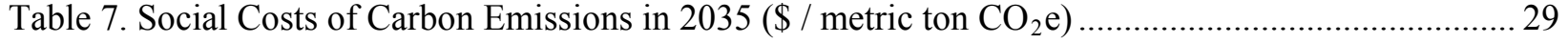


Table 8. Texas-Synthetic Gasoline Scenario Present Values at Base-Case Conditions for Three

Configurations (Negative Values Indicate Expenses and Positive Indicate Income) 36

Table 9. Texas-Synthetic Gasoline Scenario Output Summary at Base-Case Conditions for Three Configurations. 37

Table 10. Financial Comparison Between Configurations for the Texas-Synthetic Gasoline Scenario..... 38

Table 11. Financial Comparison Between Configurations for the Texas-Synthetic Gasoline Scenario,

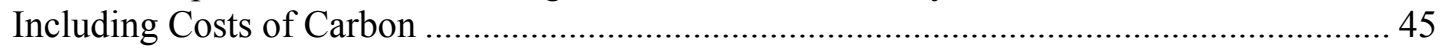

Table 12. Futures Considered for Value of Flexibility Analysis ........................................................ 50

Table 13. Percentage of Time Each Product is Produced by Configuration \#2 Under Combinations of

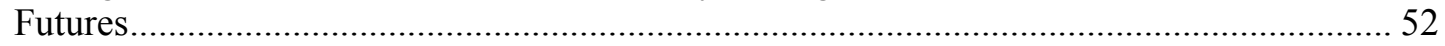

Table 14. Arizona-Desalination Scenario Present Values at Base-Case Conditions (negative values indicate expenses and positive indicate income).

Table 15. Arizona Case Output Summary at Base-Case Conditions for Two Configurations 63

Table 16. Financial Comparison Between Configurations for the Arizona-Desalination Scenario 63

Table 17. Financial Comparison Between Configurations for the Arizona-Desalination Scenario Including

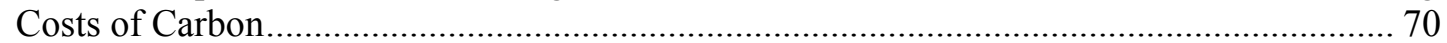

Table 18. Futures Considered for Value of Flexibility Analysis ........................................................... 74

Table 19. Percentage of Time Each Product is Produced by Configuration \#2 Under Combinations of

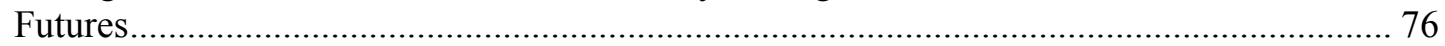

Table 20. Financial Results of Two N-R HES Scenarios Compared to Alternative Configurations.......... 89 


\section{Introduction}

Nuclear-renewable hybrid energy systems (N-R HESs) have been proposed as a technology that can generate very low-carbon, dispatchable electricity and provide very low-carbon energy to industry at a lower cost than many other options. This report provides results of an analysis of two N-R HES scenarios. The first is a Texas-synthetic gasoline scenario that includes four subsystems: a nuclear reactor, a thermal power cycle, a wind power plant, and synthetic gasoline production technology. The second is an Arizona-desalination scenario with four subsystems: a nuclear reactor, a thermal power cycle, a PV plant, and a desalination plant. The analysis focuses on the economics of the N-R HESs and how they compare to other options, including configurations without all the subsystems in each N-R HES and alternatives in which natural gas provides the energy. This section introduces N-R HESs, their possible benefits, the analysis methodology, and the two N-R HES scenarios analyzed.

\subsection{Nuclear-Renewable Hybrid Energy Systems}

Environmental, energy security, and economic concerns continue to drive change throughout the U.S. economy, especially across electric power, buildings, industry, and transportation sectors. In both regulated and restructured electric power markets, the market share of natural gas and VRE generation, such as wind and solar PV, continues to grow. That evolution is driving changes in investment and utilization strategies for generation and other assets. Policy and regulatory dynamics are also incentivizing generation portfolios with fewer GHG emissions. With these motivations, analysts are working to understand the implications of near-term goals and identify pathways that achieve deep decarbonization.

N-R HESs have been proposed as an option that can generate zero-carbon, dispatchable electricity and provide zero-carbon energy for industrial processes at a lower cost than alternatives. N-R HESs are defined as co-managed systems that link a nuclear reactor that generates heat, a thermal power cycle for heat-to-electricity conversion, at least one renewable energy source, and an industrial process that uses thermal and/or electrical energy. ${ }^{3}$ They produce multiple products and can dynamically vary the amount of each produced. Because of that flexibility, N-R HESs are potentially advantageous over traditional technologies that produce a single product and use a minimal number of energy sources. For example, an N-R HES can produce electricity at times when its value is higher than that of the industrial product and produce the industrial product when its value is higher than that of electricity. An N-R HES can also produce both electricity and the industrial product during hours when electricity services such as regulation or flexibility reserves are valuable, but the value of electrical energy alone is lower than that of the industrial product. Potential benefits of N-R HESs include the ability to generate dispatchable, flexible, zero-carbon electricity that can support the grid's resource adequacy requirements; zero-carbon energy sources for industry; real inertia to support the grid; and alleviation of the impacts of price suppression.

The U.S. electricity sector is evolving to include increased amounts of VRE generation, such as wind and solar PV, while continuing to meet the load with high reliability. Because generation from wind and $\mathrm{PV}$ is inherently variable, ${ }^{*}$ the evolving grid impacts the dispatchable generation

\footnotetext{
* Variable generation technologies can increase or decrease output unexpectedly over time (i.e., due to meteorological conditions) and their generation is not perfectly predictable.
} 
used to balance generation with load. One impact is quick and efficient generation ramping both up and down. A second impact is reduced levels of minimum generation during many hours over the year. ${ }^{4}$ These impacts affect the economics of dispatchable and baseload electricity.

Industrial emissions are also a concern. In 2013, the industrial sector, primarily using heat, directly contributed $21 \%$ of the total U.S. GHG emissions. ${ }^{5}$ Industry also used 3.26 quadrillion British thermal units of electricity, which generated additional GHG emissions. ${ }^{6}$ Combustion of coal, oil, or natural gas to generate thermal energy produces most industrial-sector emissions. The sector needs non-emitting sources of thermal energy in order to reduce its GHG emissions.

N-R HESs have been proposed to address these issues, because they have the potential to follow the grid's load (i.e., provide dispatchable electric power) while still operating key components a high percentage of the time, which is likely to improve the system's economics. Improved nuclear reactor designs and control technologies enable this capability by allowing for dynamic apportionment of heat within an integrated system. Heat not used to generate electricity can be used for energy-intensive industrial processes, reducing their use of fossil energy and subsequent GHG emissions. Linking nuclear reactors to renewable generation sources and industrial processes in close proximity to the electrical grid connection through a common relay station results in tightly coupled N-R HESs. ${ }^{7}$

Figure 1 shows a generalized, tightly coupled N-R HES. N-R HESs comprise multiple subsystems:

- A nuclear heat generator

- A power conversion subsystem (thermal power cycle) that produces electricity from thermal energy

- At least one renewable energy source

- An industrial process that utilizes thermal energy and/or electricity to produce a commodity-scale product.

Note that not all of the subsystems shown in the figure will be in every N-R HES. Instead, the NR HES configurations are likely to be location-specific and resource- and market-dependent. The renewable energy generation subsystem within a specific N-R HES depends upon resource availability. Likewise, the industrial process within a specific N-R HES depends upon regional markets and infrastructure. Energy storage (thermal and electrical) depends upon the requirements of subsystems (especially the industrial process), the generation profile, and electricity markets. The N-R HES hierarchical controller controls all aspects of the system within the boundary. 


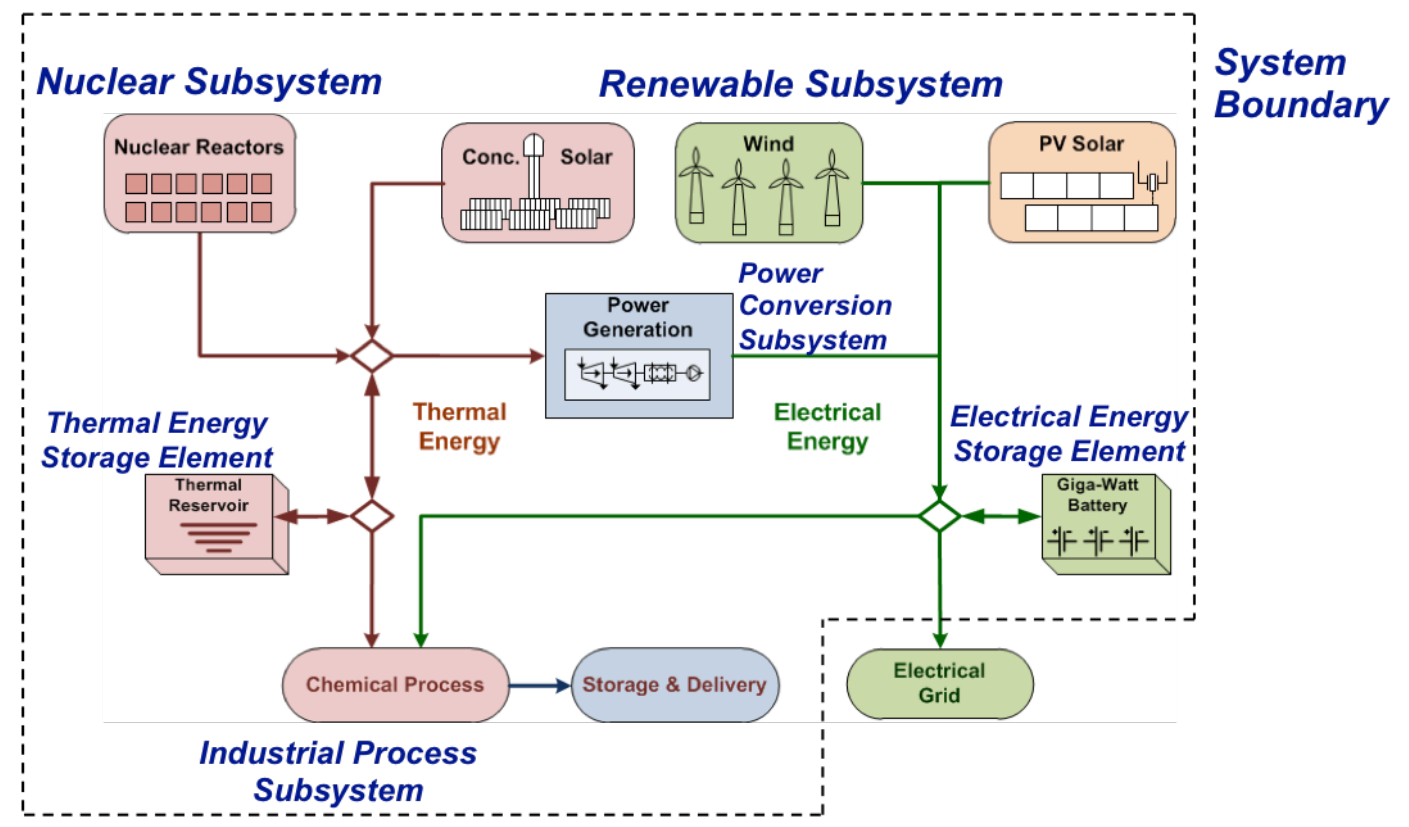

Figure 1. Generalized N-R HES showing the system boundary and linkage to the grid

The N-R HES Technology Development Program Plan discusses three options: ${ }^{8}$

1. Tightly Coupled N-R HES: all subsystems are directly coupled (i.e., linked to one another without regularly operated connections to outside entities such as the grid or thermal customers) behind a single bus to the grid and are co-managed by a single financial entity.

2. Thermally Coupled N-R HES: thermal connections are directly coupled but electrical connections may utilize the grid for physical connections. The subsystems are comanaged by a single financial entity to provide electrical energy and ancillary services to the grid as well as the industrial product in a way that maximizes profit.

3. Loosely Coupled Electricity-Only N-R HES: no thermal connections are made between the subsystems. Electrical connections between subsystems may utilize the grid. The subsystems are co-managed by a single financial entity to provide electrical energy and ancillary services to the grid as well as the industrial product in a way that maximizes profit.

\subsection{Potential Benefits of N-R HESs}

The N-R HES Technology Development Program Plan identifies a number of potential societal benefits provided by these systems ${ }^{8}$ :

1. Dispatchable, flexible, very low-carbon electricity generation that can support adequate resources on the grid

2. Reduced GHG emissions in the industrial sector

3. Synchronous electro-mechanical (real) inertia that supports the grid 
4. Alleviation of the impacts of electricity price suppression at high penetration of lowmarginal-cost generation (e.g., nuclear power and renewables).

The first benefit is dispatchable, flexible, very low-carbon electricity. Because of increased variability from wind and PV, the evolving grid requires additional flexibility on an hourly, daily, and seasonal basis. As shown in Figure 2, increasing penetrations of VRE generation can increase ramp rates, result in shorter peaks, and result in lower turn-downs. Ramp-rate requirements impact daily operation of the grid and, today, are usually managed by fastresponding dispatchable generation. Shorter peaks impact the amount of baseload electric power generation that is supplied to the grid, because the minimum net load on a grid with high penetrations of VRE generation is lower than that on a grid with lower penetrations of VRE generation.

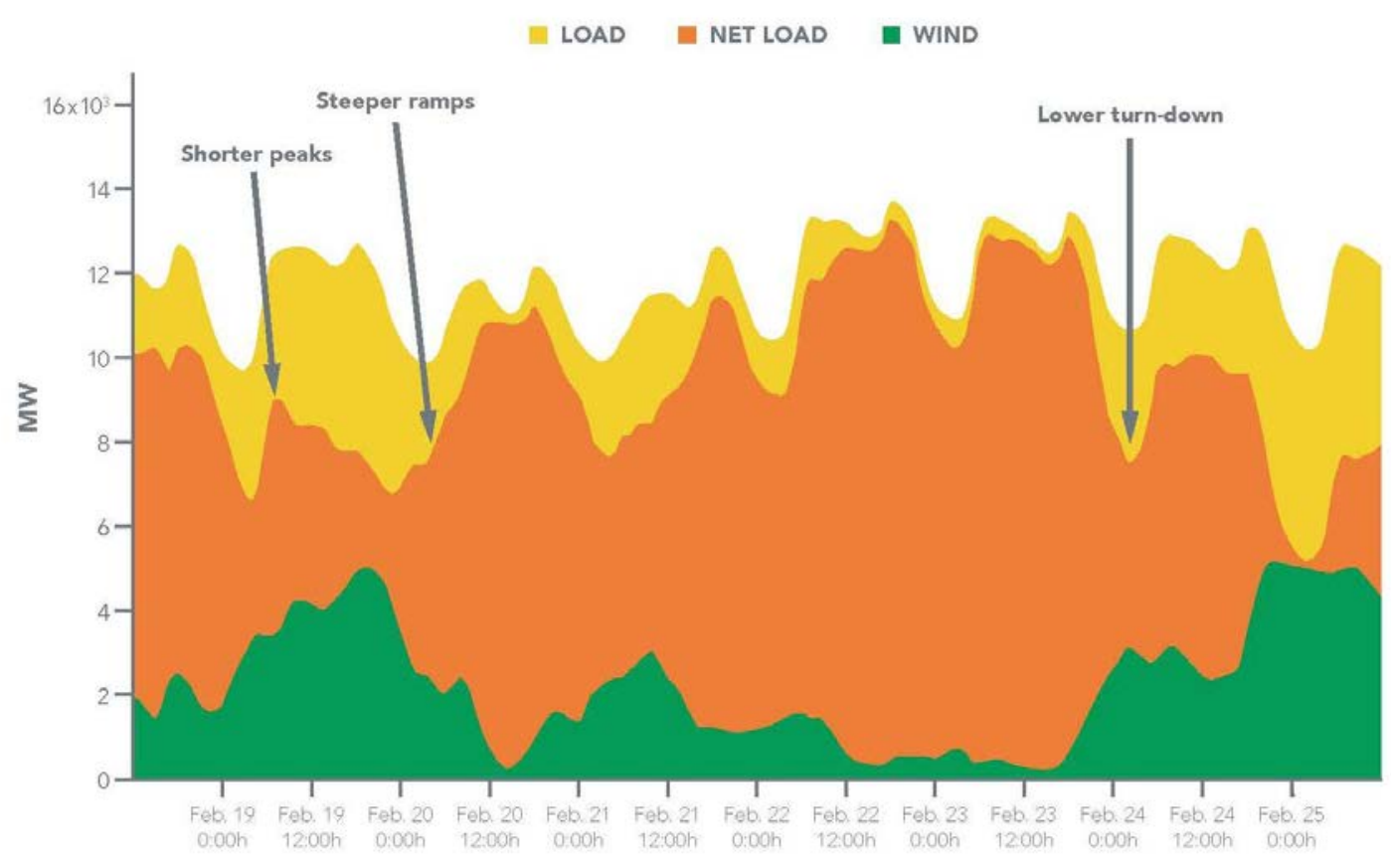

Figure 2. Variable renewable generation increases ramp rates and results in shorter peaks and lower turn-down for dispatchable generation ${ }^{9}$

Many options have been proposed to provide flexibility to the grid. Options include operational opportunities such as higher-frequency markets that are closer to real time than today's hourly or 15-minute markets; improved forecasting of wind and solar resources to reduce the need for spinning contingency; and increased collaboration between balancing areas. In addition, proposed transmission options include adding resources that reduce congestion, increasing the number of connections between balancing areas, and adding grid-scale electrical energy storage. At the locations where electricity is used, resources that could provide flexibility include distributed storage, demand response, and distributed generation; however, markets that incent those options are still under development. The primary option for flexibility today is dispatchable generation used on an as-needed basis. In most U.S. cases, natural gas combustion turbines fill that need in the absence of very low-carbon alternatives. N-R HESs may be an alternative because they have the potential to provide that peaking power while maintaining sufficient 
income to cover the necessary return on investment for components driven by capital costs (e.g., nuclear reactors, wind, and PV).

The second benefit of N-R HESs is the potential to reduce GHG emissions from the industrial sector. Of the total GHG emissions in 2014, $18 \%$ were direct emissions from the industrial sector (generation of electricity used by the industrial sector emitted additional GHGs). ${ }^{10}$ Low-emission alternatives are limited because most emissions come either directly from the processes (e.g., concrete production) or from heat for the process (in which natural gas, coal, or oil is burned to produce heat). N-R HESs may be able to provide an alternative low-carbon heat source that is present when needed by industry.

The third potential benefit is real inertia for the grid. Grid inertia and low-voltage ride-through are commonly provided by large spinning turbines. When an upset causes the frequency to change, the turbines speed up or slow down; however, the frequency upset is limited due to the turbines' inherent inertia. That effect is often called grid inertia. Low-voltage ride-through is the ability of electric power generators to stay connected through short periods when the voltage dips. Many researchers have proposed synthetic inertia options to replace the real inertia provided by spinning turbines. ${ }^{11}$ Power electronics can provide synthetic inertia by increasing electric power output when frequency dips. Other researchers are concerned that the controls on power electronics may have a tendency to over-respond or interfere with the response of other controllers. Keeping sufficient real inertia on the grid (e.g., with spinning turbines such as those present in an N-R HES) can dampen impacts from over-response. ${ }^{12}$ Because the need for and value of real inertia are not well understood, the value of real inertia is difficult to estimate.

The fourth potential benefit is alleviation of price suppression impacts. Increasing penetration of low-marginal-cost generation has the potential to suppress electricity prices because, once the generator is in place, operating and selling electricity at a low price presents greater value than not operating. Because both nuclear and VRE generation options have low marginal costs, they can both cause price suppression. Results from one analysis on price suppression are shown in Figure 3, where the blue lines show the marginal economic value of each technology at increasing penetrations, and the green lines show the time-weighted averages of day-ahead wholesale electric power prices at each penetration level.

As indicated by the green lines, the day-ahead wholesale prices do not drop until higher penetrations are reached, so the electrical energy value does not decrease dramatically. However, there is a drop in compensation from other value streams, including capacity and ancillary services, resulting in reduced compensation for the VRE technologies. Note that the economic value of each increment of the technology results in a lower return for all generators. N-R HESs can prevent price suppression impacts from being exacerbated by providing an alternative product - presumably of higher value - when the value of generated electricity is low. That capability benefits the owner of the N-R HES most, but can benefit other generators on the grid because it may increase the marginal prices on the grid. Unlike the previous three benefits, it may also impact society negatively because the overall cost of electricity may increase; however, society may also be impacted negatively due to reliability and resilience reductions if new and replacement generation is not built because electricity prices are expected to be too low. 


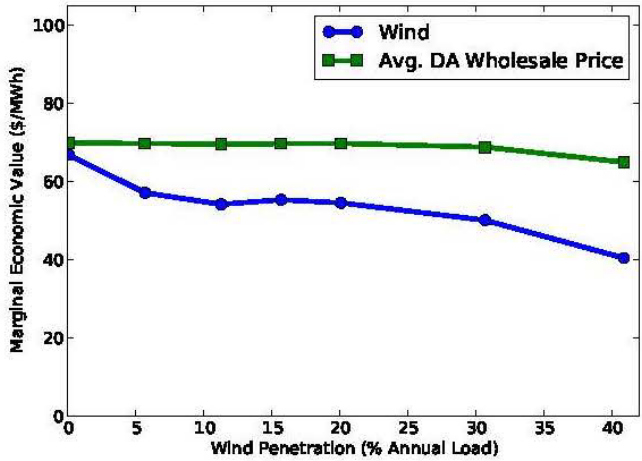

(a) Wind

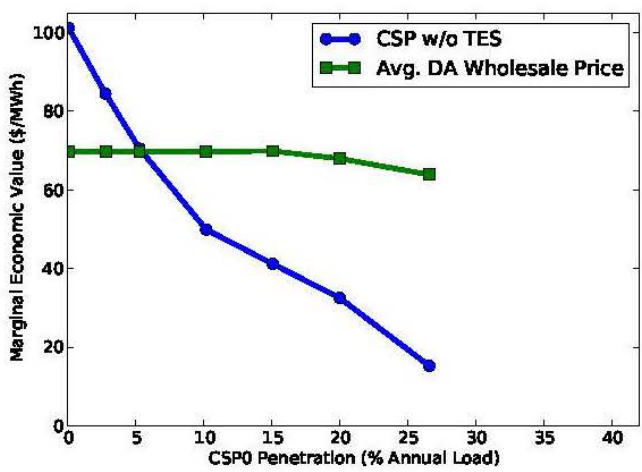

(c) $\mathrm{CSP}_{0}$

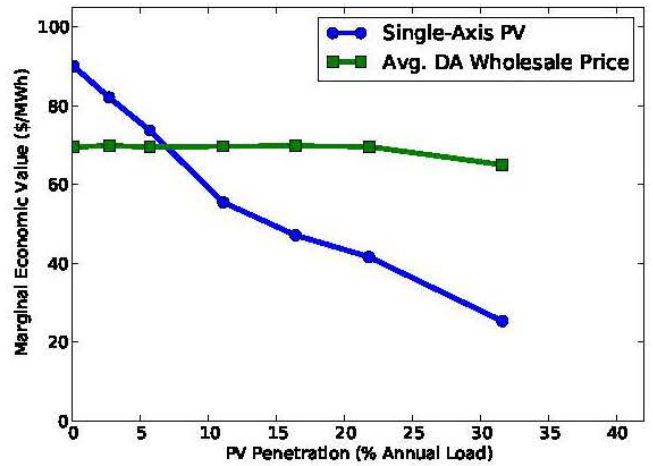

(b) PV

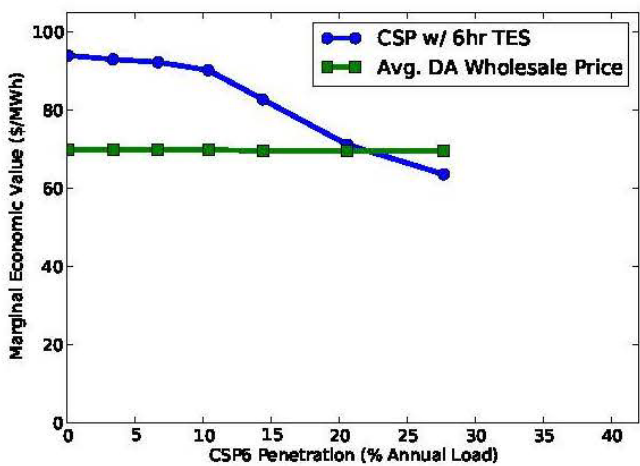

(d) $\mathrm{CSP}_{6}$

Figure 3. Price suppression impacts of several renewable generation technologies ${ }^{13}$

\subsection{Analysis Objectives}

A key question about N-R HESs is whether their benefits are sufficient to overcome the increased cost and complexity as compared to independent configurations. The analyses presented in this report focus on value to the investors with some consideration of value of N-R HESs to society. Evaluations of N-R HES market impacts (such as ability to support greater penetrations of VRE generation) and evolution (i.e., investment drivers and decision timing) are outside the scope of this analysis.

We tested five hypotheses regarding the potential benefits of the N-R HES in each of the two scenarios:

1. The N-R HES configurations analyzed have the potential to be profitable to investors and are likely to be more profitable than uncoupled configurations.

2. Using nuclear-generated heat in an N-R HES can economically reduce GHG emissions from industry. If a cost of carbon is included in economic analyses, the N-R HES will have a lower cost than competing uncoupled natural gas configurations.

3. N-R HESs can support resource adequacy for the electric power grid while maximizing production of a more profitable industrial product if the market structures incentivize that option. 
4. N-R HESs will be more profitable than uncoupled configurations because they can produce electricity when its value is high and the industrial product when the value of electricity is low.

5. The internal flexibility of N-R HESs makes them beneficial as a hedge against changing and uncertain future prices.

Value to investors was chosen as the first objective to analyze against for several reasons. First, if there is no value for investors under projected futures, the technology is unlikely to be built and will have no impacts on the grid. Second, if there is value, especially if that value is great, more N-R HESs are likely to be built and competition between the N-R HESs may drive down the price of electricity and/or the price of the industrial product, thus benefiting society by providing lower-cost resources. Third, because an N-R HES produces multiple products, multiple selling prices can be adjusted and it is outside the scope of this project to estimate the pricing strategy an owner would use.

The second and third hypotheses capture societal impacts. One impact analyzed is the potential for N-R HESs to reduce GHG emissions when compared to uncoupled configurations that use natural gas to provide heat. The third hypothesis focuses on the potential for N-R HESs to support the electric power grid by economically providing electricity when the greatest amount of dispatchable electricity is required.

The final two hypotheses focus on investor motivation. The fourth hypothesis explores the reason for profitability - specifically whether the variability in electricity prices results in increased profitability for an N-R HES that can respond and utilize energy for a higher-value product. The fifth hypothesis explores investment risk and the potential benefits from an N-R HES having multiple products in different markets.

Other potential benefits are outside the scope of this analysis. An analysis of the need for and potential of N-R HESs to provide real inertial to the grid is likely to involve dynamic grid modeling that cannot be performed using the optimization tools used for this analysis. Understanding the potential of N-R HESs to limit price suppression would also involve tools beyond those used for this analysis.

Operational and licensing issues are also outside the scope of this analysis. A previous analysis performed by INL focuses on operational issues and attempted to identify potential operational challenges. ${ }^{14}$ Licensing and regulatory challenges, especially regarding utilization of nucleargenerated heat, are also outside the scope of this analysis. Research and analysis to better understand and quantify those issues are planned. ${ }^{15}$

\subsection{Nuclear-Renewable Hybrid Energy Systems Analyzed}

As stated above, N-R HESs are defined as co-managed systems that link a nuclear reactor that generates heat, a thermal power cycle for heat-to-electricity conversion, at least one renewable energy source, and an industrial process that uses thermal and/or electrical energy. In general, all N-R HESs have a nuclear reactor, a thermal power cycle, a renewable generation technology, and an industrial process. N-R HESs produce both electricity and an industrial product and have the flexibility to switch between products to maximize profitability. In this analysis, we investigate the potential profitability of two N-R HESs and compare profitability to that of 
uncoupled configurations that provide some or all of the same services. We make comparisons both to nuclear configurations and those that use natural gas as the energy resource.

Two scenarios were chosen for this analysis. These scenarios can be considered proxies for the many different options available. The first scenario's primary energy interconnection is a thermal transfer between the nuclear reactor and the industrial process. The second scenario is an electricity-only interconnection where the industrial process does not use heat. We chose the two scenarios based on results from a Nuclear-Renewable Hybrid Energy System workshop in July $2014^{16}$, wherein participants expressed interest in these options. They also appear to have sufficient market sizes and the potential to be economically favorable and represent diverse types of N-R HESs.

INL analyzed the operating potential and economics of these two N-R HES scenarios in the spring of 2015. ${ }^{17}$ We discuss that analysis and results in Section 4.

Figure 4 shows the first N-R HES scenario analyzed. For this N-R HES, the renewable generation technology is wind power and the industrial process is one that converts natural gas to synthetic gasoline, which can be used directly within the nation's gasoline infrastructure and markets. The nuclear reactor is a small modular reactor (SMR) using light-water technology, making it a light-water SMR (LW-SMR). This N-R HES's hybridization paradigm is that the inherent variability in the electric grid is absorbed into liquid fuel production. For this scenario, we analyzed six configurations:

- The nuclear reactor and industrial process producing only liquid fuel

- The nuclear reactor and thermal power cycle (balance of plant) producing only electricity

- The wind power plant producing only electricity

- The nuclear reactor, thermal power cycle (balance of plant), and wind power plant producing only electricity

- The nuclear reactor and thermal power cycle (balance of plant) producing electricity, and the industrial process producing synthetic gasoline

- The full N-R HES, with the nuclear reactor and thermal power cycle (balance of plant) producing electricity, the wind power plant producing electricity, and the industrial process producing synthetic gasoline. 


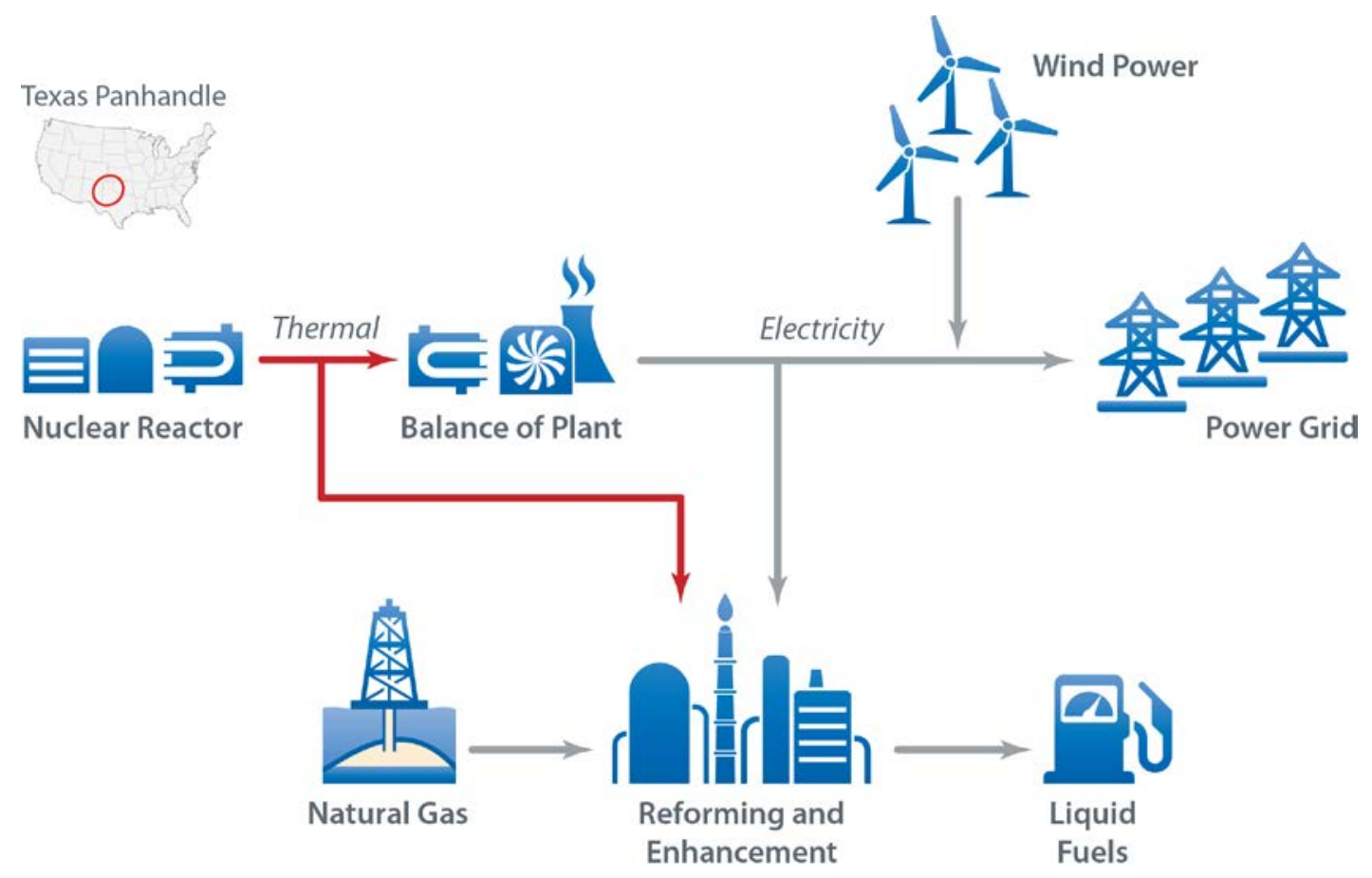

Figure 4. N-R HES Scenario \#1-the synthetic fuel industrial process is expected to use thermal energy from the nuclear reactor and electricity from both the nuclear reactor and wind power plant

We chose northern Texas as the location for the analysis of this scenario because of its wind resource (currently about $20 \%$ of the total U.S. wind capacity is located there) and many natural gas wells. In addition, the proximity of many refineries and pipelines provides nearby infrastructure that can accept the gasoline product..

Possible alternative configurations to N-R HES Scenario \#1 that we did not analyze include:

- Addition of thermal storage so the industrial process does not have to ramp to provide flexibility

- Utilization of renewable thermal energy (e.g., converting electricity generated by wind into heat that can be used by the industrial process)

- Conversion of carbon dioxide to liquid fuel rather than conversion of natural gas to liquid fuel

- Utilization of alternative sources (such as coal and biomass) to produce synthetic gasoline for the liquid fuel

- Substitution of liquid fuel with other possible products (e.g., hydrogen)

- Addition of battery storage to provide additional flexibility for the power grid (INL included this option in their analysis)

- Addition of a natural gas boiler to produce heat for the industrial process when heat from the nuclear process is used to generate electricity (INL included this option in their analysis). 
Figure 5 shows the second N-R HES scenario analyzed. For this N-R HES, the renewable generation technology is PV and the industrial process is reverse osmosis (RO) to desalinate brackish water to provide fresh water for drinking and/or agriculture. The nuclear reactor is a LW-SMR. This N-R HES's hybridization paradigm is that the inherent variability in the electric grid is transferred to the water infrastructure, which has large amounts of inventory. For this scenario, we analyzed five configurations:

- The nuclear reactor, thermal power cycle (balance of plant), and industrial process producing water and potentially selling electricity

- The PV subsystem and industrial process producing water and potentially selling electricity

- The nuclear reactor and thermal power cycle (balance of plant) producing only electricity

- The nuclear reactor and thermal power cycle (balance of plant) and PV subsystem producing only electricity

- The full N-R HES, with the nuclear reactor, thermal power cycle (balance of plant), PV subsystem, and industrial process producing water and potentially selling electricity.

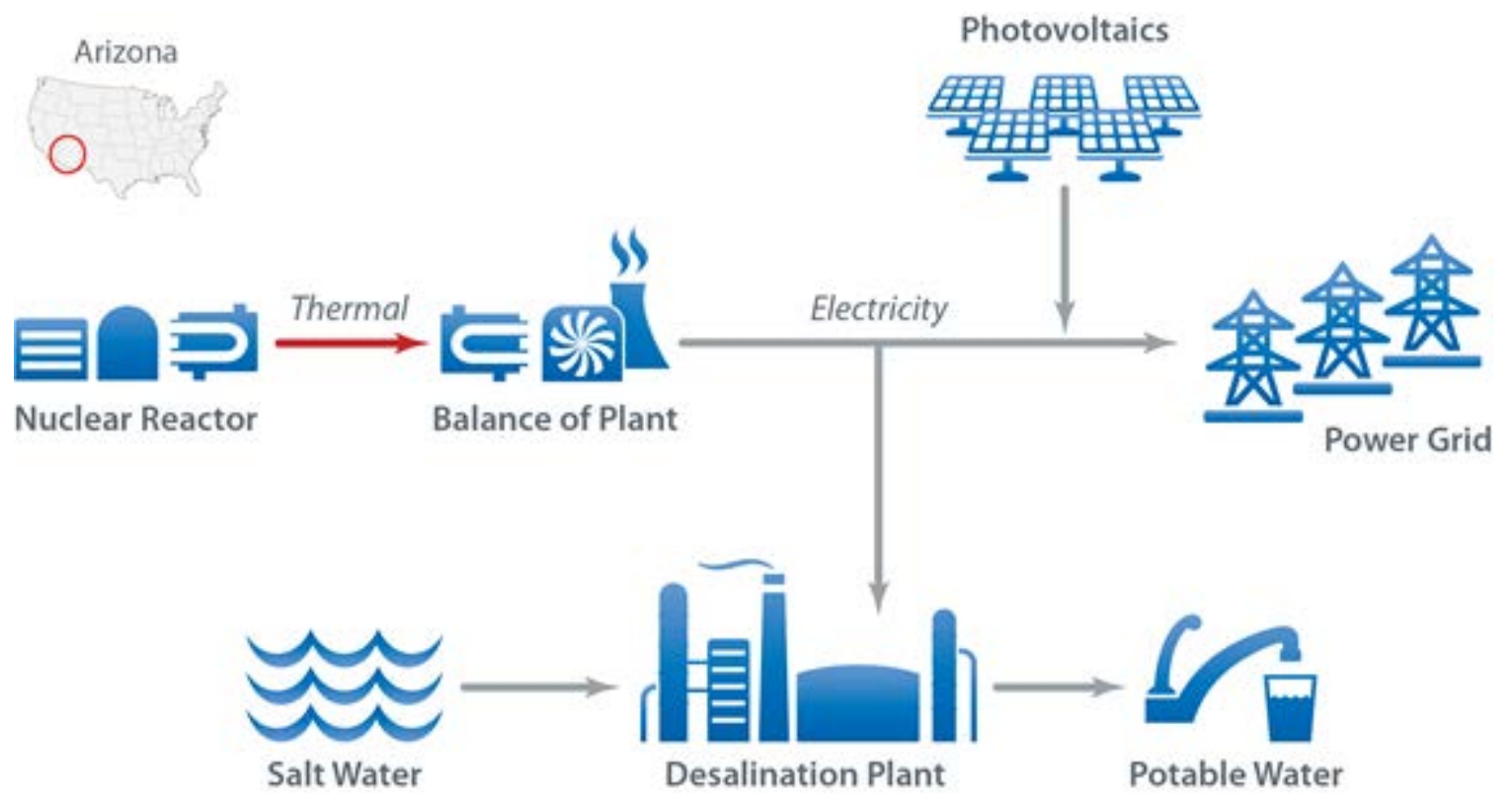

Figure 5. N-R HES Scenario \#2-the RO desalination N-R HES is expected to use electricity from both the nuclear reactor and PV

We chose Arizona as the location for the analysis of this scenario because that state projects growth in water demand that far exceeds water availability: a shortage of 600,000 to 1,200,000 acre-feet/year is expected (Appendix E provides additional detail). In addition, the demand for electric power is projected to grow, and the state has an abundant solar resource.

Possible alternative configurations to N-R HES Scenario \#2 that were not analyzed include: 
- Use nuclear energy to provide thermal preheat of brackish water before RO. Increased temperatures improve desalination efficiency.

- Replacement of RO with thermal or thermal-electric desalination technologies

- Production of renewable thermal energy

- Addition of thermal energy storage

- Addition of concentrating solar power to produce thermal energy and that can share thermal storage with the nuclear reactor

- Addition of battery storage to provide additional flexibility for the power grid (INL included this option in their analysis).

We did not include batteries in this analysis because they have the ability to absorb some of the variability from the electric grid and we did not want to obfuscate our analysis of the finances of an N-R HES by absorbing that variability. 


\section{Analysis Methodology and Parameters}

This section discusses the methodology used to perform the analysis and provides details and references for key parameters. It is intended to be a reference that provides detailed information for others performing similar modeling or comparing these results to their own.

This section consists of five subsections. The first subsection discusses the analysis methodology by outlining the methodology used to perform the analysis. The second subsection focuses on key fundamental assumptions that guided decisions for other assumptions. The third subsection discusses the market assumptions and provides an extensive description of how electricity is valued. It also lists price assumptions of natural resources and products. The final subsection discusses other key parameters including yields, financial assumptions, and cost of carbon prices.

\subsection{Analysis Methodology}

The key aspect of this analysis is the financial performance evaluation of two distinct N-R HES scenarios. This aspect focuses primarily on expenses, income, optimization of the size of each subsystem, and operational decisions (internal dispatch strategy) over a single year. This methodology is more likely to correspond to decision-making in deregulated markets than in regulated markets. We evaluated the financial performance of each scenario under various circumstances to determine the most profitable configuration, with profit expressed as NPV.

We used NREL's REopt tool to optimize the size and hourly operational decisions of each subsystem. REopt is an energy planning platform that offers concurrent, multiple technology integration and optimization capabilities. Formulated as a mixed-integer linear program, REopt identifies optimal subsystem sizes and dispatch strategies for the selected technologies. It takes into account subsystem costs (capital, fixed, and variable), fuel costs, financial parameters (discount rate, inflation, utility price escalation rates, and incentives), utility prices, and other variables that contribute to a techno-economic analysis of the proposed system. REopt also has the capability to optimize a system for objectives other than those used in this analysis, such as minimum fuel consumption or minimum GHG emissions. ${ }^{18}$ Appendix A provides additional details on REopt.

Figure 6 shows REopt inputs and outputs in addition to the pre- and post-processing steps used in this analysis. We input a number of independent prices into REopt for the analysis including hourly electricity prices, capacity payments, resource prices, and capital and operating costs of subsystems. We generated hourly electricity prices (day-ahead electrical energy, reserve, and flexibility reserves) to be input into REopt using production cost modeling techniques in the PLEXOS model. ${ }^{19}$ We estimated the capacity payment input independently, as discussed in Section 2.3.3 below. Price estimates for natural gas and gasoline came from the 2015 Annual Energy Outlook (AEO). ${ }^{20}$ Capital and operating costs for each subsystem (nuclear reactor, thermal power cycle, wind plant, PV plant, and the industrial process) were estimated independently as discussed in Sections 2.4.1. Likewise, the operational efficiency of each subsystem was estimated independently, as discussed in section 2.4.3. Wholesale (or plant gate) 
prices of the synthetic gasoline and water products in 2035 were estimated and used as REopt inputs as discussed in Sections 2.3.4 and 2.3.5 below.

Using the aforementioned inputs, REopt determined the subsystem capacities (i.e., the size of each subsystem) and hourly dispatch to maximize the NPV of the N-R HES for the scenario. All subsystems were allowed to vary in size from no capacity (i.e., not present) to a maximum capacity of 50 megawatt electrical (MWe) (167 megawatt thermal [MWt] if the subsystem generates or uses thermal energy instead of electrical energy). We set the maximum size of all subsystems to the save value because the purpose of the analysis is to understand the benefits of coupled subsystems with full flexibility. The approach avoids artificial constraints on capacity that could obfuscate decisions regarding whether to include specific subsystems and at what optimal size. We did not require any subsystem to be included in the optimal solution; hence, under some product prices, the optimal configuration does not include electricity generation.

We performed additional post-processing as necessary. For example, we added a cost of carbon to the financial analysis and calculated the financial impacts to address the second key aspect of this analysis, which is reduction in GHG emissions. In another post-processing step, we calculated the IRR and the NPV/TCI ratio, which is the quotient of the NPV and the total capital investment (TCI), and used both as metrics for each configuration's attractiveness to investors.

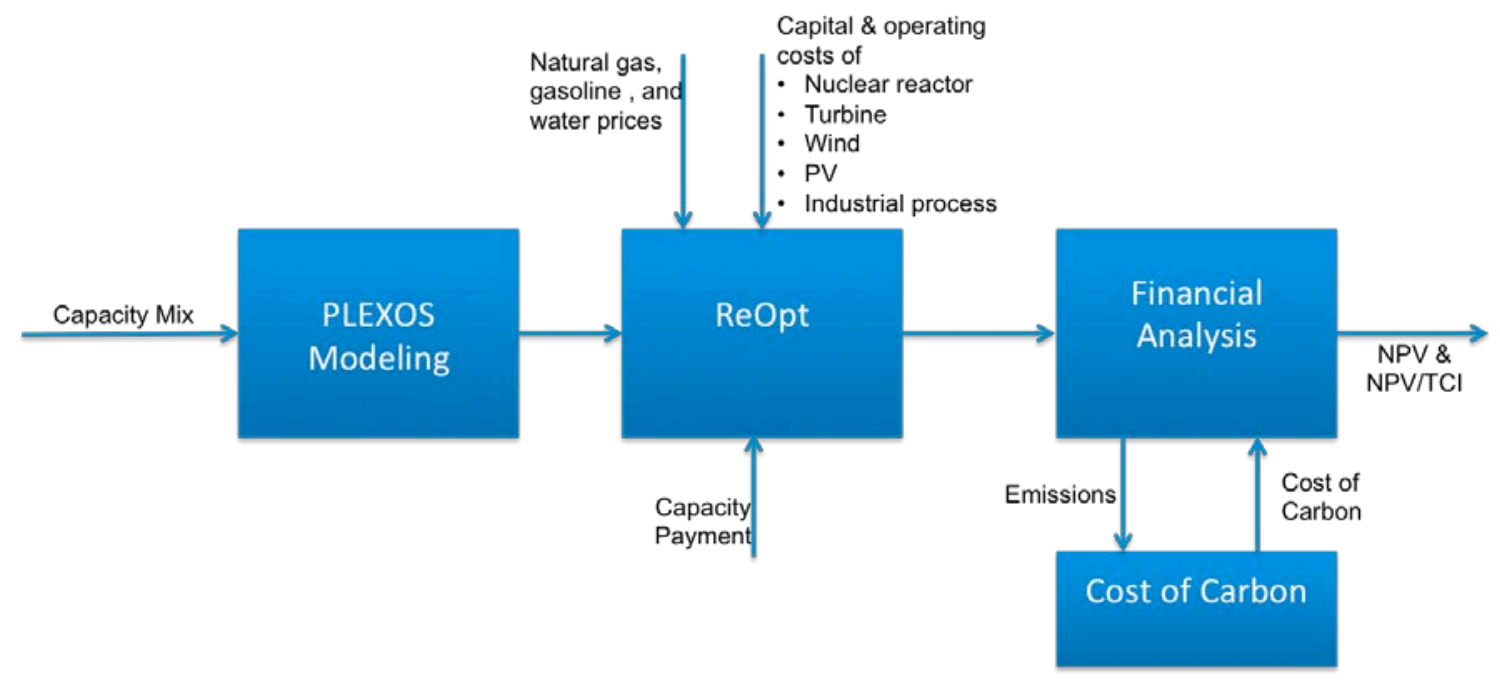

Figure 6. Analysis methodology showing REopt as the central optimization engine, its inputs, and post-processing options.

The third key aspect of this analysis is the ability of the N-R HESs analyzed to support the grid's resource adequacy requirements. We addressed this issue by including capacity payments as an economic incentive to provide resource adequacy. The rules we used for capacity payments are discussed in Section 2.3.3. When the optimal configuration provided electric power to the grid as required to receive capacity payments, we identified that configuration as one that supports the grid's resource adequacy requirements. If the optimal configuration did not provide electric power to the grid as required to receive capacity payments, we identified that configuration as one that does not support the grid's resource adequacy requirements.

\footnotetext{
${ }^{*}$ The difference between wholesale and retail is that retail prices include the additional cost of distribution and sellers profits. In the case of gasoline, taxes will also be an important adder.
} 
In 2015, INL completed an analysis of these two N-R HES scenarios. ${ }^{21}$ That analysis had different objectives and used a different approach than the one described here, with the primary focus on dynamic operability of the N-R HESs. The financial performance of each scenario was a secondary objective. Hence, the previous analysis used a detailed dynamic model, whereas we assumed the N-R HES could operate to follow the operations identified by REopt's optimizer. This effort focuses on financial optimization, so we optimized capacity and the operations of each subsystem; in the previous analysis, the capacity of each subsystem was held constant. Subsequent key differences in the analysis methodology and parameters include:

- This analysis optimizes subsystem capacities with a maximum size of $50 \mathrm{MWe}(167$ MWt at 30\% conversion efficiency from thermal energy to electricity for a simple LWSMR with a Rankine thermal power cycle). The 30\% efficiency was chosen to be consistent with the previous analysis. ${ }^{22}$ In this analysis, configurations and subsystem capacities are varied to maximize the NPV under various circumstances. In the previous analysis, all subsystem sizes were held constant. In that analysis, the LW-SMRs had a capacity of $180 \mathrm{MWe}(600 \mathrm{MWt})$, with a 45-MWe wind power plant, a $30 \mathrm{MWe} \mathrm{PV}$ system, a synthetic gasoline industrial process that used $150 \mathrm{MWt}$, and a desalination unit that used 45 MWe.

- This analysis involved selling power when the market prices for electrical energy, ancillary services, and/or capacity payments were sufficiently high for that sale to be more beneficial to the N-R HES than other options. The previous analysis required the NR HESs to provide a constant percentage of the grid's load.

- Other key parameters differed because each analysis team kept them consistent with other analyses performed within that organization.

Section 4 compares conclusions from each analysis.

\subsection{Fundamental Assumptions}

We employed several fundamental assumptions as the basis for other decisions and assumptions. First, we based the analysis on a green-field (all-new) plant—we assume all subsystems are new. We chose a green-field plant to avoid constraining the analysis to a specific plant design, operating condition, or specific location. The green-field plant approach ensures optimization of a more general case.

Second, we limited this analysis to LW-SMRs under the assumption that this reactor class will be first to commercial markets and other Generation IV advanced reactor concepts currently under development will follow years later. ${ }^{*}$ This initial analysis assumes that hybrid systems operation begins in 2035. Using subjective judgment, we decided that an "nth-of-a-kind" commercial LWSMR could be possible on this date, following completion of reactor design certification, development of steam-line combined technology and operating permits, equipment manufacturing supply chain development, and construction and operating experience. We

\footnotetext{
* The U.S. Department of Energy, private industry, and foreign countries are now developing and demonstrating high temperature nuclear reactors. The main advantage of these reactors is expected to be (1) higher power generation efficiency (up to 50\%) and (2) higher temperature for industrial uses.
} 
performed the analysis using and reporting all results in 2013 dollars, although we used price projections to 2035. We assume that inflation in materials and construction matches currency inflation or is offset by reductions in capital equipment manufacturing costs realized through repetitive manufacturing and construction experience.

The maximum size of all subsystems was set at the equivalent to $50 \mathrm{MWe}(167 \mathrm{MWt})$, and each subsystem's minimum size was set to $0 \mathrm{MWe}$. We kept the maximum size constant so that the decision between using nuclear energy for the industrial process or for grid electricity is clear. For each scenario, we ran a sensitivity case with the maximum size of the nuclear reactor and thermal power cycle set larger than the maximum size of the industrial process. We report the results of those sensitivities in Sections 3.1.1 and 3.2.1.

\subsection{Key Economic and Market Parameters}

This section reports the key economic and market parameters used in the analysis. We identify the values used for the "base-case" parameters or conditions, and provide our reasoning for the selection of those values. The base-case parameters are those that we used for all results reported in this analysis, except for those from sensitivity runs, where we note changes to the base-case parameters.

Sections 2.3.1 and 2.3.2 describe the methodology used to estimate electrical energy and ancillary service prices and report the resultant prices used for the REopt analysis. Section 2.3.3 describes the capacity payment, and Sections 2.3.4 and 2.3.5 report the cost estimates for energy resources and water, respectively.

\subsubsection{Methodology to Estimate Day-Ahead Electricity Prices}

We estimated electrical energy and ancillary services prices using production cost modeling techniques in the PLEXOS model, as shown in Figure 6. The economic environments under which future investments in nuclear reactors will be made are unknown. For stand-alone, nonhybridized generators, long-term bilateral and/or power purchase agreement contracts are likely to be preferable to competing in wholesale electric power markets. Such contracts can reduce financial and operational risks that are exacerbated by high annualized capital-to-fuel cost ratios typical of both nuclear and VRE generation. On the other hand, the plant may be (at least in part) exposed to the more volatile electricity prices within wholesale electric power markets. Because information about bilateral agreements is unavailable, we used a security-constrained, least-cost, economic dispatch approach without hurdle rates among regions. Security-constrained, least-cost economic dispatch is the short-term (day ahead) co-optimization of the electric power and ancillary service costs from a number of generators that provides the least-cost option to serve loads, subject to operational and transmission constraints.

We designed this analysis such that electricity revenue can come from three main sources (note that the N-R HES can also receive revenue by selling the industrial product):

1. Electrical energy revenue (dollars per megawatt-hour [\$/MWh])

2. Ancillary service revenue from contingency reserves, regulation, and flexibility reserves

3. Capacity payments (dollars per kilowatt-year $[\$ / \mathrm{kW}-\mathrm{yr}]$ ). 
Electricity generators usually receive revenue for the energy produced. In some markets, revenue is available for the ability to provide ancillary services that support the grid's inherent load variability and often provide backup in case a generator goes out of service. Capacity payments are beginning to be paid in some markets as a means to support generation resource adequacy (i.e., provide sufficient generation at all hours during the year, especially those hours with the highest loads), but they are not common at this time.

This analysis leverages the PLEXOS production cost model used in recent NREL integration costs research. ${ }^{23}$ The integration costs model is a modified version of the IEEE, three-region, 118-bus security-constrained unit commitment model and was designed to accommodate high penetrations of variable generation. The model consists of three interconnected regions and contains a mix of generator types in each region, with the combination of regions mimicking generation capacity through the full interconnect. The Western Electricity Coordinating Council supplied load data ${ }^{24}$ that provide realistic load variability for each region. ${ }^{*}$ Appendix B provides a one-line diagram of the reference version of the model. The model used in this study differed from the integration cost work in that the transmission constraints were removed to ensure that congestion would not bias the study results, and the generation mixes were modified to approximate the standard-scenario results (see below).

For the production cost modeling, the generation mixes were developed based on three regions from standard-scenario national results developed at NREL. ${ }^{25}$ Most of the results presented here are based on the 2036 generation mix in NREL's National Renewable Portfolio Standard (RPS) scenario, which leads to $80 \%$ renewably generated electricity in 2050 . Because the standardscenario modeling results are only calculated for even-number years, results for the year 2035 are not available. Hence, 2036 results are considered sufficient as the generator mix for the year 2035 for this effort and are used in this analysis. Throughout this report, results based on this case are reported as "RPS80." The RPS80 case has very high penetrations of renewable generation and can be considered the maximum renewable penetration in 2035.

We developed additional cases using a standard scenario with lower penetrations of renewable generation. This case is based on policies that were current as of the spring of 2015 and does not include Clean Power Plan requirements. ${ }^{26}$ We refer to sensitivities using that scenario as the "Current Law" case. Neither the RPS80 nor the Current Law case includes any N-R HESs, so this study analyzes the first N-R HES that would be incorporated in the grid interconnections.

The three regions selected for the Texas-synthetic gasoline scenario were Northern California, Public Service Company of Colorado, ${ }^{\dagger}$ and Washington, because these geographic regions have been shown to provide a reasonable approximation of an actual interconnection, yet are small enough to allow us to examine a large number of sensitivity combinations. ${ }^{27}$ They also include sufficient resource diversity within an actual interconnection. Future year 2020 was modeled from historical weather patterns and loads from 2006, the year with the most complete data sets.

\footnotetext{
* WECC provided load data statistically scaled from actual operating data.

${ }^{\dagger}$ Ideally, we would have use used time-series load data from the Texas Panhandle for the synthetic gasoline study; however, the data for that area were aggregated with data from as far north as Nebraska and as far east as Oklahoma. Since load is highly correlated with climate, we felt that data from the Front Range and Eastern Plains of Colorado better approximated the climate of the upper Panhandle (it's similar in average monthly temperatures and humidity levels).
} 
The minimum, average, and maximum loads were 11,666 MW, 16,994 MW, and 26,509 MW, respectively, for both the Current Law and RPS80 synthetic gasoline scenarios.

Similarly, we used the Northern California, Washington, and Arizona regions for the Arizonadesalination scenario. Future-year 2020 was modeled from historical weather patterns and loads from 2006. The minimum, average, and maximum loads were 11,934 MW, 17,760 MW, and 29,140 MW, respectively, for both the Current Law and RPS80 desalination cases.

The production cost models used three types of spinning reserves to estimate electrical energy and ancillary services prices: regulating, contingency, and flexibility. The methods used to calculate each respective reserve type are described below. Regulating reserves were the same for all scenarios: $1 \%$ of load.

For the production cost modeling used to estimate the electrical energy and ancillary services prices, we sized the nominal contingency reserves to match the full outage of the largest baseload electric power generator in the simulated interconnection $(840 \mathrm{MW})$. Flexibility reservesdesigned specifically to address load-following needs for wind-were held to cover $70 \%$ of the 1-hour forecast errors of wind using the method described in the Western Wind and Solar Integration Study, ${ }^{28}$ and the three regions shared flexibility reserves.

We used the PLEXOS model to estimate the annual electrical energy production from the generation mixes for both three-region, 118-bus interconnections under the RPS80 case.

Figure 7 shows the resulting annual generation mixes for the RPS80 cases across each threeregion interconnection as discussed above. The Texas-synthetic gasoline scenario under the RPS80 generation mix has $41 \%$ annual generation from VRE (20\% PV and $21 \%$ wind), but has only $0.3 \%$ curtailment due to the flexibility provided by hydropower. The Arizona-desalination scenario has 33\% annual generation from VRE (22\% PV and 11\% wind) along with $3.4 \%$ curtailment. Under the RPS80 case, the Arizona-desalination scenario has a higher curtailment than the Texas-synthetic gasoline scenario. This higher curtailment happens for two reasons: (1) the Arizona-desalination scenario has more PV that is at its tipping point - any small incremental addition results in a large fraction of that additional generation being curtailed; and (2) the generation capacity that has limited flexibility (i.e., nuclear) is higher in the Arizona-desalination scenario. Both scenarios have high fractions of hydroelectric generation because both regions include Washington. Note that natural gas combustion turbines (CTs) - often referred to as peakers - have the highest marginal costs of the generators in this study. Consequently, while the CTs are used to generate electricity in times of shortage (e.g., peak use), they are more often used to provide ancillary services (e.g., contingency and flexibility reserves). Hence, they generate a negligible amount of electricity when compared to other generation sources.

Note that the N-R HES under consideration in this analysis is not included in the generation mix used here. 

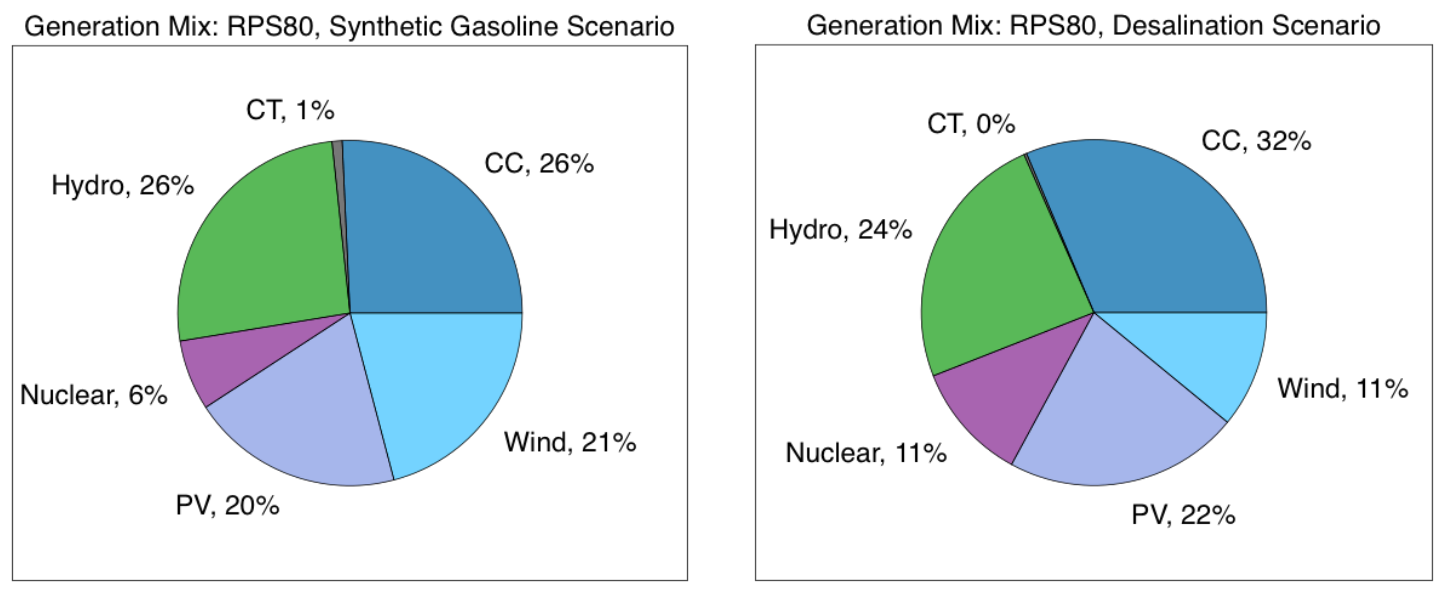

Figure 7. Generation mix by annual electrical energy production under the RPS80 scenarios for interconnection

(Texas-synthetic gasoline on the left and Arizona-desalination on the right)

CC: Natural gas combined cycle

CT: Natural gas combustion turbine

Hydro: Hydropower

PV: Photovoltaic solar generation

We also used the PLEXOS model to estimate the annual electrical energy production from the generation mixes for both three-region, 118-bus interconnections under the Current Law case.

Figure 8 shows the resulting generation mix for the Current Law cases. The Texas-synthetic gasoline scenario under the Current Law case has only $21 \%$ annual generation from VRE ( $10 \%$ PV and $11 \%$ wind) as compared to $41 \%$ under the RPS 80 case. The Arizona-desalination scenario under the Current Law case has only $16 \%$ annual generation from VRE $(12 \%$ PV and $4 \%$ wind). Due to the decreased penetrations of VRE, there is no curtailment in either location. Note that both scenarios have high fractions of hydroelectric generation because both regions include Washington. 

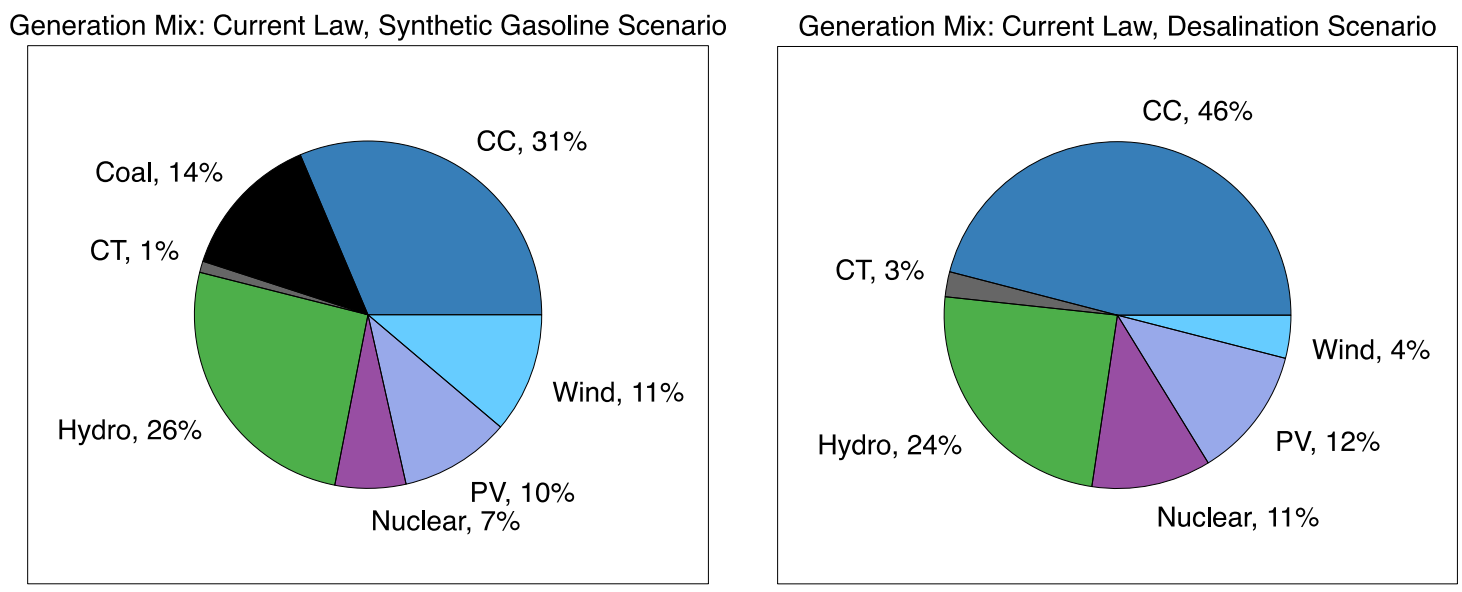

Figure 8. Generation mix by annual electrical energy production under the Current Law cases for interconnection

(Texas-synthetic gasoline on the left and Arizona-desalination on the right)

CC: Natural gas combined cycle

CT: Natural gas combustion turbine

Hydro: Hydropower

PV: Photovoltaic solar generation

Appendix B reports additional details on the simulation methodology.

\subsubsection{Hourly Electricity Prices}

Hourly electrical energy prices are estimated as those paid by the load during the period of study. These prices were derived from the short-run marginal costs of the marginal generator and do not include markups or any sort of scarcity pricing scheme. For the purposes of this initial work, we capped electrical energy prices at $\$ 100 / \mathrm{MWh}$, with the exception of the analyses on the benefits of internal flexibility to hedge against as reported in Section 3.1.5. Prices at the price cap of \$100/MW occurred primarily due to reserves violations - situations in which optimization software found it less expensive to the grid to short the reserves slightly rather than start or shutdown a generator. Reserves violations occurred $0.74 \%$ of the time for the synthetic gasolineRPS 80 generation mix, $0.66 \%$ of the time for the desalination-RPS 80 generation mix, $0.15 \%$ of the time for the synthetic gasoline-Current Law generation mix, and $0.11 \%$ of the time for the desalination-Current Law generation mix. Reserve violations are within expectations for both Current Law cases and are reasonable for the RPS80 cases, given the high renewable penetrations combined with the high amounts of nuclear power and the size of some of the VRE sites.

Figure 9 and Figure 11 show the price duration curves for the two RPS80 scenarios, and Figure 10 and Figure 12 show heat maps for the prices in the same two scenarios. In both cases, the effect of three fuel prices are reported based on different fuel-price projections in 2035 for natural gas and coal, which come from the AEO. ${ }^{29}$ We did not change the generation mix with the different scenarios - we adjusted only natural gas and coal prices. Section 2.3.4 below discusses those prices. The line in Figure 9 titled "Ref Oil Price vs Time" refers to the AEO reference case. The line titled "Low Oil Price vs Time" refers to the AEO low-oil-price scenario. 
The line titled "High Oil Price vs Time" refers to the AEO high-oil-price scenario. We developed an additional case with a $\$ 61 /$ metric ton $\mathrm{CO}_{2}$ cost of carbon assigned to the electric power plant emissions, which is the estimated social cost of carbon at a $3 \%$ average discount rate, as discussed in Section 2.4.5. As with the various energy price scenarios, we did not adjust the generation mix. Figure 10 and Figure 12 report all 8,760 hourly prices for the RPS80 reference scenario in each location. Note that the lowest prices in each location occur midday during the winter months; the highest occur during summer. Those trends match trends in other studies with high VRE penetrations. ${ }^{28}$

In the Texas-synthetic gasoline RPS80 scenario that uses the AEO reference case prices, three items are of interest. Curtailment drove prices to zero for 706 hours (8\%) of the year, as can be seen at the right of Figure 9. The black rectangles in Figure 10 indicate that most of those hours are in the middle of the day in the spring, fall, and winter. Those hours have $\$ 0 / \mathrm{MWh}$ electrical energy prices, because wind and PV generation during those hours is greater than the load." The combination of NGCCs and CTs are on the operating cost margin for most of the year, with NGCCs having a slightly lower marginal cost than CTs and thus resulting in lower electrical energy prices when they are operating and CTs are not. Yellow rectangles in Figure 10 show that many of those hours are in the evenings, especially during the summer, when demand for electrical energy increases due to higher residential loads and PV generation goes down due to the sun setting.

The difference between the prices from NGCCs and CTs is larger when a cost of carbon is included than when it is not because NGCCs are more efficient than CTs. For the Arizonadesalination case, the curtailment is approximately the same - 704 hours per year. During a small number of hours each year, the prices are at their caps — as can be seen at the left of Figure 9 and in red rectangles in Figure 10-primarily due to reserve violations during those hours. Reserve violations are caused by insufficient generation to meet the reserve requirements in addition to the load. They occur most often during hours with high rates of change in the net load, because those hours need the most generation to be turned on. One of the potential benefits of N-R HESs is that they can be more profitable than less flexible options because they can generate electricity during hours when its price is high (i.e., at the left of Figure 9 and Figure 11) and produce the industrial product when the price of electricity is low (i.e., at the right of Figure 9 and Figure 11).

\footnotetext{
${ }^{*}$ Unlike in the high-solar desalination scenarios, in which curtailment occurs during daylight hours, the high-wind synthetic gasoline scenarios have curtailment throughout the day. Curtailing even a small amount of wind drives prices to zero, revealing one of the challenges of today's market structures.
} 


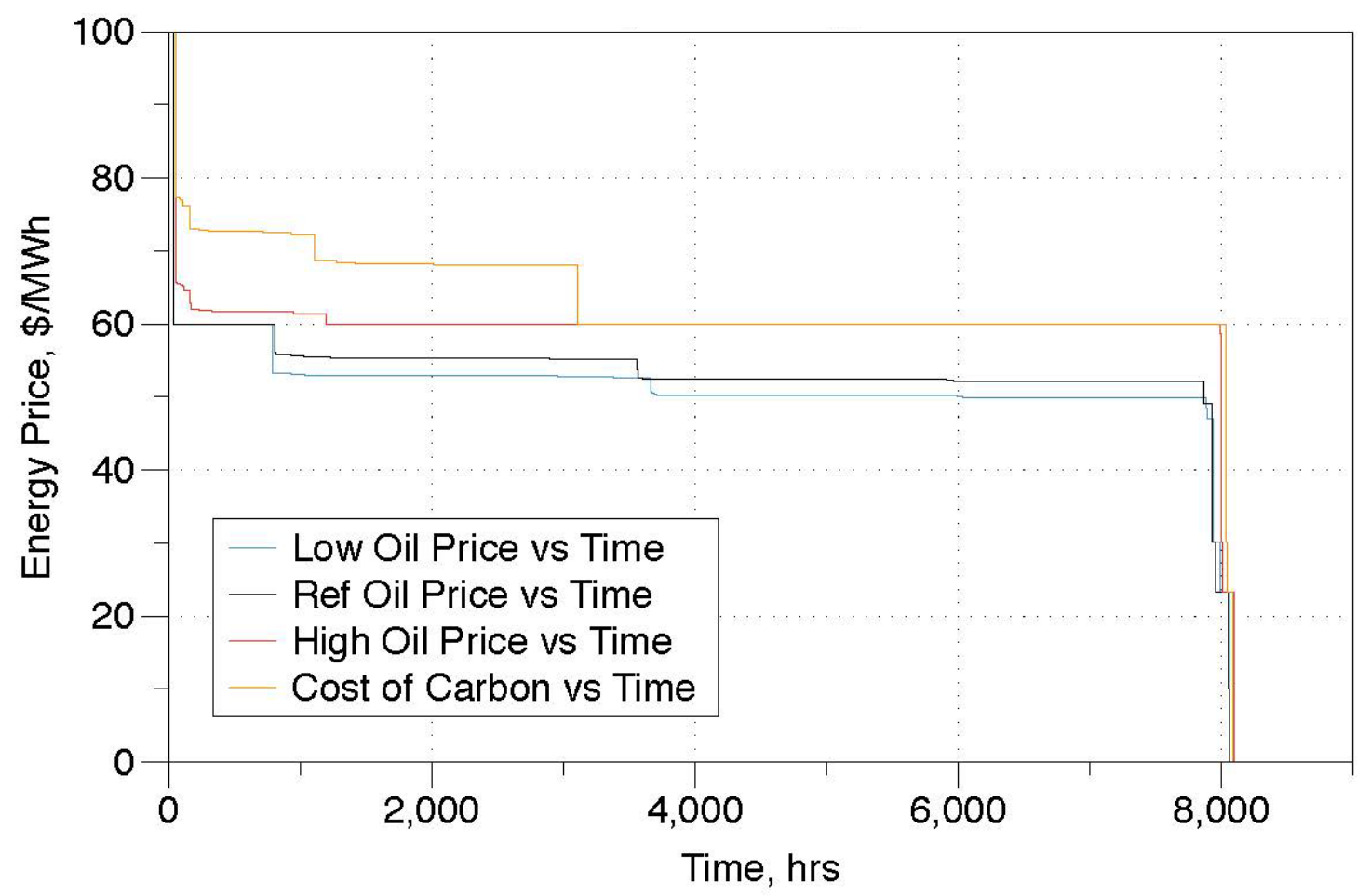

Figure 9. Texas-synthetic gasoline RPS80 scenario: electrical energy price duration curve

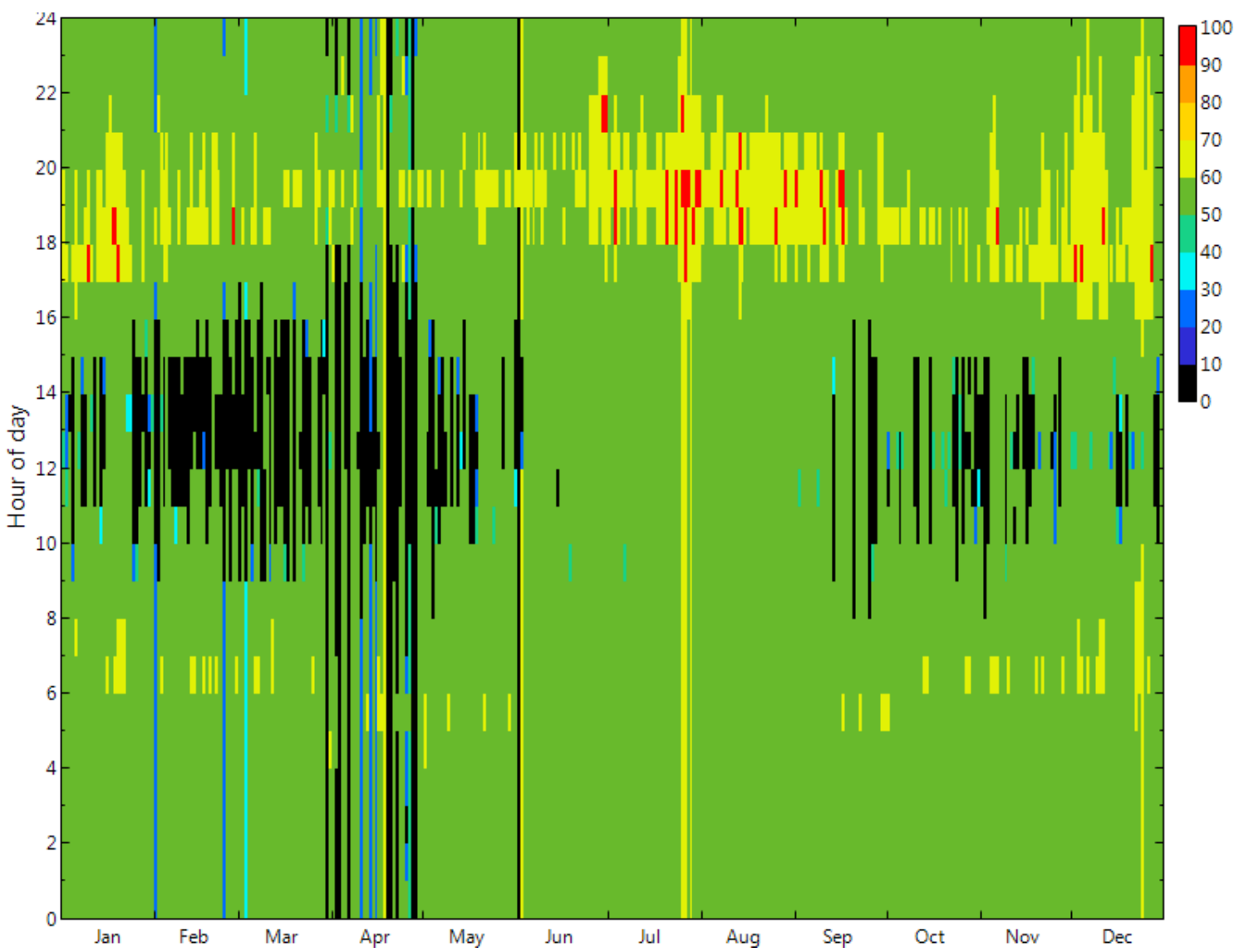

Figure 10. Texas-synthetic gasoline RPS80 scenario: electrical energy price heat map 


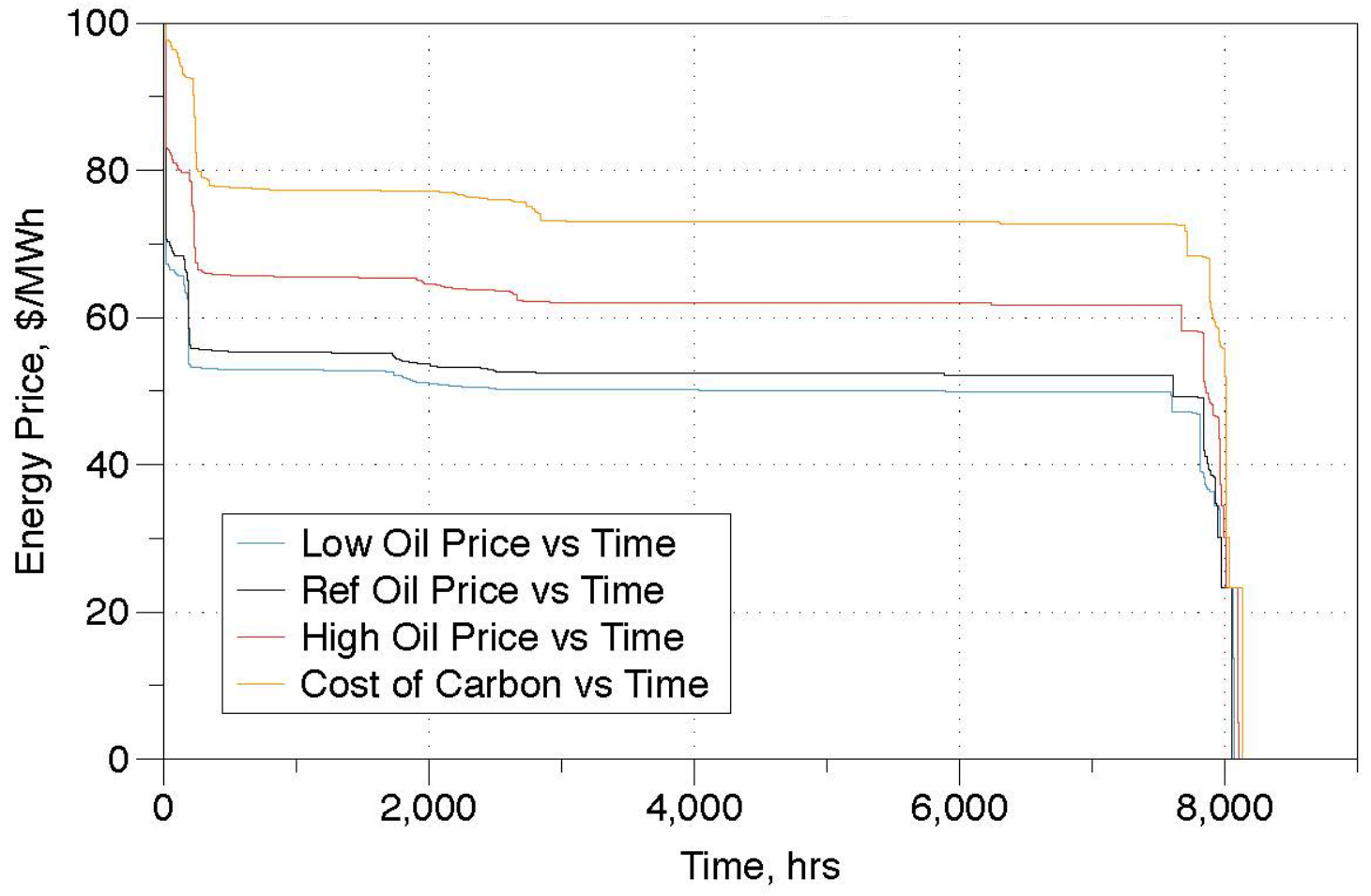

Figure 11. Arizona-desalination RPS80 scenario: electrical energy price duration curve 


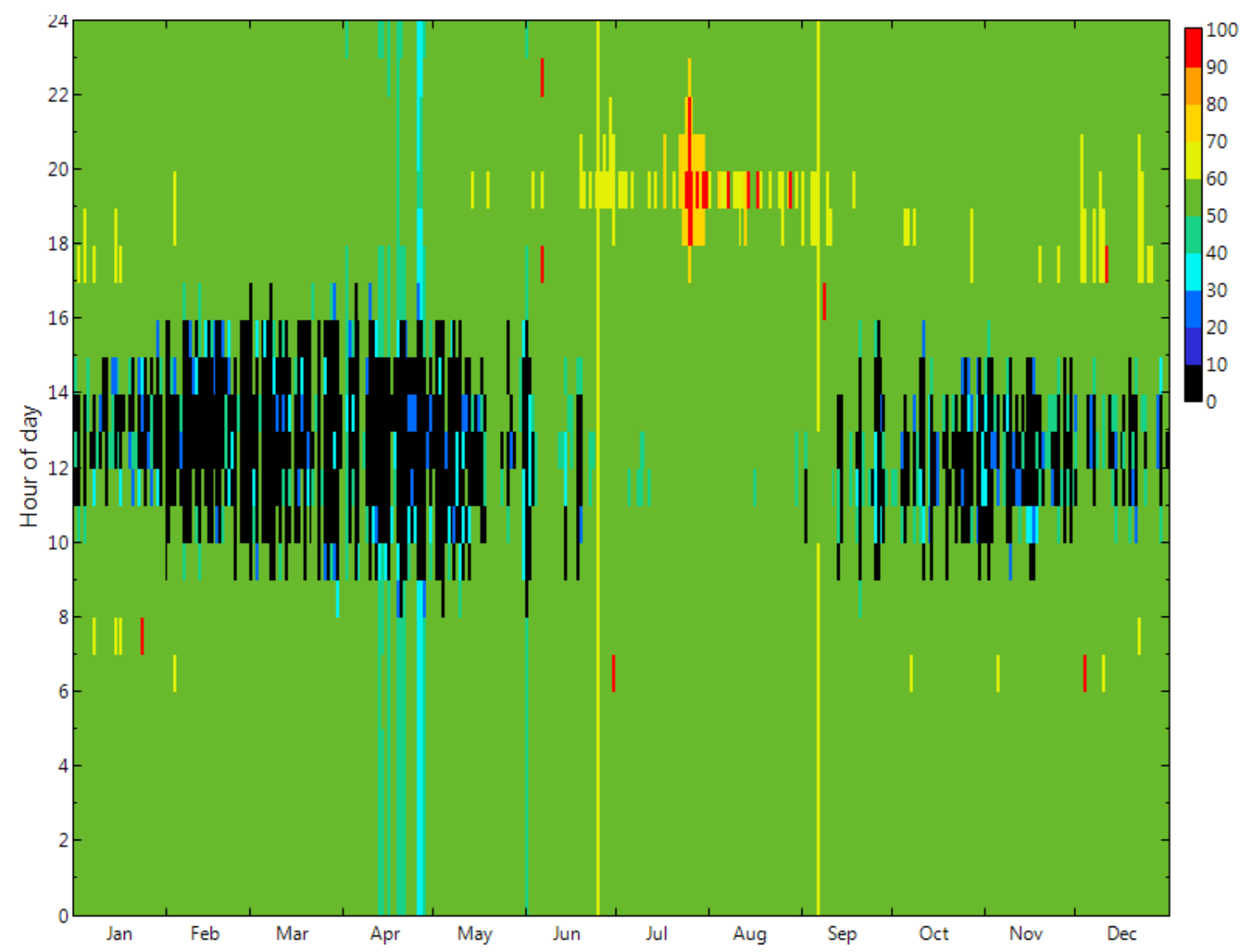

Figure 12. Arizona-desalination RPS80 scenario: electrical energy price heat map

Appendix B reports contingency, regulation, spinning, and flexibility reserve prices.

\subsubsection{Electricity Capacity Payments}

We estimated capacity payments $(\$ / \mathrm{kW}-\mathrm{yr})$ based on the observed variations in capacity payments in restructured markets over the last decade. The payments are intended to enable a new generator to earn a sufficiently large return to enter the market; this ensures that the generation resources are adequate to meet load during all hours of the year, even under unusual circumstances (e.g., an unplanned outage to a generator). Payments are usually calculated for the lowest-cost new generation option (typically a CT, though it could be a NGCC) to earn a fair rate of return. Actual values depend heavily on how well the markets operate and crucial assumptions about whether the grid is expected to have too much, too little, or exactly enough generation to be reliable; however, capacity markets are in their early development stages. Thus, the actual values of electricity capacity payments are unknown and highly uncertain. ${ }^{30}$

Based on historical trends and given uncertainty in practice, we used $\$ 50 / \mathrm{kW}$-yr for the basecase capacity payment. This is a mid-point between oversupply estimates, undersupply estimates, and the observed variation in capacity payments for different regional transmission organizations and independent system operators over the last decade. ${ }^{31}{ }^{32}$ In addition, we performed sensitivity analyses at two higher capacity payments: $\$ 100 / \mathrm{kW}-\mathrm{yr}$ and $\$ 150 / \mathrm{kW}-\mathrm{yr}$. Appendix C provides further details regarding the historical values of capacity payments. 
We validated our selected capacity payments by comparing them to the capacity payments required for a nuclear power generator and a $\mathrm{CT}$ acting as a peaking plant. We assumed that the CT would run during the $4 \%$ of the year when the electrical energy price is the highest, hourly electrical energy prices are set for the RPS80 scenario as described in Section 2.3.2, and that electrical energy would be the CT's only income source. To achieve an NPV of zero with a $10 \%$ discount rate at $100 \%$ equity in both Arizona or Texas, the CT would have to receive a capacity payment of $\$ 98 / \mathrm{kW}$-yr. The capacity payment would provide $81 \%$ of the gross income for the peaking plant. A nuclear power generator with only a nuclear reactor and thermal power cycle that generated electricity all hours during the year would require a $\$ 210 / \mathrm{kW}$-yr capacity payment in Texas. In Arizona, the same nuclear power generator would require a $\$ 218 / \mathrm{kW}$-yr capacity payment to achieve an NPV of zero.

Within this analysis, the N-R HES must provide electric power to the grid for the 50 hours during the year with the highest load to receive a capacity payment. (Note that these are the hours of gross load, not net load.) We arbitrarily chose 50 hours as the required number of hours. We allowed REopt to select the option where the N-R HES opts out of providing full capacity during those hours, but the N-R HES only receives a capacity payment for the minimum quantity of electric power provided during those hours.

\subsubsection{Fossil Fuel and Gasoline Price Projections}

For 2035 prices of coal, natural gas, and oil, we used values reported in the 2015 AEO. ${ }^{33}$ The EIA reports four "coupled" scenarios in its AEO; we used the U.S. average prices from three: reference, low oil price, and high oil price. EIA also reports a high oil and gas resource price scenario that we did not include in this analysis. The EIA also reports the wholesale prices for gasoline. Table 1 shows the prices used in this analysis, and Appendix D provides further details.

Table 1. EIA 2035 Energy Price Projections (2015 AEO - 2013\$)

\begin{tabular}{|c|c|c|c|}
\hline & Reference & High Oil & Low Oil \\
\hline Natural Gas & $\$ 6.98 / \mathrm{mmBtu}$ & $\$ 8.49 / \mathrm{mmBtu}$ & $\$ 6.62 / \mathrm{mmBtu}$ \\
\hline Coal & $\$ 2.79 / \mathrm{mmBtu}$ & $\$ 3.12 / \mathrm{mmBtu}$ & $\$ 2.62 / \mathrm{mmBtu}$ \\
\hline $\begin{array}{l}\text { Gasoline } \\
\text { (wholesale) }\end{array}$ & $\$ 3.00 /$ gal & $\$ 5.10 / \mathrm{gal}$ & $\$ 2.00 / \mathrm{gal}$ \\
\hline Oil (WTI spot) & $\$ 116 / \mathrm{bbl}$ & $\$ 215 / \mathrm{bbl}$ & $\$ 68 / \mathrm{bbl}$ \\
\hline
\end{tabular}

$\mathrm{mmBtu}=$ million British thermal units

gal = gallon

$\mathrm{bbl}=$ barrel

WTI = West Texas Intermediate

The assumption that the process that converts natural gas to synthetic gasoline is commercialized and mature predicates this analysis. If the process is mature, the competing price for the gasoline product will likely be the selling price necessary to achieve the required $10 \%$ internal rate of return (IRR) in a stand-alone plant that converts natural gas to gasoline using natural gas as the heat source. For a plant beginning operations in 2035, we calculated that required selling price at $\$ 2.12 /$ gal under the AEO reference natural gas prices. This estimate uses the same capital costs, yields, and financial parameters as the synthetic gasoline subsystem of a nuclear-synthetic 
gasoline configuration, but instead of the nuclear source for thermal energy, it uses natural gas at the EIA 2035 price projections and a 94\% super-efficient boiler with a capex of $\$ 7.1$ million. $^{34}$ The required selling price for the synthetic gasoline to achieve a $10 \%$ discount rate is $\$ 2.12 /$ gal.

\subsubsection{Water}

Estimating the price of water in the western United States is challenging due to a lack of a competitive market for water resources; multiple overlapping water management jurisdictions; differing prioritization regimes during times of drought; over-allocated water basins (e.g., more water rights exist than physical water resources); a lack of data; issues with data when the buyer is considered a beneficial user; and an organizational structure that results in prices much lower than actual cost when the resource is plentiful, much greater than actual cost when there is a shortage, and tending to spike between those circumstances.

To address these challenges and provide a framework to evaluate the price of new freshwater produced in the modeled N-R HES, we adopt an approach rooted in existing water-related studies from the Arizona Water Resources Development Commission, ${ }^{35}$ augmented by recent NREL and other research on alternative water resources. Appendix E describes the approach in detail. The approach is based on the estimated water shortage in 2035 and potential competing options to fill that shortfall. We generated a water supply curve from projected costs of the options and used the supply curve as the basis of the price of water in this analysis. That price is $\$ 1,471 /$ acre-foot (\$4.50/thousand gal and $\$ 1.19 /$ thousand liters). We assume that temporal impacts on the prices are negligible. We also assume that the cost of brackish water for desalination is negligible.

For a stand-alone RO plant using grid electricity and beginning operations in 2035, we calculated that the required selling price for the water to achieve a $10 \%$ discount rate is $\$ 1.18 /$ thousand gal $(\$ 0.000311 / \mathrm{kg})$ - a competing price using the RO desalination technology. The calculation uses the same capital costs, yields, and financial parameters as the desalination subsystem of a nuclear-thermal power cycle-desalination configuration, but instead of the nuclear electricity source, the calculation is based on grid electricity at the RPS80 case electricity prices. Actual prices are likely to be higher because they will likely include transaction, grid management, and other costs.

\subsection{Other Financial and Performance Assumptions used in Optimization}

\subsubsection{Capital and Operating Costs}

Table 2 and Table 3 report capital and operating costs used in this analysis. Costs for electricity generation equipment are from NREL's Annual Technology Baseline ${ }^{36}$ and other NREL references as listed in the tables and include all costs for a new facility (e.g., equipment, engineering, construction, financing, and land). Economies of scale were not included because scaling factors were not readily available. Costs for industrial processes are from INL's analysis. ${ }^{37}$ Capital costs include all construction costs and financing before the industrial process starts operating and selling products. Combined, the LW-SMR and thermal power cycle have a capital cost of $\$ 5,021 / \mathrm{kWe}$, which, at the assumed 30\% efficiency, is $\$ 1,506 / \mathrm{kWt}$. For comparison, other researchers have estimated the costs of nuclear power generators with thermal power cycles to cost from $\$ 1450 / \mathrm{kWt}$ to $\$ 2300 / \mathrm{kWt} ;{ }^{38}$ however, those costs are not for SMRs. 
In order to optimize the utilization of the heat energy between the industrial process and electricity generation, we modeled the thermal power cycle as an independent subsystem in REopt. We used two resources to identify appropriate capital costs for the thermal power cycle. A 2011 report from the Organization for Economic Co-operation and Development on the economics of SMRs found that the turbine, alternator, electrical, instrumentation, and controls costs account for $16.1 \%$ of the total SMR capital cost, or $26 \%$ of the direct costs, resulting in a cost of $\$ 1,312 / \mathrm{kW}$ for the thermal power cycle. ${ }^{39}$ A 2015 U.S. Environmental Protection Agency (EPA) report on combined heat and power technologies listed the cost of a thermal power cycle between $\$ 700 / \mathrm{kW}$ and $\$ 1100 / \mathrm{kW} .{ }^{40}$ We chose the higher thermal power cycle cost because it was developed specifically for nuclear power, and we applied an operations and maintenance $(\mathrm{O} \& \mathrm{M})$ cost of $\$ 95 /(\mathrm{kW}-\mathrm{yr})$ to the reactor to include the thermal power cycle O\&M costs.

Table 2. Capital and Operating Costs for Texas Scenario

\begin{tabular}{|llll|}
\hline Unit & Capital Cost & Fixed O\&M Cost & $\begin{array}{l}\text { Reference } \\
\text { Nuclear Reactor }\end{array}$ \\
\cline { 1 - 3 } & $\$ 3,716 / \mathrm{kWe}$ & $\$ 95 / \mathrm{kWe}-\mathrm{yr}$ & $\begin{array}{l}\text { Annual Technology } \\
\text { Baseline }\end{array}$ \\
\hline Thermal Power Cycle & $\$ 1,305 / \mathrm{kWe}$ & - & \\
\hline Gasoline Production Plant & $\$ 12,810 /(\mathrm{kg} / \mathrm{hr})$ & $\$ 1,537 /(\mathrm{kg} / \mathrm{hr}-\mathrm{yr})$ & INL report \\
\hline Wind Turbines & $\$ 1689 / \mathrm{kWe}^{41}$ & $\$ 46.75 / \mathrm{kWe}-\mathrm{yr}^{42}$ & See footnotes \\
\hline
\end{tabular}

Table 3. Capital and Operating Costs for Arizona Scenario

\begin{tabular}{|llll|}
\hline Unit & Capital Cost & Fixed O\&M Costs & $\begin{array}{l}\text { Reference } \\
\text { Nuclear Reactor }\end{array}$ \\
\hline Thermal Power Cycle & $\$ 1,716 / \mathrm{kWe}$ & $\$ 95 / \mathrm{kWe}-\mathrm{yr}$ & $\begin{array}{l}\text { Annual Technology } \\
\text { Baseline }\end{array}$ \\
\hline RO Desalination Plant & $\$ 32,894 /(\mathrm{kg} / \mathrm{s})^{\dagger}$ & $\$ 4,841 /(\mathrm{kg} / \mathrm{s}-\mathrm{yr})$ & INL report \\
\hline Solar PV Plant & $\$ 1,094 / \mathrm{kWe}^{43}$ & $\$ 8 /(\mathrm{kWe}-\mathrm{yr})^{24}$ & See footnotes \\
\hline
\end{tabular}

The units of $\$ / \mathrm{kg} / \mathrm{s}$ indicate the capital cost of a desalination plant that could produce water at a certain rate in units of $\mathrm{kg} / \mathrm{s}$.

\subsubsection{Financial Parameters and Calculations}

We performed an analysis of the annual cash flows for the 25-year economic life for each N-R HES because that life matches the expected lifetime of the industrial processes and renewable technologies. Table 4 shows the main parameters used in our financial calculations.

\footnotetext{
* The Annual Technology Baseline includes a \$2/MWh electricity variable O\&M cost for nuclear power generation. That variable cost was not used in this report.

${ }^{\dagger}$ A financing factor of $2.55 \%$ was added to the overnight capital cost.
} 
Table 4. Main Parameters Used in Our Financial Calculations

\begin{tabular}{|l|l|}
\hline Start of operations (year) & 2035 \\
\hline Analysis period (years) & 25 \\
\hline Tax rate & $35 \%$ \\
\hline Cost of equity & $10 \%$ \\
\hline Debt percentage & $0.00 \%$ \\
\hline Discount rate (nominal) & $10 \%$ \\
\hline $\begin{array}{l}\text { Inflation rate } \\
\text { (electricity/water/gasoline/natural } \\
\text { gas) }\end{array}$ & $3.0 \%$ \\
\hline
\end{tabular}

As can be inferred from Table 4, equity investment finances $100 \%$ of the capital expenses. All capital expenses occur during the construction period. The construction period is considered year 0 and is not discounted.

The cost of equity $(10 \%)$ is equal to the nominal discount rate because no debt was assumed. The rate is based on the recommendation of Short (1995) that an after-tax discount rate of $10 \%$ be used unless a project is either for a specific investor or well-defined, including an analysis of financial risks and a survey of discount rates on similar projects ${ }^{44}$. Lower weighted average costs of capital (WACC) are sometimes available when debt is used to provide some of the costs; however, due to a lack of more detailed information, we consider $10 \%$ reasonable for this analysis.

We used a 3\% inflation rate applicable to the price of all commodities (such as natural gas and gasoline) and services (i.e., fixed and variable O\&M); thus, costs increase at the rate of inflation. In other words, costs remain stable in real terms.

The period of analysis includes the year of construction (year 0) and the 25 years of operations (years 1 through 25). Letting $t$ denote each year of operations, we calculated the present value of each expense and revenue using the following formula:

$$
\text { Present value }=\sum_{t=1}^{\text {Analysis Period }} \frac{\text { nominal cash flow } \times(1+\text { inflation rate })^{t-1}}{(1+\text { discount rate })^{t}}
$$

As the formula implies, the first discounted period is year 1 of operations; inflation is assessed on years 2 through 25. Expenses and financing during the construction period, including all capital expenses, are not included because they are incorporated in the capital expenditures reported in Section 2.4.1.

Our analysis included a tax rate of 35\%. We used the 15-year Modified Accelerated Cost Recovery System schedule to discount capital costs of the nuclear and industrial plants and the 5year Modified Accelerated Cost Recovery System schedule to discount renewable technology capital costs. 
The main difference between these financial parameters and those used in the previous analysis is the cost of equity, for which we used $10 \%$ nominal and the previous analysis used $5 \%$ real. ${ }^{45}$ The 5\% real discount rate used in the previous analysis is equivalent to an $8.15 \%$ nominal discount rate at $3 \%$ inflation, as was used in both analyses. We performed a sensitivity using an $8.15 \%$ nominal discount rate so that the reader can compare its results to the base-case analysis.

The output of the cash flow model includes NPV, TCI, present value of revenues and expenses, nominal annual cash flows, payback period, and IRR. We often report NPV, IRR, the NPV/TCI ratio because those three values inform both the expected returns and choices between competing investments in a capital-constrained environment.

\subsubsection{Conversion Yield Assumptions}

As shown in Table 5, we based conversion assumptions on the previous analysis. ${ }^{46}$

Table 5. Conversion Assumptions ${ }^{47}$

\begin{tabular}{|ll|}
\hline Synthetic gasoline natural gas requirement & Assumed Value \\
\hline Synthetic gasoline heat requirement & $171,300 \mathrm{Btu}(\mathrm{HHV}) /$ gal gasoline \\
\hline Desalination electricity yield & $9,140 \mathrm{Btu} /$ gal gasoline \\
\hline
\end{tabular}

$\mathrm{HHV}=$ Higher heating value

\subsubsection{Levelized Cost of Energy (LCOE) Comparisons}

We calculated the levelized cost of energy (LCOE) for each electricity generation option based on the base-case parameters described above, without a cost of carbon. We report NGCC with two capacity factors (CFs): $100 \%$ to match the assumed nuclear CF and $92 \%$ to match the percentage of hours in a year during which the price of electricity is greater than $\$ 0 / \mathrm{MWh}$. Wind and PV CFs are based on their resource availability. Depreciation is estimated using the modified accelerated cost recovery system deprecation as allowed by law. Note that the depreciation schedule for nuclear is longer than for other technologies, which results in nuclear generation having a greater tax burden in the LCOE.

Often, the analysis period used for nuclear reactors is longer than the 25 -year period used throughout this report. Increasing the analysis period for nuclear generation from 25 years to 40 years reduces the LCOE by $5 \%$ from $\$ 93.33 / \mathrm{MWh}$ to $\$ 88.55 / \mathrm{MWh}$. 
Table 6. LCOEs for Electric Power Generation Technologies (\$/MWh)

\begin{tabular}{llllll} 
Capex & $\begin{array}{l}\text { Fixed } \\
\text { O\&M }\end{array}$ & $\begin{array}{l}\text { Variable O\&M } \\
\text { +Fuel }\end{array}$ & Tax & Total \\
Nuclear @ 100\% CF & $\$ 63.15$ & $\$ 13.77$ & $\$ 0.00$ & $\$ 16.41$ & $\$ 93.33$ \\
NGCC @ 92\% CF & $\$ 12.75$ & $\$ 2.28$ & $\$ 62.66$ & $\$ 3.31$ & $\$ 81.01$ \\
NGCC @ 100\% CF & $\$ 11.73$ & $\$ 2.10$ & $\$ 62.66$ & $\$ 3.05$ & $\$ 79.54$ \\
PV @ 19\% CF & $\$ 72.86$ & $\$ 6.14$ & $\$ 0$ & $\$ 8.90$ & $\$ 87.90$ \\
Wind @ 39\% CF & $\$ 54.30$ & $\$ 17.32$ & $\$ 0$ & $\$ 6.63$ & $\$ 78.25$ \\
\hline
\end{tabular}

Capex $=$ capital expenditure

\subsubsection{Cost of Carbon}

To add a cost of carbon emissions to specific scenarios, we used the range of social costs of carbon. The U.S. government provides social costs of carbon for use in analyses of the climate benefits of policies and rules. ${ }^{48}$ Social costs of carbon are estimates of the economic damages associated with small increases in $\mathrm{CO}_{2}$ emissions. Because the damage estimates are futurelooking, the government uses three different discount rates to convert the values to current-year dollars: $5 \%, 3 \%$, and $2.5 \%$. In addition, because the extent of damages is uncertain, the government provides a second value with a $3 \%$ discount rate that uses the $95^{\text {th }}$ percentile of the range of damage estimates instead of the mean. ${ }^{*}$ Table 7 reports the estimated social cost of carbon in 2035 in $2014 \$$. These values were used because we considered the difference between $2013 \$$ and $2014 \$$ negligible.

Table 7. Social Costs of Carbon Emissions in 2035 ( $\$$ / metric ton $\left.\mathrm{CO}_{2} \mathrm{e}\right)$

\begin{tabular}{|lllll|}
\hline $\begin{array}{l}\text { Discount Rate } \\
\text { and Statistic }\end{array}$ & $5 \%$ & $3 \%$ & $2.5 \%$ & $\begin{array}{l}3 \% \\
95 \text { th percentile }\end{array}$ \\
\hline 2035 Cost & $\$ 20$ & $\$ 61$ & $\$ 86$ & $\$ 186$ \\
\hline
\end{tabular}

\footnotetext{
${ }^{*}$ Values are updated from $2007 \$$ to $2014 \$$ in a printout of an EPA website available at http://denverclimatestudygroup.com/wp-content/uploads/2015/10/2015-The-Social-Cost-of-Carbon-studysummary.pdf
} 


\section{N-R HES Design on Operational Optimization Results}

\subsection{Results for the Texas-Synthetic Gasoline Scenario}

The Texas scenario consists of four primary subsystems: (1) a nuclear reactor, (2) a thermal power cycle that can be associated with the nuclear reactor, (3) a synthetic gasoline plant, and (4) a wind power plant. We set the same maximum size for the nuclear reactor, the thermal power cycle, the industrial process, and the wind power plant-50 MWe to show the impacts of each subsystem clearly. We also ran a sensitivity analysis on the size of the nuclear reactor. The thermal power cycle efficiency of 30\% implies a thermal capacity of $167 \mathrm{MWt}$ for the nuclear reactor and synthetic gasoline plant. In this scenario, either the thermal power cycle or the synthetic gasoline plant can be sized to use all of the heat generated by the nuclear reactor. The wind power plant also has a capacity of $50 \mathrm{MWe}$. REopt was used to determine the optimal size of each subsystem and the energy flow on an hourly basis. It allowed for the energy to be split (i.e., some of the thermal energy from the nuclear reactor can be used for the industrial process and the remainder for electricity) during any hour if that provided the optimal solution.

\subsubsection{Potential Profitability}

We analyzed the potential profitability of the Texas N-R HES by varying the prices of the electricity and gasoline products and using REopt to calculate the optimal subsystem combinations and internal dispatch, as discussed in Section 2. We varied the price of the gasoline product from $\$ 0 /$ gal to $\$ 3.00 /$ gal the upper value is EIA's reference case price projection for the wholesale price of gasoline in 2035 (see Table 1). We varied the price of electricity using a multiplier that affected the electrical energy price for all 8,760 hours in the year. ${ }^{*}$ In each case, the multiplier was randomly assigned a value between 0 and 2; thus, the electrical energy price in that case could be $\$ 0 / \mathrm{MWh}$ for every hour of the year, twice the electrical energy price developed for the reference and described in Section 2.3.2 above, or any other multiplied value between 0 and 2 . The electricity multiplier could be considered a combination of (1) the difference between marginal generation costs and market prices (due to bidding strategies) and (2) uncertainty in the natural gas price because natural gas is on the operating cost margin for the vast majority of the year. Unless stated otherwise, all other parameters remain at the reference values. Note that this analysis assumes perfect foresight of all expenses and product prices throughout the project life.

Figure 13 shows the optimal configuration selections for $\approx 2,000$ combinations of gasoline price and electricity multiplier. These values were independently, randomly sampled from a uniform distribution across the ranges described above. The results of this analysis indicate:

- If the electricity price multiplier is less than 1.25 and the price of gasoline is less than $\$ 2.09 /$ gal, no configurations are profitable (i.e., the NPV is less than zero for all combinations).

- If the electricity price multiplier is between 1.25 and 1.3 and the price of gasoline is less than $\$ 2.09 /$ gal (as shown in the dark blue dots), a wind plant is profitable to the owner

\footnotetext{
${ }^{*}$ Prices of ancillary services (reserves, flex reserves, and regulation up and down) were not multiplied because a change in price has little effect on the operational selection and optimization.
} 
(the NPV is positive), but the LW-SMR nuclear reactor is not profitable with either a thermal power cycle or the synthetic gasoline process.

- If the electricity price multiplier is greater than 1.3 and the price of gasoline is less than $\$ 2.09 /$ gal (as shown in the salmon-colored dots), both a wind plant and a LW-SMR nuclear reactor-power cycle combination are profitable.

- If the electricity price multiplier is less than 1.25 and the price of gasoline is greater than $\$ 2.09 /$ gal (as shown in the yellow dots), the LW-SMR nuclear reactor-synthetic gasoline process is profitable, but neither of the electricity generation subsystems are profitable.

- If the electricity price multiplier is greater than 1.25 and the price of gasoline is greater than $\$ 2.09 /$ gal (as shown in the light blue dots), the LW-SMR nuclear reactor-synthetic gasoline process is profitable on the gasoline value. Because gasoline production provides more income than electricity, REopt indicates that the synthetic gasoline plant optimally be built at its maximum capacity and that the full capacity of the nuclear reactor is optimally used to provide heat to the synthetic gasoline subsystem (i.e., the thermal power cycle is not necessary). The price of electricity is high enough that the wind power plant is profitable. A coupled configuration producing both synthetic gasoline and electricity will be optimal under these conditions if the maximum size of the industrial process is smaller than the size of the nuclear reactor.

The solid black dot indicates the reference-case gasoline price projection (\$3.00/gal) and the electricity price vector developed for this analysis (the multiplier is 1.0).

The location of the open black dot signifies the minimum selling price for synthetic gasoline for a profitable stand-alone synthetic gasoline process. That analysis was performed to determine a competing price for the synthetic gasoline technology. For that analysis, we used the same capital costs, yields, and financial parameters as the synthetic gasoline process but instead of the nuclear heat source, we used the capital cost of a natural gas-fired boiler and the included the operating cost of natural gas to fire that boiler in the operating costs. The resulting minimum selling price for the natural gas-heated synthetic fuel to achieve an NPV of $\$ 0$ at a $10 \%$ discount rate is $\$ 2.12 / \mathrm{gal}$, as discussed in Section 2.3.4., The synthetic gasoline price necessary for the nuclear-synthetic gasoline configuration to be profitable is a minimum of $\$ 2.09 / \mathrm{gal}$, slightly lower than that for the natural gas-heated synthetic gasoline configuration, because the cost of thermal energy from nuclear is less than that from natural gas at the projected natural gas price of $\$ 6.98 / \mathrm{mmBtu}$. 


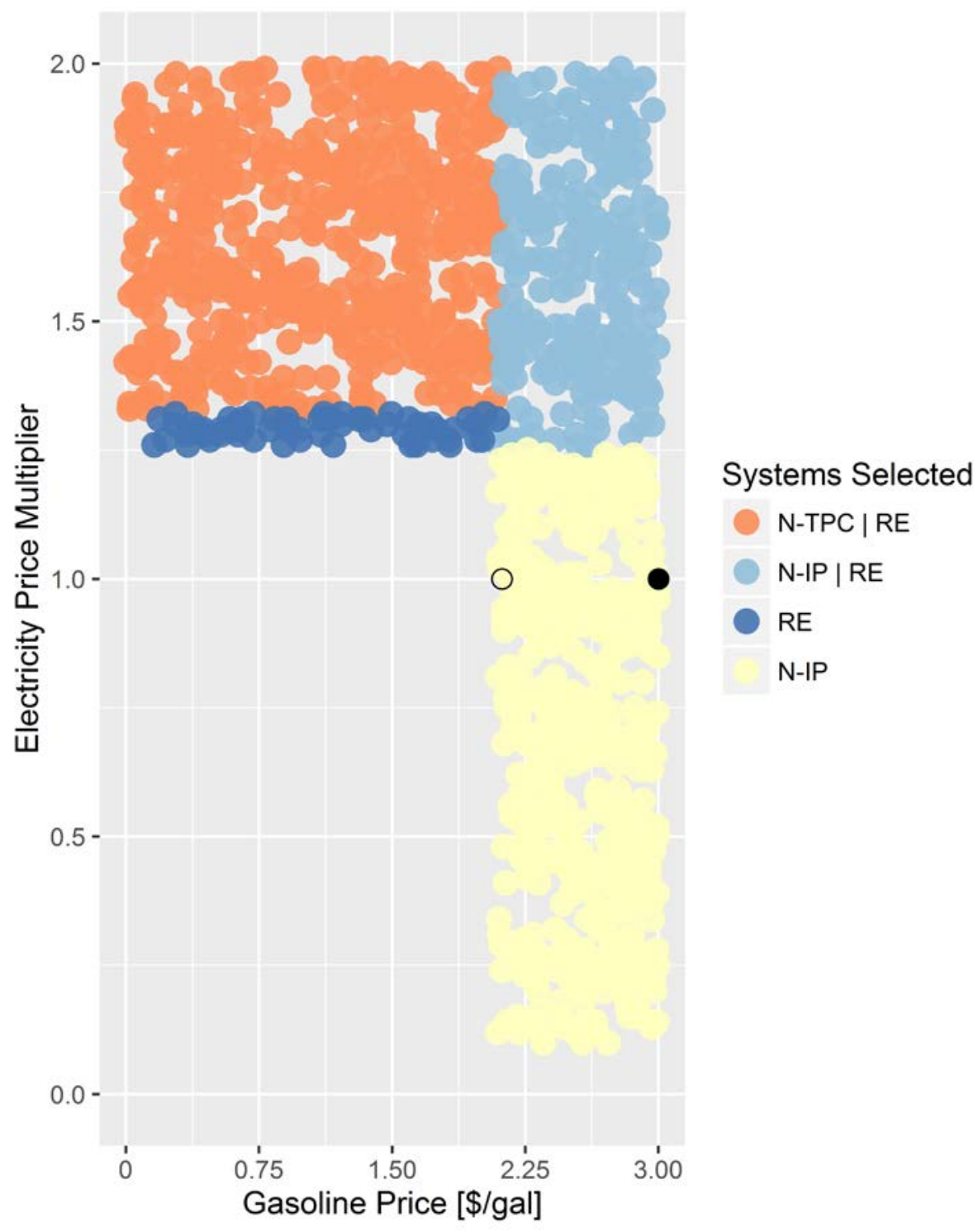

Figure 13. Optimal configurations for the Texas-synthetic gasoline scenario at various gasoline prices and electricity price multipliers

N-TPC: Nuclear reactor and thermal

N-IP: Nuclear reactor and industrial process

RE: Renewable electricity generation

Solid black dot at electricity price multiplier of 1.0 and $\$ 3.00 /$ gal gasoline price: reference case gasoline price projection; reference case electricity price vector

Open black dot: minimum gasoline selling price for a synthetic gasoline plant using natural gas heating; reference case electricity price vector

Figure 14 shows the optimal product mix based on each optimal configuration shown in Figure 13. As in Figure 13, if the projected price of gasoline is greater than $\$ 2.09 /$ gal, a nuclearsynthetic gasoline configuration would be most profitable. The right graphic in Figure 14 shows that, when the optimal configuration includes gasoline production, the gasoline production subsystem operates optimally at as close to full capacity through the year as possible. The left graphic in Figure 14 shows that the wind turbines produce a constant amount of electrical energy 
through the year (tan dots) and that, if a nuclear reactor with thermal power cycle is built, it optimally maximizes production of electricity throughout the year (black dots). That result may differ if there are negative electricity prices at some hours during the year, but we use zero or positive hourly electricity prices in this analysis.
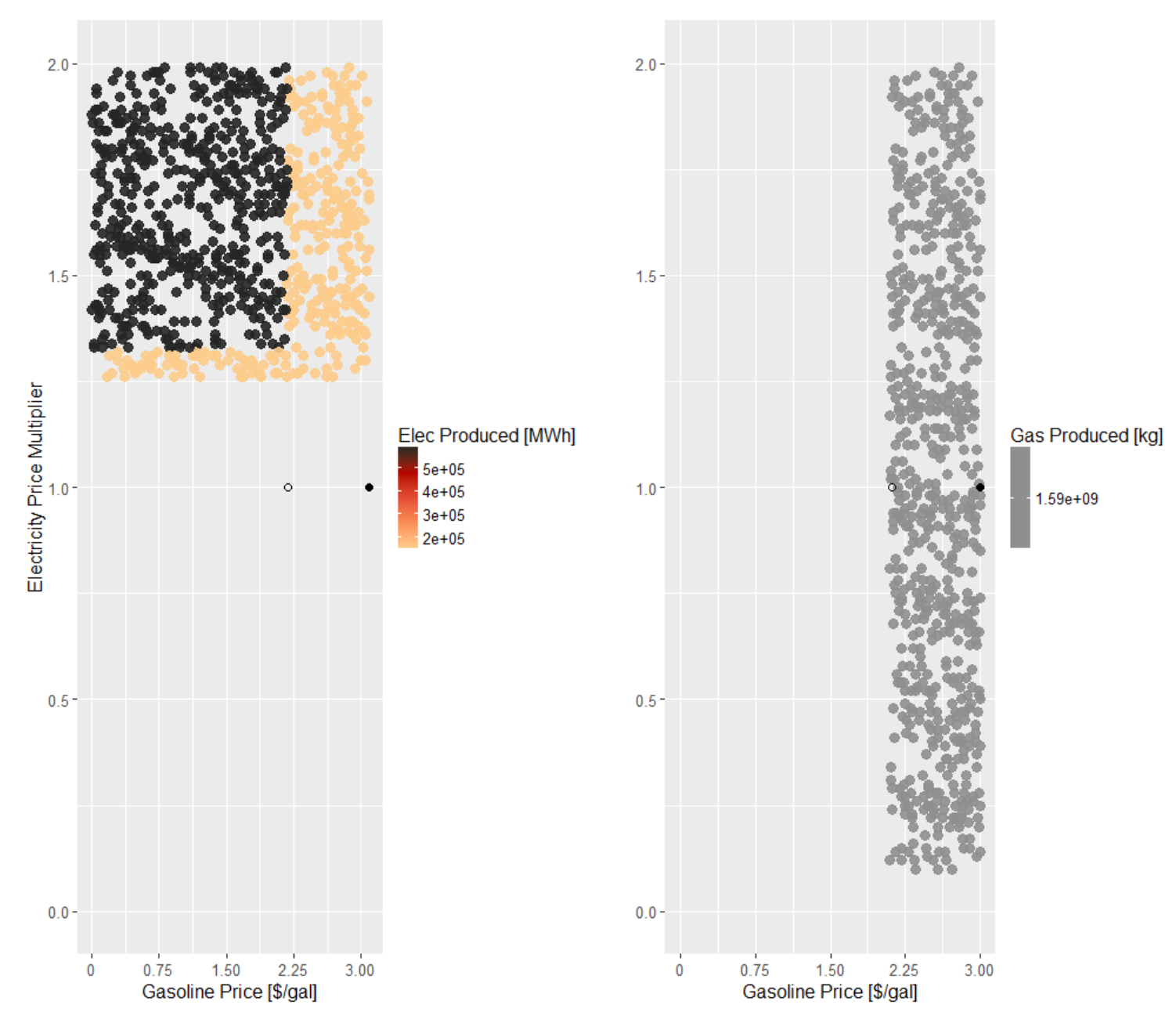

Figure 14. Optimal annual product generation at various gasoline prices and electricity price multipliers for the Texas-synthetic gasoline scenario.

Electricity is on the left with greater generation at the darker color. Synthetic gasoline is on the right. Electricity pricing based on AEO reference case and $\$ 50 / \mathrm{kW}$-yr capacity payments.

Solid black dot at electricity price multiplier of 1.0 and $\$ 3.00 /$ gal gasoline price: reference case gasoline price projection; reference case electricity price vector

Open black dot: minimum gasoline selling price for a synthetic gasoline plant using natural gas heating; reference case electricity price vector

Figure 15 shows the NPVs for the optimal configurations as shown in Figure 13 above. Note that profitability increases more dramatically with rising gasoline prices than with rising electricity prices. Also note that wind generation provides a lower NPV than the thermal power cycle because it generates electricity during hours with below-average prices (as shown by the distinctive change at an electricity price multiplier of 1.3). 


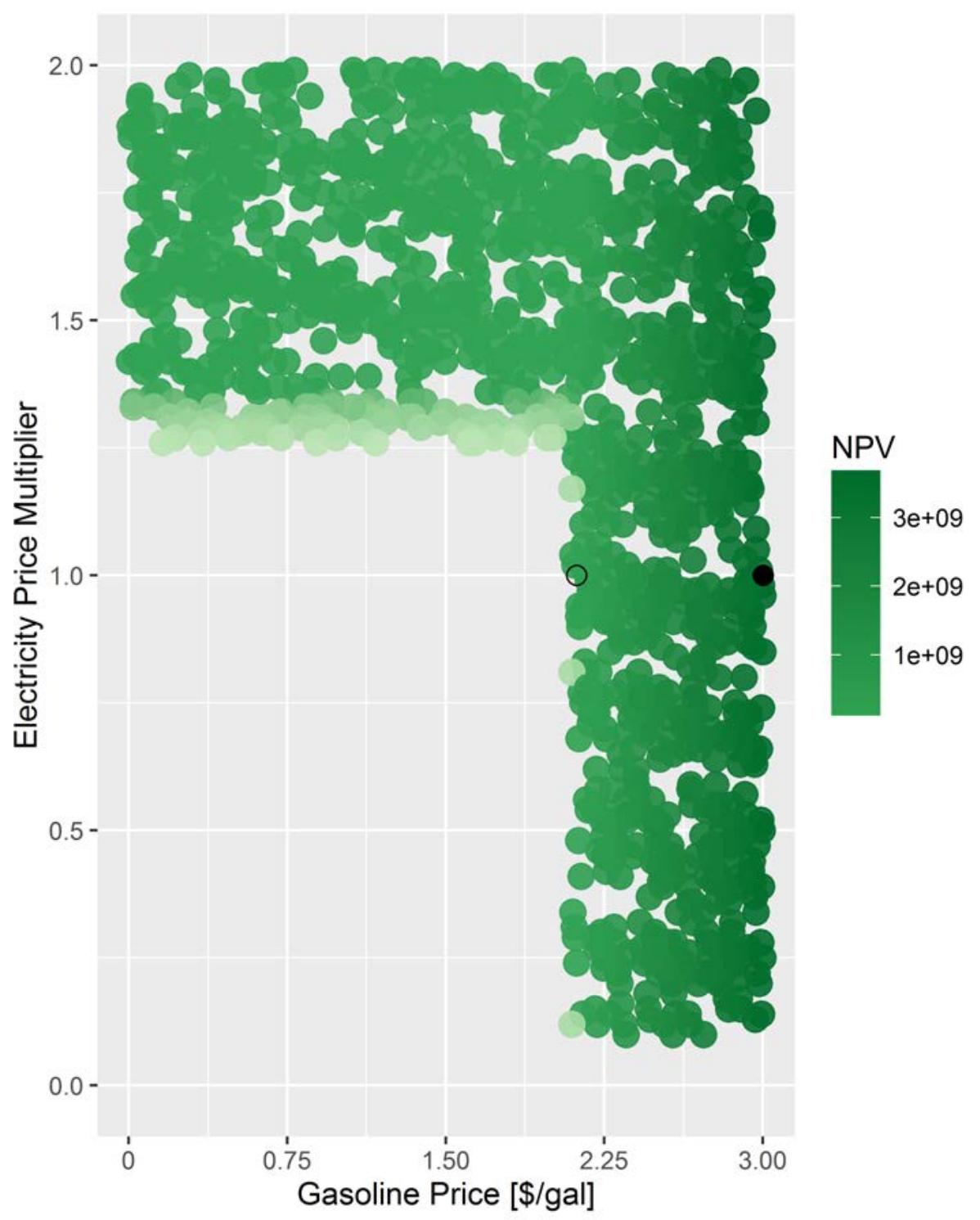

Figure 15. Texas-Synthetic Gasoline Scenario NPVs at various gasoline prices and electricity price multipliers - Electricity pricing based on AEO reference case and $\$ 50 / \mathbf{k W}$-yr capacity payments.

Darker shades indicate higher NPVs.

Solid black dot at electricity price multiplier of 1.0 and $\$ 3.00 /$ gal gasoline price: reference case gasoline price projection; reference case electricity price vector

Open black dot: minimum gasoline selling price for a synthetic gasoline plant using natural gas heating; reference case electricity price vector

In Figure 13-Figure 15, the solid black dot indicates the scenarios with base-case conditions. Table 8 provides the present values of all the annual revenues and expenses under the base-case parameters for the optimal configuration (a nuclear reactor with the synthetic gasoline industrial process). For comparison, present values for two alternative configurations are also provided. In the first of those configurations, a thermal power cycle is added; however, electricity is not produced because gasoline provides greater income than electricity for all hours during the year. The second alternative configuration adds a wind power plant to the subsystems in the first 
alternative configuration. The wind power plant produces electricity that is sold to the grid. Table 9 summarizes the production and financial results for all three configurations.

Table 8 and Table 9 show that all three configurations are profitable, with NPVs ranging from $\$ 3.631$ billion to $\$ 3.699$ billion. As shown in Figure 13, the most profitable configuration has only the LW-SMR nuclear reactor and the industrial process. Revenue for generating electricity is not high enough to produce electricity instead of synthetic gasoline.

Note that the synthetic gasoline process has a capital cost of $\$ 2.3$ billion, which is more than an order of magnitude greater than the nuclear reactor (capital cost \$186 million) and nearly an order of magnitude greater than the nuclear reactor coupled with the thermal power cycle (capital cost of \$251 million). An N-R HES configuration that includes all of the subsystems considered here has the vast majority of its capital in the industrial process, which also generates the vast majority of the configuration's net income. 
Table 8. Texas-Synthetic Gasoline Scenario Present Values at Base-Case Conditions for Three Configurations (Negative Values Indicate Expenses and Positive Indicate Income)

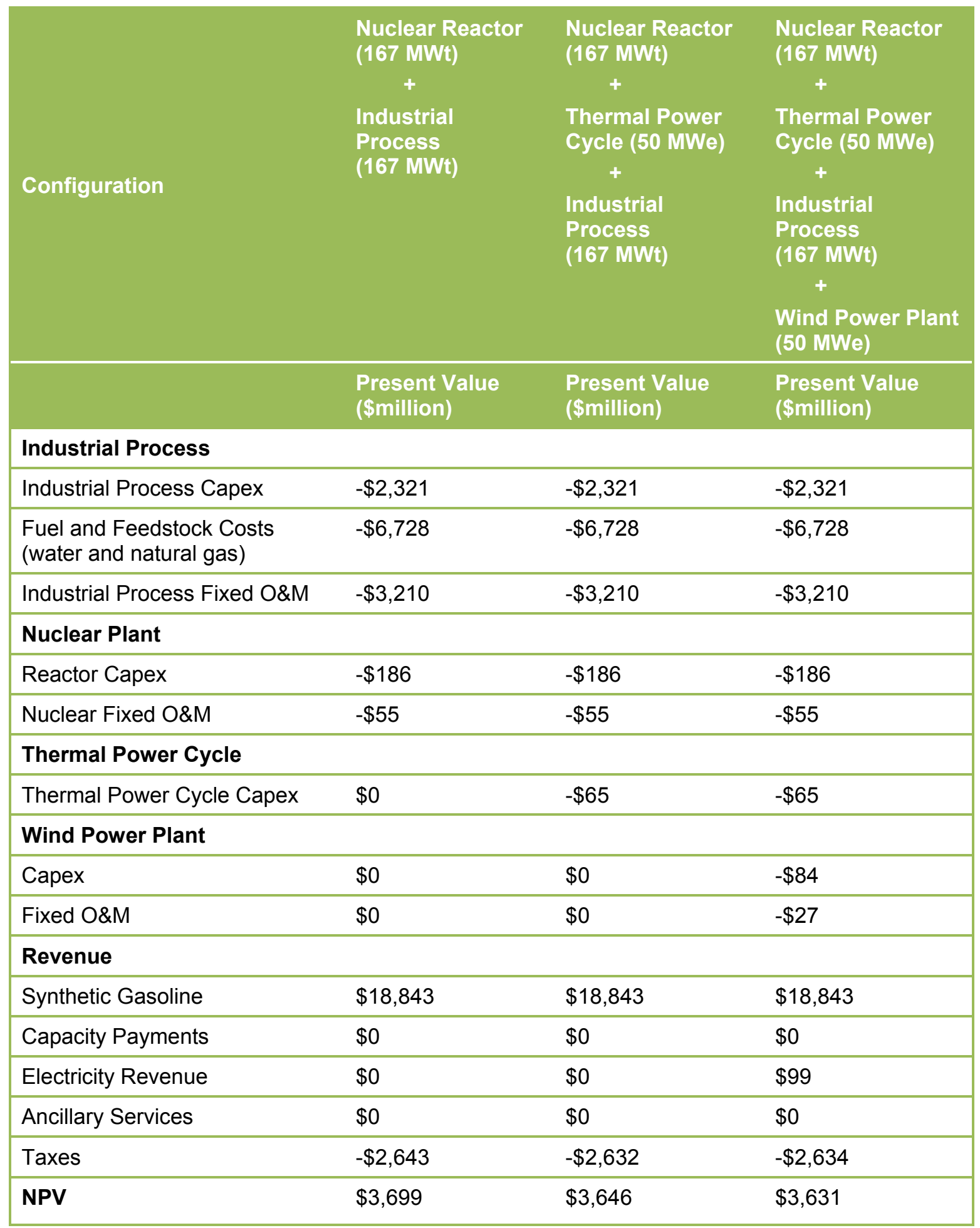


Table 9. Texas-Synthetic Gasoline Scenario Output Summary at Base-Case Conditions for Three Configurations

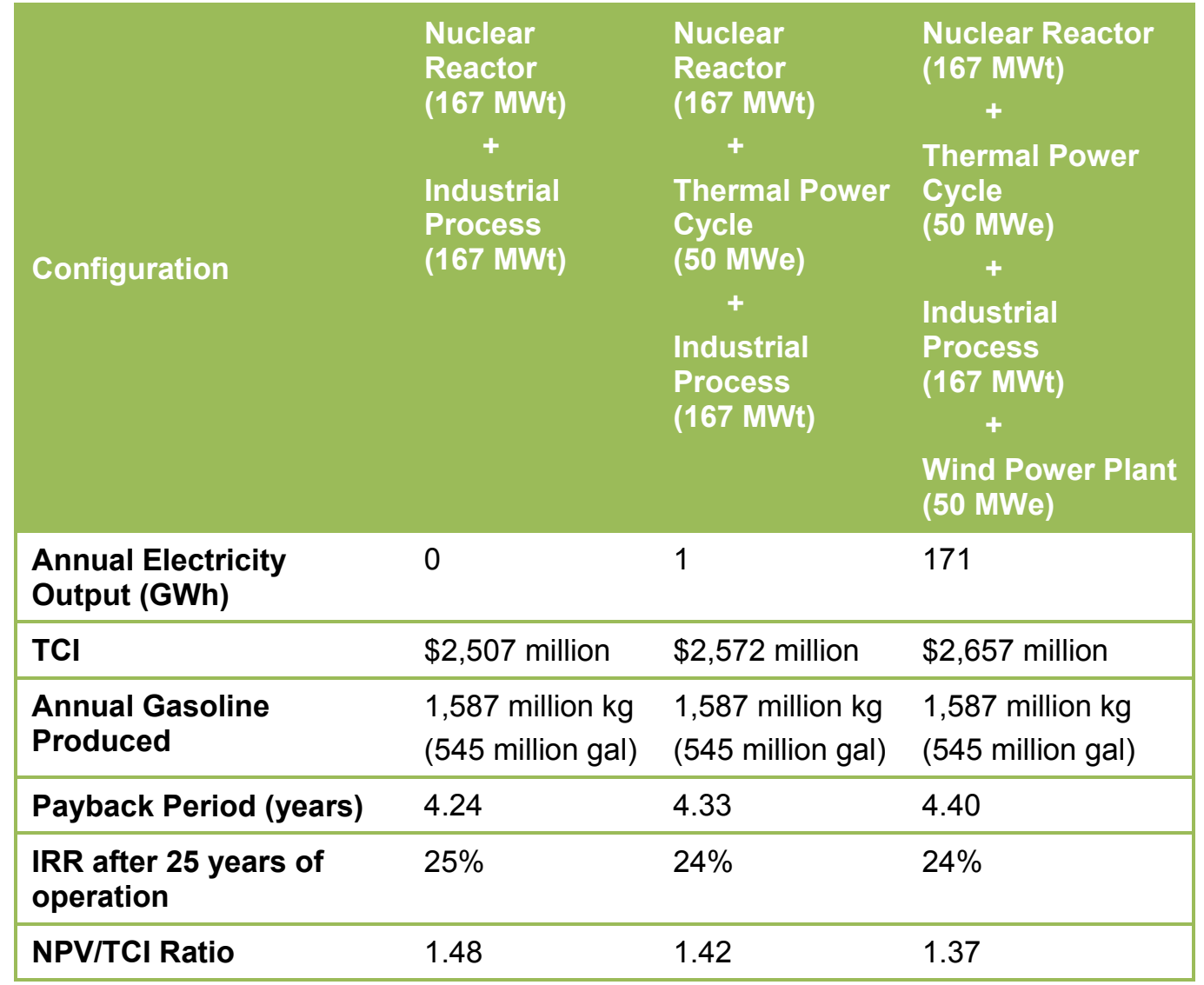

Table 10 compares finances of the coupled LW-SMR nuclear-synthetic gasoline configuration and competing options. The top two rows show configurations that only produce synthetic gasoline - these configurations do not produce electricity. For comparison, the bottom three rows show loosely coupled configurations that have both an electricity generation source (either nuclear or NGCC) and a synthetic gasoline plant where the heat requirement is met by combustion of natural gas. The second NGCC is operated only when the price of electricity is greater than $\$ 0 / \mathrm{MWh}(92 \%$ of the hours through the year). Note that the nuclear electricity generation unit does not meet the $10 \%$ hurdle rate.

Table 10 shows that the NPV and the IRR for the exclusively synthetic gasoline configuration is better than that of the configurations that produce both synthetic gasoline and electricity. This is due to the rates of return: synthetic gasoline has a rate of return greater than $10 \%$ and electricity generation by either nuclear energy or NGCC has a rate of return less than $10 \%$. In addition, the increased capital cost for electricity generation increases the denominator of the NPV/TCI ratio, reducing its value. Likewise, because nuclear energy requires a larger capital investment than an NGCC, the NPV/TCI ratio with a nuclear reactor is lower than that with an NGCC. 
Table 10. Financial Comparison Between Configurations for the Texas-Synthetic Gasoline Scenario

\begin{tabular}{|c|c|c|c|c|c|}
\hline & $\begin{array}{l}\text { NPV @ } 10 \% \\
\text { Discount Rate }\end{array}$ & $\mathrm{TCl}$ & $\begin{array}{l}\text { NPV/TCI } \\
\text { Ratio }\end{array}$ & IRR & $\begin{array}{l}\text { Annual } \\
\text { Electricity } \\
\text { Output } \\
\text { (GWh) }\end{array}$ \\
\hline $\begin{array}{l}\text { Nuclear reactor }(167 \mathrm{MWt}) \text {, } \\
\text { thermal power cycle }(50 \\
\text { MWe), synthetic gasoline } \\
\text { subsystem }(167 \mathrm{MW}), \text { wind } \\
\text { power plant }(50 \mathrm{MWe})\end{array}$ & $\$ 3.63$ billion & $\$ 2.66$ billion & 1.37 & $24 \%$ & 171 \\
\hline $\begin{array}{l}\text { Nuclear reactor }(167 \mathrm{MWt}) \text { \& } \\
\text { synthetic gasoline } \\
\text { subsystem (167 MWt) } \\
\text { (No electricity production) }\end{array}$ & & $\$ 2.51$ billion & 1.48 & $25 \%$ & 0 \\
\hline $\begin{array}{l}\text { Natural gas boiler }(167 \mathrm{MWt}) \\
\text { \& synthetic gasoline } \\
\text { subsystem (167 MWt) } \\
\text { (No electricity production) }\end{array}$ & \$3.60 billion & $\$ 2.33$ billion & 1.55 & $25 \%$ & 0 \\
\hline $\begin{array}{l}\text { Uncoupled - } \\
\text { Nuclear reactor and thermal } \\
\text { power cycle producing } 50 \\
\text { MWe at } 100 \% \text { capacity } \\
\text { factor and }\end{array}$ & $\$ 3.54$ billion & $\$ 2.58$ billion & 1.37 & $24 \%$ & 438 \\
\hline $\begin{array}{l}\text { Natural gas boiler }(167 \mathrm{MWt}) \\
\text { \& synthetic gasoline } \\
\text { subsystem (167 MWt) }\end{array}$ & & & & & \\
\hline $\begin{array}{l}\text { Uncoupled - } \\
\text { NGCC producing } 50 \mathrm{MWe} \text { at } \\
100 \% \text { capacity factor and }\end{array}$ & $\$ 3.58$ billion & $\$ 2.37$ billion & 1.51 & $25 \%$ & 438 \\
\hline $\begin{array}{l}\text { Natural gas boiler }(167 \mathrm{MWt}) \\
\text { \& synthetic gasoline } \\
\text { subsystem (167 MWt) }\end{array}$ & & & & & \\
\hline $\begin{array}{l}\text { Uncoupled - } \\
\text { NGCC producing } 50 \mathrm{MWe} \text { at } \\
92 \% \text { capacity factor and }\end{array}$ & \$3.58 billion & $\$ 2.37$ billion & 1.51 & $25 \%$ & 403 \\
\hline $\begin{array}{l}\text { Natural gas boiler }(167 \mathrm{MWt}) \\
\& \text { synthetic gasoline } \\
\text { subsystem (167 MWt) }\end{array}$ & & & & & \\
\hline
\end{tabular}

For the Texas-synthetic gasoline scenario, the full N-R HES (LW-SMR nuclear reactor- thermal power cycle-synthetic gasoline-wind) is not the economically optimal solution under the basecase electricity and synthetic gasoline prices, limiting all subsystems to the equivalent of MWe capacities. The most profitable configuration is one that includes only a nuclear reactor providing heat to the synthetic gasoline subsystem without providing electricity (and therefore not selecting between electricity and the fuel product on an hourly basis). This option has an NPV that is $\$ 70$ 
million greater than that of the full N-R HES and a 1.48 NPV/TCI ratio, compared to the 1.37 of the full N-R HES.

If the nuclear reactor is replaced with a natural gas boiler to produce heat for the synthetic gasoline process, the NPV goes down by $\$ 100$ million from the nuclear-synthetic gasoline configuration; however, the NPV/TCI ratio goes up from 1.48 to 1.55 . This indicates that a natural gas boiler supplying heat to the industrial process may be more attractive to investors than either nuclear option at the natural gas costs and cost of capital used in this analysis. Adding electricity generation to either configuration decreases profitability due to the low price of electricity unless the price of electricity is much higher than the base-case parameters (a multiplier of 1.25 is necessary to add wind electricity and 1.3 to add nuclear-generated electricity).

If the grid has less VRE generation than in the base-case generation mix, the optimal configuration does not change. In this instance, however, a lower electricity price multiplier is required for the nuclear and wind generators to be profitable. Figure 16 shows the optimal configurations at various gasoline prices and electricity price multipliers under both the RPS80 generation mix (left) and the Current Law generation mix (right). Because the Current Law generation mix has a lower penetration of VRE generation (21\%) than the RPS80 mix (41\%), its price for electricity is greater than zero for all hours of each year; whereas under the RPS80 grid mix, the price for electricity is zero for 706 hours of the year. Electricity-generating configurations can receive income during those hours, so a lower electricity price multiplier is necessary for those configurations to be profitable. As shown in Figure 16, the multiplier necessary for the wind plant to be profitable is 1.25 in the RPS80 grid mix and only 1.05 for the Current Law grid mix. The multiplier necessary for the nuclear generator and thermal power cycle to be profitable is 1.3 in the RPS 80 grid mix but only 1.1 in the Current Law grid mix. Still, the economically optimal configuration under the base-case parameters and the Current Law grid mix is one that only includes the nuclear reactor and industrial process subsystems. Appendix G.3 provides additional results for scenarios using the Current Law generation mix. 


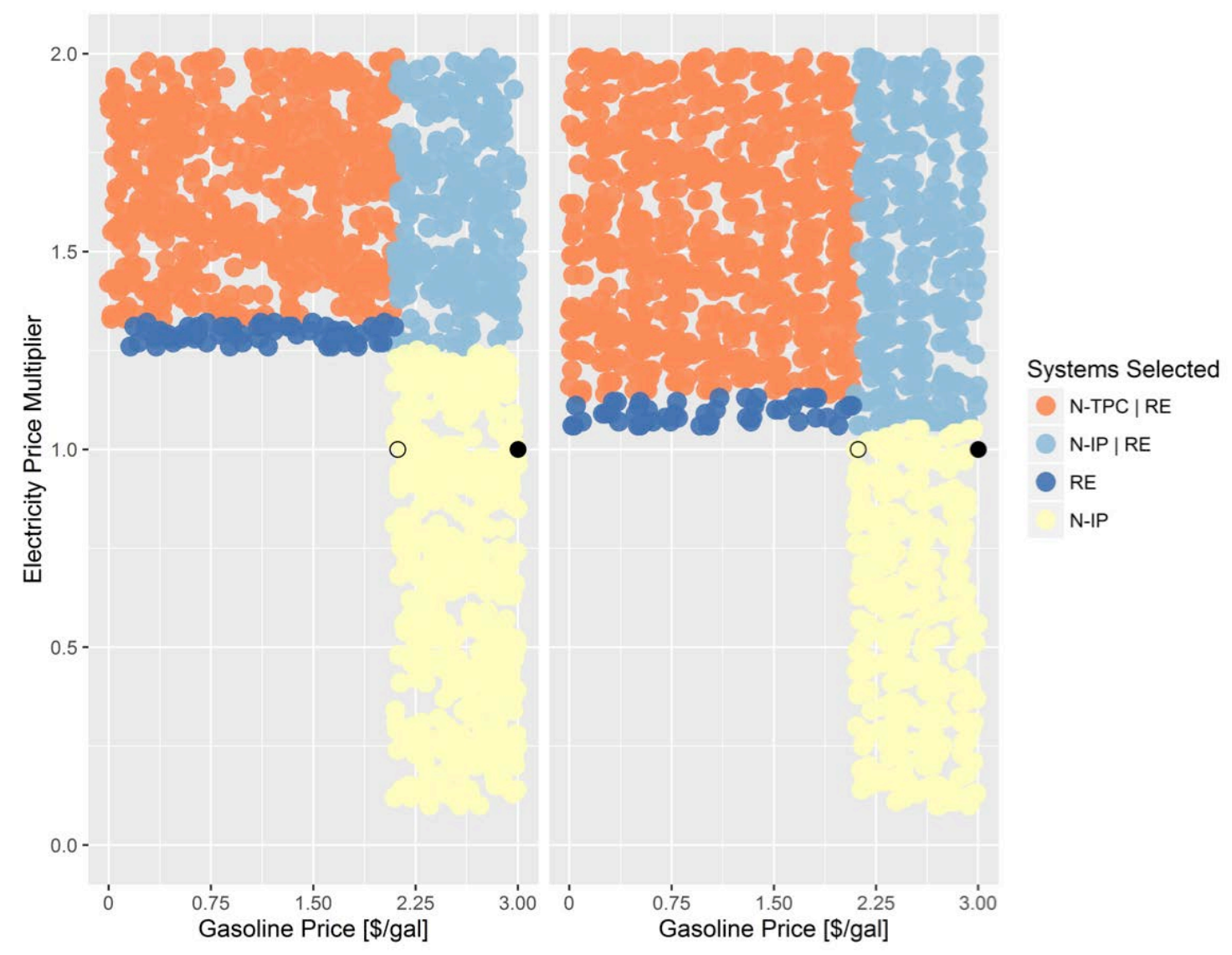

Figure 16. Optimal configurations for the Texas-synthetic gasoline scenario under the RPS80 generation mix (left) and Current Law generation mix (right)

N-TPC: Nuclear reactor and thermal

$\mathrm{N}$-IP: Nuclear reactor and industrial process

$\mathrm{RE}$ : Renewable electricity generation

Solid black dot at electricity price multiplier of 1.0 and $\$ 3.00 /$ gal gasoline price: reference case gasoline price projection; reference case electricity price vector

Open black dot: minimum gasoline selling price for a synthetic gasoline plant using natural gas heating; reference case electricity price vector

If the prices of natural resources (natural gas, coal, and crude oil) are lower than those in the base case, the optimal configuration does not change but it is less profitable. Figure 17 shows the optimal configurations at various gasoline prices and electricity price multipliers under both the AEO reference case prices (left) and the AEO low-oil-price case prices (right). The AEO low-oil case results in lower electricity prices because the natural gas for CTs and NGCCs costs less; thus, the electricity price multiplier needs to be higher for all electricity-generating configurations to be profitable. Note that the gasoline price needed for the synthetic gasolineproducing configurations to be profitable is still $\$ 2.09 / \mathrm{gal}$. The price of gasoline is $\$ 2.00 / \mathrm{gal}$ in the AEO low-oil case (as shown in the solid black dot); therefore, no configurations are profitable in this case. Appendix G.4 provides additional results for scenarios using the AEO low-oil case electricity prices. 


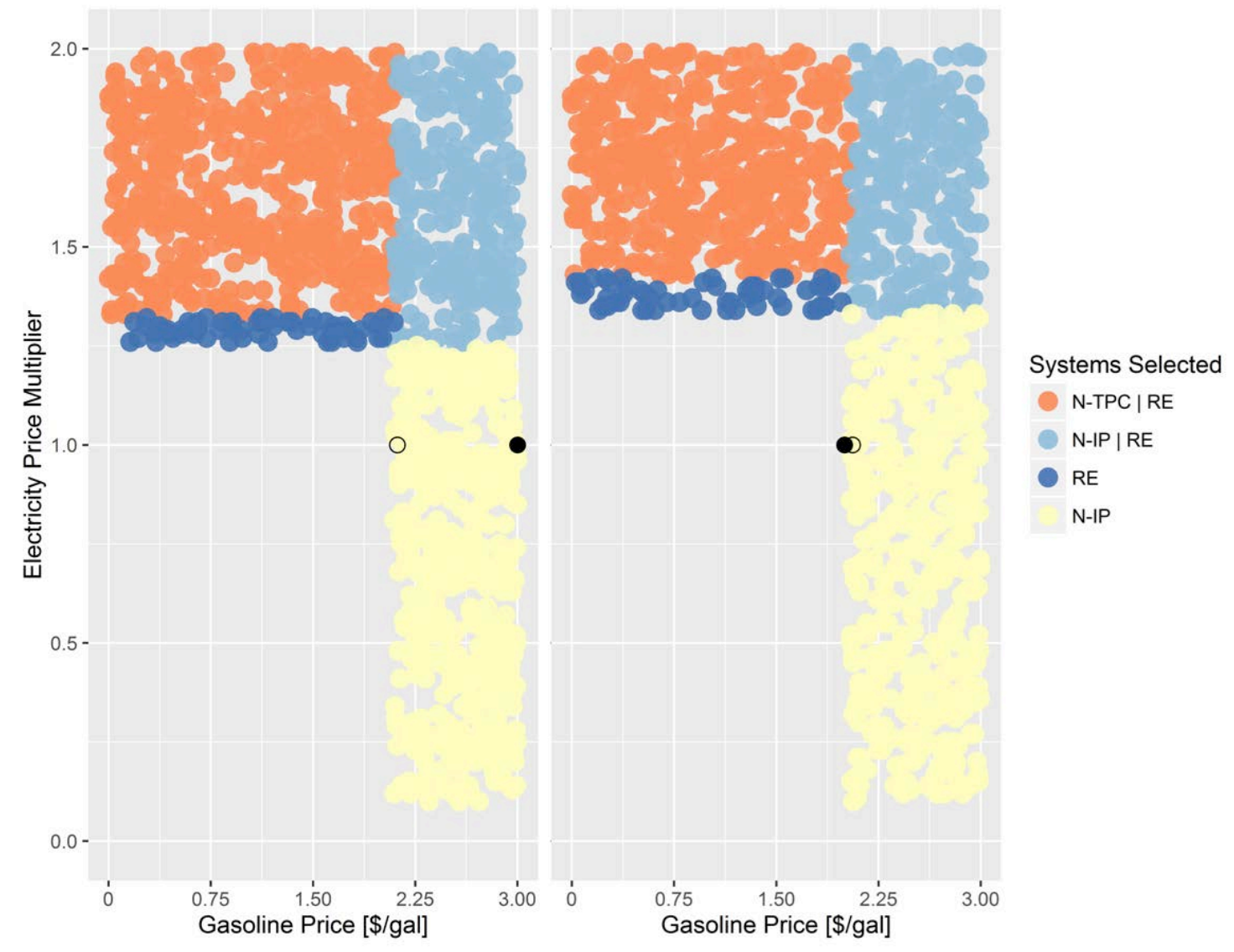

Figure 17. Optimal configurations for the Texas-synthetic gasoline scenario AEO Reference Case Energy Prices (left) and the AEO Low-Oil Case Electricity Prices (right)

N-TPC: Nuclear reactor and thermal

$\mathrm{N}$-IP: Nuclear reactor and industrial process

$\mathrm{RE}$ : Renewable electricity generation

Solid black dot at electricity price multiplier of 1.0 and $\$ 3.00 /$ gal gasoline price: reference case gasoline price projection; reference case electricity price vector

Open black dot: minimum gasoline selling price for a synthetic gasoline plant using natural gas heating; reference case electricity price vector

If a cost of carbon is assessed on all emissions, the optimal configuration does not change, but a lower electricity price multiplier is required for the nuclear and wind generators to be profitable. Figure 18 shows the optimal configurations at various gasoline prices and electricity price multipliers under both the AEO reference case prices without a cost of carbon (left) and those same prices with a cost of carbon (right). Including a cost of carbon reduces the electricity price multiplier necessary for the carbon-free nuclear and renewable electricity generation technologies to be profitable. That change does not affect the synthetic gasoline price necessary for synthetic gasoline-generating configurations to be profitable. That price is still $\$ 2.09 /$ gal. However, the minimum price for synthetic gasoline produced using natural gas-based heat increases from $\$ 2.12 / \mathrm{gal}$ to $\$ 2.17 / \mathrm{gal}$ - the range of profitable configurations is larger. Appendix G.5 provides additional results for scenarios with electricity prices that include a cost of carbon. 


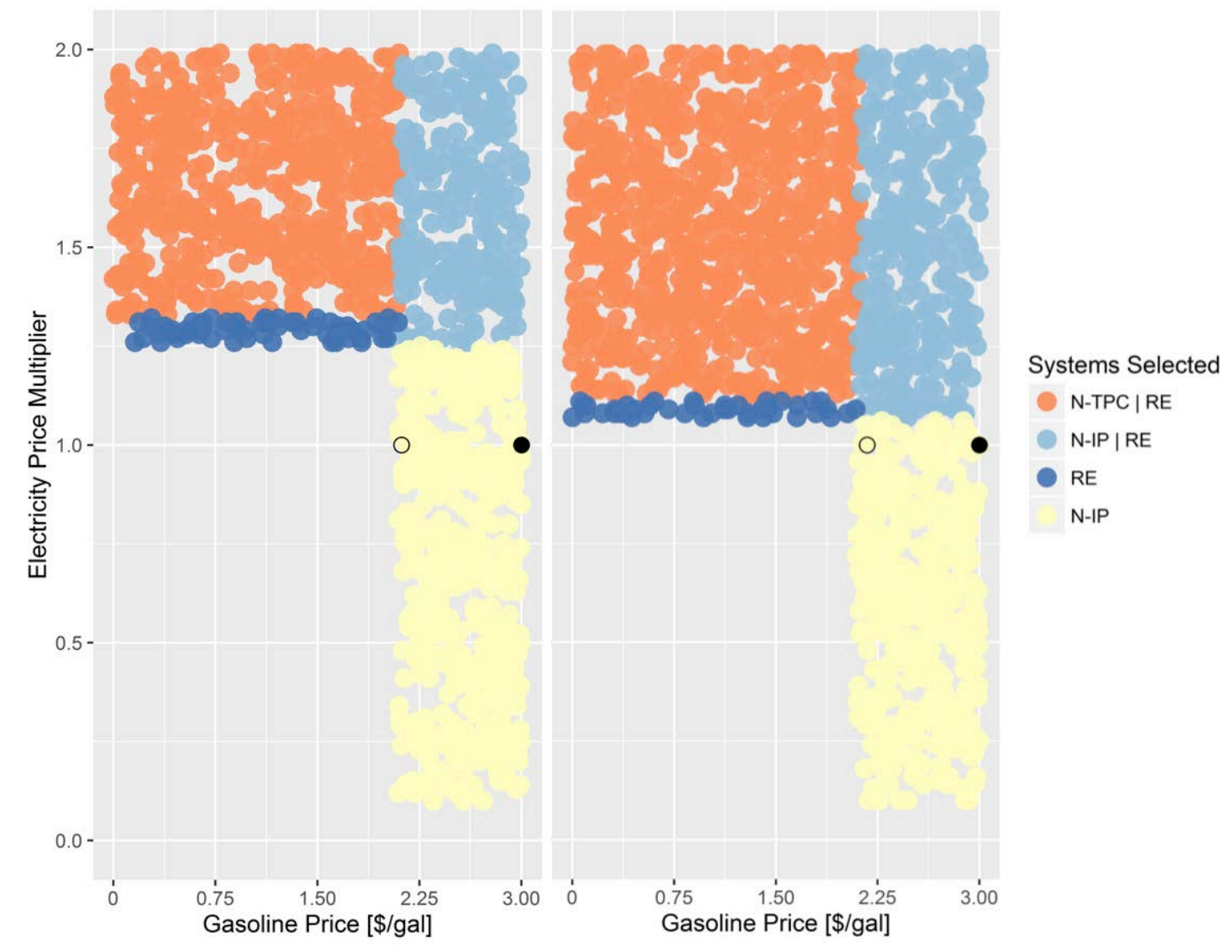

Figure 18. Optimal configurations for the Texas-synthetic gasoline scenario AEO Reference Case Energy Prices (left) and prices including a cost of carbon (right)

N-TPC: Nuclear reactor and thermal

N-IP: Nuclear reactor and industrial process

$\mathrm{RE}$ : Renewable electricity generation

Solid black dot at electricity price multiplier of 1.0 and $\$ 3.00 /$ gal gasoline price: reference case gasoline price projection; reference case electricity price vector

Open black dot: minimum gasoline selling price for a synthetic gasoline plant using natural gas heating; reference case electricity price vector

If the cost of capital (i.e., the discount rate) is lower, the optimal configuration does not change but a lower electricity price multiplier is required for the nuclear and wind generators to be profitable. A lower gasoline price is necessary for the synthetic gasoline-generating configurations to be profitable. Figure 19 shows the optimal configurations at various gasoline prices and electricity price multipliers under both the $10 \%$ nominal discount rate used in this analysis (left) and an $8.15 \%$ nominal discount rate used in the previous analysis performed by INL (right). The previous analysis used a $5 \%$ real discount rate with $3 \%$ inflation. ${ }^{49}$ Those two values result in an $8.15 \%$ nominal discount rate. Reducing the discount rate reduces the electricity price multiplier necessary for the carbon-free nuclear and renewable electricity generation technologies to be profitable, because both technologies have a high capital-tooperating investment ratio when compared to CTs and NGCCs. The capital-to-operating investment ratio of the synthetic gasoline subsystem is much lower, so the impact on the gasoline price necessary for a profitable configuration is not as dramatic; however, the lower discount rate reduces the gasoline price necessary for synthetic gasoline production to be profitable from 
$\$ 2.09 /$ gal to $\$ 2.02 /$ gal. Appendix G.6 provides additional results for scenarios using an $8.15 \%$ nominal discount rate.

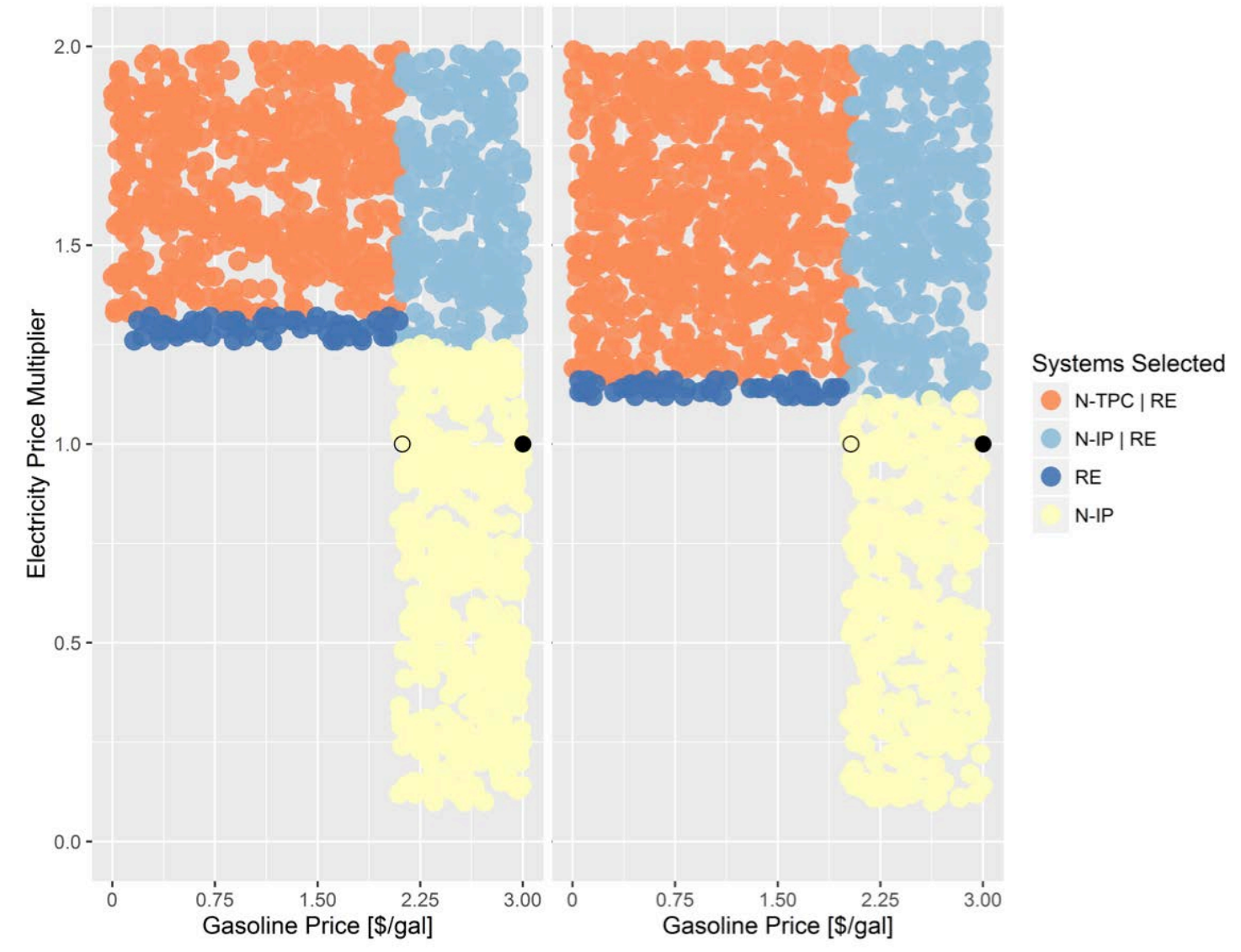

Figure 19. Optimal configurations for the Texas-synthetic gasoline scenario at a $10 \%$ nominal discount rate (left) and at an $8.15 \%$ nominal discount rate (right)

N-TPC: Nuclear reactor and thermal N-IP: Nuclear reactor and industrial process

RE: Renewable electricity generation

Solid black dot at electricity price multiplier of 1.0 and $\$ 3.00 /$ gal gasoline price: reference case gasoline price projection; reference case electricity price vector

Open black dot: minimum gasoline selling price for a synthetic gasoline plant using natural gas heating; reference case electricity price vector

If the maximum size of the nuclear reactor and thermal power cycle is larger than the maximum size of the industrial process, the only change to the optimal configuration is that it includes nuclear-electricity generation when that is profitable. Figure 20 shows the optimal configurations at various gasoline prices and electricity price multipliers when the nuclear reactor and thermal power cycle are limited to a maximum size of $50 \mathrm{MWe}$ (left) and to $180 \mathrm{MWe}$ (right). The key difference in the configurations is that, when the electricity price multiplier is greater than 1.3, a 180 MWe LW-SMR and thermal power cycle are built when allowed, instead of the maximum 50 MWe LW-SMR and thermal power cycle in the base case. The key impact is that when both the electricity price multiplier is greater than 1.3 and the gasoline price is greater than $\$ 2.09 / \mathrm{gal}$, $130 \mathrm{MW}$ of nuclear-generated electricity is produced and sold to the grid during all hours of the year and $50 \mathrm{MWe}$ of thermal energy are used by the industrial process during all hours of the 
year. When the LW-SMR is limited to a maximum capacity of $50 \mathrm{MWe}$, all the energy it produces is used for heat in the industrial process. In addition, $180 \mathrm{MW}$ of nuclear-generated electricity is sold to the grid all hours of the year when the electricity price multiplier is greater than 1.3 and the gasoline price is less than $\$ 2.09 /$ gal. Appendix G.7 provides additional results for scenarios where the maximum nuclear reactor capacity is $180 \mathrm{MWe}$.

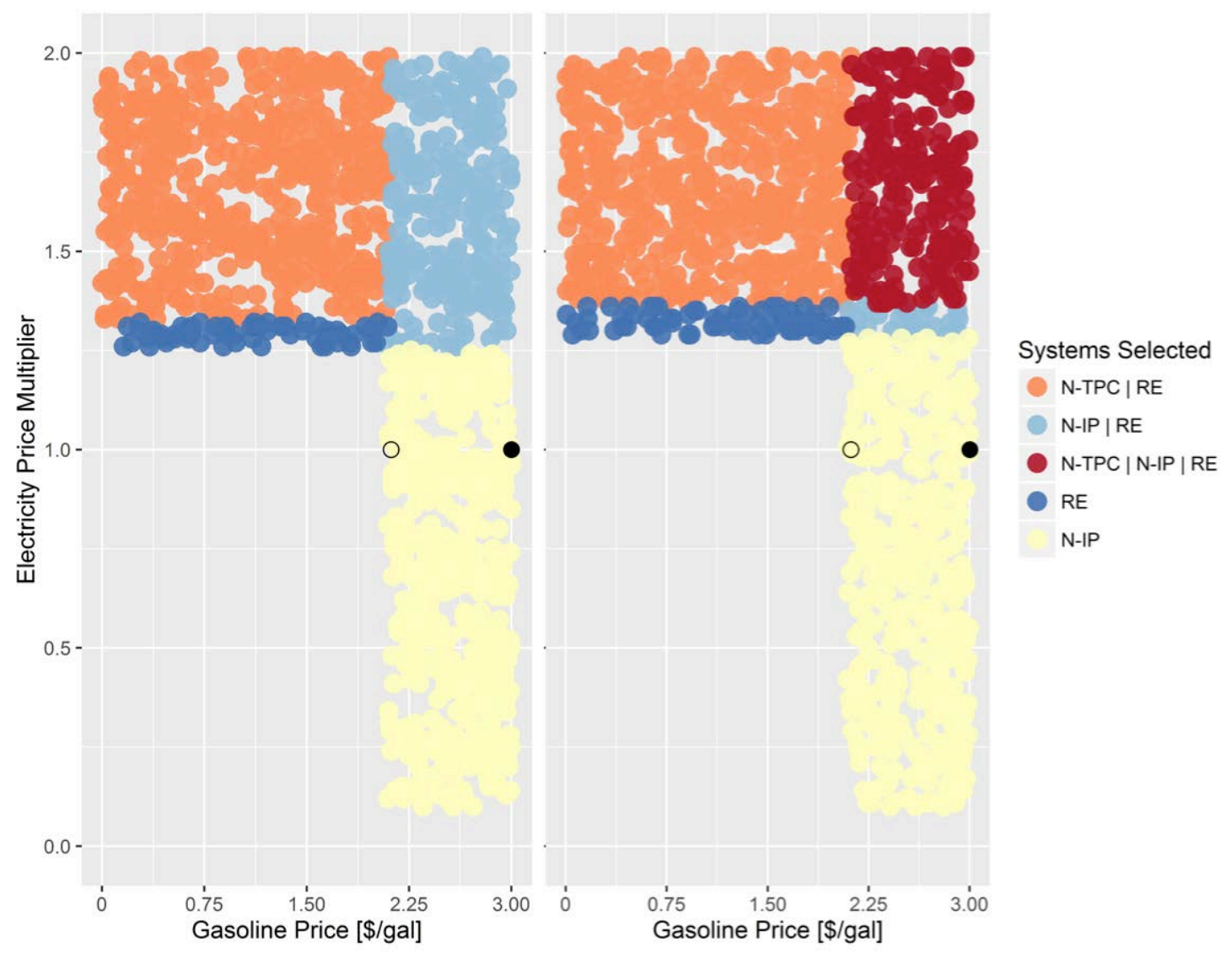

Figure 20. Optimal configurations for the Texas-synthetic gasoline scenario with a 50-MWe maximum capacity of the nuclear reactor and thermal power cycle (left) and a 180-MWe maximum capacity (right)

N-TPC: Nuclear reactor and thermal N-IP: Nuclear reactor and industrial process

$\mathrm{RE}$ : Renewable electricity generation

Solid black dot at electricity price multiplier of 1.0 and $\$ 3.00 /$ gal gasoline price: reference case gasoline price projection; reference case electricity price vector

Open black dot: minimum gasoline selling price for a synthetic gasoline plant using natural gas heating; reference case electricity price vector

The results of these sensitivity analyses affirm the conclusions regarding the profitability of the configurations in the Texas-synthetic gasoline scenario. Those conclusions appear to be robust within the ranges of sensitivities analyzed.

\subsubsection{Potential to Reduce GHG Emissions and their Associated Costs}

One of the key potential benefits of N-R HESs is the potential to reduce carbon emissions and their associated costs if there is a cost of carbon. The Texas-synthetic gasoline process replaces 
two emissions sources: electricity generation and natural gas combusted to produce heat for the synthetic gasoline process. Table 11 shows the GHG emissions and financial impacts of each of the four costs of carbon for the uncoupled electricity-synthetic gasoline configurations. The NGCCs emit $769 \mathrm{lb} \mathrm{CO}_{2} / \mathrm{MWh}$, and the industrial process emits $1.138 \mathrm{lb} /$ gal of synthetic gasoline produced when natural gas is used as the heat source (there are no emissions when nuclear provides heat). Details on the emissions are provided in Appendix F. Table 11 also shows the annual cost of carbon and potential impacts of a cost of carbon on the NPV, IRR, and NPV/TCI ratio at all four costs of carbon reported in Section 2.4.5. With the base-case parameters, using natural gas heat for the synthetic gasoline plant instead of nuclear heat increases $\mathrm{CO}_{2}$ emissions by 281,000 metric tons annually and, at carbon costs of $\$ 61 / \mathrm{metric}$ ton $\mathrm{CO}_{2}$ or greater, results in lower NPV/TCI ratios. Thus the nuclear heat configuration is likely to be more attractive to investors at those higher costs of carbon. Likewise, if the discount rate is lower, the nuclear heating option is likely to be more attractive because of the high capital cost and low operating expense relative to natural gas heat.

Table 11. Financial Comparison Between Configurations for the Texas-Synthetic Gasoline Scenario, Including Costs of Carbon

\begin{tabular}{|c|c|c|c|c|c|c|}
\hline & $\begin{array}{l}\mathrm{CO}_{2} \\
\text { Emissions } \\
\text { (metric ton } \\
\mathrm{CO}_{2} / \mathrm{yr} \text { ) }\end{array}$ & $\begin{array}{l}\text { Cost of } \\
\text { Carbon } \\
\text { (levelized) }\end{array}$ & $\begin{array}{l}\text { NPV with Cost } \\
\text { of Carbon } \\
\text { (\$billion) }\end{array}$ & $\begin{array}{l}\text { TCI } \\
\text { (\$ billion) }\end{array}$ & IRR & $\begin{array}{l}\text { NPV/TCI } \\
\text { Ratio with } \\
\text { Cost of } \\
\text { Carbon }\end{array}$ \\
\hline $\begin{array}{l}\text { Nuclear heat for } \\
\text { synthetic gasoline - } \\
\text { no electricity }\end{array}$ & 0 & $\$ 0$ & $\$ 3.70$ & $\$ 2.51$ & $25 \%$ & 1.48 \\
\hline $\begin{array}{l}\text { Natural gas heat for } \\
\text { synthetic gasoline - } \\
\text { no electricity }\end{array}$ & 281,000 & $\begin{array}{l}\$ 82 \\
\$ 228 \\
\$ 318 \\
\$ 700\end{array}$ & $\begin{array}{l}\$ 3.52 \\
\$ 3.38 \\
\$ 3.29 \\
\$ 2.90\end{array}$ & $\$ 2.32$ & $\begin{array}{l}25 \% \\
25 \% \\
24 \% \\
23 \%\end{array}$ & $\begin{array}{l}1.51 \\
1.45 \\
1.41 \\
1.25\end{array}$ \\
\hline $\begin{array}{l}\text { Uncoupled - Nuclear } \\
\text { electricity and natural } \\
\text { gas produced heat for } \\
\text { synthetic gasoline }\end{array}$ & 281,000 & $\begin{array}{l}\$ 82 \\
\$ 228 \\
\$ 318 \\
\$ 700\end{array}$ & $\begin{array}{l}\$ 3.46 \\
\$ 3.32 \\
\$ 3.23 \\
\$ 2.84\end{array}$ & $\$ 2.58$ & $\begin{array}{l}24 \% \\
23 \% \\
23 \% \\
22 \%\end{array}$ & $\begin{array}{l}1.34 \\
1.29 \\
1.25 \\
1.10\end{array}$ \\
\hline $\begin{array}{l}\text { Uncoupled - NGCC } \\
\text { electricity at } 100 \% \\
\text { capacity factor and } \\
\text { natural gas produced } \\
\text { heat synthetic gasoline }\end{array}$ & 434,000 & $\begin{array}{l}\$ 126 \\
\$ 352 \\
\$ 490 \\
\$ 1,080\end{array}$ & $\begin{array}{l}\$ 3.45 \\
\$ 3.23 \\
\$ 3.09 \\
\$ 2.50\end{array}$ & $\$ 2.37$ & $\begin{array}{l}25 \% \\
24 \% \\
23 \% \\
21 \%\end{array}$ & $\begin{array}{l}1.45 \\
1.36 \\
1.30 \\
1.05\end{array}$ \\
\hline $\begin{array}{l}\text { Uncoupled - NGCC (165 } \\
\text { MWe) at } 92 \% \text { capacity } \\
\text { factor and natural gas } \\
\text { produced heat for } \\
\text { synthetic gasoline }\end{array}$ & 422,000 & $\begin{array}{l}\$ 122 \\
\$ 342 \\
\$ 476 \\
\$ 1,050\end{array}$ & $\begin{array}{l}\$ 3.47 \\
\$ 3.25 \\
\$ 3.12 \\
\$ 2.54\end{array}$ & $\$ 2.37$ & $\begin{array}{l}25 \% \\
24 \% \\
23 \% \\
21 \%\end{array}$ & $\begin{array}{l}1.46 \\
1.37 \\
1.31 \\
1.07\end{array}$ \\
\hline
\end{tabular}


Using nuclear heat for this industrial process reduces the $\mathrm{CO}_{2}$ emissions. A moderate cost of carbon would be required to make the financial impacts of those emissions great enough to incentivize nuclear heat electricity generation.

\subsubsection{Potential to Support Resource Adequacy}

We tested the hypothesis that N-R HESs can support electricity resource adequacy while maximizing production of a more profitable industrial product with sufficient incentives (i.e., a capacity payment that is sufficiently high). In this analysis, the Texas-synthetic gasoline option did not select a configuration that includes the thermal power cycle, because its cost - combined with the opportunity cost of not making gasoline during the hours necessary to receive the capacity payment — was greater than the potential income.

Increased capacity payments increase the incentive to build electricity generation. As shown in Figure 21, increased capacity payments result in lower hourly electricity prices necessary to build profitable nuclear electricity generation. The capacity payment increase from $\$ 50 / \mathrm{kW}$-yr to $\$ 100 / \mathrm{kW}$-yr reduces the electricity price multiplier necessary for profitable nuclear power generation to be built from 1.3 to 1.2 , and an additional increase to $\$ 150 / \mathrm{kW}$-yr further reduces the necessary multiplier to 1.1 ; increasing the capacity payment results in increased generation. Capacity payments do not incentivize wind because its variability prevents it from being capable of providing the electrical energy necessary during the capacity payment hours.

The increased generation produces baseload electricity. Figure 22 displays the optimal annual electricity production under the three capacity payments. It shows that electricity generation by the nuclear reactor is maximized whenever the reactor is coupled with a thermal power cycle. The salmon-colored dots show that full capacity generation coupled with maximum generation by wind, and the red dots show full generation without wind. 

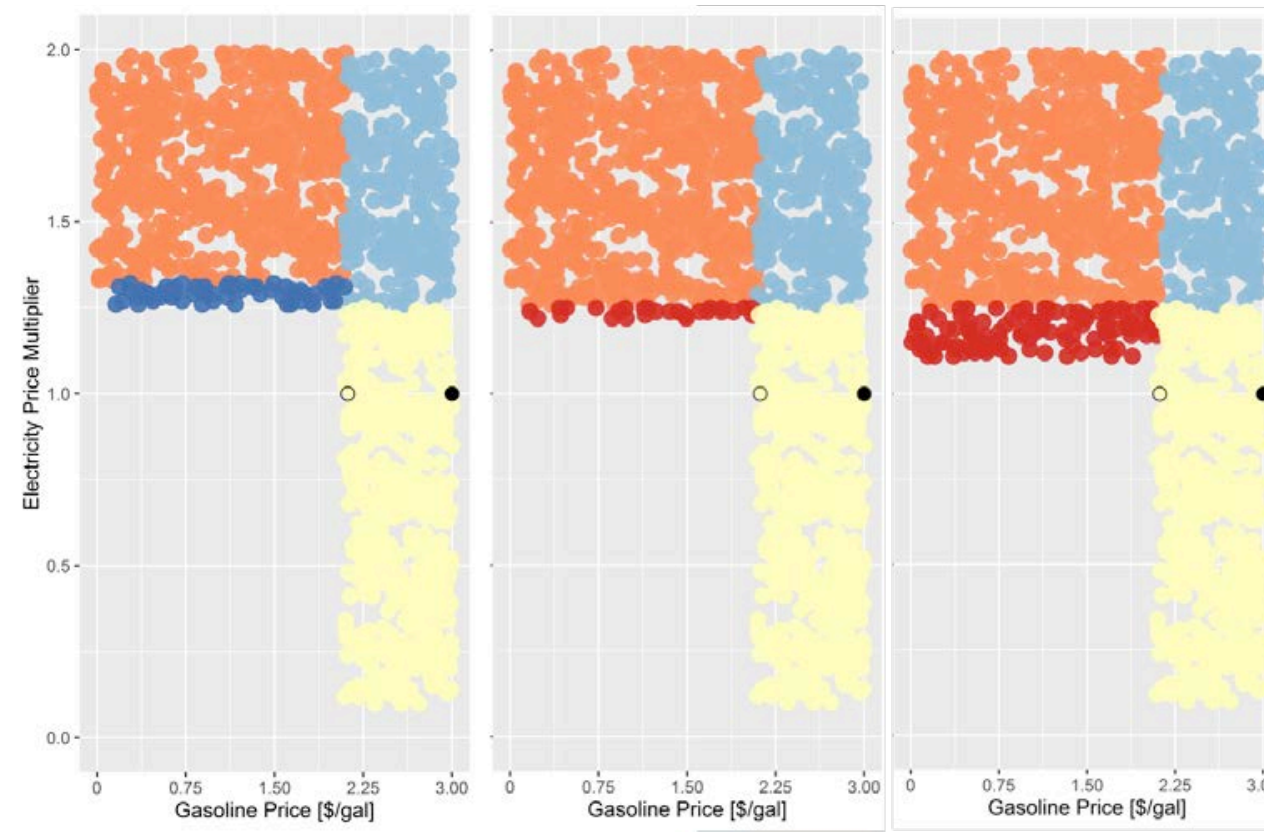

Systems Selected

- N-TPCIRE

- n-ipire

- N-TPC

N-IP

- RE

Figure 21. Optimal configurations for the Texas-synthetic gasoline scenario at various gasoline prices and electricity price multipliers at three levels of capacity payments.

\$50/kW-yr (left); \$100/kW-yr (middle); \$150/kW-yr (right)

N-TPC: Nuclear reactor and thermal

N-IP: Nuclear reactor and industrial process

$\mathrm{RE}$ : Renewable electricity generation

Solid black dot at electricity price multiplier of 1.0 and $\$ 3.00 /$ gal gasoline price: reference case gasoline price projection; reference case electricity price vector

Open black dot: minimum gasoline selling price for a synthetic gasoline plant using natural gas heating; reference case electricity price vector 

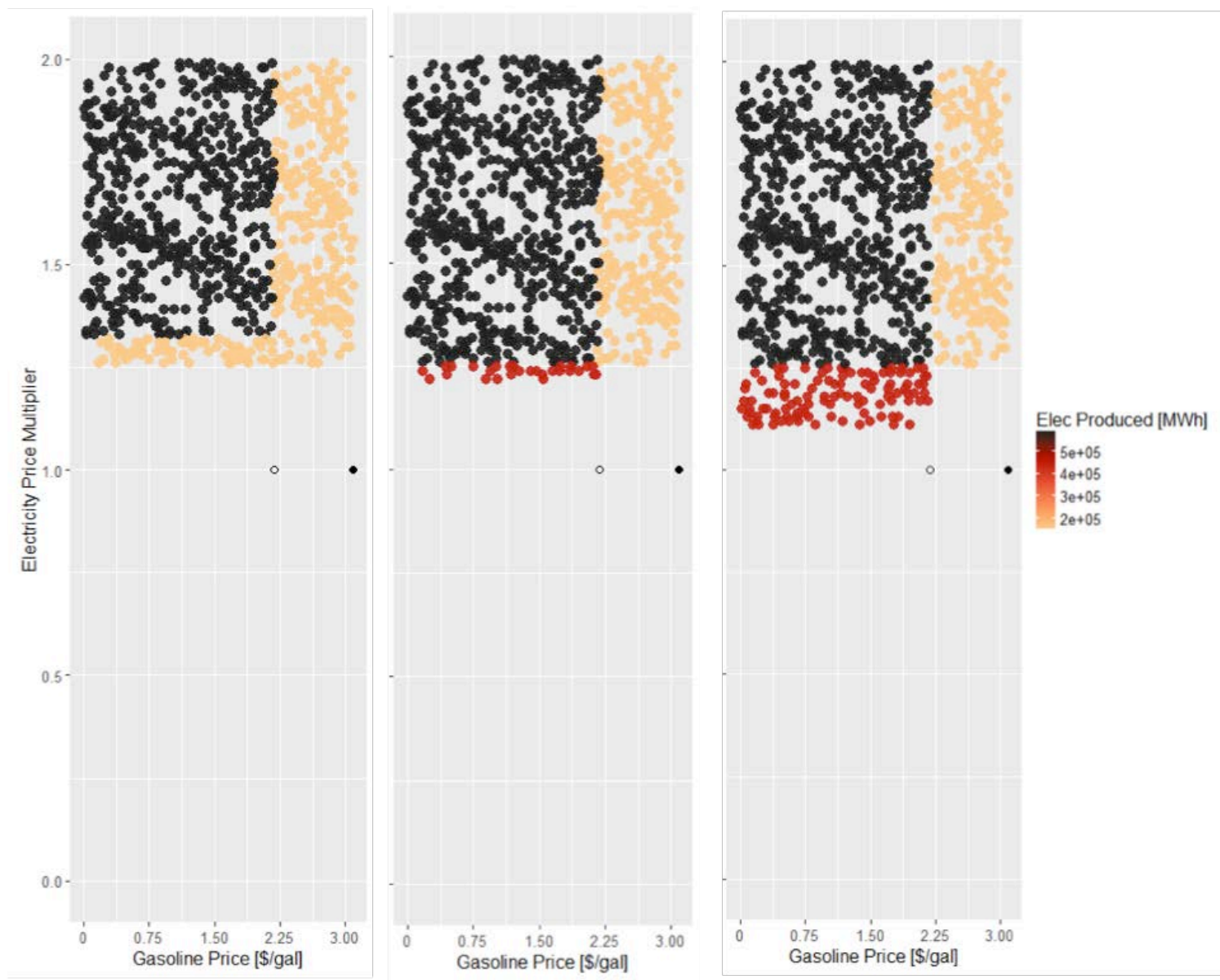

Figure 22. Optimal annual electricity production for Texas-synthetic gasoline system at various gasoline prices and electricity price multipliers at three levels of capacity payments

\$50/kW-yr (left); \$100/kW-yr (middle); \$150/kW-yr (right)

Solid black dot at electricity price multiplier of 1.0 and $\$ 3.00 /$ gal gasoline price: reference case gasoline price projection; reference case electricity price vector

Open black dot: minimum gasoline selling price for a synthetic gasoline plant using natural gas heating; reference case electricity price vector

Within the parameters tested and under the perfect foresight these analyses utilize, the Texassynthetic gasoline N-R HES does not identify any condition where either a capacity payment or high electrical energy prices results in selling electricity to support electricity resource adequacy instead of maximizing production of synthetic gasoline. Two reasons are likely. The first is the difficulty of overcoming the opportunity cost of not producing the synthetic gasoline, whose capital expense has already been paid and whose equipment is operating. At a selling price of $\$ 3.00$ /gal, the configuration's hourly synthetic gasoline revenue minus the cost for natural gas feedstock is $\$ 112,000 / \mathrm{hr}$; thus, if synthetic gasoline is not produced for 50 hours per year to receive the capacity payment, the opportunity cost is $\$ 5,610,000 / \mathrm{yr}$. The capacity payment necessary to overcome that opportunity cost is $\$ 112 / \mathrm{kW}$-yr. The second is the difficulty in meeting the electricity income requirement to overcome the cost of the thermal power cycle. The thermal power cycle's capital cost is $\$ 63$ million, which results in a levelized cost of $\$ 7,200,000 / \mathrm{yr}$ at the $10 \%$ nominal discount rate on $100 \%$ equity used in this analysis. 
If the capacity payment were the only source of income during those hours, the capacity payment necessary to overcome that capital expenditure would be $\$ 144 / \mathrm{kW}-\mathrm{yr}$. If the electricity price is $\$ 100 / \mathrm{MWh}$ during the 50 hours electricity is generated to receive the capacity payment, the total electricity income is $\$ 250,000 / \mathrm{yr}$, or $\$ 5 / \mathrm{kW}$-yr for the 50 hours during which the capacity payment is made. To overcome all expenses, the necessary capacity payment for the Texas scenario is the sum of the opportunity cost and the cost of the turbine minus the potential income from electrical energy, which equals $\$ 251 / \mathrm{kW}$-yr. Without a capacity payment of approximately $\$ 251 / \mathrm{kW}-\mathrm{yr}$, the Texas scenario will not economically choose to provide resource adequacy for the grid.

\subsubsection{Potential for Flexibility to Increase Profitability}

We tested the hypothesis that, at some combinations of electricity and product prices, N-R HESs will be more profitable than uncoupled configurations, because they can produce electricity when its price is high (e.g., when the electrical energy price is greater than $\$ 60 / \mathrm{MWh}$ in Figure 9) and the industrial product when the price of electricity is low (e.g., when the electrical energy price is less than $\$ 40 / \mathrm{MWh}$ in Figure 9).

Based on this analysis, some configurations are profitable at a variety of potential future gasoline and electricity prices; however, the price variations are not large enough to incentivize investments in both the industrial process and a thermal power cycle under the base-case parameters. Thus, the Texas-synthetic gasoline N-R HES is unlikely to enjoy additional profitability due to its potential inherent flexibility.

\subsubsection{Potential Value of Product Flexibility to Hedge Against Uncertainty in Future Market Conditions}

The economic conditions over the life of an N-R HES are inherently uncertain, which may affect the net revenue streams available for plants designed to sell electricity, gasoline, or both. The NR HES is designed to have the ability to switch between using the heat to generate electricity and using heat to produce synthetic gasoline on an hourly basis, depending on electricity prices.

Adding such flexibility potentially adds value (in the net incremental revenue sense) compared to the single-product configurations. However, whether adding this capability makes economic sense to an investor depends on a number of factors, including the incremental capital investment, incremental operating costs, and the price and price volatility of gasoline and electricity. The ability to switch operating patterns over a variety of timescales within and across years can also reduce the variability of net cash flows over the lifetime of the plant, which acts as a partial natural hedge against the uncertainty of future market conditions. The value of that flexibility depends on many factors, including the expected variability of future prices for each product, the time over which that variability occurs, and the size of the investments needed to provide the flexibility. Analyzing both NPV and the NPV/TCI ratio informs both the expected returns and choices between competing investments in a capital-constrained environment.

Because the distributions of future product prices and their correlations are highly uncertain, and also because of the location-specific nature of the analysis and its assumptions, the analysis in this section is intended to be illustrative only.

Given these caveats, we tested the potential benefits of three configurations. One configuration includes internal flexibility and can select between two products. We compared that 
configuration to two configurations that provide only one product - in this case either electricity or synthetic gasoline. The three configurations are:

1. 50-MWe nuclear reactor with 50-MWe thermal power cycle to generate electricity

2. 50-MWe nuclear reactor with 50-MWe thermal power cycle and 50-MWe equivalent synthetic gasoline process

3. 50-MWe nuclear reactor with $50 \mathrm{MWe}$ equivalent synthetic gasoline process

The second configuration can switch between generating electricity and producing synthetic gasoline, whichever is more profitable in a given hour. In contrast, the first and the third configurations have fixed production, and we assume they operate at maximum capacity for 8,760 hours per year. The TCI is $\$ 251$ million for configuration 1, \$2.57 billion for configuration 2 , and $\$ 2.51$ billion for configuration 3. The nuclear reactor subsystem's capex (without the thermal power cycle) is $\$ 186$ million. The thermal power cycle (included in configurations 1 and 2 ) has a capex of $\$ 65$ million. The synthetic gasoline subsystem has a capex of $\$ 2.321$ billion, so the incremental capital costs required to use heat to generate synthetic gasoline are more than ten times the capital costs of the nuclear heat source ( $\$ 2.321$ billion vs. $\$ 186$ million)

Various timeframes for switching can be considered: within the year (hourly within a given year due to, for example, large differences in electricity prices during different hours), or more general switching that arises from changes in year-to-year market dynamics (across years).

To model the longer-term annual effects on a multi-decadal basis, we considered two discrete annually based futures. Table 12 shows the futures' parameters, which are intended to be illustrative:

- High-priced electricity and low-priced gasoline (Future A): All hourly electricity prices increased by a factor of two relative to the base case parameters described in Section 2.3.2 above. The low gasoline price for this future was $\$ 1.00 / \mathrm{gal}$.

- High-priced gasoline and low-priced electricity (Future B): All hourly electricity prices matched to the base case parameters described in Section 2.3.2 above. The high gasoline price was set to $\$ 3.00 /$ gal (base case price for synthetic gasoline).

Table 12. Futures Considered for Value of Flexibility Analysis

\begin{tabular}{lll} 
& Future A: & Future B: \\
& High Electricity & Low Electricity \\
& Low Gasoline & High Gasoline \\
Electricity Price Multiplier & 2.0 & 1.0 \\
\hline Gasoline Price & $\$ 1.00 /$ gal & $\$ 3.00 /$ gal \\
\hline
\end{tabular}

How to view these annual futures over the 25-year life of the system is subjective, given the uncertainty about the future. Because this analysis is intended to be illustrative, we considered a number of combinations of the two futures. The notation $0 \%$ indicates that the annual electricity 
and gasoline prices corresponding to Future A occur over the entire life of the system (i.e., highpriced electricity and low-priced gasoline occur over the entire analysis period). The notation $100 \%$ indicates that electricity and gasoline prices corresponding to Future B occur over the entire life of the system (i.e., high-priced gasoline and low-priced electricity occur over the entire life of the system). The notation $25 \%$ indicates that $25 \%$ of the years in the analysis period have prices corresponding to Future $\mathrm{B}$ and the remaining $75 \%$ correspond to Future A. The notation $50 \%$ indicates that $50 \%$ of the years in the analysis period have prices corresponding to Future B and the other $50 \%$ correspond to Future A. Finally, the notation $75 \%$ indicates that $75 \%$ of the years in the analysis period have prices corresponding to Future B and the remaining 25\% correspond to Future A. Instead of attempting to forecast which years will be under Future A and which will be under Future B, we assume that each year has the same probability of being either A or B. Differences in timing will impact net present value due to the effects of discounting; however, that is likely to be a second-order effect and negligible when compared to the intended accuracy of this effort.

Because of the use of price multipliers, we did not cap electricity prices at $\$ 100 / \mathrm{kWh}$ in this flexibility analysis, unlike the other sections in this report. Instead, we used the PLEXOScalculated maximum prices for the hours when those prices were applicable. The maximum price in the year was $\$ 3,960 / \mathrm{MWh}$, and that price occurred 40 hours/year for all analyses in this section only.

Figure 23 shows the discounted gross revenue minus feedstock costs of all three configurations under five combinations of futures. Fixed costs are not included in the results shown in Figure 23. Table 13 shows the percentage of time that each product is produced by the configuration that can switch between electricity and synthetic gasoline production (Configuration 2).

It is important to note that the likelihood of the five combinations of futures shown in Figure 23 may not be equal. For example, if there was an equal likelihood of Future A or Future B occurring in any given year, then over the life of the asset the relative probabilities of $0 \%, 25 \%$, $50 \%, 75 \%$ and $100 \%$ scenarios (as defined above) occurring is 1: 4: 6: 4: 1 . Hence, observations in the figures should be weighted more heavily towards the central 50:50 scenario rather than the more extreme $0 \%$ and $100 \%$ scenarios. This weighting should be carefully considered because it is implicitly dependent upon Futures A and B being equally probable, which is unlikely. 


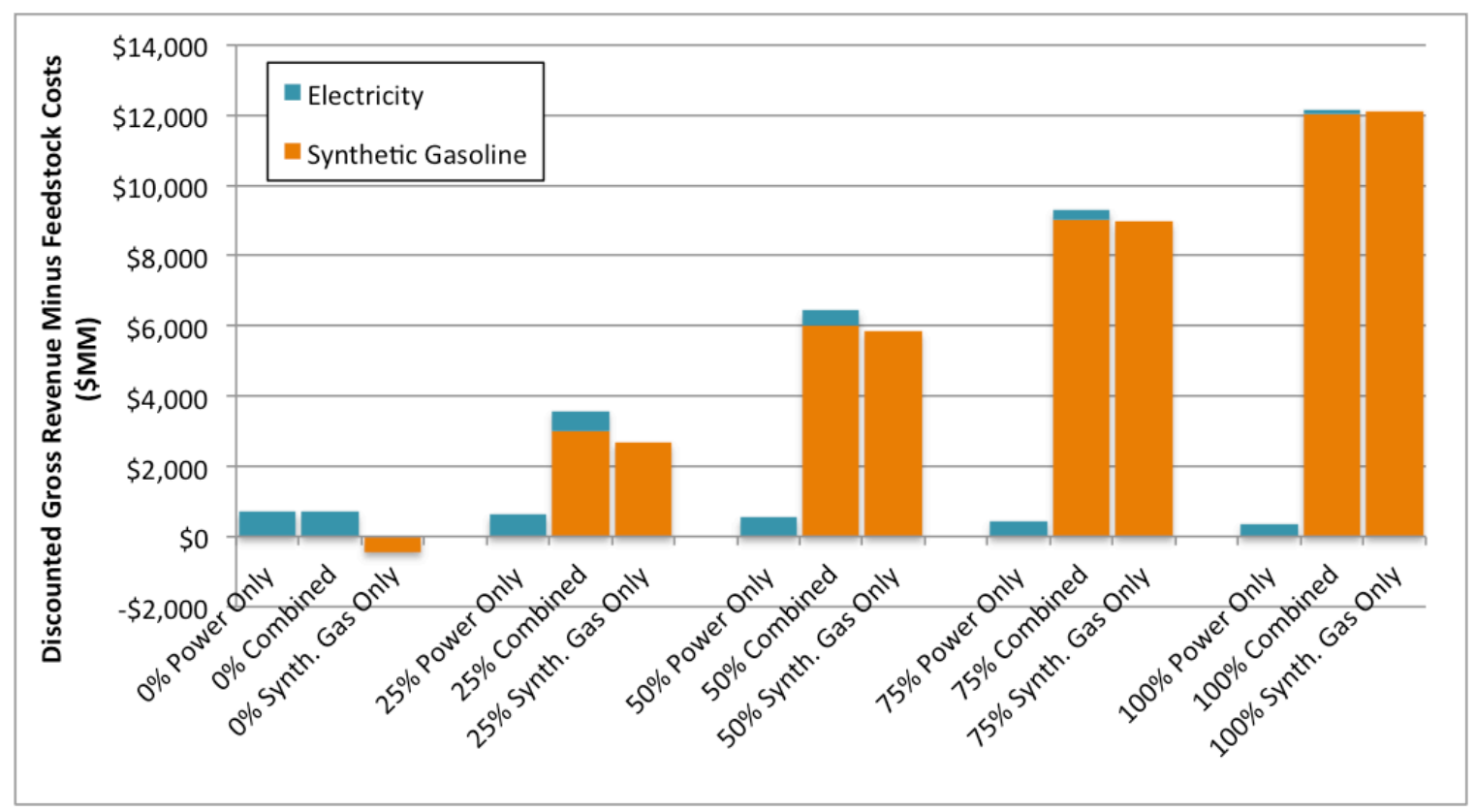

Figure 23. Impacts of various combinations of futures on the discounted gross revenue minus feedstock costs of three configurations in the Texas-synthetic gasoline scenario

Table 13. Percentage of Time Each Product is Produced by Configuration \#2 Under Combinations of Futures

\begin{tabular}{|lccccc|}
\hline & $0 \%$ & $25 \%$ & $50 \%$ & $75 \%$ & $100 \%$ \\
\hline Gasoline & $0 \%$ & $24.85 \%$ & $49.71 \%$ & $74.57 \%$ & $99.42 \%$ \\
\hline Electricity & $100 \%$ & $75.15 \%$ & $50.29 \%$ & $25.44 \%$ & $0.58 \%$ \\
\hline
\end{tabular}

Figure 23 and Table 13 show:

- In the exclusively high-gasoline-price future (100\%; on the right side of Figure 23 ), the present value of gross revenue minus the feedstock cost for the gasoline-only configuration is about $\$ 12.1$ billion. The corresponding discounted revenue for the electricity-only configuration is much lower- $\$ 370$ million. The electricity revenue in this case is $48 \%$ less than the electricity revenue under the high electricity price future ( $0 \%$ in Figure 23$)$. It is not quite $50 \%$ less because, even though the $100 \%$ scenario uses an electricity price multiplier of 1 while the $0 \%$ scenario uses a price multiplier of 2 , the $\$ 50 / \mathrm{kW}$-year capacity payment does not change between the two scenarios. The flexible configuration (Configuration 2) has a higher gross revenue minus feedstock cost in all scenarios. In the $100 \%$ scenario, the flexible configuration can produce electricity rather than gasoline during the 50 hours of the year necessary to receive the capacity payments, thus receiving the higher income provided by electricity plus capacity payments during those hours. 
- In the 50\% combination, the electricity-only configuration's (Configuration 1) gross revenue minus feedstock cost increases from \$368 million to \$537 million and the gasoline-only configuration's (Configuration 3) gross revenue minus feedstock cost decreases from $\$ 12.1$ billion to $\$ 5.83$ billion as compared to the $100 \%$ scenario. Again, the flexible configuration receives an incremental revenue due to 50 hours with the highest electricity prices and capacity payments. Its total gross revenue minus feedstock cost is $\$ 6.43$ billion - $\$ 600$ million higher than the gasoline-only configuration.

- Finally, in the exclusively high-electricity-price future $(0 \%$; on the left hand side of Figure 23), the electricity-only configuration and flexible configuration both generate only electricity for all 8,760 hours each year. The flexible configuration produces electricity exclusively because the value of gasoline is lower than the cost of the natural gas feedstock, as shown by the negative discounted net revenue minus feedstock cost for the gasoline-only system configuration.

Figure 23 indicates that the combined system may both increase and partially hedge the gross revenue minus feedstock costs as defined by the two futures.

Figure 24 shows the estimated NPV for each configuration under each of the five combinations of futures. For the $0 \%$ and $25 \%$ scenarios, the NPVs for the gasoline-only and the flexible configurations are negative. This happens in the $25 \%$ scenario (even though the gross revenue minus feedstock cost is positive for both configurations in that combination) for two interrelated reasons: first, the relative investment for the gasoline facilities are approximately ten times greater than for the thermal power cycle, and second, small changes in the future outcome substantially affect profitability.

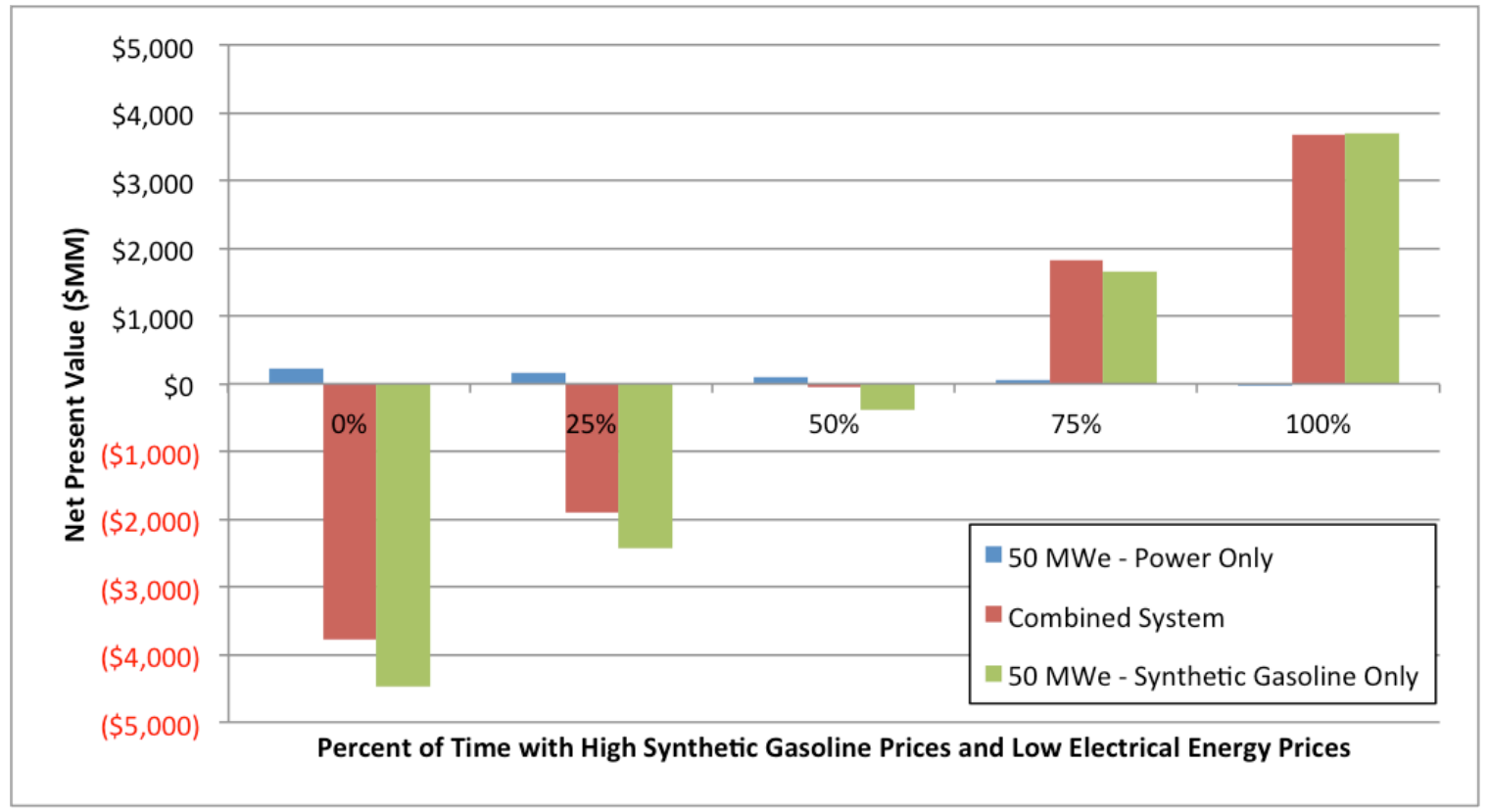

Figure 24. Impacts of various combinations of futures on the NPV of three configurations in the Texas-synthetic gasoline scenario 
Figure 25 shows the NPV/TCI ratio, which further demonstrates the impact of the five combinations of futures on the attractiveness of the investment. The gasoline-only configuration is the least attractive investment under all but the most favorable combinations. The flexible configuration is somewhat more attractive than the gasoline-only configuration under the other scenarios because of the ability to produce electricity when its price is high; however, it cannot fully eliminate the challenges related to the income required to provide a return on the high capital investment required for the industrial process. The differences between Figure 23 and Figure 24 show that electricity production is more attractive to investors because the capital expense for the thermal power cycle is much lower than that of the synthetic gasoline process.

This flexibility analysis shows that electricity production is relatively more attractive than gasoline production given the uncertainty about the future, because gasoline production requires a large capital expenditure and thus has a greater downside risk. That result suggests that alternative uses of heat that have lower capital requirements would be valuable to consider. Alternatives may identify opportunities for electricity production when its price is high and use of the thermal heat when the price of electricity is low.

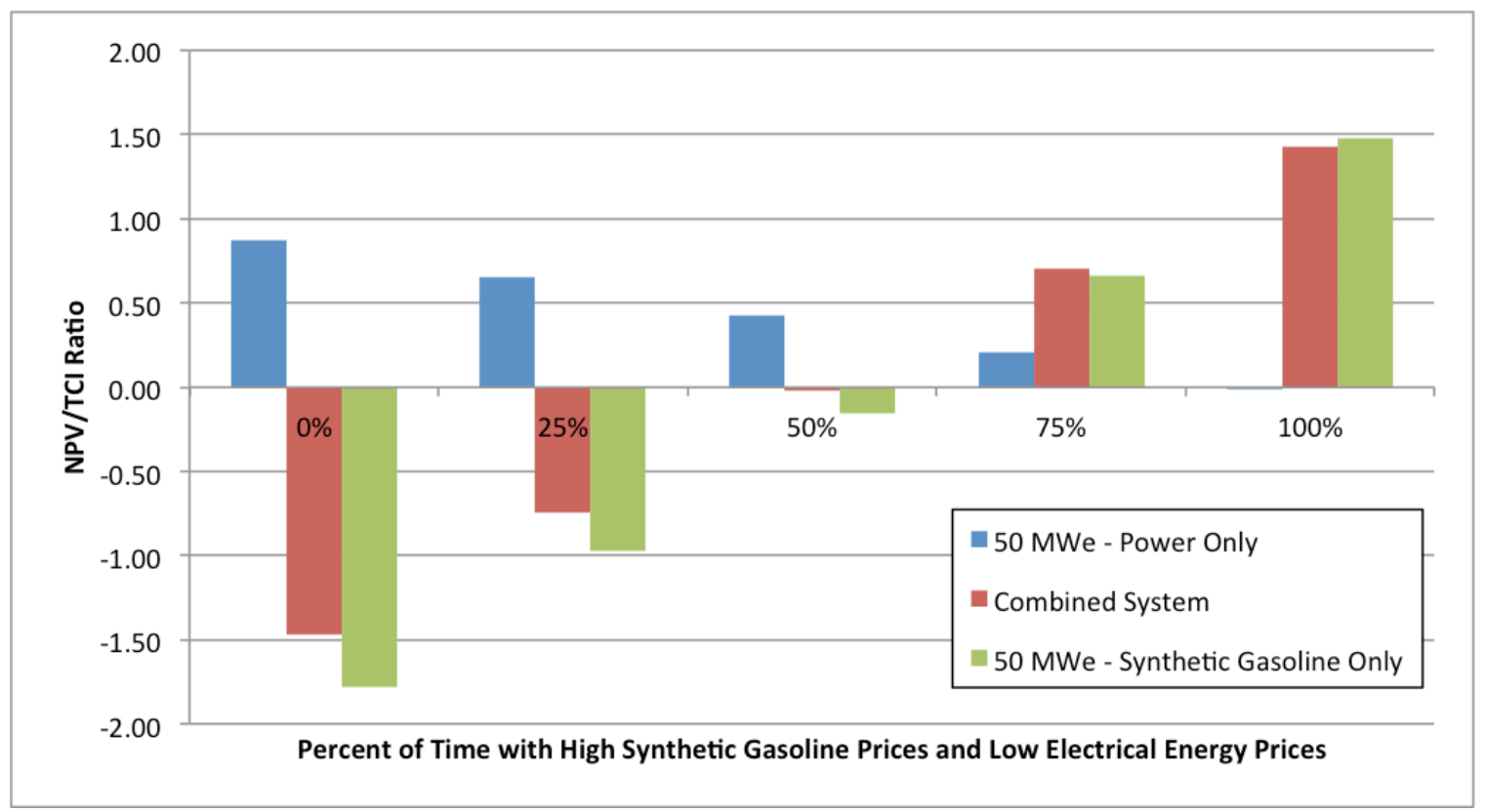

Figure 25. Impacts of various combinations of futures on the NPV/TCI ratio of three configurations in the Texas-synthetic gasoline scenario

This analysis indicates that the internal flexibility of the flexible configuration can be an effective method to partially hedge against uncertain product prices; however, the increased capital expense for and the low capacity factors of the subsystems being switched out limit the benefits in this case.

Alternative conditions may influence these conclusions. For example, in this analysis, low-cost renewable energy rarely sets the marginal price of electricity. In addition, the electricity price duration curve (Figure 9) is flat, largely because the NGCCs and CTs are new and replace the existing generation fleet, which has more diverse heat rates. It is likely that the actual future grid will have a wider range of heat rates and marginal prices than those in this simplified analysis. 
The presence of electricity price caps may also influence the price duration curve both at the end, where prices are capped, and in the generation fleet.

\subsection{Results for the Arizona-Desalination Scenario}

The Arizona-desalination scenario consists of three primary subsystems: (1) a nuclear reactor and associated thermal power cycle combined into a single subsystem, (2) an RO desalination unit, and (3) a PV system. The nuclear reactor and thermal power cycle are combined into a single subsystem because the thermal power cycle always has the same capacity as the nuclear reactor due to the purely electrical coupling of the desalination subsystem (i.e., the industrial process can only use electricity so nuclear heat is only valuable as electricity). In this way, this case differs from the Texas scenario where the thermal energy may be diverted from electricity production to be directly used in an industrial process. For the Arizona scenario, we set the same maximum size for the nuclear reactor, the thermal power cycle, the industrial process, and the PV system-50 MWe. The thermal power cycle efficiency of 30\% implies a thermal capacity of $167 \mathrm{MWt}$ for the nuclear reactor. In this scenario, the RO unit can use up to the maximum amount of electricity generated by the nuclear reactor. These capacities are consistent with the Texas scenario, thus allowing some degree of comparison of the economic attractiveness between the scenarios.

\subsubsection{Potential Profitability}

We analyzed the potential profitability of the Arizona scenario by varying the price of the electricity and water products and using REopt to calculate the optimal subsystem combinations and internal dispatch, as discussed in Section 2 above. We varied the price of the water product from $\$ 0 /$ thousand gal to $\$ 4.50$ /thousand gal. The upper value is the reference price described in Section 2.3.5. As in the Texas-synthetic gasoline scenario, we varied the price vector of electricity using a multiplier that affected the electrical energy price for all 8,760 hours in the year, but not ancillary services. In each case, the multiplier was randomly assigned a value between 0 and 2; thus, the electrical energy price in that case could be $\$ 0 / \mathrm{MWh}$ for every hour of the year, twice the electrical energy price developed for the reference and described in Section 2.3.2 above, or any other multiplied value between 0 and 2. Unless stated otherwise, all other parameters remain at the base-case values. Note that this analysis assumes perfect foresight of all expenses and product prices throughout the project life.

Optimal system selections are reported in Figure 26 reports optimal system selection and indicates:

- If the electricity price multiplier is less than 1.3 and the price of water is less than $\$ 1.26 /$ thousand gal, no configurations are profitable (i.e., the NPV is less than zero for all combinations).

- If the electricity price multiplier is between 1.3 and 1.6 and the price of water is less than $\$ 1.26 /$ thousand gal (as shown in the red dots), the LW-SMR nuclear reactor-thermal power cycle configuration is profitable (the NPV is positive), but it is not profitable to include a desalination subsystem. The electricity price is not high enough for the PV system to have an NPV greater than 0 at the $10 \%$ discount rate used in this analysis. 
- If the electricity price multiplier is greater than 1.6 and the price of water is less than $\$ 1.26 /$ thousand gal (as shown in the salmon-colored dots), the configuration with both the LW-SMR nuclear reactor-thermal power cycle and a PV subsystem is profitable in the electricity market but not in the water market.

- If the price of water is greater than $\$ 1.26 /$ thousand gal (as shown in both the yellow and light blue dots) the LW-SMR nuclear reactor-thermal power cycle-RO desalination configuration is profitable with the nuclear reactor-thermal power cycle generating electricity primarily for desalination.

- The price of water (greater than \$1.26/thousand gal) affects the point at which a PV subsystem is included in the optimal configuration. If the electricity price multiplier is less than 1.6 at electricity prices greater than but close to a water price of $\$ 1.26 /$ thousand gal or less than 1.4 at higher water prices (as shown in the yellow dots), the PV subsystem is not included. Increasing water prices increase the benefits of producing PVgenerated electricity, as discussed below.

The solid black dot indicates the reference-case water price projection ( $\$ 4.50 /$ thousand gal) and the electricity price vector developed for this analysis (the multiplier is 1.0).

The location of the open black dot signifies the minimum water selling price for a profitable stand-alone RO desalination unit. A stand-alone RO plant using grid electricity and beginning operations in 2035 has a required selling price for water of \$1.18/thousand gal $(\$ 0.000311 / \mathrm{kg})$, as discussed in Section 2.3.5. 


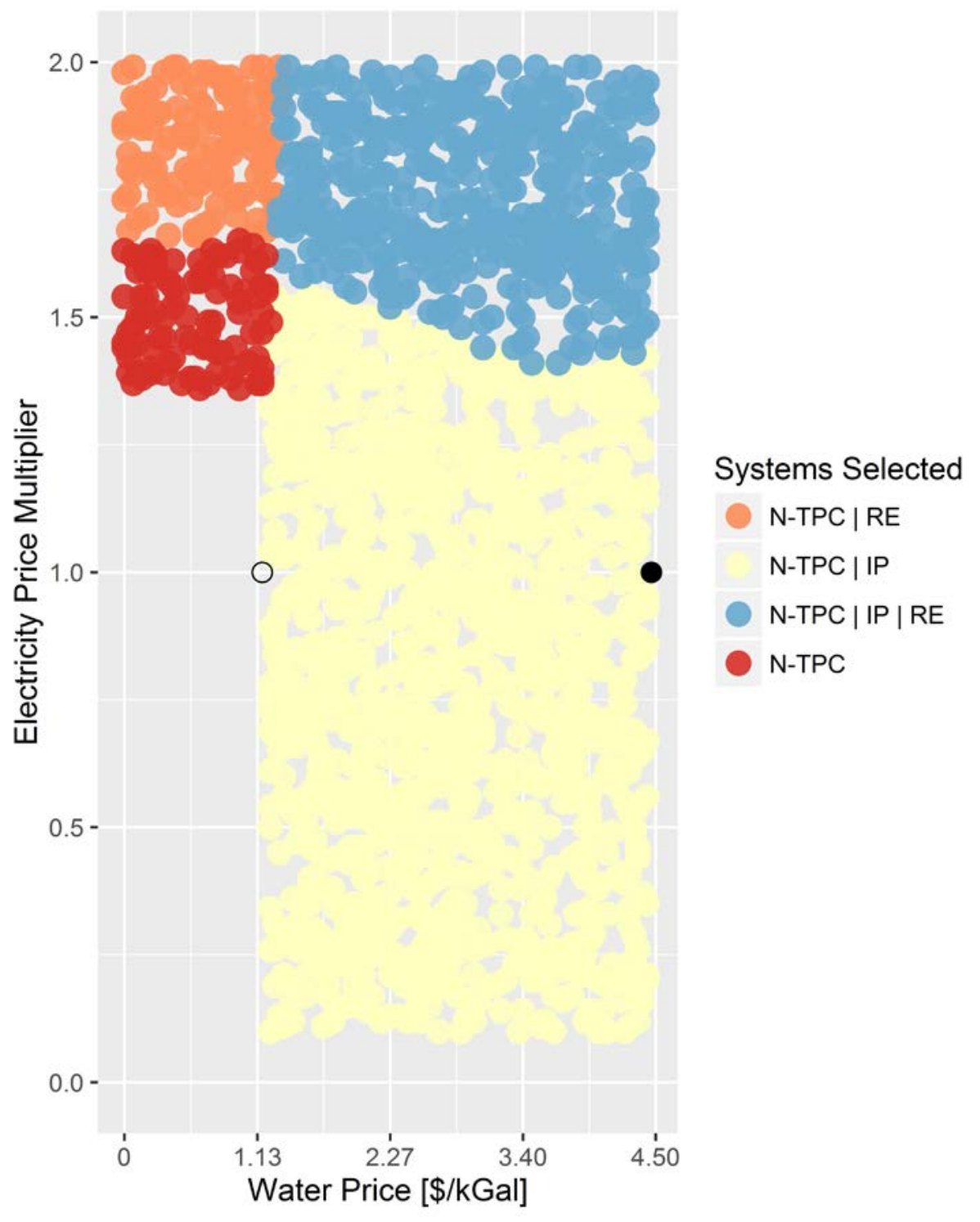

Figure 26. Optimal configurations for Arizona-desalination scenario at various water prices and electricity price multipliers

N-TPC: Nuclear reactor and thermal

N-IP: Nuclear reactor and industrial process

RE: Renewable electricity generation

Solid black dot at electricity price multiplier of 1.0 and $\$ 4.50 /$ thousand gal water price: reference case water price projection; reference case electricity price vector

Open black dot: minimum water selling price for an $\mathrm{RO}$ desalination plant; reference case electricity price vector

Figure 27 shows the optimal product mix based on each optimal combination shown in Figure 26. As in Figure 26, if the projected price of water is greater than $\$ 1.26 /$ thousand gal, a nuclearRO configuration would be profitable. The graphic on the right in Figure 27 shows that optimal water production is maximized at the highest water prices combined with lower electricity prices. At either lower water prices or higher electricity prices, providing sufficient electricity to participate in the capacity market is more profitable than generating the maximum amount of 
water. The difference between the dark blue dots (where water production is maximized) and the white dots is that water production is reduced by $2,000 \mathrm{AF} / \mathrm{yr}^{*}$ to allow for participation in the capacity markets and electricity generation during the hours required to receive the capacity payment (as shown in the tan dots in the left figure).

When the PV subsystem is included in the configuration, the reduction in water production is only about $500 \mathrm{~kg} / \mathrm{yr}$ (indicated by the presence of moderately blue dots instead of white) because PV provides much, but not all, of the electricity required to participate in the capacity markets. The opportunity cost of excluding PV is equivalent to the reduction in water produced to participate in the capacity markets; hence, as the price of water increases, the value of the electricity price multiplier does not have to be as high for configurations including PV to be optimal.

For that reason, the co-management of the PV system and the nuclear-RO system enables profitable installation of PV systems at lower electricity prices; a nuclear-PV-desalination N-R HES is beneficial over separate systems for the range shown in the light blue dots in Figure 26.

* One AF, or acre-foot, is 325,851 gallons. 

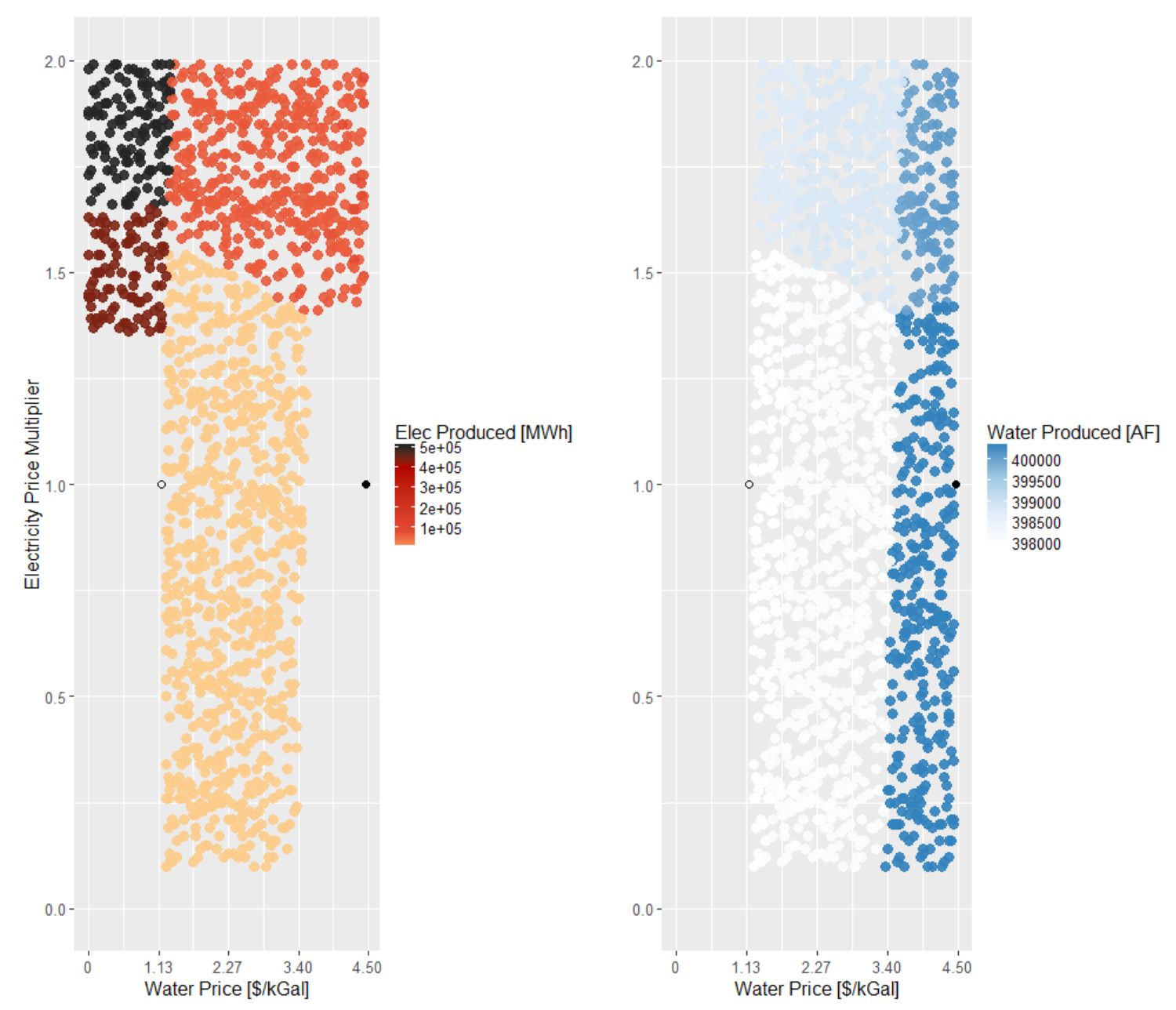

Figure 27. Optimal annual product generation at various water prices and electricity price multipliers for Arizona-desalination scenario

Electricity is on the left with greater generation at the darker color. Water is on the right. Electricity pricing based on AEO reference case and $\$ 50 / \mathrm{kW}$-yr capacity payments

Solid black dot at electricity price multiplier of 1.0 and $\$ 4.50 /$ thousand gal water price: reference case water price projection; reference case electricity price vector

Open black dot: minimum water selling price for an $\mathrm{RO}$ desalination plant; reference case electricity price vector

Figure 28 shows the NPVs for the optimal configurations as shown in Figure 26 above. Note that profitability increases more dramatically with rising water prices than with rising electricity prices. 


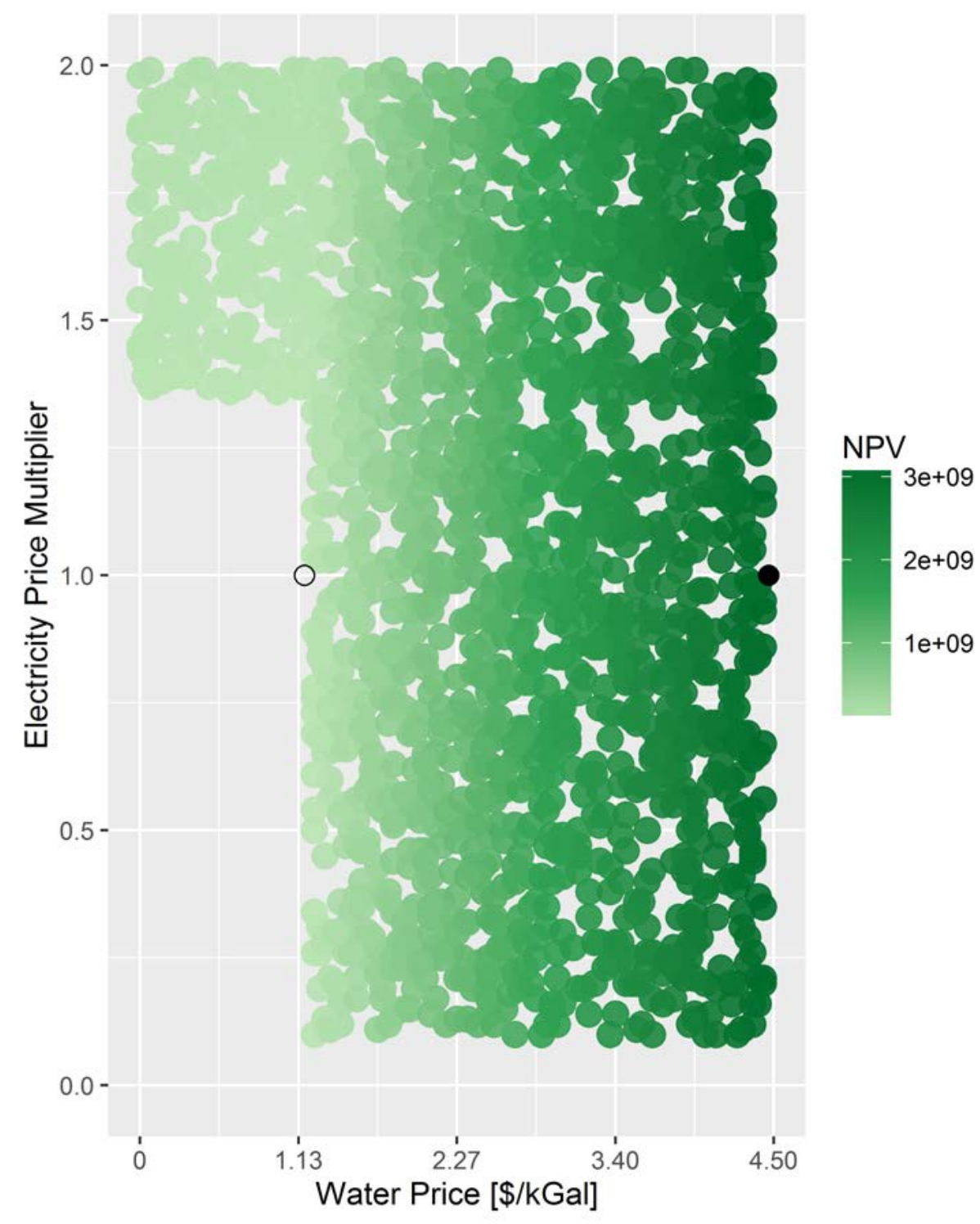

Figure 28. Arizona-Desalination NPVs at various water prices and electricity price multipliers Electricity pricing based on AEO reference case and $\$ 50 / \mathrm{kW}$-yr capacity payments.

Darker shades indicate higher NPVs.

Solid black dot at electricity price multiplier of 1.0 and $\$ 4.50 /$ thousand gal water price: reference case water price projection; reference case electricity price vector

Open black dot: minimum water selling price for an RO desalination plant; reference case electricity price vector

In Figure 26-Figure 28, the solid black dot indicates the scenarios with base-case conditions. Table 14 provides present values of all the annual revenues and expenses under the base-case parameters for the optimal configuration (a nuclear reactor, thermal power cycle, and RO desalination subsystem). For comparison, present values for the alternative coupled configuration that includes PV are also provided. Table 15 summarizes the production and financial results for both configurations. 
Table 14 and Table 15 show both configurations are profitable with NPVs of $\$ 3.164$ billion and \$3.151 billion. As shown in Figure 26, the most profitable configuration has only the LW-SMR nuclear reactor with the thermal power cycle and the industrial process (RO desalination). At the base-case water price, even capacity payments are insufficient to incentivize electricity sales instead of generating water, due to the opportunity cost of not selling water.

Note that including PV reduces the NPV slightly because the value of electricity produced does not cover the increased capital cost. Taxes paid for the configuration with PV are essentially the same as for the one without PV because depreciation of the PV subsystem reduces the tax burden and increased income does not overcome that reduction (note that this analysis does not include an investment tax credit, a production tax credit, or other PV incentives). 
Table 14. Arizona-Desalination Scenario Present Values at Base-Case Conditions (negative values indicate expenses and positive indicate income)

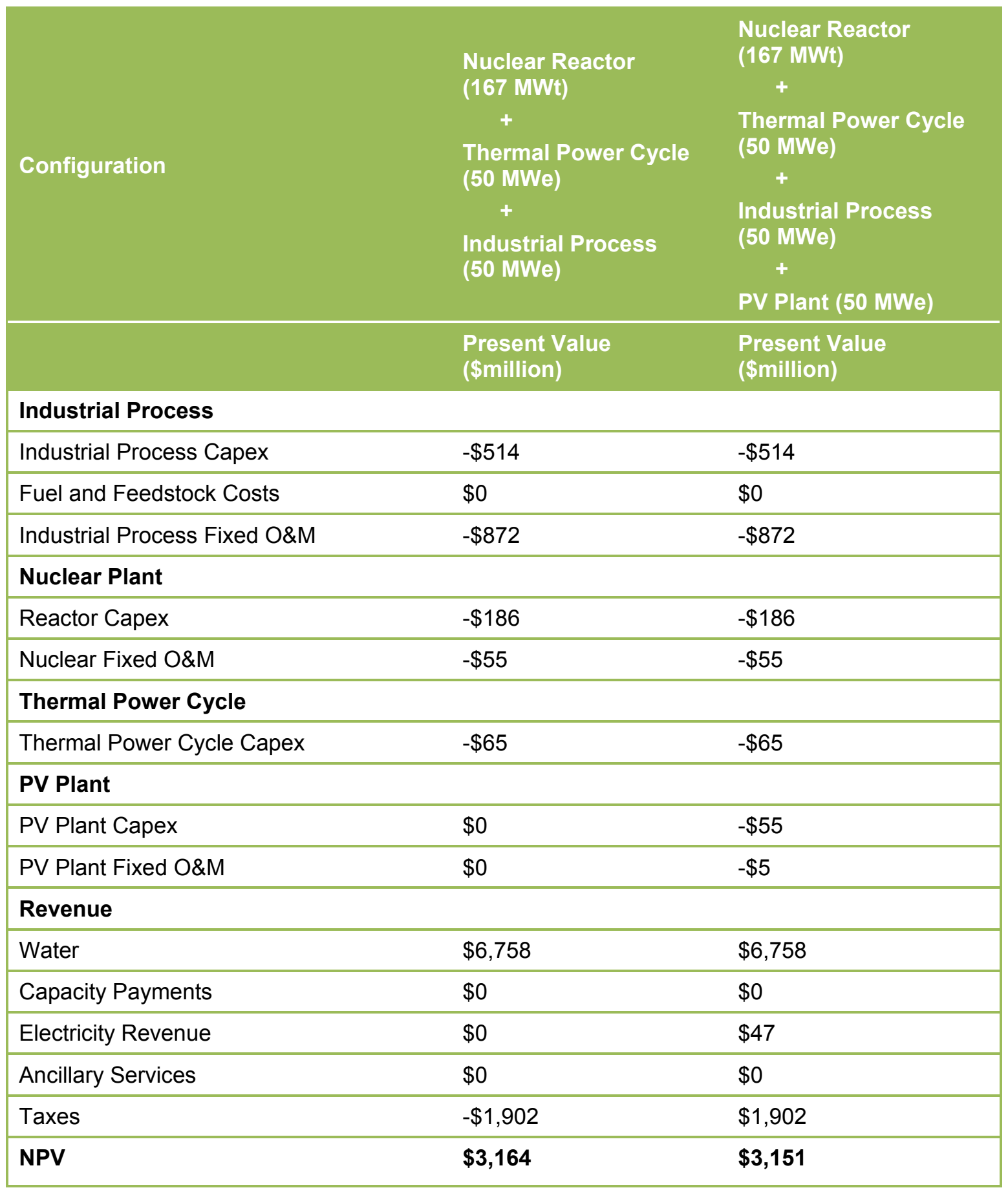

Even though the NPV of the Arizona-desalination scenario at base-case conditions is lower than the Texas-synthetic gasoline scenario, the payback period for the Arizona scenario is shorter and the IRR is higher, because capital costs are lower. 
Table 15. Arizona Case Output Summary at Base-Case Conditions for Two Configurations

\begin{tabular}{|lll|} 
Configuration & $\begin{array}{l}\text { Nuclear Reactor } \\
(167 \mathrm{MWt})\end{array}$ & $\begin{array}{l}\text { Nuclear Reactor } \\
(167 \mathrm{MWt})\end{array}$ \\
$\begin{array}{l}\text { Thermal power } \\
\text { cycle }(50 \mathrm{MWe}) \\
\text { Industrial Process } \\
(50 \mathrm{MWe})\end{array}$ & $\begin{array}{l}\text { Thermal power } \\
\text { cycle (50 MWe) } \\
\text { Industrial Process } \\
(50 \mathrm{MWe})\end{array}$ \\
\hline Annual Electricity Output (GWh) & 0 & 83 \\
\hline TCI & $\$ 765$ million & $\$ 820$ million \\
\hline Annual Water Produced (gal) & 130 billion & 130 billion \\
\hline Payback Period (years) & $(400,000 \mathrm{AF})$ & $(400,000 \mathrm{AF})$ \\
\hline IRR after 25 years of operation & 2.2 & 2.2 \\
\hline NPV/TCI Ratio & $48 \%$ & $46 \%$ \\
\hline
\end{tabular}

Table 16 compares the finances of the coupled LW-SMR nuclear-RO configuration to the competing option where an NGCC provides electricity to an RO desalination subsystem. Both configurations produce water exclusively because the price of water is high enough that the water income impacts the bottom line more than electricity and capacity payments (as shown in Figure 26). The NGCC-RO configuration has a slightly higher NPV and much lower capital investment than the nuclear reactor-thermal power cycle-RO configuration, so it has both a higher IRR and NPV/TCI ratio.

Table 16. Financial Comparison Between Configurations for the Arizona-Desalination Scenario

\begin{tabular}{|c|c|c|c|c|c|}
\hline & $\begin{array}{l}\text { NPV @ 10\% } \\
\text { Discount Rate }\end{array}$ & $\mathrm{TCl}$ & $\begin{array}{l}\text { NPV/TCI } \\
\text { Ratio }\end{array}$ & IRR & $\begin{array}{l}\text { Annual } \\
\text { Electricity } \\
\text { Output (GWh) }\end{array}$ \\
\hline $\begin{array}{l}\text { Nuclear reactor ( } 167 \\
\text { MWt), thermal power } \\
\text { cycle ( } 50 \mathrm{MWe}), \mathrm{RO} \\
\text { subsystem ( } 50 \mathrm{MWe}) \text {, } \\
\text { and PV subsystem ( } 50 \\
\mathrm{MWe})\end{array}$ & $\$ 3.15$ billion & $\$ 0.82$ billion & 3.84 & $46 \%$ & 83 \\
\hline $\begin{array}{l}\text { Nuclear reactor ( } 167 \\
\mathrm{MWt}) \text {, thermal power } \\
\text { cycle }(50 \mathrm{MWe}) \text {, and RO } \\
\text { subsystem }(50 \mathrm{MWe})\end{array}$ & $\$ 3.16$ billion & $\$ 0.77$ billion & 4.14 & $48 \%$ & 0 \\
\hline $\begin{array}{l}\text { NGCC }(50 \mathrm{MWe}) \text { and RO } \\
\text { subsystem }(50 \mathrm{MWe})\end{array}$ & $\$ 3.20$ billion & $\$ 0.70$ billion & 5.53 & $62 \%$ & 0 \\
\hline
\end{tabular}


For the Arizona-desalination scenario, the full N-R HES configuration (nuclear-thermal power cycle-desalination-PV) is not the optimal configuration under the base-case parameters. Instead, the nuclear reactor-thermal power cycle-desalination system is optimal. At higher electricity prices, PV becomes part of the optimal solution. Because PV can provide a large fraction of the electrical energy necessary to participate in the capacity markets, it allows a combined system to limit the opportunity cost of not producing water while still receiving a capacity payment. That result realizes a benefit for co-managing the system and a key benefit of an N-R HES. At the base-case parameters, the nuclear-thermal power cycle-RO configuration is profitable, but not as profitable as its key competition, NGCC-RO, because the NGCC subsystem has a lower capital expense.

If the grid has less VRE generation than the base-case generation mix, the electricity price multiplier necessary for both nuclear and PV power generation to be profitable drops. The resulting optimal configuration for the base-case parameters changes to one that includes all the subsystems in this scenario (nuclear reactor, thermal power cycle, industrial process [RO desalination], and PV). Figure 29 shows the optimal configurations at various water prices and electricity price multipliers under both the RPS80 generation mix (left) and the Current Law generation mix (right). Because the Current Law generation mix has a lower penetration of VRE generation (16\%) than the RPS80 mix (33\%), its price for electricity is greater than zero for all hours of each year, whereas under the RPS80 grid mix, the price for electricity is zero for 704 hours of the year. Electricity-generating configurations can receive income during those hours, so a lower electricity price multiplier is necessary for them to be profitable. The synergistic impacts of the lower VRE penetration and the ability of PV to provide much, but not all, of the electricity required to participate in the capacity markets, results in a configuration that is beneficial to all the subsystems. Appendix H.3 provides additional results for scenarios using the Current Law generation mix. 


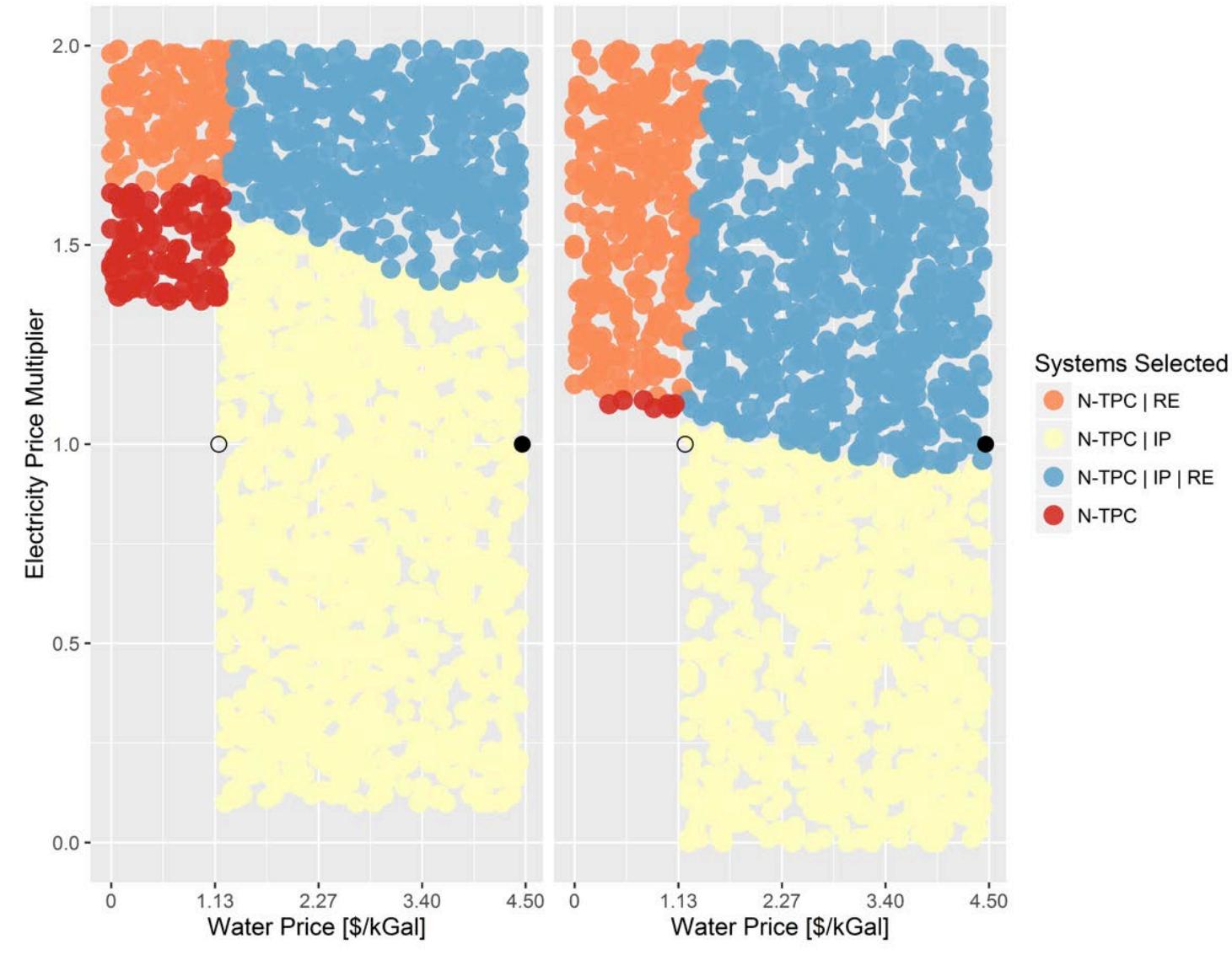

Figure 29. Optimal configurations for the Arizona-desalination scenario under the RPS80 generation mix (left) and Current Law generation mix (right)

N-TPC: Nuclear reactor and thermal

$\mathrm{N}$-IP: Nuclear reactor and industrial process

$\mathrm{RE}$ : Renewable electricity generation

Solid black dot at electricity price multiplier of 1.0 and $\$ 4.50 /$ thousand gal water price: reference case water price projection; reference case electricity price vector Open black dot: minimum water selling price for an $\mathrm{RO}$ desalination plant; reference case electricity price vector

If the prices of natural resources (natural gas, coal, and crude oil) are lower than the base case, the optimal configuration does not change, but it is less profitable. Figure 30 shows the optimal configurations at various water prices and electricity price multipliers under both the AEO reference case prices (left) and the AEO low-oil-price case prices (right). The AEO low-oil case results in lower electricity prices because the natural gas for CTs and NGCCs costs less; thus, the electricity price multiplier needs to be larger for all electricity-generating configurations to be profitable. Appendix H.4 provides additional results for scenarios using the AEO low-oil-case electricity prices. 


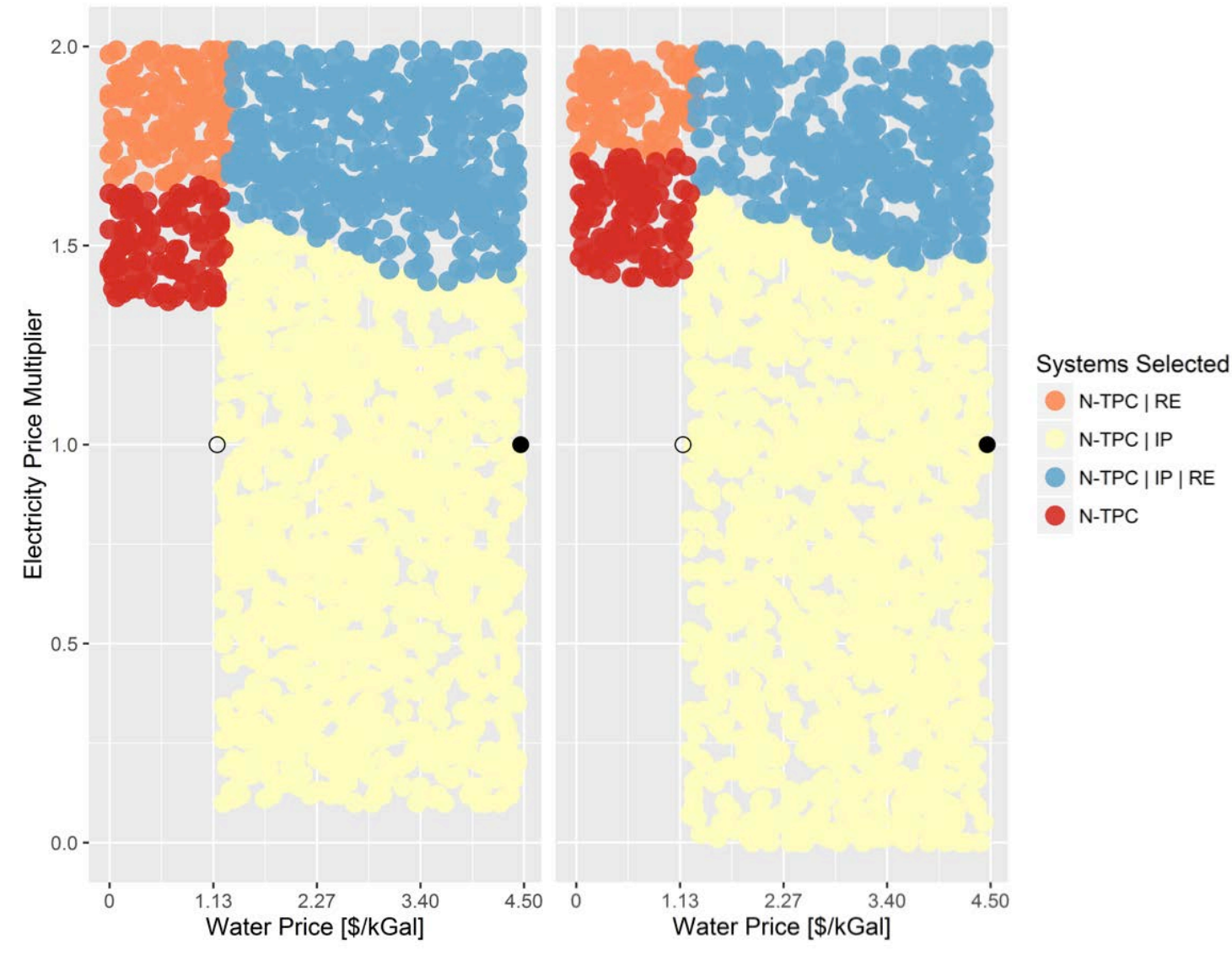

Figure 30. Optimal configurations for the Arizona-desalination scenario AEO Reference Case Energy Prices (left) and the AEO Low Oil Case Electricity Prices (right)

N-TPC: Nuclear reactor and thermal

$\mathrm{N}$-IP: Nuclear reactor and industrial process

$\mathrm{RE}$ : Renewable electricity generation

Solid black dot at electricity price multiplier of 1.0 and $\$ 4.50 /$ thousand gal water price: reference case water price projection; reference case electricity price vector Open black dot: minimum water selling price for an $\mathrm{RO}$ desalination plant; reference case electricity price vector

If a cost of carbon is assessed on all emissions, a smaller electricity price multiplier is required for the nuclear and PV generators to be profitable. The resulting optimal configuration at the base-case parameters changes to one that includes all the subsystems in this scenario (nuclear reactor, thermal power cycle, industrial process [RO desalination], and PV). Figure 31 shows the optimal configurations at various water prices and electricity price multipliers under both the AEO reference case prices without a cost of carbon (left) and those same prices with a cost of carbon (right). As with the grid with lower penetrations of VRE, the synergistic impacts of the cost of carbon and the ability of PV to provide much, but not all, of the electricity required to participate in the capacity markets, results in a configuration that is beneficial to all the subsystems. Appendix H.5 provides additional results for scenarios with electricity prices that include a cost of carbon. 


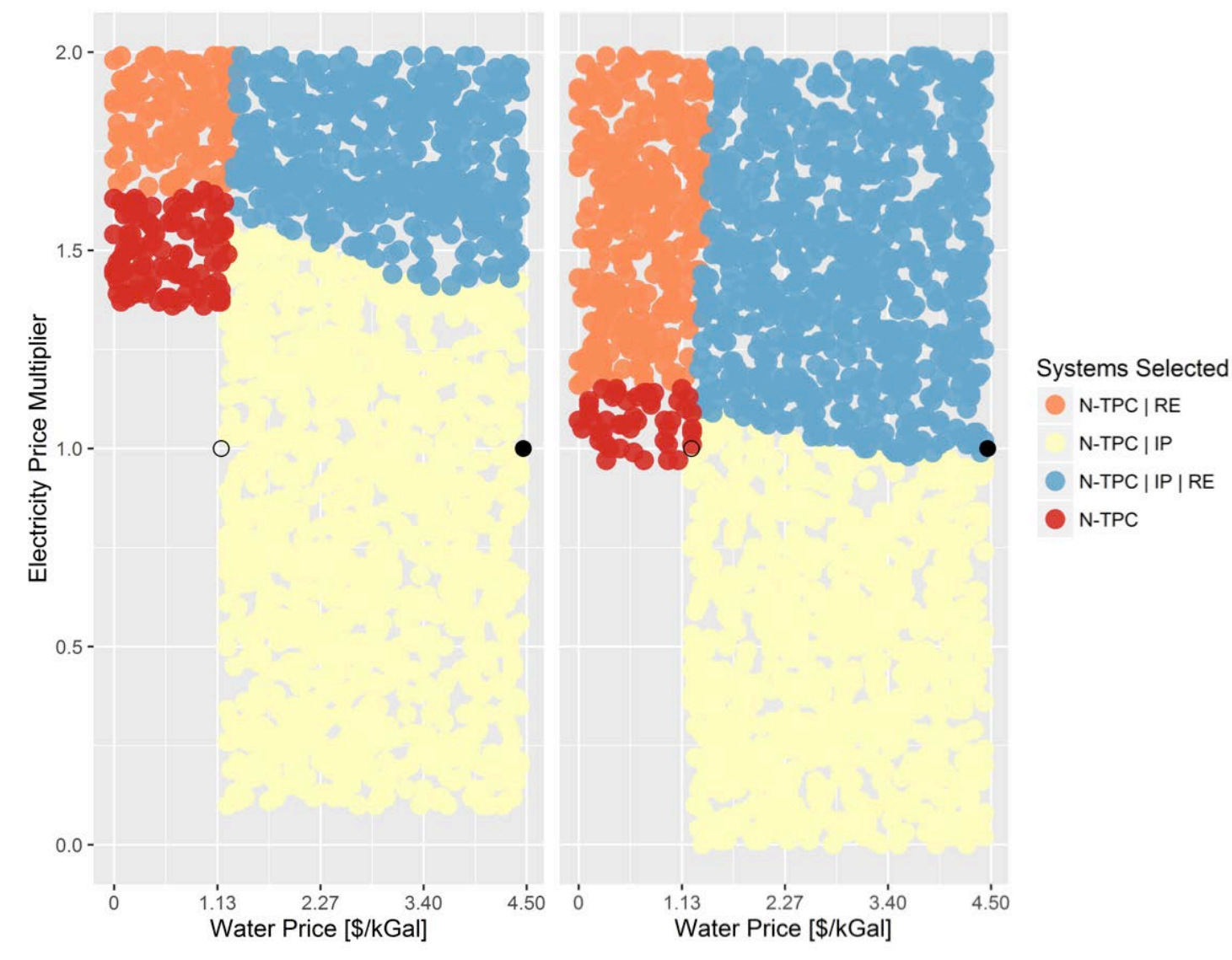

Figure 31. Optimal configurations for the Arizona-desalination scenario AEO Reference Case Energy Prices (left) and prices including a cost of carbon(right)

N-TPC: Nuclear reactor and thermal

N-IP: Nuclear reactor and industrial process

RE: Renewable electricity generation

Solid black dot at electricity price multiplier of 1.0 and $\$ 4.50 /$ thousand gal water price: reference case water price projection; reference case electricity price vector

Open black dot: minimum water selling price for an RO desalination plant; reference case electricity price vector

If the cost of capital (i.e., the discount rate) is lower, the optimal configuration does not change, but a smaller electricity price multiplier is required for the nuclear and PV generators to be profitable, and a lower water price is necessary for the desalination configurations to be profitable. Figure 32 shows the optimal configurations at various water prices and electricity price multipliers under both the $10 \%$ nominal discount rate used in this analysis (left) and an $8.15 \%$ nominal discount rate used in the previous analysis performed by INL (right). The previous analysis used a 5\% real discount rate with $3 \%$ inflation. ${ }^{50}$ Those two values result in an $8.15 \%$ nominal discount rate. Reducing the discount rate reduces the electricity price multiplier necessary for the carbon-free nuclear and renewable electricity generation technologies to be profitable, because both technologies have a high capital-to-operating investment ratio when compared to CTs and NGCCs. The capital-to-operating investment ratio of the desalination subsystem is much lower, so the impact on it is negligible. Appendix H.6 provides additional results for scenarios using an $8.15 \%$ nominal discount rate. 


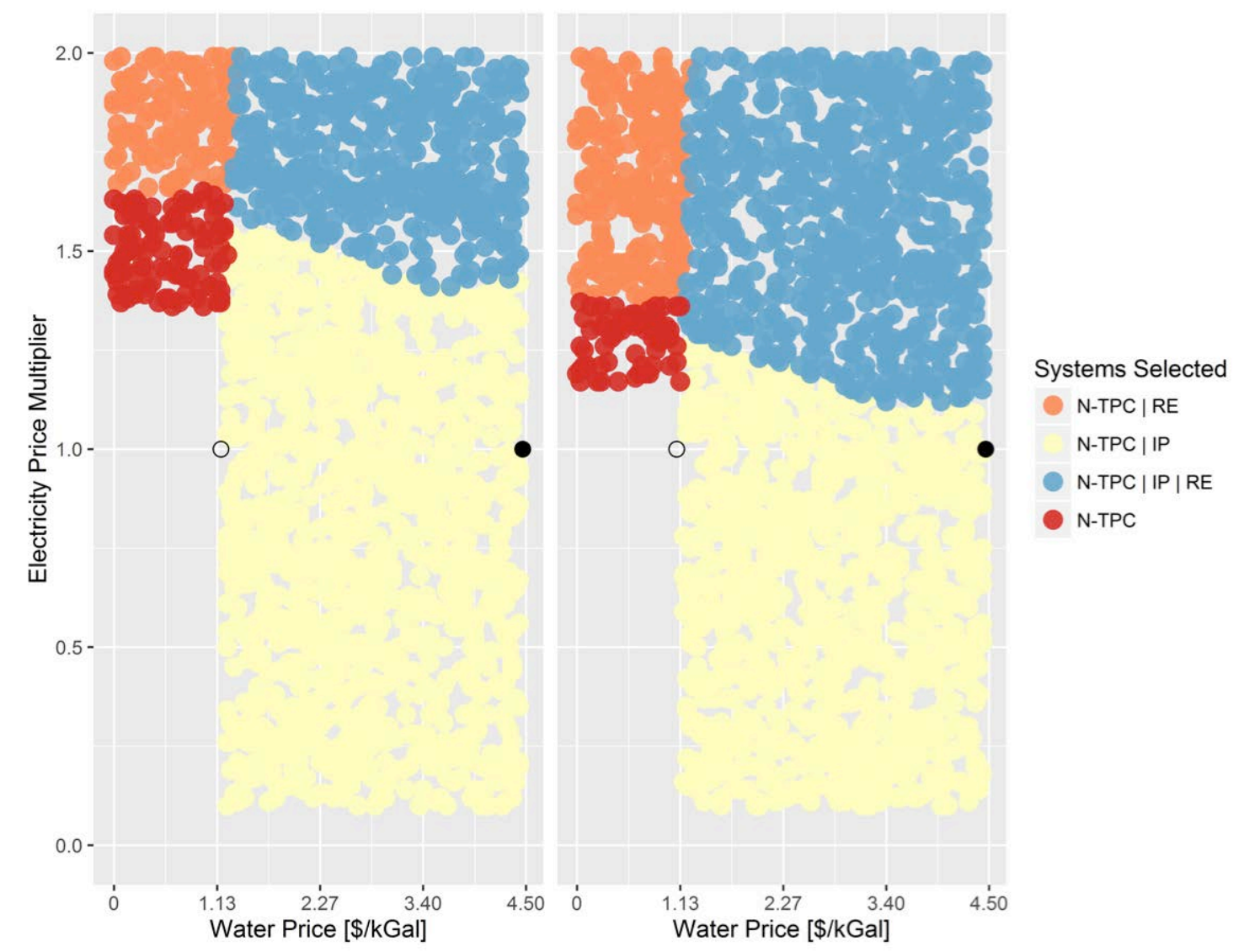

Figure 32. Optimal configurations for the Arizona-desalination scenario at a $10 \%$ nominal discount rate (left) and at an $8.15 \%$ nominal discount rate (right)

N-TPC: Nuclear reactor and thermal

N-IP: Nuclear reactor and industrial process

$\mathrm{RE}$ : Renewable electricity generation

Solid black dot at electricity price multiplier of 1.0 and $\$ 4.50 /$ thousand gal water price: reference case water price projection; reference case electricity price vector

Open black dot: minimum water selling price for an RO desalination plant; reference case electricity price vector

If the maximum size of the nuclear reactor and thermal power cycle is larger than the maximum size of the industrial process, the only change to the optimal configuration is that it includes nuclear-electricity generation when that is profitable. Figure 33 shows the optimal configurations at various water prices and electricity price multipliers when the nuclear reactor and thermal power cycle are limited to a maximum size of $50 \mathrm{MWe}$ (left) and to $180 \mathrm{MWe}$ (right). The key difference is that whenever the nuclear reactor and thermal power cycle are profitable selling electricity to the grid, they will be built with a 180-MWe capacity. That condition occurs when the electricity price multiplier is greater than 1.3. Appendix H.7 provides additional results for scenarios where the maximum nuclear reactor capacity is $180 \mathrm{MWe}$. 


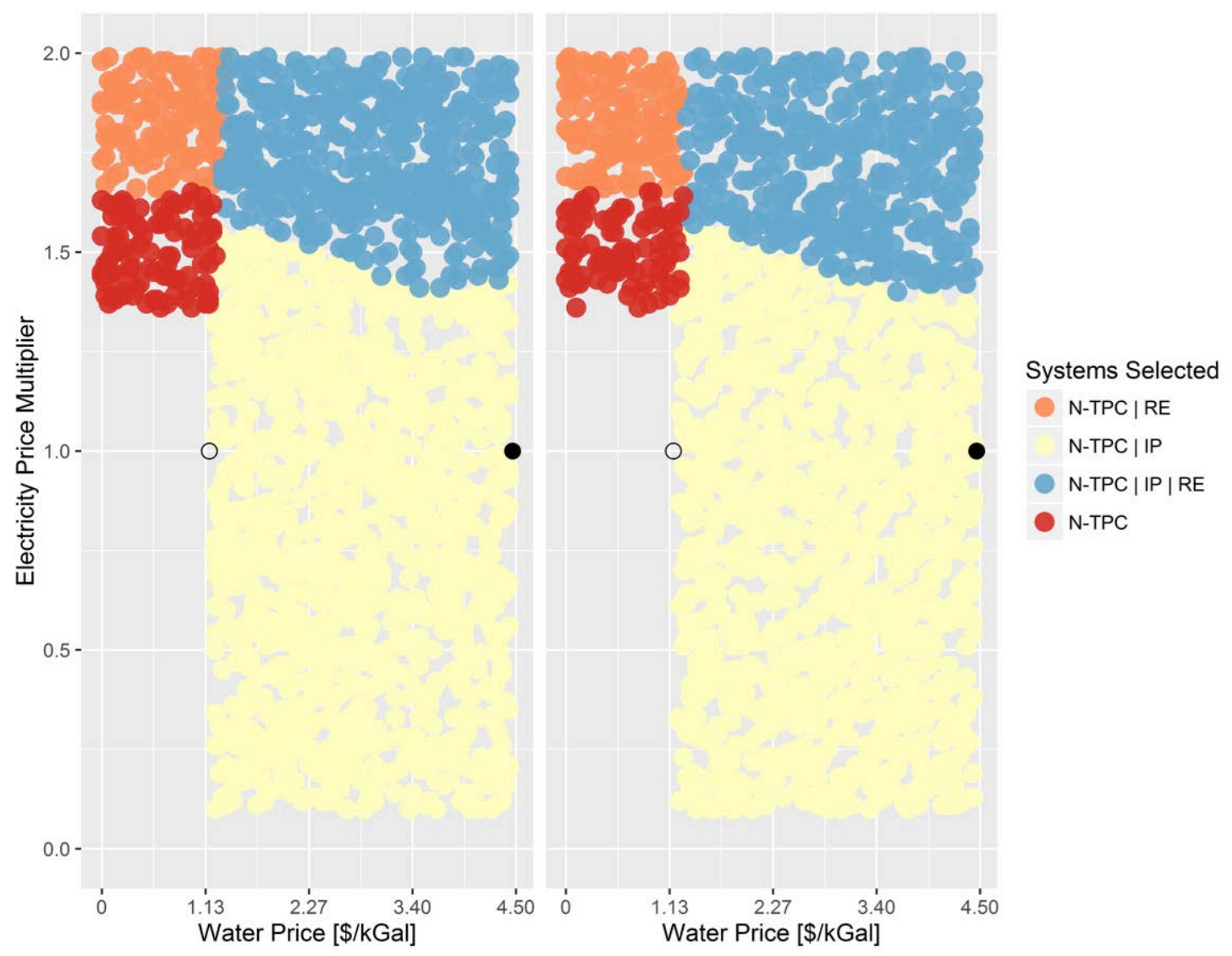

Figure 33. Optimal configurations for the Arizona-desalination scenario with a 50-MWe maximum capacity of the nuclear reactor and thermal power cycle (left) and a 180-MWe maximum capacity (right)

N-TPC: Nuclear reactor and thermal

N-IP: Nuclear reactor and industrial process

$\mathrm{RE}$ : Renewable electricity generation

Solid black dot at electricity price multiplier of 1.0 and $\$ 4.50 /$ thousand gal water price: reference case water price projection; reference case electricity price vector

Open black dot: minimum water selling price for an $\mathrm{RO}$ desalination plant; reference case electricity price vector

Figures showing additional results from the base case and sensitivity runs for the Arizonadesalination scenario are in Appendix $\mathrm{H}$.

The results of these sensitivities indicate that a number of synergistic impacts, coupled with the ability of PV to provide much, but not all, of the electricity required to participate in the capacity markets, can benefit all the subsystems. Those results indicate that co-management of the PV subsystem with flexible nuclear generation allows the PV subsystem to benefit from the increased value of water production.

\subsubsection{Potential to Reduce GHG Emissions and Their Associated Costs}

One of the key potential benefits of N-R HESs is the potential to reduce carbon emissions and their associated costs (if there is a cost of carbon). The Arizona-desalination scenario replaces electricity generated by carbon-emitting sources with emissions-free nuclear electricity. Table 17 
compares the financial impacts of NGCC-generated electricity to those of nuclear-generated electricity. The NGCCs emit $769 \mathrm{lb} \mathrm{CO} / \mathrm{MWh}$ as described in Appendix F. Table 17 also shows the annual cost of carbon and potential impacts of a cost of carbon on the NPV, IRR, and $\mathrm{NPV} / \mathrm{TCI}$ ratio at all four costs of carbon used in this analysis (see Section 2.4.5 for details). Under the base-case parameters, using an NGCC to produce electricity for the RO desalination subsystem instead of nuclear electricity increases $\mathrm{CO}_{2}$ emissions by 153,000 metric tons annually; however, only at the highest cost of carbon $\left(\$ 168 /\right.$ metric ton $\left.\mathrm{CO}_{2}\right)$ does the NPV/TCI ratio fall below that of the nuclear electricity-RO configuration.

Table 17. Financial Comparison Between Configurations for the Arizona-Desalination Scenario Including Costs of Carbon

\begin{tabular}{|c|c|c|c|c|c|c|}
\hline & $\begin{array}{l}\mathrm{CO}_{2} \\
\text { Emissions } \\
\text { (metric ton } \\
\mathrm{CO}_{2} / \mathrm{yr} \text { ) }\end{array}$ & $\begin{array}{l}\begin{array}{l}\text { Cost of } \\
\text { Carbon } \\
\text { (levelized) }\end{array} \\
\text { (\$million) }\end{array}$ & $\begin{array}{l}\text { NPV with Cost } \\
\text { of Carbon } \\
\text { (\$billion) }\end{array}$ & $\begin{array}{l}\mathrm{TCI} \\
\text { (\$ million) }\end{array}$ & IRR & $\begin{array}{l}\text { NPV/TCI } \\
\text { Ratio with } \\
\text { Cost of } \\
\text { Carbon }\end{array}$ \\
\hline $\begin{array}{l}\text { Nuclear electricity for } \\
\text { the RO system }\end{array}$ & 0 & $\$ 0$ & $\$ 3.16$ & $\$ 765$ & $48 \%$ & 4.14 \\
\hline \multirow{4}{*}{$\begin{array}{l}\text { NGCC electricity for } \\
\text { the RO system }\end{array}$} & \multirow{4}{*}{153,000} & $\$ 44$ & $\$ 3.16$ & \multirow{4}{*}{$\$ 700$} & $61 \%$ & 4.51 \\
\hline & & $\$ 124$ & $\$ 3.08$ & & $60 \%$ & 4.40 \\
\hline & & $\$ 172$ & $\$ 3.03$ & & $60 \%$ & 4.33 \\
\hline & & $\$ 380$ & $\$ 2.82$ & & $57 \%$ & 4.03 \\
\hline
\end{tabular}

\subsubsection{Potential to Support Resource Adequacy}

We tested the hypothesis that N-R HESs can support electricity resource adequacy while maximizing production of a more profitable industrial product with sufficient incentives (i.e., a capacity payment that is sufficiently high). At the base-case parameters, the nuclear-thermal power cycle-desalination configuration shuts off the desalination subsystem to provide electricity during the 50 highest load hours out of the year (those required to receive the capacity payments) when the capacity payments are high $(\$ 100 / \mathrm{kW}-\mathrm{yr}$ and $\$ 150 / \mathrm{kW}-\mathrm{yr})$, but not at the base-case capacity payment $(\$ 50 / \mathrm{kW}-\mathrm{yr})$.

Increased capacity payments increase the incentive to build electricity generation. As shown in Figure 34, increased capacity payments result in lower hourly electricity prices required to build nuclear electricity generation profitably. The capacity payment increase from $\$ 50 / \mathrm{kW}$-yr to $\$ 100 / \mathrm{kW}$-yr reduces the electricity price multiplier necessary for nuclear power generation to be profitable from 1.3 to 1.2 , and an additional increase to $\$ 150 / \mathrm{kW}$-yr further reduces the necessary multiplier to 1.1 ; increasing the capacity payment results in incentives for increased generation. Capacity payments also affect PV generation because, in combination with nuclear power, it can support electricity generation required for the capacity payments. 


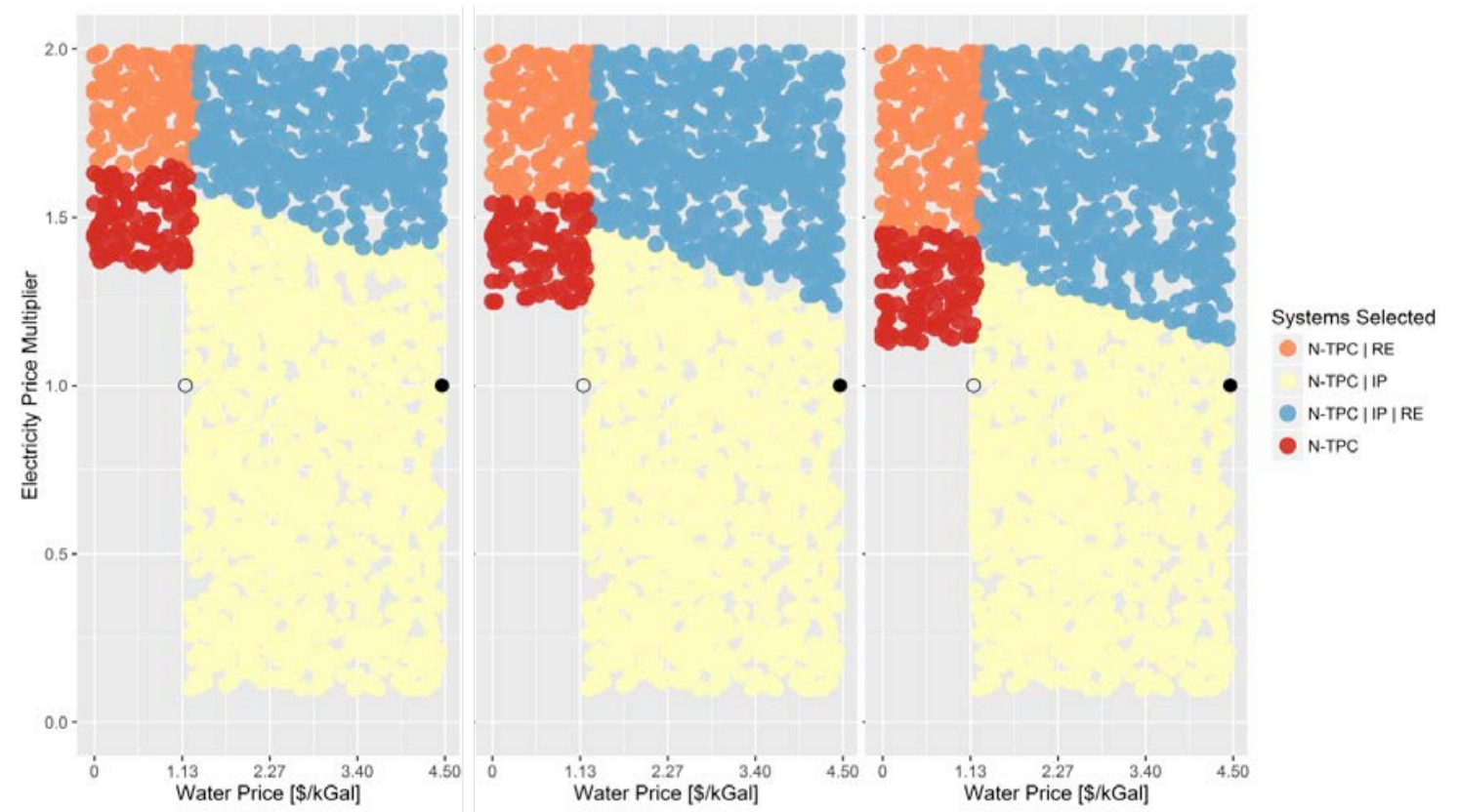

Figure 34. Optimal configurations for Arizona-desalination scenario at various water prices and electricity price multipliers at three levels of capacity payments.

$\$ 50 / k W-y r$ (left); \$100/kW-yr (middle); \$150/kW-yr (right)

N-TPC: Nuclear reactor and thermal

$\mathrm{N}-\mathrm{IP}$ : Nuclear reactor and industrial process

RE: Renewable electricity generation

Solid black dot at electricity price multiplier of 1.0 and $\$ 4.50 /$ thousand gal water price: reference case water price projection; reference case electricity price vector

Open black dot: minimum water selling price for an RO desalination plant; reference case electricity price vector 

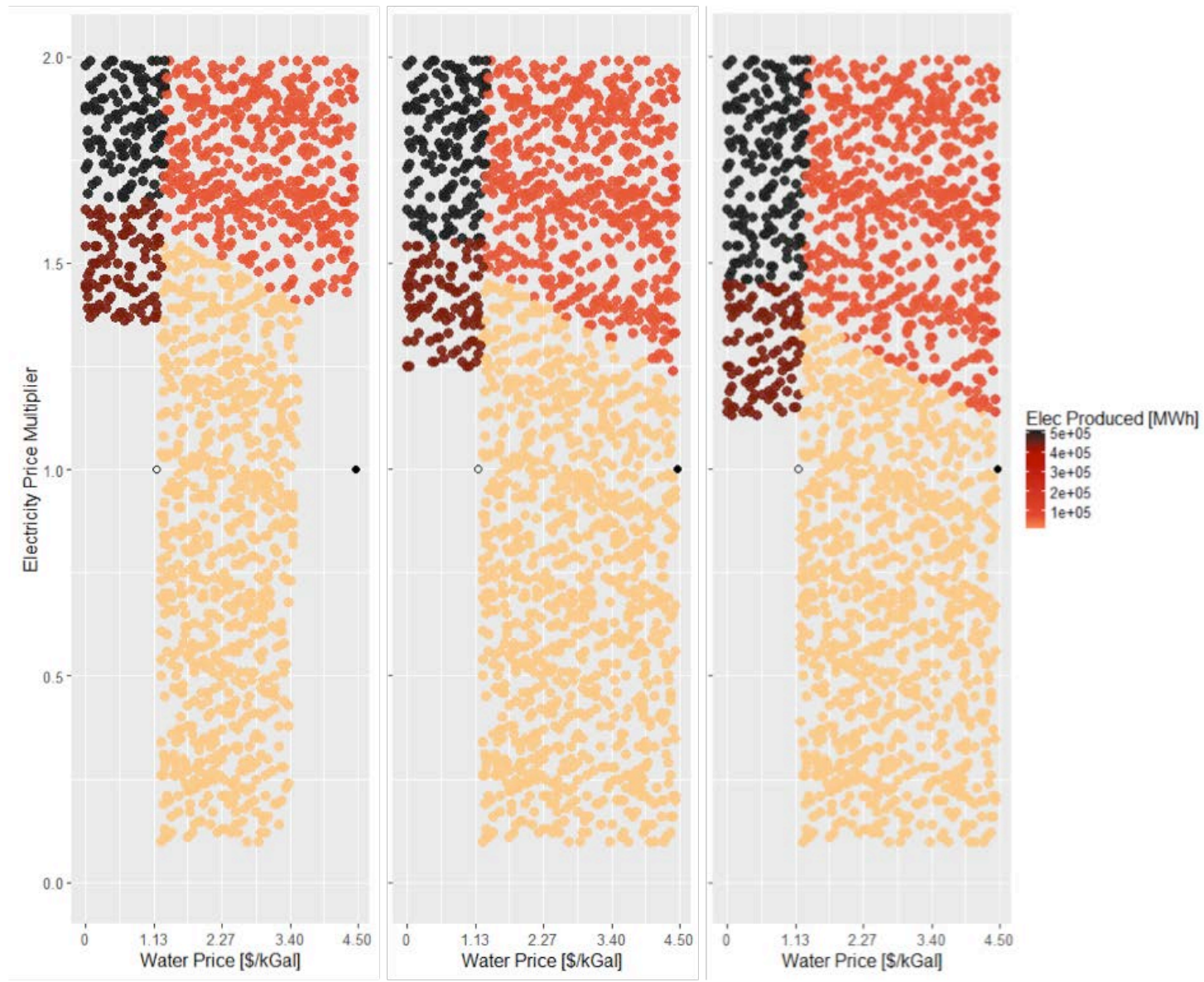

Figure 35. Optimal annual electricity generation for Arizona-desalination scenario at various water prices and electricity multipliers at three levels of capacity payments.

\$50/kW-yr (left); \$100/kW-yr (middle); \$150/kW-yr (right)

Solid black dot at electricity price multiplier of 1.0 and $\$ 4.50 /$ thousand gal water price: reference case water price projection; reference case electricity price vector

Open black dot: minimum water selling price for an $\mathrm{RO}$ desalination plant; reference case electricity price vector

A key difference between the configurations in this scenario and those in the nuclear-synthetic gasoline scenario is that, under a number of water prices, the nuclear-desalination case provides electrical energy during the capacity payment hours instead of producing the industrial product during those hours. Figure 35 displays the optimal annual electricity production under the three capacity payments. For all capacity payment levels, there is a range of water prices where, for 50 hours during the year, electricity is sold to the grid instead of being used to desalinate water ( $\tan$ dots). By selling electricity during the year, capacity payments are an income stream. The key difference between the two scenarios is that the desalination scenario inherently includes a thermal power cycle, so electricity production requires no additional capital cost. The capital cost for the thermal power cycle (and the opportunity costs of the Texas-synthetic gasoline scenario not generating gasoline during those hours) dis-incentivizes the nuclear-synthetic gasoline configuration in the Texas scenario from participating in the capacity markets. 
Within the parameters tested and under the perfect foresight these analyses assume, the Arizonadesalination scenario provides resource adequacy to the grid when the water price is sufficient for desalination subsystem to be profitable but not so high that the value of water is greater than that of electricity with a capacity payment. This conclusion differs from that for the Texassynthetic gasoline scenario because the RO subsystem inherently includes the thermal power cycle; hence, no additional capital cost is required to sell electricity. In addition, the RO subsystem's capital cost and the value of water are both lower than those for the synthetic gasoline subsystem; therefore, the opportunity cost of not producing water is lower and an easier hurdle to overcome.

\subsubsection{Potential for Flexibility to Increase Profitability}

We tested the hypothesis that, at some combinations of electricity and product prices, N-R HESs will be more profitable than uncoupled systems because they can produce electricity when its price is high and the industrial product when the price of electricity is low. At the price combinations shown in Figure 35, optimal configurations include flexibility to receive capacity payments; however, the price of water is unlikely to be high enough to utilize that flexibility to sell electricity instead of making water during the remaining hours of the year under base-case parameters.

\subsubsection{Potential for Flexibility to Hedge Against Uncertainty}

The economic conditions over the life of an N-R HES are inherently uncertain, which may affect the net revenue streams available for plants designed to sell electricity, water, or both. The N-R HES is designed to have the ability to switch on an hourly basis between selling electricity into the wholesale market or using it to desalinate water, depending on market conditions. Adding such flexibility potentially adds value (in the net incremental revenue sense) compared to the single-product configurations. However, whether adding this capability makes economic sense to an investor depends on a number of factors, including the incremental capital investment, incremental operating costs, and the prices and price volatility of water and electricity. The ability to switch operating patterns over a variety of timescales within and across years can also reduce the variability of net cash flows over the lifetime of the plant, which acts as a partial natural hedge against the uncertainty of future market conditions. The value of that flexibility depends on many factors, including the expected variability of future prices for each product, the time over which that variability occurs, and the size of the investments needed to provide the flexibility. Analyzing both NPV and the NPV/TCI ratio informs both the expected returns and choices between competing investments in a capital-constrained environment.

Because the distributions of future product prices and their correlations are highly uncertain and because of the location-specific nature of the analysis and the assumptions, the analysis in this section is intended to be illustrative only.

Given these caveats, we tested the potential benefits of three configurations. One configuration includes internal flexibility and can select between two products. That configuration is compared to two configurations that provide only one product - in this case either electricity or electricity to water. The three configurations are:

1. 50-MWe nuclear reactor with 50-MWe thermal power cycle to generate electricity 
2. 50-MWe nuclear reactor with 50-MWe thermal power cycle to generate electricity and that electricity can be switched on an hourly basis between grid sales and water desalination

3. 50-MWe nuclear reactor with 50-MWe thermal power cycle to generate electricity and all that electricity is used to produce water.

The second configuration can switch between selling electricity to the grid and using that electricity to desalinate water, whichever is more profitable in a given hour. In contrast, the first and the third configurations have fixed production, and we assume they operate at maximum capacity for 8,760 hours per year. The TCI is $\$ 251$ million for configuration $1, \$ 765$ million for configuration 2, and $\$ 765$ million for configuration 3. The nuclear reactor subsystem's capex (without the thermal power cycle) is $\$ 186$ million. The thermal power cycle (included in configurations 1 and 2) has a capex of $\$ 65$ million. The desalination subsystem has a capex of \$514 million, so the incremental capital costs required to use electricity to desalinate water are more than twice the capital costs of the nuclear reactor.

Various timeframes for switching can be considered: within the year (hourly within a given year due to, for example, large differences in in electricity prices during different hours), or more general switching that arises from changes in year-to-year market dynamics (across years).

To model the longer-term annual effects on a multi-decadal basis, we considered two discrete annually based futures. Table 18 shows the futures' parameters, which are intended to be illustrative:

- High-price electricity and low-price water (Future A): All hourly electricity prices increased by a factor of two relative to the base-case parameters described in Section above. The low water price for this future was $\$ 0.5 /$ thousand gal.

- High-price water and low-price electricity (Future B): All hourly electricity prices matched to the base-case parameters described in Section 2.3.2 above. The high water price was set to $\$ 4.5 /$ thousand gal (base-case price for water).

Table 18. Futures Considered for Value of Flexibility Analysis

\begin{tabular}{lll} 
& Future A: & Future B: \\
& High Electricity & Low Electricity \\
& Low Water & High Water \\
Electricity Price Multiplier & 2.0 & 1.0 \\
\hline Water Price & $\$ 0.50 /$ kilogal & $\$ 4.50 /$ kilogal \\
\hline
\end{tabular}

How to view these annual futures over the 25-year life of the system is subjective, given the uncertainty about the future. Because this analysis is intended to be illustrative, we considered a number of combinations of the two futures. The notation $0 \%$ indicates that the annual electricity and water prices corresponding to Future A occur over the entire life of the system (i.e., high price electricity and low price water occur over the entire analysis period). The notation $100 \%$ indicates that electricity and water prices corresponding to Future B occur over the entire life of the system (i.e., high price water and low price electricity occur over the entire life of the 
system). The notation $25 \%$ indicates that $25 \%$ of the years in the analysis period have prices corresponding to Future B and the remaining $75 \%$ correspond to Future A. The notation 50\% indicates that $50 \%$ of the years in the analysis period have prices corresponding to Future B and the other $50 \%$ correspond to Future A. Finally, the notation $75 \%$ indicates that $75 \%$ of the years in the analysis period have prices corresponding to Future B and the remaining $25 \%$ correspond to Future A. Instead of attempting to forecast which years will be under Future A and which will be under Future B, we assume that each year has the same probability of being either A or B. Differences in timing will impact NPV due to the effects of discounting; however, that is likely to be a second-order effect and negligible when compared to the intended accuracy of this effort.

Because of the use of price multipliers, we did not cap electricity prices at $\$ 100 / \mathrm{kWh}$ in this flexibility analysis, unlike in other sections in this report. Instead, we used the PLEXOScalculated maximum prices for the hours when those prices were applicable. The maximum price in the year was $\$ 5,646 / \mathrm{MWh}$, and that price occurred one hour/year. An additional 20 hours had prices greater than $\$ 100 / \mathrm{kWh}$. Those prices were used for all analyses in this section only.

Figure 36 shows the discounted gross revenue minus feedstock costs of all three configurations under five combinations of futures. Fixed costs are not included in the results shown in Figure 36 . Table 19 shows the percentage of time each product is produced by the configuration that can switch between electricity and water production (Configuration 2).

It is important to note that the likelihood of the five combinations of futures shown in Figure 36 may not be equal. For example, if there was an equal likelihood of Future A or Future B occurring in any given year, then over the life of the asset the relative probabilities of $0 \%, 25 \%$, $50 \%, 75 \%$ and $100 \%$ scenarios (as defined above) occurring is 1: $4: 6: 4: 1$. Hence, observations in the figures should be weighted more heavily towards the central 50:50 scenario rather than the extreme $0 \%$ and $100 \%$ scenarios. This weighting should be carefully considered because it is implicitly dependent upon Futures A and B being equally probable, which is unlikely. 


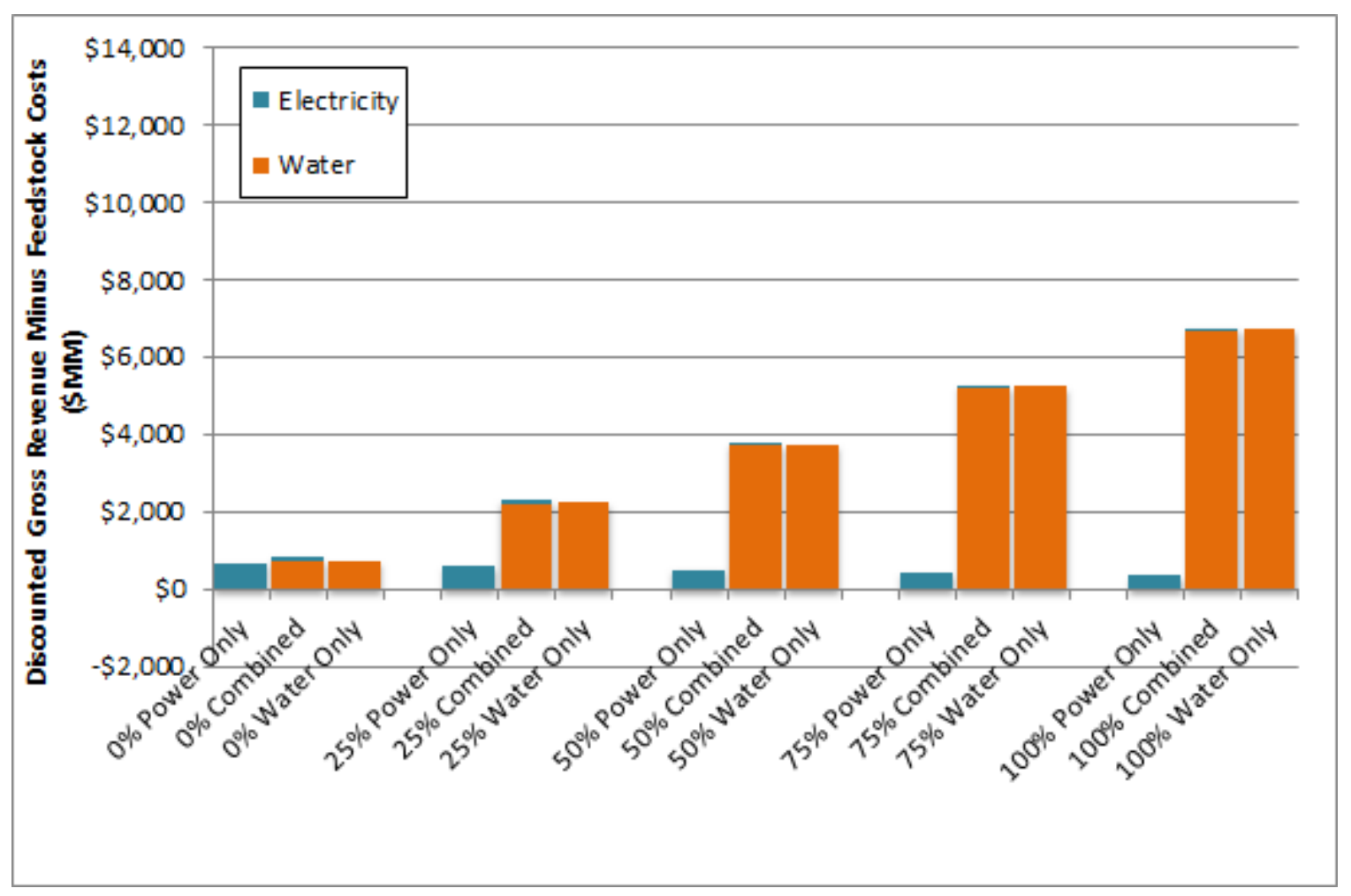

Figure 36. Impacts of various combinations of futures on the discounted gross revenue minus feedstock costs/electricity costs of three configurations in the Arizona scenario

Table 19. Percentage of Time Each Product is Produced by Configuration \#2 Under Combinations of Futures

\begin{tabular}{|lccccc|} 
& $0 \%$ & $25 \%$ & $50 \%$ & $75 \%$ & $100 \%$ \\
\hline Water & $99.30 \%$ & $99.33 \%$ & $99.36 \%$ & $99.39 \%$ & $99.42 \%$ \\
\hline Electricity & $0.70 \%$ & $0.67 \%$ & $0.64 \%$ & $0.61 \% 4 \%$ & $0.58 \%$ \\
\hline
\end{tabular}

Figure 36 and Table 19 show:

- The flexible configuration (Configuration 2) has the highest gross revenue minus feedstock cost in all scenarios. In the $100 \%$ scenario, the flexible configuration can produce electricity rather than water during the 50 hours of the year necessary to receive the capacity payments, thus receiving the higher income provided by electricity plus capacity payments during those hours.

- In the exclusively high-water-price future (100\%; on the right side of Figure 36$)$, the present value of gross revenue minus the feedstock cost for the water-only configuration is about $\$ 6.76$ billion. The corresponding discounted revenue for electricity-only configuration is much lower- $\$ 370$ million. The electricity revenue in this case is $48 \%$ less than the electricity revenue under the high electricity price future $(0 \%$ in Figure 36$)$. It is not quite $50 \%$ less because, even though the $100 \%$ scenario uses an electricity price 
multiplier of 1 while the $0 \%$ scenario uses a price multiplier of 2 , the $\$ 50 / \mathrm{kW}$-year capacity payment does not change between the two scenarios.

- In the 50\% combination, the electricity-only configuration's gross revenue minus feedstock cost increases from \$368 million to \$537 million, and the water-only configuration's (Configuration 3) gross revenue minus feedstock cost decreases from $\$ 6.76$ billion to $\$ 3.75$ billion, as compared to the $100 \%$ scenario. Again, the flexible configuration receives an incremental revenue due to 50 hours with the highest electricity prices and capacity payments. Its total gross revenue minus feedstock cost is $\$ 3.81$ billion.

- Finally, in the exclusively high electricity price future $(0 \%$; on the left hand side of Figure 36 ), the flexible configuration still sells electricity only during the hours necessary to receive a capacity payment.

Figure 37 indicates that the combined system may both increase and partially hedge the gross revenue minus feedstock costs as defined by the two futures.

Figure 38 shows the estimated NPV for each configuration under each of the five combinations of futures. In the $0 \%$ scenario, the NPVs of the water-only and the flexible configurations are negative.

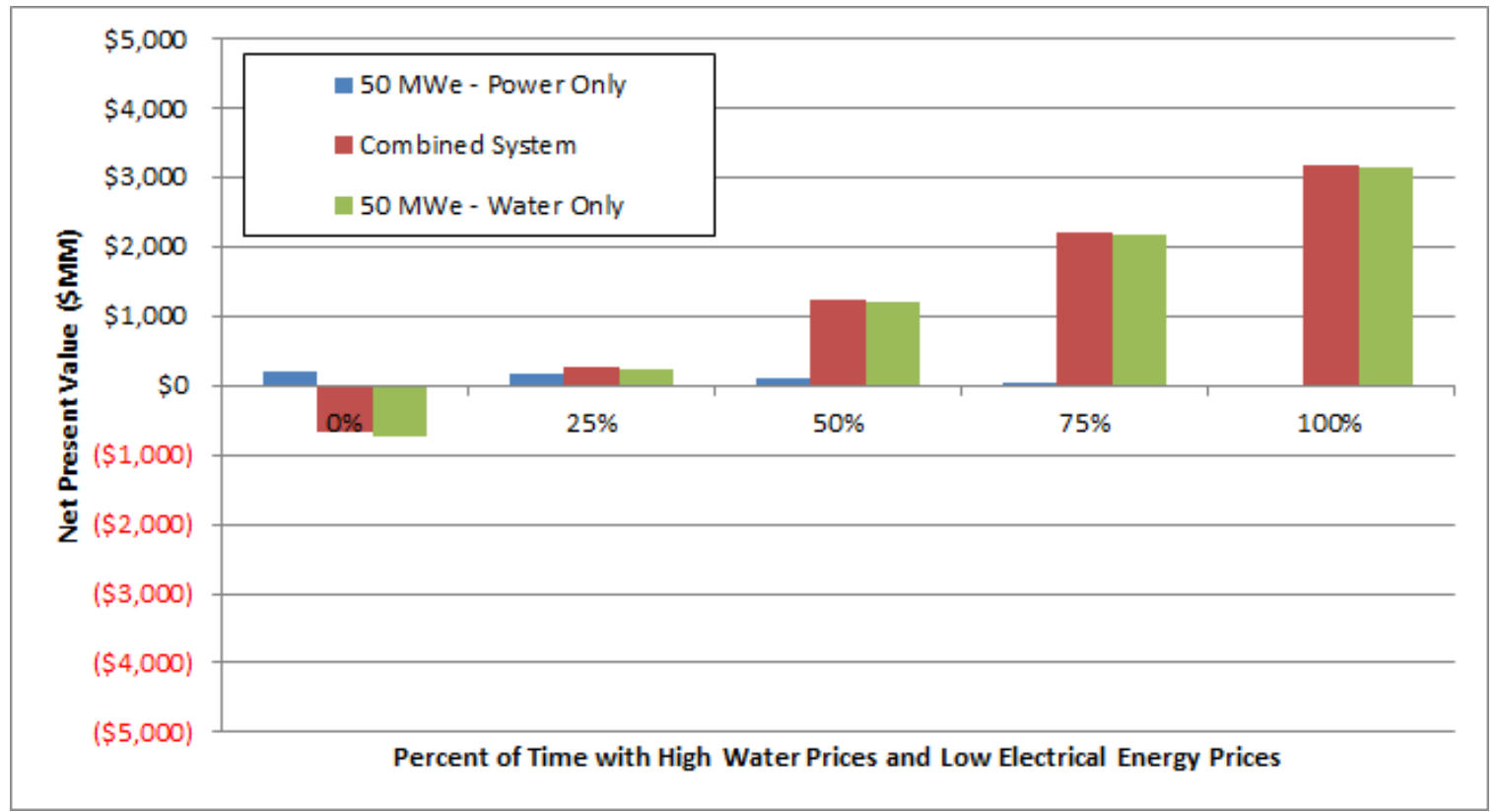

Figure 37. Impacts of various combinations of futures on the NPV of three configurations in the Arizona water scenario

Figure 38 shows the NPV/TCI ratio, which further demonstrates the impact of the five combinations of futures on the attractiveness of the investment. The flexible configuration is the most attractive investment under all conditions but those with the lowest water and highest electricity prices ; however, it is only slightly more attractive than the water-only system. This finding differs than that in the Texas-synthetic gasoline scenario. The scenarios differ because 
the flexible configuration here has no increased cost over the water-only configuration (i.e., both require a thermal power cycle); whereas the flexible configuration in the Texas-synthetic gasoline scenario requires purchase of the thermal power cycle, and the increased value of electricity sales does not overcome that increased cost.

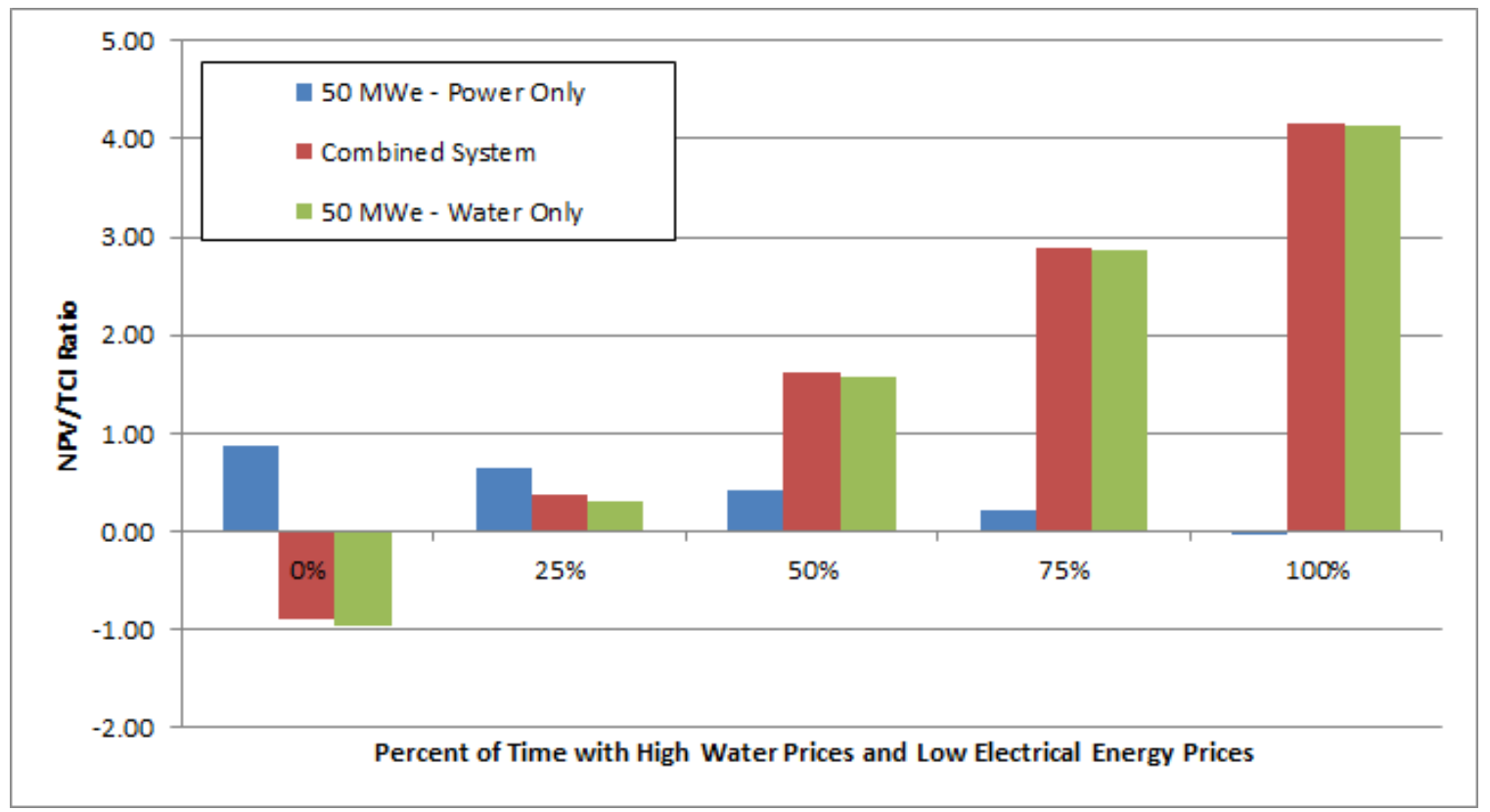

Figure 38. Impacts of various combinations of futures on the NPV/TCI ratio of three configurations in the Arizona water scenario 


\section{Comparison to Previous Analysis}

\subsection{Modeling and Analysis Approach}

In 2015, INL completed an analysis of these two N-R HES scenarios. ${ }^{51}$ That analysis had different objectives and used a different approach than the one described here. The primary focus of that analysis was on dynamic operability of the N-R HESs. Financial performance of each was a secondary objective. Hence, the previous analysis used a detailed dynamic model, whereas we assumed the N-R HES could operate to follow the operations identified by REopt's optimizer. This effort focuses on financial optimization, so the capacity and operations of each subsystem are optimized; whereas, in the previous analysis, the capacity of each subsystem was held constant.

INL developed its modeling and simulation approach starting with process models to optimize the design of the synthetic gasoline and RO plants in order to incorporate them into integrated heat applications. Once the static models had been developed, they were integrated into a larger dynamic simulation environment using the Modelica modeling language.

The Modelica language was designed to enable dynamic simulations, incorporating time series data for commodity price fluctuations, fuel costs, and varying electric load and grid services. The model used by INL also included a control system, enabling dynamic feedback loops between subsystems. The model allowed the subsystems to ramp their output up and down in response to grid load. The control system also managed battery charge and discharge. Figure 39 provides a high-level view of INL's model.

INL ran simulations using the dynamic models with time-series inputs for resource price trends and product prices specific to a given regional market, Arizona and Texas in this case.

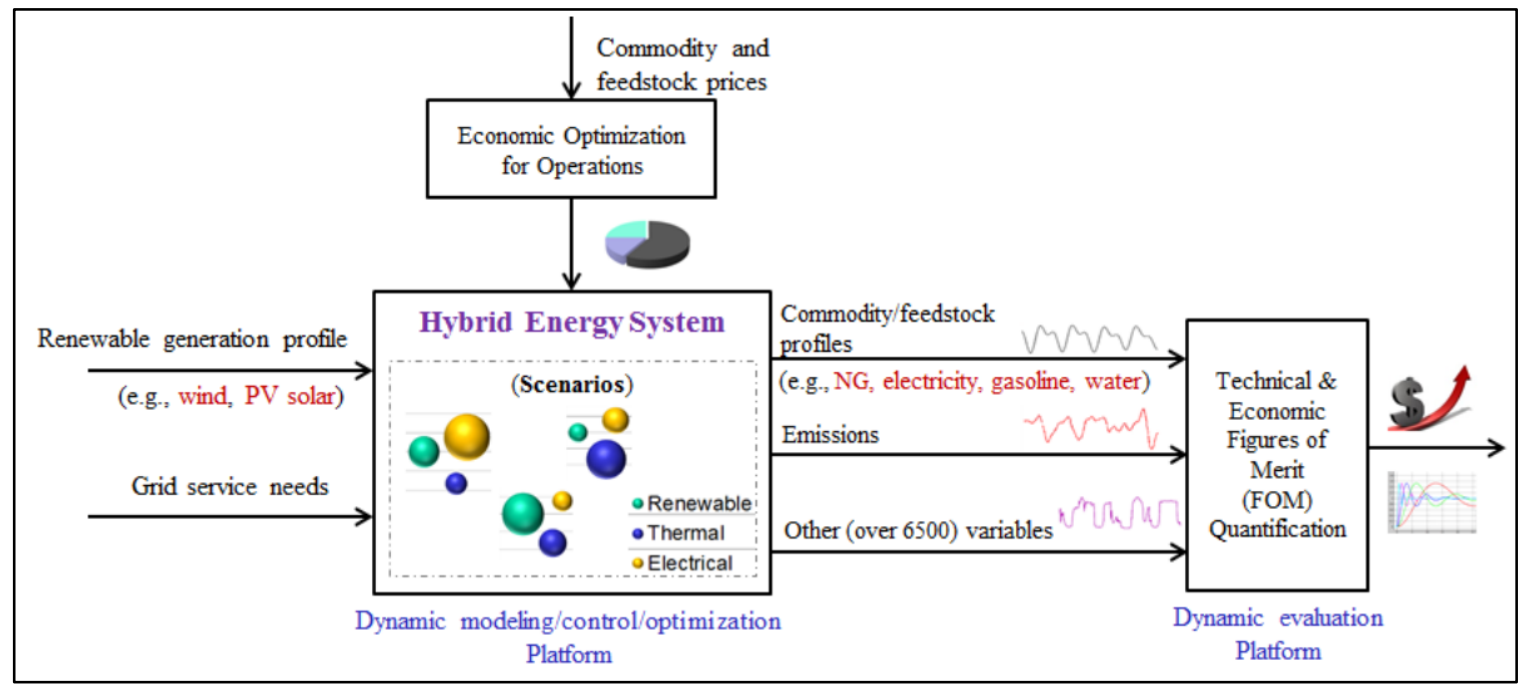

Figure 39. High-level diagram of the INL model (Credit: Garcia ${ }^{17}$ )

INL ran two types of simulations using their models. The first type of simulation analyzed participation in the ancillary services market. In this simulation mode, the priority was meeting the grid requirements. The second simulation mode prioritized the sale of commodities, either gasoline/liquefied petroleum gas or water, depending on the model, with the goal of optimizing 
an economic figure of merit (FOM) such as NPV while still meeting generation requirements. Other FOMs evaluated include TCI, pre-tax gross profit, capital payback time in years, and IRR. All of the FOMs included sales of products such as gasoline/liquefied petroleum gas, desalinated water, electricity, and ancillary services for the electric grid as well as system capital and O\&M costs. INL used prices from current markets instead of projections (as in this analysis).

\subsection{Comparison Between this Analysis and the Previous Analyses}

This section provides key results and comparisons between this analysis and the previous one that INL performed. ${ }^{52}$ Appendix I provides further details.

\subsubsection{Texas-Synthetic Gasoline System}

Two key differences between this study and the previous analysis of the Texas-synthetic gasoline scenario are that the previous analysis did not vary the subsystem size and INL used different subsystem capacities. INL included a larger LW-SMR nuclear reactor $(180 \mathrm{MWe}-600 \mathrm{MWt}$ SMR) than used in this study. That reactor was always coupled with a thermal power cycle to generate electricity even when it provided heat for the synthetic gasoline subsystem. The synthetic gasoline subsystem also had a natural gas-powered $150 \mathrm{MWt}$ auxiliary heat generation unit, which provided heat to the gasoline plant when heat from the SMR was diverted to make electricity for the grid. To represent renewable generation, INL used a wind power plant capable of producing up to $45 \mathrm{MWe}$, coupled with a battery for power smoothing (an option that we did not include).

Another key difference is that INL forced the N-R HES to follow the electricity net load on the grid. This means that the INL-modeled N-R HES provided a constant fraction of the grid's total net load. The systems modeled in this analysis participated in the grid during hours when income from electricity sales maximized profit.

The previous analysis showed the following results for the Texas-synthetic gasoline system:

- The LW-SMR nuclear reactor mainly provides electricity to the grid because the nuclear reactor's capacity is much larger than the thermal load of the industrial process.

- The economics of the system are favorable when optimizing profit.

- The system has a capital payback of 11 years at a 5\% real WACC $(8.15 \%$ nominal WACC).

- The system has an IRR of $11 \%$ for a 20 -year payback, including the cost of carbon.

- The system payback period is 8.27 and 8.45 years when optimized for NPV and when not optimized, respectively.

- The system economics demonstrate a high sensitivity to the prices of gasoline and natural gas.

- The system is relatively insensitive to changes in electricity prices $( \pm 10 \%)$.

This analysis differs from the previous analysis in the following ways: 
1. We used REopt to optimize the size and hourly operational decisions of each subsystem to maximize NPV. We then performed sensitivity analyses to identify parameters that affect the optimal configuration. INL set subsystem capacities that were not economically optimized, and they did not investigate the impacts of various configurations on the N-R HES's economics.

2. Our modeled system sold electricity and synthetic gasoline at market prices and optimized the product mix to maximize profitability. INL followed the grid load without determining the economic impacts of producing other products instead of electricity.

3. Our modeled system did not include a battery for electric power smoothing. We removed the battery in order to study the N-R HES's dynamics of the system on its own merits.

4. We separated the capital costs of the nuclear reactor and the thermal power cycle as discussed in Section 2.4.1. This allowed the reactor and thermal power cycle subsystems to be sized independently from each other; thus, allowing optimization of the heat flow for electric generation and the industrial process.

5. We based price projections of water, gasoline, and natural gas on data from the AEO. INL used price data from currently existing commodity prices.

6. We based electricity prices on the generation mix developed from two of NREL's standard scenarios. ${ }^{53}$ INL's model held the costs fixed and the N-R HES followed the load.

7. We did not include a natural gas boiler to enable the gasoline plant to run at a steady state. Instead, we allowed the gasoline plant output to fluctuate as heat from the SMR was diverted for electric power generation.

8. Our model used wind resource data from wind turbine power curves in the REopt model, using a localized data source from AWS TruePower. ${ }^{54}$

\subsubsection{Arizona-Desalination N-R HES}

Like the Texas-synthetic gasoline N-R HES, NREL optimized subsystem capacities, whereas INL fixed subsystem capacities in the previous analysis. NREL optimized market participation to maximize profit, while INL followed net loads. The previous analysis of the Arizonadesalination scenario consisted of a SMR and a 30-MWe solar PV array providing electricity to the grid as well as an RO desalination plant. The RO plant was capable of using between 15 MWe and $35 \mathrm{MWe}$ of electricity, producing between $6,500 \mathrm{~kg} / \mathrm{s}$ and $15,800 \mathrm{~kg} / \mathrm{s}(102,000$ $\mathrm{gal} / \mathrm{min}$ and $251,000 \mathrm{gal} / \mathrm{min}$ ) of fresh water from a brackish water aquifer. The SMR was originally designed to provide a constant $165 \mathrm{MWe}$ to the grid as well as providing the minimum electric power to the RO plant to make water. A battery bank was included in the original INL model to provide electric power smoothing for the solar PV system.

The previous analysis showed the following results for the Arizona-desalination system:

- As with the Texas case, the LW-SMR nuclear reactor mainly provides reserve electricity to the grid

- The economics of the system are favorable when optimizing profit

- The system had a capital payback of 15 years at a $5 \%$ discount rate 
- The system had an IRR of 7\% for a 20 -year payback, including the cost of carbon. This analysis differed from the previous analysis in the following ways:

1. We used REopt, which optimized subsystem capacity mixes depending on cost and price parameters. The previous analysis included set subsystem capacities that were not economically optimized.

2. Our modeled system sold electricity and water at market prices and optimized the product mix to maximize profitability. INL followed the grid load without determining the economic impacts of producing other products instead of electricity.

3. REopt model used solar PV generation information from NREL's PVWatts calculator. ${ }^{55}$ PVWatts produces hourly generation data for a full year using localized typical meteorological year weather data set. PVWatts is an accepted standard in the industry for estimating electrical energy generation from solar PV systems.

4. As with the Texas model, our Arizona modeled scenario did not include a battery for electric power smoothing. We removed the battery in order the study the dynamics of the system on its own merits.

5. We separated the capital costs of the nuclear reactor and the thermal power cycle, as discussed in Section 2.4.1. This allowed the reactor and thermal power cycle subsystems to be sized independently from each other, allowing optimization of the electricity production for sales and desalination.

The differences in the models led to key differences in conclusions. Both the previous analysis and this analysis show that the N-R HES subsystems could develop profitable systems and that use of nuclear energy could reduce $\mathrm{CO}_{2}$ emissions from the industrial processes. NREL found that the potential economic benefits of the flexibility provided by an N-R HES are insufficient to overcome the costs of providing that flexibility. The previous analysis focused more on the technical potential and requirements of providing the flexibility and found that the two N-R HESs can technically provide the flexibility necessary to follow the bulk electric power grid. 


\section{Potential Future Work}

This effort warrants additional analyses. We identified a set of tasks necessary to better understand the potential of N-R HESs and synergies between nuclear and renewable systems. These tasks move beyond this level of analysis into other issues that affect the potential of N-R HESs and related technologies to improve understanding of market opportunities and impacts. If we pursue these tasks, we intend to leverage efforts in other parts of DOE and other research and analysis institutes to better inform our analysis.

\subsection{Technologies that Provide Synergies}

\subsubsection{Thermal Energy for Industrial Processes}

In the analyses reported here, the optimal configurations with the base-case parameters did not include any variable generation (i.e., wind or PV). N-R HESs may be able to provide value for variable generation subsystems if they can produce alternate products instead of just electricity (as the nuclear subsystems in this analysis are capable of doing). One possible product for variable renewable generation is thermal energy for the industrial subsystem via electric heaters. The electric heaters could provide direct heat or energy storage if they use ceramic or fire-brick systems. Alternatively, electric boilers could convert electricity to steam that can then be used directly in an industrial process or to charge a thermal storage unit. Analyzing this opportunity is warranted because such an opportunity could provide value for renewable electricity that is not available in the N-R HESs discussed in this report.

In addition, this analysis focused on a single thermal energy user (conversion of natural gas to synthetic gasoline); however, many industrial processes require thermal energy. An effort to catalogue and identify key opportunities for N-R HESs to provide thermal energy for industry is underway. That effort uses the HAZUS General Build Stock database of non-residential buildings and their Standard Industrial Classification (SIC) codes, and it links that information with energy data from the latest Manufacturing Energy Consumption Survey (MECS). MECS provides average process, non-process, combustion, feedstock, electricity, and other data by industry code. Together, HAZUS and MECS may reveal average industrial energy use by location. Estimating the size of industries in particular geographic areas may improve the analysis and could be accomplished to some degree using economic census data. Further research and analysis is planned to characterize the quality of heat (e.g., temperature range, steam pressure) needed for each type of industry identified.

\subsubsection{Hydrogen Production}

The two N-R HES scenarios analyzed here did not involve full electrical and thermal integration with the capability of selecting between electricity and thermal during design (i.e., a natural gasto-liquid fuels industrial process subsystem requires primarily thermal energy, and the desalination subsystem requires exclusively electricity, because an RO desalination design was selected). An analysis of an N-R HES with a hydrogen production subsystem (as shown in Figure 40) would determine whether that capability provides benefits through co-location and/or flexibility of the N-R HES. The price of hydrogen could be set based on the price of natural gas and estimated conversion process costs. 


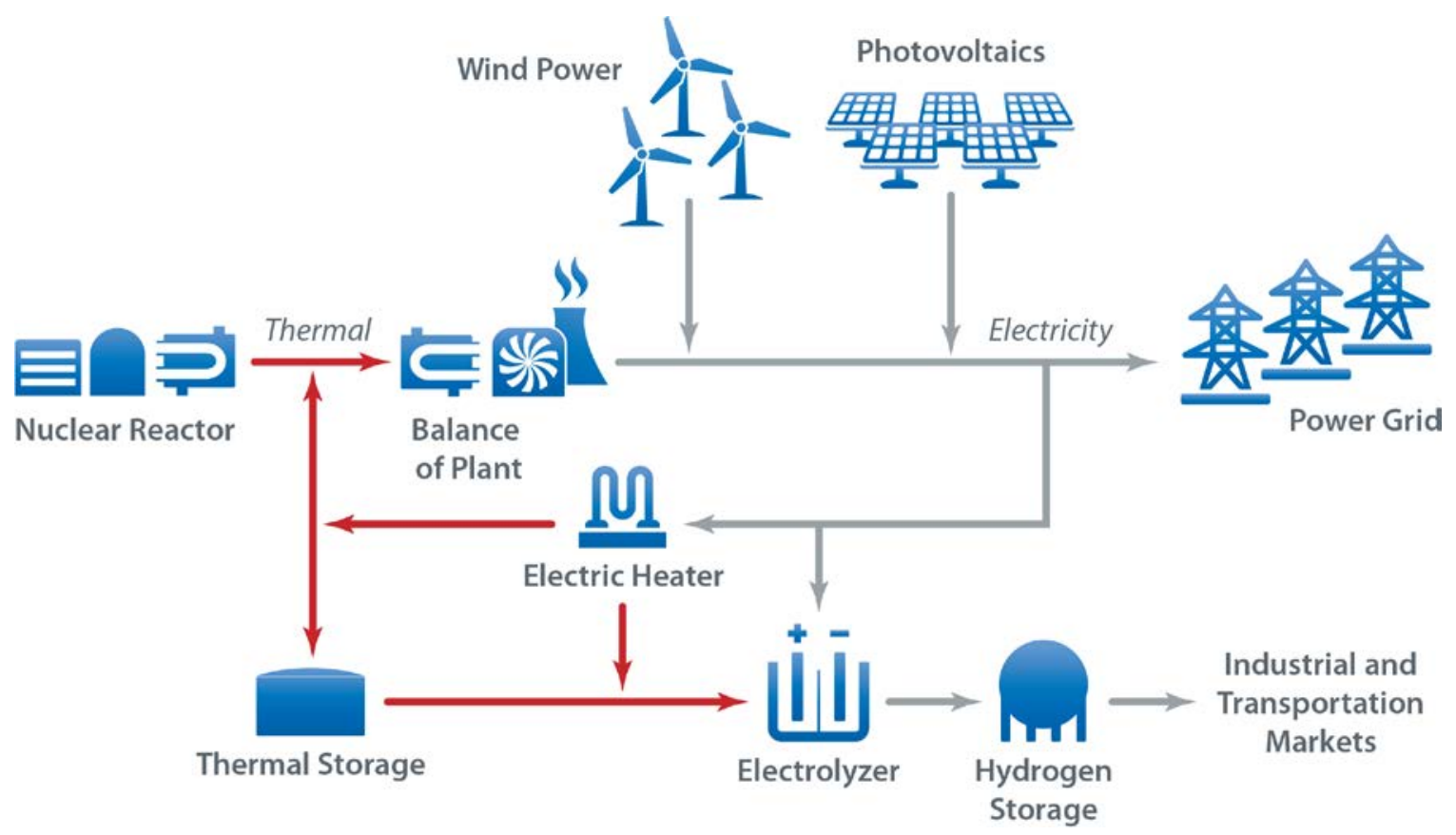

Figure 40. Potential N-R HES to produce hydrogen

\subsubsection{Improved Characterization of Dynamic Systems}

The mixed integer linear programming modeling structure used here is limited because the transition dynamics are not fully characterized. Using the dynamic models developed by INL ${ }^{56}$ to identify limitations in switching between products is warranted. Those tests would also allow for improvement of the REopt model's performance characterization. Ultimately, an electronic method that links optimization within REopt to dynamic modeling may be worthwhile.

\subsubsection{Thermal and Mixed Thermal/Electrical Desalination}

The Arizona-desalination scenario discussed in this report only included an RO desalination system without preheating the brackish water before desalination. Since preheating water can reduce the electricity required by the $\mathrm{RO}$ unit, a future analysis that includes preheating is warranted. In addition, RO desalination systems are just one of many different types of solarpowered desalination configurations possible (Figure 41). 


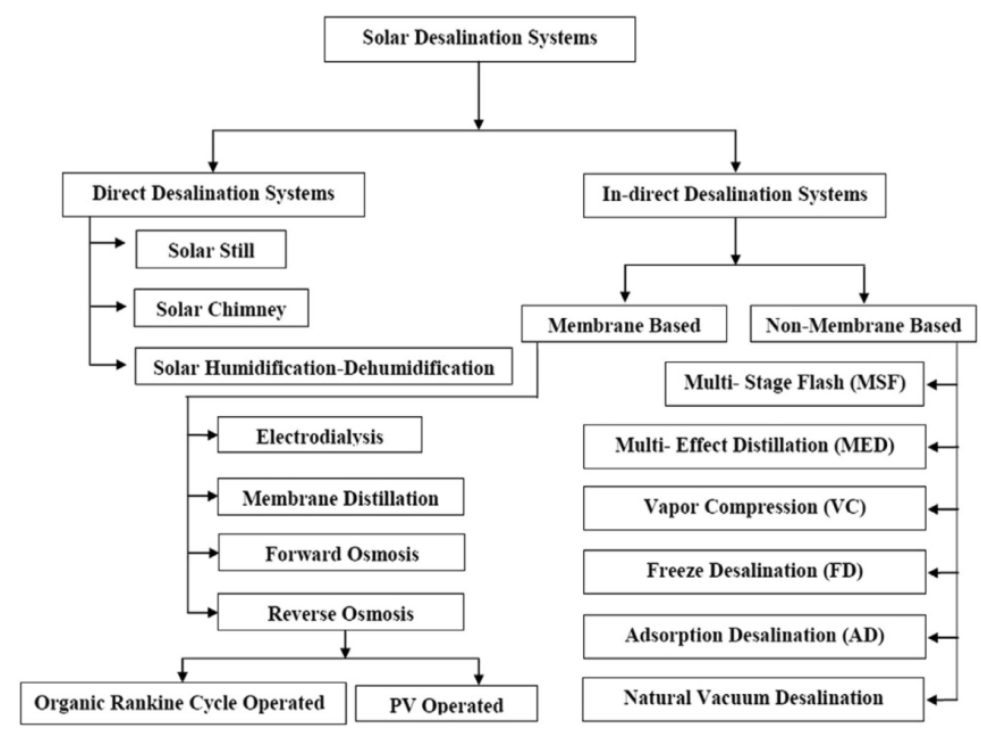

Figure 41. Schematic of desalination technologies that could be integrated with solar energy technologies

Source: Sharon and Reddy $2015^{57}$

Future efforts could evaluate alternative desalination technologies and configurations that could lead to lower water-treatment costs. Desalination technologies that utilize membranes, such as $\mathrm{RO}$, can require large supplies of electricity, whereas other non-membrane technologies require primarily thermal energy. Both concentrated solar and nuclear technologies can provide that thermal energy. Recently, there has been considerable progress on technologies that utilize membranes but also are able to improve efficiencies through low-temperature thermal energy. One such technology is membrane distillation, which is a separation process that only allows vapors to pass through a hydrophobic porous membrane with sufficient vapor pressure differences. ${ }^{58}$ Figure 42 shows a diagram of a membrane distillation technology configuration. The heat source within the figure could be a concentrated solar plant, a nuclear reactor, or another option. 


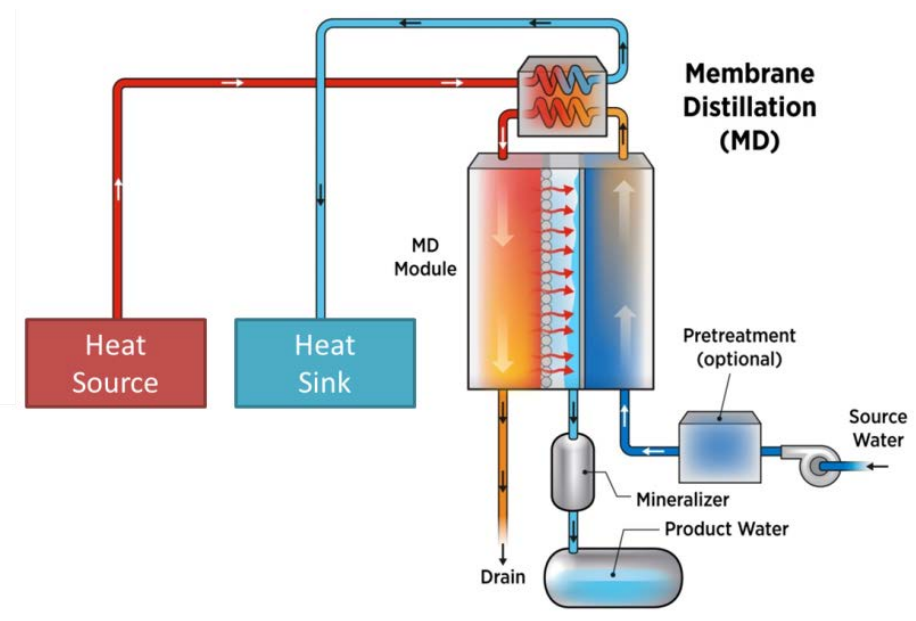

Figure 42. Diagram of membrane distillation treatment technology

Source: NREL

Future efforts could evaluate the cost, performance, and systems integration characteristics of alternative treatment technologies, including membrane distillation. Such alternative treatment technologies could use low temperature thermal energy produced by nuclear and/or concentrating solar power technologies.

\subsection{Improved Understanding Of Market Opportunities and Impacts}

\subsubsection{Long-Run Marginal Cost Bids/Improved Electricity Pricing}

In the analyses discussed in this report, we used short-run marginal costs as proxies for prices in electricity markets. We assumed the capacity payment was a method to pay fixed costs and provide some return on the capital investment. Another option to provide revenue sufficiency is to use long-run marginal costs instead of short-run marginal costs. One way to estimate long-run marginal costs is to compare simulation results to historic market prices and use that information to calibrate modeled prices and capture the impacts of periods of scarcity pricing. Following that effort, identifying "least-cost" generators that represent the optimal buildout process for the grid could be indicative of market deployments under a functioning market responding to appropriate price signals.

Another aspect of long-term bidding strategies is to support VRE bidding into day-ahead markets by using the N-R HES to guarantee that generation. Others have considered the potential for energy storage to support bidding. ${ }^{59}$ That effort could be extended to include the benefits of an N-R HES bidding strategy that supports VRE generation technologies.

\subsubsection{Co-Optimization of N-R HES and the Grid}

In the current study, we optimized the operation of the N-R HES independent of the operation of the electric grid. While this provided a first approximation of the value of hybrid energy systems, co-optimizing N-R HES production and grid generation could potentially reveal additional synergies. 


\subsubsection{Identifying Deep Decarbonization Scenarios and Potential Synergies}

To achieve economy-wide deep decarbonization, society may need to identify and exploit synergies between nuclear and renewable energy sources. Further work could identify the form of those synergies - whether they involve additional nuclear generation of thermal energy used by industry, what the level of fixed dispatchable generation must be, or other opportunities. Deep decarbonization analyses that include product diversity (instead of limited to electricity) and spatial and temporal detail are warranted to identify potential synergies. The analyses could also consider transition pathways to identify potential technology selection that preclude implementation of subsequent technologies. 


\section{Conclusions}

We analyzed the financial performances of two N-R HES scenarios. The first includes a 167MWt nuclear reactor, a 50-MWe thermal power cycle that converts the nuclear-generated heat to electricity, a 50-MWe wind power plant, and a synthetic gasoline production subsystem that can use $167 \mathrm{MWt}$ heat energy in Texas. The second includes a 167-MWt nuclear reactor, a 50-MWe thermal power cycle, a $50 \mathrm{MWe}$ PV plant, and a desalination plant that can use $50 \mathrm{MWe}$ in Arizona.

We tested five hypotheses regarding the potential benefits of the N-R HES in each of the two scenarios:

1. The N-R HES configurations analyzed have the potential to be profitable to investors and are likely to be more profitable than uncoupled configurations.

2. Using nuclear-generated heat in an N-R HES can economically reduce GHG emissions from industry. If a cost of carbon is included in economic analyses, the N-R HES will have a lower cost than competing uncoupled natural gas configurations.

3. N-R HESs can support resource adequacy for the electric power grid while maximizing production of a more profitable industrial product if the market structures incentivize that option.

4. N-R HESs will be more profitable than uncoupled configurations because they can produce electricity when its price is high and the industrial product when the price of electricity is low.

5. The internal flexibility of N-R HESs makes them beneficial as a hedge against changing and uncertain future prices.

For the base-case analyses, the financial assumptions include $100 \%$ equity, a $10 \%$ nominal discount rate, a 3\% inflation rate, and startup in 2035. Capital and operating cost estimates are from other published analyses and are very uncertain. Other uncertainties include prices of electricity and industrial products. We performed sensitivity analyses around some of the uncertain parameters to quantify their impacts.

Our analysis partly supports hypothesis \#1. The full N-R HES configurations of both the Texassynthetic gasoline and Arizona-desalination scenarios are projected to be profitable under the base case parameters; however, the full N-R HES configurations are not projected to be as profitable as alternative configurations that produce the industrial product but not electricity. Table 20 shows that the Texas-synthetic gasoline scenario's full N-R HES (the right column in the Texas-synthetic gasoline section) is profitable with an NPV of $\$ 3,631$ million; however, a reduced configuration with only a nuclear reactor and the synthetic gasoline subsystem (the left column in the Texas-synthetic gasoline section) is more profitable with an NPV of $\$ 3,699$ million. In addition, the nuclear-industrial process configuration has a lower total capital investment (TCI). The combination results in an internal rate of return (IRR) of $25 \%$, which is higher than the $24 \%$ of the full N-R HES configuration. The significance of the difference between those values is dependent upon the investor's profile; however, the reduced nuclearindustrial process configuration may to be more attractive to many investors due to the lower capital investment and higher net present value. We also provide the NPV/TCI ratio as an 
alternative method to assess profitability because it shows the impact of capital investments that may be risky. Adding electricity generation to the nuclear reactor-synthetic gasoline configuration does not increase the NPV unless the price of electricity is higher than the basecase parameters (a multiplier of 1.25 is necessary to add wind generation and of 1.3 to add nuclear-generated electricity).

Table 20 also shows that the Arizona-desalination scenario's full N-R HES configuration (the right column in the Arizona-desalination section) is profitable with an NPV of \$3,151 million but, like the Texas-synthetic gasoline scenario, a reduced configuration that includes the industrial process is more profitable. The reduced configuration also has a lower TCI. The combination makes both the IRR and the NPV/TCI ratio larger than the full N-R HES, so the reduced configuration is likely to be more attractive to investors. A key difference between the two scenarios is that, under the lower VRE penetration grid mix or including a cost of carbon for the natural gas generation, co-management of the PV subsystem with flexible nuclear generation allows the PV subsystem to benefit from the increased value from water production. As a result, the configuration with the nuclear reactor, thermal power cycle, desalination unit, and PV generation is the most profitable.

Table 20. Financial Results of Two N-R HES Scenarios Compared to Alternative Configurations

\begin{tabular}{|c|c|c|c|c|}
\hline \multirow[t]{2}{*}{ Scenario } & \multicolumn{2}{|c|}{ Texas-Synthetic Gasoline } & \multicolumn{2}{|c|}{ Arizona-Desalination } \\
\hline & $\begin{array}{l}\text { Nuclear } \\
\text { Reactor } \\
\text { (167 MWt) }\end{array}$ & $\begin{array}{l}\text { Nuclear } \\
\text { Reactor } \\
\text { (167 MWt) }\end{array}$ & $\begin{array}{l}\text { Nuclear } \\
\text { Reactor } \\
\text { (167 MWt) }\end{array}$ & $\begin{array}{l}\text { Nuclear } \\
\text { Reactor } \\
\text { (167 MWt) }\end{array}$ \\
\hline \multirow{3}{*}{ Configuration } & & $\begin{array}{l}\text { Thermal } \\
\text { Power } \\
\text { Cycle } \\
\text { (50 MWe) }\end{array}$ & $\begin{array}{l}\text { Thermal } \\
\text { power cycle } \\
\text { (50 MWe) }\end{array}$ & $\begin{array}{l}\text { Thermal } \\
\text { power } \\
\text { cycle ( } 50 \\
\text { MWe) }\end{array}$ \\
\hline & $\begin{array}{l}\text { Industrial } \\
\text { Process } \\
\text { (167 MWt) }\end{array}$ & $\begin{array}{l}\text { Industrial } \\
\text { Process } \\
\text { (167 MWt) }\end{array}$ & $\begin{array}{l}\text { Industrial } \\
\text { Process (50 } \\
\text { MWe) }\end{array}$ & $\begin{array}{l}\text { Industrial } \\
\text { Process } \\
\text { (50 MWe) }\end{array}$ \\
\hline & & $\begin{array}{l}\text { Wind Power } \\
\text { Plant } \\
\text { (50 MWe) }\end{array}$ & & $\begin{array}{l}\text { PV Plant } \\
\text { (50 MWe) }\end{array}$ \\
\hline NPV (\$ million) & $\$ 3,699$ & $\$ 3,631$ & $\$ 3,164$ & $\$ 3,151$ \\
\hline IRR & $25 \%$ & $24 \%$ & $48 \%$ & $46 \%$ \\
\hline TCI (\$ million) & $\$ 2,507$ & $\$ 2,657$ & $\$ 765$ & $\$ 820$ \\
\hline NPV/TCI Ratio & 1.48 & 1.37 & 4.14 & 3.84 \\
\hline
\end{tabular}

Our analysis also supports hypothesis \#2. The analysis shows that for both scenarios analyzed, industrial processes using nuclear-generated energy can be more profitable if a cost of carbon is included. The Texas-synthetic gasoline scenario's configuration with only the nuclear reactor and industrial process has an NPV of $\$ 3,699$ million, an IRR of $25 \%$, and an NPV/TCI ratio of 1.48. Replacing the nuclear reactor with a natural gas boiler reduces the NPV to $\$ 3,600$ million and does not change the IRR, but it increases the NPV/TCI ratio to 1.55. Although the natural 
gas-heated system has less profit (lower NPV) it is likely to be more attractive to investors who are concerned about the uncertainty of recovering their capital investment due to the higher NPV/TCI ratio. The U.S. government provides four sets of social costs of carbon for regulatory analyses because the cost of climate-related impacts is uncertain. ${ }^{60}$ For most analyses, we used the 2035 value with a $3 \%$ discount rate- $\$ 61 /$ metric ton $\mathrm{CO}_{2}$. The natural gas-heated synthetic gasoline configuration emits 281,000 metric tons $\mathrm{CO}_{2}$ annually. If it is assessed at $\$ 61 / \mathrm{metric}$ ton $\mathrm{CO}_{2}$, its NPV is $\$ 3,520$ million and its NPV/TCI ratio is 1.45 ; thus, the nuclear-industrial process is both more profitable and may be more attractive to investors at that cost of carbon.

Using an NGCC to produce the electric power for desalination results in emissions of 153,000 metric tons $\mathrm{CO}_{2}$ annually. Using the $\$ 61 /$ metric ton $\mathrm{CO}_{2}$ cost of carbon, the NPV for the nuclear-powered process is slightly higher than the NGCC-powered process- $\$ 3.16$ billion as compared to $\$ 3.08$ billion; however, at $48 \%$ the IRR for the nuclear-powered process is lower than that of the NGCC-powered process, which is $60 \%$. Thus, a high cost of carbon may be necessary to make the nuclear-desalination configuration more attractive than one powered by an NGCC.

Our analysis supports hypothesis \#3 in the Arizona-desalination scenario, but not in the Texassynthetic gasoline scenario, under the base-case parameters and the capacity payments used in this analysis. Analysis of the Texas-synthetic gasoline N-R HES does not identify any condition where either a capacity payment or high electrical energy prices result in selling electricity to support electricity resource adequacy instead of maximizing production of synthetic gasoline. This is because synthetic gasoline is a more valuable product than electricity, and electricity generation requires a thermal power cycle, which is an additional investment. The capital cost for the thermal power cycle (and the opportunity costs of not generating gasoline during hours when the N-R HES generates electricity instead of producing gasoline) disincentivizes the nuclearsynthetic gasoline configuration from participating in the capacity markets.

The Arizona-desalination system is likely to optimally generate sufficient electricity to receive the capacity payment while maximizing production of water (a more profitable product) for the majority of the year with a $\$ 50 / \mathrm{kW}$-yr capacity payment, providing the water price is between $\$ 1.15 /$ thousand gal and $\$ 3.50 /$ thousand gal (i.e., high enough for the desalination unit to be profitable but not so high that the opportunity cost of not producing water is greater than the value of electricity including the capacity payment). At higher capacity payments, the Arizonadesalination scenario is likely to optimally generate electricity to receive the capacity payments. The key difference between the two scenarios is that the desalination scenario inherently includes a thermal power cycle, so electricity production requires no additional capital cost.

Our analysis does not support hypothesis \#4. The analysis indicates that no configurations in the Texas-synthetic gasoline scenario realize sufficient value from the capacity payments to include the thermal power cycle necessary for a system capable of switching without decreasing its NPV; hence, the configuration with the maximum NPV is unlikely to select between products. The Arizona-desalination system only switches from water desalination to electricity production as necessary to receive capacity payments under the base case parameters. Thus, the key value provided for electricity generation is the capacity payments. Without higher electricity prices, short periods of high-priced electricity are insufficient to incentivize N-R HESs to produce 
additional electricity, because the opportunity cost of not producing the industrial product is too high.

Our analysis partially supports hypothesis \#5. N-R HESs have internal flexibility that make them beneficial as a partial hedge against uncertain product prices. However, the benefits of using a combined system are limited by the additional capital cost of a flexible configuration when compared to a configuration with fewer subsystems; the increase in fixed operating costs over a configuration with fewer subsystems; and the reduction in capacity factors because some subsystems in the flexible configuration are not operated at all times.

In summary, this analysis shows that N-R HES configurations in the two scenarios analyzed are profitable, and the key driver for each is the industrial product. For electricity production to increase each N-R HES's value, the price of electricity needs to be higher than considered in this analysis. In addition, we found co-management of the nuclear and renewable assets to be beneficial only when the VRE subsystem generates some of the electricity necessary to receive capacity payments while minimizing the reduction in production of the industrial product, as it does in the Arizona-desalination scenario. Under the limitations of this analysis, we find that full hybridization does not improve the economics of these two scenarios; however, it may be beneficial under different market conditions or for other scenarios. Additional analysis of the potential for tightly coupled nuclear and renewable energy generators to provide thermal energy for industrial processes and both thermal and electrical energy for hydrogen production would be useful, because those options introduce more potential thermal loads. In addition, improving analyses of markets may identify opportunities for N-R HESs that were not identified in this analysis. 


\section{Notes}

1 H. Garcia, J. Chen, J. S. Kim, M. G. McKellar, W. Deason, R. Vilim, S. M. Bragg-Sitton, R. D. Boardman "Nuclear Hybrid Energy Systems - Regional Studies: West Texas \& Northeastern Arizona" INL Report INL/EXT-15-34503 (April 2015).

2 Interagency Working Group on Social Cost of Carbon, United States Government. "Technical Support Document: Technical Update of the Social Cost of Carbon for Regulatory Impact Analysis - Under Executive Order 12866" https://www.whitehouse.gov/sites/default/files/omb/inforeg/scc-tsd-final-july-2015.pdf (July 2015)

3 Mark F. Ruth, Owen R. Zinaman, Mark Antkowiak, Richard D. Boardman, Robert S. Cherry, Morgan D. Bazilian, "Nuclear-renewable hybrid energy systems: Opportunities, interconnections, and needs," Energy Conversion and Management, Volume 78, February 2014, Pages 684-694, ISSN 0196-8904, http://dx.doi.org/10.1016/j.enconman.2013.11.030.

4 J. Cochran, et al "Flexibility in 21st Century Power Systems. 21st Century Power Partnership" NREL/TP-6A20-91721 (2014).

5 Inventory of U.S. Greenhouse Gas Emissions and Sinks: 1990-2013

6 DOE/EIA-0035(2014-03), March 2014.

7 Mark F. Ruth, Owen R. Zinaman, Mark Antkowiak, Richard D. Boardman, Robert S. Cherry, Morgan D. Bazilian, "Nuclear-renewable hybrid energy systems: Opportunities, interconnections, and needs," Energy Conversion and Management, Volume 78, February 2014, Pages 684-694, ISSN 0196-8904, http://dx.doi.org/10.1016/j.enconman.2013.11.030.

8 Bragg-Sitton, et al. "Nuclear-Renewable Hybrid Energy Systems: 2016 Technology Development Program Plan" Idaho National Laboratory Report INL/EXT-16-38165. (March 2016)

9 J Cochran; P Denholm; B Speer; M Miller (2015) "Grid Integration and the Carrying Capacity of the U.S. Grid to Incorporate Variable Renewable Energy” NREL/TP-6A20-62607.

10 DOE/EIA0035 (2014-03), March 2014.

11 Pieter Tielens, Dirk Van Hertem, "The relevance of inertia in power systems," Renewable and Sustainable Energy Reviews, Volume 55, March 2016, Pages 999-1009, ISSN 1364-0321, http://dx.doi.org/10.1016/j.rser.2015.11.016.

12 A Ulbig, T. S. Borsche, G. Andersson "Impact of Low Rotational Inertia on Power System Stability and Operation" IFAC World Congress 2014, Capetown, South Africa http://arxiv.org/abs/1312.6435 
13 A. Mills \& R. Wiser (2012) "Changes in the Economic Value of Variable Generation at High Penetration Levels: A Pilot Case Study of California” Technical Report: LBNL-5445E

14 H. Garcia, J. Chen, J. S. Kim, M. G. McKellar, W. Deason, R. Vilim, S. M. Bragg-Sitton, R. D. Boardman "Nuclear Hybrid Energy Systems - Regional Studies: West Texas \& Northeastern Arizona” INL Report INL/EXT-15-34503 (April 2015).

15 Bragg-Sitton, et al. "Nuclear-Renewable Hybrid Energy Systems: 2016 Technology Development Program Plan” Idaho National Laboratory Report INL/EXT-16-38165. (March 2016)

16 S.M. Bragg-Sitton; R. Boardman; M. Ruth; O. Zinaman, "Integrated Nuclear-Renewable Energy Systems: Foundational Workshop Report.” INL/EXT-14-32857 Rev. 1. August 2014. http://www.osti.gov/scitech/biblio/1170315

17 H. Garcia, J. Chen, J. S. Kim, M. G. McKellar, W. Deason, R. Vilim, S. M. Bragg-Sitton, R. D. Boardman "Nuclear Hybrid Energy Systems - Regional Studies: West Texas \& Northeastern Arizona" INL Report INL/EXT-15-34503 (April 2015).

18 T. Simpkins, D. Cutler, K. Anderson, D. Olis, E. Elgqvist, M. Callahan, and A. Walker, "REopt: A Platform for Energy System Integration and Optimization," in Proc. 8th International Conf. on Energy Sustainability, Boston, MA, 2014.

19 http://energyexemplar.com/software/plexos-desktop-edition/

20 Energy Information Administration “2015 Annual Energy Outlook” DOE/EIA-0383 (April 2015)

21 H. Garcia, J. Chen, J. S. Kim, M. G. McKellar, W. Deason, R. Vilim, S. M. Bragg-Sitton, R. D. Boardman "Nuclear Hybrid Energy Systems - Regional Studies: West Texas \& Northeastern Arizona” INL Report INL/EXT-15-34503 (April 2015).

22 H. Garcia, J. Chen, J. S. Kim, M. G. McKellar, W. Deason, R. Vilim, S. M. Bragg-Sitton, R. D. Boardman "Nuclear Hybrid Energy Systems - Regional Studies: West Texas \& Northeastern Arizona” INL Report INL/EXT-15-34503 (April 2015).

23 G. Stark “A Systematic Approach to Better Understanding Integration Costs” NREL Report NREL/TP-5D00-64502 (September 2015)

24 D. Lew, G. Brinkman, E. Ibanez, A. Florita, M. Heaney, B.-M. Hodge, M. Hummon, G. Stark, J. King, S.A. Lefton, N. Kumar, D. Agan, G. Jordan, S. Venkateraman "The Western Wind and Solar Integration Study Phase 2" NREL Report NREL/TP500-55588 (September 2013) 
25 Sullivan, Patrick., Cole, Wesley, Blair, Nate, Lantz, Eric, Krishnan, Venkat, Mai, Trieu, Mulcahy, David, and Porro, Gian. 2015 Standard Scenarios Annual Report: U.S. Electric Sector Scenario Exploration (2015). http://www.nrel.gov/docs/fy15osti/64072.pdf

26 Environmental Protection Agency "Carbon Pollution Emission Guidelines for Existing Stationary Sources: Electric Utility Generating Units” Federal Register V80, No 205, p 6466264964 (October 2015)

27 D. Lew, G. Brinkman, E. Ibanez, A. Florita, M. Heaney, B.-M. Hodge, M. Hummon, G. Stark, J. King, S.A. Lefton, N. Kumar, D. Agan, G. Jordan, S. Venkateraman "The Western Wind and Solar Integration Study Phase 2" NREL Report NREL/TP500-55588 (September 2013)

28 D. Lew, G. Brinkman, E. Ibanez, A. Florita, M. Heaney, B.-M. Hodge, M. Hummon, G. Stark, J. King, S.A. Lefton, N. Kumar, D. Agan, G. Jordan, S. Venkateraman "The Western Wind and Solar Integration Study Phase 2" NREL Report NREL/TP500-55588, pp. 75-77, (September 2013)

29 U.S. Energy Information Administration. 2015 Annual Energy Outlook. DOE/EIA0383(2015). Washington, D.C.: U.S. Energy Information Administration, April.

30 Ela, Erik, Michael R. Milligan, Aaron Bloom, A. Botterud, A. Townsend, and T. Levin. Evolution of wholesale electricity market design with increasing levels of renewable generation. NREL, 2014; Spees, K., S. Newell, J. Pfeifenberger. 2013. "Capacity Markets: Lessons Learned from the First Decade." Economics of Energy \& Environmental Policy, Symposium on 'Capacity Markets,' 2, no. 2: 1-26.

31 Bowring, J. 2013. "Capacity Markets in PJM." Economics of Energy \& Environmental Policy 2, no. 2: 47-64.

32 Jenkin, Thomas, Philipp Beiter, and Robert Margolis. Capacity Payments in Restructured Markets under Low and High Penetration Levels of Renewable Energy. No. NREL/TP-6A2065491. NREL (2016)

33 U.S. Energy Information Administration. 2015 Annual Energy Outlook. DOE/EIA-0383 (2015). Washington, D.C.: U.S. Energy Information Administration, April.

34 MIT Energy Initiative "The Future of Natural Gas An Interdisciplinary MIT Study" (2011) Appendix 5. https://mitei.mit.edu/system/files/NaturalGas_Appendix5A.PDF

35 Arizona Water Resources Development Commission. Final Report. 2011. Volume II. Available at: http://www.azwater.gov/AzDWR/WaterManagement/WRDC_HB2661/Meetings_Schedule.htm

36 Annual Technology Baseline and Standard Scenarios. NREL. http://www.nrel.gov/analysis/data_tech_baseline.html 
37 H. Garcia, J. Chen, J. S. Kim, M. G. McKellar, W. Deason, R. Vilim, S. M. Bragg-Sitton, R. D. Boardman "Nuclear Hybrid Energy Systems - Regional Studies: West Texas \& Northeastern Arizona" INL Report INL/EXT-15-34503 (April 2015).

38 Gandrik, Anastasia M. TEV-1196: Assessment of High Temperature Gas-Cooled Reactor (HTGR) Capital and Operating Costs. TEV, Idaho Falls: Idaho National Laboratory, 2011; Locatelli, Giorgio, Chris Bingham, and Mauro Mancini. "Small modular reactors: A comprehensive overview of their economics and strategic aspects." Progress in Nulcear Energy 73, 2014: 75-85; Wood, Richard A. TEV-667: Nuclear-Integrated Methanol-to Gasoline Production Analysis. TEV, Idaho Falls: Idaho National Laboratory, 2010.

39 Organisation of Economic Cooperation and Development Nuclear Energy Agency. Current Status, Technical Feasibility and Economics of Small Nuclear Reactors. June 2011.

40 U.S. Environmental Protection Agency Combined Heat and Power Partnership "Catalog of CHP Technologies Section 4. Technology Characterization - Steam Turbines" (March 2015)

41 Annual Technology Baseline and Standard Scenarios. NREL. http://www.nrel.gov/analysis/data_tech_baseline.html

42 S. Tegen, et al. 2011 Cost of Wind Energy Review. NREL Technical Report TP-5000-56266. March 2013. http://www.nrel.gov/docs/fy13osti/56266.pdf

43 D. Feldman et al. Photovoltaic System Pricing Trends 2014 Edition. U.S. Department of Energy SunShot Program. Sept 22, 2014. http://www.nrel.gov/docs/fy14osti/62558.pdf

44 Short, W., D. J. Packey, T. Holt “A Manual for the Economic Evaluation of Energy Efficiency and Renewable Energy Technologies” NREL/TP-462-5173 (March 1995).

45 H. Garcia, J. Chen, J. S. Kim, M. G. McKellar, W. Deason, R. Vilim, S. M. Bragg-Sitton, R. D. Boardman "Nuclear Hybrid Energy Systems - Regional Studies: West Texas \& Northeastern Arizona" INL Report INL/EXT-15-34503 (April 2015).

46 H. Garcia, J. Chen, J. S. Kim, M. G. McKellar, W. Deason, R. Vilim, S. M. Bragg-Sitton, R. D. Boardman "Nuclear Hybrid Energy Systems - Regional Studies: West Texas \& Northeastern Arizona” INL Report INL/EXT-15-34503 (April 2015).

47 Ibid.

48 Interagency Working Group on Social Cost of Carbon, United States Government. "Technical Support Document: Technical Update of the Social Cost of Carbon for Regulatory Impact Analysis - Under Executive Order 12866" https://www.whitehouse.gov/sites/default/files/omb/inforeg/scc-tsd-final-july-2015.pdf (July 2015) 
49 H. Garcia, J. Chen, J. S. Kim, M. G. McKellar, W. Deason, R. Vilim, S. M. Bragg-Sitton, R. D. Boardman "Nuclear Hybrid Energy Systems - Regional Studies: West Texas \& Northeastern Arizona" INL Report INL/EXT-15-34503 (April 2015).

50 H. Garcia, J. Chen, J. S. Kim, M. G. McKellar, W. Deason, R. Vilim, S. M. Bragg-Sitton, R. D. Boardman "Nuclear Hybrid Energy Systems - Regional Studies: West Texas \& Northeastern Arizona” INL Report INL/EXT-15-34503 (April 2015).

51 H. Garcia, J. Chen, J. S. Kim, M. G. McKellar, W. Deason, R. Vilim, S. M. Bragg-Sitton, R. D. Boardman "Nuclear Hybrid Energy Systems - Regional Studies: West Texas \& Northeastern Arizona” INL Report INL/EXT-15-34503 (April 2015).

52 . Garcia, J. Chen, J. S. Kim, M. G. McKellar, W. Deason, R. Vilim, S. M. Bragg-Sitton, R. D. Boardman "Nuclear Hybrid Energy Systems - Regional Studies: West Texas \& Northeastern Arizona” INL Report INL/EXT-15-34503 (April 2015).

53 National Renewable Energy Laboratory. Annual Technology Baseline and Standard Scenarios. http://www.nrel.gov/analysis/data tech baseline.html?print (Accessed April 14, 2016)

54 https://www.awstruepower.com/ (Accessed April 14, 2016)

55 http://pvwatts.nrel.gov/ accessed April 14, 2016

56 H. Garcia, J. Chen, J. S. Kim, M. G. McKellar, W. Deason, R. Vilim, S. M. Bragg-Sitton, R. D. Boardman "Nuclear Hybrid Energy Systems - Regional Studies: West Texas \& Northeastern Arizona" INL Report INL/EXT-15-34503 (April 2015).

57 H. Sharon, K.S. Reddy. A review of solar energy driven desalination technologies. Renewable and Sustainable Energy Reviews. (2015). 41: 1080-1118.

58 Qtaishat, M.R., Banat, F. Desalination by solar powered membrane distillation systems. Desalination (2012) 308 (2):186-97.

59 Bidding strategies (see Thatte, A.A.; Dept. of Electr. \& Comput. Eng., Texas A\&M Univ., College Station, TX, USA ; Viassolo, D.E.; Le Xie --

Robust bidding strategy for wind power plants and energy storage in electricity markets http://ieeexplore.ieee.org/xpls/abs all.jsp?arnumber $=6344870$ )

60 Interagency Working Group on Social Cost of Carbon, United States Government. "Technical Support Document: Technical Update of the Social Cost of Carbon for Regulatory Impact Analysis - Under Executive Order 12866" https://www.whitehouse.gov/sites/default/files/omb/inforeg/scc-tsd-final-july-2015.pdf (July 2015) 


\section{Appendix A REopt Description}

\section{A.1 General Description}

REopt is an energy-planning platform (developed by the National Renewable Energy

Laboratory) that offers concurrent, multiple-technology integration and optimization capabilities to help clients meet their cost savings and energy performance goals. The REopt platform provides techno-economic decision-support analysis to help a site (or portfolio of sites) determine the cost-optimal mix of renewable and traditional generation assets to meet a client's goals. Formulated as a mixed-integer linear program (MILP), REopt recommends optimal system sizes and dispatch strategies for the selected technologies. The model takes into account system costs (capital, fixed, and variable), fuel costs, financial parameters (discount rate, inflation, utility-cost escalation rates, incentives), utility costs, and other variables that contribute to a techno-economic analysis of a renewable energy system. For example, REopt can optimize a system for objectives such as to minimize life-cycle cost, minimize fuel consumption, or minimize greenhouse gas emissions. Figure A-1 shows some of the key input and output fields of the model.

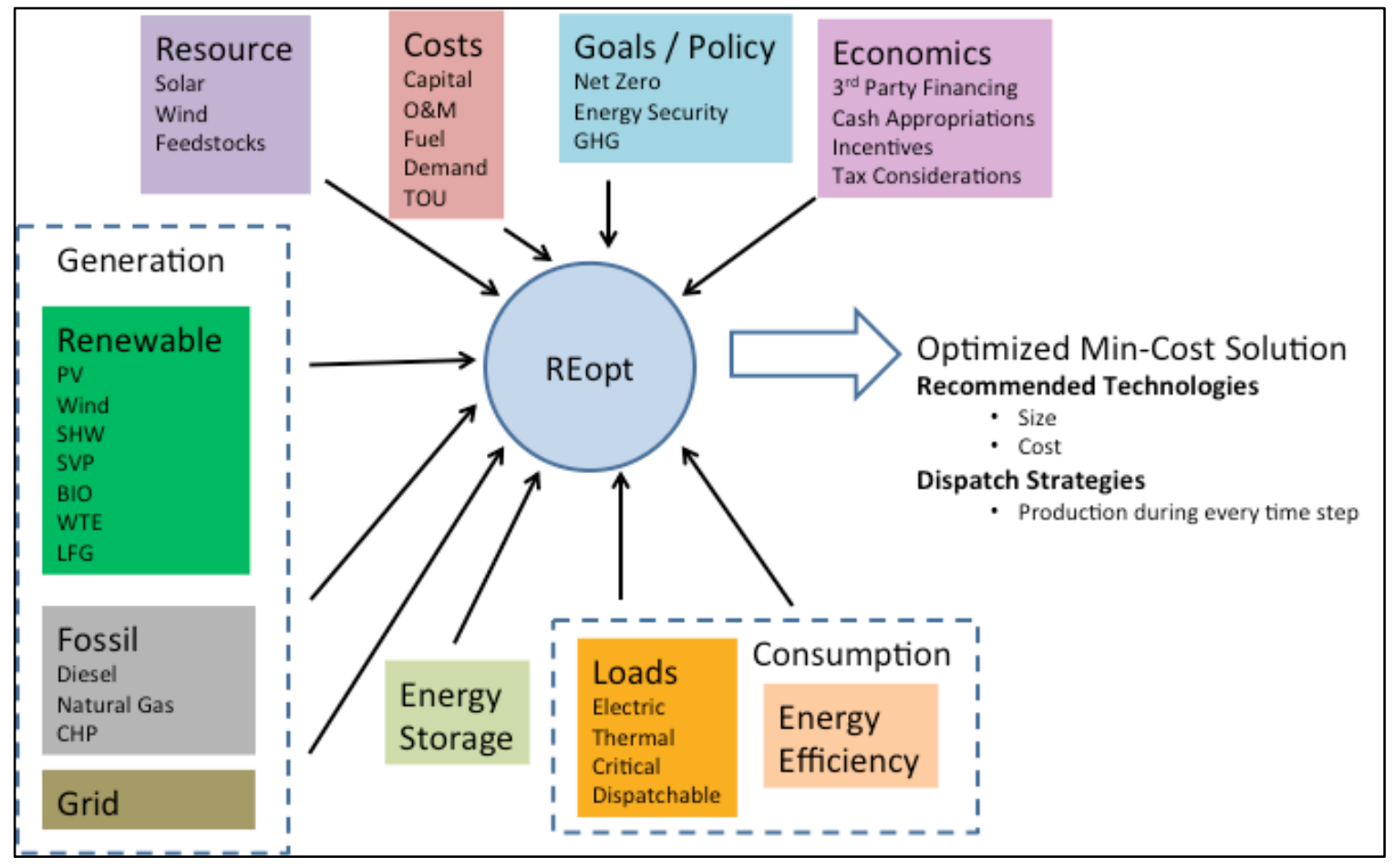

Figure A-1. Diagram of REopt inputs and outputs

In the current analysis, REopt was used to identify the appropriate sizes of selected technologies for each of the scenarios and evaluate the cost-optimal dispatch strategies at each time step in the solution for a nuclear-renewable hybrid energy system that would maximize net present value for the owner.

\section{A.2 Implementation of Electricity Market Rules}

The REopt model used the following assumptions for electrical energy market participation: 
1. Locational marginal pricing (LMP) for electricity was based on data from the PLEXOS analysis and capped at $\$ 100 / \mathrm{MWh}$.

2. Contingency reserve: receive the contingency reserve market value generated from PLEXOS.

A. This reduces the production of the industrial product by the probability of providing a service ( $50 \%$ probability assumed).

B. Bid into the contingency reserve market when operating the industrial process at maximum. (The industrial process can be turned down, and the electrical generation can be increased to provide the reserves.)

3. Regulation down: receive the regulation-down value from PLEXOS (plus the LMP to make the operator whole for avoided opportunity).

A. Bid into the regulation-down market when operating the industrial process at a minimum.

4. Regulation up: receive the regulation-up value from PLEXOS.

A. This reduces the production of the industrial product by the probability of providing a service ( $50 \%$ probability assumed).

B. Effectively, the behavior is same as that of the contingency reserve, implying that the model chooses the higher of the two.

5. Capacity market: the capacity value is based on the ability of the plant to provide electrical power during $n$ peak load hours. ( $n$ was set at 50 hours for this analysis.)

A. This is a minimum of the thermal power cycle + renewables production during $n$ peak hours.

B. In the base case, values are at $\$ 50 / \mathrm{kW}-\mathrm{yr}$.

\section{A.3 Constraints on Technology Optimization}

REopt was used to find an optimal solution by solving an MILP. An MILP is a mathematical optimization problem wherein some variables are allowed to take non-integer values. The remaining variables are restricted to integer values. REopt can use different objective functions, depending on the analysis. The objective function used in this analysis was to minimize the present value of all future energy costs (life-cycle costs) during the analysis period subject to various constraints on load, resource, system size, etc. Examples of such constraints include:

- Reactor heat must be consumed by operating technologies at every time step.

- Minimum and maximum sizes for the subsystems are specified.

- Maximum turndown for certain technologies (such as thermal power cycle and synthetic gasoline plant) are specified.

- The system is only able to bid into capacity reserves or regulation-up markets if there is available capacity in electric generation.

- The system is only able to bid into regulation-down markets if the electric output can be curtailed by ramping up the industrial process. 
The REopt MILP is also subject to decision-making variables such as the size of generation systems and the dispatch of those systems at each time step in the problem. Table A-1 lists the variables in the objective function for each case.

Table A-1. REopt Objective Function Variables

\begin{tabular}{|c|c|}
\hline Arizona Case Study & Texas Case Study \\
\hline \multicolumn{2}{|c|}{ Industrial process CapExa } \\
\hline \multicolumn{2}{|c|}{ Reactor CapEx } \\
\hline \multicolumn{2}{|c|}{ Thermal power cycle CapEx } \\
\hline \multirow{2}{*}{ Water value } & Gasoline value \\
\hline & $\mathrm{NG} / \mathrm{H}_{2} \mathrm{O}$ costs \\
\hline \multicolumn{2}{|c|}{ Nuclear reactor fixed O\&M } \\
\hline \multicolumn{2}{|c|}{ Industrial process fixed O\&M } \\
\hline \multicolumn{2}{|c|}{ Capacity payments } \\
\hline \multicolumn{2}{|c|}{ Electricity revenue } \\
\hline
\end{tabular}




\section{Appendix B Additional Production Cost Modeling Details}

Given the high capital costs, and the high annualized capital cost to fuel cost ratio for nuclear power generation (which is similar in some ways to variable renewable energy), it is likely that nuclear power plants will be built under long-term power purchase agreements to reduce financial and operational risk while allowing the owner to earn a fair rate of return. However, this study seeks to explore the option that the plant may be (at least in part) exposed to the more volatile electricity prices within wholesale electricity power markets; this may partly reflect the anticipated smaller size of the plant (50 MWe). In this case, revenue from the electricity market can come from three main sources:

1. Electrical energy revenue $(\$ / M W h)$

2. Ancillary service revenue from reserves, regulation, and flexibility reserves

3. Capacity payments $(\$ / \mathrm{kW}-\mathrm{m}$ or year).

We utilized production cost modeling techniques to estimate the market values for electricity products (with the exception of the capacity market). We chose to leverage the production cost model from recent National Renewable Energy Laboratory (NREL) integration costs research $(\text { Stark 2015) })^{1}$. This integration cost model is a modified version of the Institute of Electrical and Electronics Engineers (IEEE) three-region, 118-bus, security-constrained unit commitment model, and it was designed to accommodate high penetrations of variable generation. The model consists of three interconnected regions and contains a mix of generator types in each region. We used load data supplied from the Western Electricity Coordinating Council (WECC) (WECC $2011)^{2}$ to provide realistic load variability for each region. ${ }^{3}$ Figure B-1 shows a one-line diagram of the reference version of the model.

\footnotetext{
${ }^{1}$ G. Stark "A Systematic Approach to Better Understanding Integration Costs" NREL Report NREL/TP-5D00-64502 (September 2015)

2 WECC (2011). Assumptions Matrix for the 2020 TEPPC Dataset. Accessed January 2013: www.wecc.biz/library/StudyReport/Documents/Assumptions\%20Matrix\%20for\%20the\%202020 \%20TEPPC\%20Dataset.pdf

${ }^{3}$ WECC provided load data that had been statistically scaled from actual operating data
} 


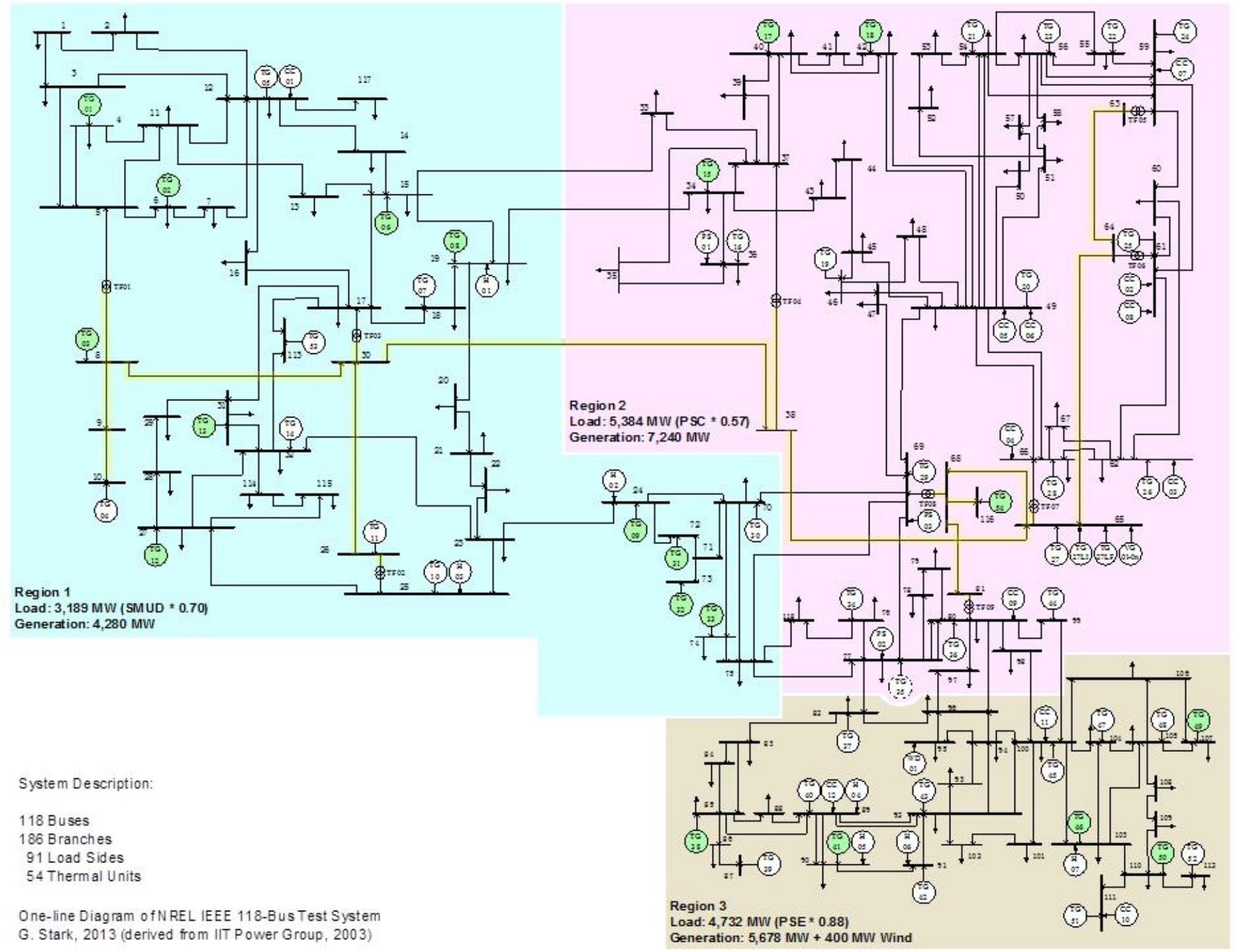

Figure B-1. One-line diagram of the reference version of the IEEE 118-bus model 
The generation mixes and transmission availability were developed based on three regions from standard-scenario national results developed at NREL. ${ }^{4}$ Most of the results presented here are based on the 2036 generation mix in the national renewable portfolio standard (RPS) scenario that leads to $80 \%$ renewably generated electricity in 2050 (RPS 80 ). Some sensitivities were performed using the central scenario, which was based on policies that were current as of the spring of 2015. It does not include the Environmental Protection Agency's Clean Power Plan requirements. We refer to those sensitivities as "Current Law" scenarios throughout this report.

The production cost models were developed such that the three regions selected for the synthetic gasoline configuration were Northern California, Public Service Company of Colorado, ${ }^{5}$ and Washington, D.C. These geographic regions were selected to provide reasonable approximations of actual interconnections yet are small enough to allow the team to examine a large number of scenarios and sensitivity combinations. Future year 2020 was modeled from historical weather patterns and loads from 2006. The maximum, average, and minimum loads were 11,666 MW, 16,994 MW, and 26,509 MW for both the Current Law and RPS80 synthetic gasoline scenarios.

Similarly, Northern California, Washington, and Arizona were used for the desalination configuration. Future year 2020 was modeled from historical weather patterns and loads from 2006. The maximum, average, and minimum loads were 11,934 MW, 17,760 MW, and 29,140 MW for both the Current Law and RPS80 desalination scenarios.

Transmission constraints in these initial scenarios were removed to ensure that congestion would not bias the study results; thus, the methodology used in this analysis could be considered "copper plate."

All studies used two unit commitment runs: a day-ahead unit commitment for hydro and coal generation and a 4-hour-ahead unit commitment for the combined-cycle plants. We used the two commitment runs so that the model could incorporate improving forecasts during the two time horizons. Additional information about each commitment run is provided below.

A day-ahead unit commitment model was used to commit the coal and hydro units. The model included day-ahead wind and solar forecasts, used a resolution of 1 hour, and had an optimization horizon of 48 hours. Data from the first 24 hours of horizon were saved to provide hydro and coal power plant commitment information to the 4-hour-ahead model and then later to the real-time dispatch model; and the extra 24 hours in the optimization horizon helped ensure that the coal power plants, with long start times and high start costs, were properly committed.

Next, a 4-hour-ahead unit commitment simulation was used to commit the combined-cycle plants. The 1-hour resolution model included 4-hour-ahead wind and solar forecasts along with

\footnotetext{
${ }^{4}$ Sullivan, Patrick, Wesley Cole, Nate Blair, Eric Lantz, Venkat Krishnan, Trieu Mai, David Mulcahy, and Gian Porro. 2015. 2015 Standard Scenarios Annual Report: U.S. Electric Sector Scenario Exploration (Technical Report NREL/6A20-64072). Golden, CO: National Renewable Energy Laboratory. http://www.nrel.gov/docs/fy15osti/64072.pdf.

${ }^{5}$ Ideally, we would have use used time-series load data from the Texas Panhandle for the synthetic gasoline study; however, the data for that area were aggregated with data from as far north as Nebraska and as far east as Oklahoma. Because load is highly correlated with climate, we felt that data from the Front Range and Eastern Plains of Colorado better approximated the climate of the upper Panhandle (average monthly temperatures and humidity levels are similar).
} 
the hydro and coal commitments from the day-ahead model. The 4-hour-ahead commitment model used an 8-hour time horizon. Commitment data from the first 4 hours from each run were saved for the real-time model, and the extra 4 hours in the optimization horizon helped ensure that the combined-cycle units were optimally dispatched.

Note that for all unit-commitment simulations (day-ahead, 4-hour-ahead, and hour-ahead), the load forecasts were assumed to be perfect because a consistent set of load forecasts were unavailable.

\section{B.1 Security-Constrained Economic Dispatch}

After the unit commitment simulations were complete, a real-time economic dispatch model with 5-minute resolution and a 2-hour look-ahead was used to dispatch the remaining units (i.e., combustion turbines). Hydro, coal, and combined-cycle commitments were passed to the realtime dispatch model from the 4-hour-ahead period (hour-ahead in the case of the fast-start generation simulations). The 2-hour look-ahead period was implemented to capture how an operator would account for their expectations for the near future before deciding to start a machine.

\section{B.2 Reserves}

Regulating and contingency reserves were held in the day-ahead, 4-hour-ahead, hour-ahead, and real-time markets. Flexibility reserves, when used, were held in the day-ahead and 4-hour-ahead markets and released in the real-time market. Table B-1 shows penalties for violating load and regulating, contingency, and flexibility reserve requirements. These penalties were chosen to be high enough that starting a new unit to provide reserves would typically lower system costs rather than allow the reserves to go unserved. Infrequently, small reserve violations $(<1 \mathrm{MW})$ occurred in situations when it was more expensive to start a machine than allow the violation; however, all loads were served throughout the simulations.

Table B-1. Penalties for Unserved Load and Reserves Violations

\begin{tabular}{|ll|}
\hline Loads and Reserves & Penalty (\$/MWh) \\
\hline Load & 6,000 \\
\hline Regulating reserves & 4,100 \\
\hline Contingency reserves & 4,000 \\
\hline Flexibility reserves & 3,900 \\
\hline
\end{tabular}

\section{B.3 Hydro Operation}

Hydro generation was optimized on a monthly basis, and the limits were iteratively adjusted in the preliminary configuration runs until hydro provided approximately $11 \%$ of the annual electrical energy. The individual units were operated with a minimum stable level set to $25 \%$ of their maximum capacity, and the ramp rates were limited to $10 \%$ of the unit's maximum capacity per minute. 


\section{B.4 Maintenance and Expected Forced Outages}

Maintenance and forced outages were not simulated.

\section{B.5 Input Data}

The wind, solar, and load data as well as generator operating parameters (e.g., ramp rates and start times) were obtained from the Western Wind and Solar Integration Study Phase 2 (WWSIS2) (Lew et al. 2013) ${ }^{6}$. Additional information about the input data is provided below.

\section{B.5.1 Load Data}

The original source of the load data was the WECC Variable Generation Subcommittee, which provided 1-minute load data that had been statistically scaled to match the Transmission Expansion Planning Policy Committee 2020 load projections. Load forecast data were not available, so perfect load forecasts were used in the unit commitment simulations.

Note that the use of perfect load forecasts caused all operations uncertainty to be attributed to wind and solar.

\section{B.5.2 Wind Data}

The wind data used in this study were derived from a data set that was created by 3TIER for WWSIS-1 (GE Energy 2010) ${ }^{7}$. This data set included both day-ahead forecasts as well as wind "actuals" (3TIER 2010 ${ }^{8}$; Potter et al. 2008 ; Potter et al. 2007 $7^{10}$ ). Information about how the WWSIS-2 team used the 3TIER data to create the wind day-ahead forecasts, 4-hour-ahead forecasts, and wind output data ("actuals") can be found in Section 2.4 of WWSIS-2 (Lew et al. $2013)^{6}$.

\section{B.5.3 Solar Data}

Hummon and colleagues (2012) ${ }^{11}$ developed the solar data by using NREL-developed statistical algorithms to combine data from WWSIS-1; satellite-derived irradiance data from Clean Power Research's SolarAnywhere data, which were based on a semiempirical model developed by

\footnotetext{
${ }^{6}$ D. Lew, G. Brinkman, E. Ibanez, A. Florita, M. Heaney, B.-M. Hodge, M. Hummon, G. Stark, J. King, S.A. Lefton, N. Kumar, D. Agan, G. Jordan, S. Venkateraman "The Western Wind and Solar Integration Study Phase 2” NREL Report NREL/TP500-55588 (September 2013)

${ }^{7}$ GE Energy (2010). Western Wind and Solar Integration Study. NREL/SR-550-47434. Golden, CO: NREL. Accessed January 2013: http://www.nrel.gov/docs/fy10osti/47434.pdf

8 3Tier. 2010. Development of Regional Wind Resource and Wind Plant Output Data Sets. (Technical Report). NREL/SR-550-47676. Golden, CO: NREL. Accessed January 2013: www.nrel.gov/docs/fy10osti/47676.pdf

${ }^{9}$ Potter, C., H. Gil, and J. McCaa. 2007. "Wind Power Data for Grid Integration Studies.” IEEE Power Engineering Society General Meeting Proceedings, June 24-28, Tampa, Florida

${ }^{10}$ Potter, C., D. Lew, J. McCaa, S. Cheng, S. Eichelberger, and E. Grimit, E. 2008. "Creating the Dataset for the Western Wind and Solar Integration Study.” Wind Engineering 32(4). Accessed January 2013: http://dx.doi.org/10.1260/0309-524X.32.4.325

${ }^{11}$ Hummon, M.; Ibanez, E.; Brinkman, G.; Lew, D. (2012). "Sub-Hour Solar Data for Power System Modeling from Static Spatial Variability Analysis: Preprint." Prepared for the 2nd International Workshop on Integration of Solar Power into Power Systems, November 12-13, Lisbon, Portugal. NREL/CP-6A20-56204. Golden, CO: NREL. 9 pp. Accessed January 2013: www.nrel.gov/docs/fy13osti/56204.pdf
} 
Perez (2002) $)^{12}$ and Perez et al. (2002) ${ }^{13}$; and sub-hourly data collected through NREL's Measurement and Instrumentation Data Center. ${ }^{14}$ Section 2.5 of WWSIS-2 (Lew et al. 2013) ${ }^{15}$ describes how the WWSIS-2 team created the wind day-ahead forecasts, 4-hour-ahead forecasts, and solar output data ("actuals").

\section{B.5.4 Generator Data}

The generator data came from Intertek-APTECH's report on Power Plant Cycling Costs (Kumar et al. 2012) ${ }^{16}$, which was jointly commissioned by WECC and NREL as part of WWSIS-2. An exception was the heat rate data, which were derived from WWSIS-2 (Lew et al. 2013) ${ }^{17}$.

\section{B.5.4.1 Heat Rates}

The generator heat rates used were derived from WWSIS-2. They differed slightly from WWSIS-2 values in that the categories for the coal and combined-cycle generators were divided into two: small generators and large generators. The dividing point was $300 \mathrm{MW}$ for the coal power plants and $200 \mathrm{MW}$ for the combined-cycle plants, and the heat rates assigned to the larger plants were assumed to be slightly better than those of the smaller plants (see Stark 2015) ${ }^{1}$.

Although heat rate degradation is a known problem associated with generator cycling (Kumar et al. 2012 $)^{16}$, these effects were not included in the current study.

\section{B.5.4.2 Start-Related Generator Costs}

Start costs and start fuel requirements were derived from APTECH's report on Power Plant Cycling Costs (Kumar et al. 2012) ${ }^{16}$. Start penalties (start-related wear-and-tear), start fuel, and nonfuel start-related variable operations and maintenance (VO\&M) (e.g., auxiliary power, chemicals) were modeled. All values were set to median, except for the start penalties, which were set to the average of the hot-, warm-, and cold-start median values (i.e., no differentiation was made among start types).

To simplify modeling efforts, all units started with their primary fuel. Although this assumption likely underestimated start fuel costs, these costs were small compared to other start costs, so the simplification was found to be adequate for modeling purposes.

A summary of the nominal generator start parameters is shown in Stark (2015) ${ }^{1}$.

\footnotetext{
12 Perez, R. (2002). “Time-Specific Irradiances Derived from Geostationary Satellite Images.” Journal of Solar Energy Engineering - Transactions of the ASME (124:1); pp. 1-1

13 Perez, R.; Ineichen, P.; Moore, K.; Kmiecik, M.; Chain, C.; George, R.; Vignola, F. (2002). "A New Operational Satellite-to-Irradiance Model.” Solar Energy (75:5); pp. 307-317

${ }^{14}$ See www.nrel.gov/midc.

${ }^{15}$ D. Lew, G. Brinkman, E. Ibanez, A. Florita, M. Heaney, B.-M. Hodge, M. Hummon, G. Stark, J. King, S.A. Lefton, N. Kumar, D. Agan, G. Jordan, S. Venkateraman "The Western Wind and Solar Integration Study Phase 2" NREL Report NREL/TP500-55588 (September 2013)

${ }^{16}$ Kumar, N.; Besuner, P.; Lefton, S.; Agan, D.; Hilleman, D. (2012). Power Plant Cycling Costs. NREL/SR-550055433. Work performed by Intertek-APTECH, Sunnyvale, California. Golden, CO: NREL. Accessed January 2013: www.nrel.gov/docs/fy12osti/55433.pdf

${ }^{17}$ D. Lew, G. Brinkman, E. Ibanez, A. Florita, M. Heaney, B.-M. Hodge, M. Hummon, G. Stark, J. King, S.A. Lefton, N. Kumar, D. Agan, G. Jordan, S. Venkateraman "The Western Wind and Solar Integration Study Phase 2” NREL Report NREL/TP500-55588 (September 2013)
} 
B.5.4.3 Ramping-Related Generator Costs

Ramp events were determined post simulation by examining generator movement over time. Any time a generator's output moved more than $30 \%$ of its rated capacity (excluding on/off cycles and independent of operating duration), a ramp event charge was created, and the ramp starting point was reset. The ramp event charge used in the calculations was as determined in (Kumar et al. 2012) ${ }^{16}$.

B.5.4.4 Summary of Generator Parameters

Stark $(2015)^{1}$ summarizes the key generator parameters that were used in the production cost modeling optimizations. 
Table B-2. Thermal Unit Simulation Parameters

\begin{tabular}{|c|c|c|c|c|c|c|c|}
\hline & $\begin{array}{l}\text { Baseload } \\
\text { Coal } \\
\geq 700 \mathrm{MW}\end{array}$ & $\begin{array}{l}\text { Large Coal } \\
<700 \mathrm{MW}- \\
\geq 300 \mathrm{MW}\end{array}$ & $\begin{array}{l}\text { Small } \\
\text { Coal } \\
<300 \\
\text { MW }\end{array}$ & $\begin{array}{l}\text { Large } \\
\text { CC }^{\mathrm{a}} \\
\geq 200 \\
\mathrm{MW}\end{array}$ & $\begin{array}{l}\text { Small } \\
\text { CC } \\
<200 \\
\mathrm{MW}\end{array}$ & $\mathbf{C T}^{\mathrm{b}}$ Gas & CT Oil \\
\hline Heat rate (BTU/kWh) & 10,000 & 10,080 & 10,940 & 7,020 & 7,220 & 12,580 & 12,710 \\
\hline Equivalent forced outage rate (\%) & $5.82 \%$ & $5.82 \%$ & $4.51 \%$ & $5.91 \%$ & $5.57 \%$ & $4.28 \%$ & $3.91 \%$ \\
\hline Mean time to repair $(h)$ & 40 & 38 & 35 & 24 & 24 & 55 & 67 \\
\hline $\begin{array}{l}\text { Minimum generation } \\
\text { (\% of maximum capacity) }\end{array}$ & $50 \%$ & $50 \%$ & $50 \%$ & $50 \%$ & $50 \%$ & $50 \%$ & $50 \%$ \\
\hline $\begin{array}{l}\text { Minimum up time after generator start- } \\
\text { up (h) }\end{array}$ & 10 & 8 & 5 & 2 & 2 & 1 & 1 \\
\hline $\begin{array}{l}\text { Minimum downtime after generator } \\
\text { shutdown (h) }\end{array}$ & 24 & 24 & 20 & 4 & 4 & 1 & 1 \\
\hline Ramp rate (\%/min) & $1.1 \%$ & $1.1 \%$ & $1.1 \%$ & $0.9 \%$ & $0.9 \%$ & $4.5 \%$ & $4.5 \%$ \\
\hline Ramp charge (\$/MW) & 2.45 & 2.45 & 3.34 & 0.64 & 0.77 & 1.59 & 2.07 \\
\hline Ramp event charge (\$/Ramp Event) ${ }^{18}$ & 245 & 245 & 334 & 64 & 77 & 159 & 207 \\
\hline $\begin{array}{l}\text { Start cost: nonfuel VO\&M } \\
\text { (\$/MW capacity/start) }\end{array}$ & 8.67 & 7.91 & 6.22 & 1.11 & 1.01 & 0.95 & 1.24 \\
\hline $\begin{array}{l}\text { Start cost: wear and tear } \\
\text { (\$/MW capacity/start) }\end{array}$ & 75 & 76 & 133 & 56 & 67 & 87 & 107 \\
\hline Start fuel (MMBTU/MW capacity) & 15.8 & 10.5 & 7.0 & 0.21 & 0.25 & 0.2 & 0.26 \\
\hline VO\&M (\$/MWh) & 2.96 & 2.68 & 2.82 & 1.02 & 1.22 & 0.57 & 0.74 \\
\hline
\end{tabular}

a Combined cycle

b Combustion turbine

\footnotetext{
${ }^{18}$ Ramp events occur any time a generator moves more than $30 \%$ of its rated capacity (e.g., a 100-MW unit moved from 55 MW to 86 MW).
} 


\section{B.6 Production Cost Modeling Results for RPS80 Scenarios}

\section{B.6.1 Capacity and Generation Mixes for RPS80 Scenarios}

As discussed above, the generation mixes and transmission availability were developed based on three regions from the RPS scenario that leads to $80 \%$ renewably generated electricity in 2050 standard-scenario national results developed at NREL. ${ }^{19}$ Generation capacities for three regions were extracted from the standard-scenario results for Texas-synthetic gasoline production cost modeling: Northern California, Public Service Colorado, ${ }^{20}$ and Washington. These geographic regions were selected to provide a reasonable approximation of an actual interconnection, yet they are small enough to allow the team to examine a large number of scenarios and sensitivity combinations. Similarly, we chose Northern California, Washington, and Arizona for the Arizona-desalination scenario.

Table B-3 reports the system load statistics for both cases.

Table B-4 reports the generation capacity of the three regions for the Texas-synthetic gasoline cases, and

Table B-5 reports that information for the Arizona-desalination case. Figure B-2 shows the generation mixes for the two scenarios. The synthetic gasoline scenario had $41 \%$ variable generation (20\% photovoltaic [PV] and $21 \%$ wind), but due to the assumed flexibility provided by hydropower it had only $0.3 \%$ system curtailment. The desalinization scenario had $33 \%$ variable generation (22\% PV and $11 \%$ ) along with $3.4 \%$ curtailment.

Table B-3. System Load for Both RPS80 Scenarios

\begin{tabular}{|lll|}
\hline Load Statistics & Texas - Synthetic Gasoline & Arizona-Desalination \\
\hline Peak load & $26,509 \mathrm{MW}$ & $29,329 \mathrm{MW}$ \\
\hline Average load & $16,994 \mathrm{MW}$ & $17,768 \mathrm{MW}$ \\
\hline Minimum load & $11,666 \mathrm{MW}$ & $11,934 \mathrm{MW}$ \\
\hline
\end{tabular}

\footnotetext{
${ }^{19}$ Sullivan, Patrick, Wesley Cole, Nate Blair, Eric Lantz, Venkat Krishnan, Trieu Mai, David Mulcahy, and Gian Porro. 2015 Standard Scenarios Annual Report: U.S. Electric Sector Scenario Exploration. NREL/TP-6A20-64072. Golden, CO: National Renewable Energy Laboratory. http://www.nrel.gov/docs/fy15osti/64072.pdf.

${ }^{20}$ Ideally, we would have used time-series load data from the Texas Panhandle for the synthetic gasoline study; however, the data for that area were aggregated with data from as far north as Nebraska and as far east as Oklahoma. Because load is highly correlated with climate, we felt that data from the Front Range and Eastern Plains of Colorado better approximated the climate of the upper Panhandle (average monthly temperatures and humidity levels are similar).
} 
Table B-4. Capacity Mixes under the Texas-Synthetic Gasoline RPS80 Scenario

\begin{tabular}{|lll|}
\hline Common Units & Fuel & Capacity (MW) \\
\hline Combined cycle & Gas & 6,050 \\
\hline Combustion turbine & Gas & 4,200 \\
\hline Hydro & - & 15,448 \\
\hline Steam & Coal & 0 \\
\hline Steam & Nuclear & 1,114 \\
\hline PV & - & 15,621 \\
\hline Wind & - & 11,420 \\
\hline Total & - & $\mathbf{5 6 , 0 3 7}$ \\
\hline
\end{tabular}

Table B-5. Capacity Mixes under the Arizona-Desalination RPS80 Scenario

\begin{tabular}{|lll|}
\hline Common Units & Fuel & Capacity (MW) \\
\hline Combined cycle & Gas & 10,100 \\
\hline Hydro & Gas & 2,900 \\
\hline Steam & - & 15,448 \\
\hline Steam & Coal & 0 \\
\hline PV & Nuclear & 1,987 \\
\hline Wind & - & 21,724 \\
\hline Total & - & 6,702 \\
\hline
\end{tabular}



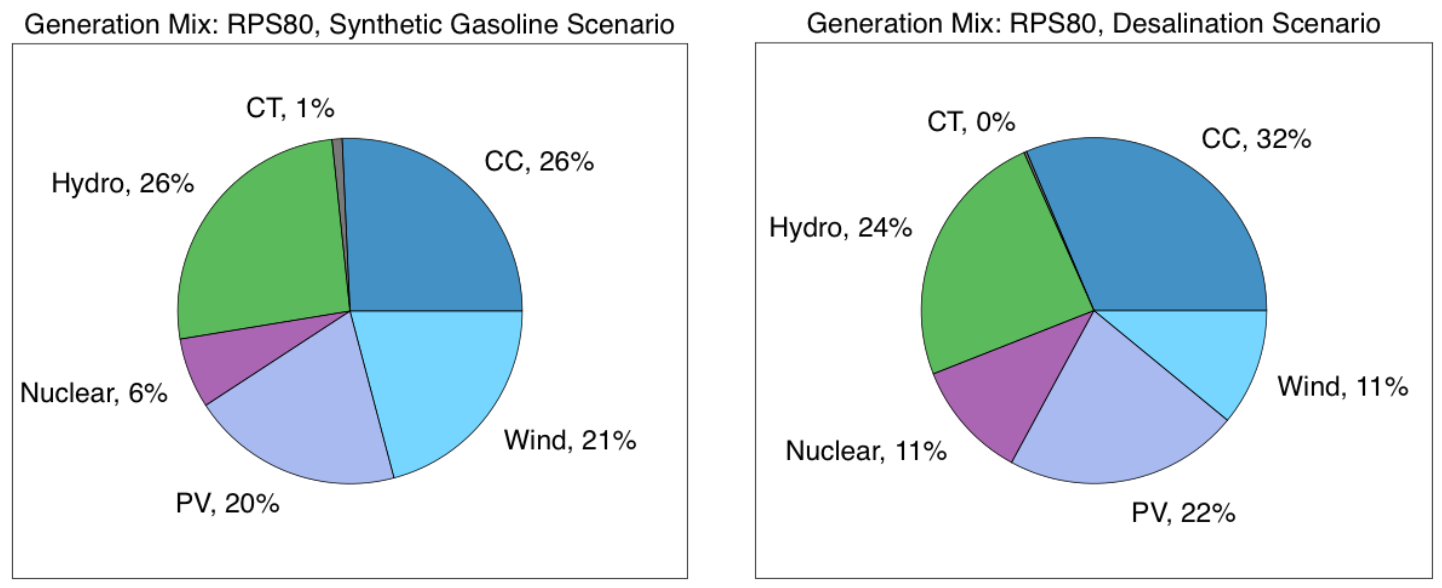

Figure B-2. Generation mix by annual energy production under the RPS80 scenarios.

Texas-synthetic gasoline is shown on the left. Arizona-desalination is shown on the right.

The annual electrical energy production from the generation mixes for both three-region, 118bus systems under the current law scenario are shown in Figure B-3. The Texas-synthetic gasoline scenario had only $21 \%$ variable generation (10\% PV and $11 \%$ wind) compared to $21 \%$ in the RPS 80 scenario. The Arizona-desalination scenario had only $16 \%$ variable generation ( $12 \% \mathrm{PV}$ and $4 \%$ wind). Due to the decreased penetrations of variable renewable energy, there was no curtailment in either location.
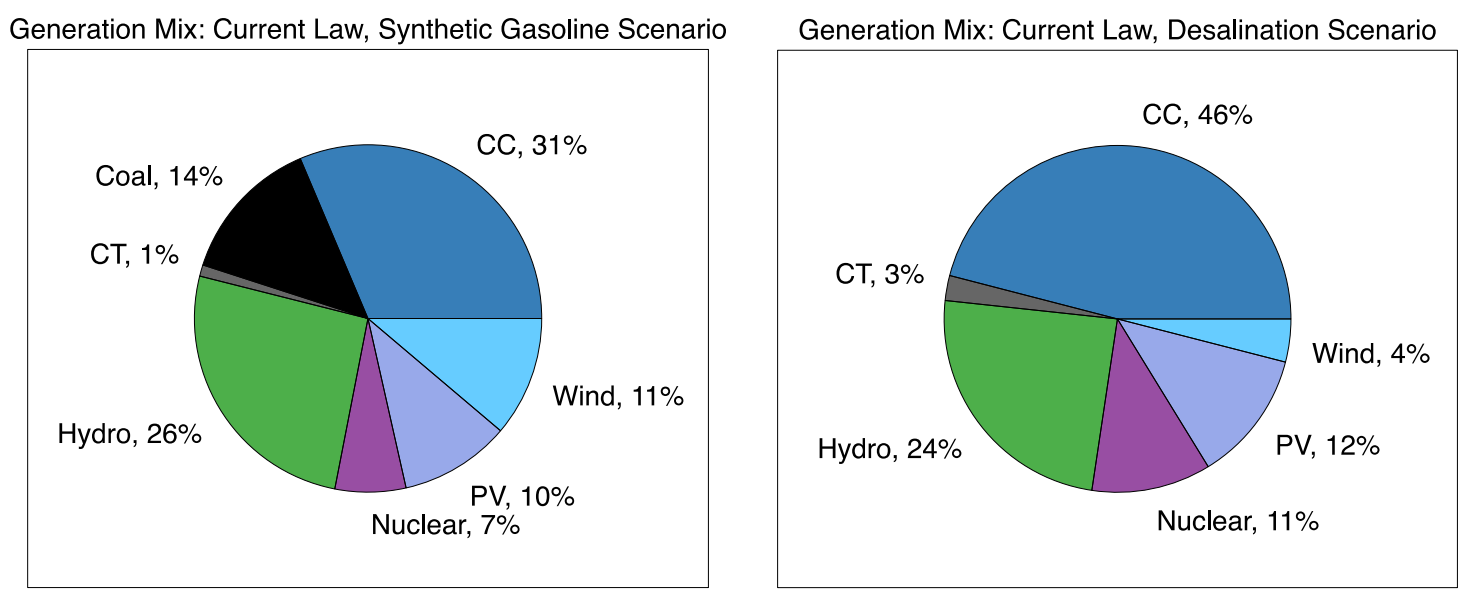

\section{Figure B-3. Generation mix by annual electrical energy production under the current law scenarios.}

Texas-Synthetic gasoline is shown on the left. Arizona-desalination is shown on the right.

\section{B.6.2 Hourly Electricity Prices}

Hourly electrical energy prices were estimated as those paid by the load during the period of study. These prices were derived from the short-run marginal costs of the marginal generator, and they did not include markups or any sort of scarcity pricing scheme. Note that for the 
purposes of this initial work, all prices were capped at $\$ 100 / \mathrm{MW}$. Prices at the price cap occurred primarily due to reserves violations - situations where optimization software found it less expensive to the system to short the reserves slightly rather than start or shut down a generator. Reserves violations occurred less than $0.03 \%$ of the time, well within typical modeling practices. Figure B-4 shows the electrical energy price duration curves for the reference-case feedstock prices in each location and generation mix.

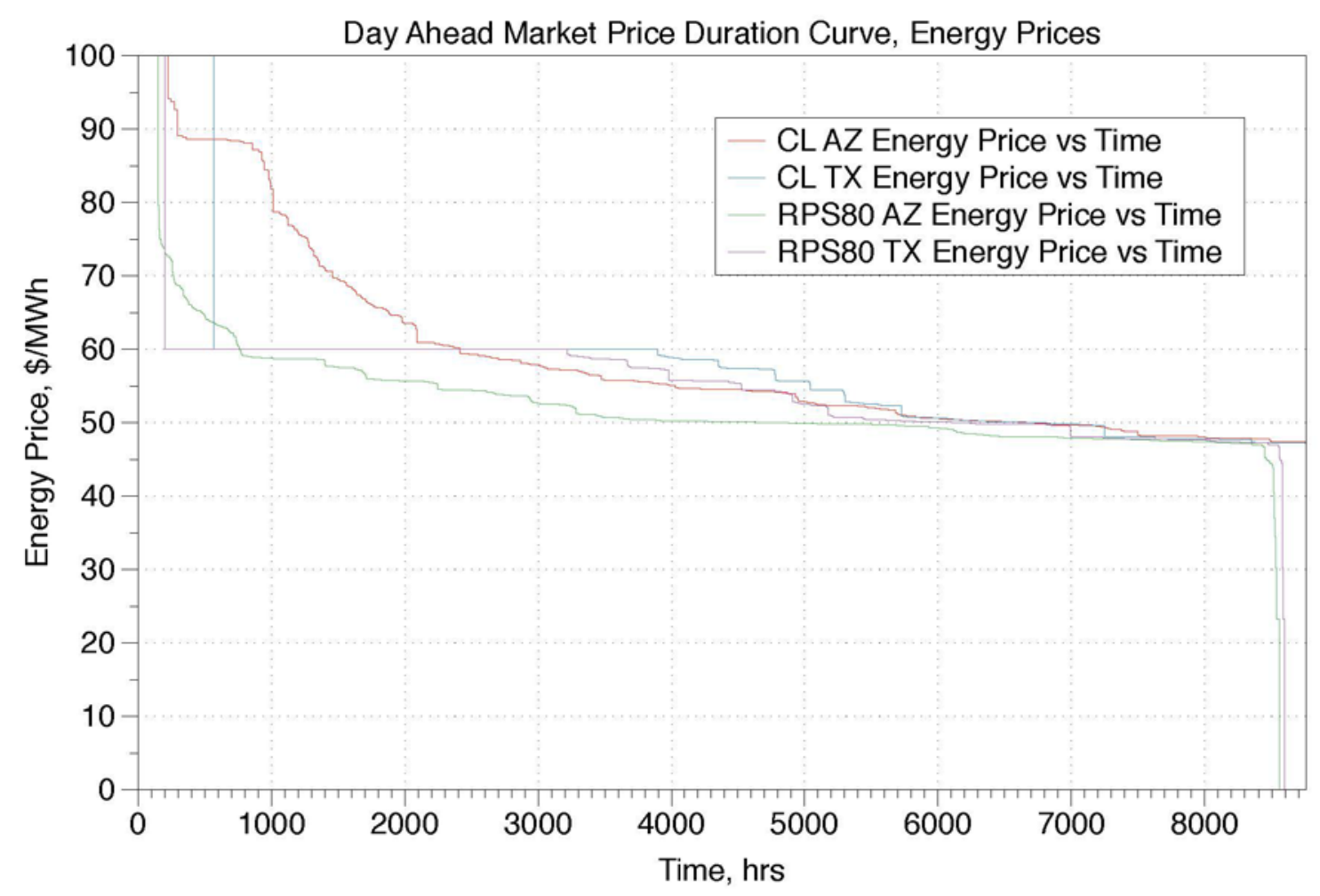

Figure B-4. Desalination scenario: electrical energy price duration curves

As with the synthetic gasoline scenarios, natural gas was primarily on the margin $(\sim 4,000$ hours) and set the electrical energy prices during times of the year when prices are above zero.

\section{B.6.3 Contingency Reserves Prices for RPS80 Scenarios}

Figure B-5 shows price duration curves for the contingency reserves. Under all scenarios, contingency reserves prices are zero for most of the year and modestly priced for the balance of the year. This pattern is typical for systems that have adequate capacity wherein the generation that is online often has headroom to provide contingency reserves for "free." 


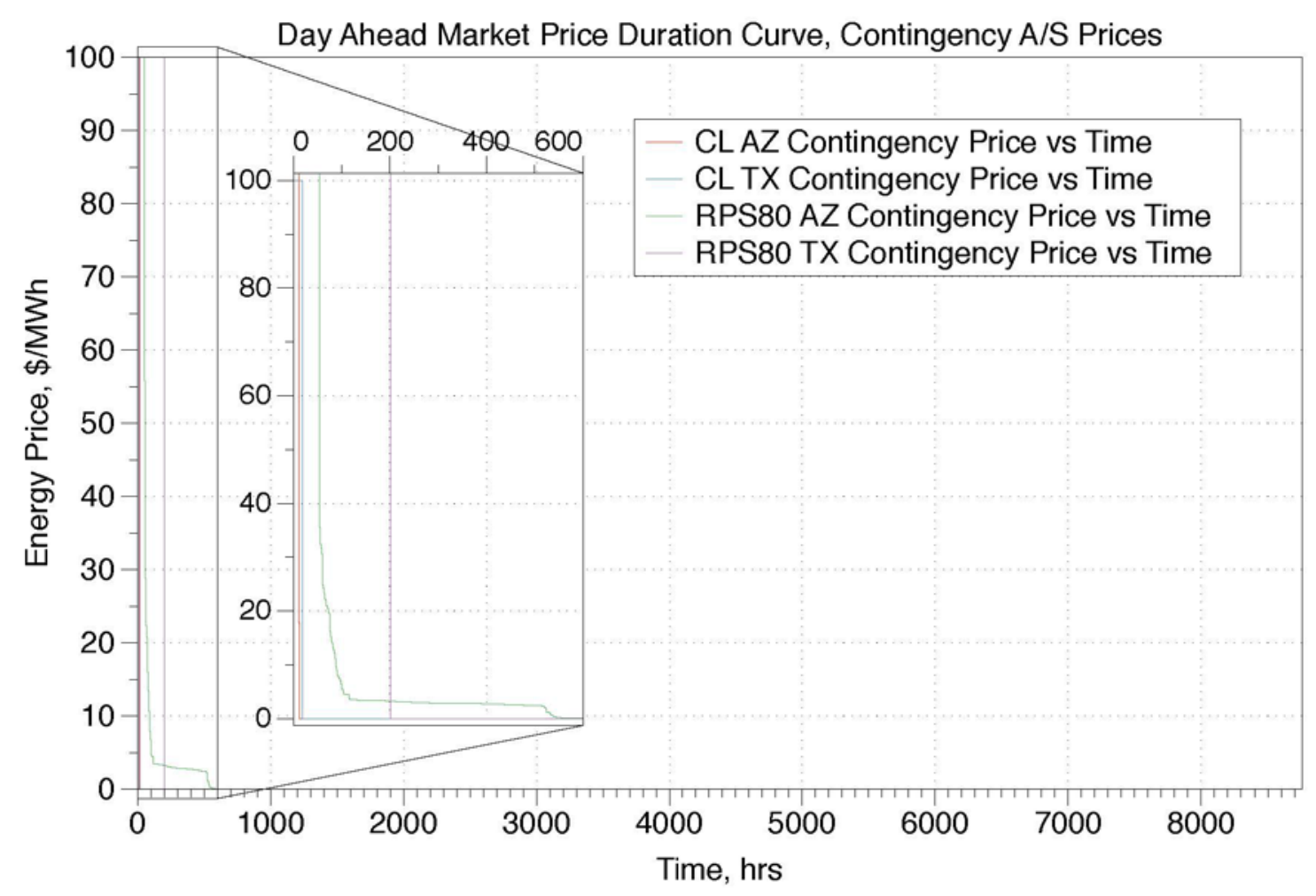

Figure B-5. Contingency reserve price duration curves

\section{B.6.4 Regulation-Up Prices for RPS80 Scenarios}

As with the contingency reserves, the prices for the regulation-up reserves were zero for most of the year (see Figure B-6). When prices hit their cap (approximately 20 hours out of the year), it was because it is cheaper to pay a penalty than start another machine (the penalty is $\$ 4,100 / \mathrm{MW}$ of shortfall, and typical shortages in these types of situations are in the sub-megawatt rangeleading to penalties of a few hundred dollars). 


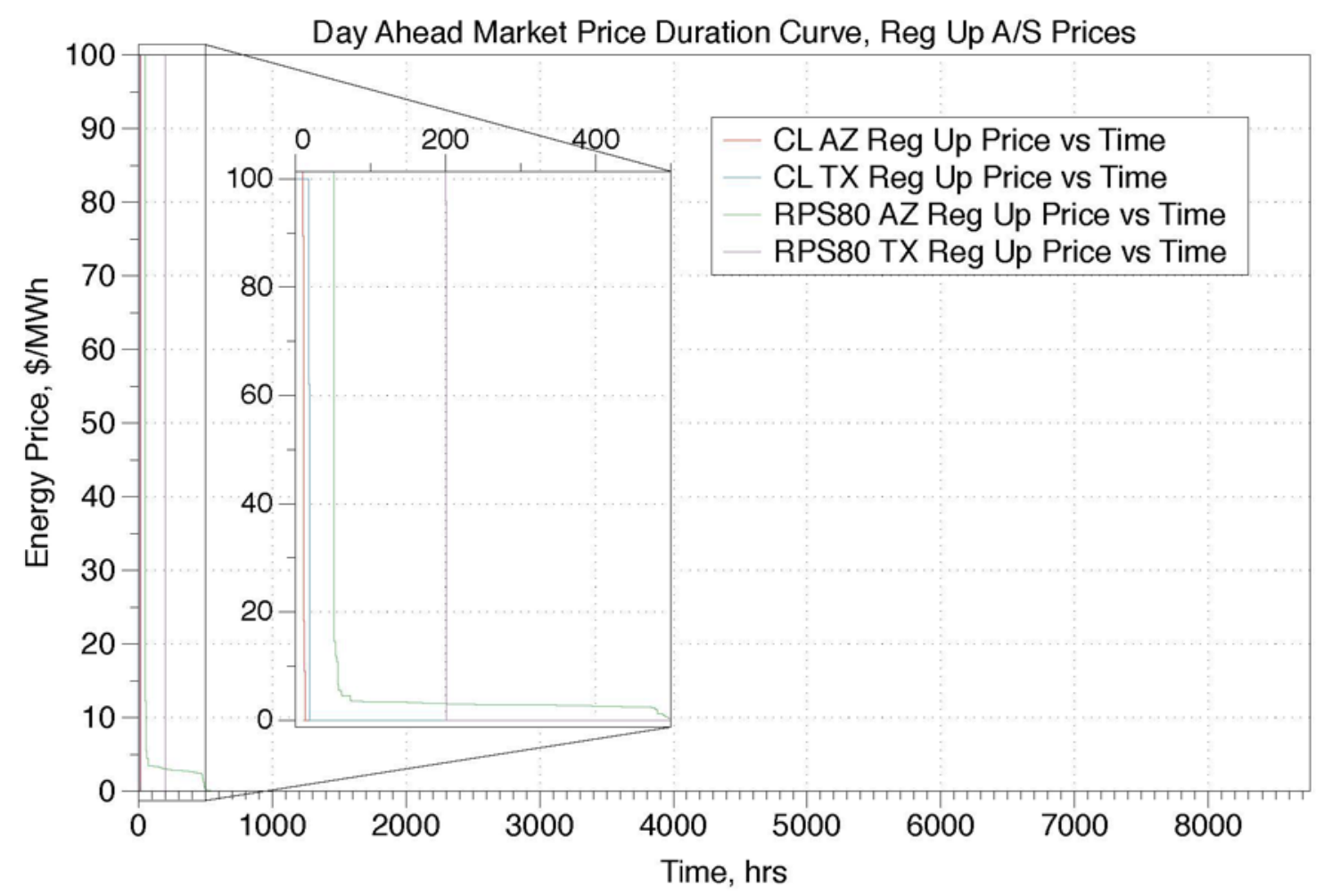

Figure B-6. Regulation-up price duration curves

\section{B.6.5 Regulation-Down Prices for RPS80 Scenarios}

The regulation-down price patterns for both the desalinization scenario and the synthetic gasoline scenario are somewhat unexpected in that under today's operating conditions (i.e., modest variable generation penetrations) regulation-down prices are typically similar to those of regulation-up prices (see Figure B-7).

To date, only limited research has been done regarding expected prices for regulation-down services, but the extended period of nonzero prices appears to be related to the level of penetration of variable generation because the number of hours with nonzero prices is higher in the higher variable generation penetration scenario (i.e., prices are higher in the synthetic gasoline scenario). Additional work will be done in this area to better understand the cause of these of these price differences. 


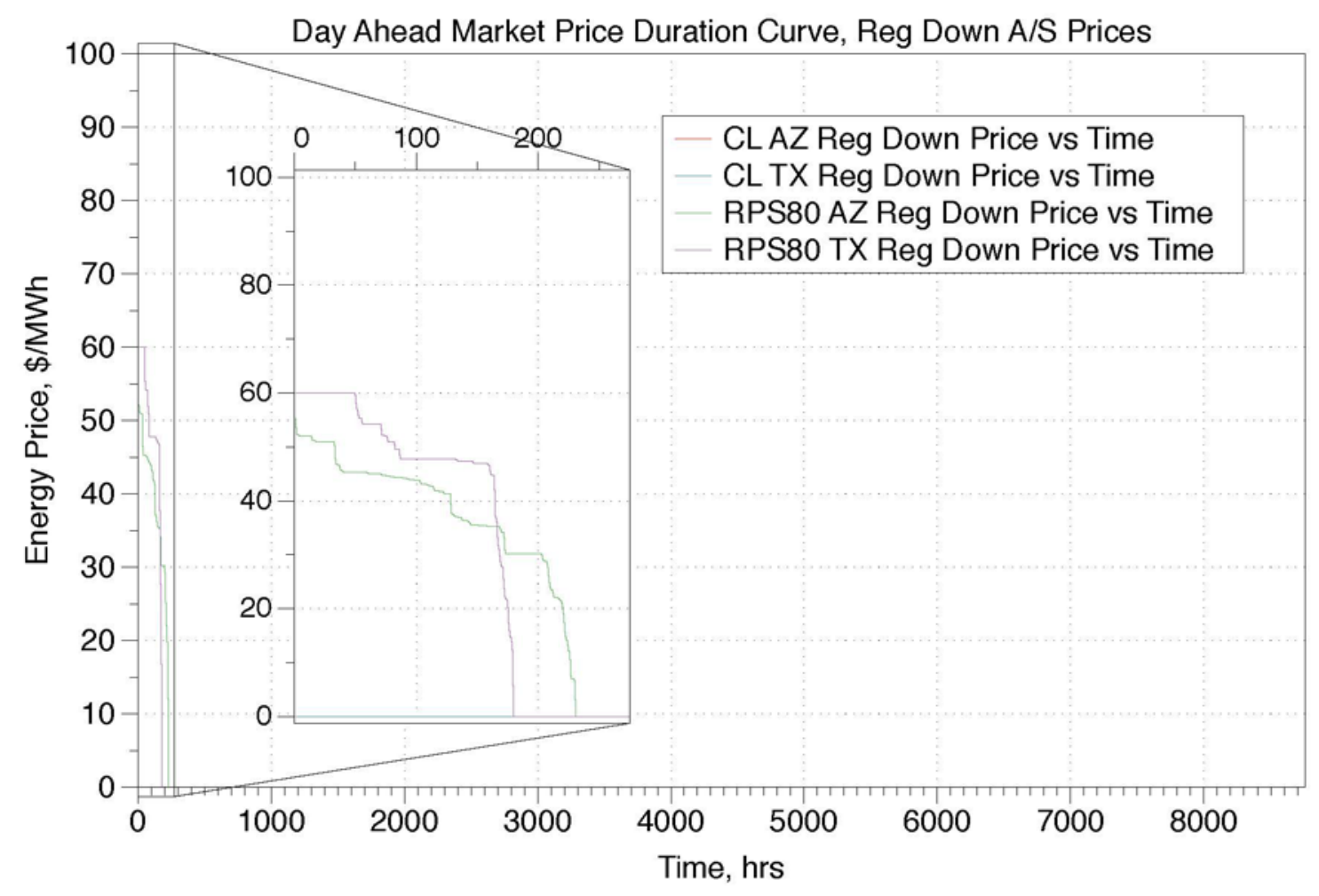

Figure B-7. Regulation-down price duration curves

\section{B.6.6 Flexibility Reserve Prices for RPS80 Scenarios}

Flexibility reserve prices are reported in Figure B-8. 


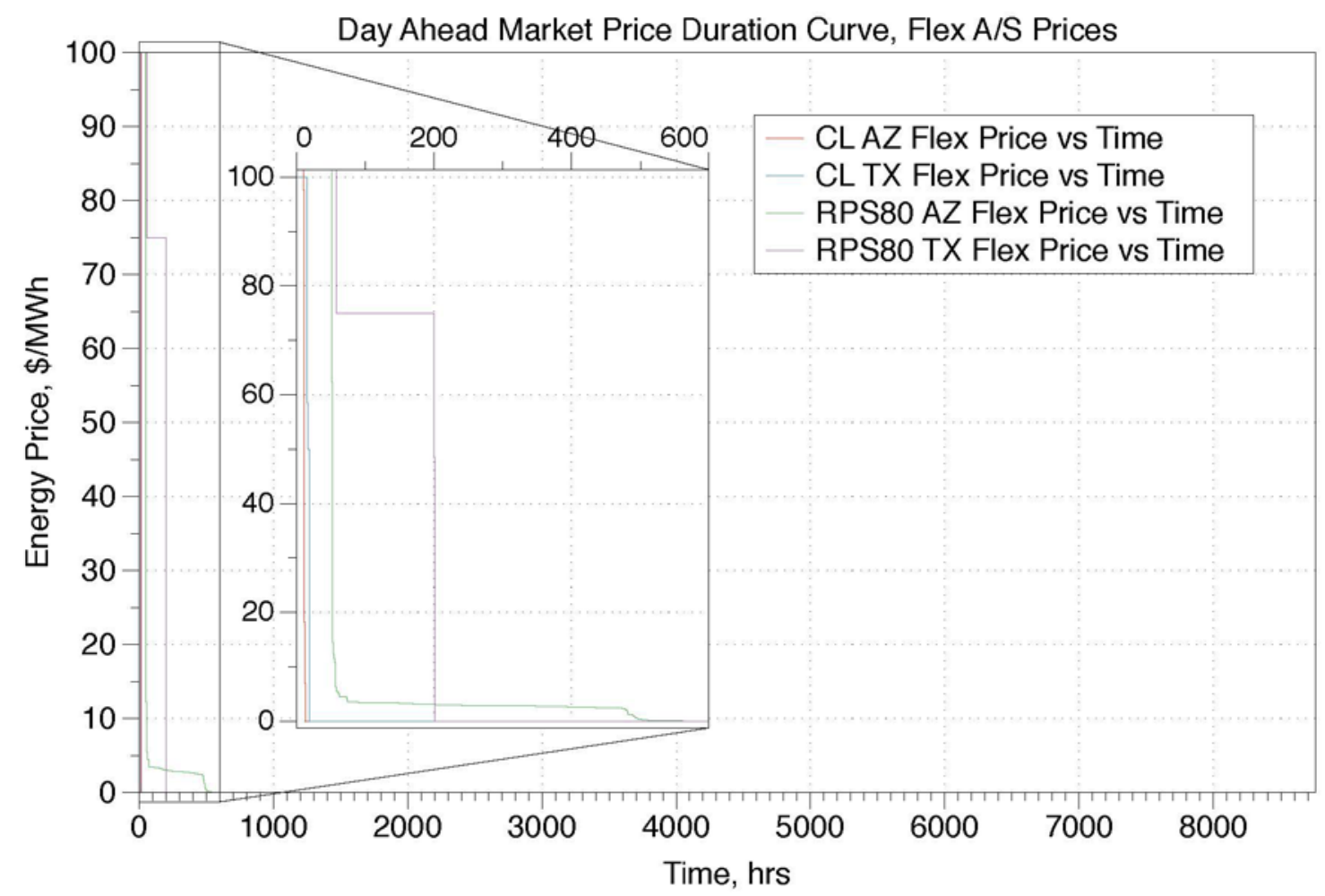

Figure B-8. Flexibility reserves price duration curves

The average system load was 6,595 MW, and, consequently, the impact of one 50-MWe generator had little effect on the overall system, affecting only the day-ahead cost-to-load estimates. 


\section{Appendix C Additional Information on Capacity Payments and Resource Price Estimates}

Figure C-1 shows capacity payments $(\$ / \mathrm{kW}$-year) for future years for a variety of regional transmission organizations (RTOs) and independent system operators (ISOs) in the United States, where the upper limit of $\$ 100 / \mathrm{kW}$-year corresponds roughly to net revenue required for combustion turbines that makes no net revenue from other sources.

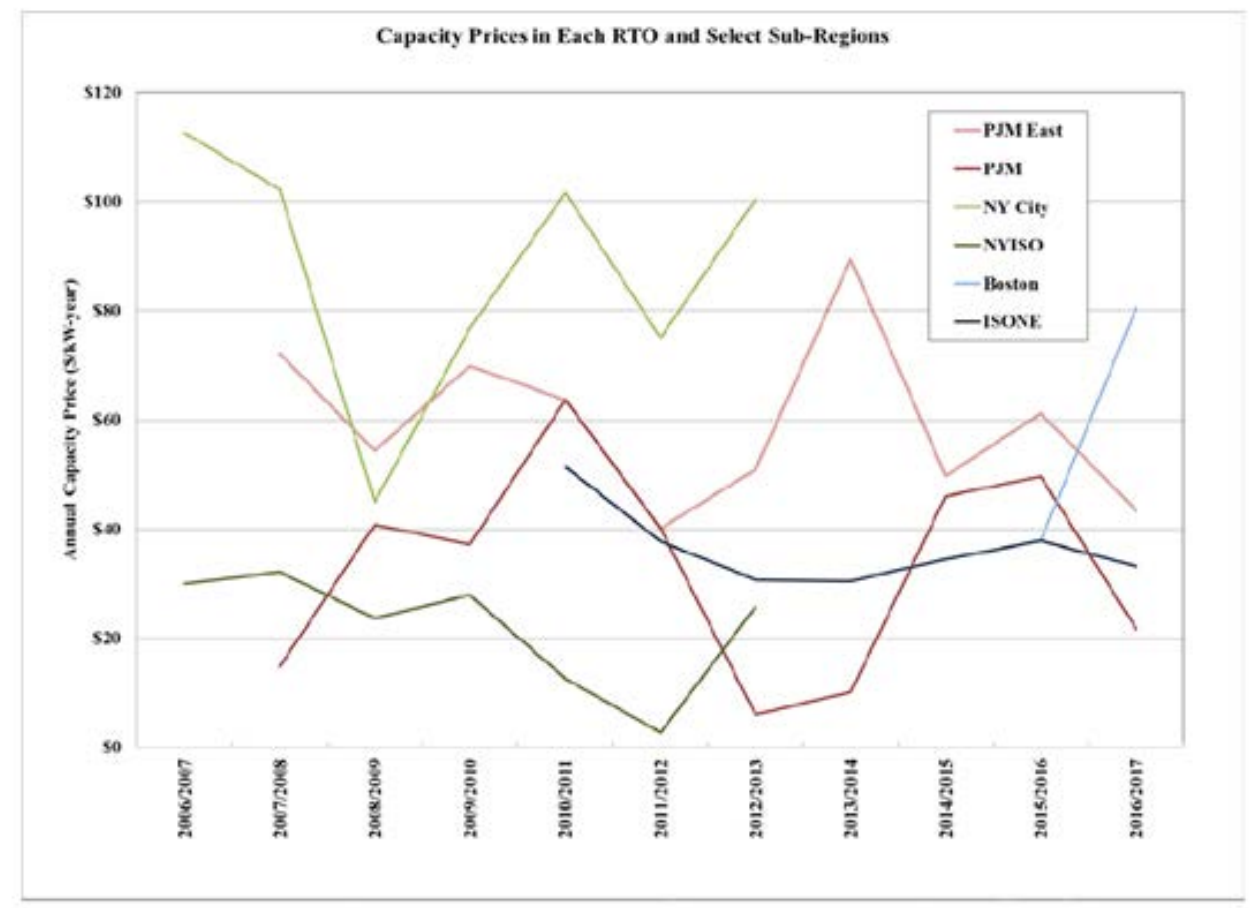

Figure C-1. Capacity payments from one RTO/ISO to another.

Source: Ela et al. (2014) $)^{21}$ and based on FERC (2013)

Based on Figure C-1 and given uncertainty in practice, we used $\$ 50 / \mathrm{kW}$-year for the base caseas the midpoint between the oversupply and undersupply estimates - and we observed variation in capacity payments from one RTO/ISO to another during the last decade. In addition, we considered a high-capacity payment case of $\$ 100 / \mathrm{kW}$-year that corresponded to the replacement value of a combustion turbine and was also reflective of higher payments in recent auctions.

It is also possible to estimate capacity payments based on the net cost of new entry (CONE) directly, though this is not without significant challenges, including: (1) recognizing that net CONE may be determined 3 years in advance (which is typical), so in general it will not correspond to the net CONE required (or determined) in any actual year of operation; (2) both the size and fraction of net CONE paid changes with a reserve margin is determined in a number of ways that are quite complex, asymmetric, and dependent on human and regulatory choices; and (3) arguably the net CONE estimate should be considered after explicit consideration of all

${ }^{21}$ Ela, E., M. Milligan, A. Bloom, A. Botterud, A. Townsend, and T. Levin. 2014. Evolution of Wholesale Electricity Market Design with Increasing Levels of Renewable Generation. NREL/TP-5D00-61765. Golden, CO: National Renewable Energy Laboratory, September. 
revenue. The latter requires giving careful consideration to the interaction effects because the allocation among different revenue sources is one of the main objectives of this study. Also, as mentioned above, we do not know how much supply there will be in 2035 in different regions compared to reliability-based targets. 


\section{Appendix D Additional Details on Fossil Fuel and Gasoline Price Projections}

The projected 2025 fossil-fuel prices in the United States for coal, natural gas, and oil are highly uncertain, and we used the U.S. Energy Information Administration (EIA) scenarios given in the most recent (2015) Annual Energy Outlook. EIA has four "coupled" scenarios that account for the fact that different fossil-fuel prices may be strongly or weakly correlated. The scenarios taken from the Annual Energy Outlook include: ${ }^{22}$

- Reference-Central Case

- Low fossil-fuel prices

- High fossil-fuel prices

- Low gas price, reference price oil—due to large shale gas/oil (which the EIA refers to as the high oil and gas resource case).

For this initial study, we used the U.S. average estimates - though future work may allow for regional price differences; however, these differences are likely to be much less than those among various scenarios, so this is really a second-order effect. "Coupling" different fossil-fuel commodity prices for a given scenario (as is done by the EIA in their estimates) is important for internal consistency-i.e., it is not realistic to simply mix one fossil-fuel commodity price in one scenario with a different commodity in another scenario because they will not be internally consistent (and this may have important implications for gasoline production choices with natural gas).

Figure D-1 shows historical and EIA projected energy prices (U.S. average) for oil, natural gas, and coal from 2005 to 2040 in their usually reported units.
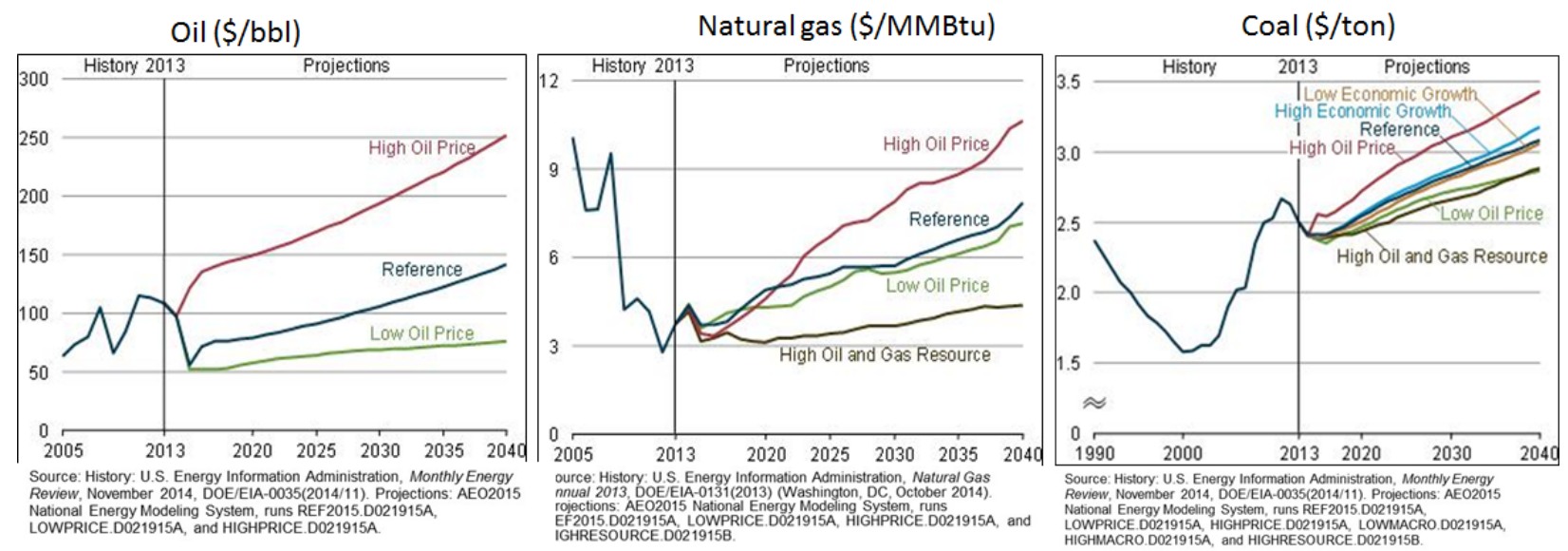

Figure D-1. EIA energy price projection from 2013 to 2040

Table D-1 reports the prices used in this analysis.

${ }^{22}$ U.S. Energy Information Administration. Annual Energy Outlook 2015: With Projections to 2040. Washington, D.C. 
Table D-1. EIA 2035 Energy Price Projections (\$2013) (Annual Energy Outlook 2015)

\begin{tabular}{|llll|} 
& Reference & High Oil & Low Oil \\
\hline Natural gas & $\$ 6.98 / \mathrm{mmBtu}$ & $\$ 8.49 / \mathrm{mmBtu}$ & $\$ 6.62 / \mathrm{mmBtu}$ \\
\hline Coal & $\$ 2.79 / \mathrm{mmBtu}$ & $\$ 3.12 / \mathrm{mmBtu}$ & $\$ 2.62 / \mathrm{mmBtu}$ \\
\hline $\begin{array}{l}\text { Gasoline } \\
\text { (wholesale) }\end{array}$ & $\$ 3.00 / \mathrm{gal}$ & $\$ 5.10 / \mathrm{gal}$ & $\$ 2.00 / \mathrm{gal}$ \\
\hline $\begin{array}{l}\text { Oil: West Texas } \\
\text { Intermediate } \\
\text { spot }\end{array}$ & $\$ 116 / \mathrm{bbl}$ & $\$ 215 / \mathrm{bbl}$ & $\$ 68 / \mathrm{bbl}$ \\
\hline
\end{tabular}

Table D-2 shows the variations among coal, natural gas, and oil prices in real $2013 \$$ on a comparable \$/MMBtu basis for 2014, 2015, and 2035 for the different scenarios. We show prices for both 2014 and 2015 because of the substantial recent drop in oil prices in 2015. This makes 2035 prices and "current prices" very different depending on whether the comparison is made to the most recent current price estimate (2015) or recent history (e.g., 2014 and prior)-i.e., the increase in oil prices in real terms between 2015 and 2035 is quite substantial $(+120 \%)$, whereas the increase is much more modest when compared to $2014(+25 \%)$. Also of note in the reference case is that projected natural gas prices are substantially greater than they are today $(\mathrm{a}+50 \%$ increase from $\$ 4 / \mathrm{MMbtu}$ to nearly $\$ 7 / \mathrm{MMBtu}$ by 2035). Only the "High oil and gas resource" scenario projects the recent low (compared to history) shale-driven natural gas prices as being sustained out to 2035. The "low oil" scenario has natural gas at more than $\$ 6 / \mathrm{MMBtu}$, and the "high oil" scenario projects a price of more than $\$ 8 / \mathrm{MMBtu}$. In other words, there is an expectation that natural gas prices will rise between $50 \%$ and $100 \%$ in real terms, with some unspecified (and unknown) likelihood that the natural gas prices may remain similar to their prices today. 
Table D-2. EIA Energy Price Projection from 2013 to 2040

\begin{tabular}{|c|c|c|c|c|c|}
\hline \multicolumn{4}{|c|}{2015 Annual Energy Outlook ( $\$ 2013$ ) in common $\$ / M M B t u$ units } & \multirow{2}{*}{\multicolumn{2}{|c|}{ High oil and gas resource }} \\
\hline & Reference & High oil & Low oil & & \\
\hline \multicolumn{6}{|l|}{ Oil $(\$ / b b l)$} \\
\hline 2014 & 97.5 & 97.5 & 97.5 & 97.5 & \\
\hline 2015 & 55.6 & 121.5 & 51.8 & 55.6 & \\
\hline 2035 & 122.2 & 220.7 & 72.0 & 122.2 & \\
\hline \multicolumn{6}{|l|}{ Oil (\$/MMbtu) } \\
\hline 2014 & 17.0 & 17.0 & 17.0 & 17.0 & \\
\hline 2015 & 9.7 & 21.1 & 9.0 & 9.7 & \\
\hline 2035 & 21.3 & 38.4 & 125 & 21.3 & \\
\hline \multicolumn{6}{|l|}{ NG (\$MMBtu) } \\
\hline 2014 & 4.4 & 4.3 & 4.4 & 4.2 & \\
\hline 2015 & 3.7 & 3.4 & 3.6 & 3.1 & \\
\hline 2035 & 6.6 & 8.8 & 6.1 & 4.2 & \\
\hline \multicolumn{6}{|l|}{ Coal (\$/ton) } \\
\hline 2014 & 2.4 & 2.4 & 2.4 & 2.4 & \\
\hline 2015 & 2.4 & 2.6 & 2.4 & 2.4 & \\
\hline 2035 & 3.0 & 3.3 & 2.8 & 2.8 & \\
\hline & & & & & \\
\hline Notes: Oil assume & d to be 5.75 & $\mathrm{u} / \mathrm{lbl}$ & & & \\
\hline
\end{tabular}

We again used the EIA Annual Energy Outlook scenarios to estimate the prices of wholesale gasoline in 2035. Oil, wholesale, and retail gasoline prices are strongly correlated. As the EIA has noted:

"in wholesale gasoline spot prices have a consistent and predictable effect on changes in retail gasoline prices. Other factors equal, a \$1-per-barrel change in the price of crude oil will result in a \$1-per-barrel, or \$0.024-per-gallon (1/42 of \$1 because there are 42 gallons in one barrel) change in the price of wholesale and retail gasoline. Statistical analysis demonstrates about half of the change in crude oil price is passed through to retail prices within two weeks of the price change, all other market factors equal."

Figure D-2 shows the price variation for the central gas case for oil, wholesale gasoline, and retail gasoline (U.S. average) in \$2013 on a comparable \$/MMBtu basis. We found that for the central scenario the cost of wholesale gasoline increase from \$24.1 and \$15.3/MMBtu in 2014 and 2015, respectively, to $\$ 26.3 / \mathrm{MMBtu}$ in 2035. In terms of \$/gallon, the wholesale gas prices in 2014 and 2015 increase from $\$ 2.75$ and \$1.75/gallon, respectively, to \$3.00/gallon in 2035 . 


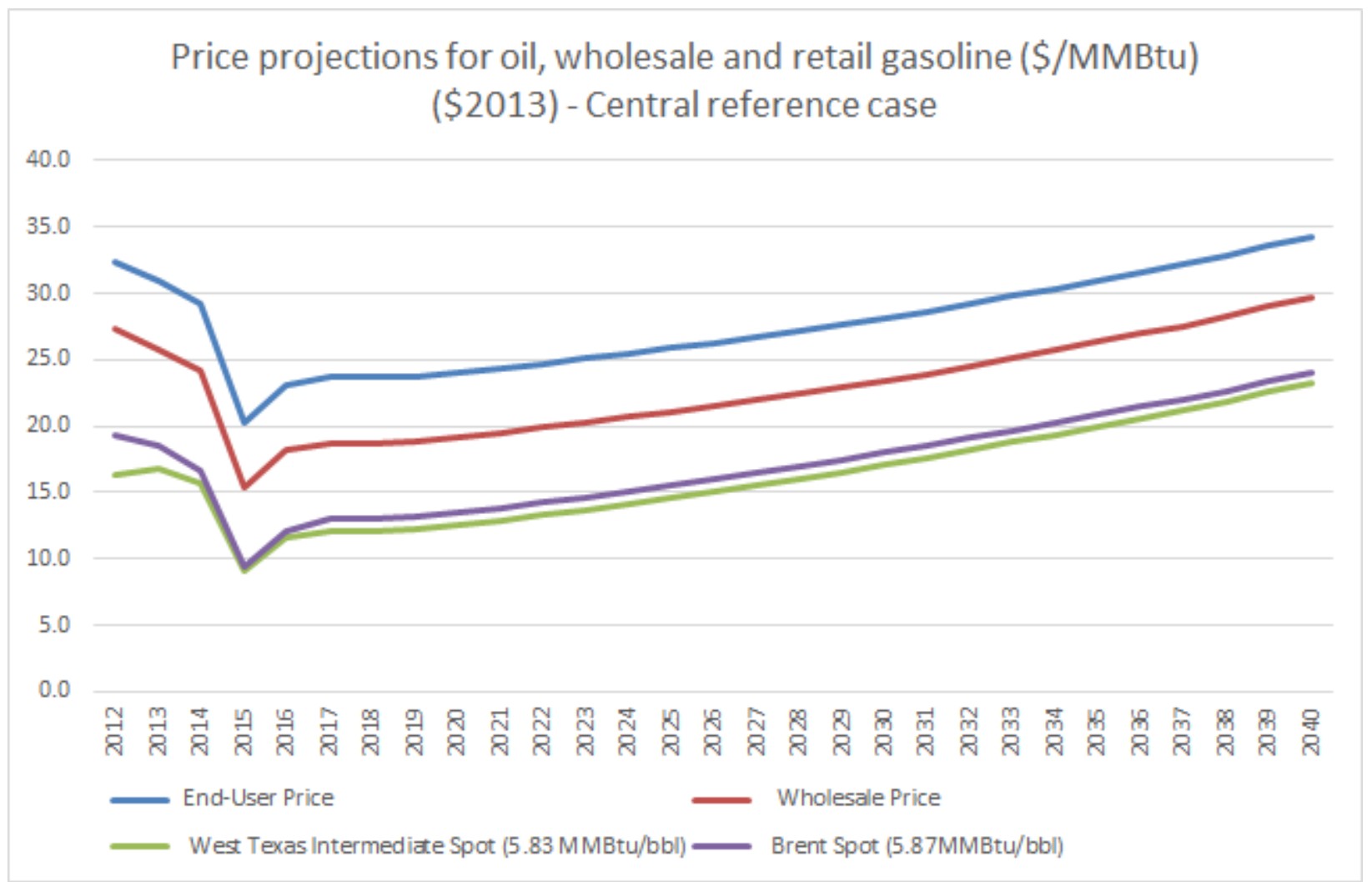

Figure D-2. EIA oil price projection from 2013 to 2040

This analysis was predicated on the assumption that the process that converts natural gas to synthetic gasoline is commercialized and mature. If it is mature, the competing price for the gasoline product is likely to be the selling price necessary to achieve the required $10 \%$ internal rate of return in a plant that converts natural gas to gasoline using natural gas as the heat source. Table D-3 reports the results of that analysis. 
Table D-3. Calculated Required Selling Price for Synthetic Gasoline Produced In a Plan That Uses Natural Gas for Heat

\begin{tabular}{|lcc|}
\hline & Annual Cost, First Year & \\
\hline Capital cost & $\$ 2,154$ & million \\
\hline Natural gas as feedstock (\$/yr) & $\$ 526$ & million \\
\hline Natural gas for heating (\$/yr) & $\$ 116$ & million \\
\hline Water cost $(\$ / y r)$ & $\$ 1.5$ & million \\
\hline Fixed O\&Ma costs $(\$ / y r)$ & $\$ 254$ & million \\
\hline Annual production (gal/yr) & 488 & million \\
\hline $\begin{array}{l}\text { Cost of synthetic gasoline to meet 10\% } \\
\text { internal rate of return }(\$ / g a l)\end{array}$ & $\$ 2.32$ & \\
\hline
\end{tabular}

${ }^{a}$ Operations and maintenance 


\section{Appendix E Additional Details on Water Prices}

This appendix describes efforts to provide an appropriate valuation scheme to water resources and the value of producing new freshwater resources in Arizona in 2035. Estimating the value of water in the western United States is challenging due to a lack of a competitive market for water resources, multiple overlapping jurisdictions of water management, differing prioritization regimes during times of drought, and the presence of overallocated water basins (e.g., more water rights exist than physical water resources). Data are notoriously difficult to obtain for prices of transfers of water rights, and the data that do exist can have substantially different values depending on the seller (e.g., agriculture, industry) and the buyer (e.g., energy, industry, municipalities), especially when the buyer represents a different beneficial use of the water resource. Additionally, when water is plentiful, its price is often well below its actual cost; when there is a shortage of water, its price can spike in a nonlinearly or step-change fashion. To address these challenges, we adopted an approach rooted in existing water-related studies from the Arizona Water Resources Development Commission (AZWRDC) ${ }^{23}$ augmented by recent National Renewable Energy Laboratory and other research on alternative water resources to provide a framework for evaluating the value of new freshwater water produced in the study system.

To address long-term water planning needs, the AZWRDC undertook a comprehensive assessment of state-level water resource availability compared to future needs in 2035, 2060, and 2110. The AZWRDC identified a water shortage of 600,000 to 1,200,000 acre-feet per year (AFY) in 2035, with shortages increasing for later years (AZWRDC 2011). The 2035 shortage represents approximately $7-13 \%$ of current freshwater demands in Arizona. The AZWRDC took an additional step of identifying and performing an economic analysis of promising projects to augment freshwater supply in Arizona in 2035. Of 18 potential projects (none of which considered the use of brackish water resources), three were determined to be financially viable for Arizona. These three projects were found to have costs varying from $\$ 1,400$ per acre-foot (AF) to $\$ 2,700$ per AF and would provide approximately 51,000 AFY (AZWRDC 2011). Given that these three projects represent the most likely options that the state of Arizona will consider in augmenting freshwater resources to meet 2035 demands, these costs of providing water were used as the baseline value of water in this analysis and represent the foundation of a water supply curve (Figure E-1). This analysis assumes the most economical water price option, \$1,400 per AF, although additional water supply augmentation efforts would likely involve higher prices.

${ }^{23}$ AZWRDC. 2011. Final Report. Vol. II. Phoenix, AZ. . 


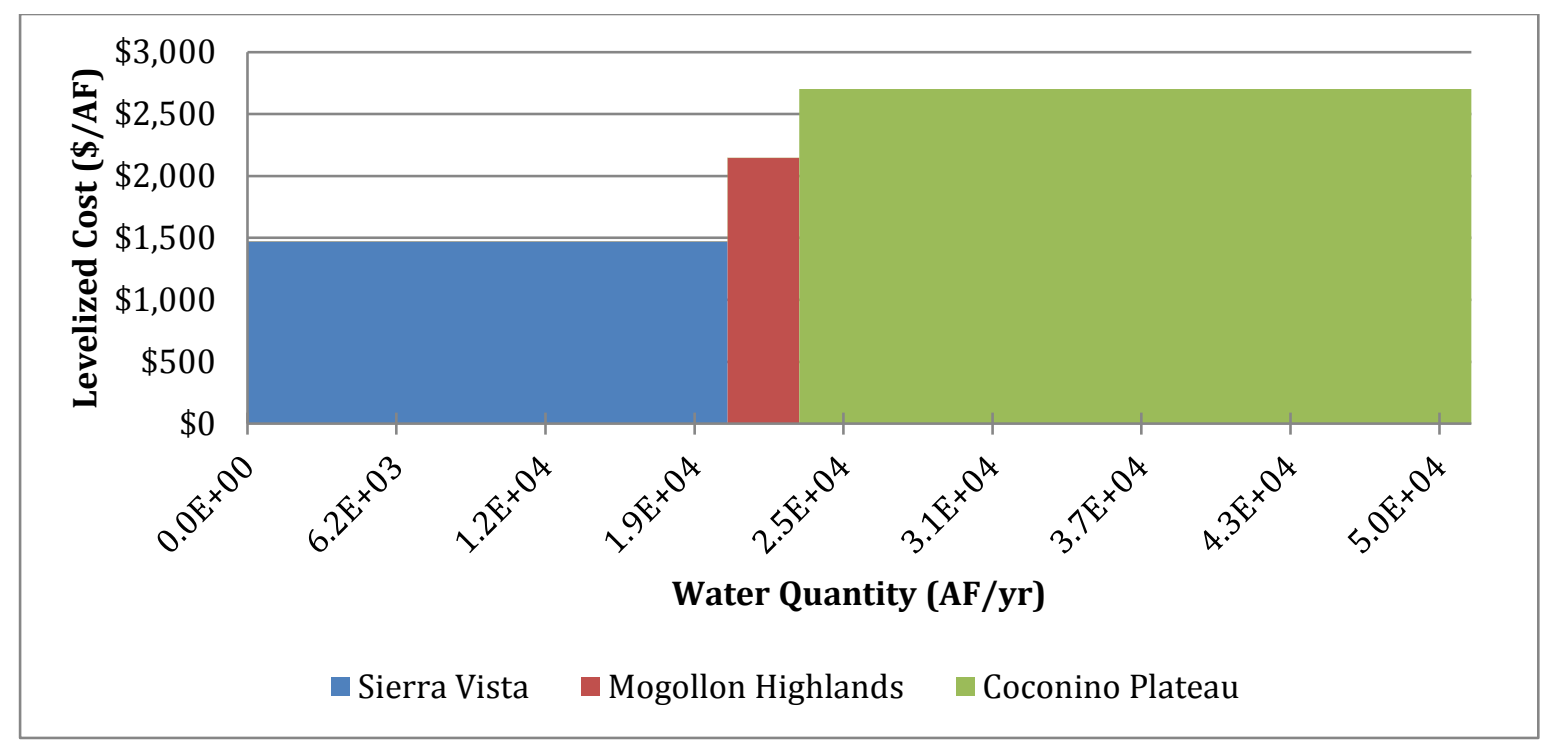

Figure E-1. Water supply curve for Arizona to meet projected supply shortfalls in $\mathbf{2 0 3 5}$

Data Source: AZWRDC (2011)

Building on the fundamental water supply curve, this effort utilized spatially resolved information about Arizona's brackish water resources to estimate viable supplies suitable for water treatment based on the quantity, quality, and depth of the brackish water resource. Utilizing data from 84 watershed units in Arizona recently developed and analyzed for beneficial use, this effort could examine cost and availability profiles of treating brackish water resources in each region (Tidwell et al. 2013; Tidwell et al. 2014) ${ }^{24},{ }^{25}$ Arizona has close to 3,000,000 AFY of recoverable brackish water resources, with total dissolved solids measurements ranging from 1,000 to $8,000 \mathrm{mg} / \mathrm{l}$ and depths ranging from 100 to 1,000 feet. The quality and depth of water resources play an important role in determining the energy intensity and overall cost of treating water resources (Cooley and Wilkinson 2012). ${ }^{26}$ In addition, the distance treated water must be transported for final distribution and use can represent a substantial energy cost (CPUC 2015). ${ }^{27}$ These various energy and economic costs along with sensitivity analyses are integrated into the modeling framework utilized to compare the development of brackish water resources to AZWRDC-identified water projects.

The approach undertaken in this effort represented a unique and defensible method to evaluate costs and feasibility of new water development projects. Grounded in the state of Arizona's analyses as well as recent literature and research on alternative water resource development, this approach could be adapted for multiple water treatment technologies or system configuration designs. In addition, this framework could be adapted to other states and regions given the availability of data.

\footnotetext{
${ }^{24}$ Tidwell, V.C., K. Zemlick, and G.T. Klise. 2013. Nationwide Water Availability Data for Energy-Water Modeling. SAND2013-9968. Albuquerque, NM: Sandia National Laboratories.

25 Tidwell, V., J. Macknick, K. Zemlick, J. Sanchez, and T. Woldeyesus. 2014. "Transitioning to Zero Freshwater Withdrawal in the U.S. for Thermoelectric Generation." Applied Energy 131: 508-516.

${ }^{26}$ Cooley, H., and R. Wilkinson. 2012. Implications of Future Water Supply Sources for Energy Demands.

Alexandria, VA: WateReuse Research Foundation.

${ }^{27}$ California Public Utilities Commission. 2015. "Water-Energy Calculator."

http://www.cpuc.ca.gov/nexus_calculator/.
} 


\section{Appendix F Additional Details on GHG Emissions}

\section{F.1 Additional Details on GHG Emissions from Natural Gas Combined Cycle}

The NGCCs emit $769 \mathrm{lb} \mathrm{CO}_{2} / \mathrm{MWh}$. The emission factor is $117 \mathrm{lb} \mathrm{CO} / \mathrm{mmBtu}$ natural gas combusted $^{28}$ and the NGCC's heat rate is $6,750 \mathrm{Btu}$ natural gas $/ \mathrm{kWh} ;{ }^{29}$ thus, the emissions are $769 \mathrm{lb} \mathrm{CO} / \mathrm{kWh}$ produced.

\section{F.2 Additional Details on GHG Emissions from Natural Gas Boiler}

The synthetic gasoline process emits $1.138 \mathrm{lb} \mathrm{CO}_{2} /$ gal of synthetic gasoline produced. The emission factor is $117 \mathrm{lb} \mathrm{CO} 2 \mathrm{e} / \mathrm{mmBtu}$ natural gas combusted, ${ }^{28} 1.0872 \mathrm{~kg}$ of gasoline are produced per kWh-th heat added to the synthetic gasoline process,${ }^{30}$ and the boiler is $94 \%$ efficient. ${ }^{31}$ The industrial process produces $181,200 \mathrm{~kg} / \mathrm{hr}$ so, at the assumed capacity factor of $100 \%$, it produces $1,587,312,000 \mathrm{~kg}$ synthetic gasoline/yr. It requires $1,553,191,000 \mathrm{kWh}-\mathrm{th} / \mathrm{yr}$, which is equivalent to $5,299,000 \mathrm{mmBtu} / \mathrm{yr}$. The $\mathrm{GHG}$ emissions generated in heat production are $620,040,000 \mathrm{lb} \mathrm{CO}_{2} \mathrm{e} / \mathrm{yr}$. Because 1,587,312,000 $\mathrm{kg}$ synthetic gasoline are equivalent to $545,000,000 \mathrm{gal} / \mathrm{yr}$, the emissions factor is $1.138 \mathrm{lb} \mathrm{CO}_{2} \mathrm{e} / \mathrm{gal}$.

\footnotetext{
${ }^{28}$ EIA, Table A.3. Carbon Dioxide Uncontrolled Emission Factors, http://www.eia.gov/electricity/annual/html/epa a 03.html

${ }^{29}$ Annual Technology Baseline and Standard Scenarios. NREL. http://www.nrel.gov/analysis/data tech_baseline.html

${ }^{30}$ H. Garcia, J. Chen, J. S. Kim, M. G. McKellar, W. Deason, R. Vilim, S. M. Bragg-Sitton, R. D. Boardman "Nuclear Hybrid Energy Systems - Regional Studies: West Texas \& Northeastern Arizona” INL Report INL/EXT15-34503 (April 2015).

${ }^{31}$ MIT Energy Initiative "The Future of Natural Gas An Interdisciplinary MIT Study” (2011) Appendix 5. https://mitei.mit.edu/system/files/NaturalGas_Appendix5A.PDF
} 


\section{Appendix G Additional Results from the Texas- Synthetic Gasoline Scenario}

\section{G.1 Sensitivities on the Impacts of Electricity and Gasoline Prices Based on the RPS80 Generation Mix and Annual Energy Outlook reference-case electricity prices}

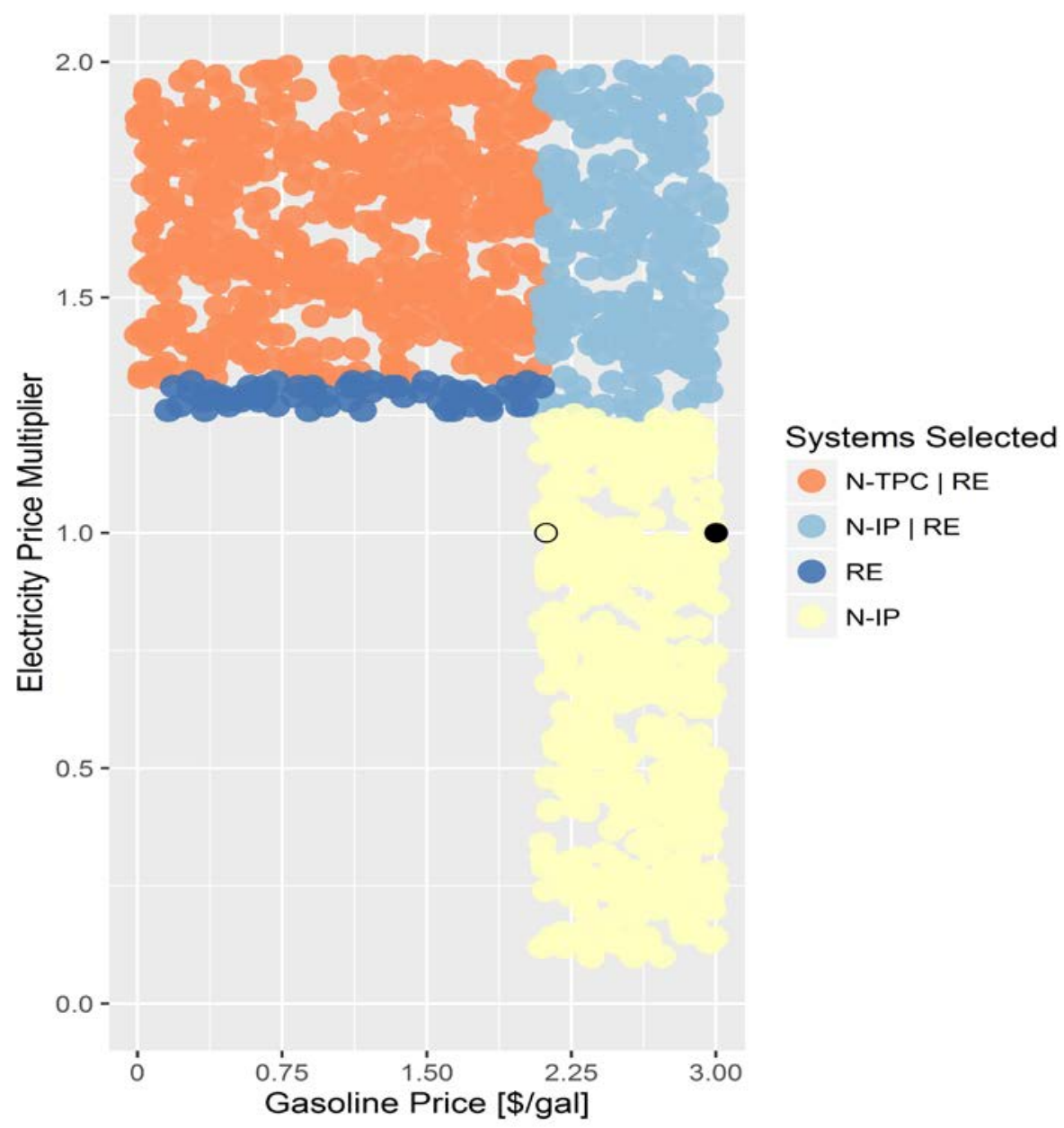

Figure G-1. Optimal configurations for the Texas-synthetic gasoline scenario at various gasoline prices and electricity price multipliers based on RPS80 generation mix, Annual Energy Outlook (AEO) reference-case prices, and $\$ 50 / \mathrm{kW}$-yr capacity payments

N-TPC: Nuclear reactor and thermal

N-IP: Nuclear reactor and industrial process

$\mathrm{RE}$ : Renewable electricity generation

Solid black dot at electricity price multiplier of 1.0 and $\$ 3.00 /$ gal gasoline price: reference case gasoline price projection; reference-case electricity price vector

Open black dot: minimum gasoline selling price for a synthetic gasoline plant using natural gas heating; reference-case electricity price vector 


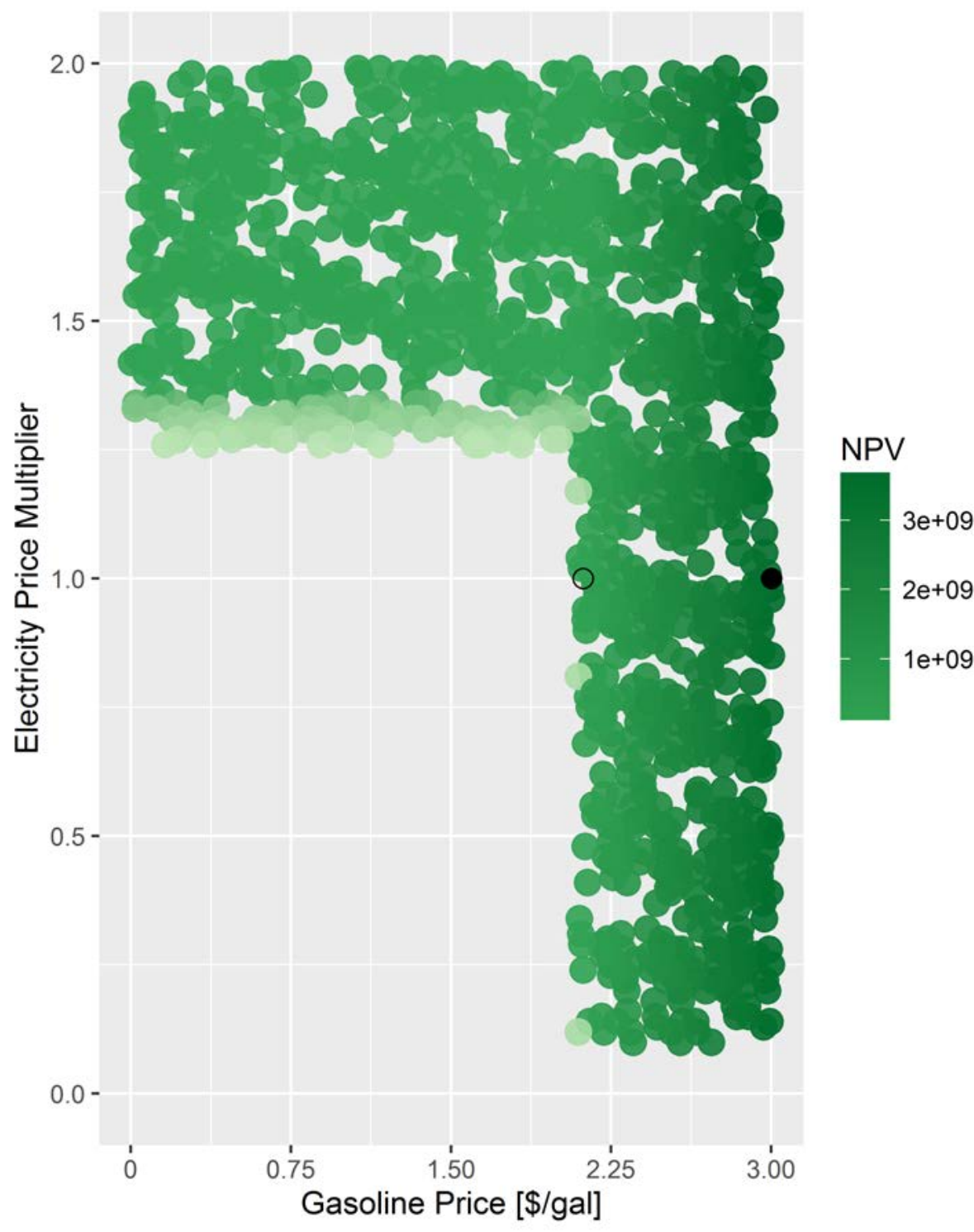

Figure G-2. Texas-synthetic gasoline scenario NPVs at various gasoline prices and electricity price multipliers based on RPS80 generation mix, AEO reference-case prices, and $\$ 50 / \mathrm{kW}$-yr capacity payments.

Darker shades indicate higher NPVs.

Solid black dot at electricity price multiplier of 1.0 and $\$ 3.00 /$ gal gasoline price: reference case gasoline price projection; reference-case electricity price vector

Open black dot: minimum gasoline selling price for a synthetic gasoline plant using natural gas heating; reference-case electricity price vector 

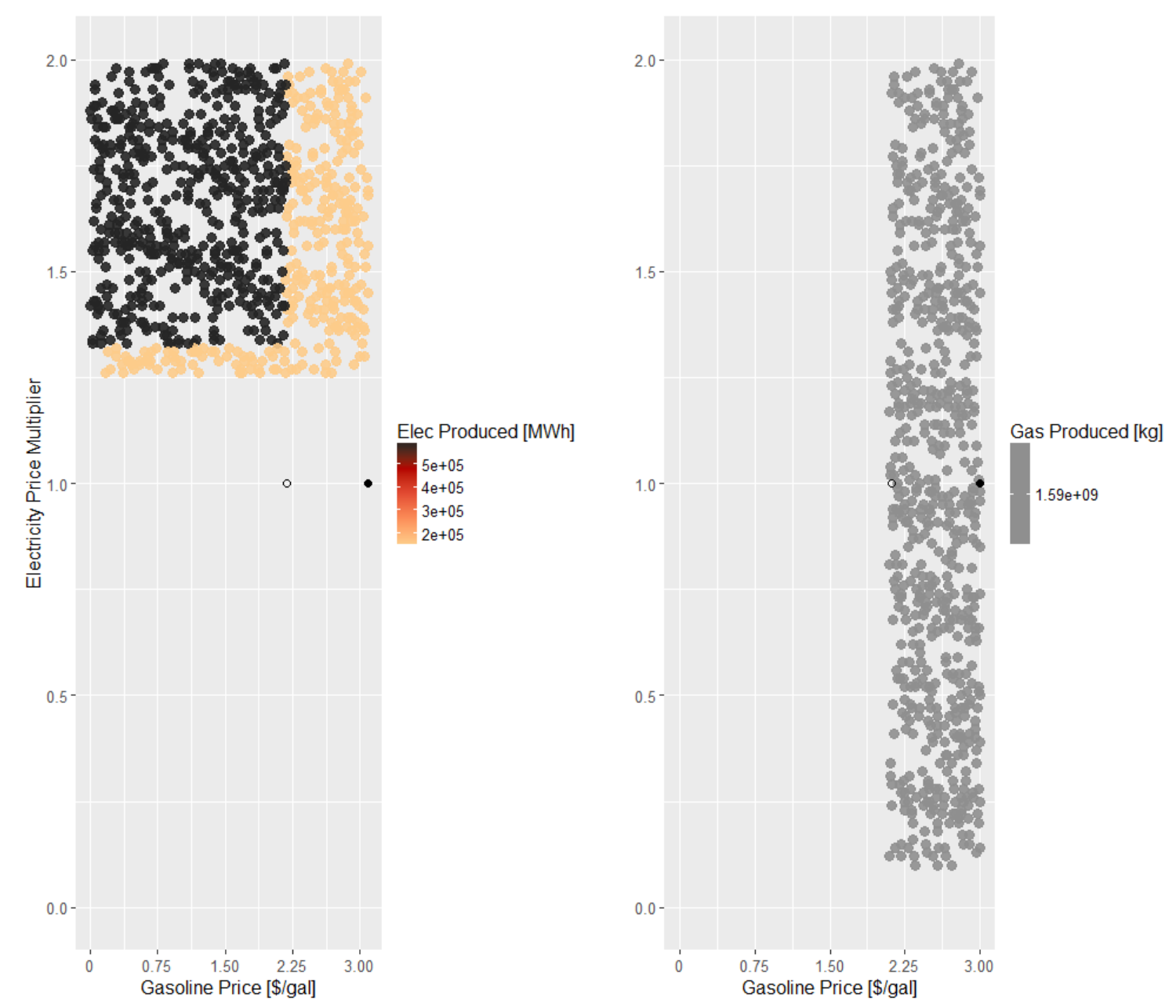

Figure G-3. Optimal annual product generation at various gasoline prices and electricity price multipliers for the Texas-synthetic gasoline scenario based on RPS80 generation mix, AEO reference-case prices, and $\$ 50 / \mathrm{kW}$-yr capacity payments.

Electricity is shown on the left with greater generation at the darker color.

Synthetic gasoline is shown on the right.

Solid black dot at electricity price multiplier of 1.0 and $\$ 3.00 /$ gal gasoline price: reference case gasoline price projection; reference-case electricity price vector

Open black dot: minimum gasoline selling price for a synthetic gasoline plant using natural gas heating; reference-case electricity price vector 


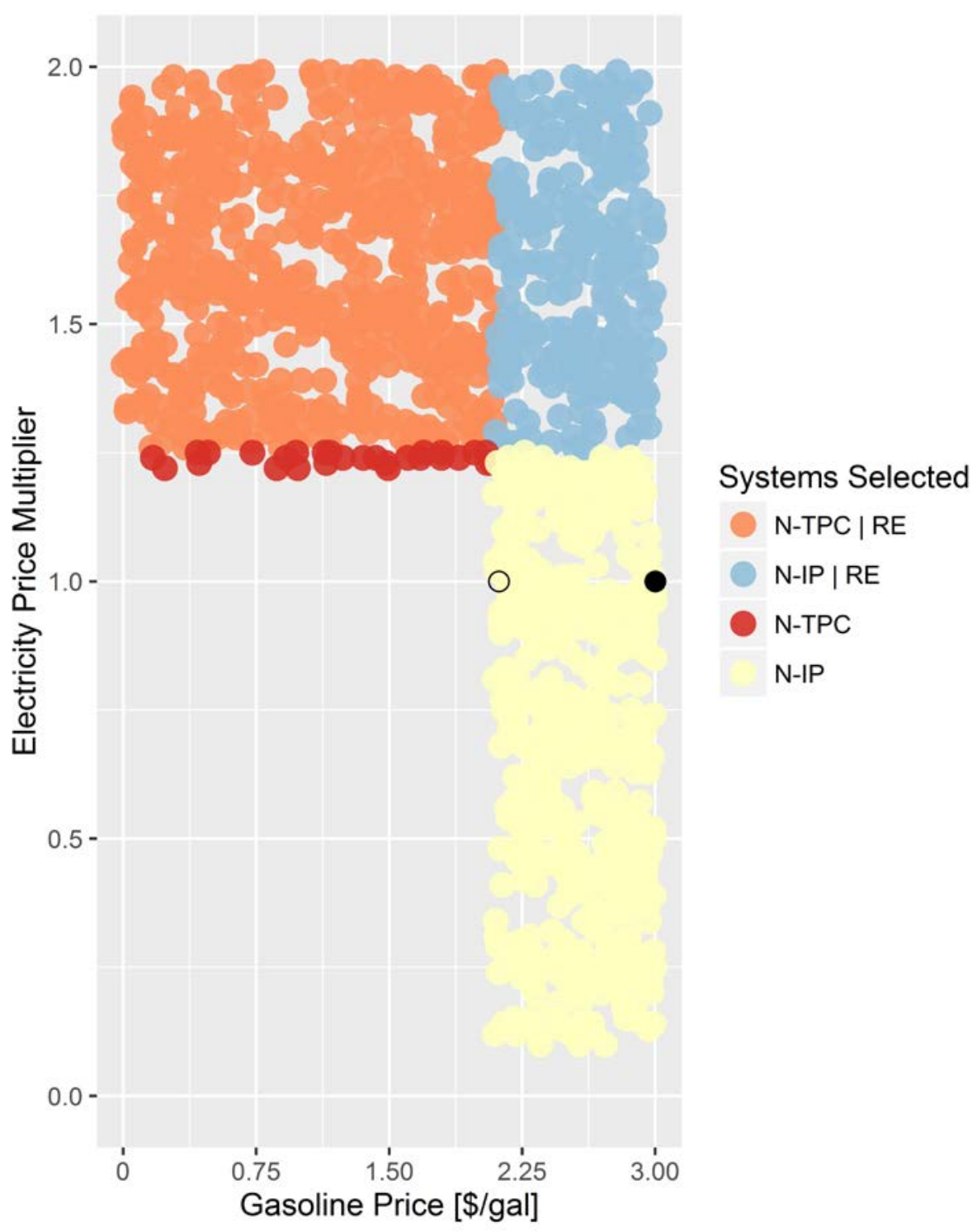

Figure G-4. Optimal configurations for the Texas-synthetic gasoline scenario at various gasoline prices and electricity price multipliers based on RPS80 generation mix, AEO reference-case prices, and $\$ 100 / \mathrm{kW}$-yr capacity payments

N-TPC: Nuclear reactor and thermal

N-IP: Nuclear reactor and industrial process

$\mathrm{RE}$ : Renewable electricity generation

Solid black dot at electricity price multiplier of 1.0 and $\$ 3.00 /$ gal gasoline price: reference case gasoline price projection; reference-case electricity price vector

Open black dot: minimum gasoline selling price for a synthetic gasoline plant using natural gas heating; reference-case electricity price vector 


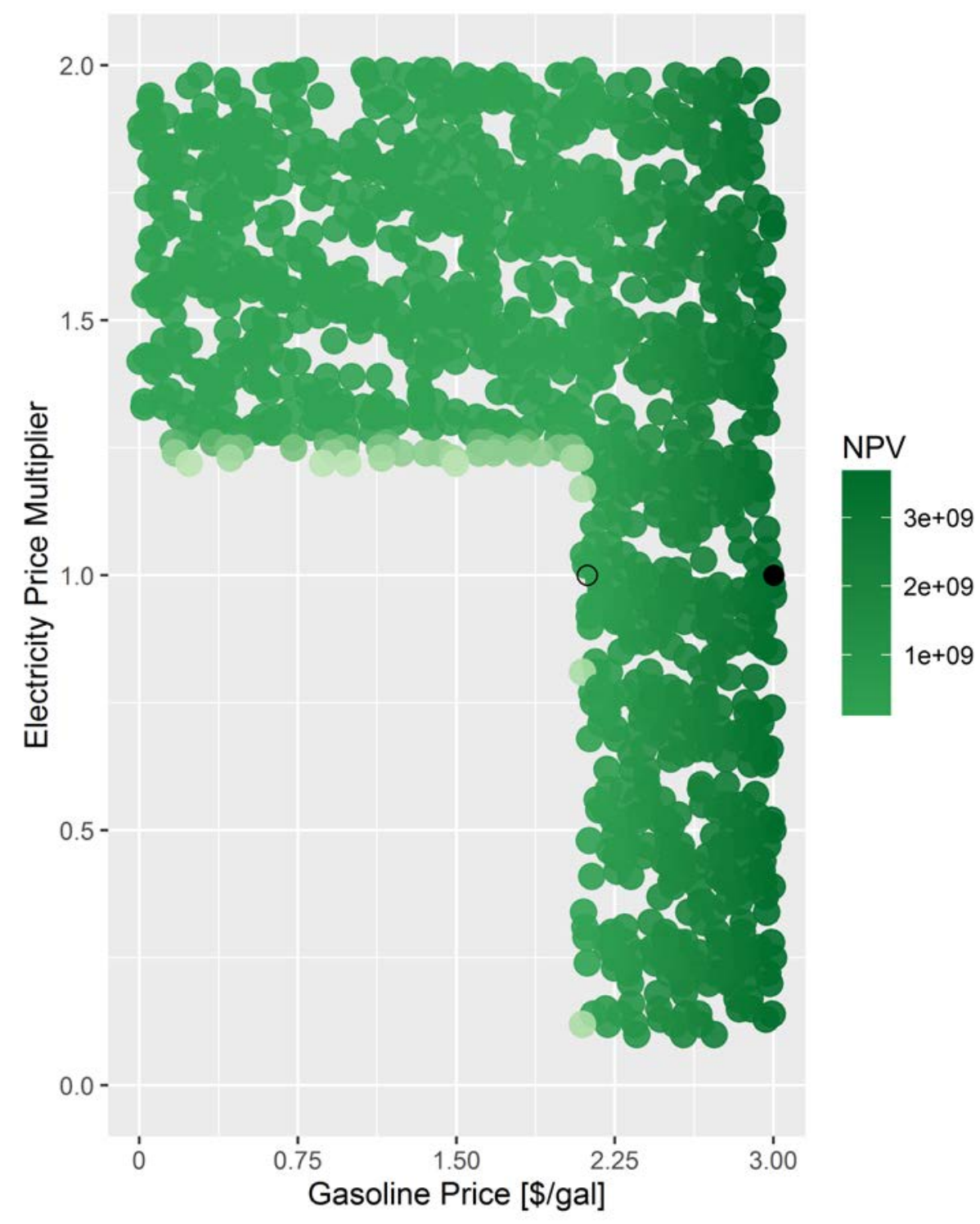

Figure G-5. Texas-synthetic gasoline scenario NPVs at various gasoline prices and electricity price multipliers based on RPS80 generation mix, AEO reference-case prices, and $\$ 100 / \mathrm{kW}$-yr capacity payments.

Darker shades indicate higher NPVs.

Solid black dot at electricity price multiplier of 1.0 and $\$ 3.00 /$ gal gasoline price: reference case gasoline price projection; reference-case electricity price vector

Open black dot: minimum gasoline selling price for a synthetic gasoline plant using natural gas heating; reference-case electricity price vector 

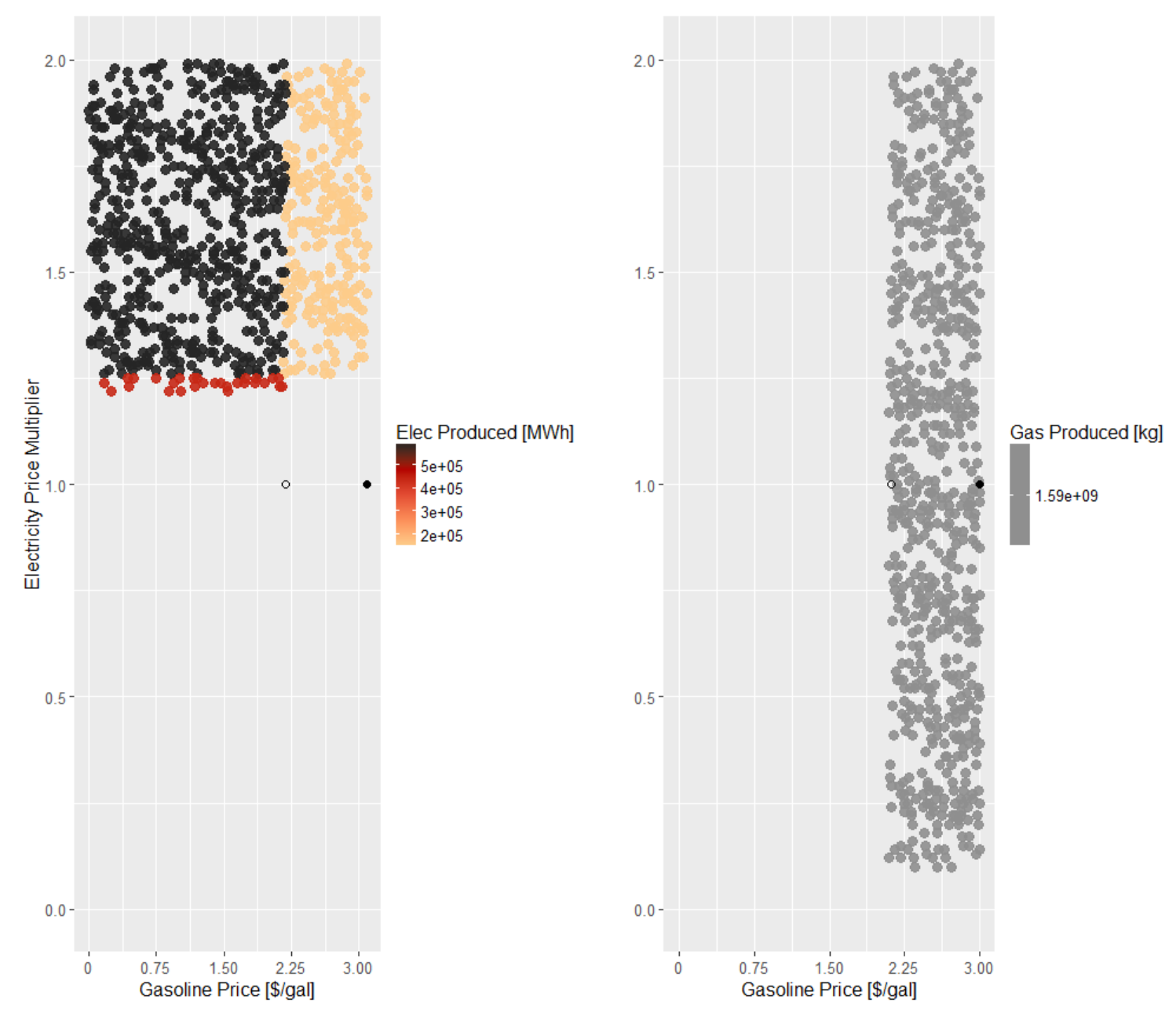

Figure G-6. Optimal annual product generation at various gasoline prices and electricity price multipliers for the Texas-synthetic gasoline scenario based on RPS80 generation mix, AEO reference-case prices, and $\$ 100 / \mathrm{kW}$-yr capacity payments.

Electricity is shown on the left with greater generation at the darker color.

Synthetic gasoline is shown on the right.

Solid black dot at electricity price multiplier of 1.0 and $\$ 3.00 /$ gal gasoline price: reference case gasoline price projection; reference-case electricity price vector

Open black dot: minimum gasoline selling price for a synthetic gasoline plant using natural gas heating; reference-case electricity price vector 


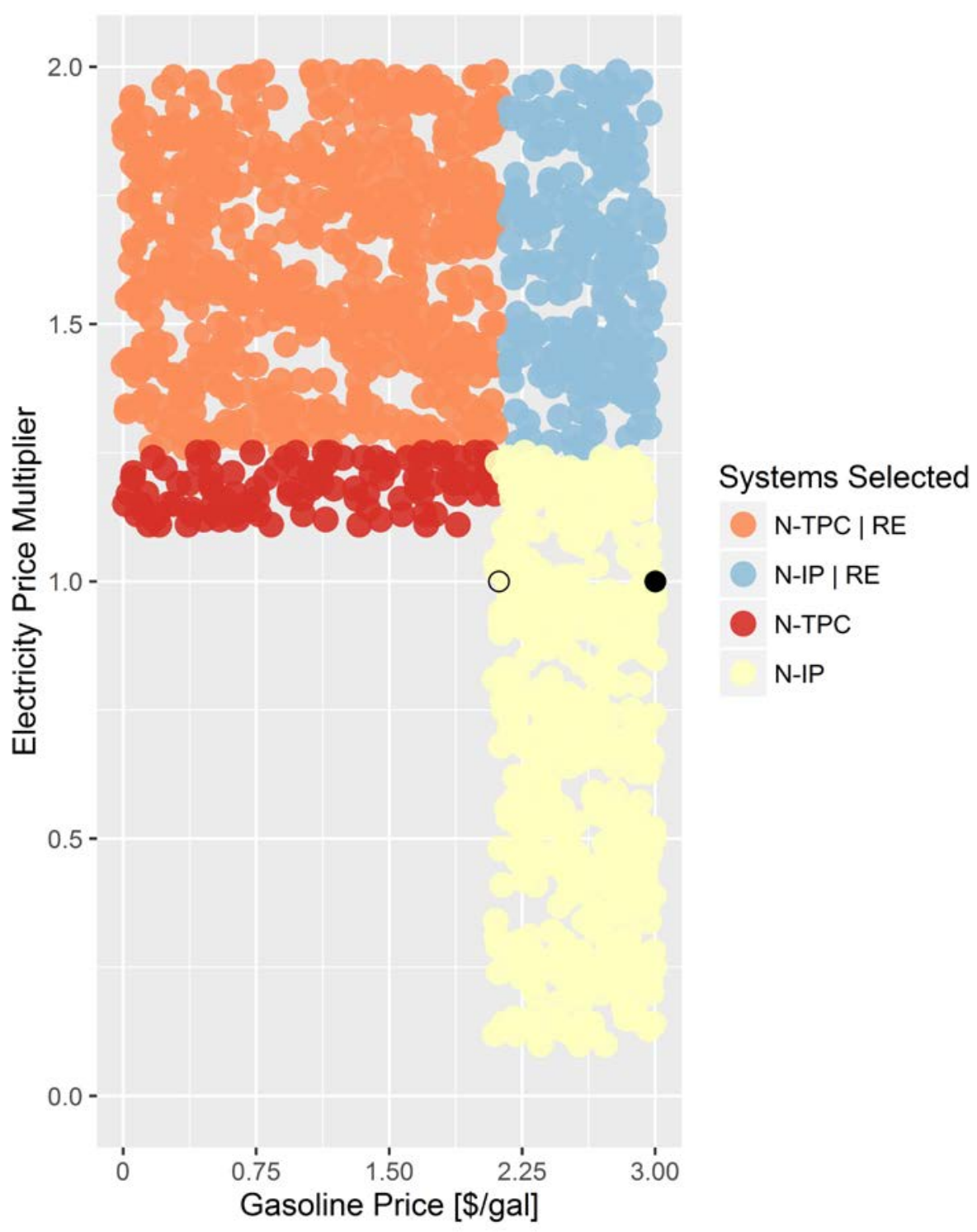

Figure G-7. Optimal configurations for the Texas-synthetic gasoline scenario at various gasoline prices and electricity price multipliers based on RPS80 generation mix, AEO reference-case prices, and $\$ 150 / \mathrm{kW}$-yr capacity payments

N-TPC: Nuclear reactor and thermal

N-IP: Nuclear reactor and industrial process

$\mathrm{RE}$ : Renewable electricity generation

Solid black dot at electricity price multiplier of 1.0 and $\$ 3.00 /$ gal gasoline price: reference case gasoline price projection; reference-case electricity price vector

Open black dot: minimum gasoline selling price for a synthetic gasoline plant using natural gas heating; reference-case electricity price vector 


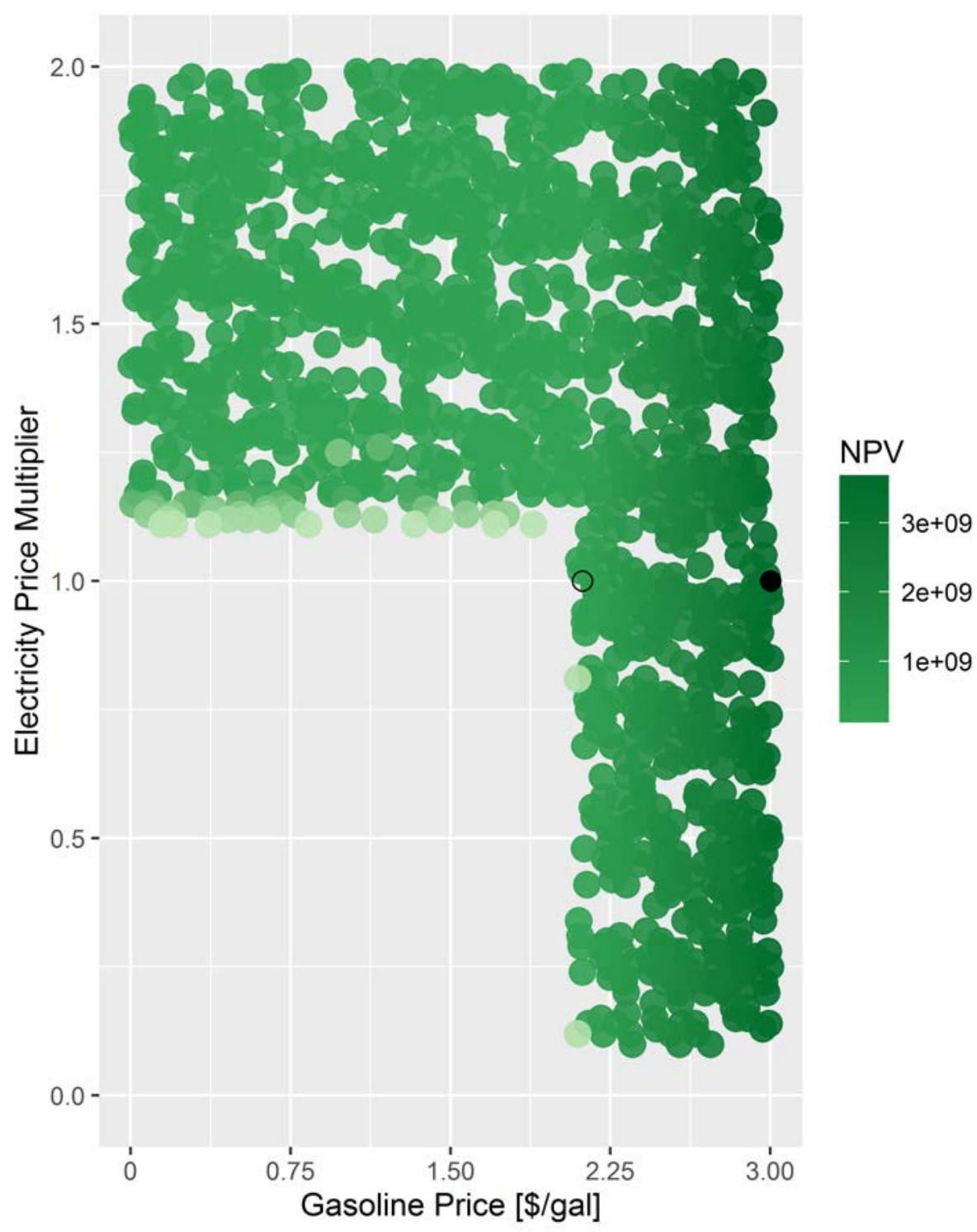

Figure G-8. Texas-synthetic gasoline scenario NPVs at various gasoline prices and electricity price multipliers based on RPS80 generation mix, AEO reference-case prices, and $\$ 150 / \mathrm{kW}$-yr capacity payments.

Darker shades indicate higher NPVs.

Solid black dot at electricity price multiplier of 1.0 and $\$ 3.00 /$ gal gasoline price: reference case gasoline price projection; reference-case electricity price vector

Open black dot: minimum gasoline selling price for a synthetic gasoline plant using natural gas heating; reference-case electricity price vector 

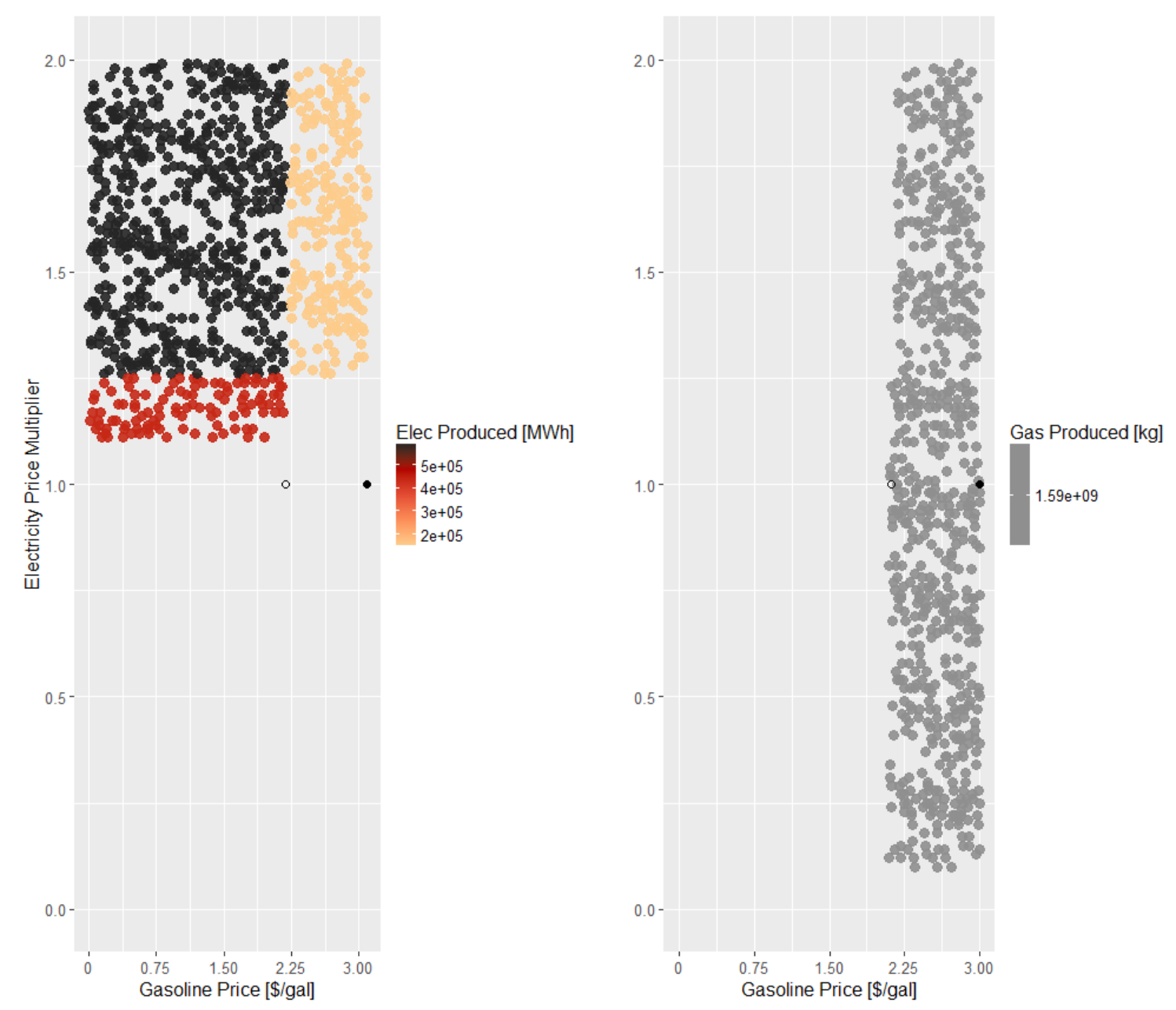

Figure G-9. Optimal annual product generation at various gasoline prices and electricity price multipliers for the Texas-synthetic gasoline scenario based on RPS80 generation mix, AEO reference-case prices, and $\$ 150 / \mathrm{kW}$-yr capacity payments.

Electricity is shown on the left with greater generation at the darker color.

Synthetic gasoline is shown on the right.

Solid black dot at electricity price multiplier of 1.0 and $\$ 3.00 /$ gal gasoline price: reference case gasoline price projection; reference-case electricity price vector

Open black dot: minimum gasoline selling price for a synthetic gasoline plant using natural gas heating; reference-case electricity price vector 


\section{G.2 Sensitivities on the Impacts of Gasoline Prices and Gasoline Production Efficiencies Based on the RPS80 Generation Mix and Reference-Case Electricity Prices}

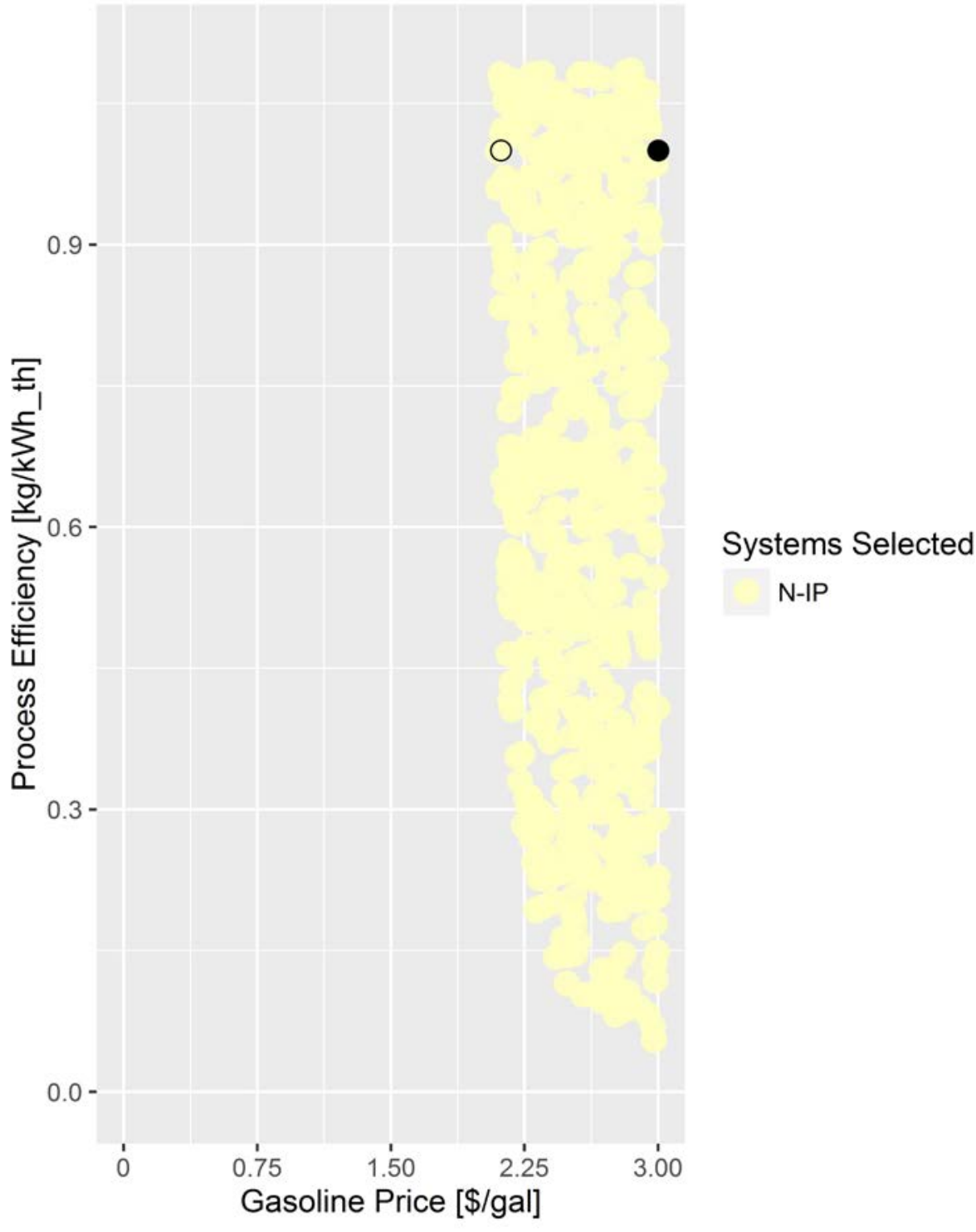

Figure G-10. Optimal configurations for the Texas-synthetic gasoline scenario at various gasoline prices and industrial process efficiencies based on RPS80 generation mix, AEO reference-case prices, and $\$ 50 / \mathrm{kW}$-yr capacity payments

N-TPC: Nuclear reactor and thermal

N-IP: Nuclear reactor and industrial process

$\mathrm{RE}$ : Renewable electricity generation

Solid black dot at electricity price multiplier of 1.0 and $\$ 3.00 /$ gal gasoline price: reference case gasoline price projection; reference-case electricity price vector

Open black dot: minimum gasoline selling price for a synthetic gasoline plant using natural gas heating; reference-case electricity price vector 


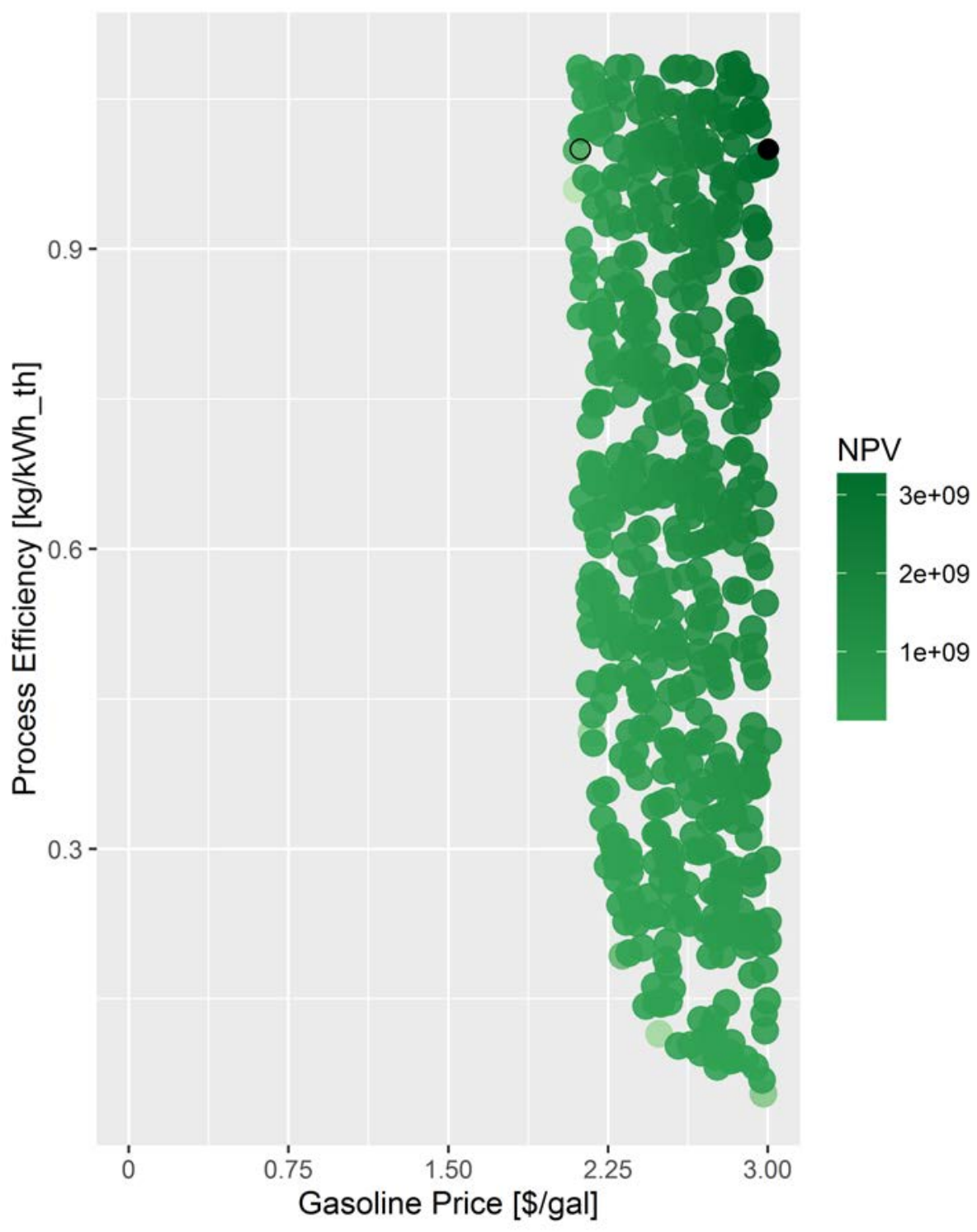

Figure G-11. Texas-synthetic gasoline scenario NPVs at various gasoline prices and industrial process efficiencies based on RPS80 generation mix, AEO reference-case prices, and \$50/kW-yr capacity payments.

Darker shades indicate higher NPVs.

Solid black dot at electricity price multiplier of 1.0 and $\$ 3.00 /$ gal gasoline price: reference case gasoline price projection; reference-case electricity price vector

Open black dot: minimum gasoline selling price for a synthetic gasoline plant using natural gas heating; reference-case electricity price vector 

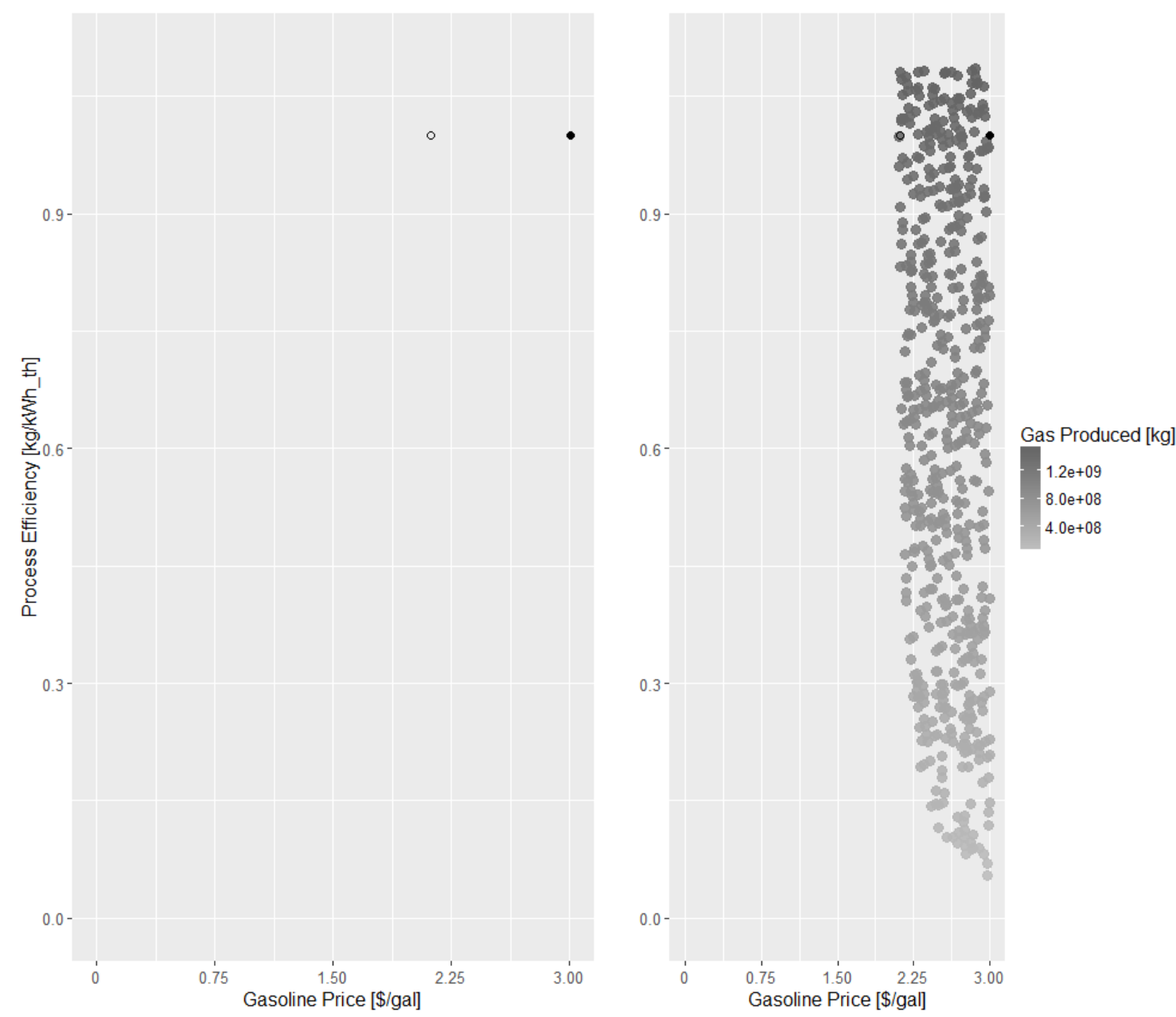

Figure G-12. Optimal annual product generation at various gasoline prices and industrial process efficiencies for the Texas-synthetic gasoline scenario based on RPS80 generation mix, AEO reference-case prices, and $\$ 50 / \mathrm{kW}$-yr capacity payments.

Electricity is shown on the left with greater generation at the darker color. Synthetic gasoline is shown on the right.

Solid black dot at electricity price multiplier of 1.0 and $\$ 3.00 /$ gal gasoline price: reference case gasoline price projection; reference-case electricity price vector

Open black dot: minimum gasoline selling price for a synthetic gasoline plant using natural gas heating; reference-case electricity price vector 


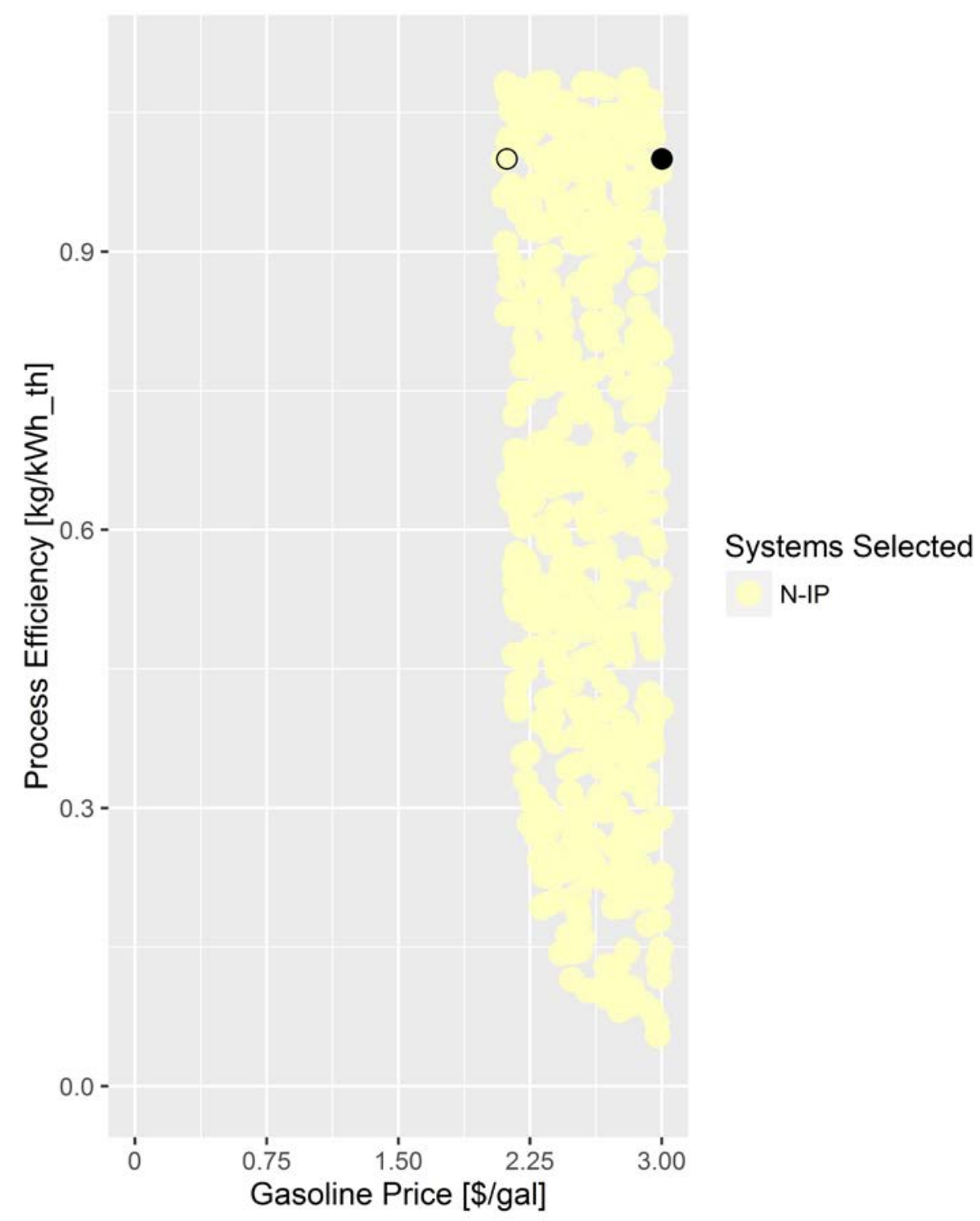

Figure G-13. Optimal configurations for the Texas-synthetic gasoline scenario at various gasoline prices and industrial process efficiencies based on RPS80 generation mix, AEO reference-case prices, and $\$ 100 / \mathrm{kW}$-yr capacity payments

N-TPC: Nuclear reactor and thermal

$\mathrm{N}-\mathrm{IP}$ : Nuclear reactor and industrial process

RE: Renewable electricity generation

Solid black dot at electricity price multiplier of 1.0 and $\$ 3.00 /$ gal gasoline price: reference case gasoline price projection; reference-case electricity price vector

Open black dot: minimum gasoline selling price for a synthetic gasoline plant using natural gas heating; reference-case electricity price vector 


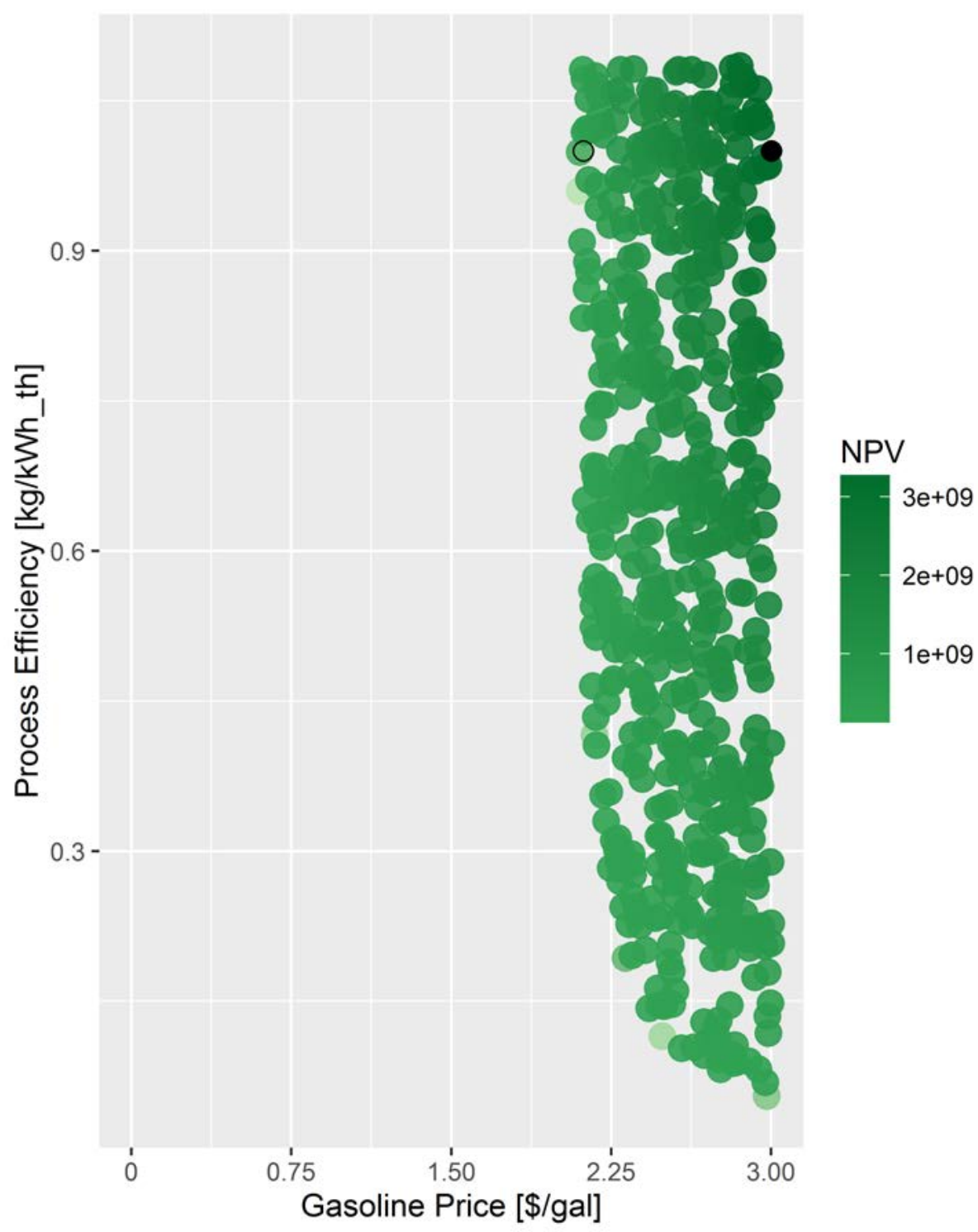

Figure G-14. Texas-synthetic gasoline scenario NPVs at various gasoline prices and industrial process efficiencies based on RPS80 generation mix, AEO reference-case prices, and $\$ 100 / \mathrm{kW}$-yr capacity payments.

Darker shades indicate higher NPVs.

Solid black dot at electricity price multiplier of 1.0 and $\$ 3.00 /$ gal gasoline price: reference case gasoline price projection; reference-case electricity price vector

Open black dot: minimum gasoline selling price for a synthetic gasoline plant using natural gas heating; reference-case electricity price vector 

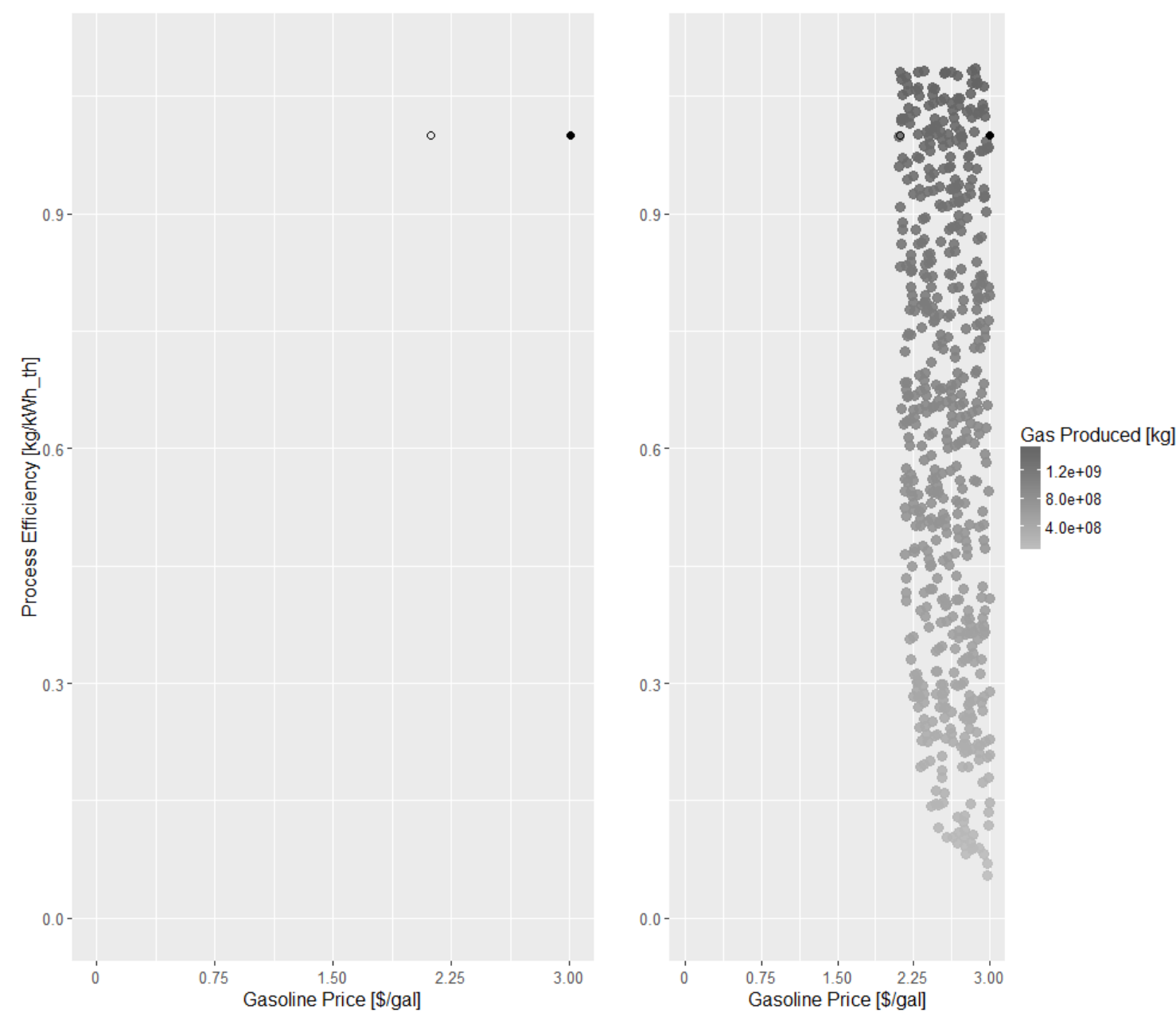

Figure G-15. Optimal annual product generation at various gasoline prices and industrial process efficiencies for the Texas-synthetic gasoline scenario based on RPS80 generation mix, AEO reference-case prices, and $\$ 100 / \mathbf{k W}$-yr capacity payments.

Electricity is shown on the left with greater generation at the darker color. Synthetic gasoline is shown on the right.

Solid black dot at electricity price multiplier of 1.0 and $\$ 3.00 /$ gal gasoline price: reference case gasoline price projection; reference-case electricity price vector

Open black dot: minimum gasoline selling price for a synthetic gasoline plant using natural gas heating; reference-case electricity price vector 


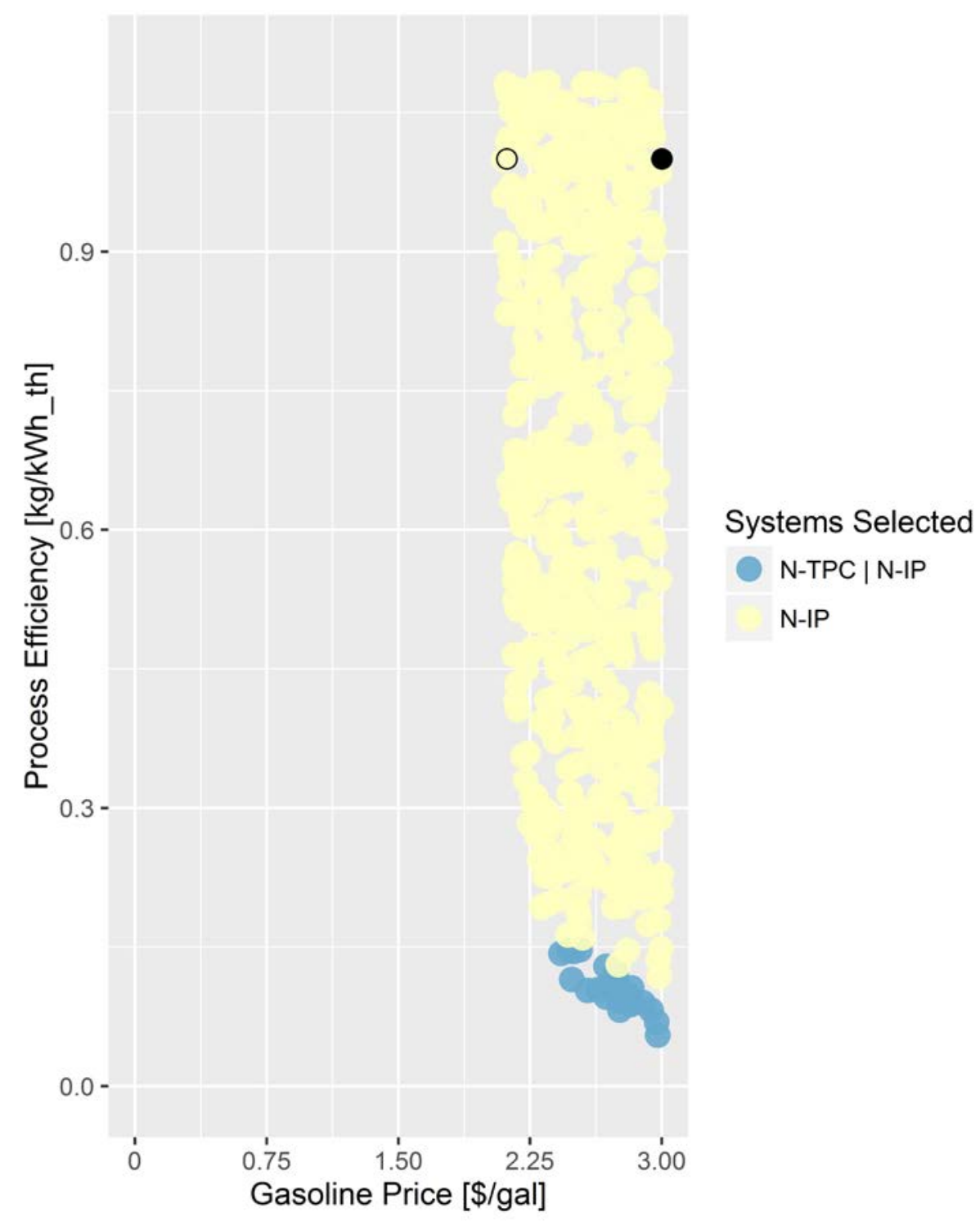

Figure G-16. Optimal configurations for the Texas-synthetic gasoline scenario at various gasoline prices and industrial process efficiencies based on RPS80 generation mix, AEO reference-case prices, and $\$ 150 / \mathrm{kW}$-yr capacity payments

N-TPC: Nuclear reactor and thermal

$\mathrm{N}-\mathrm{IP}$ : Nuclear reactor and industrial process

RE: Renewable electricity generation

Solid black dot at electricity price multiplier of 1.0 and $\$ 3.00 /$ gal gasoline price: reference case gasoline price projection; reference-case electricity price vector

Open black dot: minimum gasoline selling price for a synthetic gasoline plant using natural gas heating; reference-case electricity price vector 


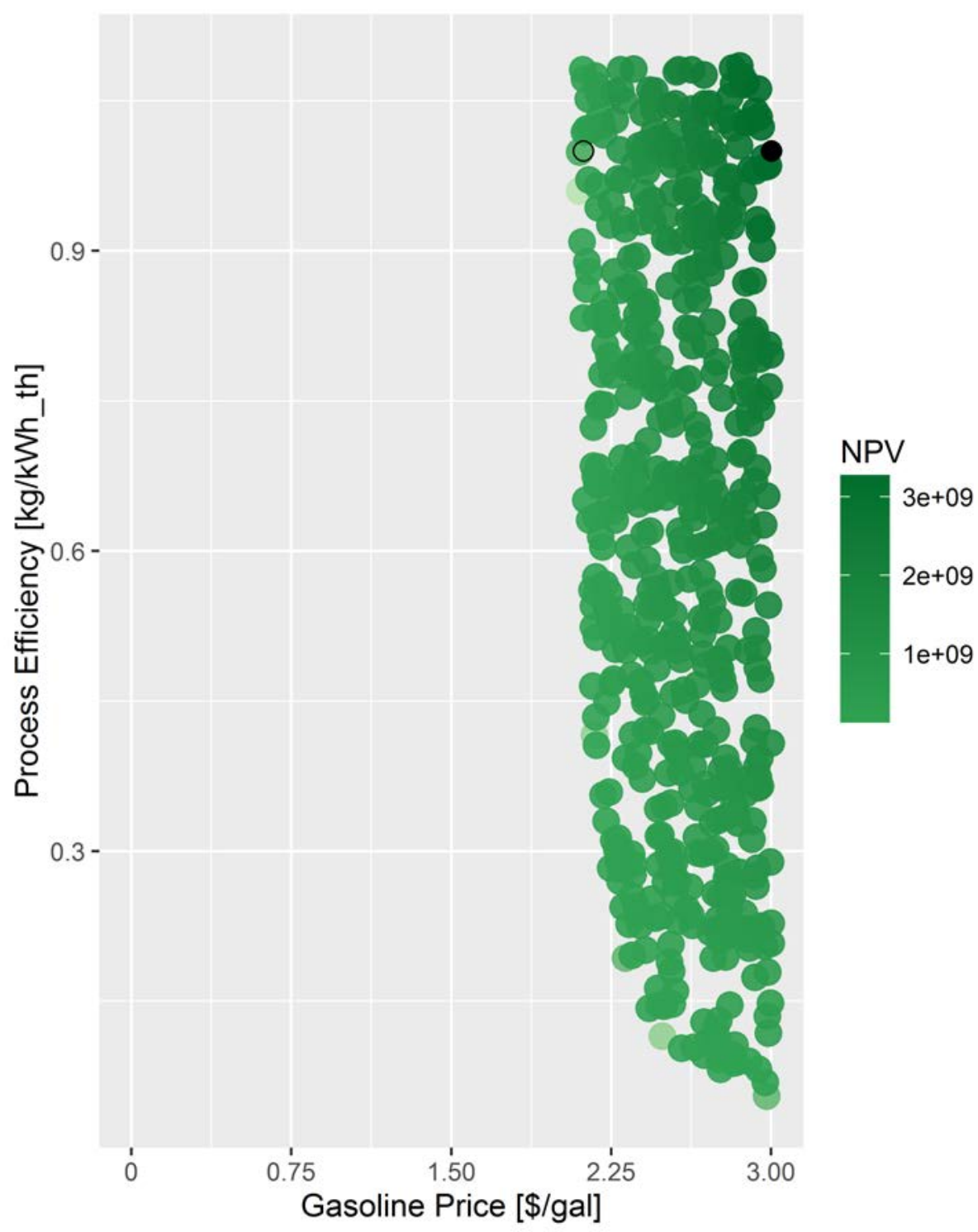

Figure G-17. Texas-synthetic gasoline scenario NPVs at various gasoline prices and industrial process efficiencies based on RPS80 generation mix, AEO reference-case prices, and \$150/kW-yr capacity payments.

Darker shades indicate higher NPVs.

Solid black dot at electricity price multiplier of 1.0 and $\$ 3.00 /$ gal gasoline price: reference case gasoline price projection; reference-case electricity price vector

Open black dot: minimum gasoline selling price for a synthetic gasoline plant using natural gas heating; reference-case electricity price vector 

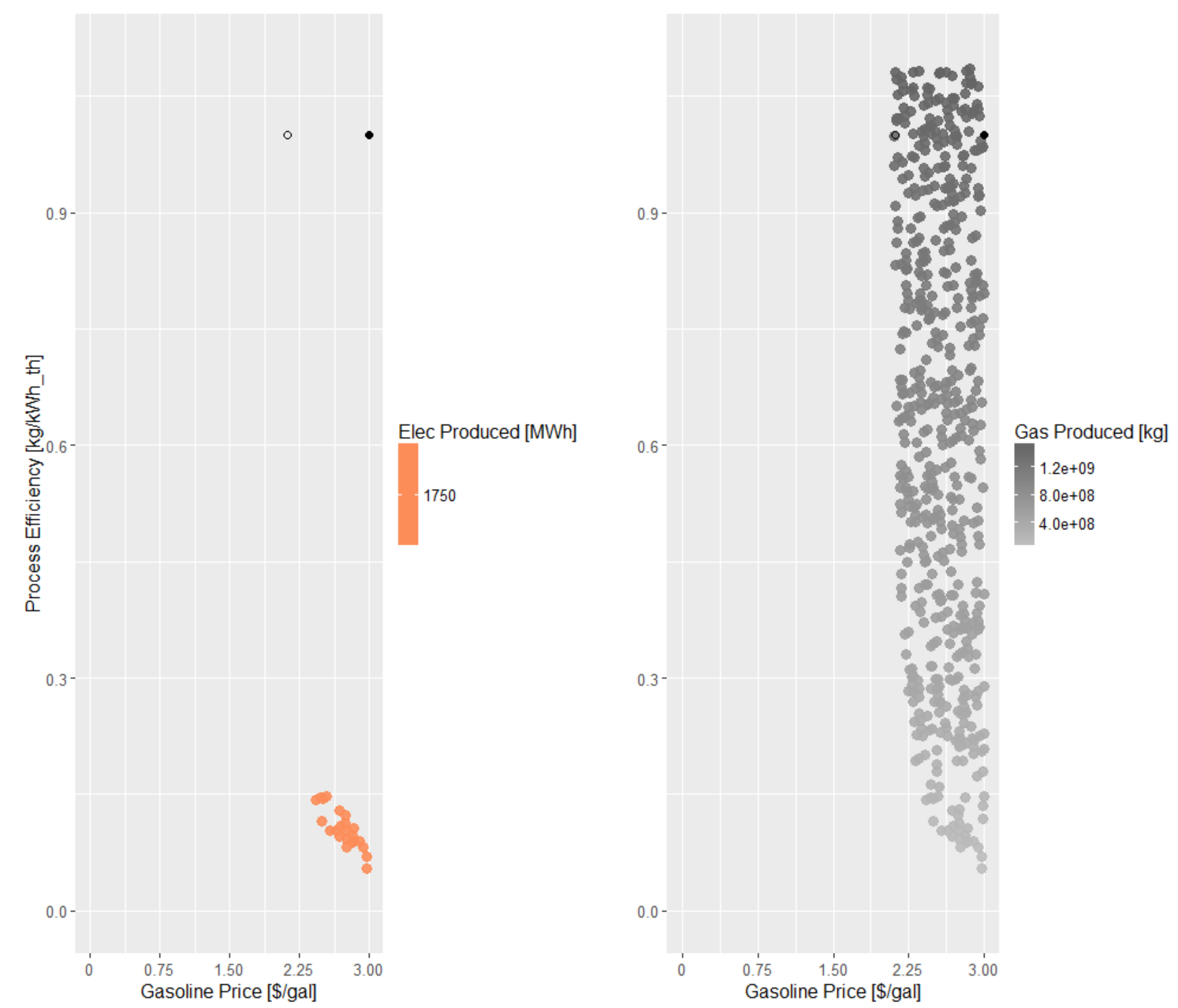

Figure G-18. Optimal annual product generation at various gasoline prices and industrial process efficiencies for the Texas-synthetic gasoline scenario based on RPS80 generation mix, AEO reference-case prices, and $\$ 150 / \mathbf{k W}$-yr capacity payments.

Electricity is shown on the left with greater generation at the darker color.

Synthetic gasoline is shown on the right.

Solid black dot at electricity price multiplier of 1.0 and $\$ 3.00 /$ gal gasoline price: reference case gasoline price projection; reference-case electricity price vector

Open black dot: minimum gasoline selling price for a synthetic gasoline plant using natural gas heating; reference-case electricity price vector 


\section{G.3 Sensitivities on the Impacts of Electricity and Gasoline Prices Based on Current Law Generation Capacities and Annual Energy Outlook Reference-Case Scenario}

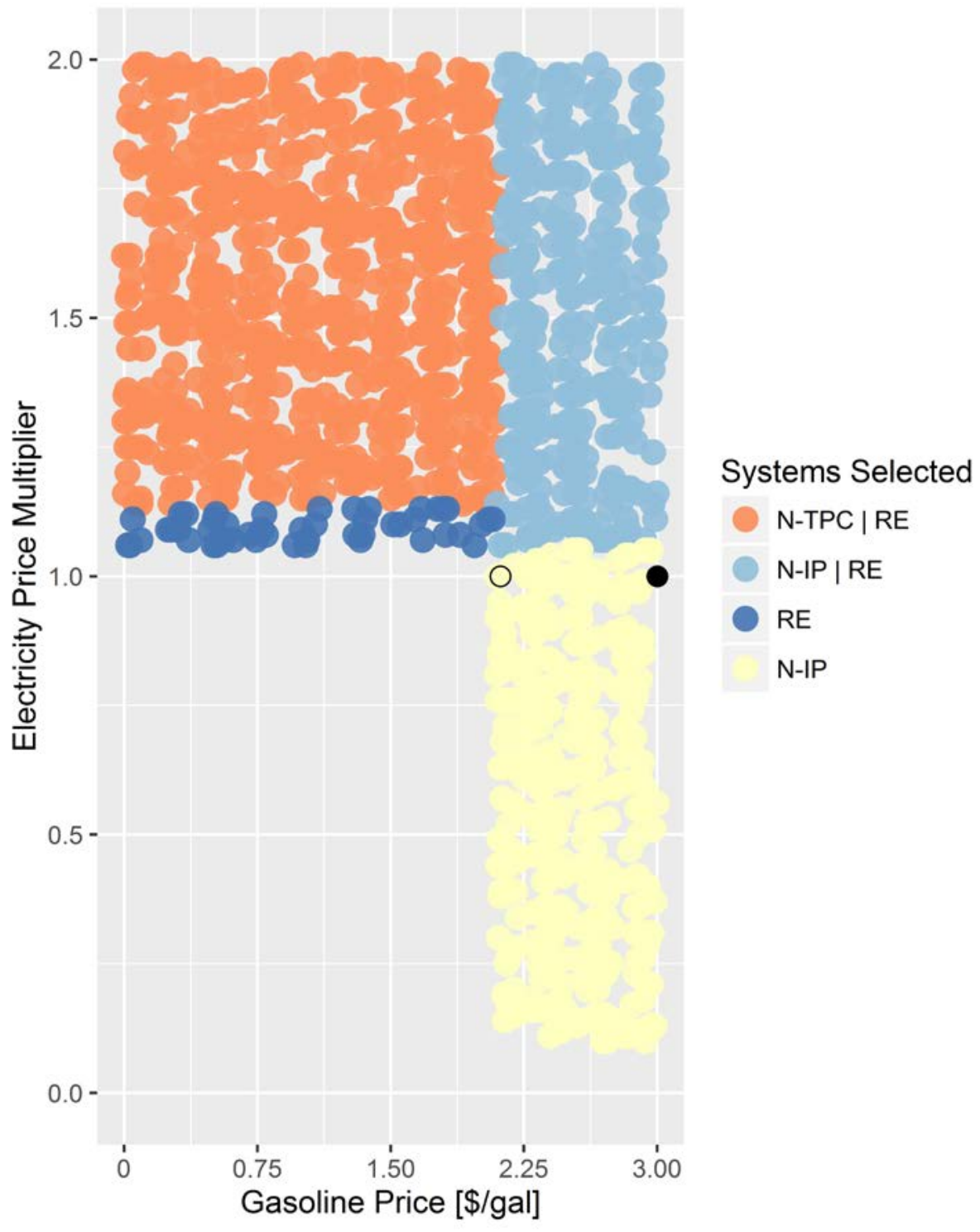

Figure G-19. Optimal configurations for the Texas-synthetic gasoline scenario at various gasoline prices and electricity price multipliers based on current law generation mix, AEO reference-case prices, and $\$ 50 / \mathrm{kW}$-yr capacity payments

N-TPC: Nuclear reactor and thermal

N-IP: Nuclear reactor and industrial process

$\mathrm{RE}$ : Renewable electricity generation

Solid black dot at electricity price multiplier of 1.0 and $\$ 3.00 /$ gal gasoline price: reference case gasoline price projection; reference-case electricity price vector

Open black dot: minimum gasoline selling price for a synthetic gasoline plant using natural gas heating; reference-case electricity price vector 


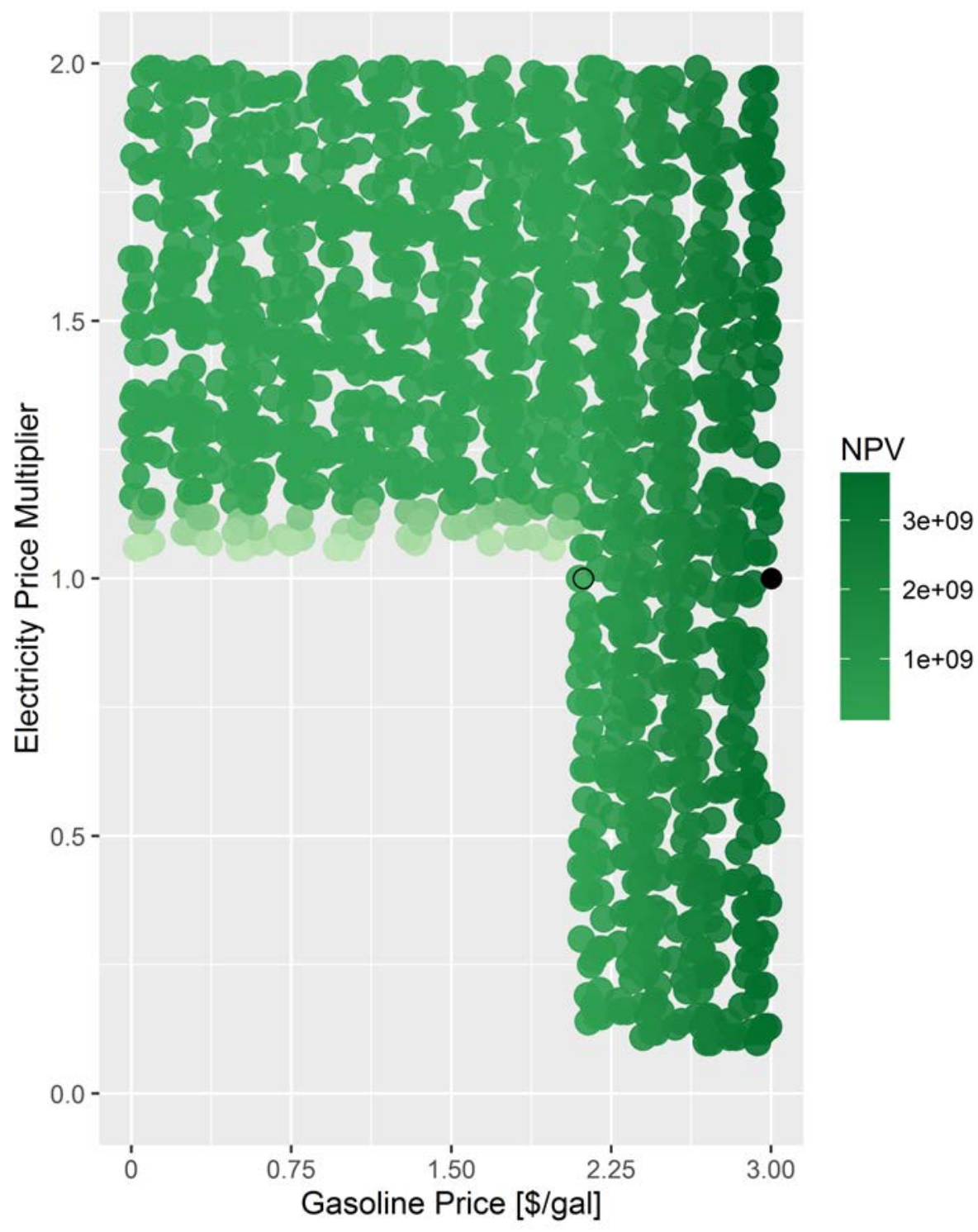

Figure G-20. Texas-synthetic gasoline scenario NPVs at various gasoline prices and electricity price multipliers based on current law generation mix, AEO reference-case prices, and $\$ 50 / \mathrm{kW}-\mathrm{yr}$ capacity payments.

Darker shades indicate higher NPVs.

Solid black dot at electricity price multiplier of 1.0 and $\$ 3.00 /$ gal gasoline price: reference case gasoline price projection; reference-case electricity price vector

Open black dot: minimum gasoline selling price for a synthetic gasoline plant using natural gas heating; reference-case electricity price vector 

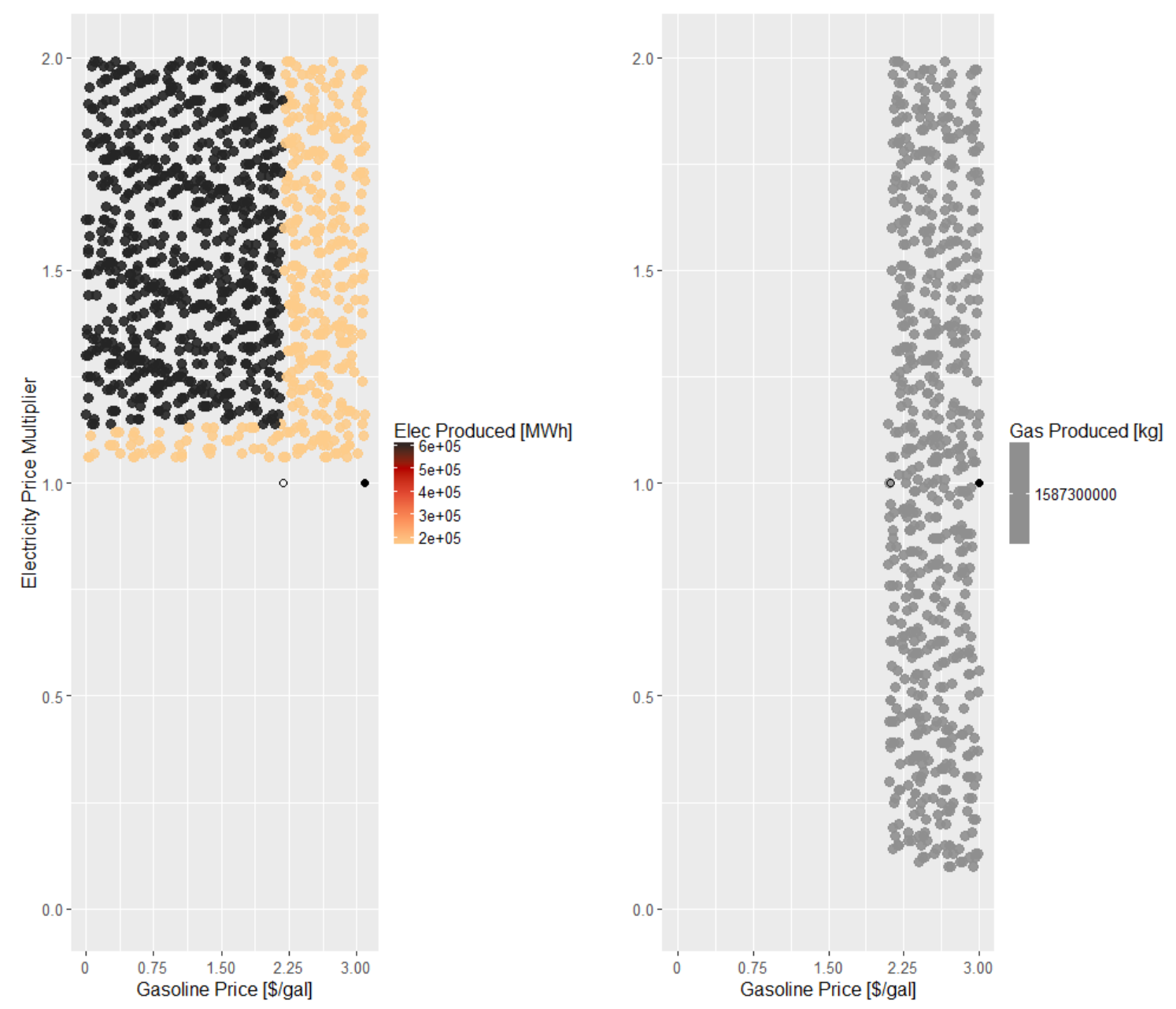

Figure G-21. Optimal annual product generation at various gasoline prices and electricity price multipliers for the Texas-synthetic gasoline scenario based on current law generation mix, AEO reference-case prices, and $\$ 50 / \mathrm{kW}$-yr capacity payments.

Electricity is shown on the left with greater generation at the darker color. Synthetic gasoline is shown on the right.

Solid black dot at electricity price multiplier of 1.0 and $\$ 3.00 /$ gal gasoline price: reference case gasoline price projection; reference-case electricity price vector

Open black dot: minimum gasoline selling price for a synthetic gasoline plant using natural gas heating; reference-case electricity price vector 


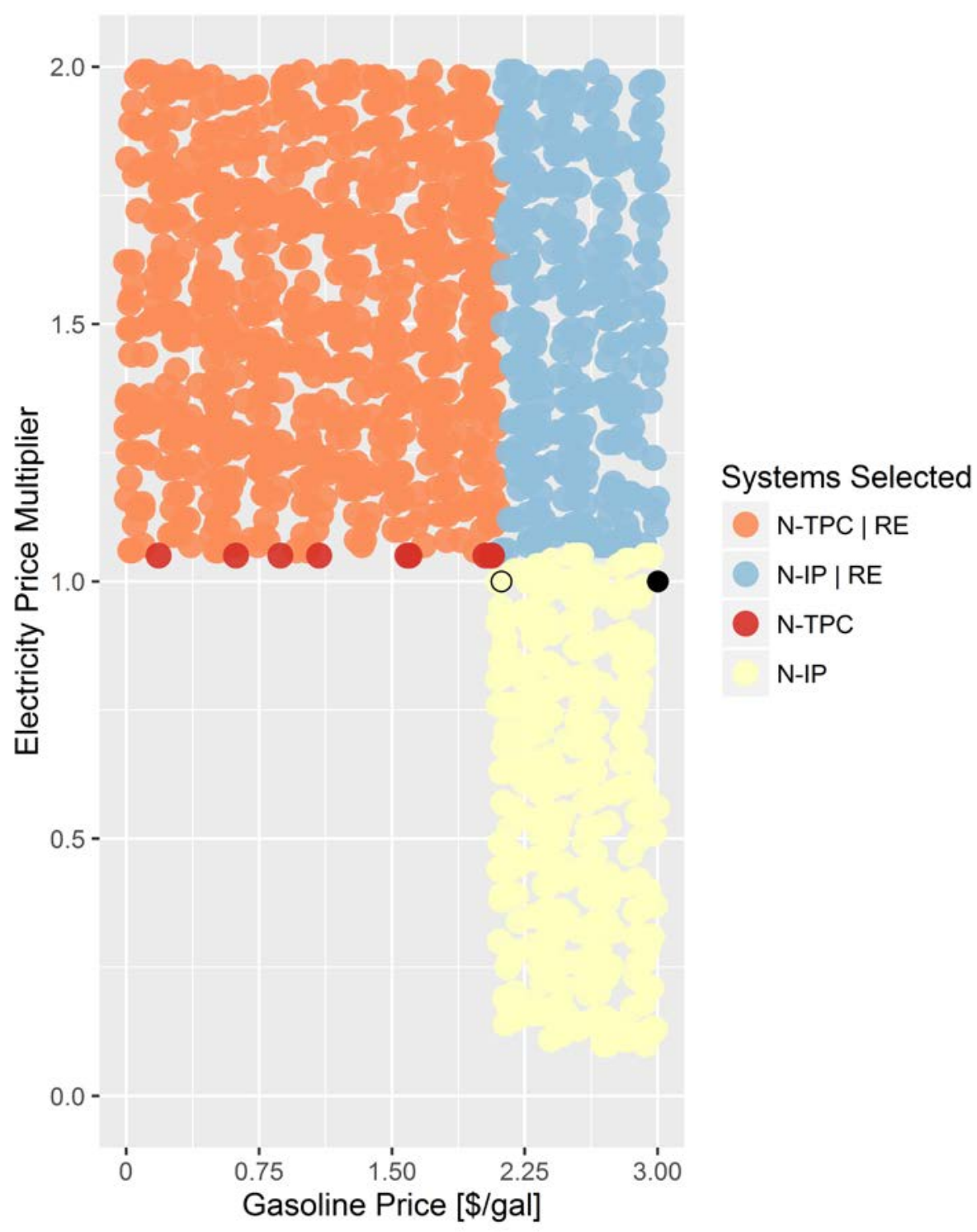

Figure G-22. Optimal configurations for the Texas-synthetic gasoline scenario at various gasoline prices and electricity price multipliers based on current law generation mix, AEO reference-case prices, and $\$ 100 / \mathrm{kW}$-yr capacity payments

N-TPC: Nuclear reactor and thermal

N-IP: Nuclear reactor and industrial process

$\mathrm{RE}$ : Renewable electricity generation

Solid black dot at electricity price multiplier of 1.0 and $\$ 3.00 /$ gal gasoline price: reference case gasoline price projection; reference-case electricity price vector

Open black dot: minimum gasoline selling price for a synthetic gasoline plant using natural gas heating; reference-case electricity price vector 


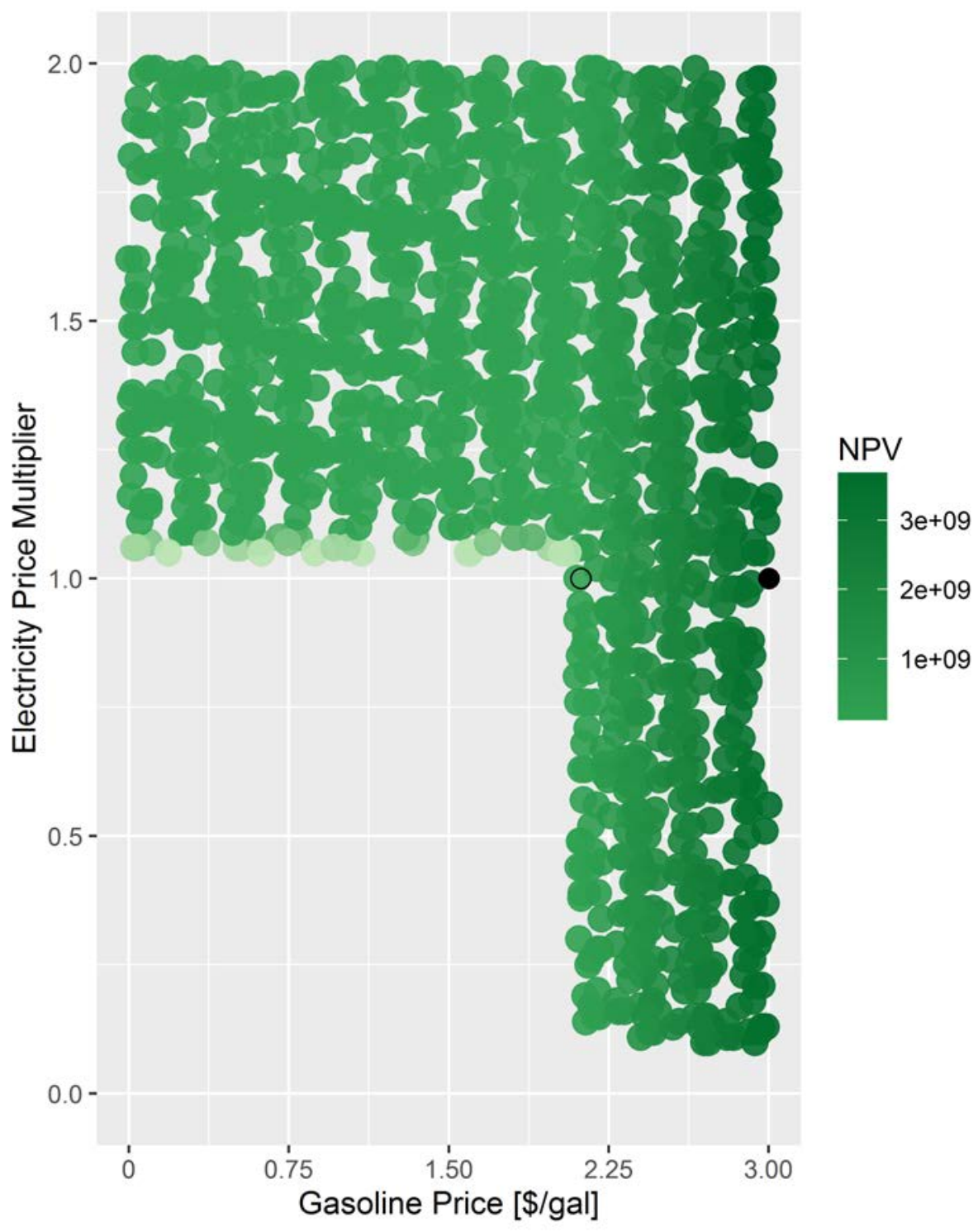

Figure G-23. Texas-synthetic gasoline scenario NPVs at various gasoline prices and electricity price multipliers based on current law generation mix, AEO reference-case prices, and $\$ 100 / \mathrm{kW}-\mathrm{yr}$ capacity payments.

Darker shades indicate higher NPVs.

Solid black dot at electricity price multiplier of 1.0 and $\$ 3.00 /$ gal gasoline price: reference case gasoline price projection; reference-case electricity price vector

Open black dot: minimum gasoline selling price for a synthetic gasoline plant using natural gas heating; reference-case electricity price vector 

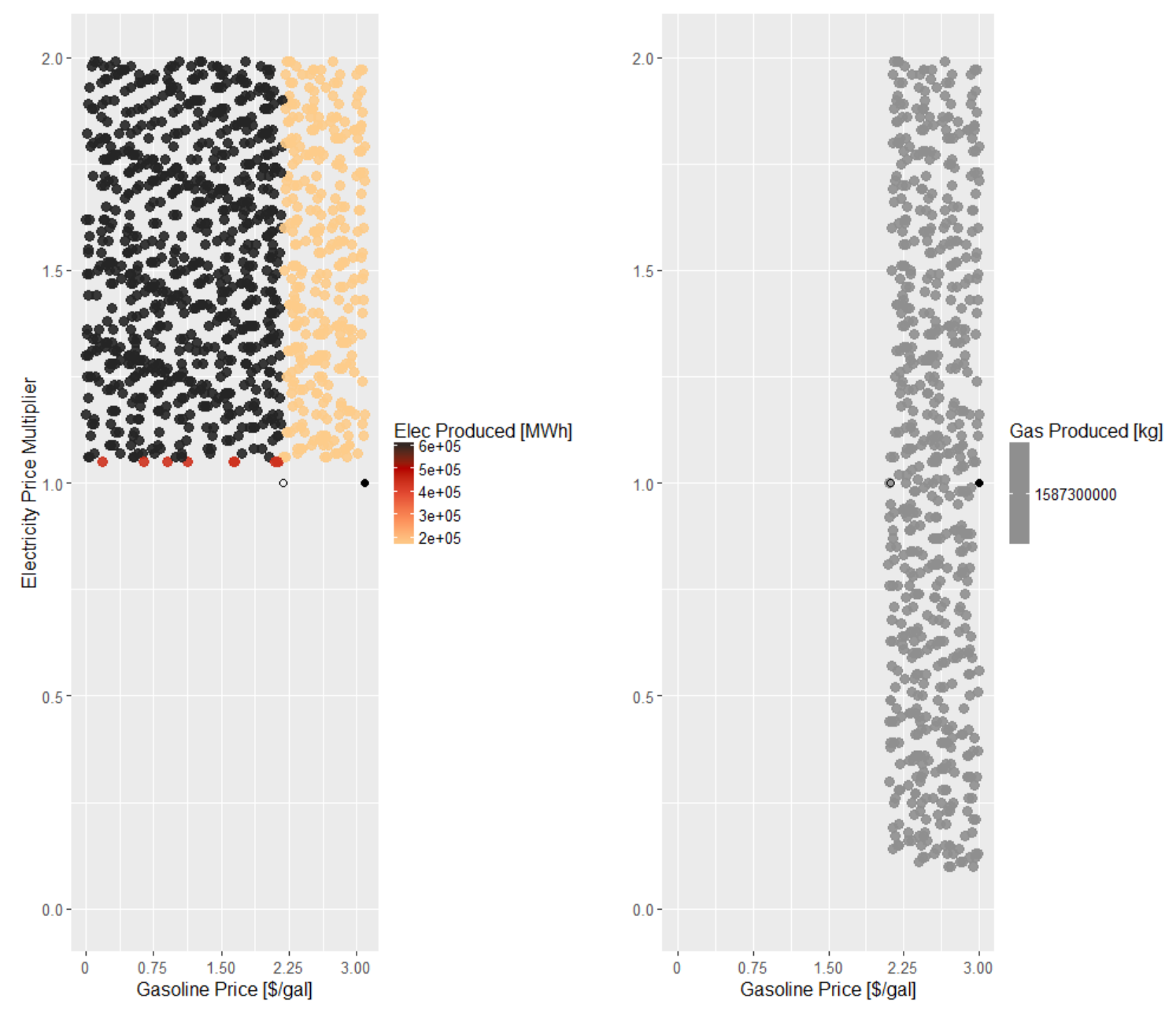

Figure G-24. Optimal annual product generation at various gasoline prices and electricity price multipliers for the Texas-synthetic gasoline scenario based on current law generation mix, AEO reference-case prices, and $\$ 100 / \mathrm{kW}$-yr capacity payments.

Electricity is shown on the left with greater generation at the darker color.

Synthetic gasoline is shown on the right.

Solid black dot at electricity price multiplier of 1.0 and $\$ 3.00 /$ gal gasoline price: reference case gasoline price projection; reference-case electricity price vector

Open black dot: minimum gasoline selling price for a synthetic gasoline plant using natural gas heating; reference-case electricity price vector 


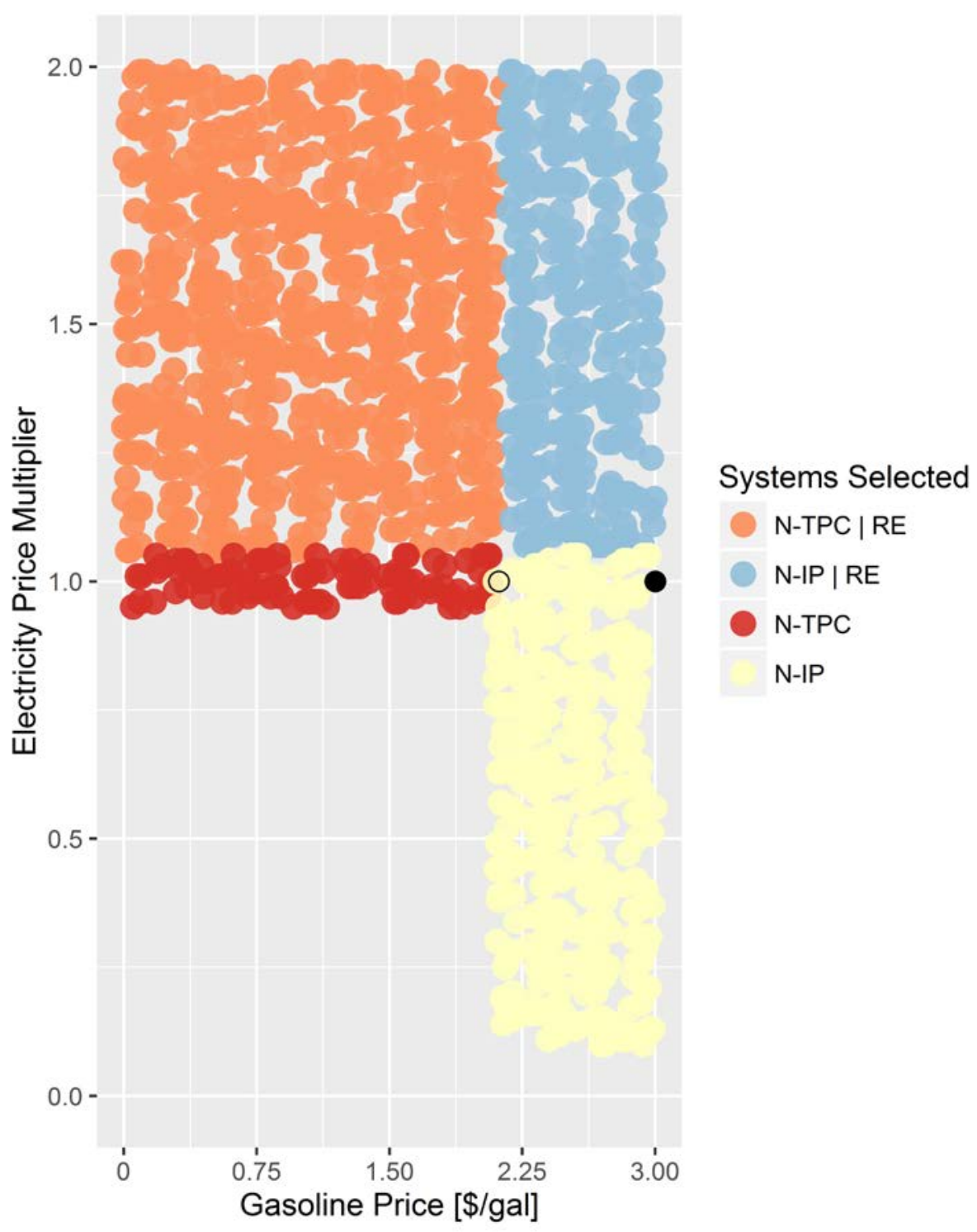

Figure G-25. Optimal configurations for the Texas-synthetic gasoline scenario at various gasoline prices and electricity price multipliers based on current law generation mix, AEO reference-case prices, and $\$ 150 / \mathrm{kW}$-yr capacity payments

N-TPC: Nuclear reactor and thermal

N-IP: Nuclear reactor and industrial process

$\mathrm{RE}$ : Renewable electricity generation

Solid black dot at electricity price multiplier of 1.0 and $\$ 3.00 /$ gal gasoline price: reference case gasoline price projection; reference-case electricity price vector

Open black dot: minimum gasoline selling price for a synthetic gasoline plant using natural gas heating; reference-case electricity price vector 


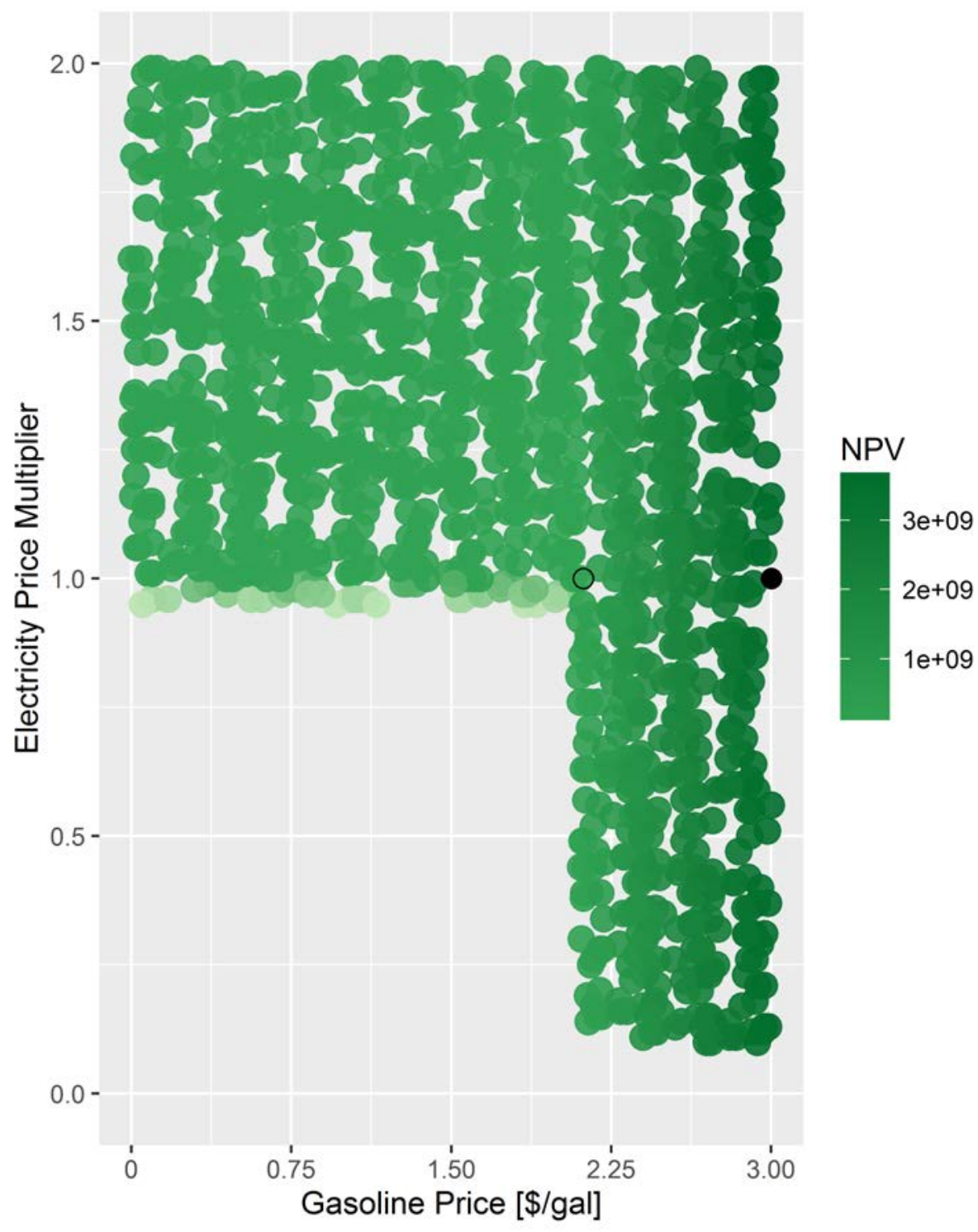

Figure G-26. Texas-synthetic gasoline scenario NPVs at various gasoline prices and electricity price multipliers based on current law generation mix, AEO reference-case prices, and $\$ 150 / \mathrm{kW}$-yr capacity payments.

Darker shades indicate higher NPVs.

Solid black dot at electricity price multiplier of 1.0 and $\$ 3.00 /$ gal gasoline price: reference case gasoline price projection; reference-case electricity price vector

Open black dot: minimum gasoline selling price for a synthetic gasoline plant using natural gas heating; reference-case electricity price vector 

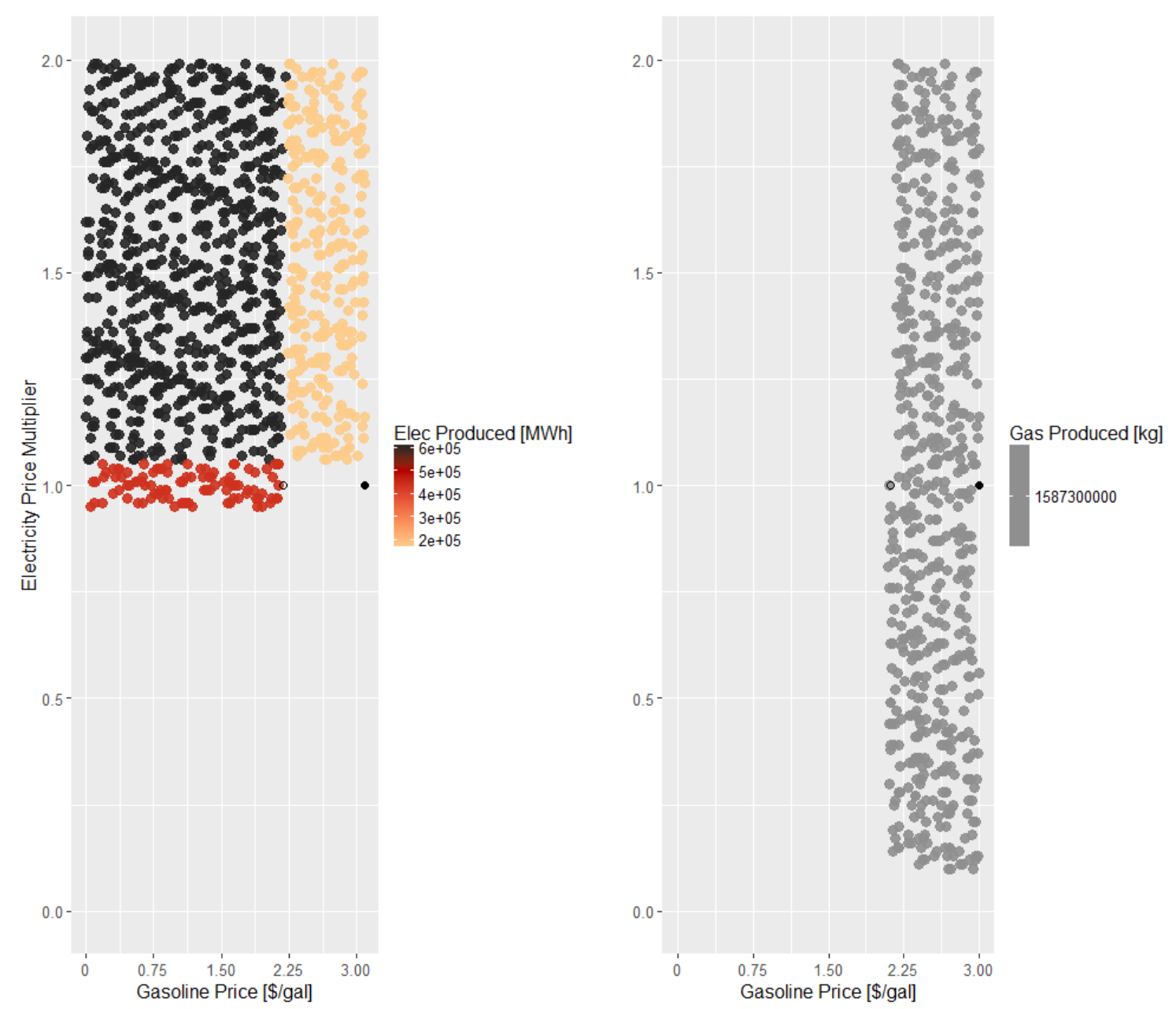

Figure G-27. Optimal annual product generation at various gasoline prices and electricity price multipliers for the Texas-synthetic gasoline scenario based on current law generation mix, AEO reference-case prices, and $\$ 150 / \mathbf{k W}$-yr capacity payments.

Electricity is shown on the left with greater generation at the darker color.

Synthetic gasoline is shown on the right.

Solid black dot at electricity price multiplier of 1.0 and $\$ 3.00 /$ gal gasoline price: reference case gasoline price projection; reference-case electricity price vector

Open black dot: minimum gasoline selling price for a synthetic gasoline plant using natural gas heating; reference-case electricity price vector 


\section{G.4 Sensitivities on the Impacts of Electricity and Gasoline Prices Based on Electricity Prices Using the RPS80 Generation Mix and the Annual Energy Outlook Low-Oil-Price Scenario}

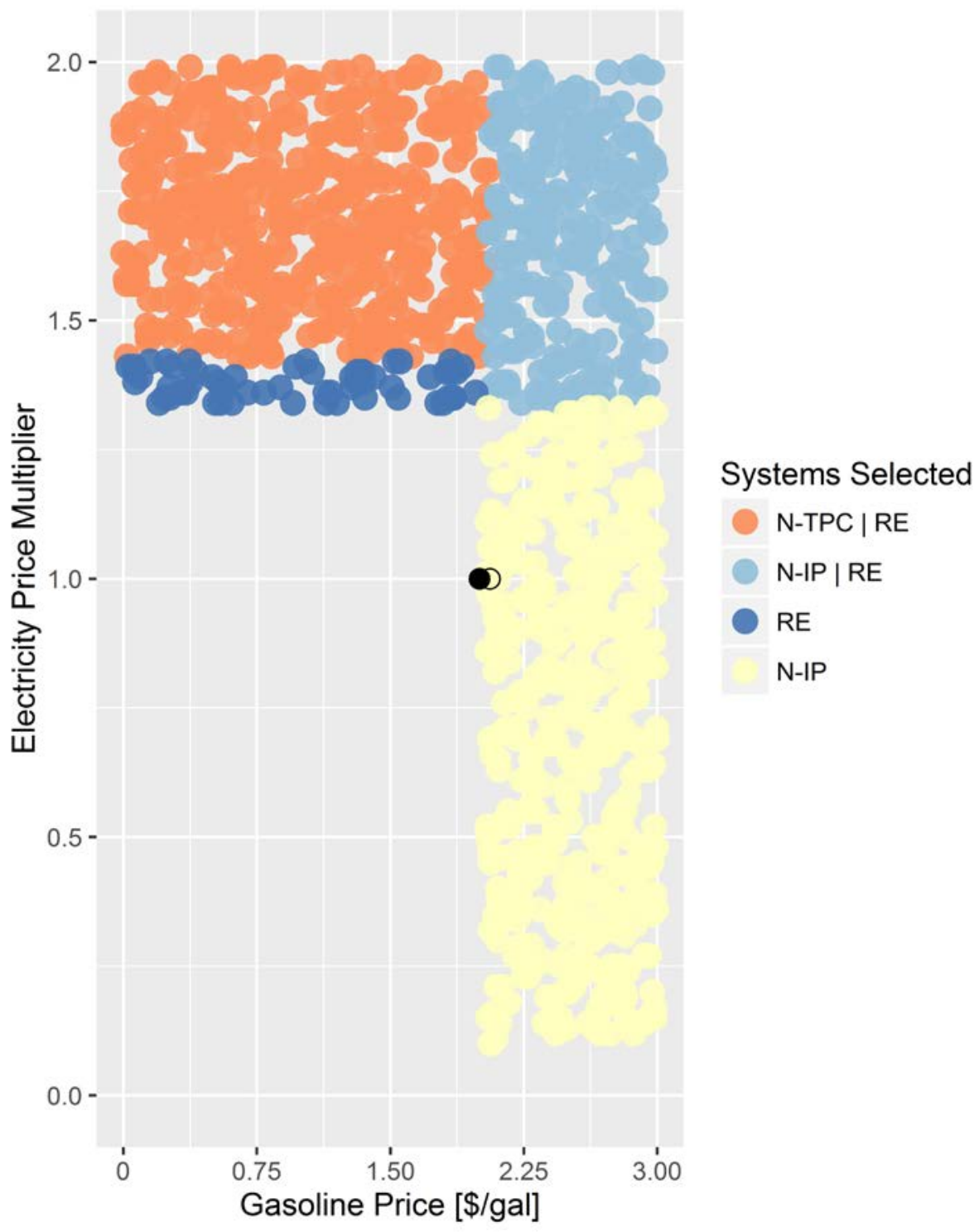

Figure G-28. Optimal configurations for the Texas-synthetic gasoline scenario at various gasoline prices and electricity price multipliers based on RPS80 generation mix, AEO low-oil-price case, and $\$ 50 / k W-y r$ capacity payments

N-TPC: Nuclear reactor and thermal

N-IP: Nuclear reactor and industrial process

$\mathrm{RE}$ : Renewable electricity generation

Solid black dot at electricity price multiplier of 1.0 and $\$ 3.00 /$ gal gasoline price: reference case gasoline price projection; reference-case electricity price vector

Open black dot: minimum gasoline selling price for a synthetic gasoline plant using natural gas heating; reference-case electricity price vector 


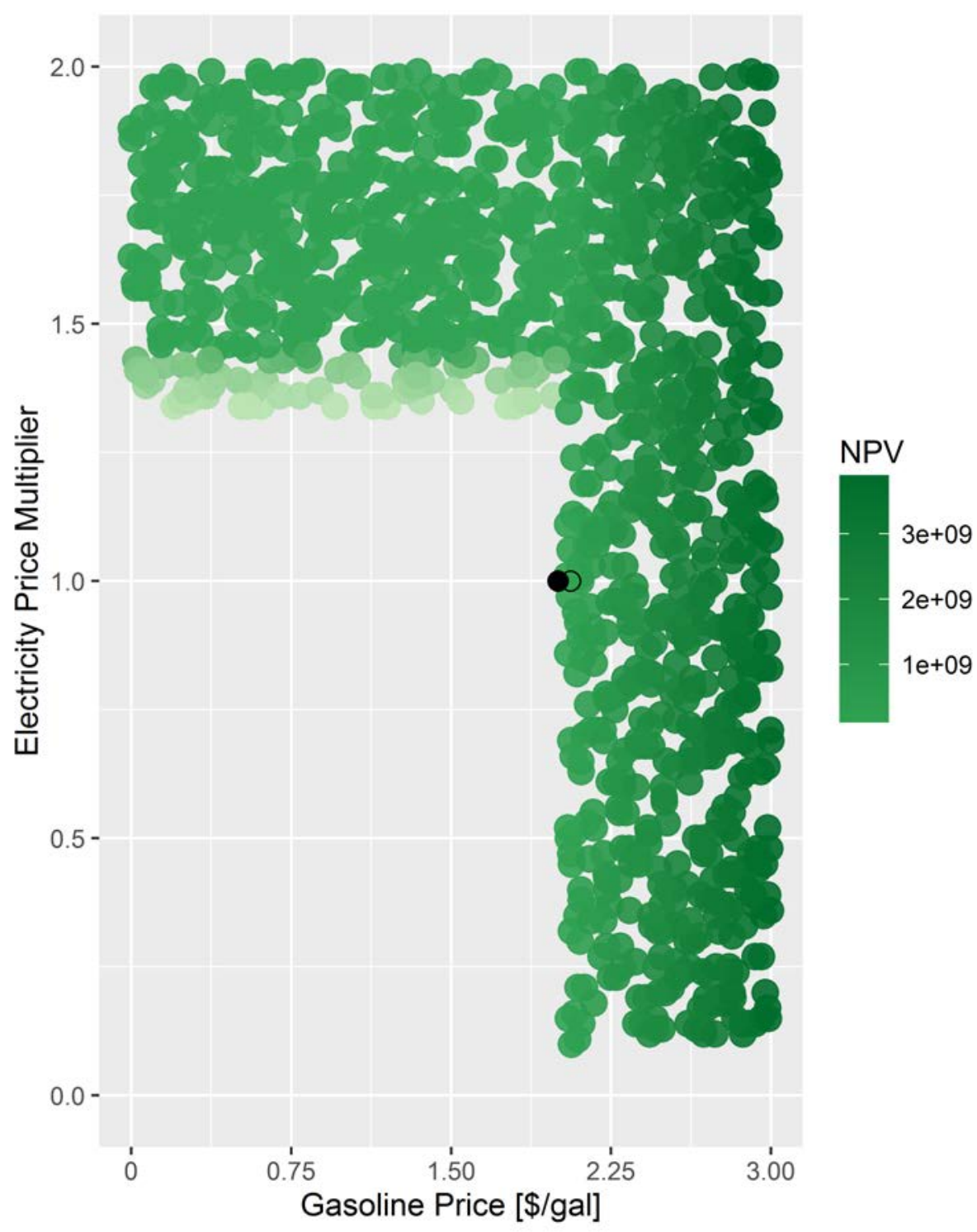

Figure G-29. Texas-synthetic gasoline scenario NPVs at various gasoline prices and electricity price multipliers based on RPS80 generation mix, AEO low-oil-price case, and \$50/kW-yr capacity payments.

Darker shades indicate higher NPVs.

Solid black dot at electricity price multiplier of 1.0 and $\$ 3.00 /$ gal gasoline price: reference case gasoline price projection; reference-case electricity price vector

Open black dot: minimum gasoline selling price for a synthetic gasoline plant using natural gas heating; reference-case electricity price vector 

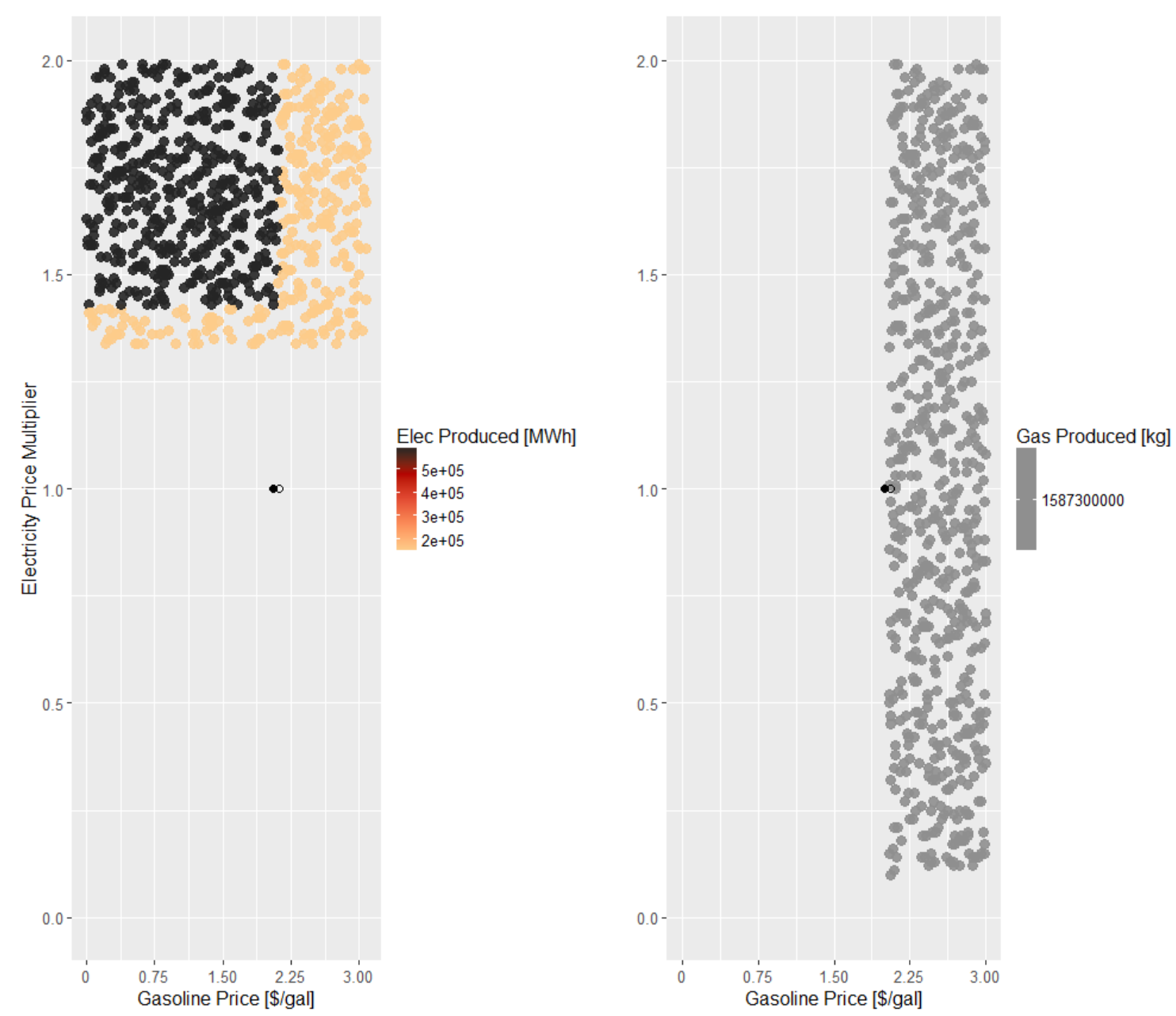

Figure G-30. Optimal annual product generation at various gasoline prices and electricity price multipliers for the Texas-synthetic gasoline scenario based on RPS80 generation mix, AEO lowoil-price case, and $\$ 50 / \mathbf{k W}$-yr capacity payments.

Electricity is shown on the left with greater generation at the darker color.

Synthetic gasoline is shown on the right.

Solid black dot at electricity price multiplier of 1.0 and $\$ 3.00 /$ gal gasoline price: reference case gasoline price projection; reference-case electricity price vector

Open black dot: minimum gasoline selling price for a synthetic gasoline plant using natural gas heating; reference-case electricity price vector 


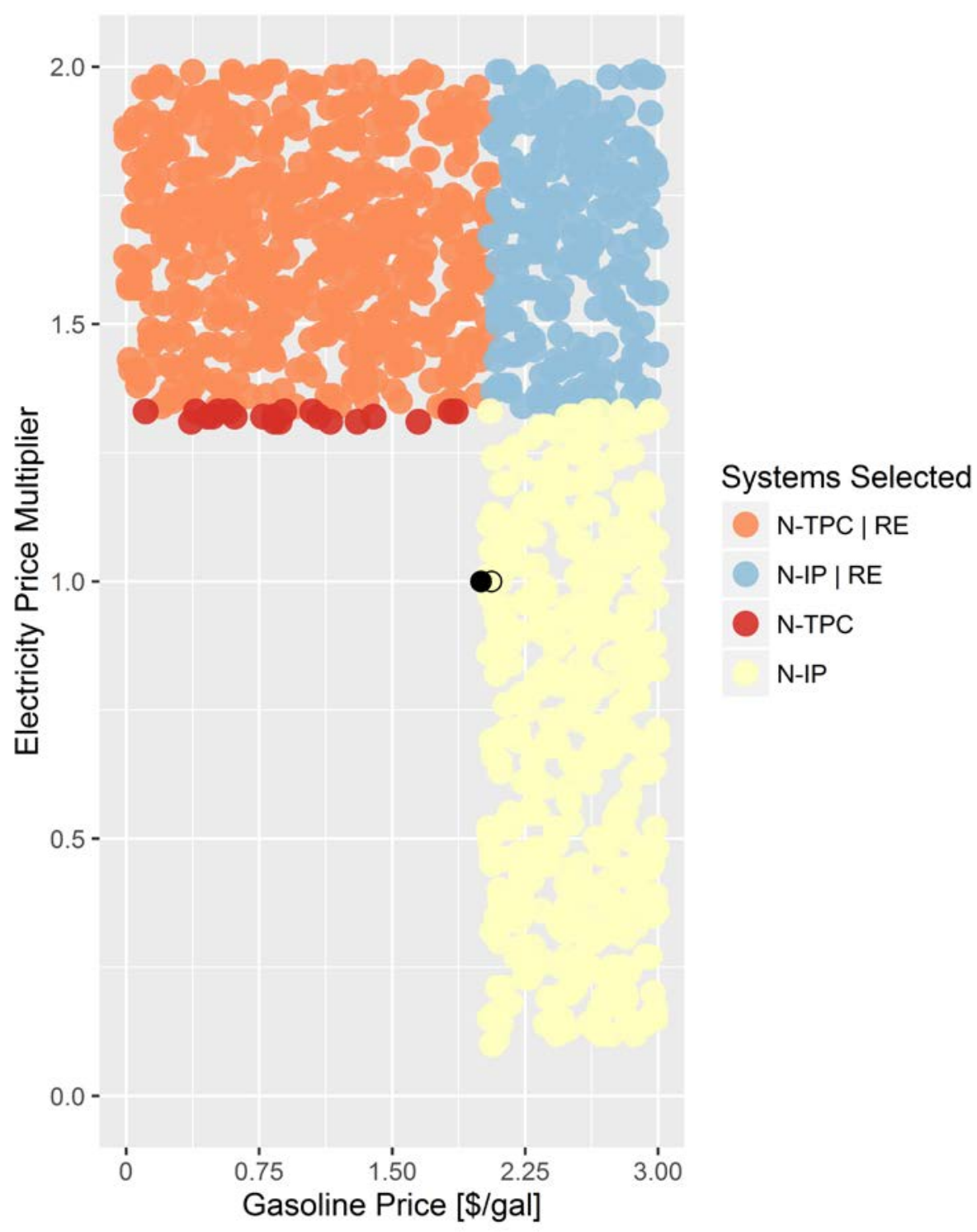

Figure G-31. Optimal configurations for the Texas-synthetic gasoline scenario at various gasoline prices and electricity price multipliers based on RPS80 generation mix, AEO low-oil-price case, and $\$ 100 / k W-y r$ capacity payments

N-TPC: Nuclear reactor and thermal

N-IP: Nuclear reactor and industrial process

$\mathrm{RE}$ : Renewable electricity generation

Solid black dot at electricity price multiplier of 1.0 and $\$ 3.00 /$ gal gasoline price: reference case gasoline price projection; reference-case electricity price vector

Open black dot: minimum gasoline selling price for a synthetic gasoline plant using natural gas heating; reference-case electricity price vector 


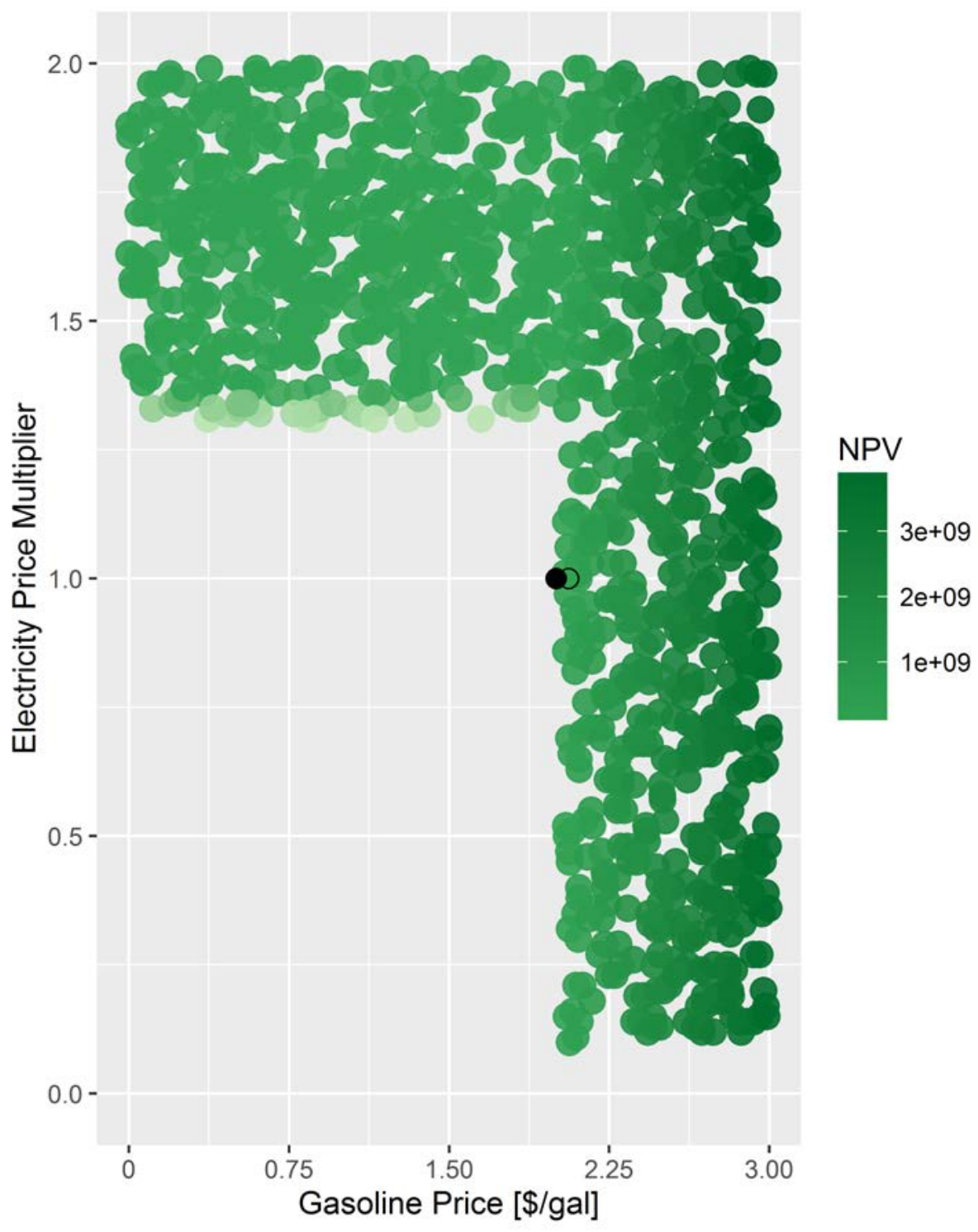

Figure G-32. Texas-synthetic gasoline scenario NPVs at various gasoline prices and electricity price multipliers based on RPS80 generation mix, AEO low-oil-price case, and \$100/kW-yr capacity payments.

Darker shades indicate higher NPVs.

Solid black dot at electricity price multiplier of 1.0 and $\$ 3.00 /$ gal gasoline price: reference case gasoline price projection; reference-case electricity price vector

Open black dot: minimum gasoline selling price for a synthetic gasoline plant using natural gas heating; reference-case electricity price vector 

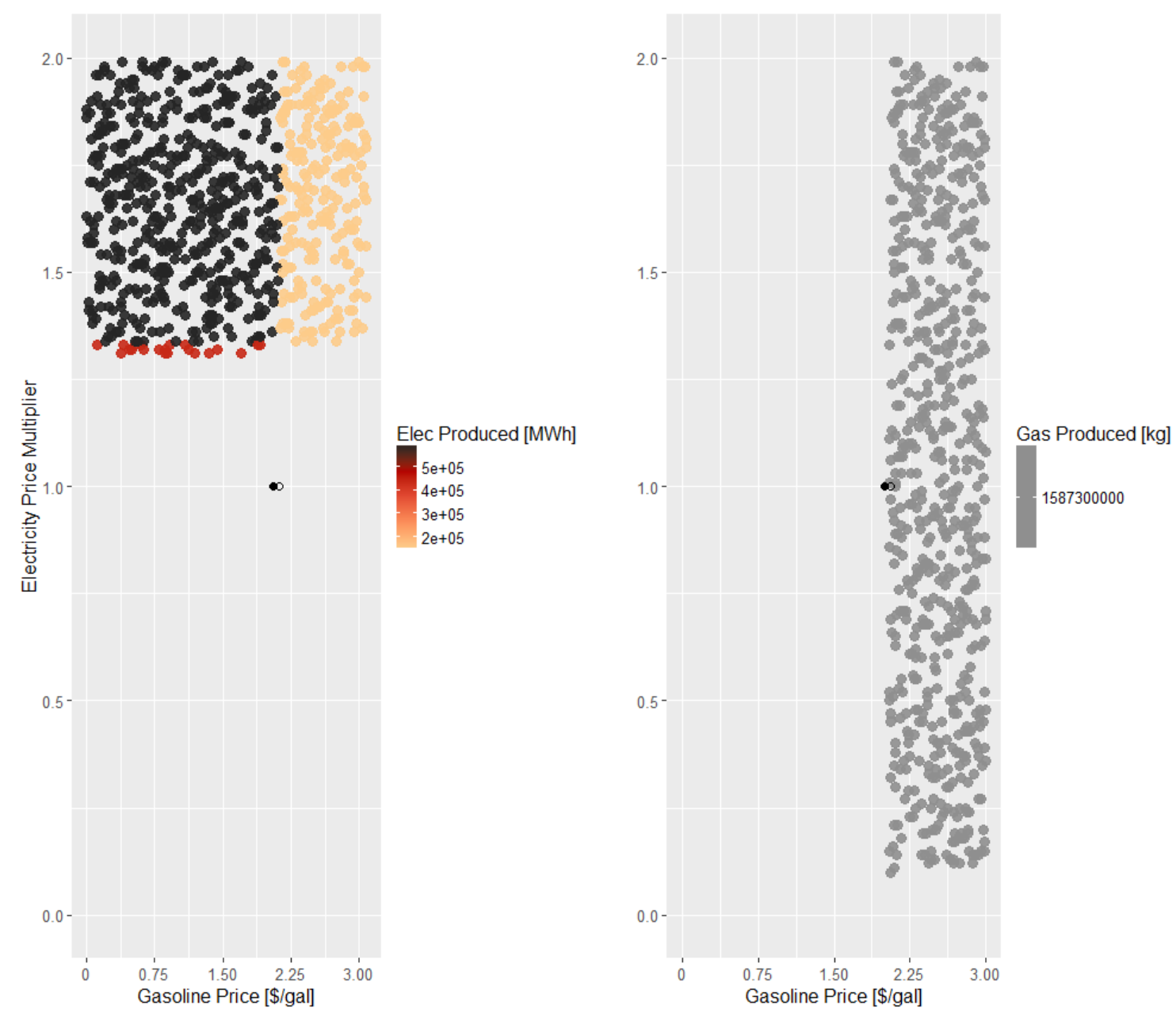

Figure G-33. Optimal annual product generation at various gasoline prices and electricity price multipliers for the Texas-synthetic gasoline scenario based on RPS80 generation mix, AEO lowoil-price case, and $\$ 100 / \mathrm{kW}$-yr capacity payments.

Electricity is shown on the left with greater generation at the darker color.

Synthetic gasoline is shown on the right.

Solid black dot at electricity price multiplier of 1.0 and $\$ 3.00 /$ gal gasoline price: reference case gasoline price projection; reference-case electricity price vector

Open black dot: minimum gasoline selling price for a synthetic gasoline plant using natural gas heating; reference-case electricity price vector 


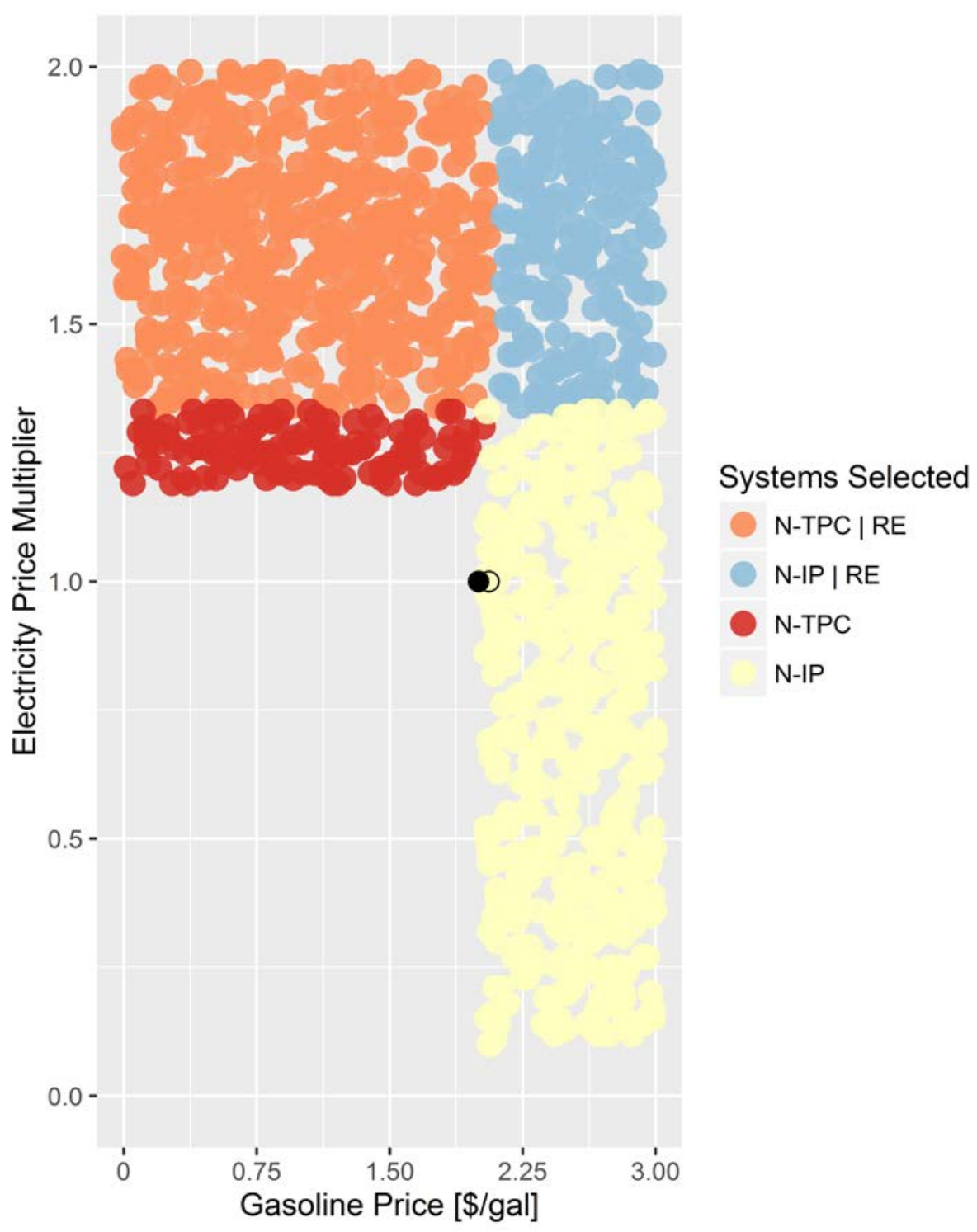

Figure G-34. Optimal configurations for the Texas-synthetic gasoline scenario at various gasoline prices and electricity price multipliers based on RPS80 generation mix, AEO low-oil-price case, and $\$ 150 / k W-y r$ capacity payments

N-TPC: Nuclear reactor and thermal

N-IP: Nuclear reactor and industrial process

$\mathrm{RE}$ : Renewable electricity generation

Solid black dot at electricity price multiplier of 1.0 and $\$ 3.00 /$ gal gasoline price: reference case gasoline price projection; reference-case electricity price vector

Open black dot: minimum gasoline selling price for a synthetic gasoline plant using natural gas heating; reference-case electricity price vector 


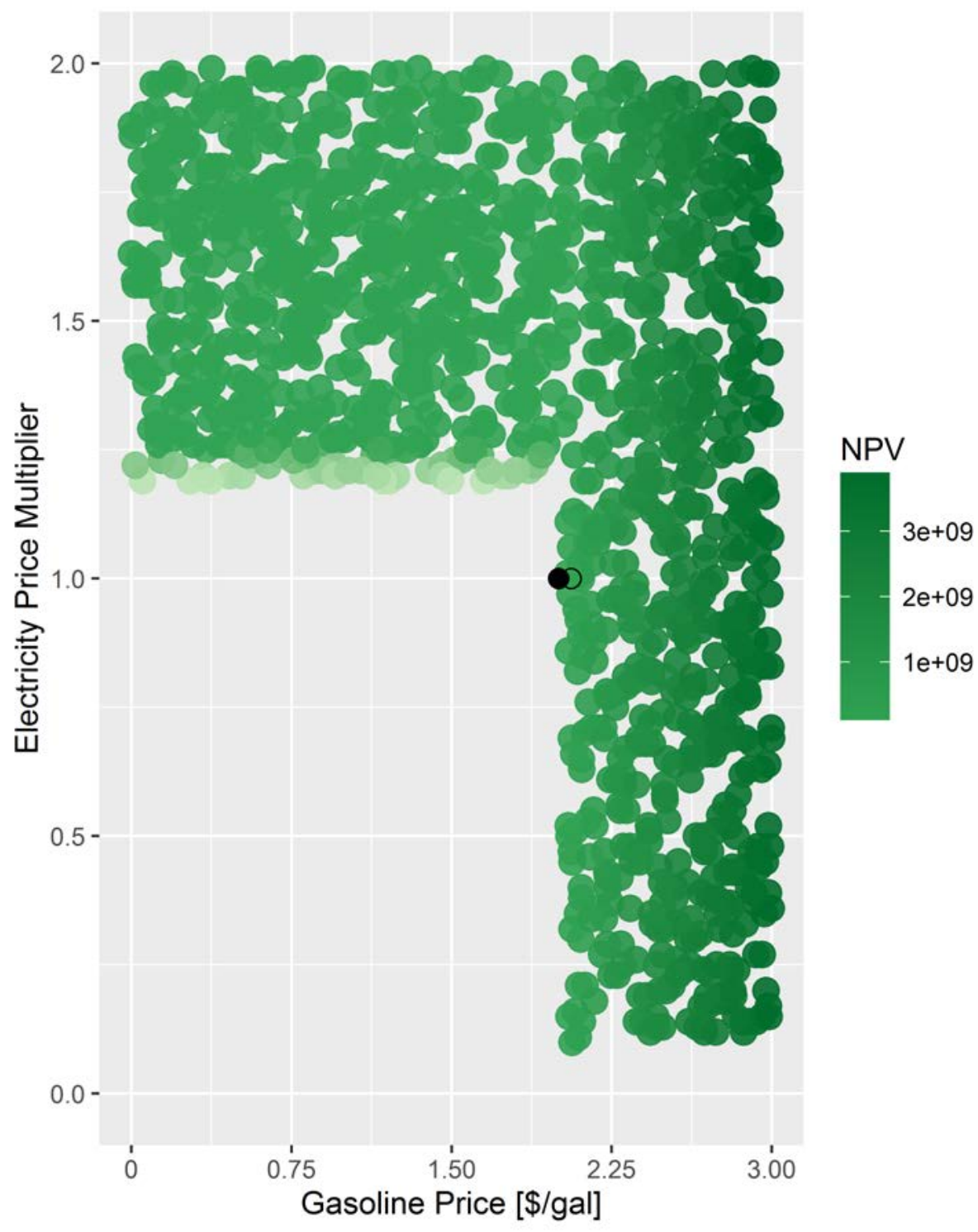

Figure G-35. Texas-synthetic gasoline scenario NPVs at various gasoline prices and electricity price multipliers based on RPS80 generation mix, AEO low-oil-price case, and \$150/kW-yr capacity payments.

Darker shades indicate higher NPVs.

Solid black dot at electricity price multiplier of 1.0 and $\$ 3.00 /$ gal gasoline price: reference case gasoline price projection; reference-case electricity price vector

Open black dot: minimum gasoline selling price for a synthetic gasoline plant using natural gas heating; reference-case electricity price vector 

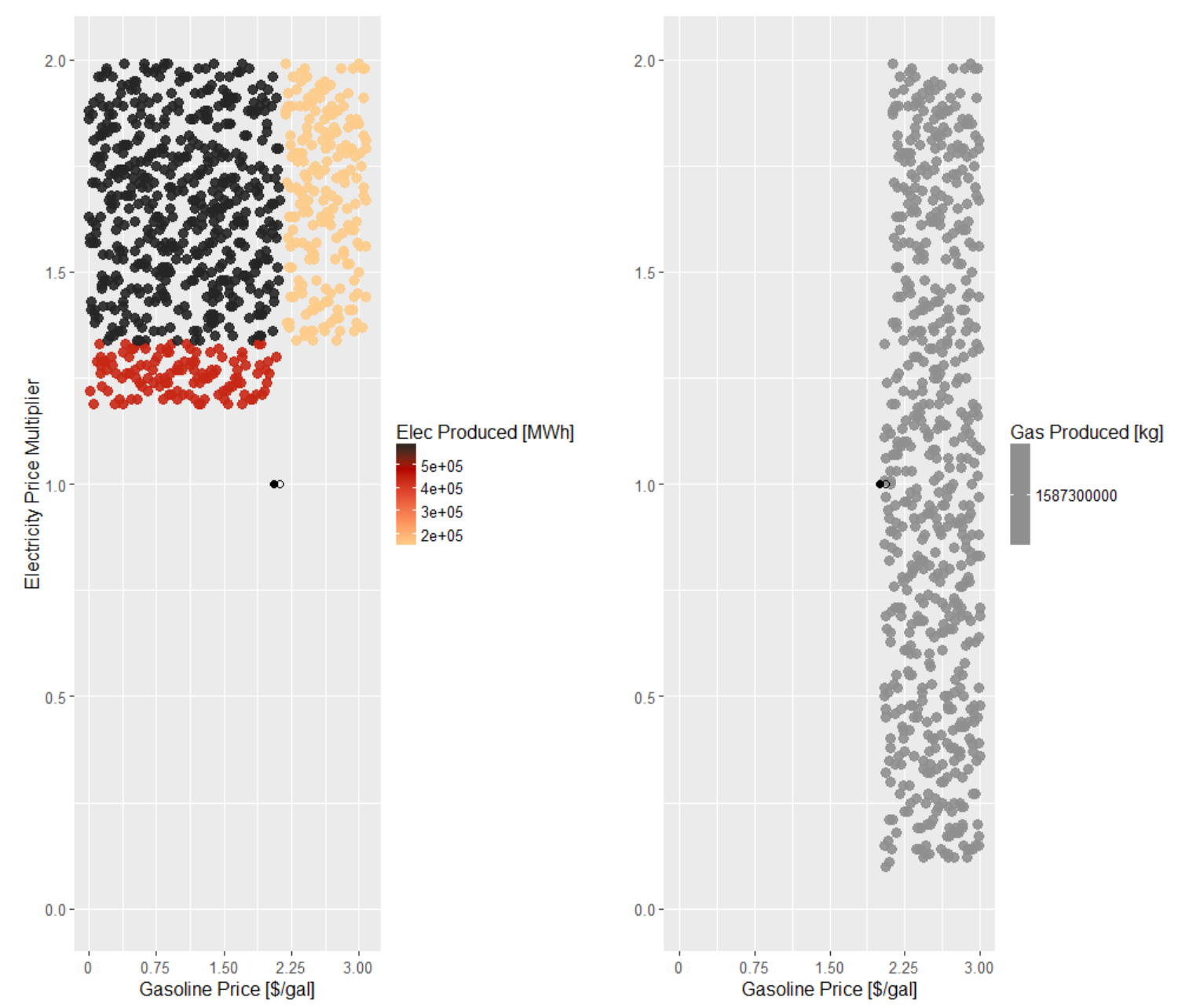

Figure G-36. Optimal annual product generation at various gasoline prices and electricity price multipliers for the Texas-synthetic gasoline scenario based on RPS80 generation mix, AEO lowoil-price case, and $\$ 150 / \mathrm{kW}$-yr capacity payments.

Electricity is shown on the left with greater generation at the darker color. Synthetic gasoline is shown on the right.

Solid black dot at electricity price multiplier of 1.0 and $\$ 3.00 /$ gal gasoline price: reference case gasoline price projection; reference-case electricity price vector

Open black dot: minimum gasoline selling price for a synthetic gasoline plant using natural gas heating; reference-case electricity price vector 
G.5 Sensitivities on the Impacts of Electricity and Gasoline Prices Based on Electricity Prices Using the RPS80 Generation Mix and the Annual Energy Outlook Reference Case with a Cost of Carbon

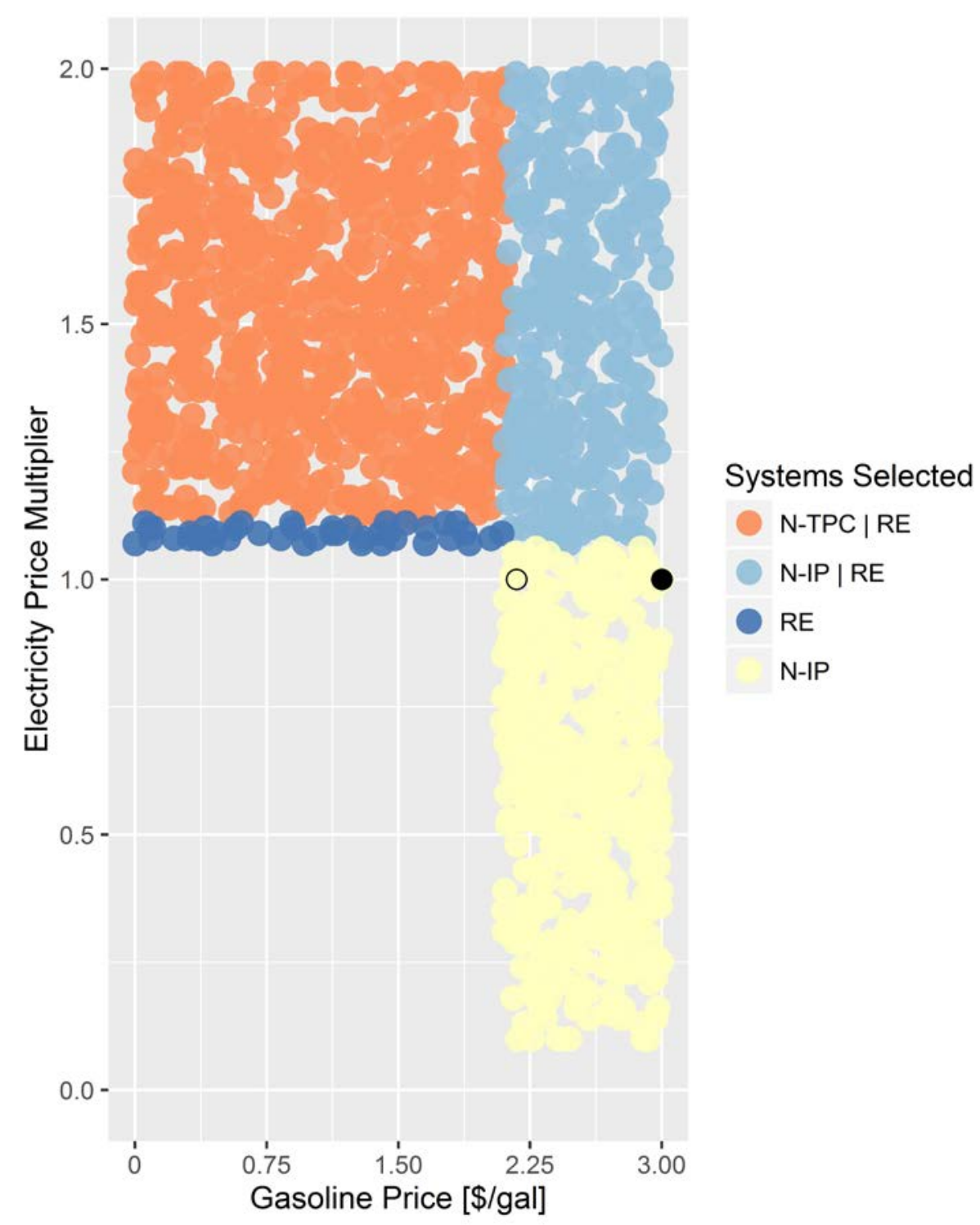

Figure G-37. Optimal configurations for the Texas-synthetic gasoline scenario at various gasoline prices and electricity price multipliers based on RPS80 generation mix, AEO reference case plus a cost of carbon of $\$ 61 /$ metric ton $\mathrm{CO}_{2}$, and $\$ 50 / \mathrm{kW}$-yr capacity payments

N-TPC: Nuclear reactor and thermal

N-IP: Nuclear reactor and industrial process

RE: Renewable electricity generation

Solid black dot at electricity price multiplier of 1.0 and $\$ 3.00 /$ gal gasoline price: reference case gasoline price projection; reference-case electricity price vector

Open black dot: minimum gasoline selling price for a synthetic gasoline plant using natural gas heating; reference-case electricity price vector 


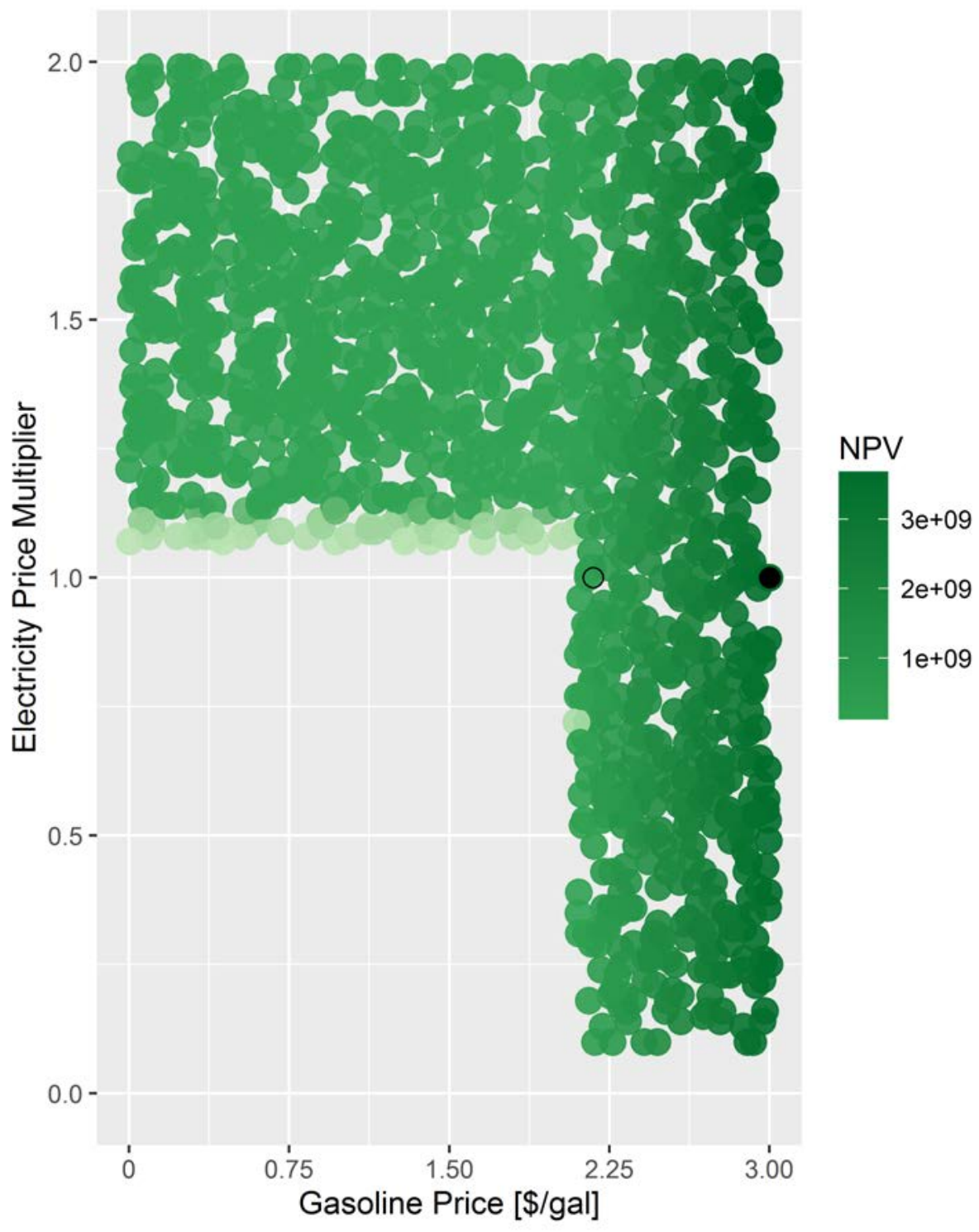

Figure G-38. Texas-synthetic gasoline scenario NPVs at various gasoline prices and electricity price multipliers based on RPS80 generation mix, AEO reference case plus a cost of carbon of $\$ 61 /$ metric ton $\mathrm{CO}_{2}$, and $\$ 50 / \mathrm{kW}$-yr capacity payments.

Darker shades indicate higher NPVs.

Solid black dot at electricity price multiplier of 1.0 and $\$ 3.00 /$ gal gasoline price: reference case gasoline price projection; reference-case electricity price vector

Open black dot: minimum gasoline selling price for a synthetic gasoline plant using natural gas heating; reference-case electricity price vector 

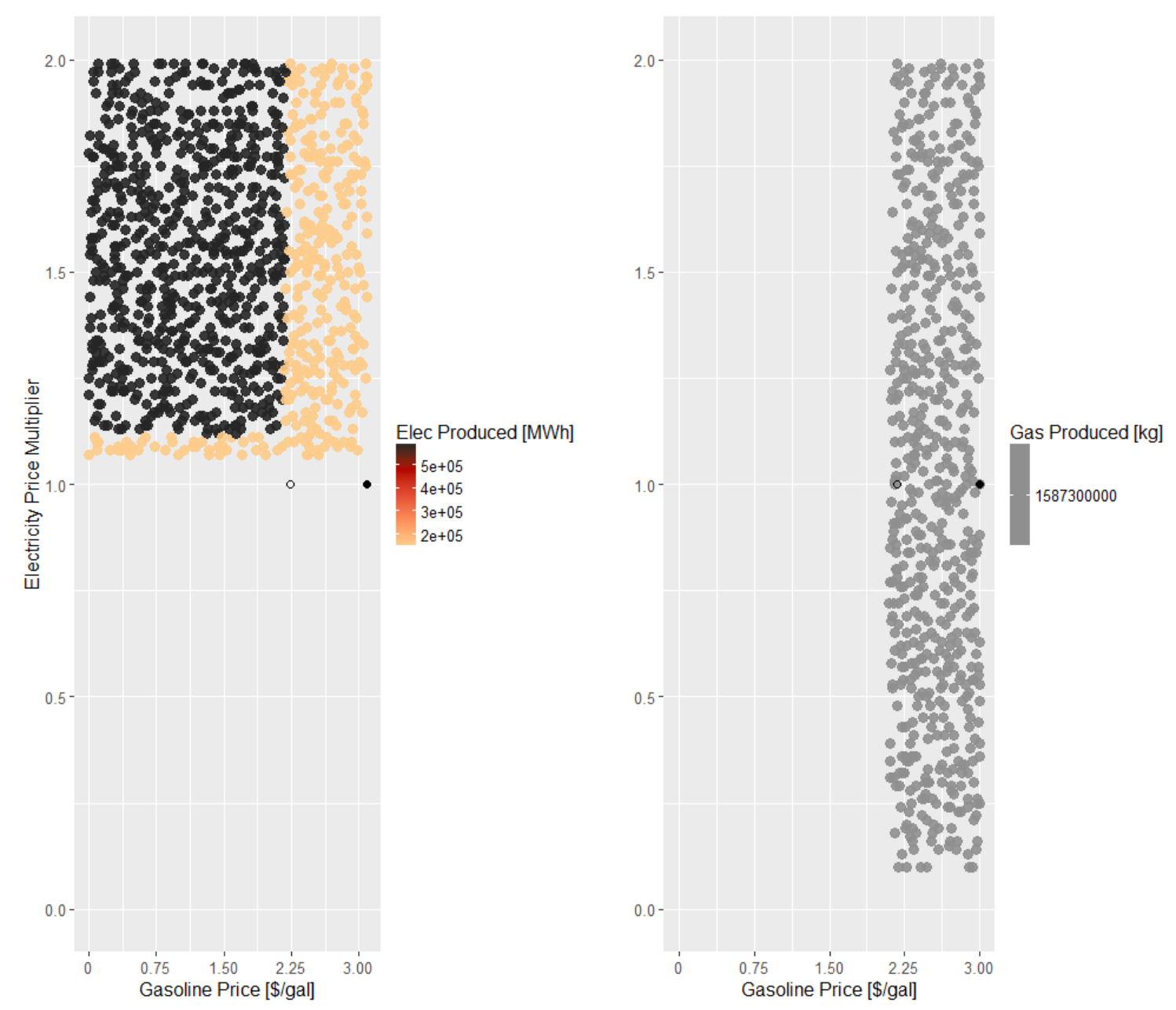

Figure G-39. Optimal annual product generation at various gasoline prices and electricity price multipliers for the Texas-synthetic gasoline scenario based on RPS80 generation mix, AEO reference case plus a cost of carbon of $\$ 61 /$ metric ton $\mathrm{CO}_{2}$, and $\$ 50 / \mathrm{kW}$-yr capacity payments.

Electricity is shown on the left with greater generation at the darker color.

Synthetic gasoline is shown on the right.

Solid black dot at electricity price multiplier of 1.0 and $\$ 3.00 /$ gal gasoline price: reference case gasoline price projection; reference-case electricity price vector

Open black dot: minimum gasoline selling price for a synthetic gasoline plant using natural gas heating; reference-case electricity price vector 


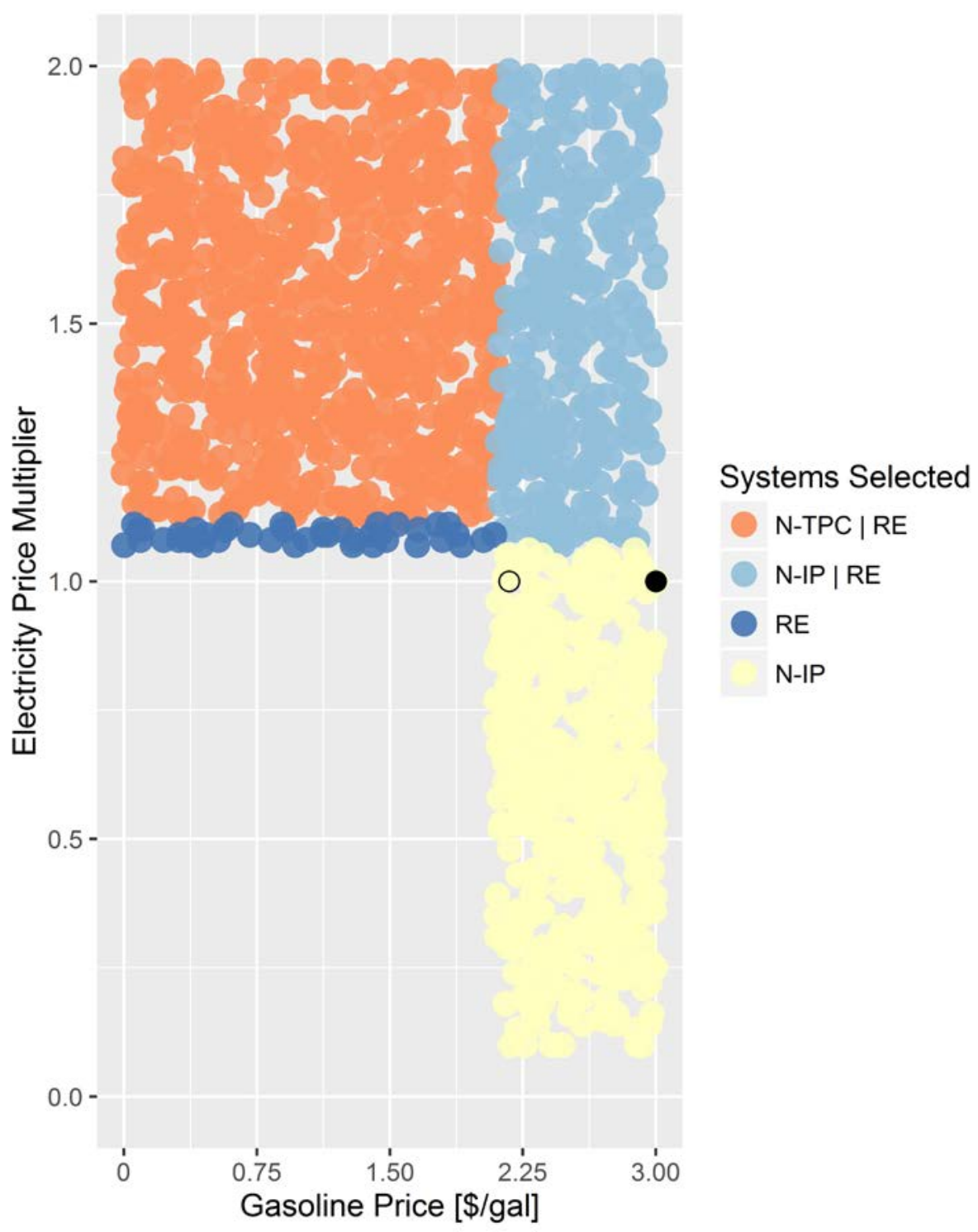

Figure G-40. Optimal configurations for the Texas-synthetic gasoline scenario at various gasoline prices and electricity price multipliers based on RPS80 generation mix, AEO reference case plus a cost of carbon of $\$ 61 /$ metric ton $\mathrm{CO}_{2}$, and $\$ 100 / \mathrm{kW}$-yr capacity payments

N-TPC: Nuclear reactor and thermal

N-IP: Nuclear reactor and industrial process

$\mathrm{RE}$ : Renewable electricity generation

Solid black dot at electricity price multiplier of 1.0 and $\$ 3.00 /$ gal gasoline price: reference case gasoline price projection; reference-case electricity price vector

Open black dot: minimum gasoline selling price for a synthetic gasoline plant using natural gas heating; reference-case electricity price vector 


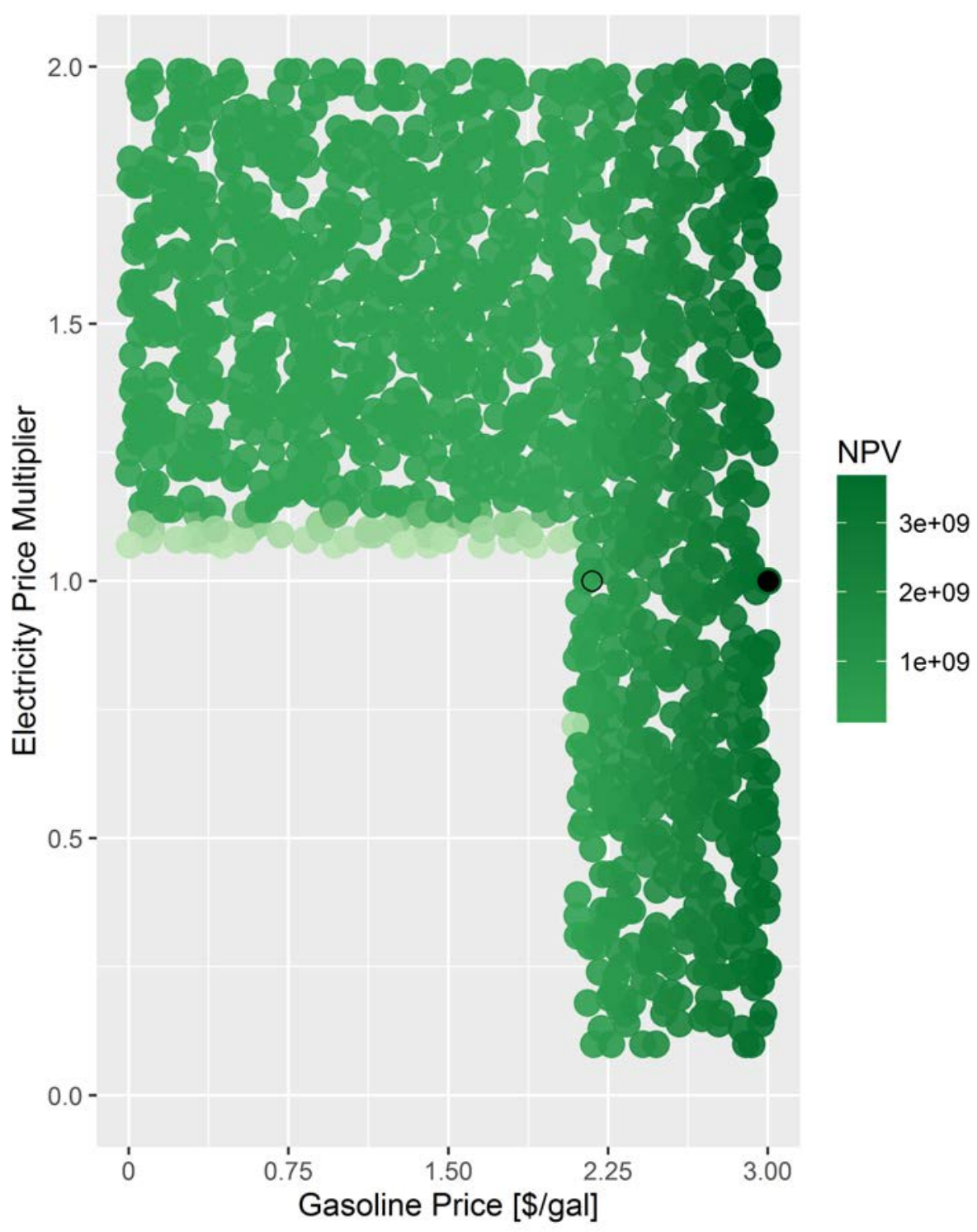

Figure G-41. Texas-synthetic gasoline scenario NPVs at various gasoline prices and electricity price multipliers based on RPS80 generation mix, AEO reference case plus a cost of carbon of $\$ 61 /$ metric ton $\mathrm{CO}_{2}$, and $\$ 100 / \mathrm{kW}$-yr capacity payments.

Darker shades indicate higher NPVs.

Solid black dot at electricity price multiplier of 1.0 and $\$ 3.00 /$ gal gasoline price: reference case gasoline price projection; reference-case electricity price vector

Open black dot: minimum gasoline selling price for a synthetic gasoline plant using natural gas heating; reference-case electricity price vector 

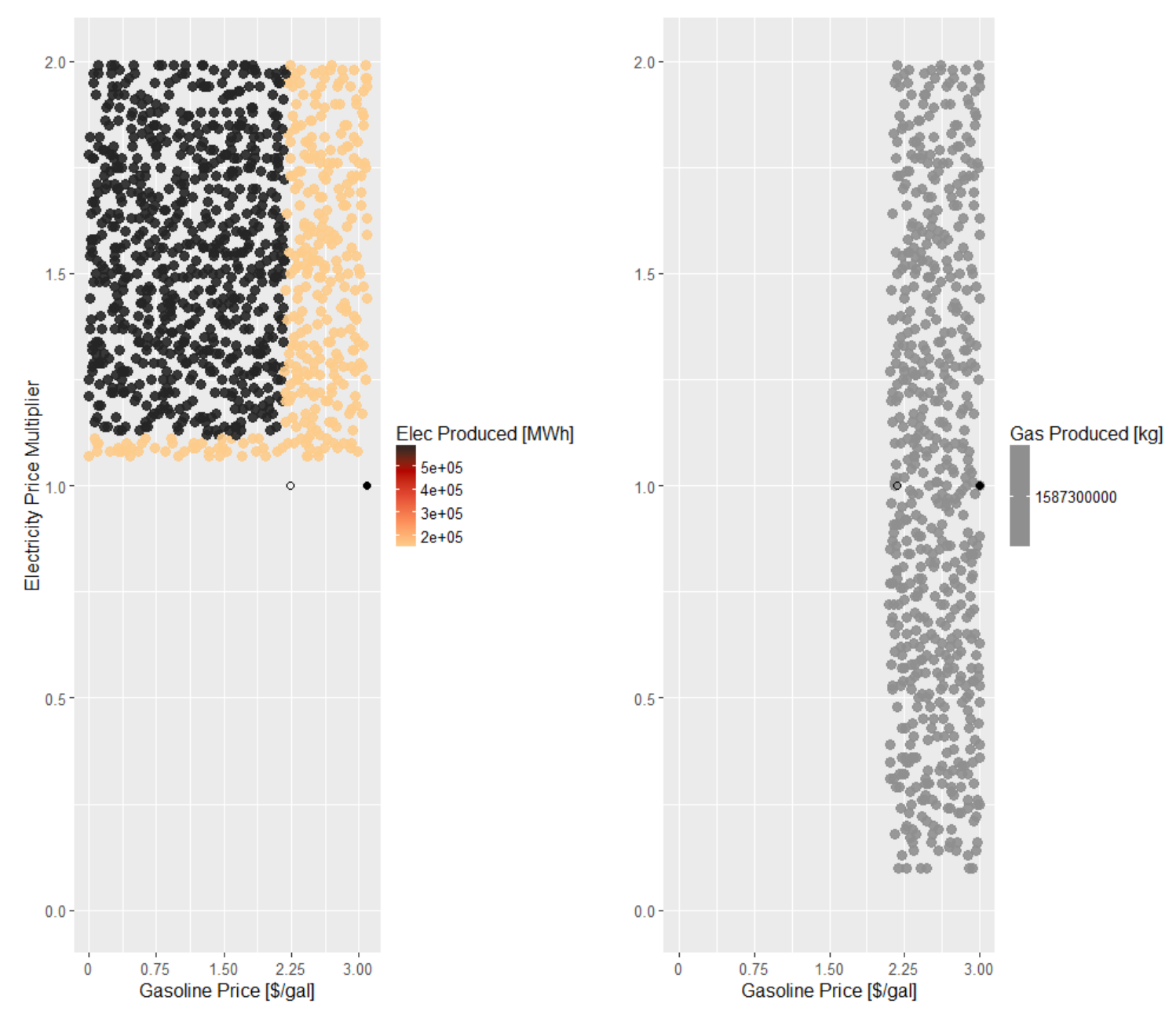

Figure G-42. Optimal annual product generation at various gasoline prices and electricity price multipliers for the Texas-synthetic gasoline scenario based on RPS80 generation mix, AEO reference case plus a cost of carbon of $\$ 61 /$ metric ton $\mathrm{CO}_{2}$, and $\$ 100 / \mathrm{kW}$-yr capacity payments.

Electricity is shown on the left with greater generation at the darker color.

Synthetic gasoline is shown on the right.

Solid black dot at electricity price multiplier of 1.0 and $\$ 3.00 /$ gal gasoline price: reference case gasoline price projection; reference-case electricity price vector

Open black dot: minimum gasoline selling price for a synthetic gasoline plant using natural gas heating; reference-case electricity price vector 


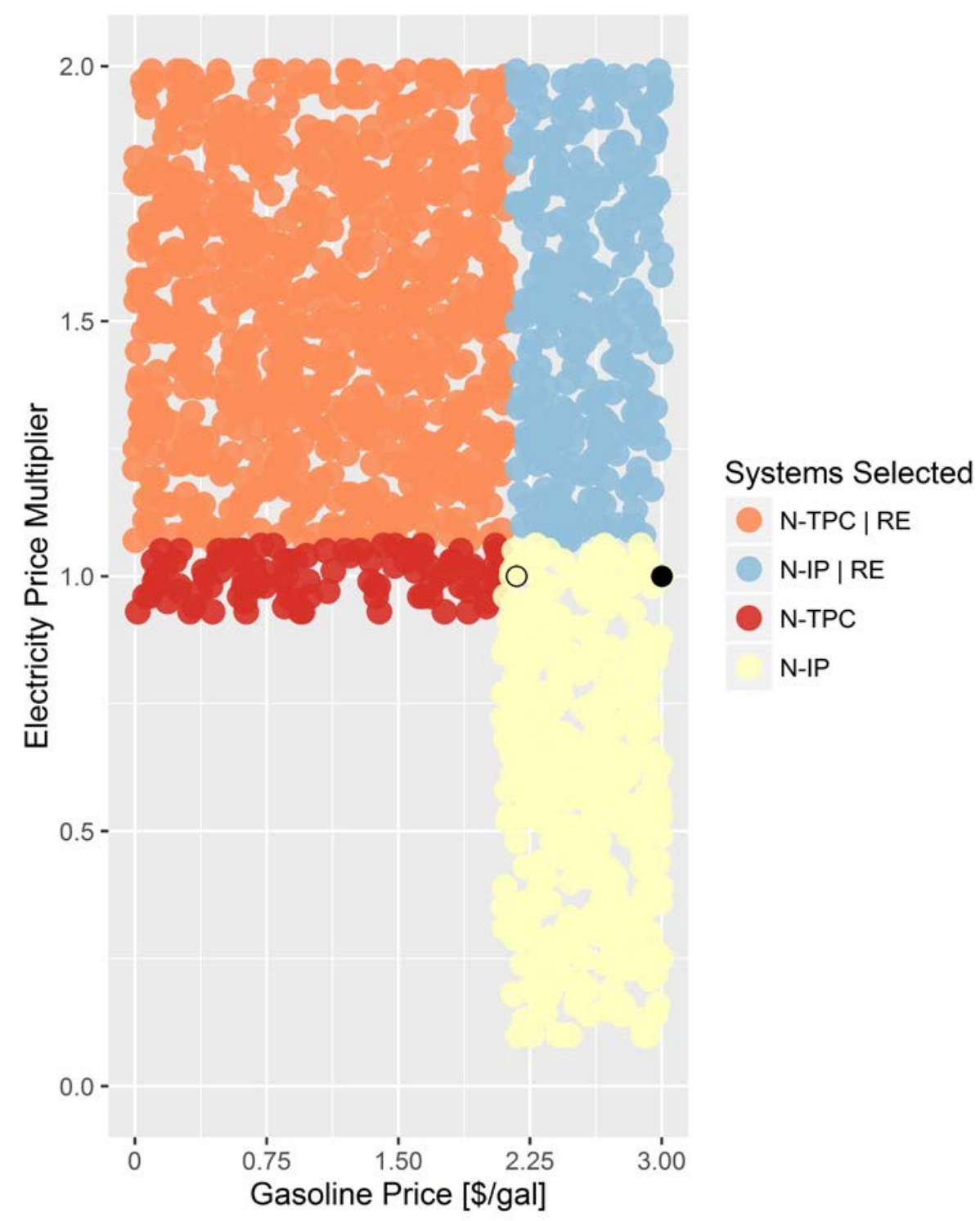

Figure G-43. Optimal configurations for the Texas-synthetic gasoline scenario at various gasoline prices and electricity price multipliers based on RPS80 generation mix, AEO reference case plus a cost of carbon of $\$ 61 /$ metric ton $\mathrm{CO}_{2}$, and $\$ 150 / \mathrm{kW}$-yr capacity payments

N-TPC: Nuclear reactor and thermal

N-IP: Nuclear reactor and industrial process

$\mathrm{RE}$ : Renewable electricity generation

Solid black dot at electricity price multiplier of 1.0 and $\$ 3.00 /$ gal gasoline price: reference case gasoline price projection; reference-case electricity price vector

Open black dot: minimum gasoline selling price for a synthetic gasoline plant using natural gas heating; reference-case electricity price vector 


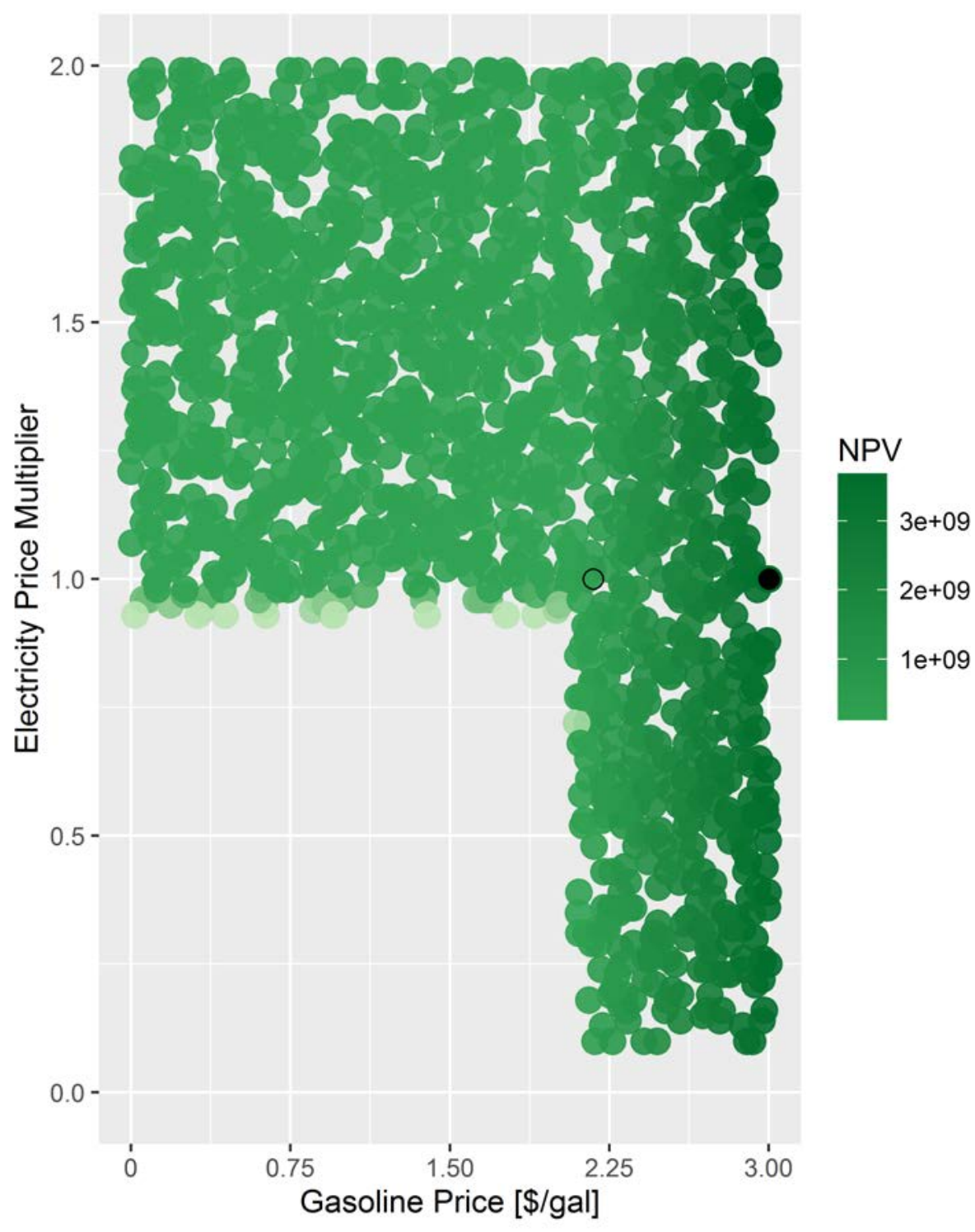

Figure G-44. Texas-synthetic gasoline scenario NPVs at various gasoline prices and electricity price multipliers based on RPS80 generation mix, AEO reference case plus a cost of carbon of $\$ 61 /$ metric ton $\mathrm{CO}_{2}$, and $\$ 150 / \mathrm{kW}$-yr capacity payments.

Darker shades indicate higher NPVs.

Solid black dot at electricity price multiplier of 1.0 and $\$ 3.00 /$ gal gasoline price: reference case gasoline price projection; reference-case electricity price vector

Open black dot: minimum gasoline selling price for a synthetic gasoline plant using natural gas heating; reference-case electricity price vector 

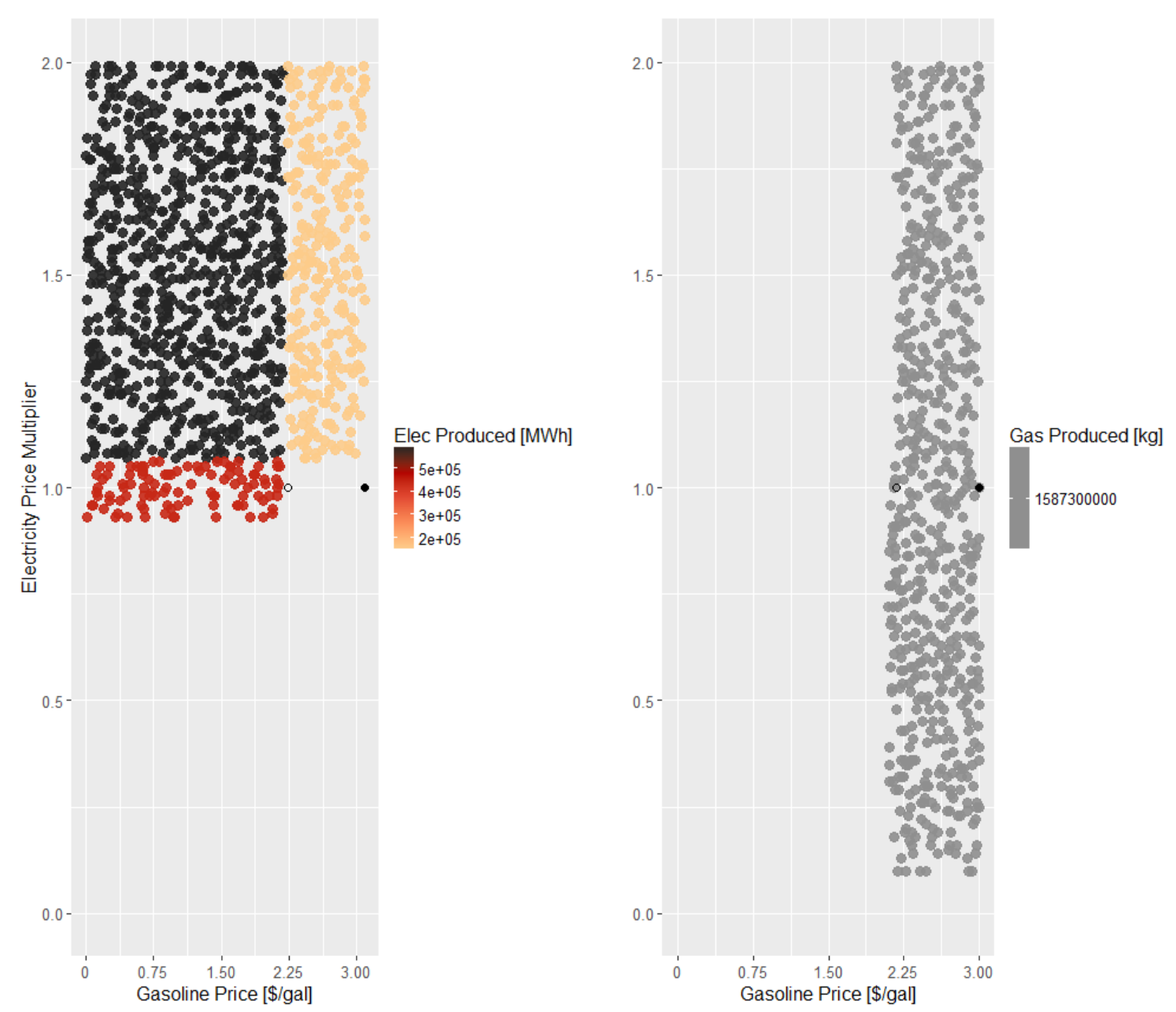

Figure G-45. Optimal annual product generation at various gasoline prices and electricity price multipliers for the Texas-synthetic gasoline scenario based on RPS80 generation mix, AEO reference case plus a cost of carbon of $\$ 61 /$ metric ton $\mathrm{CO}_{2}$, and $\$ 150 / \mathrm{kW}$-yr capacity payments.

Electricity is shown on the left with greater generation at the darker color.

Synthetic gasoline is shown on the right.

Solid black dot at electricity price multiplier of 1.0 and $\$ 3.00 /$ gal gasoline price: reference case gasoline price projection; reference-case electricity price vector

Open black dot: minimum gasoline selling price for a synthetic gasoline plant using natural gas heating; reference-case electricity price vector 


\section{G.6 Sensitivities on the Impacts of Electricity and Gasoline Prices Based on Electricity Prices Using the Annual Energy Outlook Reference Case with a Nominal Discount Rate of $8.15 \%$}

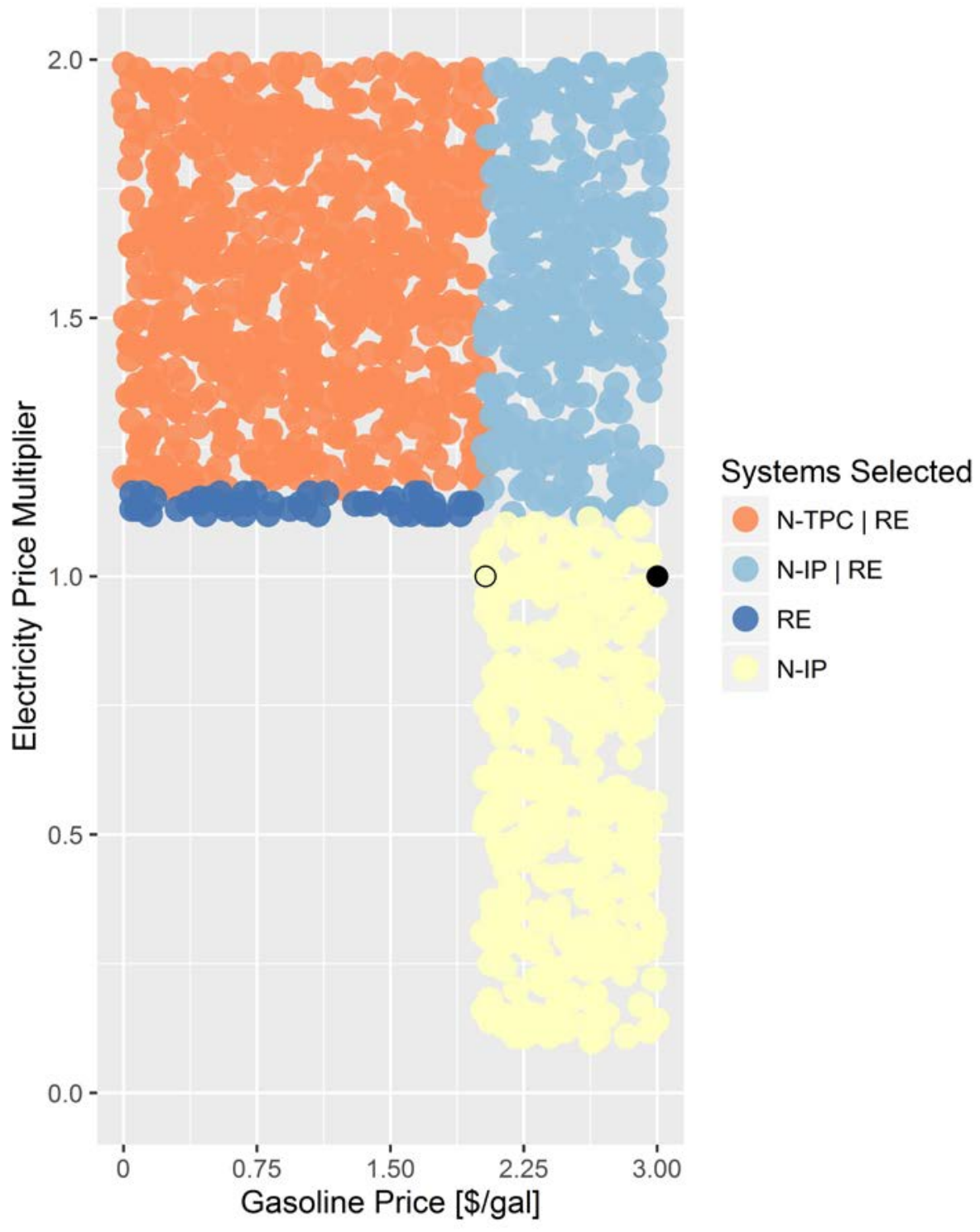

Figure G-46. Optimal configurations for the Texas-synthetic gasoline scenario at various gasoline prices and electricity price multipliers based on RPS80 generation mix, AEO reference case, nominal discount rate of $8.15 \%$, and $\$ 50 / \mathrm{kW}$-yr capacity payments

N-TPC: Nuclear reactor and thermal

N-IP: Nuclear reactor and industrial process

$\mathrm{RE}$ : Renewable electricity generation

Solid black dot at electricity price multiplier of 1.0 and $\$ 3.00 /$ gal gasoline price: reference case gasoline price projection; reference-case electricity price vector

Open black dot: minimum gasoline selling price for a synthetic gasoline plant using natural gas heating; reference-case electricity price vector 


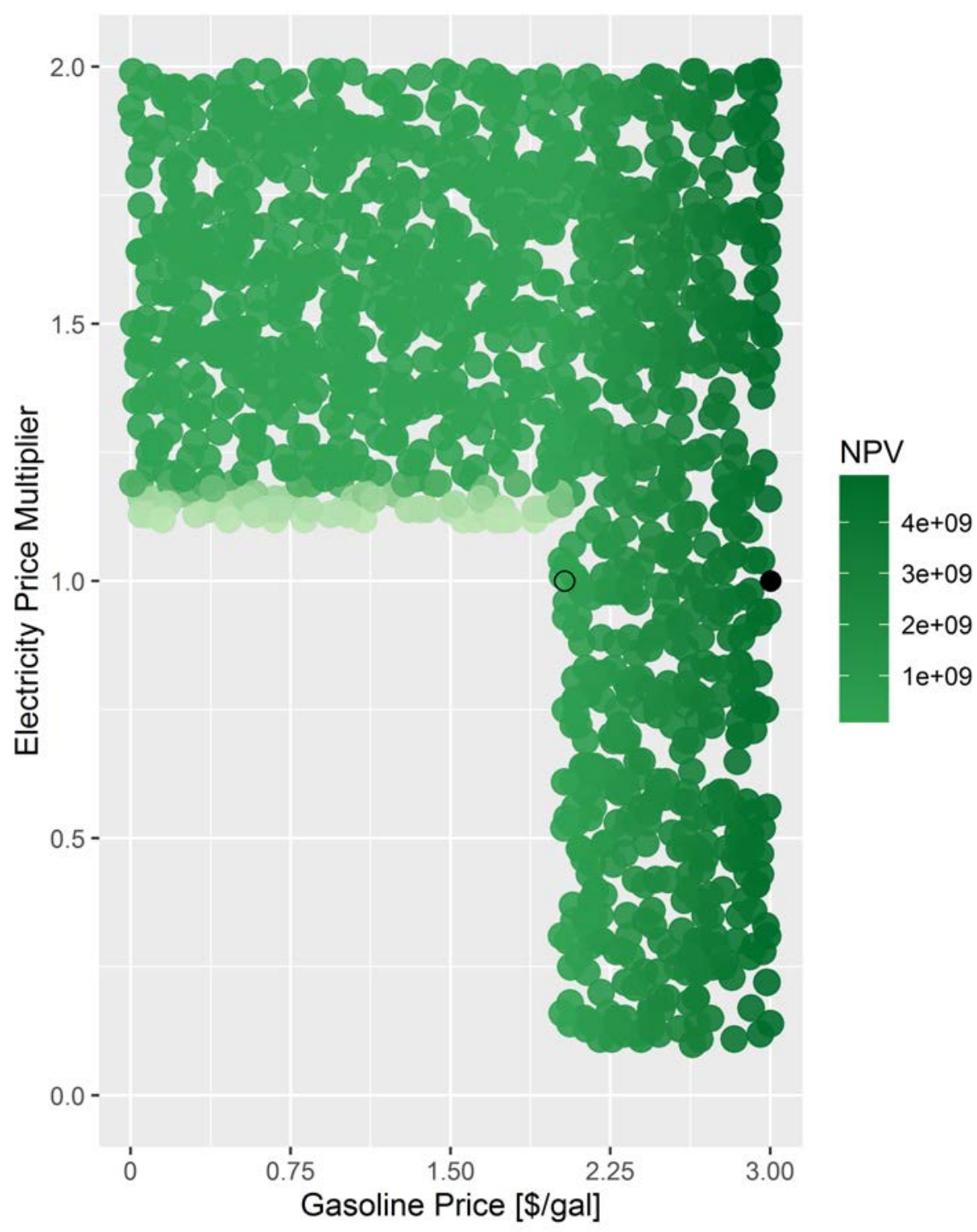

Figure G-47. Texas-synthetic gasoline scenario NPVs at various gasoline prices and electricity price multipliers based on RPS 80 generation mix, AEO reference case, nominal discount rate of $8.15 \%$, and $\$ 50 / \mathrm{kW}$-yr capacity payments.

Darker shades indicate higher NPVs.

Solid black dot at electricity price multiplier of 1.0 and $\$ 3.00 /$ gal gasoline price: reference case gasoline price projection; reference-case electricity price vector

Open black dot: minimum gasoline selling price for a synthetic gasoline plant using natural gas heating; reference-case electricity price vector 

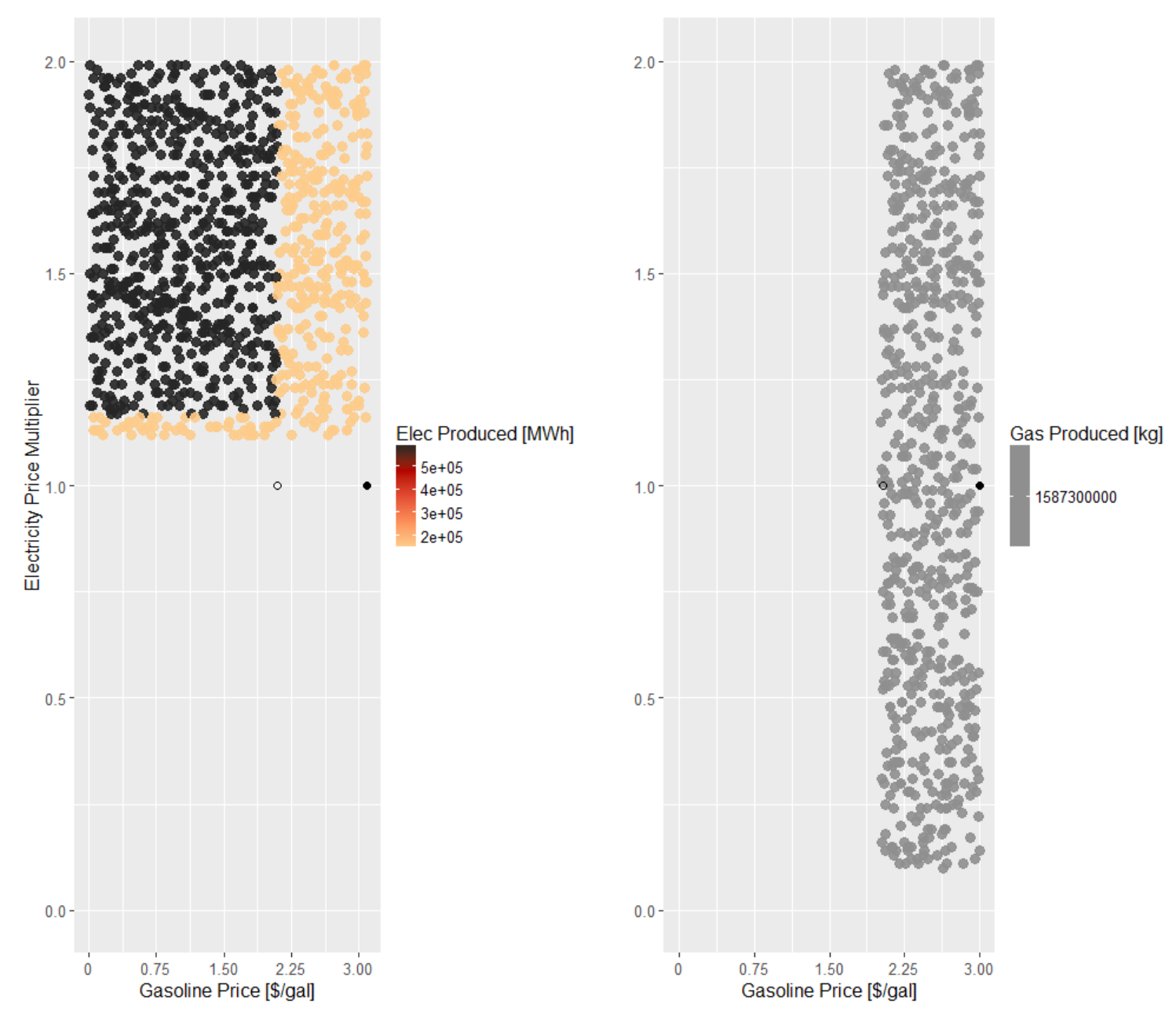

Figure G-48. Optimal annual product generation at various gasoline prices and electricity price multipliers for the Texas-synthetic gasoline scenario based on RPS80 generation mix, AEO reference case, nominal discount rate of $8.15 \%$, and $\$ 50 / \mathrm{kW}$-yr capacity payments.

Electricity is shown on the left with greater generation at the darker color. Synthetic gasoline is shown on the right.

Solid black dot at electricity price multiplier of 1.0 and $\$ 3.00 /$ gal gasoline price: reference case gasoline price projection; reference-case electricity price vector

Open black dot: minimum gasoline selling price for a synthetic gasoline plant using natural gas heating; reference-case electricity price vector 


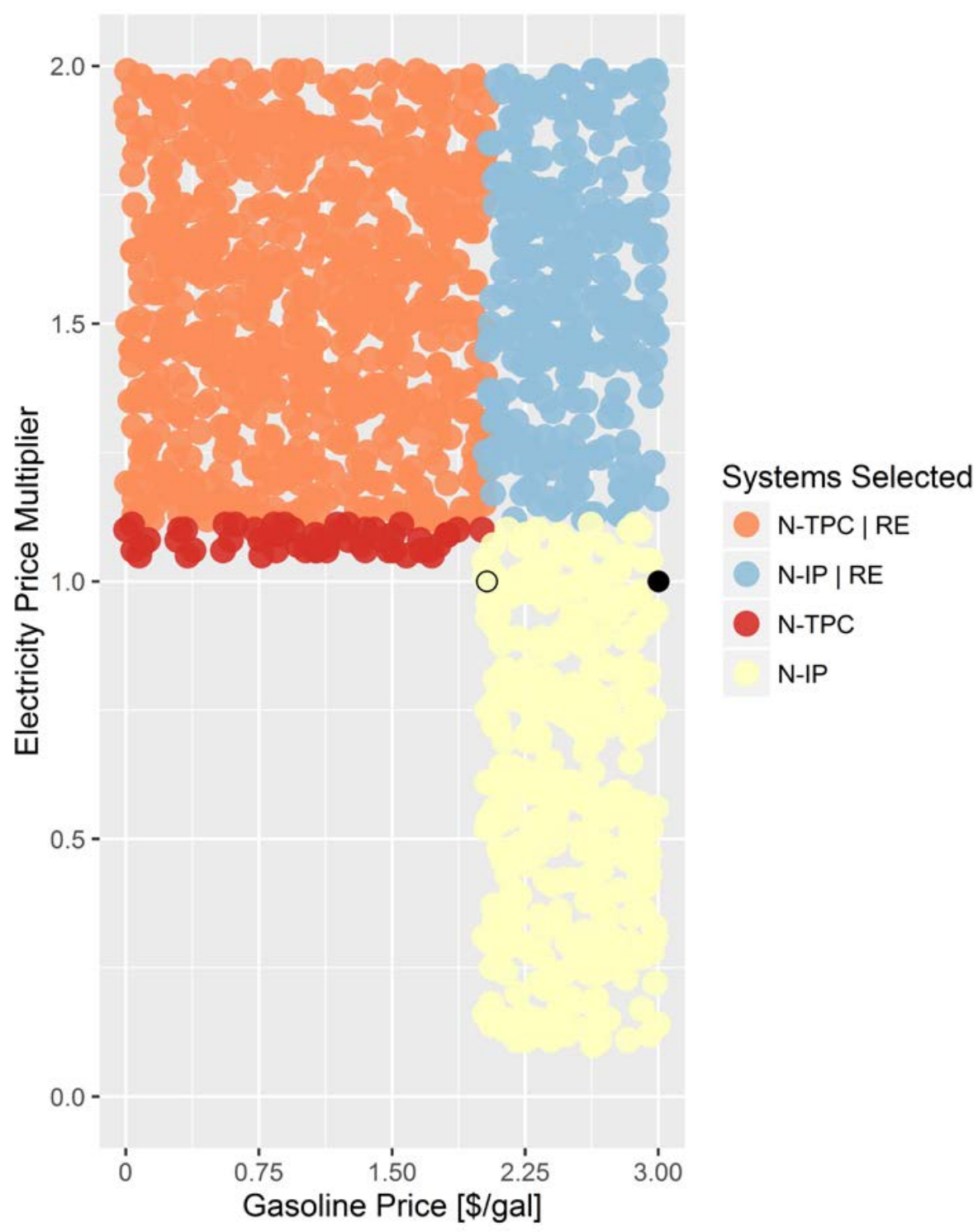

Figure G-49. Optimal configurations for the Texas-synthetic gasoline scenario at various gasoline prices and electricity price multipliers based on RPS80 generation mix, AEO reference case, nominal discount rate of $8.15 \%$, and $\$ 100 / \mathrm{kW}$-yr capacity payments

N-TPC: Nuclear reactor and thermal

N-IP: Nuclear reactor and industrial process

$\mathrm{RE}$ : Renewable electricity generation

Solid black dot at electricity price multiplier of 1.0 and $\$ 3.00 /$ gal gasoline price: reference case gasoline price projection; reference-case electricity price vector

Open black dot: minimum gasoline selling price for a synthetic gasoline plant using natural gas heating; reference-case electricity price vector 


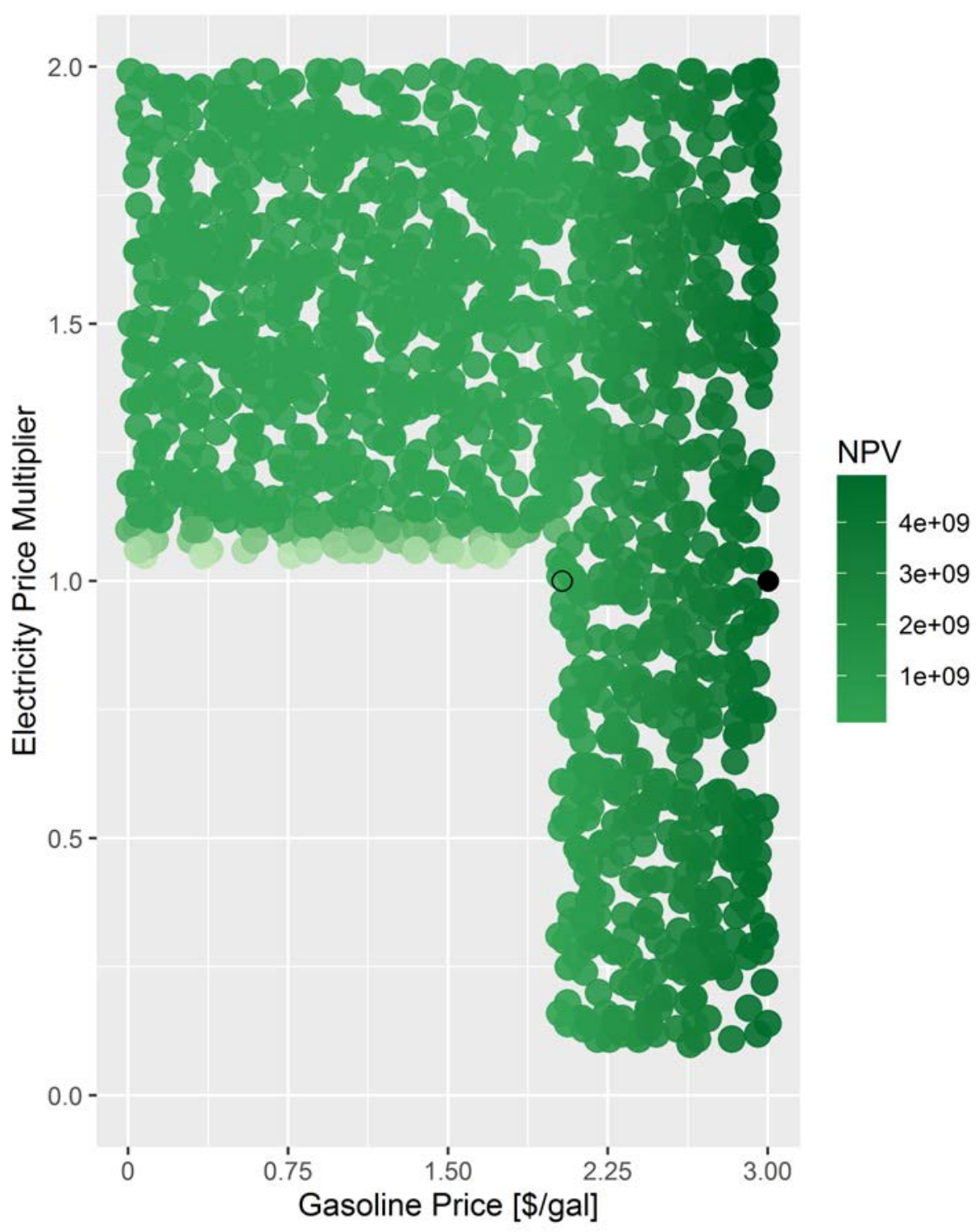

Figure G-50. Texas-synthetic gasoline scenario NPVs at various gasoline prices and electricity price multipliers based on RPS 80 generation mix, AEO reference case, nominal discount rate of $8.15 \%$, and $\$ 100 / k W$-yr capacity payments.

Darker shades indicate higher NPVs.

Solid black dot at electricity price multiplier of 1.0 and $\$ 3.00 /$ gal gasoline price: reference case gasoline price projection; reference-case electricity price vector

Open black dot: minimum gasoline selling price for a synthetic gasoline plant using natural gas heating; reference-case electricity price vector 

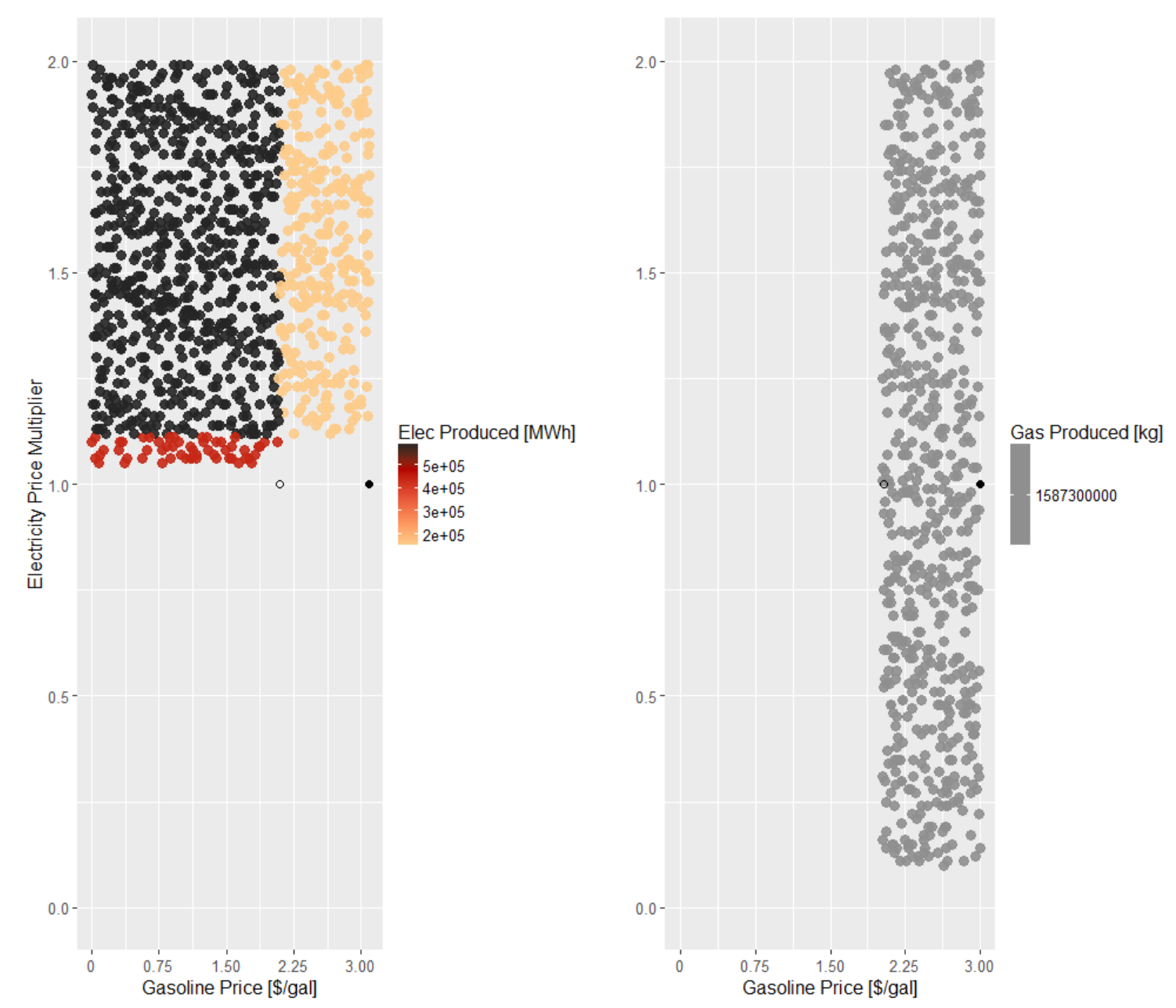

Figure G-51. Optimal annual product generation at various gasoline prices and electricity price multipliers for the Texas-synthetic gasoline scenario based on RPS80 generation mix, AEO reference case, nominal discount rate of $8.15 \%$, and $\$ 100 / \mathrm{kW}$-yr capacity payments.

Electricity is shown on the left with greater generation at the darker color. Synthetic gasoline is shown on the right.

Solid black dot at electricity price multiplier of 1.0 and $\$ 3.00 /$ gal gasoline price: reference case gasoline price projection; reference-case electricity price vector

Open black dot: minimum gasoline selling price for a synthetic gasoline plant using natural gas heating; reference-case electricity price vector 


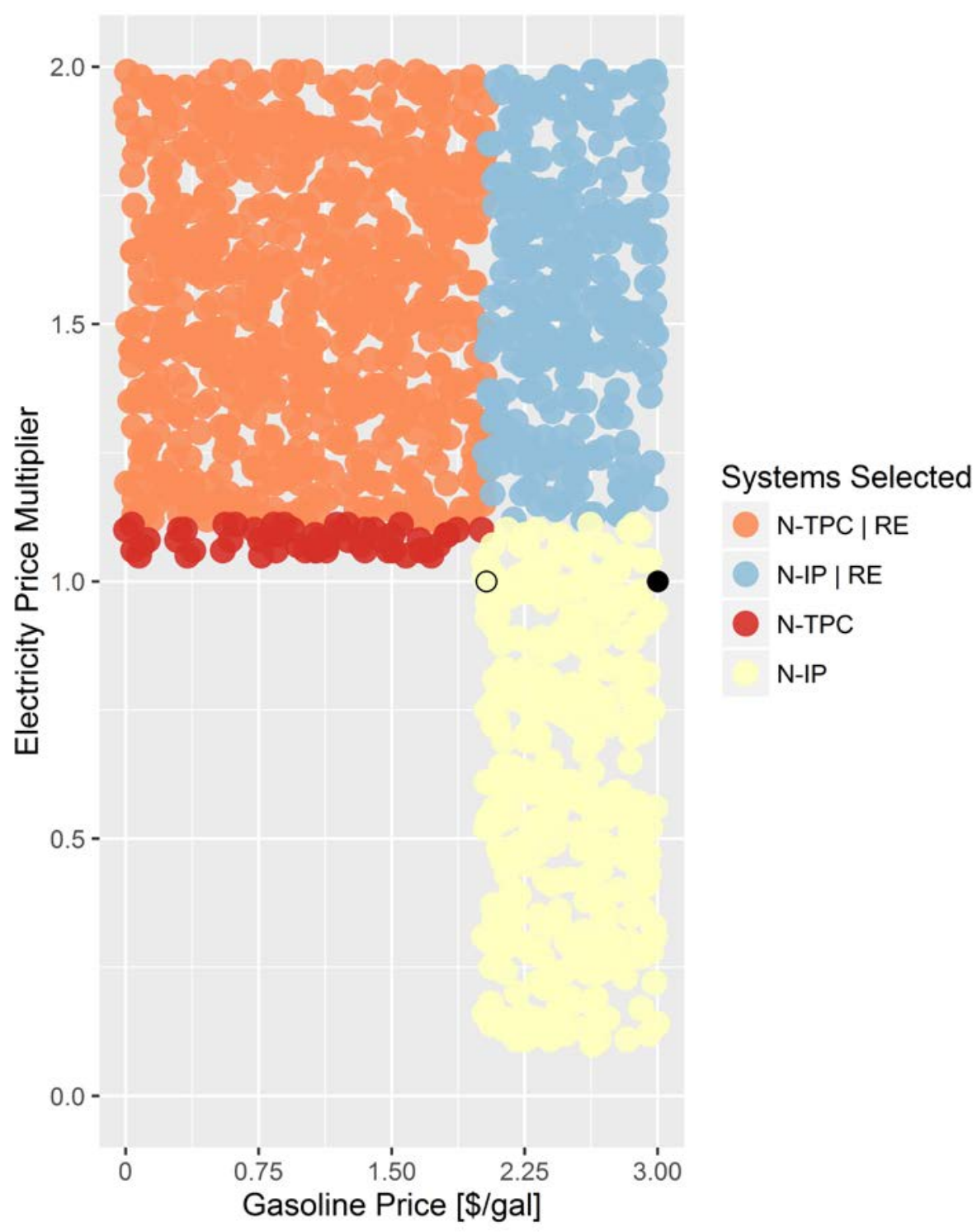

Figure G-52. Optimal configurations for the Texas-synthetic gasoline scenario at various gasoline prices and electricity price multipliers based on RPS80 generation mix, AEO reference case, nominal discount rate of $8.15 \%$, and $\$ 150 / \mathrm{kW}$-yr capacity payments

N-TPC: Nuclear reactor and thermal

N-IP: Nuclear reactor and industrial process

$\mathrm{RE}$ : Renewable electricity generation

Solid black dot at electricity price multiplier of 1.0 and $\$ 3.00 /$ gal gasoline price: reference case gasoline price projection; reference-case electricity price vector

Open black dot: minimum gasoline selling price for a synthetic gasoline plant using natural gas heating; reference-case electricity price vector 


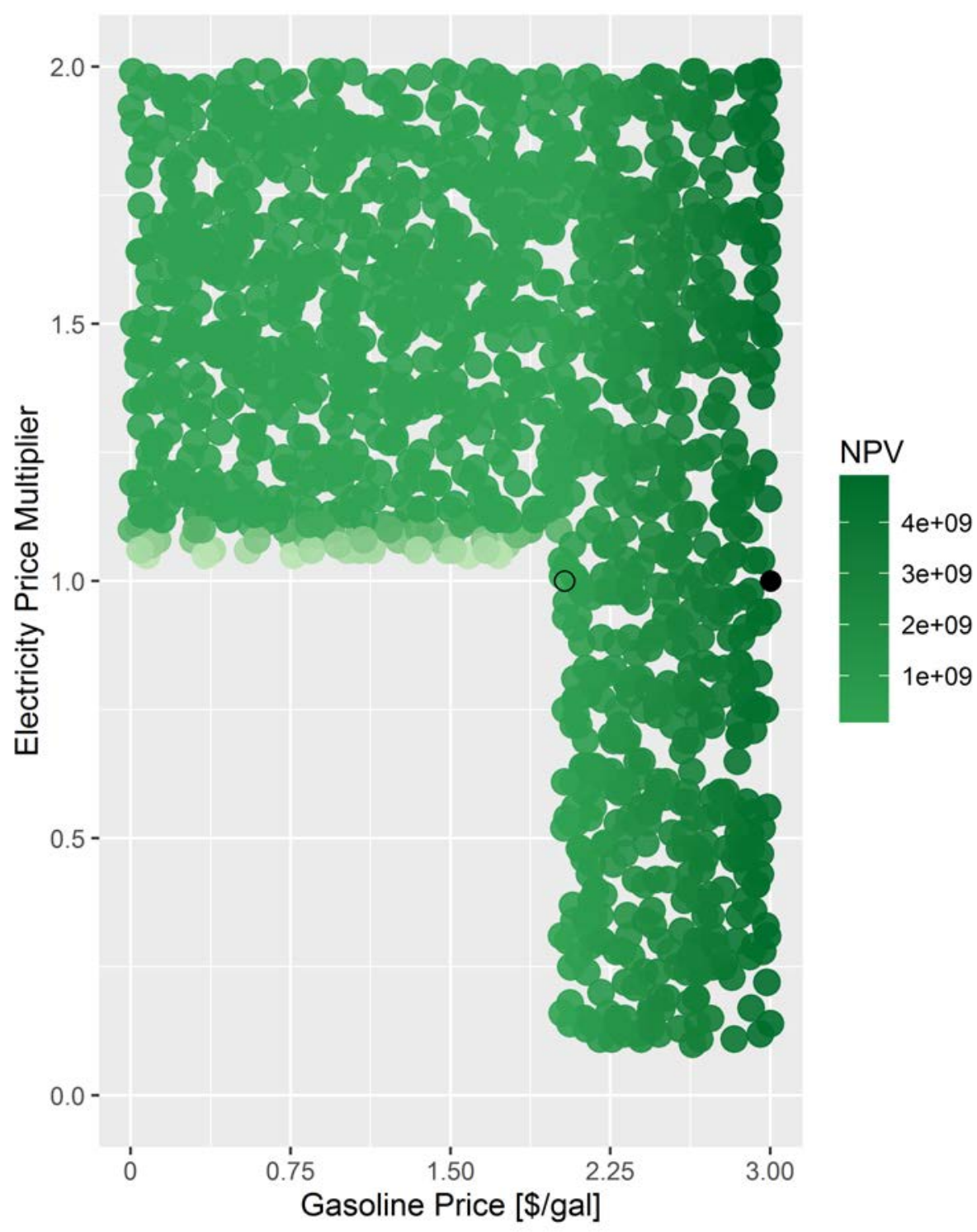

Figure G-53. Texas-synthetic gasoline scenario NPVs at various gasoline prices and electricity price multipliers based on RPS 80 generation mix, AEO reference case, nominal discount rate of $8.15 \%$, and $\$ 150 / k W$-yr capacity payments.

Darker shades indicate higher NPVs.

Solid black dot at electricity price multiplier of 1.0 and $\$ 3.00 /$ gal gasoline price: reference case gasoline price projection; reference-case electricity price vector

Open black dot: minimum gasoline selling price for a synthetic gasoline plant using natural gas heating; reference-case electricity price vector 

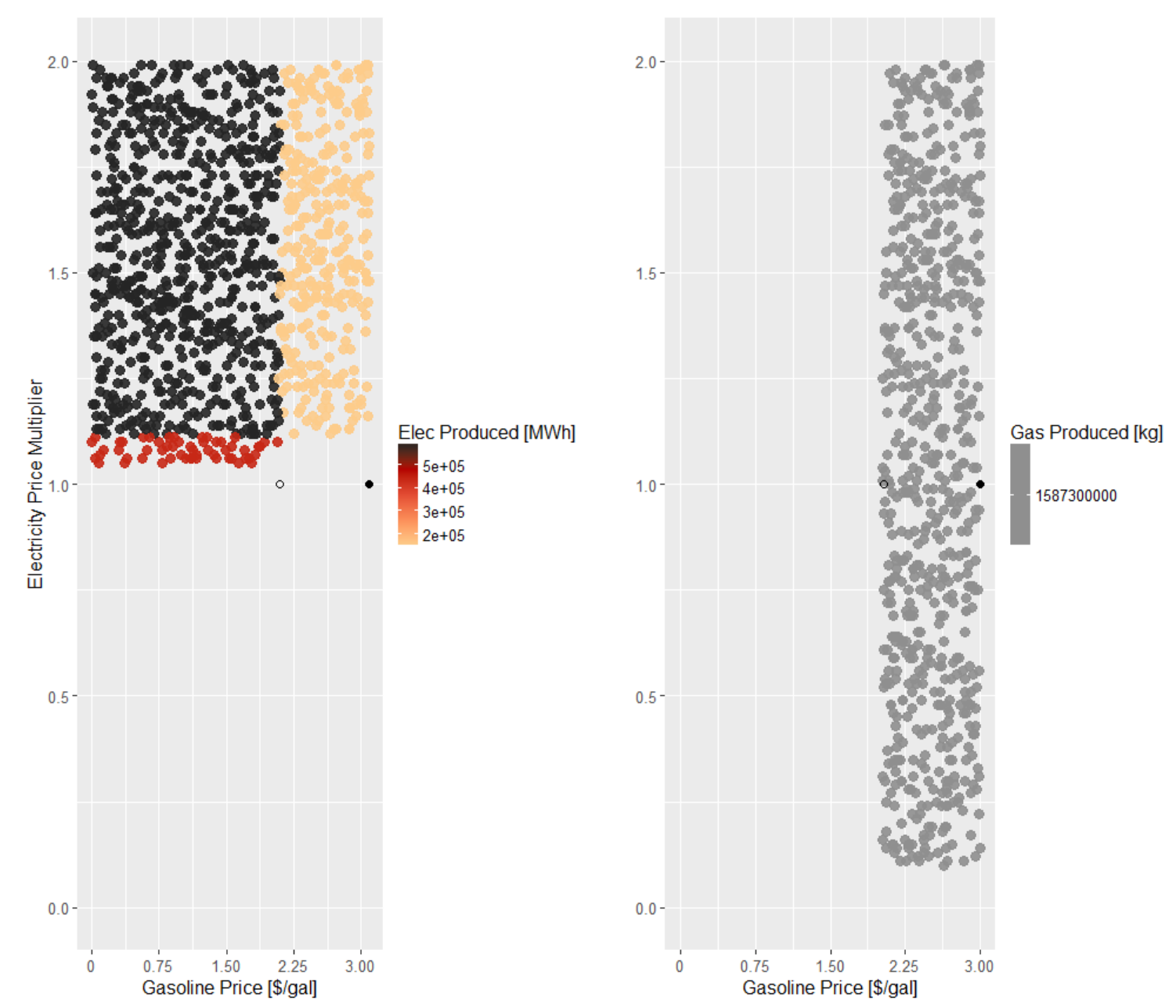

Figure G-54. Optimal annual product generation at various gasoline prices and electricity price multipliers for the Texas-synthetic gasoline scenario based on RPS80 generation mix, AEO reference case, nominal discount rate of $8.15 \%$, and $\$ 150 / \mathrm{kW}$-yr capacity payments.

Electricity is shown on the left with greater generation at the darker color. Synthetic gasoline is shown on the right.

Solid black dot at electricity price multiplier of 1.0 and $\$ 3.00 /$ gal gasoline price: reference case gasoline price projection; reference-case electricity price vector

Open black dot: minimum gasoline selling price for a synthetic gasoline plant using natural gas heating; reference-case electricity price vector 


\section{G.7 Sensitivities on the Impacts of Electricity and Gasoline Prices Based on a $600 \mathrm{MWt}(180 \mathrm{MWe})$ Maximum Capacity of the Nuclear Reactor and Thermal Power Cycle}

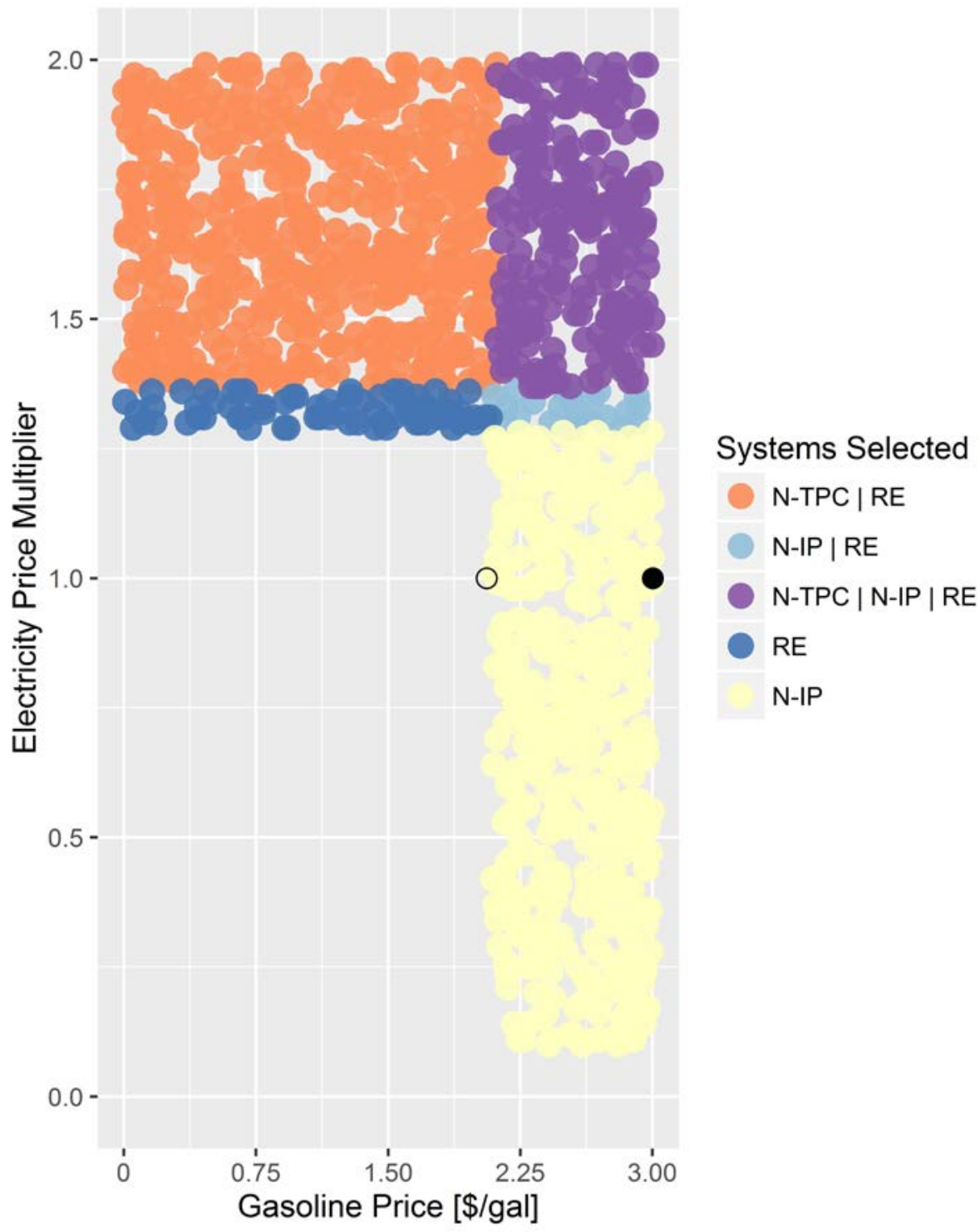

Figure G-55. Optimal configurations for the Texas-synthetic gasoline scenario at various gasoline prices and electricity price multipliers based on a $600 \mathrm{MWt}(180 \mathrm{MWe})$ maximum capacity of the nuclear reactor and thermal power cycle and $\$ 50 / \mathrm{kW}$-yr capacity payments

N-TPC: Nuclear reactor and thermal

N-IP: Nuclear reactor and industrial process

$\mathrm{RE}$ : Renewable electricity generation

Solid black dot at electricity price multiplier of 1.0 and $\$ 3.00 /$ gal gasoline price: reference case gasoline price projection; reference-case electricity price vector

Open black dot: minimum gasoline selling price for a synthetic gasoline plant using natural gas heating; reference-case electricity price vector 


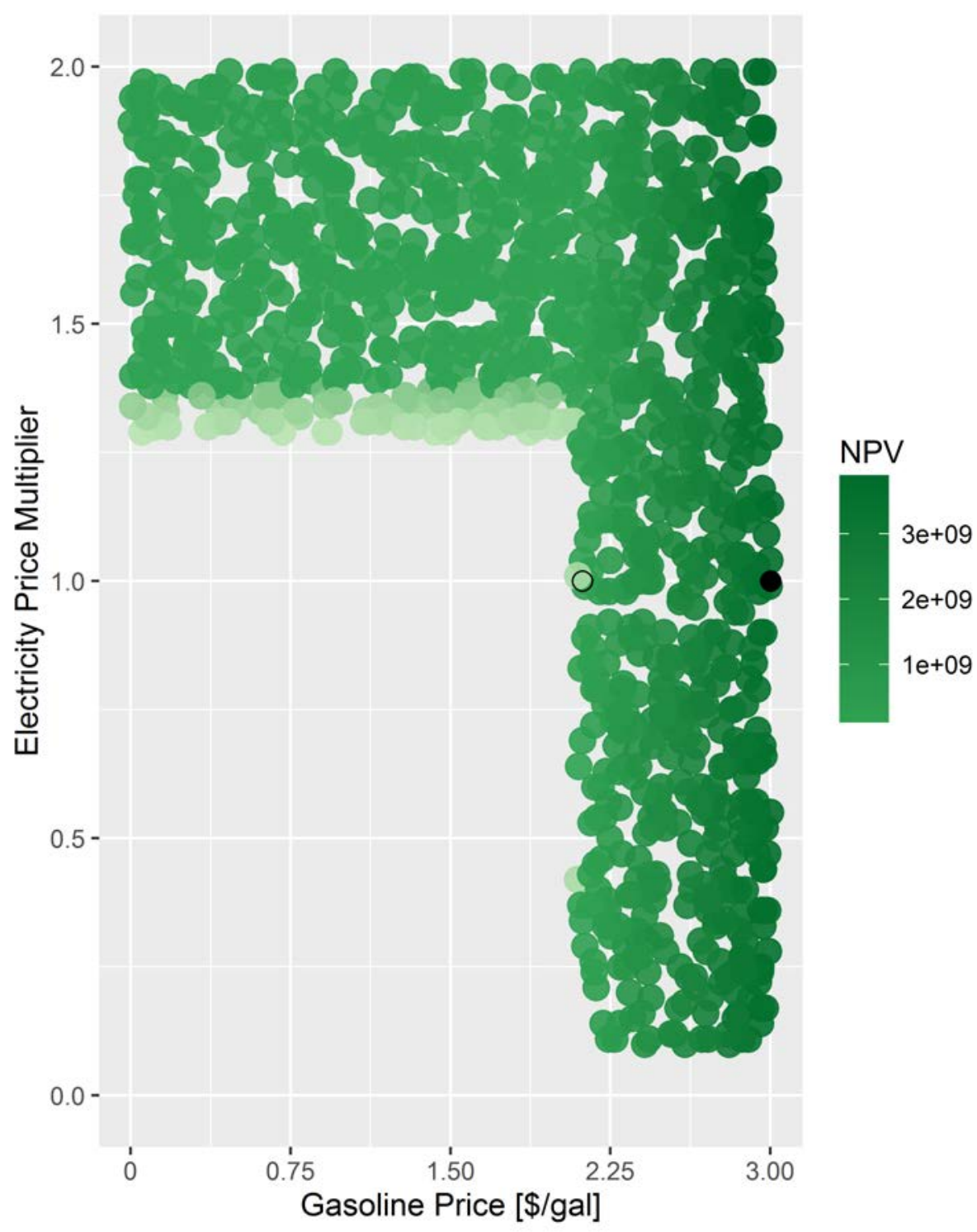

Figure G-56. Texas-synthetic gasoline scenario NPVs at various gasoline prices and electricity price multipliers based on a $600 \mathrm{MWt}(180 \mathrm{MWe})$ maximum capacity of the nuclear reactor and thermal power cycle and $\$ 50 / k W-y r$ capacity payments.

Darker shades indicate higher NPVs.

Solid black dot at electricity price multiplier of 1.0 and $\$ 3.00 /$ gal gasoline price: reference case gasoline price projection; reference-case electricity price vector

Open black dot: minimum gasoline selling price for a synthetic gasoline plant using natural gas heating; reference-case electricity price vector 


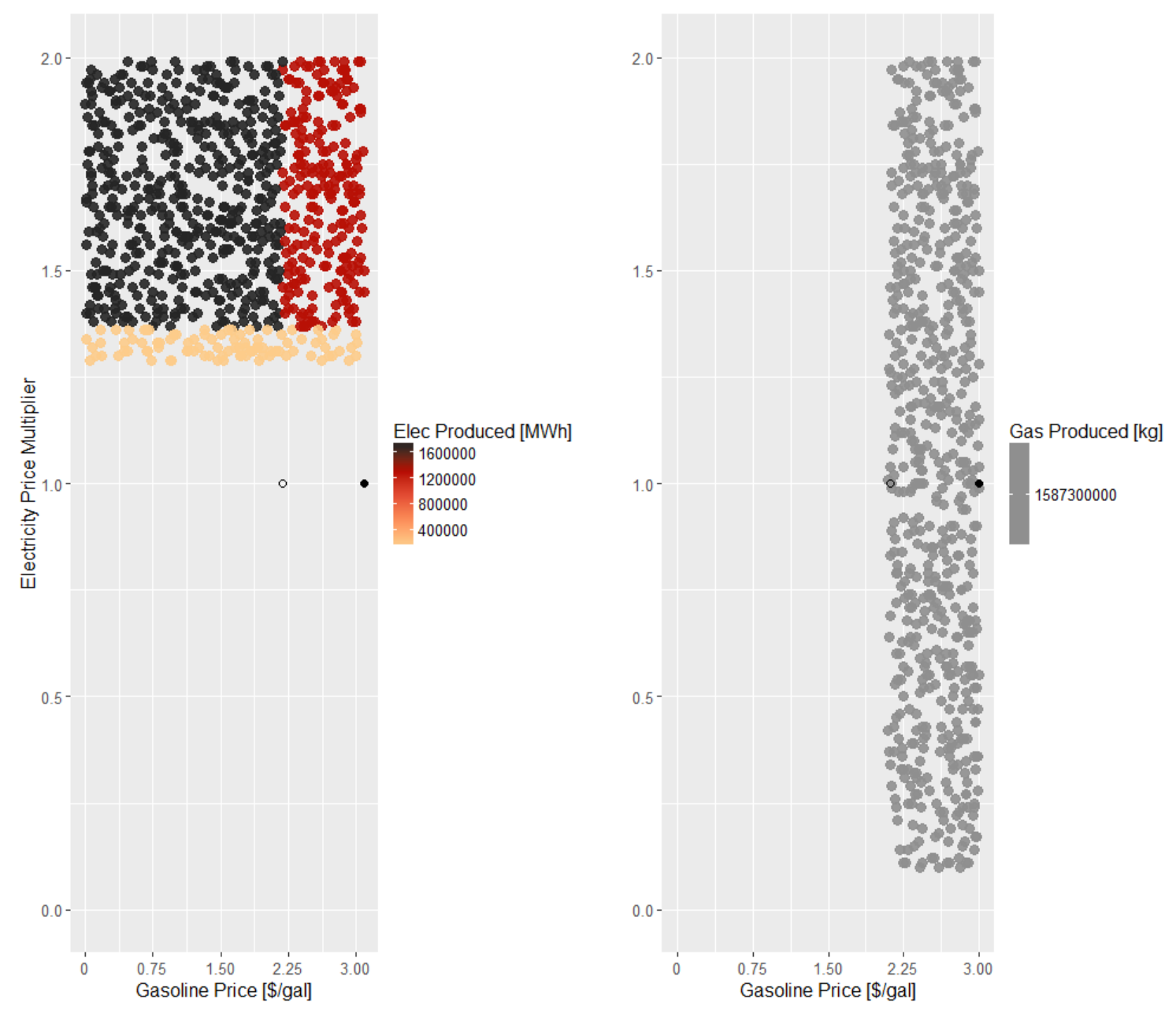

Figure G-57. Optimal annual product generation at various gasoline prices and electricity price multipliers for the Texas-synthetic gasoline scenario based on a $600 \mathrm{MWt}(180 \mathrm{MWe})$ maximum capacity of the nuclear reactor and thermal power cycle and $\$ 50 / \mathbf{k W}$-yr capacity payments.

Electricity is shown on the left with greater generation at the darker color.

Synthetic gasoline is shown on the right.

Solid black dot at electricity price multiplier of 1.0 and $\$ 3.00 /$ gal gasoline price: reference case gasoline price projection; reference-case electricity price vector

Open black dot: minimum gasoline selling price for a synthetic gasoline plant using natural gas heating; reference-case electricity price vector 


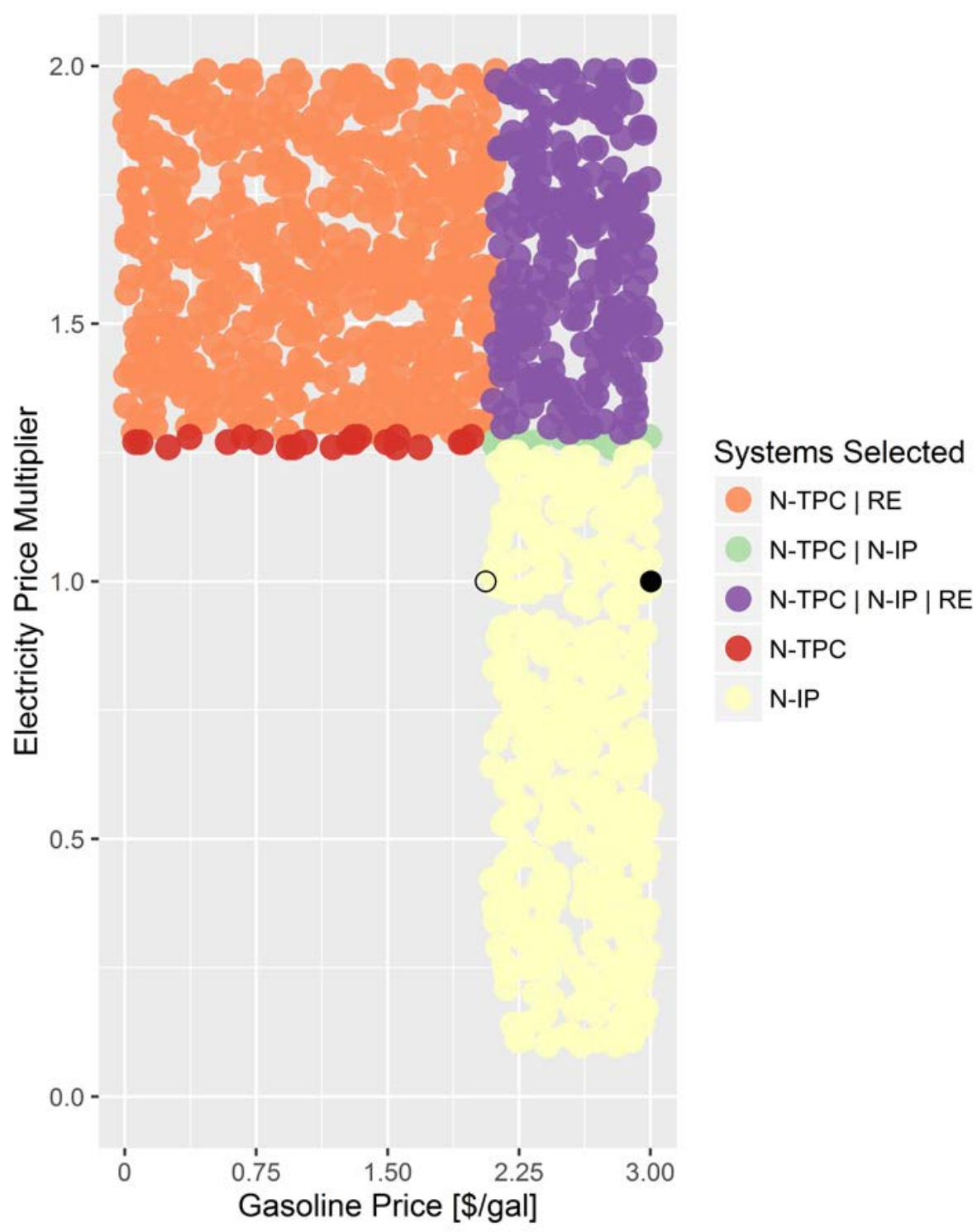

Figure G-58. Optimal configurations for the Texas-synthetic gasoline scenario at various gasoline prices and electricity price multipliers based on a $600 \mathrm{MWt}(180 \mathrm{MWe})$ maximum capacity of the nuclear reactor and thermal power cycle and $\$ 100 / \mathrm{kW}$-yr capacity payments

N-TPC: Nuclear reactor and thermal

N-IP: Nuclear reactor and industrial process

$\mathrm{RE}$ : Renewable electricity generation

Solid black dot at electricity price multiplier of 1.0 and $\$ 3.00 /$ gal gasoline price: reference case gasoline price projection; reference-case electricity price vector

Open black dot: minimum gasoline selling price for a synthetic gasoline plant using natural gas heating; reference-case electricity price vector 


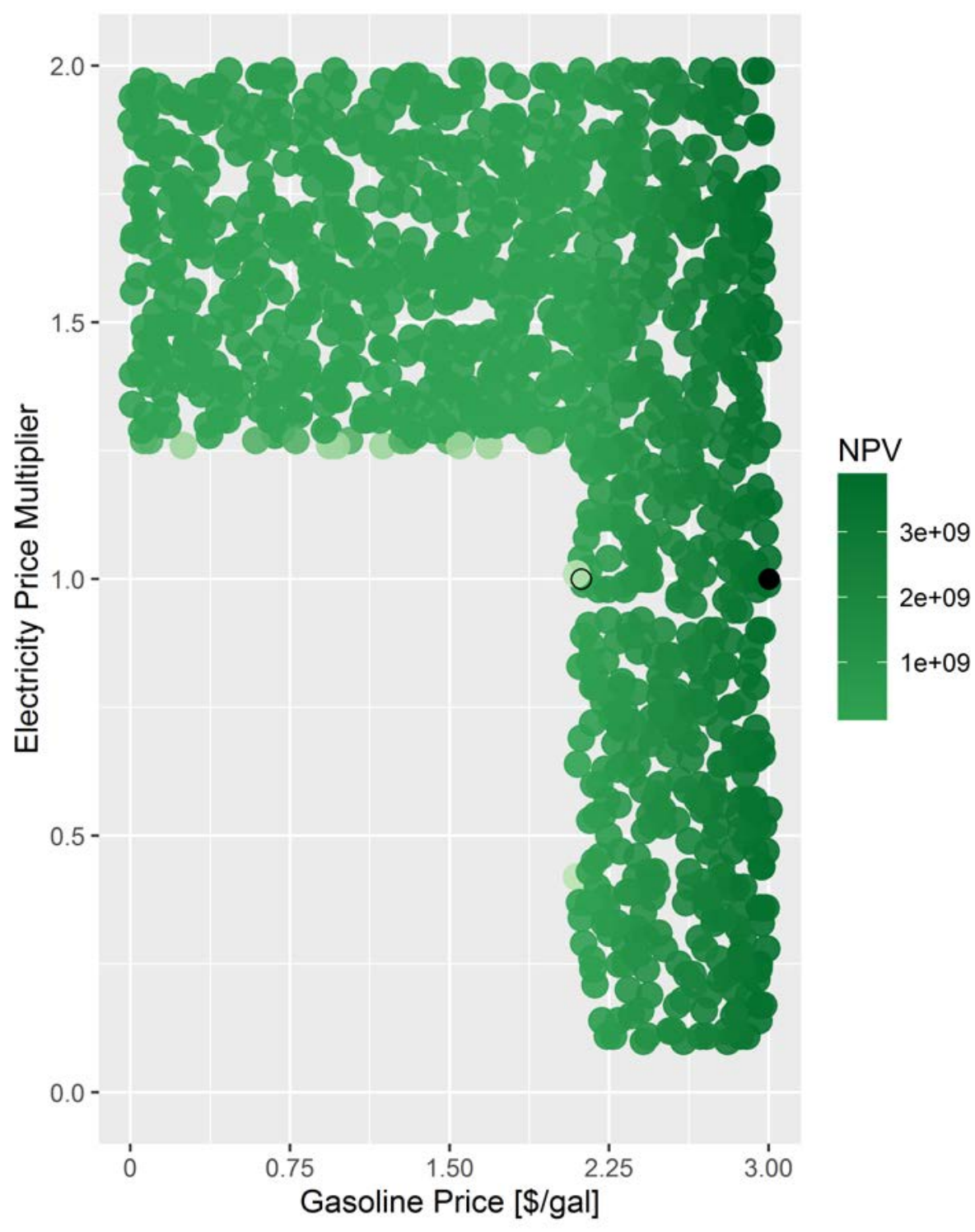

Figure G-59. Texas-synthetic gasoline scenario NPVs at various gasoline prices and electricity price multipliers based on a $600 \mathrm{MWt}(180 \mathrm{MWe})$ maximum capacity of the nuclear reactor and thermal power cycle and $\$ 100 / \mathrm{kW}$-yr capacity payments.

Darker shades indicate higher NPVs.

Solid black dot at electricity price multiplier of 1.0 and $\$ 3.00 /$ gal gasoline price: reference case gasoline price projection; reference-case electricity price vector

Open black dot: minimum gasoline selling price for a synthetic gasoline plant using natural gas heating; reference-case electricity price vector 

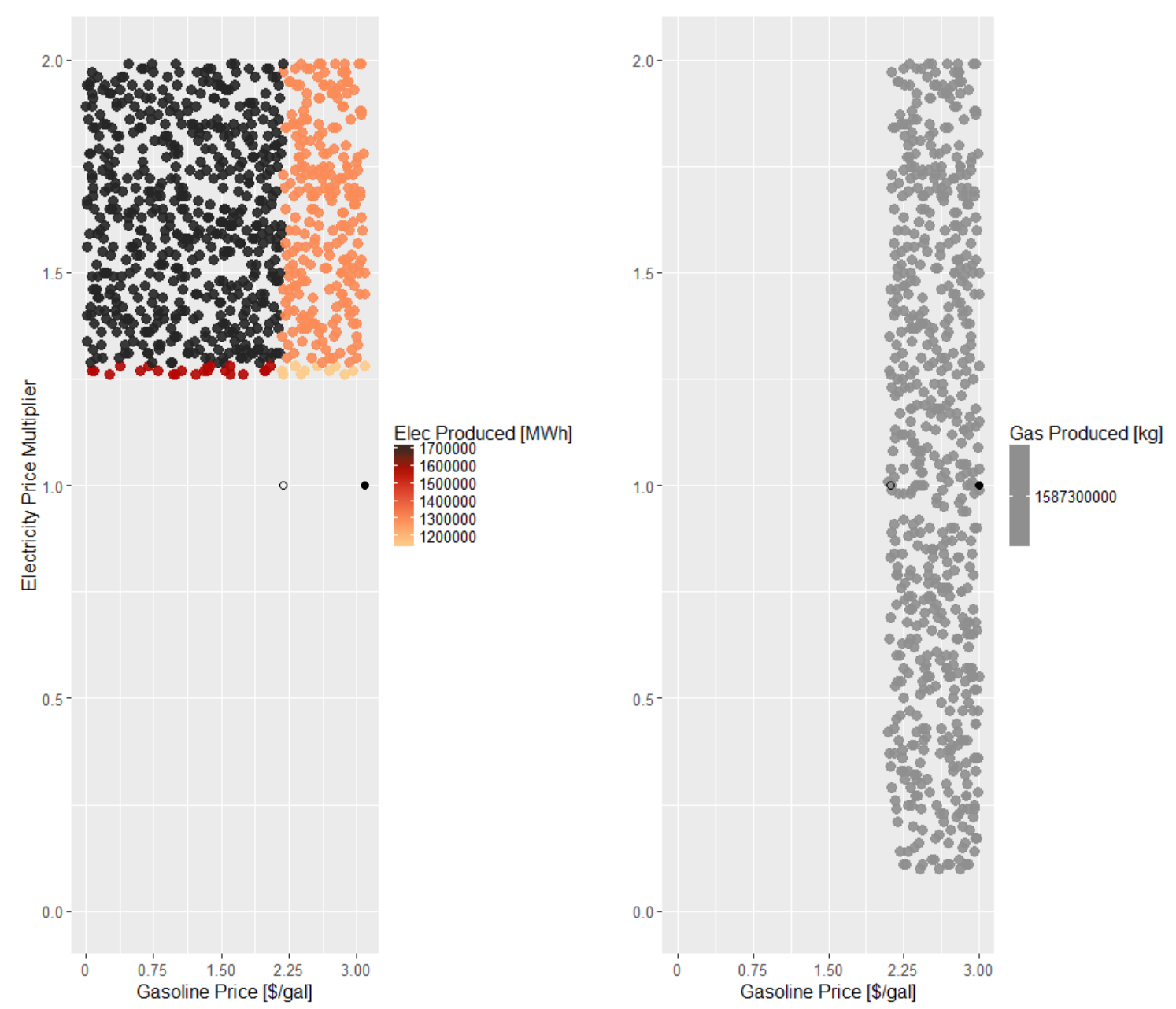

Figure G-60. Optimal annual product generation at various gasoline prices and electricity price multipliers for the Texas-synthetic gasoline scenario based on a $600 \mathrm{MWt}$ (180MWe) maximum capacity of the nuclear reactor and thermal power cycle and $\$ 100 / \mathrm{kW}$-yr capacity payments.

Electricity is shown on the left with greater generation at the darker color.

Synthetic gasoline is shown on the right.

Solid black dot at electricity price multiplier of 1.0 and $\$ 3.00 /$ gal gasoline price: reference case gasoline price projection; reference-case electricity price vector

Open black dot: minimum gasoline selling price for a synthetic gasoline plant using natural gas heating; reference-case electricity price vector 


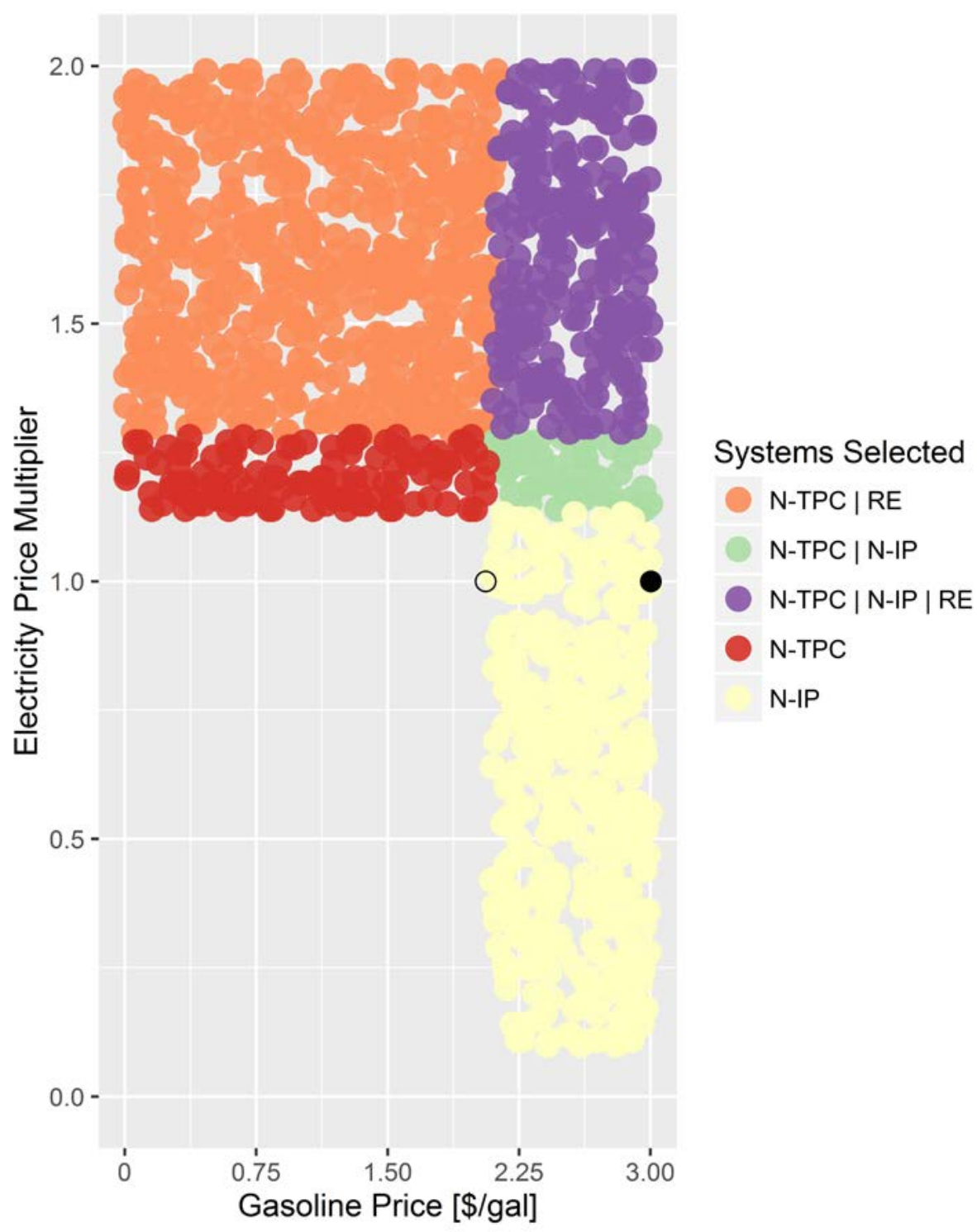

Figure G-61. Optimal configurations for the Texas-synthetic gasoline scenario at various gasoline prices and electricity price multipliers based on a $600 \mathrm{MWt}(180 \mathrm{MWe})$ maximum capacity of the nuclear reactor and thermal power cycle and $\$ 150 / \mathrm{kW}$-yr capacity payments

N-TPC: Nuclear reactor and thermal

N-IP: Nuclear reactor and industrial process

$\mathrm{RE}$ : Renewable electricity generation

Solid black dot at electricity price multiplier of 1.0 and $\$ 3.00 /$ gal gasoline price: reference case gasoline price projection; reference-case electricity price vector

Open black dot: minimum gasoline selling price for a synthetic gasoline plant using natural gas heating; reference-case electricity price vector 


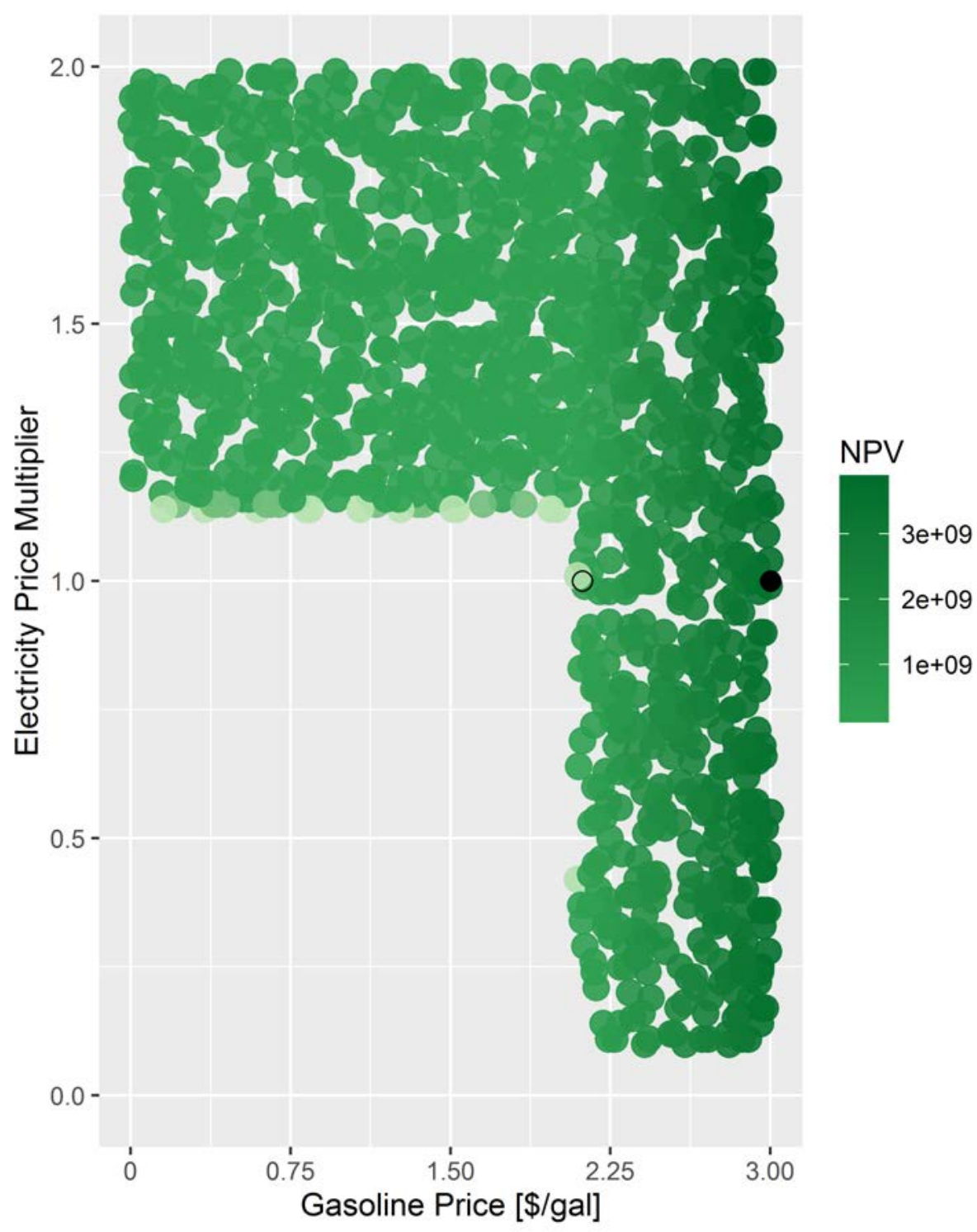

Figure G-62. Texas-synthetic gasoline scenario NPVs at various gasoline prices and electricity price multipliers based on a $600 \mathrm{MWt}(180 \mathrm{MWe})$ maximum capacity of the nuclear reactor and thermal power cycle and $\$ 150 / \mathrm{kW}$-yr capacity payments.

Darker shades indicate higher NPVs.

Solid black dot at electricity price multiplier of 1.0 and $\$ 3.00 /$ gal gasoline price: reference case gasoline price projection; reference-case electricity price vector

Open black dot: minimum gasoline selling price for a synthetic gasoline plant using natural gas heating; reference-case electricity price vector 

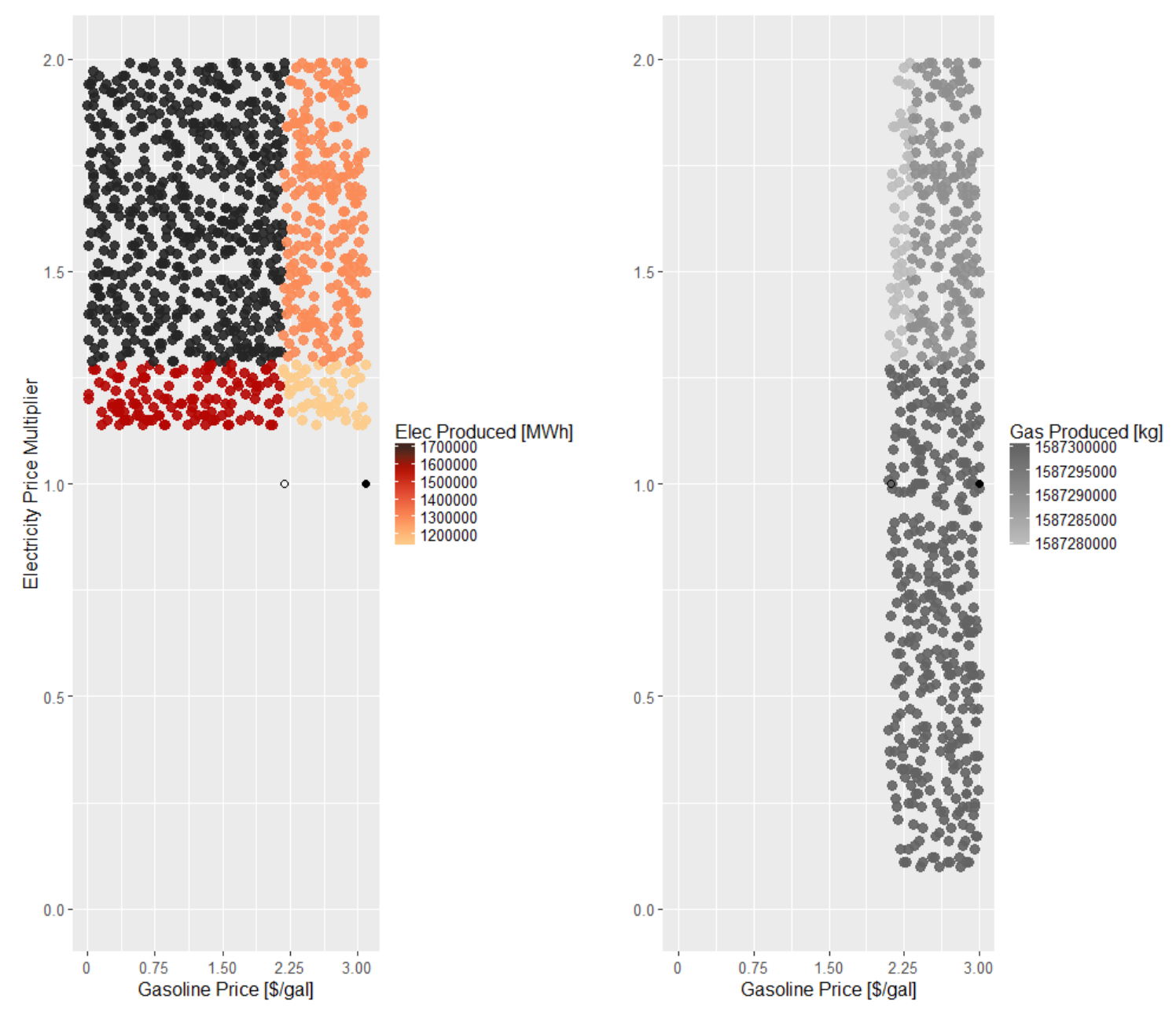

Figure G-63. Optimal annual product generation at various gasoline prices and electricity price multipliers for the Texas-synthetic gasoline scenario based on a $600 \mathrm{MWt}(180 \mathrm{MWe})$ maximum capacity of the nuclear reactor and thermal power cycle and $\$ 150 / \mathrm{kW}$-yr capacity payments.

Electricity is shown on the left with greater generation at the darker color. Synthetic gasoline is shown on the right.

Solid black dot at electricity price multiplier of 1.0 and $\$ 3.00 /$ gal gasoline price: reference case gasoline price projection; reference-case electricity price vector

Open black dot: minimum gasoline selling price for a synthetic gasoline plant using natural gas heating; reference-case electricity price vector 


\section{Appendix H Additional Results from the Arizona- Desalination Case}

\section{H.1 Sensitivities on the Impacts of Electricity and Water Prices Based on the RPS80 Generation Mix and Annual Energy Outlook Reference-Case Electricity Prices}

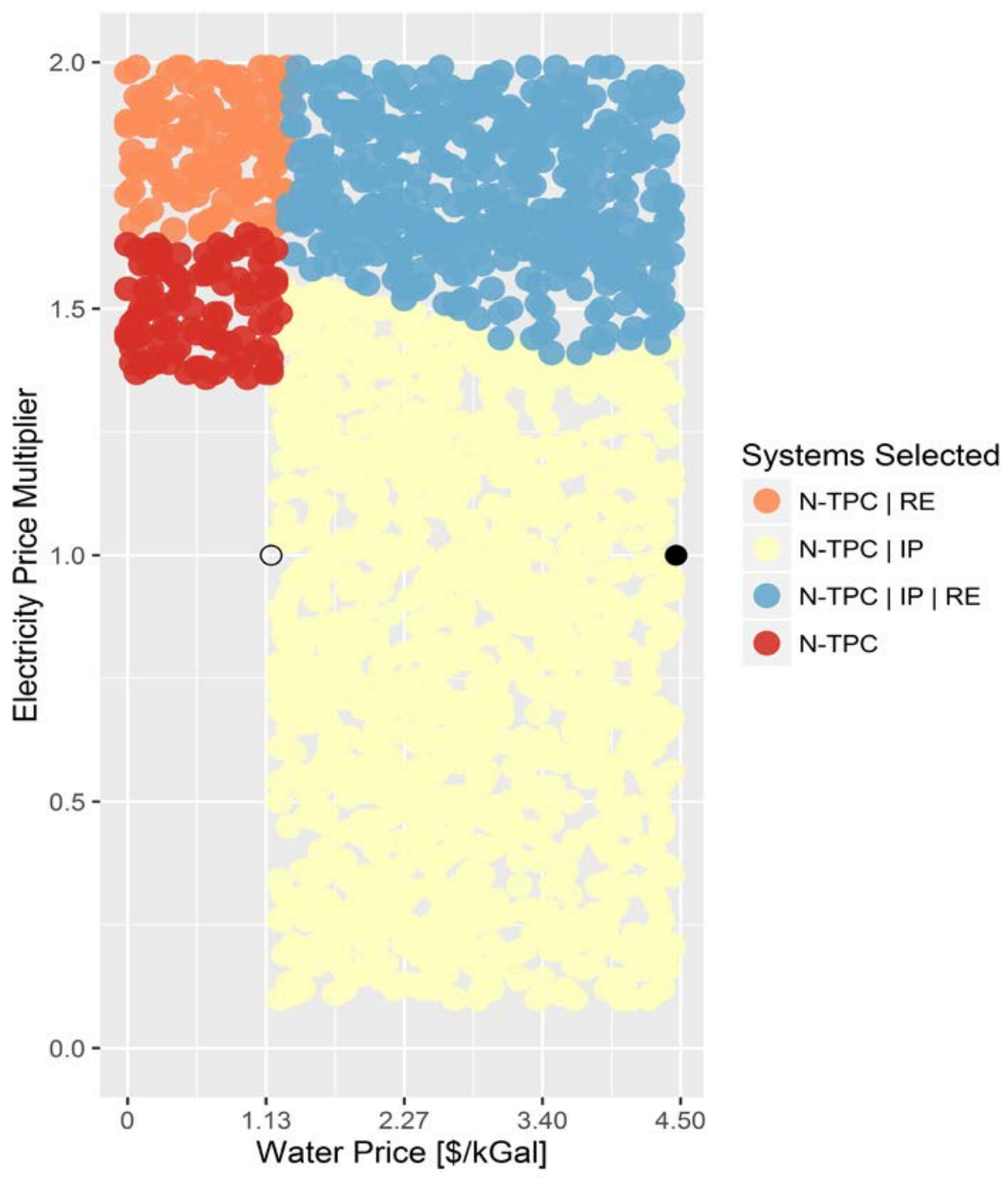

Figure H-1. Optimal configurations for Arizona-desalination scenario at various water prices and electricity price multipliers based on RPS80 generation mix, AEO reference case prices, and $\$ 50 / k W-y r$ capacity payments

N-TPC: Nuclear reactor and thermal

$\mathrm{N}$-IP: Nuclear reactor and industrial process

$\mathrm{RE}$ : Renewable electricity generation

Solid black dot at electricity price multiplier of 1.0 and $\$ 4.50 /$ thousand gal water price: reference case water price projection; reference-case electricity price vector

Open black dot: minimum water selling price for an RO desalination plant; reference-case electricity price vector 


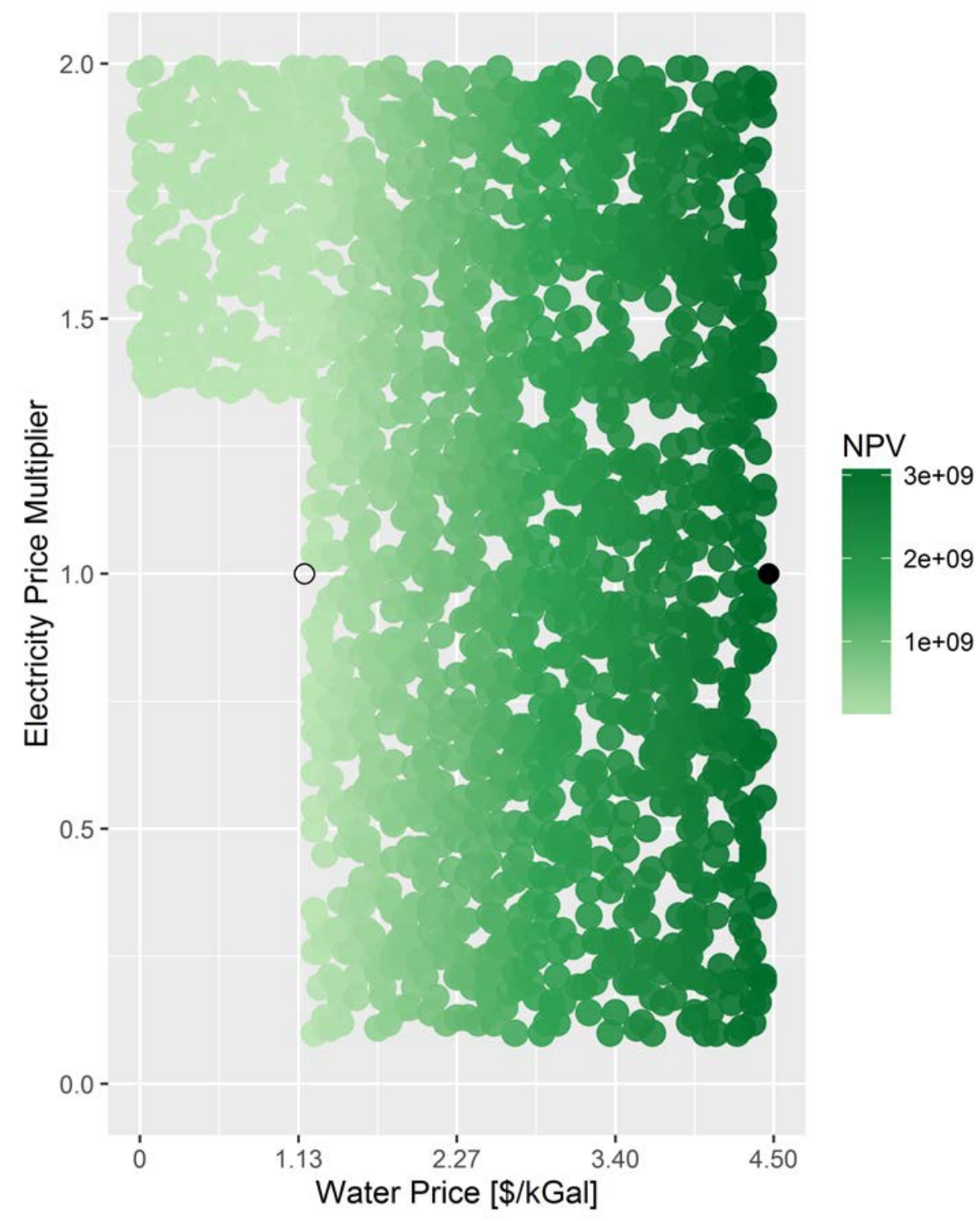

Figure H-2. Arizona-desalination scenario NPVs at various water prices and electricity price multipliers based on RPS80 generation mix, AEO reference-case prices, and $\$ 50 / \mathbf{k W}$-yr capacity payments.

Darker shades indicate higher NPVs.

Solid black dot at electricity price multiplier of 1.0 and $\$ 4.50 /$ thousand gal water price: reference case water price projection; reference-case electricity price vector

Open black dot: minimum water selling price for an $\mathrm{RO}$ desalination plant; reference-case electricity price vector 

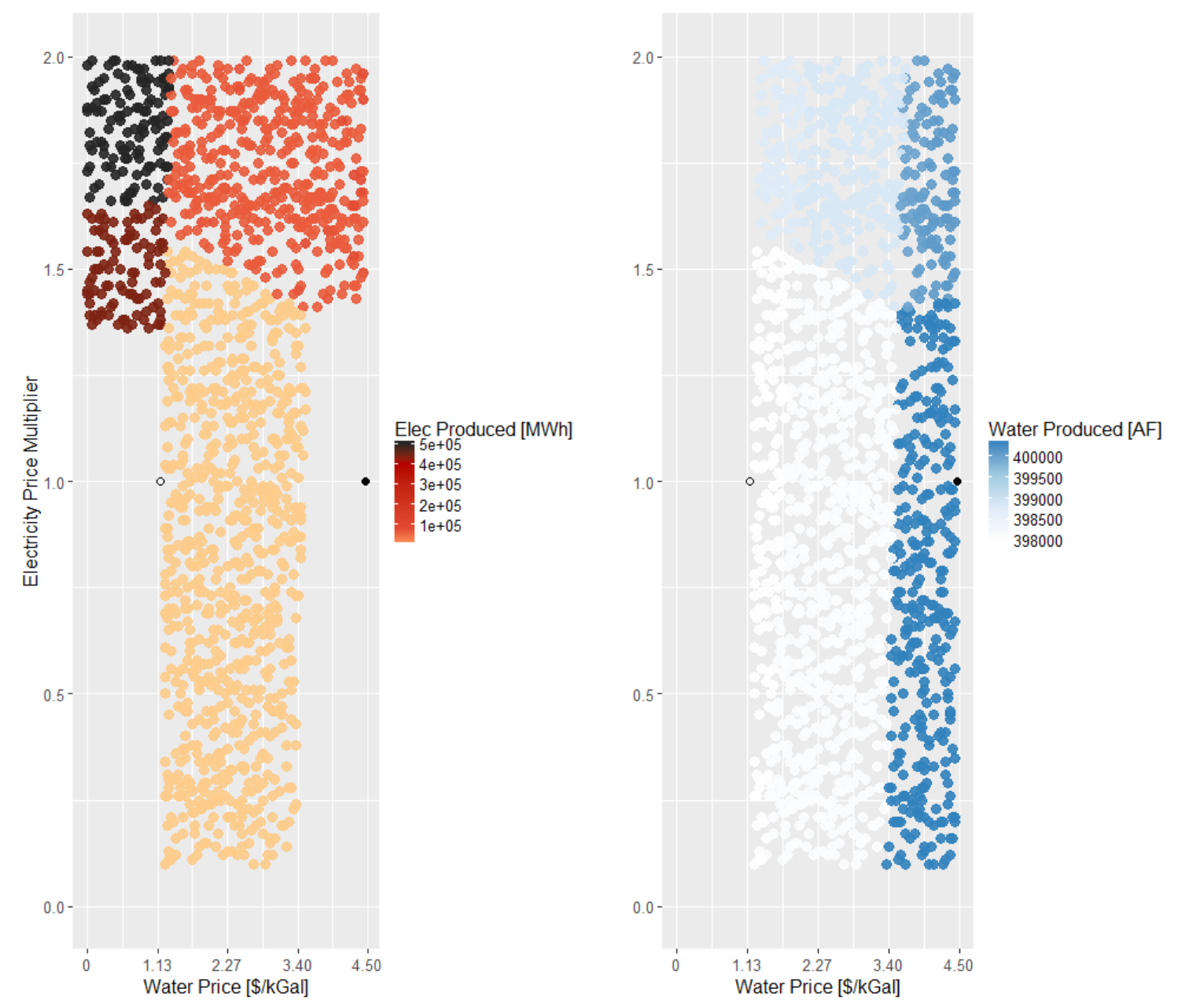

Figure H-3. Optimal annual product generation for Arizona-desalination scenario at various water prices and electricity price multipliers based on RPS80 generation mix, AEO reference-case prices, and $\$ 50 / \mathrm{kW}-\mathrm{yr}$ capacity payments.

Electricity is shown on the left with greater generation at the darker color. Water is shown on the right.

Solid black dot at electricity price multiplier of 1.0 and $\$ 4.50 /$ thousand gal water price: reference case water price projection; reference-case electricity price vector

Open black dot: minimum water selling price for an RO desalination plant; reference-case electricity price vector 


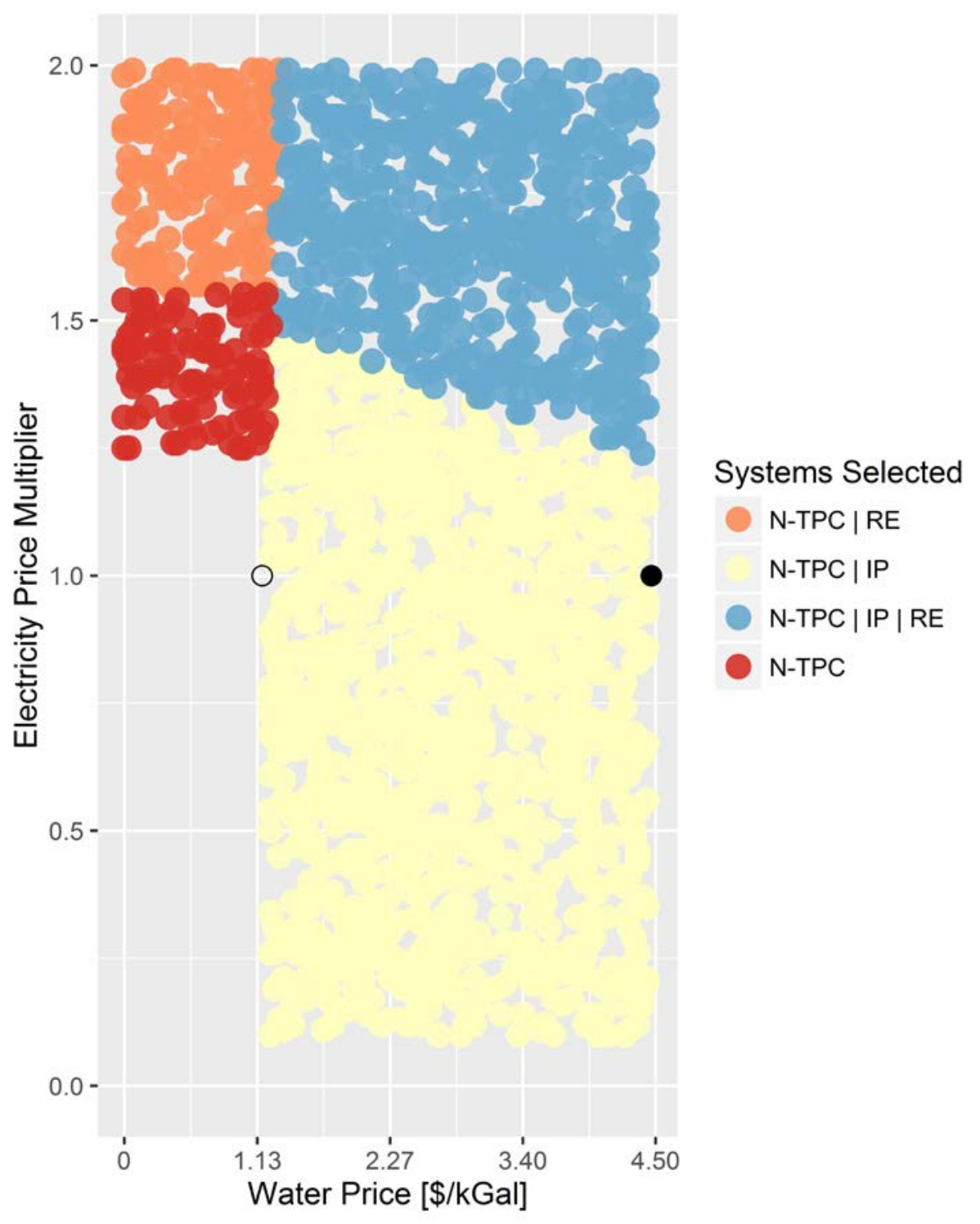

Figure H-4. Optimal configurations for Arizona-desalination scenario at various water prices and electricity price multipliers based on RPS80 generation mix, AEO reference-case prices, and $\$ 100 / \mathrm{kW}$-yr capacity payments

N-TPC: Nuclear reactor and thermal

N-IP: Nuclear reactor and industrial process

RE: Renewable electricity generation

Solid black dot at electricity price multiplier of 1.0 and $\$ 4.50 /$ thousand gal water price: reference case water price projection; reference-case electricity price vector

Open black dot: minimum water selling price for an RO desalination plant; reference-case electricity price vector 


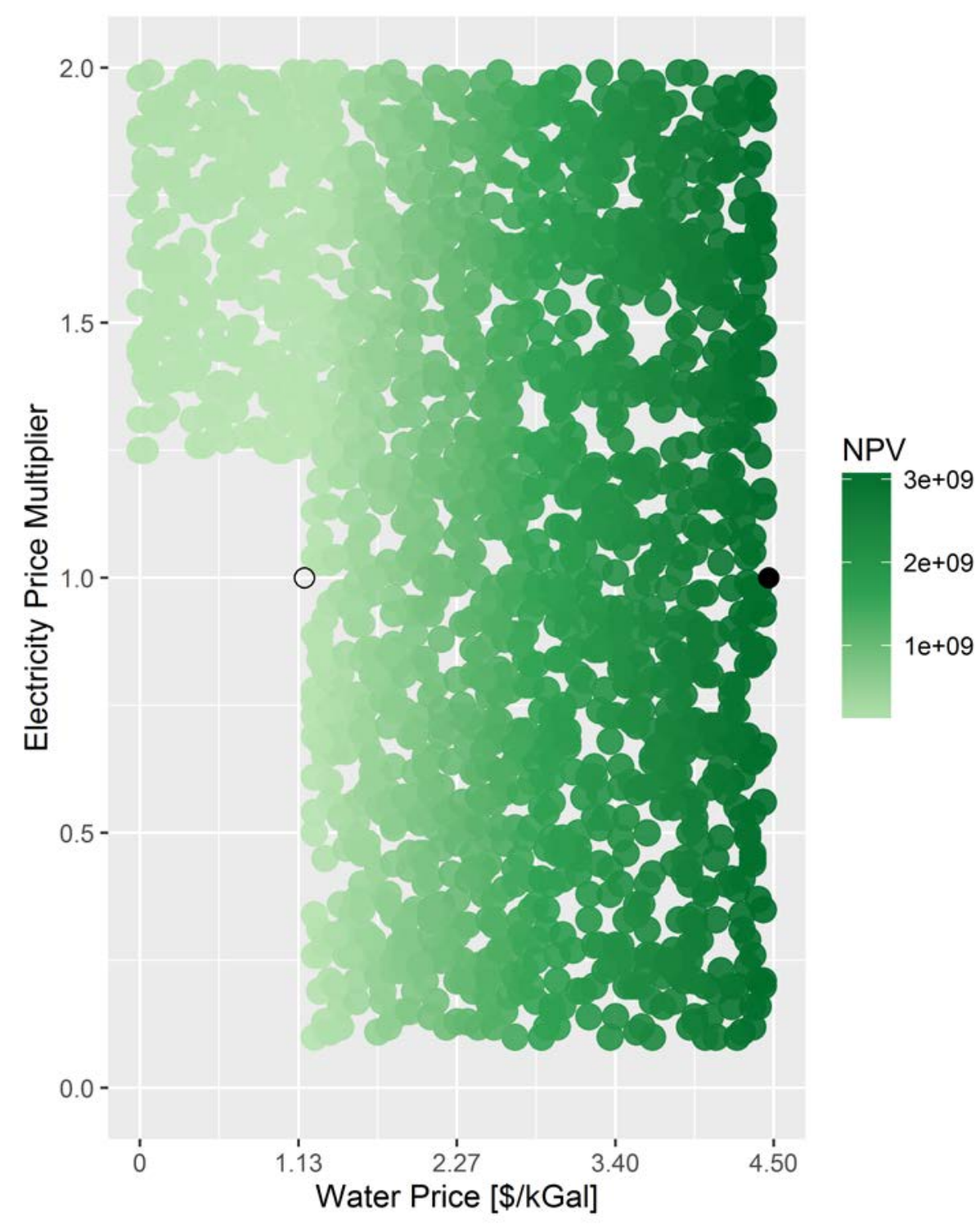

Figure H-5. Arizona-desalination scenario NPVs at various water prices and electricity price multipliers based on RPS80 generation mix, AEO reference-case prices, and \$100/kW-yr capacity payments.

Darker shades indicate higher NPVs.

Solid black dot at electricity price multiplier of 1.0 and $\$ 4.50 /$ thousand gal water price: reference case water price projection; reference-case electricity price vector

Open black dot: minimum water selling price for an $\mathrm{RO}$ desalination plant; reference-case electricity price vector 

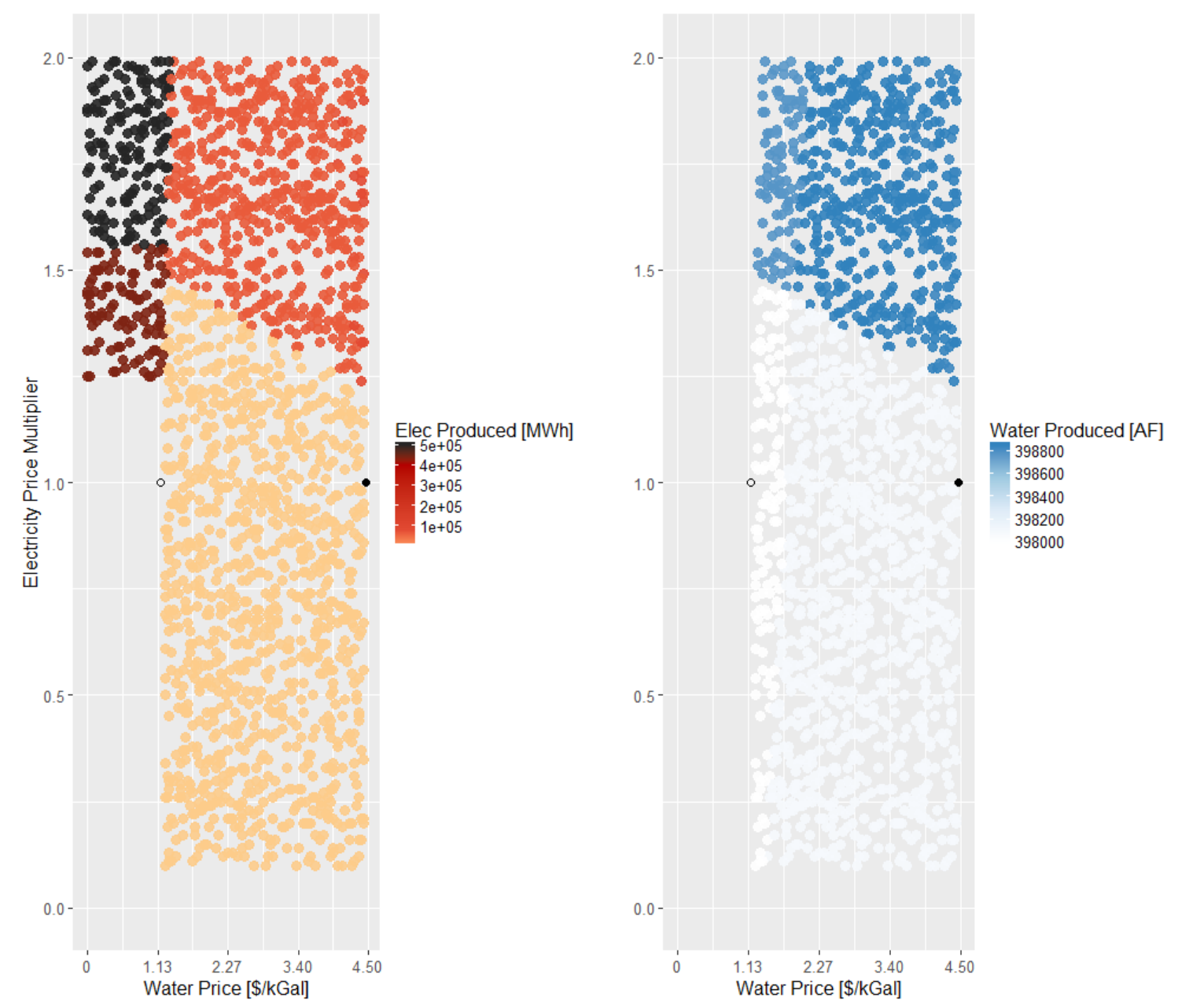

Figure H-6. Optimal annual product generation for Arizona-desalination scenario at various water prices and electricity price multipliers based on RPS80 generation mix, AEO reference-case prices, and $\$ 100 / \mathrm{kW}-\mathrm{yr}$ capacity payments.

Electricity is shown on the left with greater generation at the darker color. Water is shown on the right.

Solid black dot at electricity price multiplier of 1.0 and $\$ 4.50 /$ thousand gal water price: reference case water price projection; reference-case electricity price vector

Open black dot: minimum water selling price for an $\mathrm{RO}$ desalination plant; reference-case electricity price vector 


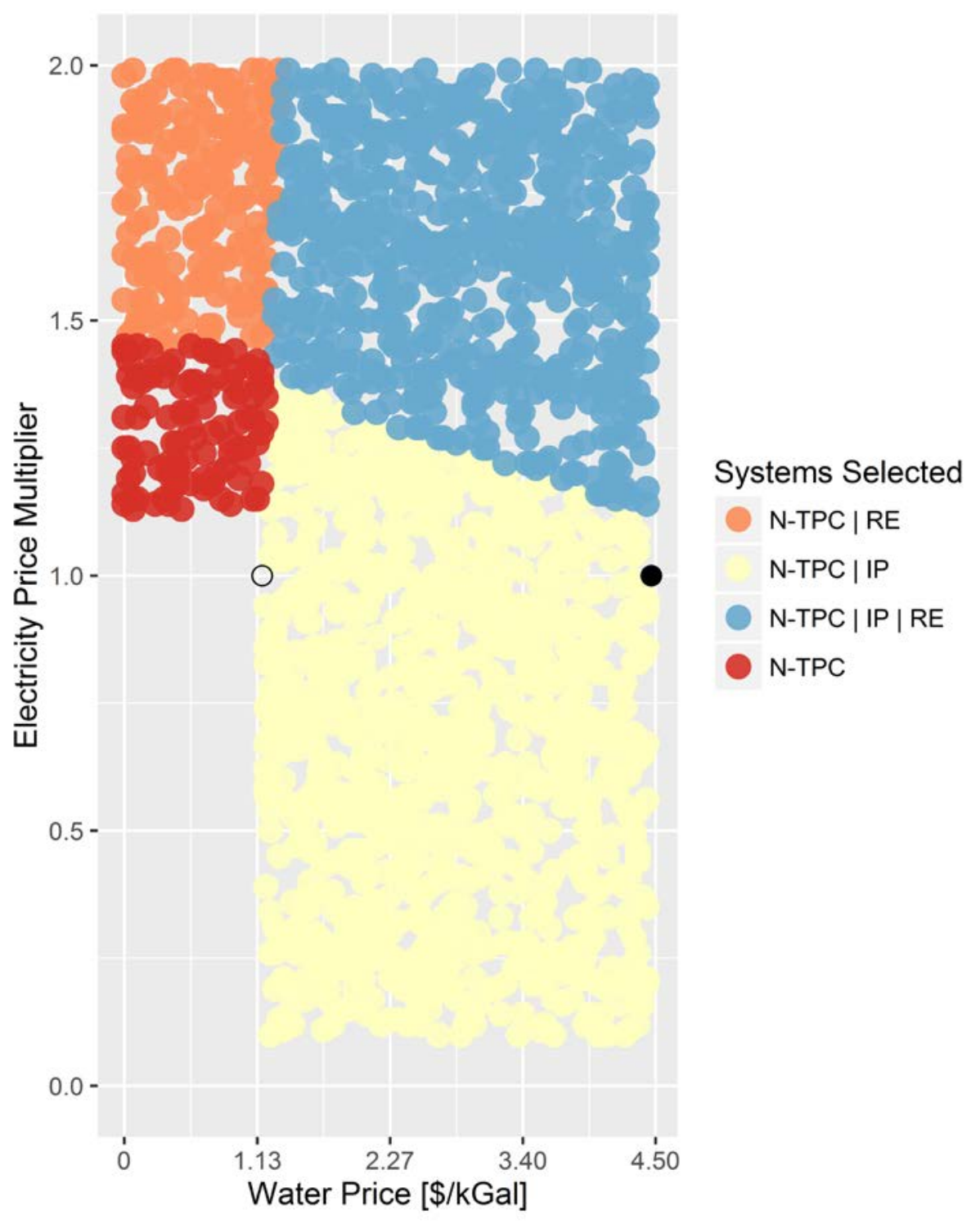

Figure H-7. Optimal configurations for Arizona-desalination scenario at various water prices and electricity price multipliers based on RPS80 generation mix, AEO reference-case prices, and $\$ 150 / k W-y r$ capacity payments

N-TPC: Nuclear reactor and thermal

N-IP: Nuclear reactor and industrial process

RE: Renewable electricity generation

Solid black dot at electricity price multiplier of 1.0 and $\$ 4.50 /$ thousand gal water price: reference case water price projection; reference-case electricity price vector

Open black dot: minimum water selling price for an RO desalination plant; reference-case electricity price vector 


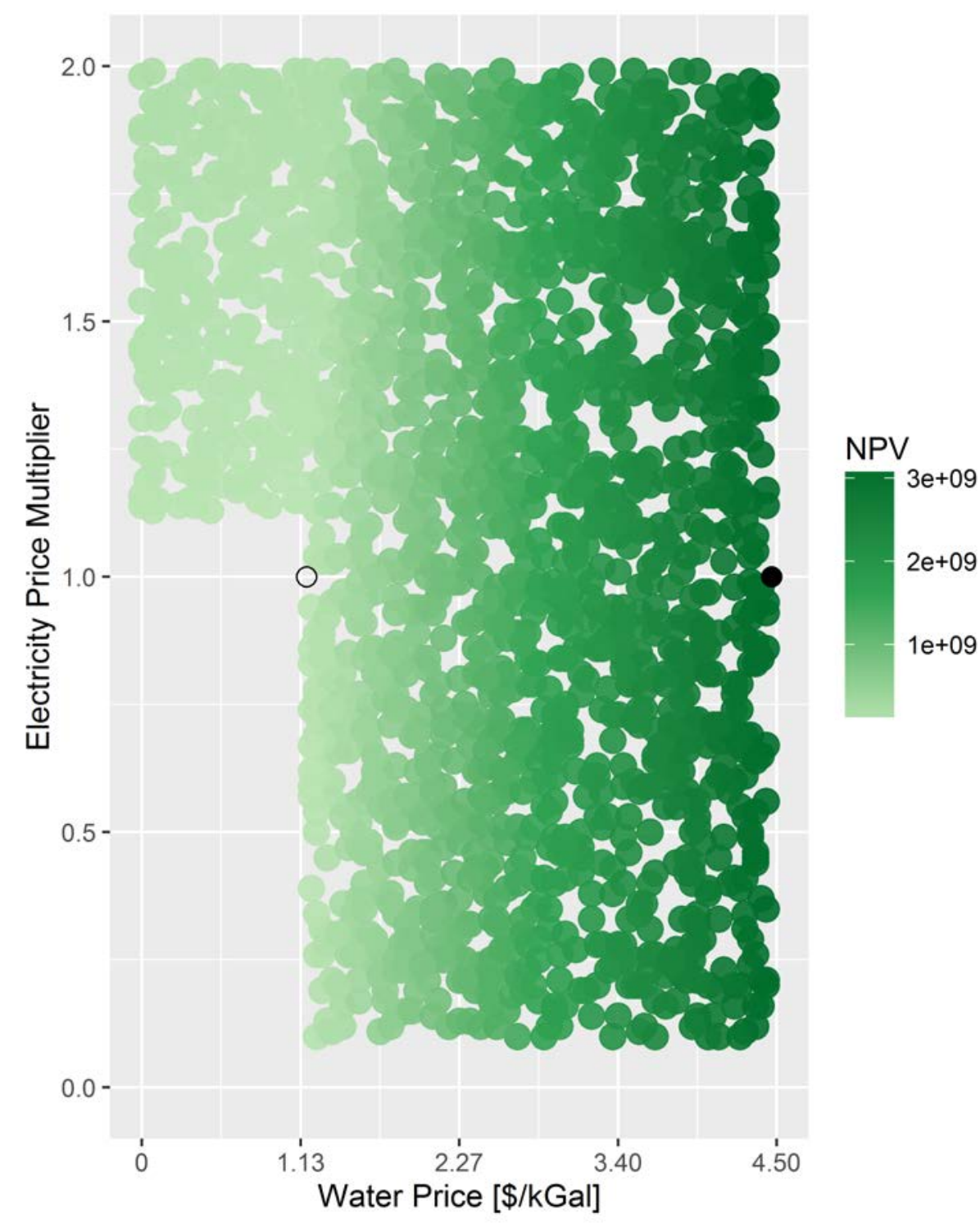

Figure H-8. Arizona-desalination scenario NPVs at various water prices and electricity price multipliers based on RPS80 generation mix, AEO reference-case prices, and \$150/kW-yr capacity payments.

Darker shades indicate higher NPVs.

Solid black dot at electricity price multiplier of 1.0 and $\$ 4.50 /$ thousand gal water price: reference case water price projection; reference-case electricity price vector

Open black dot: minimum water selling price for an $\mathrm{RO}$ desalination plant; reference-case electricity price vector 

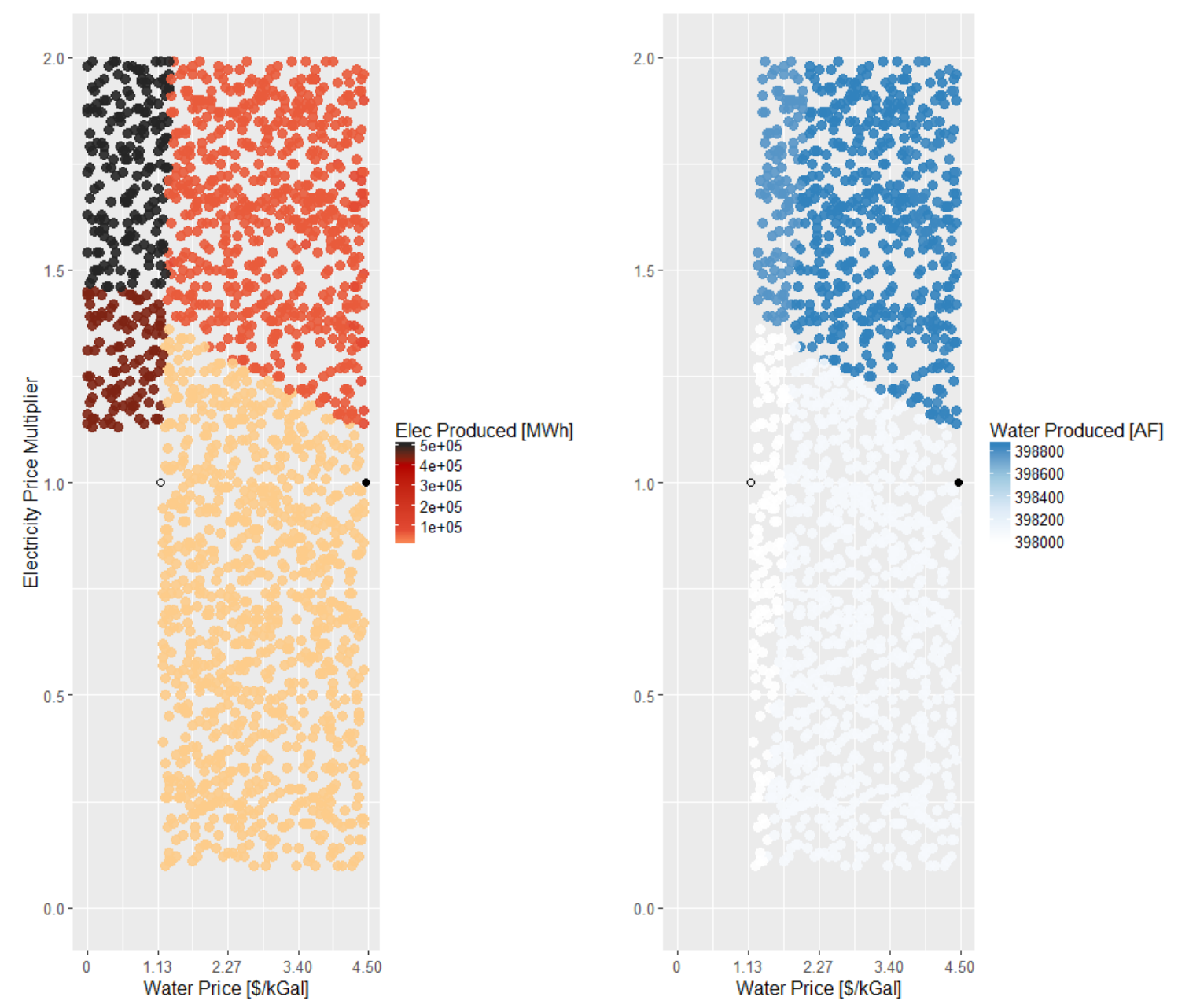

Figure H-9. Optimal annual product generation for Arizona-desalination scenario at various water prices and electricity price multipliers based on RPS80 generation mix, AEO reference-case prices, and $\$ 150 / \mathrm{kW}-\mathrm{yr}$ capacity payments.

Electricity is shown on the left with greater generation at the darker color. Water is shown on the right. Solid black dot at electricity price multiplier of 1.0 and $\$ 4.50 /$ thousand gal water price: reference case water price projection; reference-case electricity price vector

Open black dot: minimum water selling price for an RO desalination plant; reference-case electricity price vector 


\section{H.2 Sensitivities on the Impacts of Water Prices and Water Production Efficiencies Based on the RPS80 Generation Mix and Reference-Case Electricity Prices}

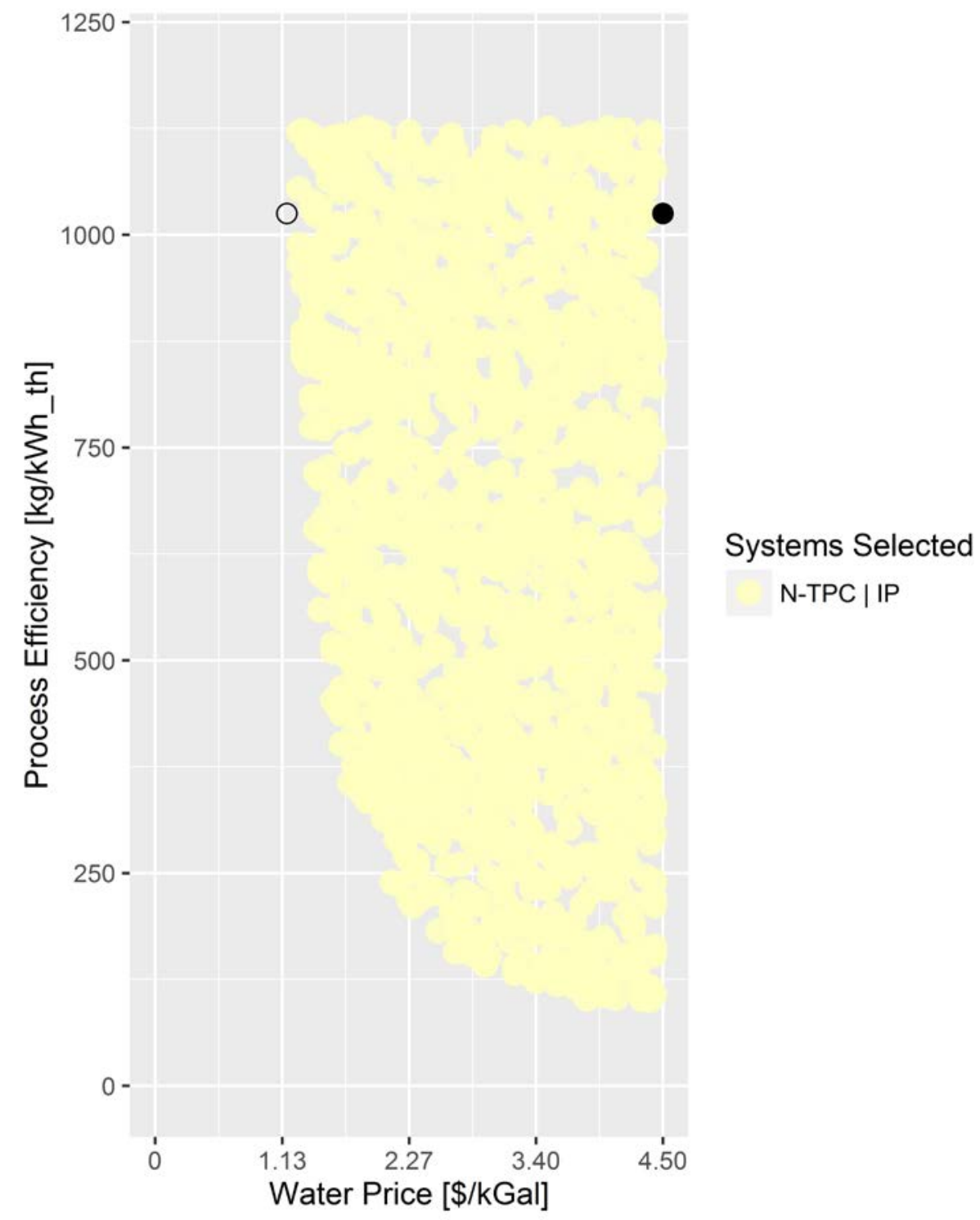

Figure H-10. Optimal configurations for Arizona-desalination scenario at various water prices and industrial process efficiencies based on RPS80 generation mix, AEO reference-case prices, and $\$ 50 / k W$-yr capacity payments

N-TPC: Nuclear reactor and thermal

N-IP: Nuclear reactor and industrial process

$\mathrm{RE}$ : Renewable electricity generation

Solid black dot at electricity price multiplier of 1.0 and $\$ 4.50 /$ thousand gal water price: reference case water price projection; reference-case electricity price vector

Open black dot: minimum water selling price for an RO desalination plant; reference-case electricity price vector 


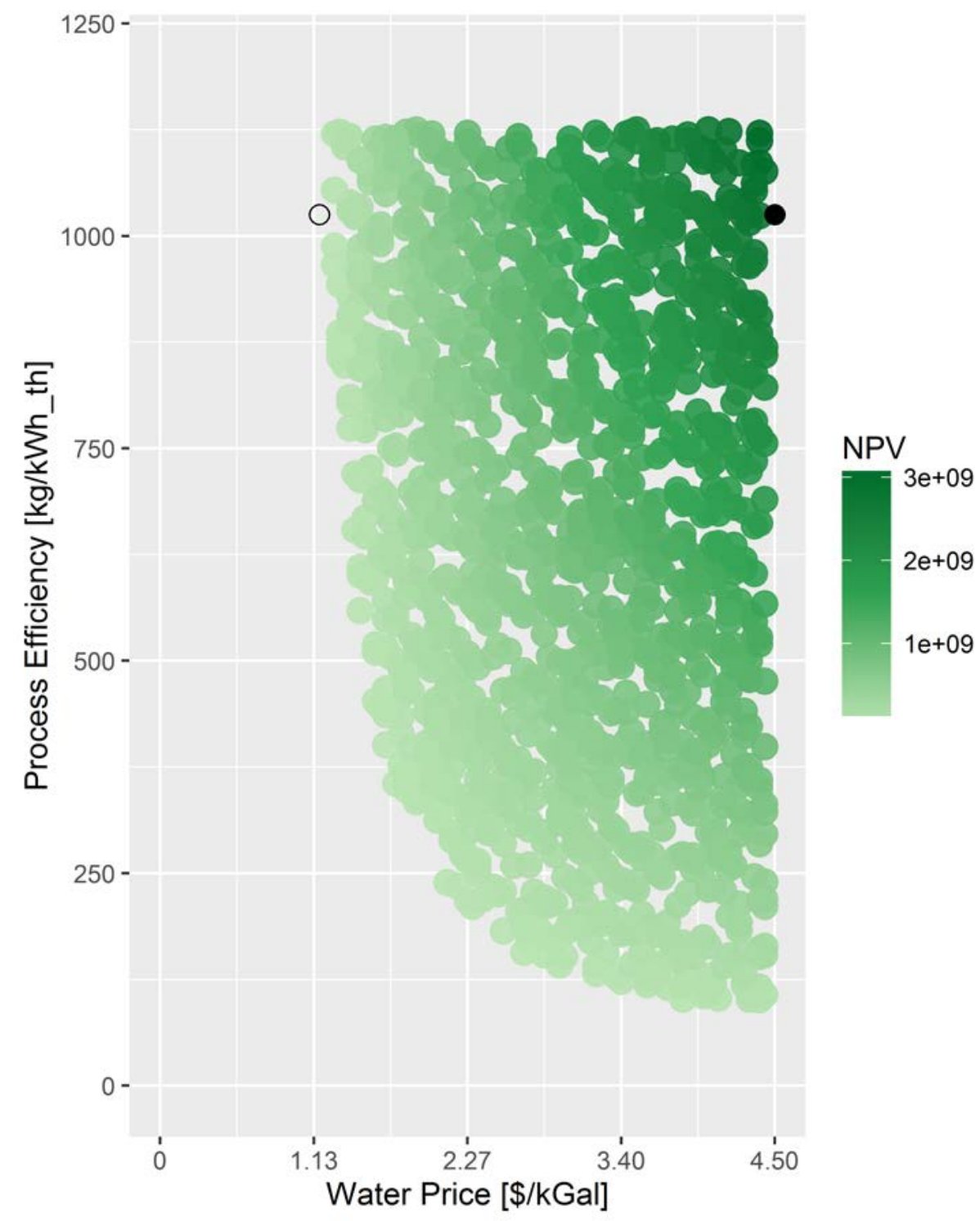

Figure $\mathrm{H}-11$. Arizona-desalination scenario NPVs at various water prices and industrial process efficiencies based on RPS80 generation mix, AEO reference-case prices, and $\$ 50 / \mathbf{k W}$-yr capacity payments.

Darker shades indicate higher NPVs.

Solid black dot at electricity price multiplier of 1.0 and $\$ 4.50 /$ thousand gal water price: reference case water price projection; reference-case electricity price vector

Open black dot: minimum water selling price for an $\mathrm{RO}$ desalination plant; reference-case electricity price vector 

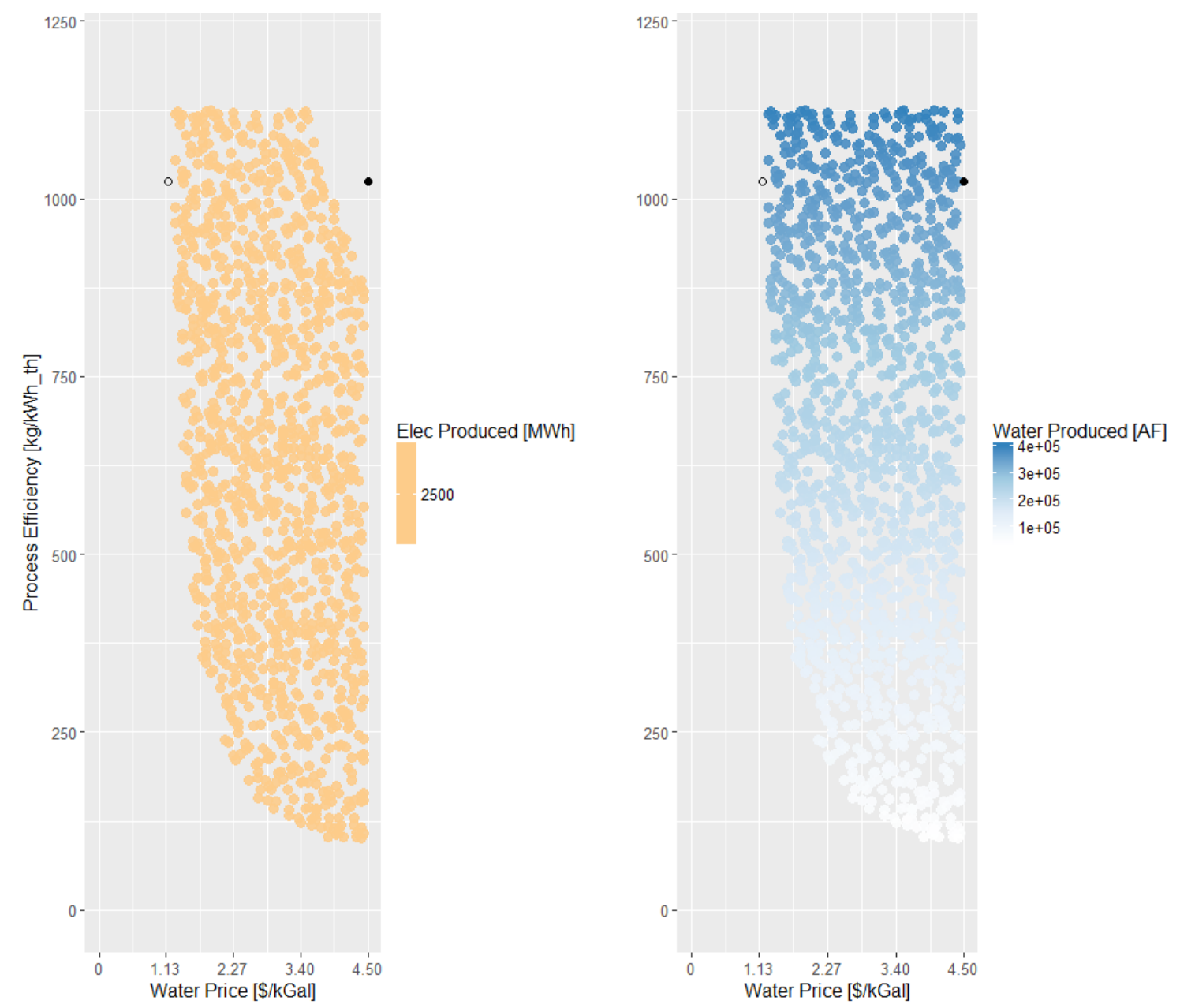

Figure H-12. Optimal annual product generation for Arizona-desalination scenario at various water prices and industrial process efficiencies based on RPS80 generation mix, AEO reference-case prices, and $\$ 50 / \mathrm{kW}$-yr capacity payments.

Electricity is shown on the left with greater generation at the darker color. Water is shown on the right.

Solid black dot at electricity price multiplier of 1.0 and $\$ 4.50 /$ thousand gal water price: reference case water price projection; reference-case electricity price vector

Open black dot: minimum water selling price for an RO desalination plant; reference-case electricity price vector 


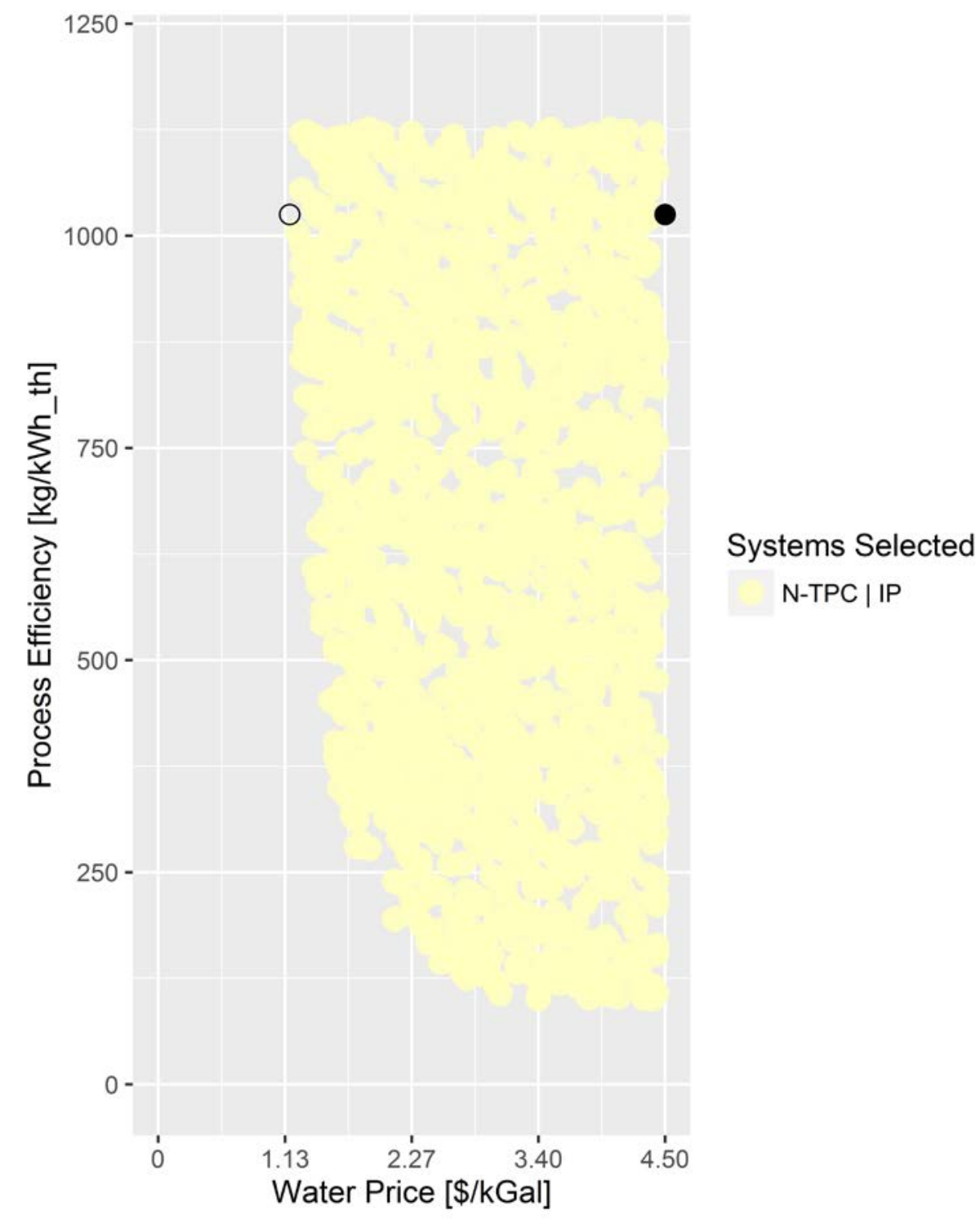

Figure H-13. Optimal configurations for Arizona-desalination scenario at various water prices and industrial process efficiencies based on RPS80 generation mix, AEO reference-case prices, and $\$ 100 / k W-y r$ capacity payments

N-TPC: Nuclear reactor and thermal

$\mathrm{N}-\mathrm{IP}$ : Nuclear reactor and industrial process

RE: Renewable electricity generation

Solid black dot at electricity price multiplier of 1.0 and $\$ 4.50 /$ thousand gal water price: reference case water price projection; reference-case electricity price vector

Open black dot: minimum water selling price for an RO desalination plant; reference-case electricity price vector 


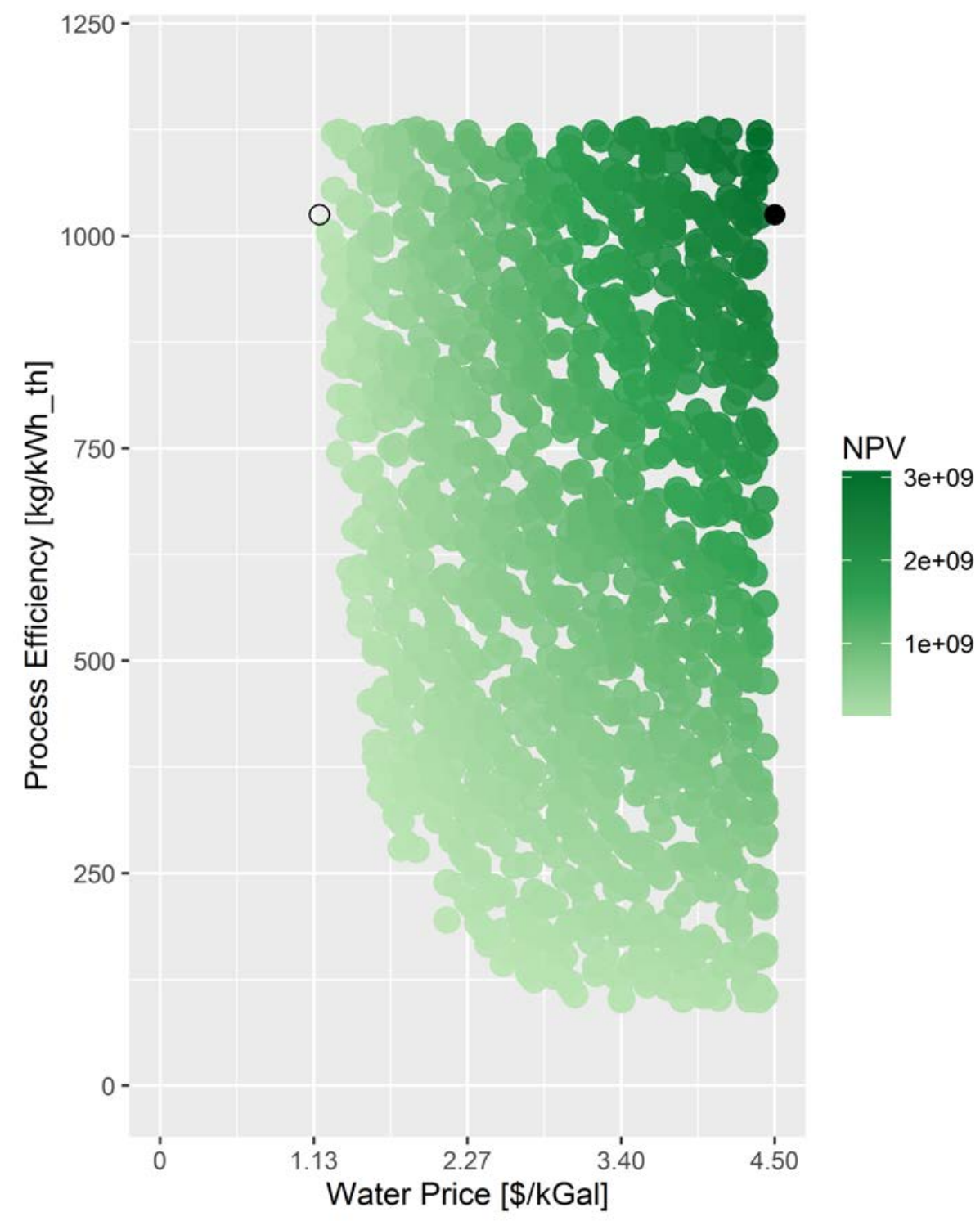

Figure H-14. Arizona-desalination scenario NPVs at various water prices and industrial process efficiencies based on RPS80 generation mix, AEO reference-case prices, and $\$ 100 / \mathrm{kW}$-yr capacity payments.

Darker shades indicate higher NPVs.

Solid black dot at electricity price multiplier of 1.0 and $\$ 4.50 /$ thousand gal water price: reference case water price projection; reference-case electricity price vector

Open black dot: minimum water selling price for an $\mathrm{RO}$ desalination plant; reference-case electricity price vector 

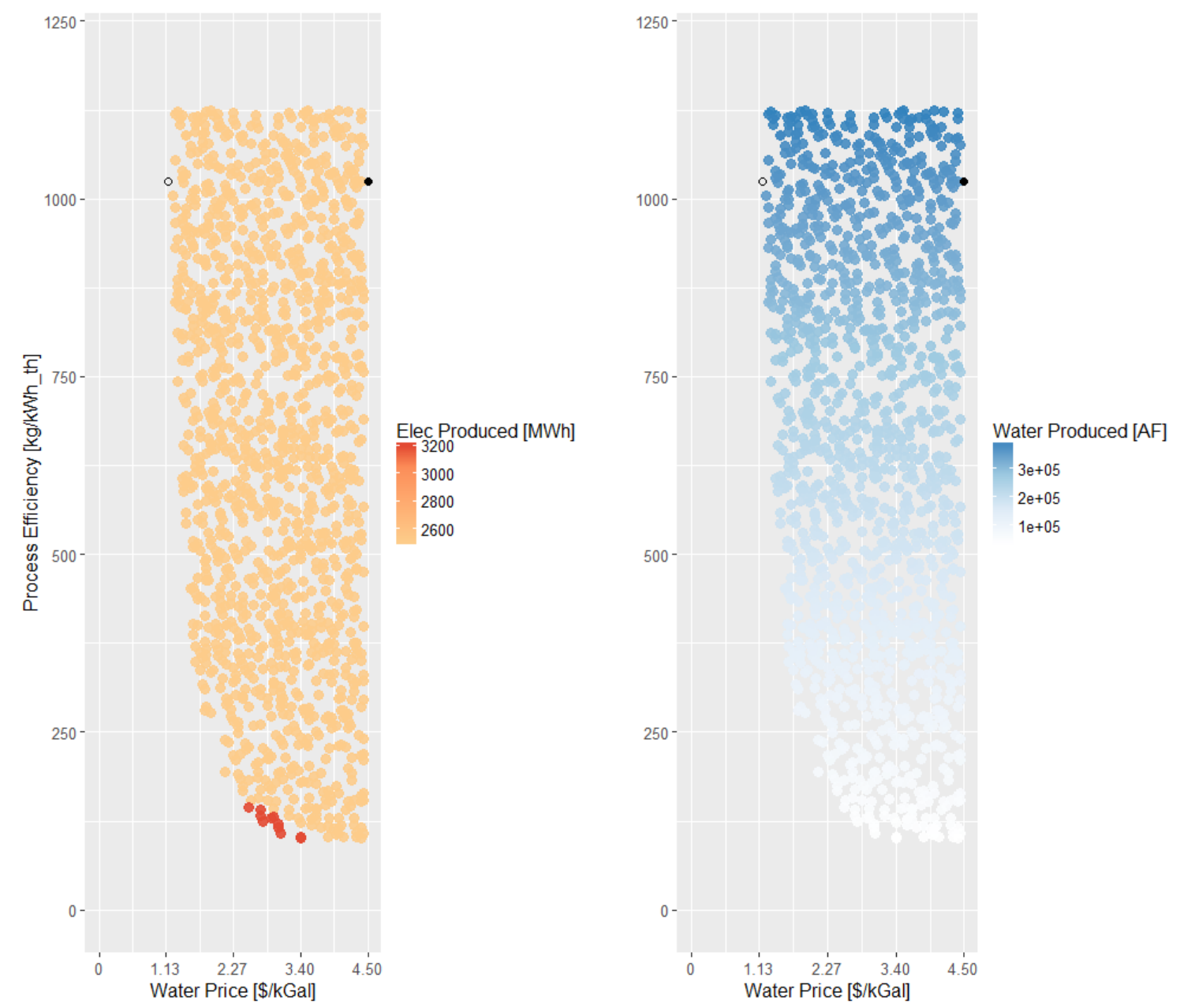

Figure H-15. Optimal annual product generation for Arizona-desalination scenario at various water prices and industrial process efficiencies based on RPS80 generation mix, AEO reference-case prices, and $\$ 100 / \mathrm{kW}-\mathrm{yr}$ capacity payments.

Electricity is shown on the left with greater generation at the darker color. Water is shown on the right. Red dots indicate that electrical energy is sold 64 hours during the year. Tan dots indicate the sale of electricity only 50 hours per year to receive capacity payments.

Solid black dot at electricity price multiplier of 1.0 and $\$ 4.50 /$ thousand gal water price: reference case water price projection; reference-case electricity price vector

Open black dot: minimum water selling price for an RO desalination plant; reference-case electricity price vector 


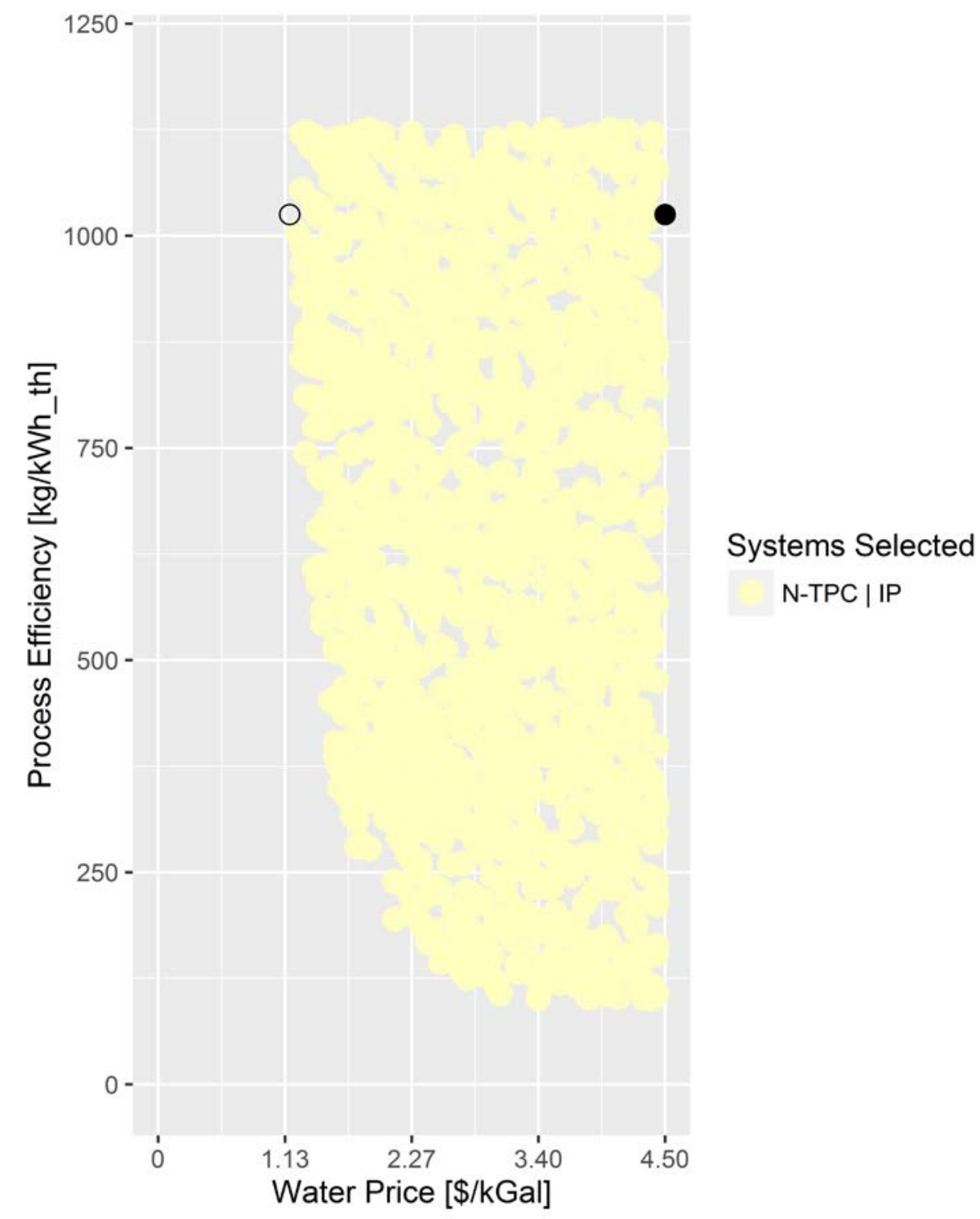

Figure H-16. Optimal configurations for Arizona-desalination scenario at various water prices and industrial process efficiencies based on RPS80 generation mix, AEO reference-case prices, and $\$ 150 / \mathrm{kW}$-yr capacity payments.

Electricity pricing is based on the AEO reference case and $\$ 150 / \mathrm{kW}$-yr capacity payments.

N-TPC: Nuclear reactor and thermal

$\mathrm{N}$-IP: Nuclear reactor and industrial process

RE: Renewable electricity generation

Solid black dot at electricity price multiplier of 1.0 and $\$ 4.50 /$ thousand gal water price: reference case water price projection; reference-case electricity price vector

Open black dot: minimum water selling price for an $\mathrm{RO}$ desalination plant; reference-case electricity price vector 


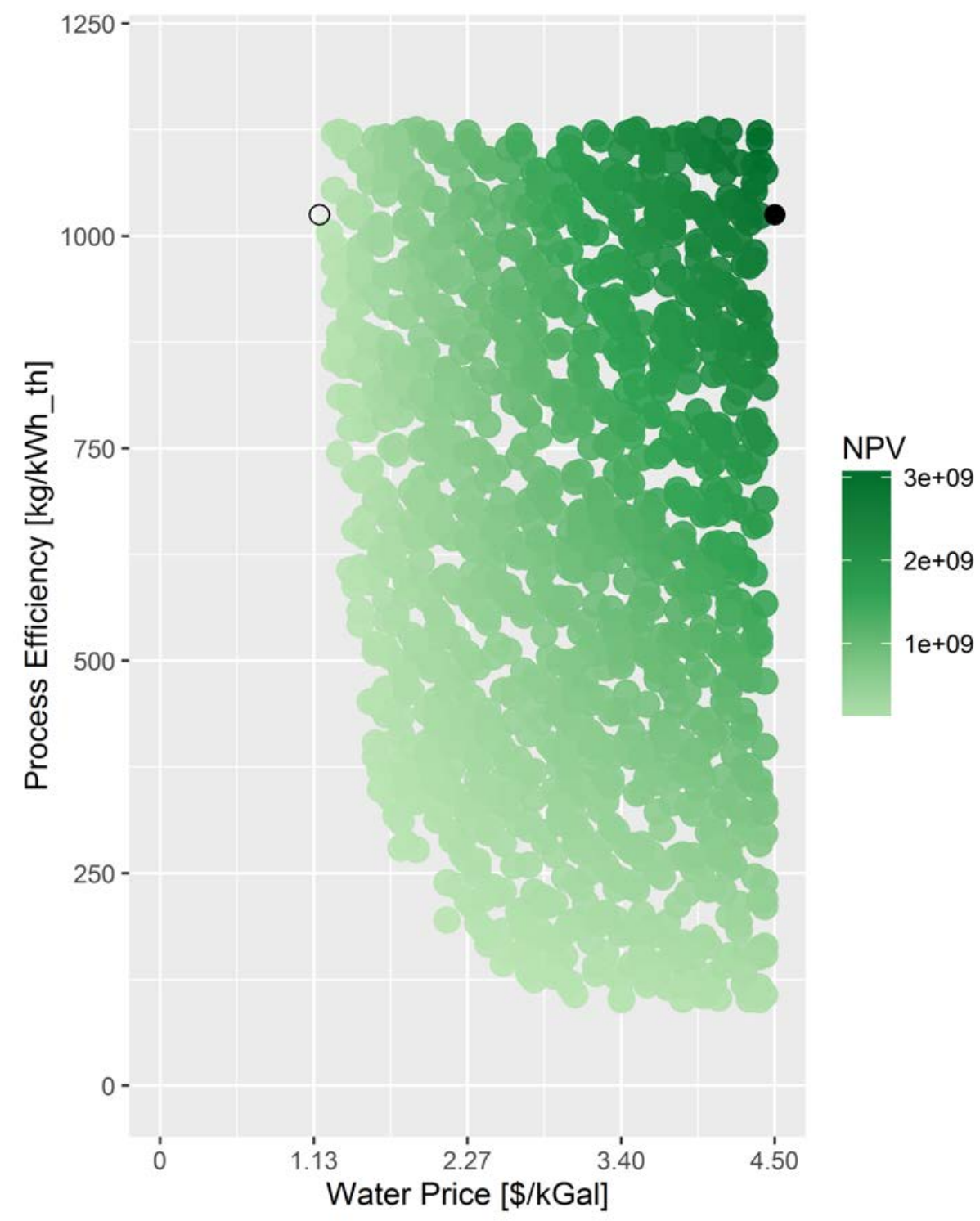

Figure H-17. Arizona-Desalination Scenario NPVs at various water prices and industrial process efficiencies based on RPS80 generation mix, AEO reference-case prices, and $\$ 150 / \mathbf{k W}$-yr capacity payments.

Darker shades indicate higher NPVs.

Solid black dot at electricity price multiplier of 1.0 and $\$ 4.50 /$ thousand gal water price: reference case water price projection; reference-case electricity price vector

Open black dot: minimum water selling price for an $\mathrm{RO}$ desalination plant; reference-case electricity price vector 

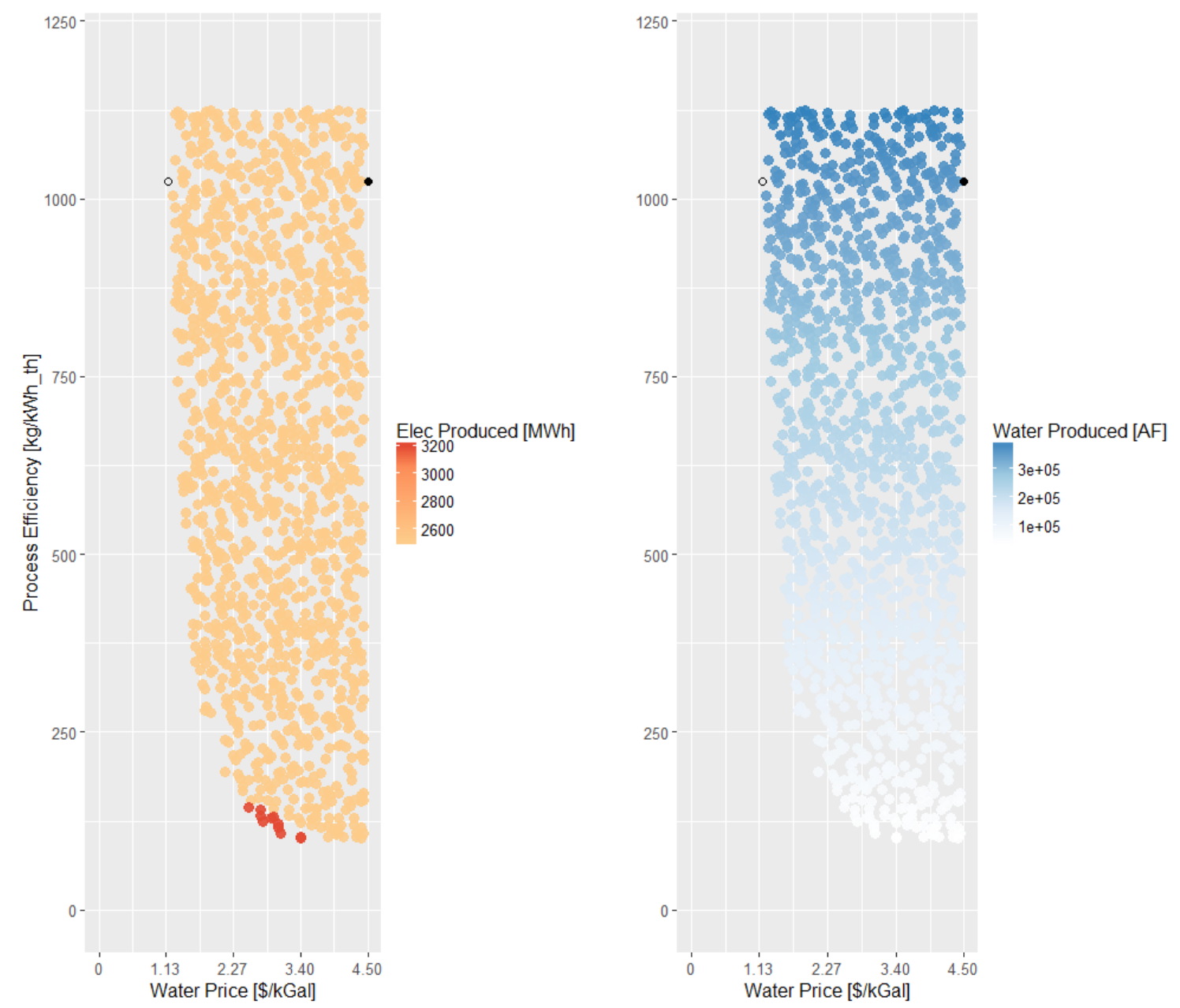

Figure H-18. Optimal annual product generation for Arizona-desalination scenario at various water prices and industrial process efficiencies based on RPS80 generation mix, AEO reference-case prices, and $\$ 150 / \mathrm{kW}-\mathrm{yr}$ capacity payments.

Electricity is shown on the left with greater generation at the darker color. Water is shown on the right. Red dots indicate that electrical energy is sold 64 hours during the year. Tan dots indicate the sale of electricity only 50 hours per year to receive capacity payments.

Solid black dot at electricity price multiplier of 1.0 and $\$ 4.50 /$ thousand gal water price: reference case water price projection; reference-case electricity price vector

Open black dot: minimum water selling price for an $\mathrm{RO}$ desalination plant; reference-case electricity price vector 


\section{H.3 Sensitivities on the Impacts of Electricity and Water Prices Based on Current Law Generation Capacities and Annual Energy Outlook Reference-Case Scenario}

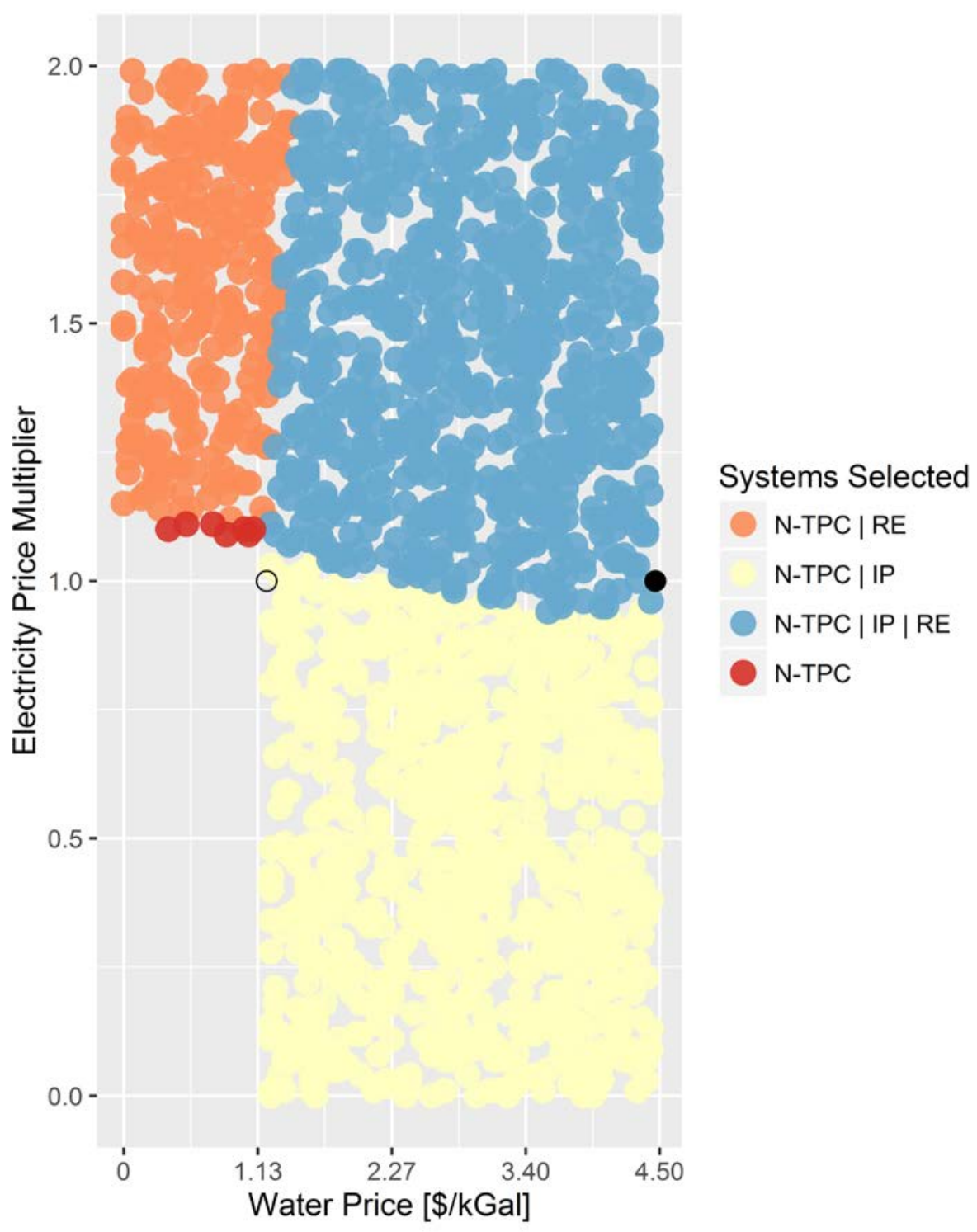

Figure H-19. Optimal configurations for Arizona-desalination scenario at various water prices and electricity price multipliers based on current law generation mix, AEO reference-case prices, and $\$ 50 / k W-y r$ capacity payments

N-TPC: Nuclear reactor and thermal

N-IP: Nuclear reactor and industrial process

$\mathrm{RE}$ : Renewable electricity generation

Solid black dot at electricity price multiplier of 1.0 and $\$ 4.50 /$ thousand gal water price: reference case water price projection; reference-case electricity price vector

Open black dot: minimum water selling price for an RO desalination plant; reference-case electricity price vector 


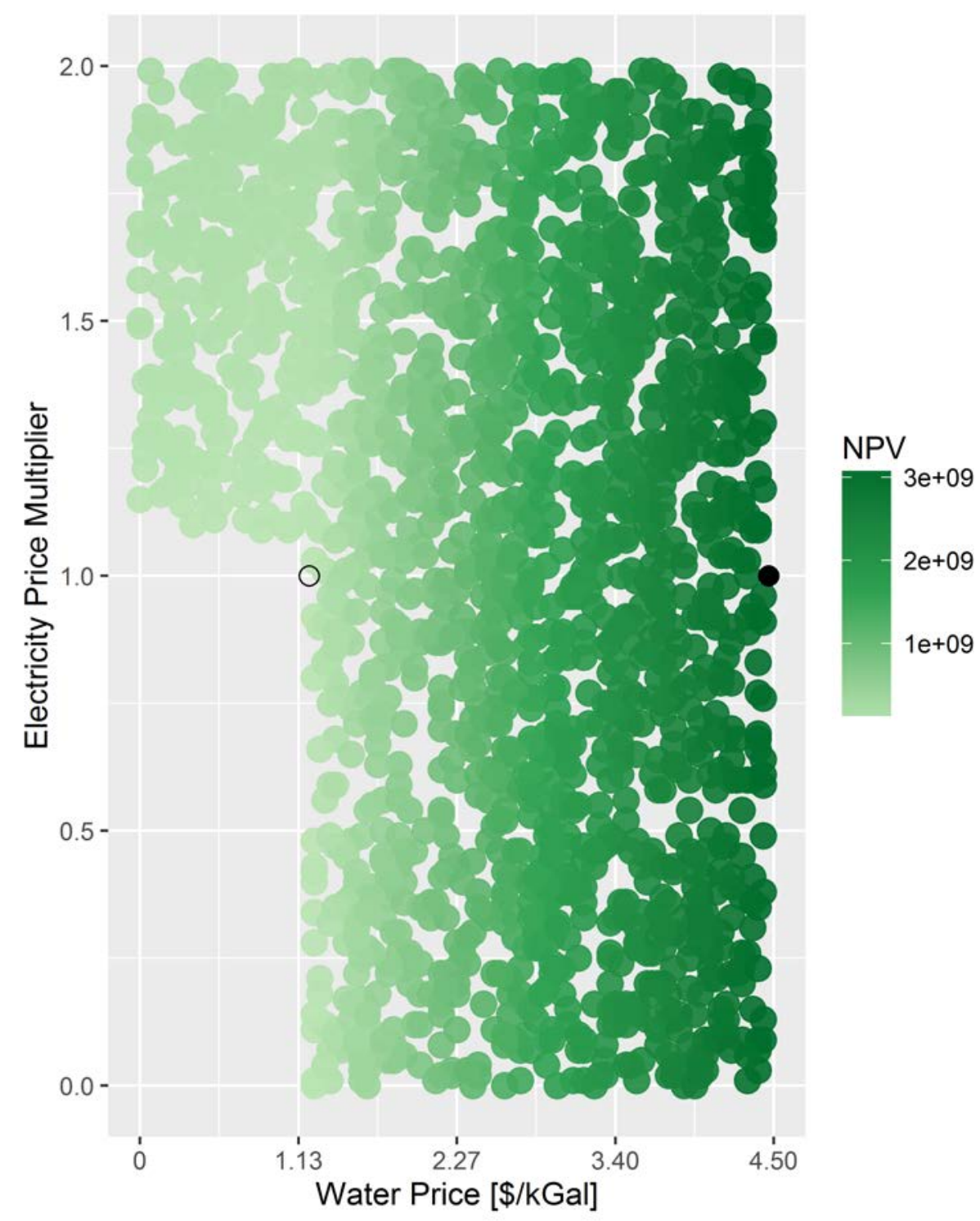

Figure H-20. Arizona-Desalination Scenario NPVs at various water prices and electricity price multipliers based on current law generation mix, AEO reference-case prices, and $\$ 50 / \mathrm{kW}$-yr capacity payments.

Darker shades indicate higher NPVs.

Solid black dot at electricity price multiplier of 1.0 and $\$ 4.50 /$ thousand gal water price: reference case water price projection; reference-case electricity price vector

Open black dot: minimum water selling price for an $\mathrm{RO}$ desalination plant; reference-case electricity price vector 

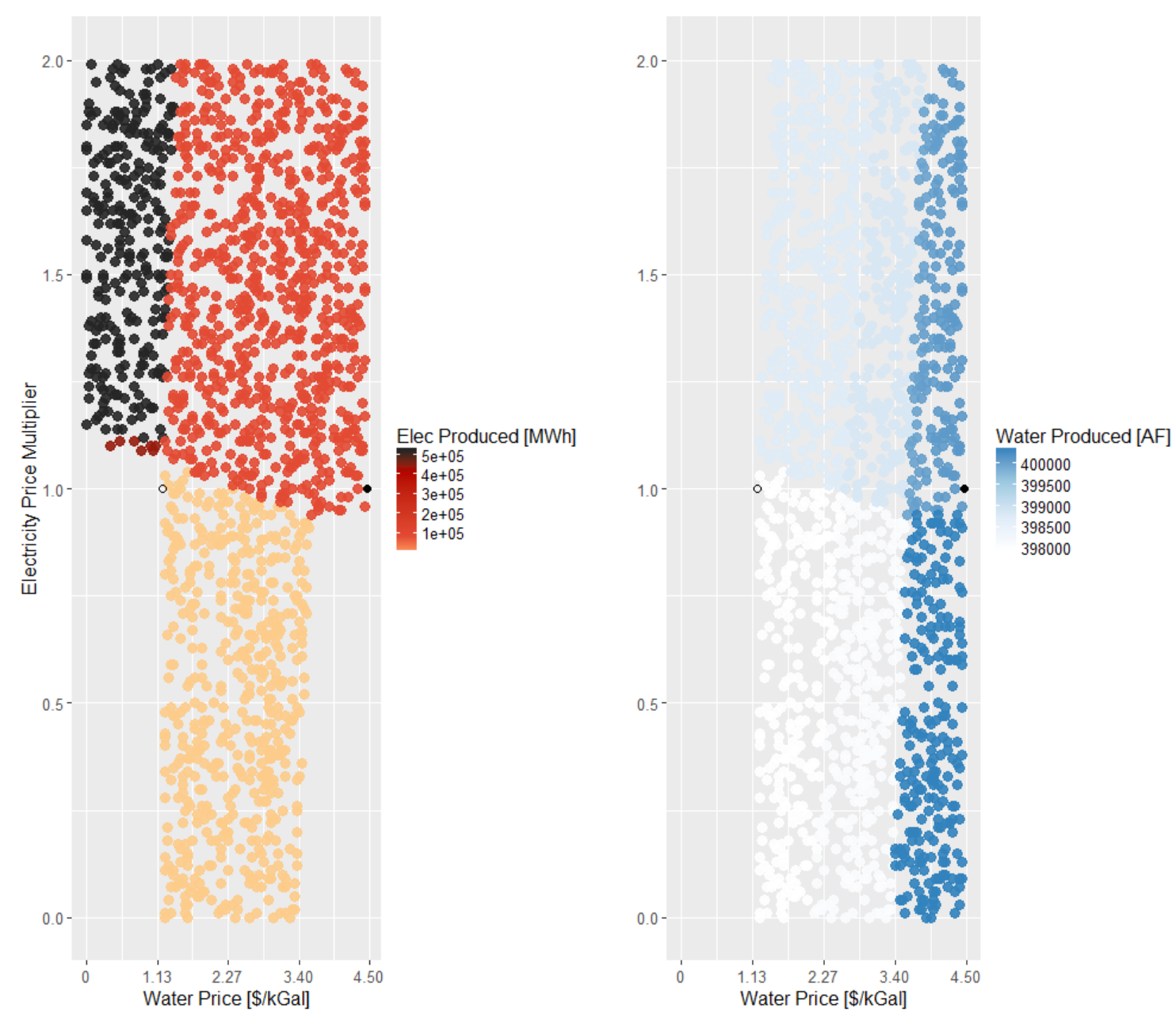

Figure H-21. Optimal annual product generation for Arizona-desalination scenario at various water prices and electricity price multipliers based on current law generation mix, AEO reference-case prices, and $\$ 50 / \mathrm{kW}$-yr capacity payments.

Electricity is shown on the left with greater generation at the darker color. Water is shown on the right.

Solid black dot at electricity price multiplier of 1.0 and $\$ 4.50 /$ thousand gal water price: reference case water price projection; reference-case electricity price vector

Open black dot: minimum water selling price for an RO desalination plant; reference-case electricity price vector 


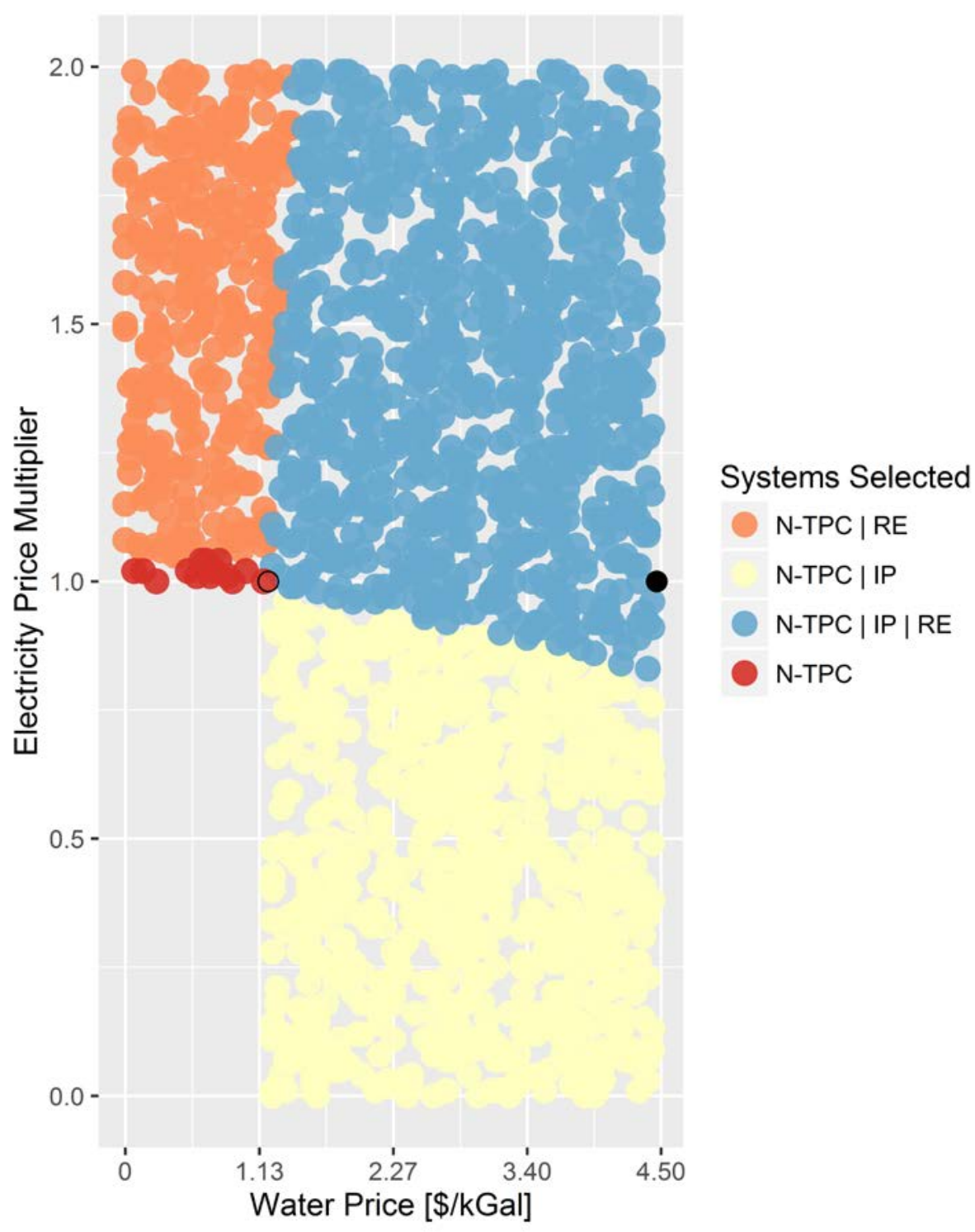

Figure H-22. Optimal configurations for Arizona-desalination scenario at various water prices and electricity price multipliers based on current law generation mix, AEO reference-case prices, and $\$ 100 / k W-y r$ capacity payments

N-TPC: Nuclear reactor and thermal

N-IP: Nuclear reactor and industrial process

$\mathrm{RE}$ : Renewable electricity generation

Solid black dot at electricity price multiplier of 1.0 and $\$ 4.50 /$ thousand gal water price: reference case water price projection; reference-case electricity price vector

Open black dot: minimum water selling price for an RO desalination plant; reference-case electricity price vector 


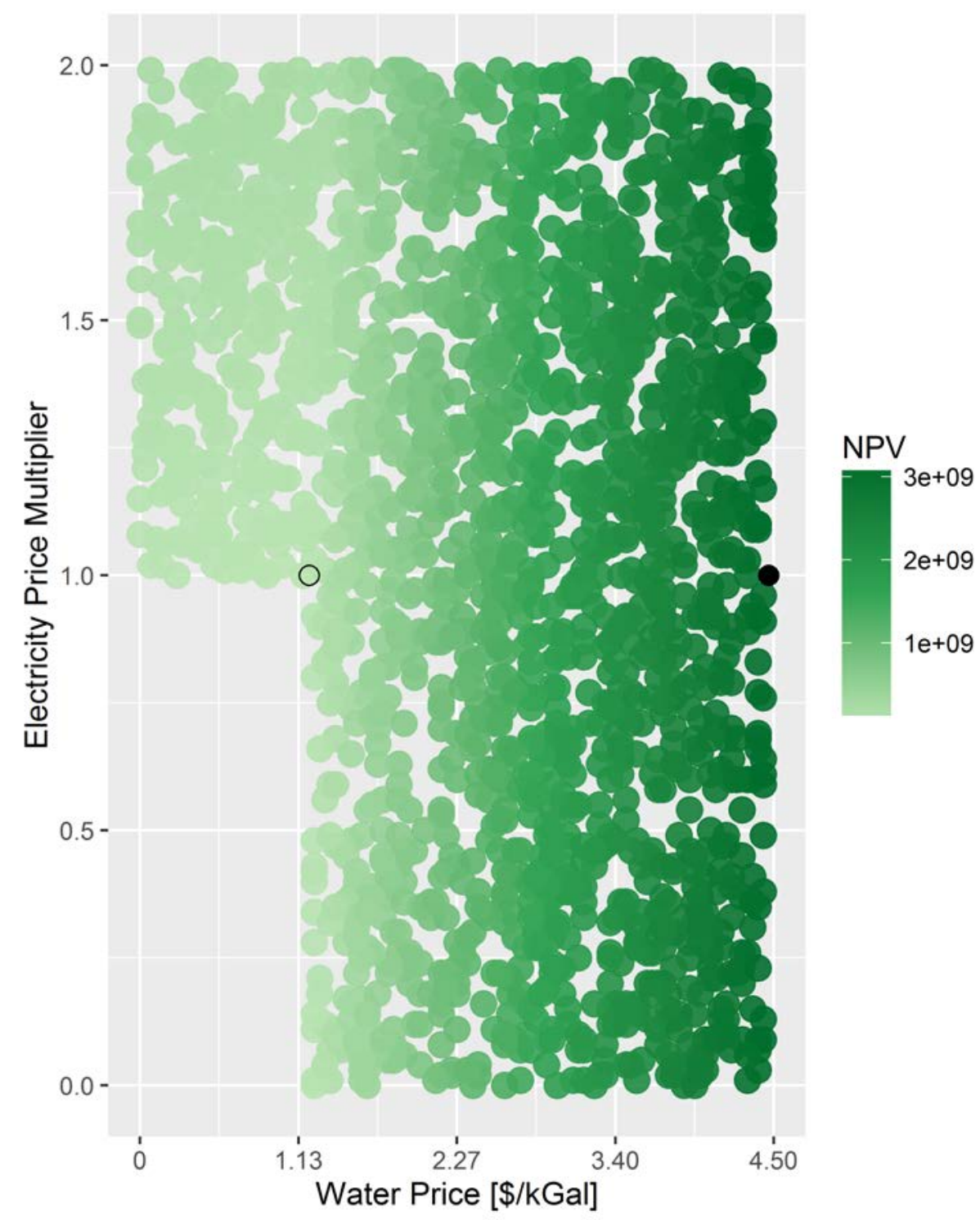

Figure H-23. Arizona-desalination scenario NPVs at various water prices and electricity price multipliers based on current law generation mix, AEO reference-case prices, and $\$ 100 / \mathrm{kW}$-yr capacity payments.

Darker shades indicate higher NPVs.

Solid black dot at electricity price multiplier of 1.0 and $\$ 4.50 /$ thousand gal water price: reference case water price projection; reference-case electricity price vector

Open black dot: minimum water selling price for an $\mathrm{RO}$ desalination plant; reference-case electricity price vector 

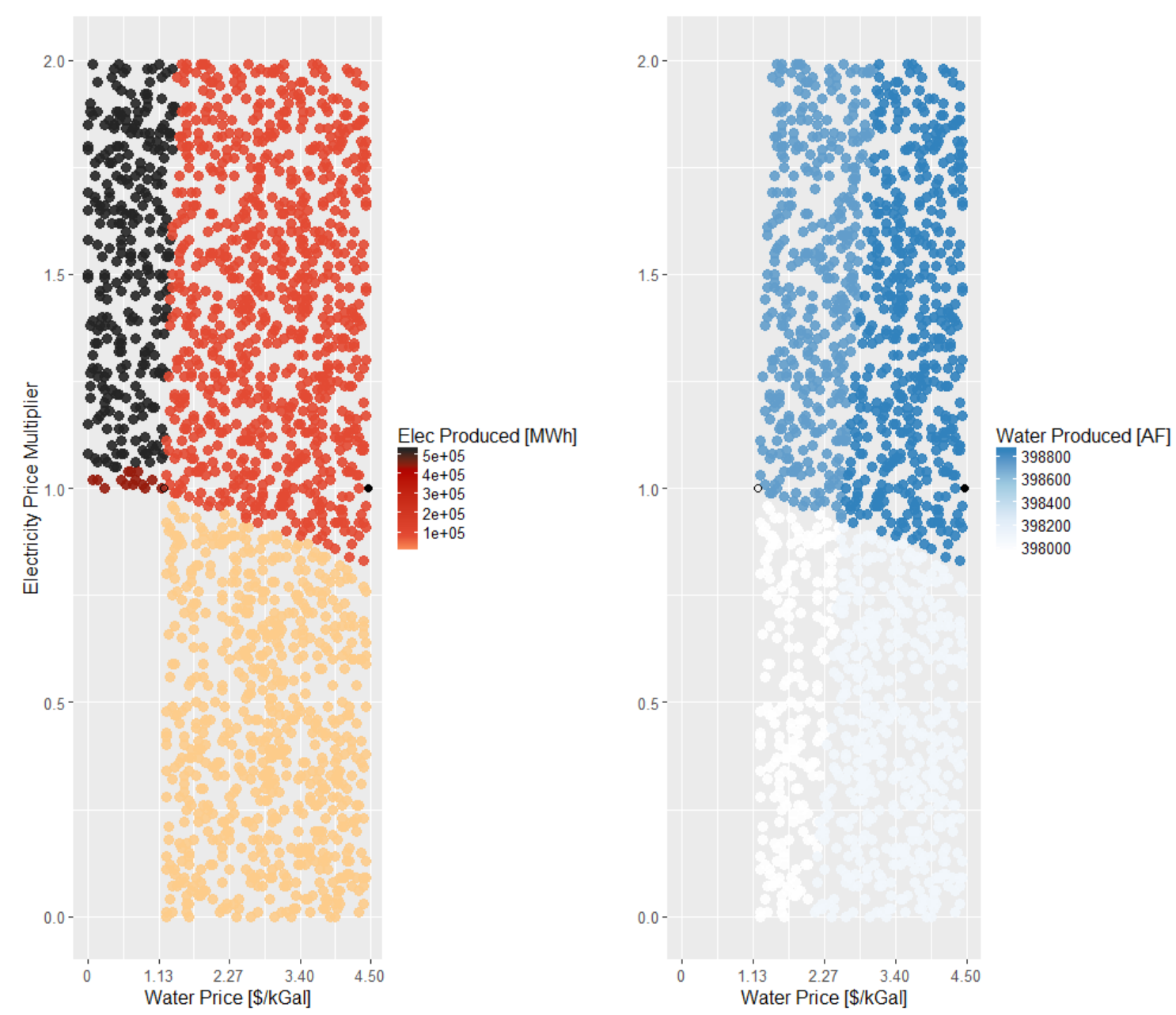

Figure H-24. Optimal annual product generation for Arizona-desalination scenario at various water prices and electricity price multipliers based on current law generation mix, AEO reference-case prices, and $\$ 100 / \mathrm{kW}-\mathrm{yr}$ capacity payments.

Electricity is shown on the left with greater generation at the darker color. Water is shown on the right.

Solid black dot at electricity price multiplier of 1.0 and $\$ 4.50 /$ thousand gal water price: reference case water price projection; reference-case electricity price vector

Open black dot: minimum water selling price for an $\mathrm{RO}$ desalination plant; reference-case electricity price vector 


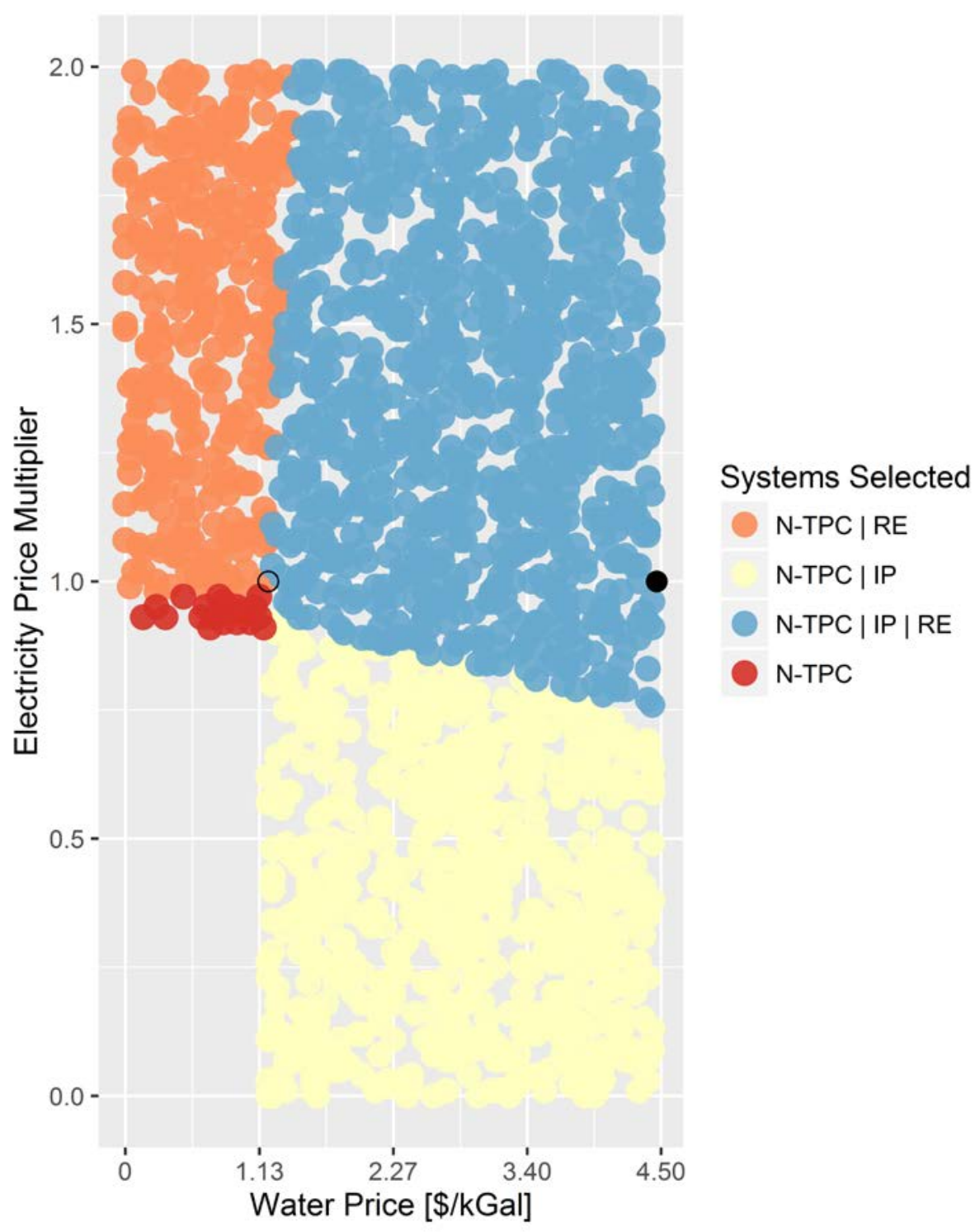

Figure H-25. Optimal configurations for Arizona-desalination scenario at various water prices and electricity price multipliers based on current law generation mix, AEO reference-case prices, and $\$ 150 / k W-y r$ capacity payments

N-TPC: Nuclear reactor and thermal

N-IP: Nuclear reactor and industrial process

$\mathrm{RE}$ : Renewable electricity generation

Solid black dot at electricity price multiplier of 1.0 and $\$ 4.50 /$ thousand gal water price: reference case water price projection; reference-case electricity price vector

Open black dot: minimum water selling price for an RO desalination plant; reference-case electricity price vector 


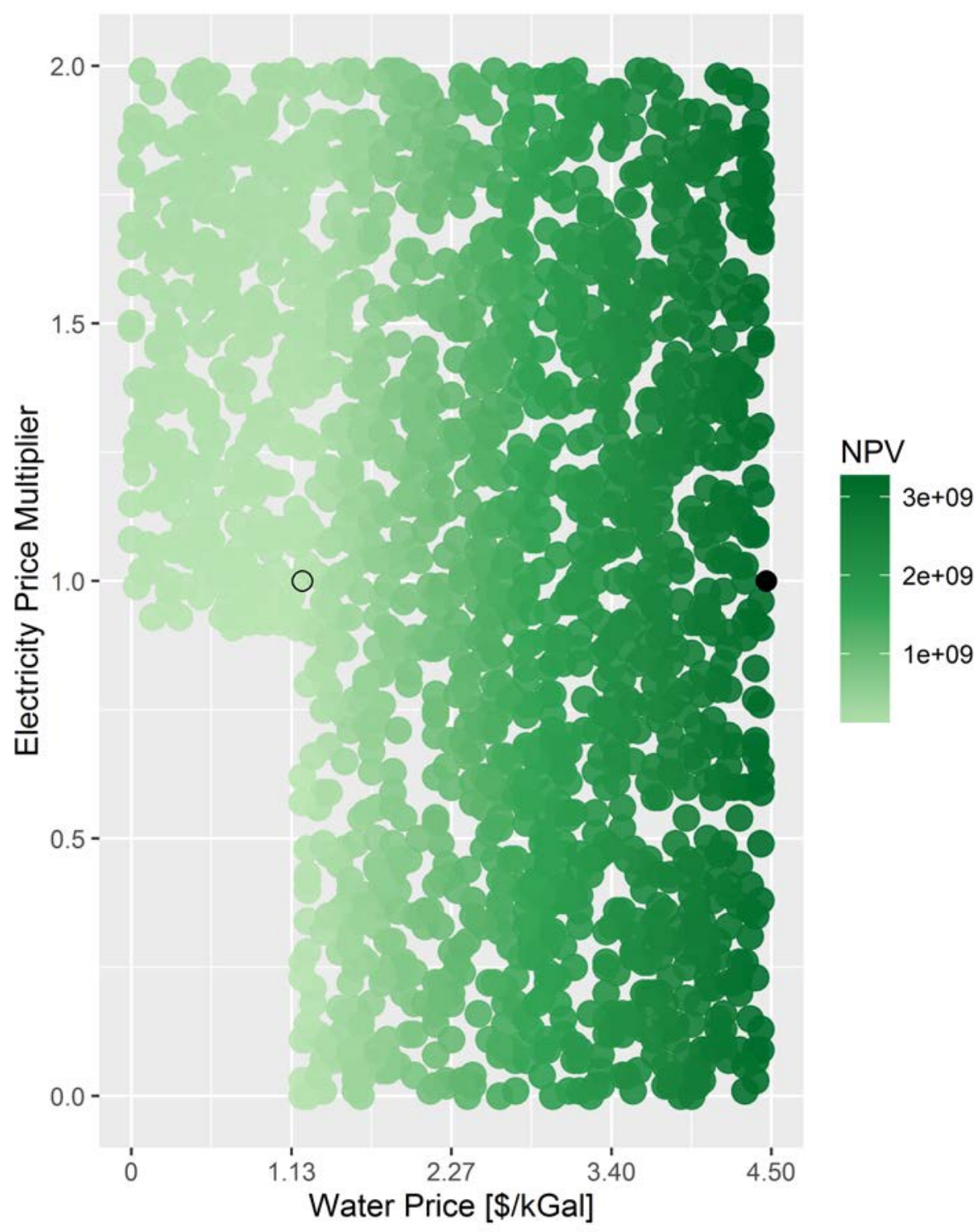

Figure H-26. Arizona-desalination scenario NPVs at various water prices and electricity price multipliers based on current law generation mix, AEO reference-case prices, and $\$ 150 / \mathbf{k W}$-yr capacity payments.

Darker shades indicate higher NPVs.

Solid black dot at electricity price multiplier of 1.0 and $\$ 4.50 /$ thousand gal water price: reference case water price projection; reference-case electricity price vector

Open black dot: minimum water selling price for an $\mathrm{RO}$ desalination plant; reference-case electricity price vector 

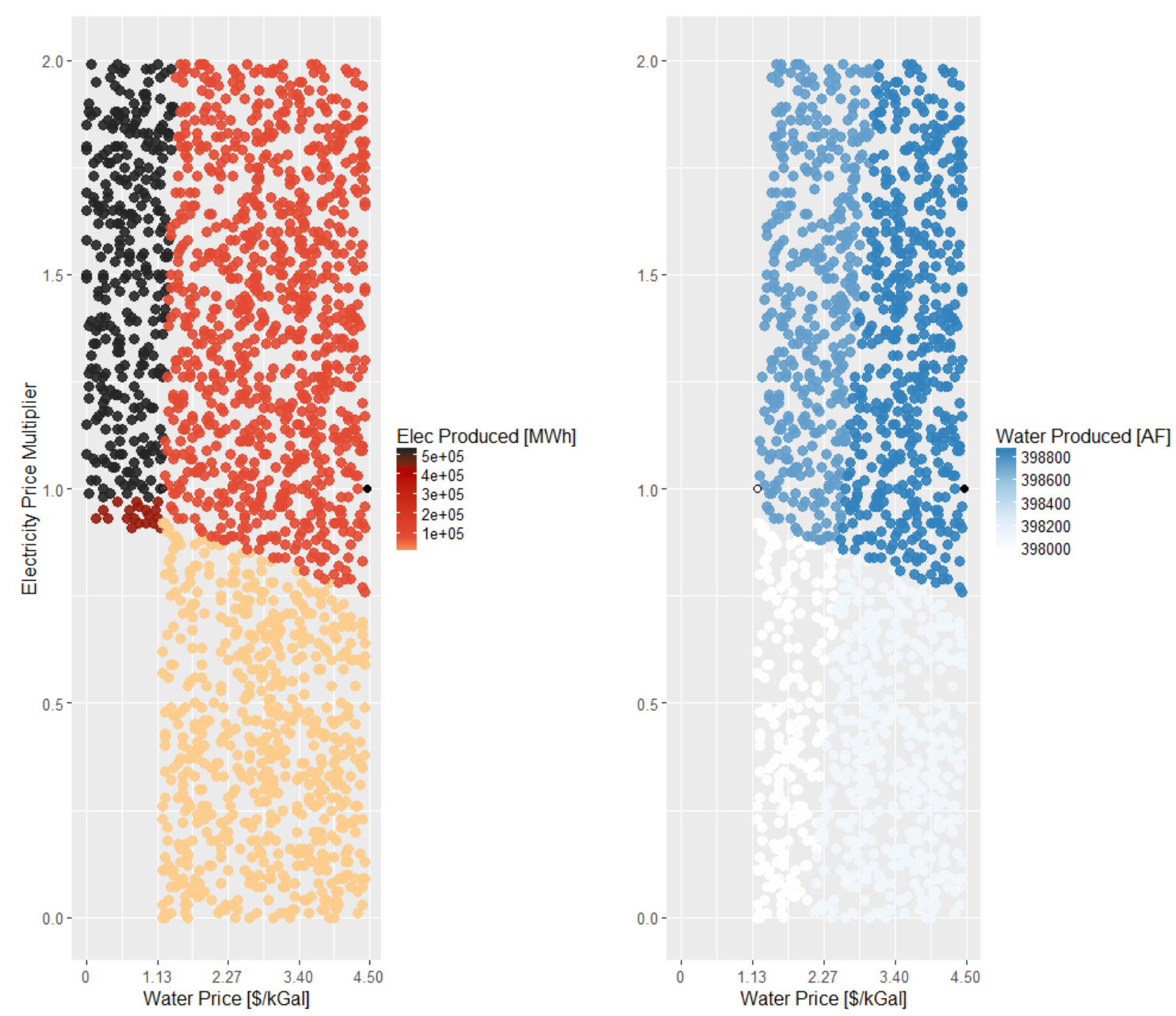

Figure H-27. Optimal annual product generation for Arizona-desalination scenario at various water prices and electricity price multipliers based on current law generation mix, AEO reference-case prices, and $\$ 150 / \mathrm{kW}-\mathrm{yr}$ capacity payments.

Electricity is shown on the left with greater generation at the darker color. Water is shown on the right.

Solid black dot at electricity price multiplier of 1.0 and $\$ 4.50 /$ thousand gal water price: reference case water price projection; reference-case electricity price vector

Open black dot: minimum water selling price for an $\mathrm{RO}$ desalination plant; reference-case electricity price vector 


\section{H.4 Sensitivities on the Impacts of Electricity and Water Prices Based on Electricity Prices Using the RPS80 Generation Mix and the Annual Energy Outlook Low-Oil-Price Scenario}

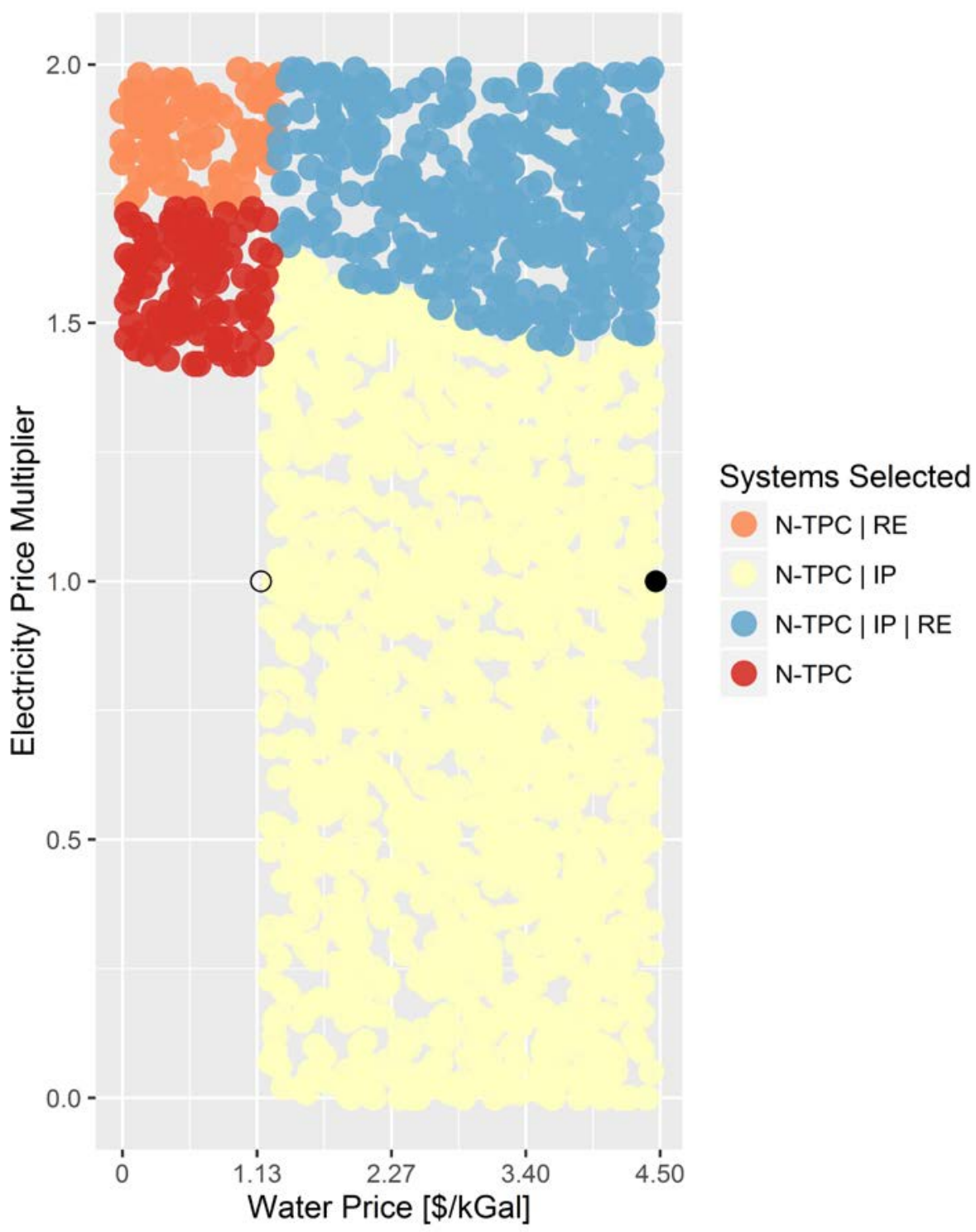

Figure H-28. Optimal configurations for Arizona-desalination scenario at various water prices and electricity price multipliers based on RPS80 generation mix, AEO low-oil-price case, and $\$ 50 / \mathrm{kW}$-yr capacity payments

N-TPC: Nuclear reactor and thermal

N-IP: Nuclear reactor and industrial process

$\mathrm{RE}$ : Renewable electricity generation

Solid black dot at electricity price multiplier of 1.0 and $\$ 4.50 /$ thousand gal water price: reference case water price projection; reference-case electricity price vector

Open black dot: minimum water selling price for an RO desalination plant; reference-case electricity price vector 


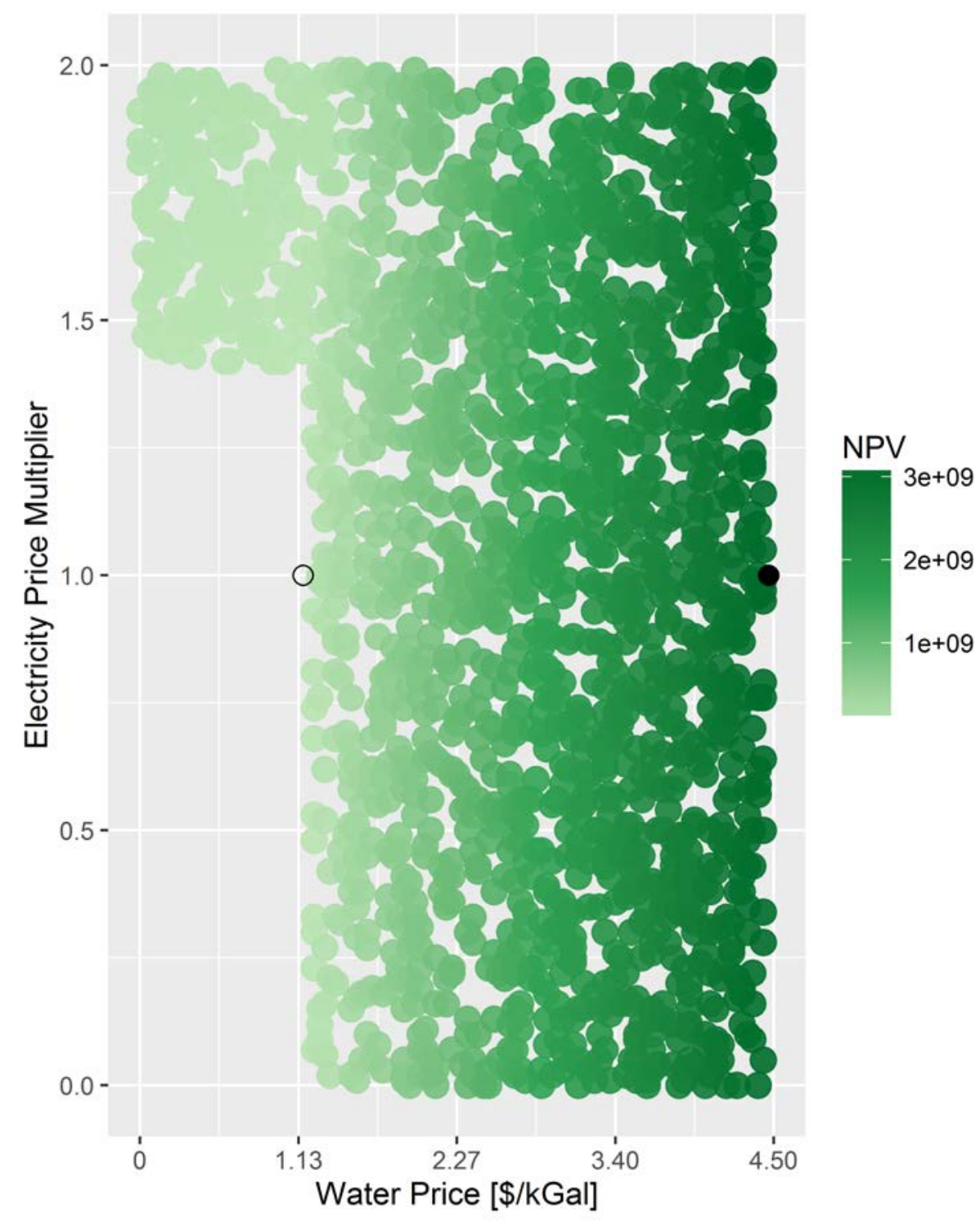

Figure H-29. Arizona-Desalination Scenario NPVs at various water prices and electricity price multipliers based on RPS80 generation mix, AEO low-oil-price case, and \$50/kW-yr capacity payments.

Darker shades indicate higher NPVs.

Solid black dot at electricity price multiplier of 1.0 and $\$ 4.50 /$ thousand gal water price: reference case water price projection; reference-case electricity price vector

Open black dot: minimum water selling price for an RO desalination plant; reference-case electricity price vector 

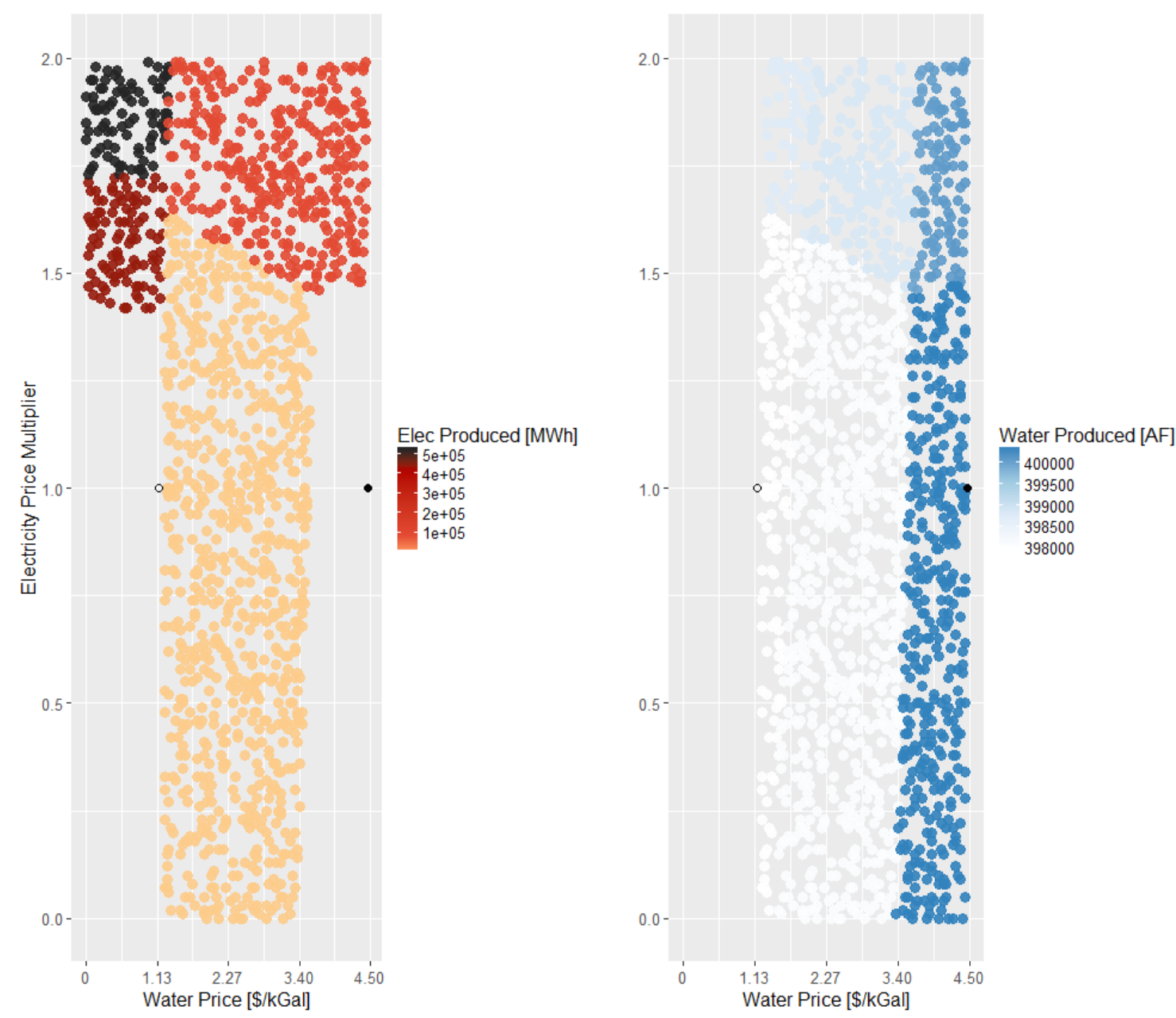

Figure H-30. Optimal annual product generation for Arizona-desalination scenario at various water prices and electricity price multipliers based on RPS80 generation mix, AEO low-oil-price case, and $\$ 50 / \mathbf{k W}$-yr capacity payments.

Electricity is shown on the left with greater generation at the darker color. Water is shown on the right.

Solid black dot at electricity price multiplier of 1.0 and $\$ 4.50 /$ thousand gal water price: reference case water price projection; reference-case electricity price vector

Open black dot: minimum water selling price for an RO desalination plant; reference-case electricity price vector 


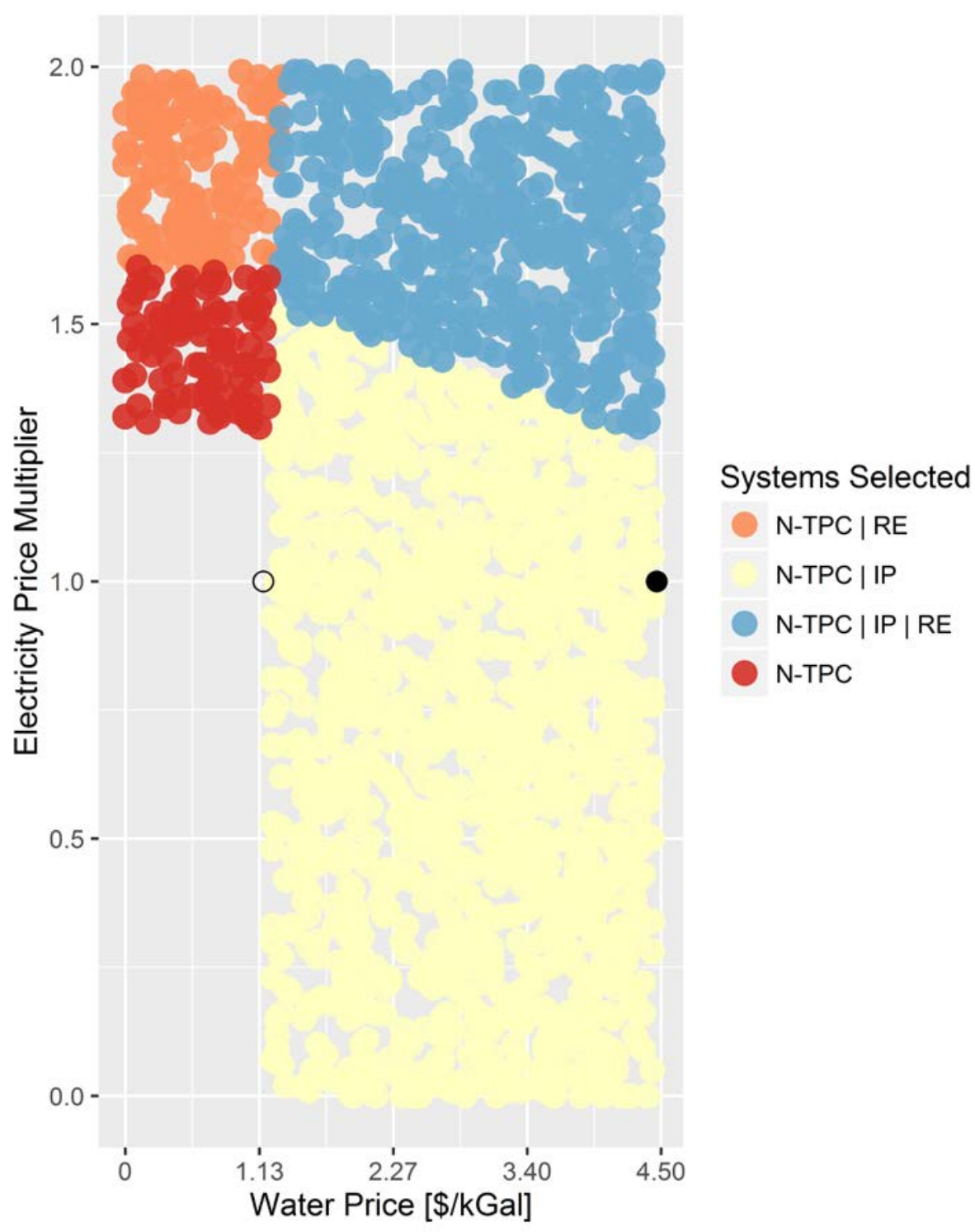

Figure H-31. Optimal configurations for Arizona-desalination scenario at various water prices and electricity price multipliers based on RPS80 generation mix, AEO low-oil-price case, and \$100/kWyr capacity payments

N-TPC: Nuclear reactor and thermal

N-IP: Nuclear reactor and industrial process

RE: Renewable electricity generation

Solid black dot at electricity price multiplier of 1.0 and $\$ 4.50 /$ thousand gal water price: reference case water price projection; reference-case electricity price vector

Open black dot: minimum water selling price for an RO desalination plant; reference-case electricity price vector 


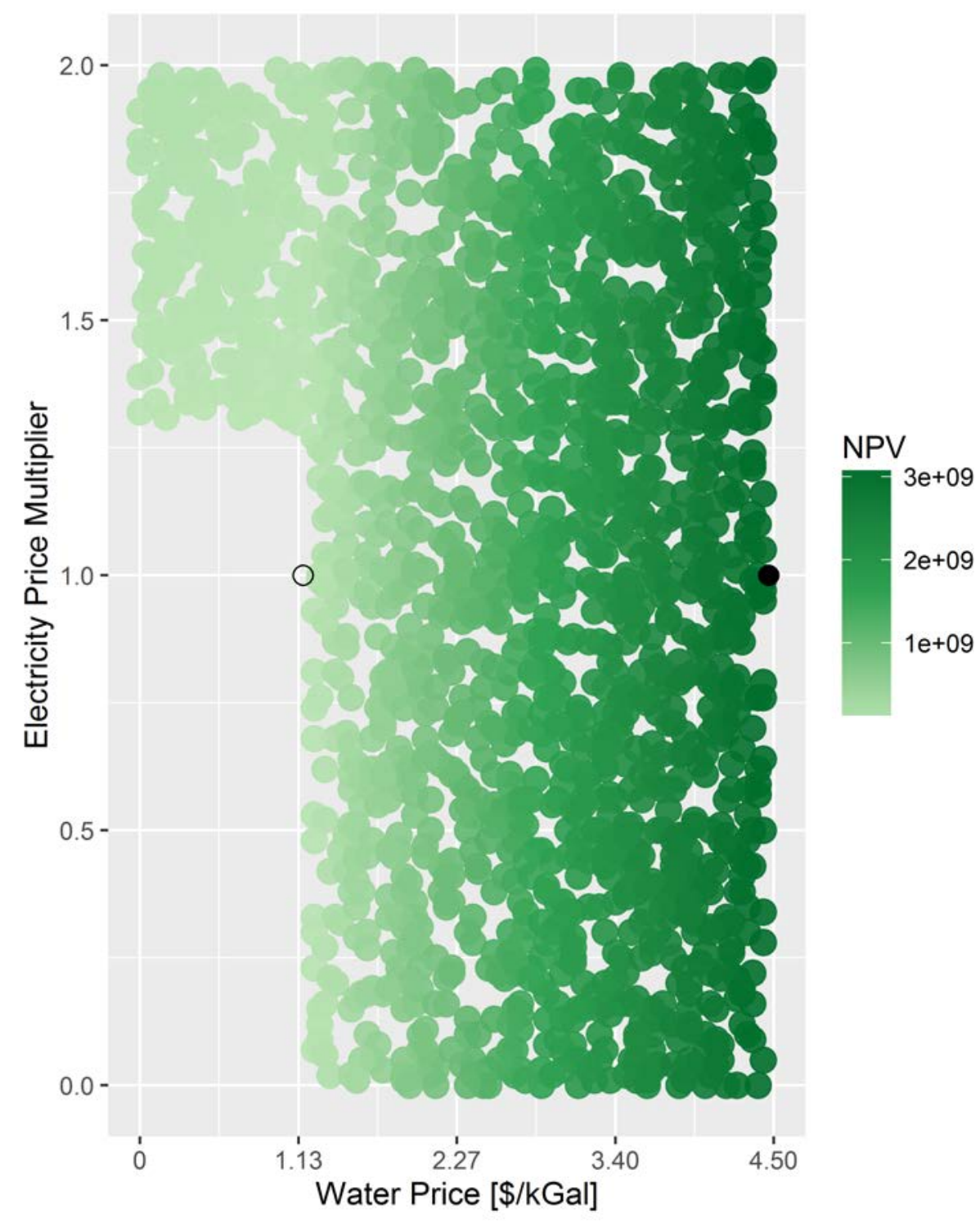

Figure H-32. Arizona-Desalination Scenario NPVs at various water prices and electricity price multipliers based on RPS80 generation mix, AEO low-oil-price case, and \$100/kW-yr capacity payments.

Darker shades indicate higher NPVs.

Solid black dot at electricity price multiplier of 1.0 and $\$ 4.50 /$ thousand gal water price: reference case water price projection; reference-case electricity price vector

Open black dot: minimum water selling price for an $\mathrm{RO}$ desalination plant; reference-case electricity price vector 

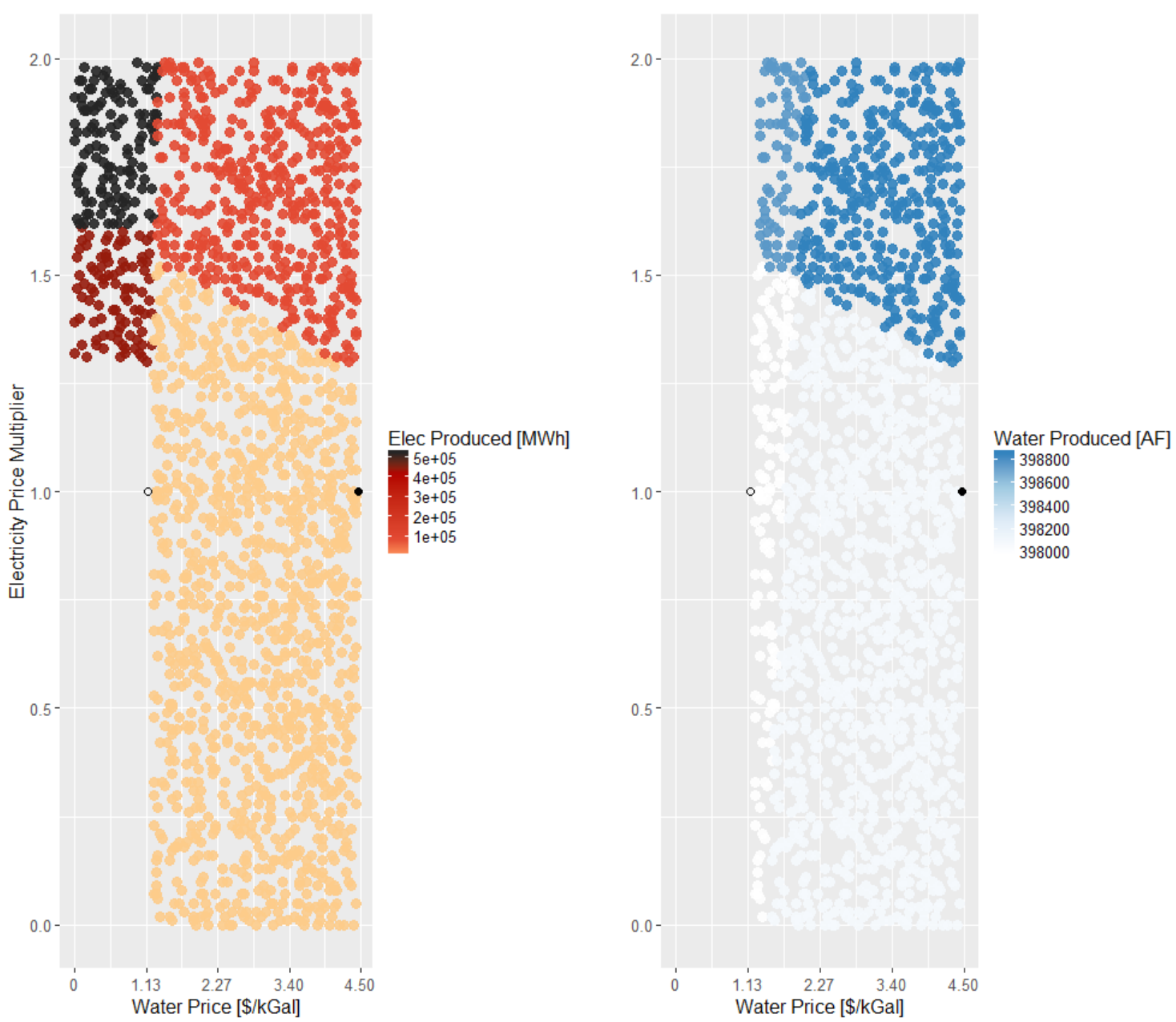

Figure H-33. Optimal annual product generation for Arizona-desalination scenario at various water prices and electricity price multipliers based on RPS80 generation mix, AEO low-oil-price case, and $\$ 100 / \mathrm{kW}$-yr capacity payments.

Electricity is shown on the left with greater generation at the darker color. Water is shown on the right.

Solid black dot at electricity price multiplier of 1.0 and $\$ 4.50 /$ thousand gal water price: reference case water price projection; reference-case electricity price vector

Open black dot: minimum water selling price for an RO desalination plant; reference-case electricity price vector 


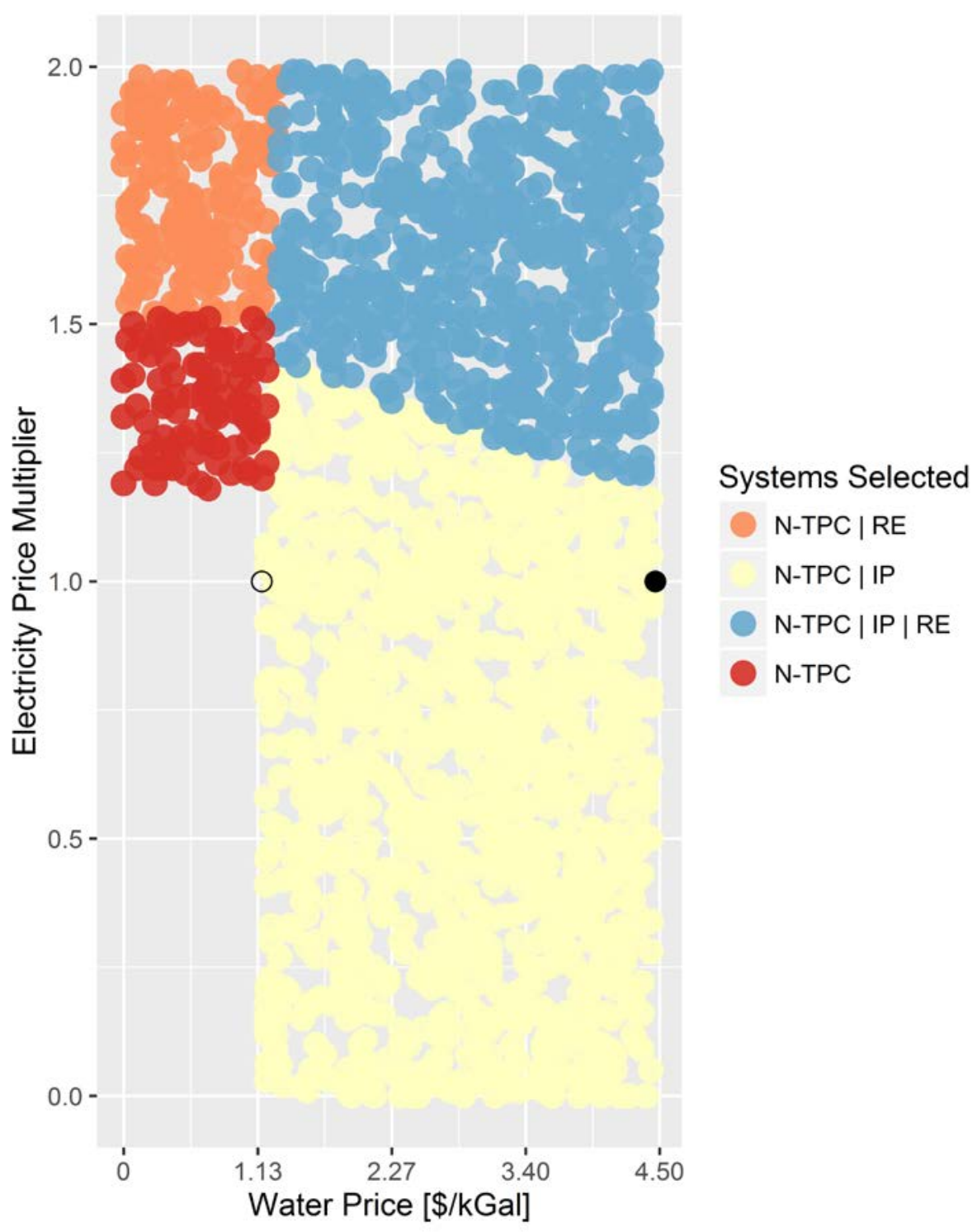

Figure H-34. Optimal configurations for Arizona-desalination scenario at various water prices and electricity price multipliers based on RPS80 generation mix, AEO low-oil-price case, and \$150/kWyr capacity payments

N-TPC: Nuclear reactor and thermal $\mathrm{N}-\mathrm{IP}$ : Nuclear reactor and industrial process

RE: Renewable electricity generation

Solid black dot at electricity price multiplier of 1.0 and $\$ 4.50 /$ thousand gal water price: reference case water price projection; reference-case electricity price vector

Open black dot: minimum water selling price for an RO desalination plant; reference-case electricity price vector 


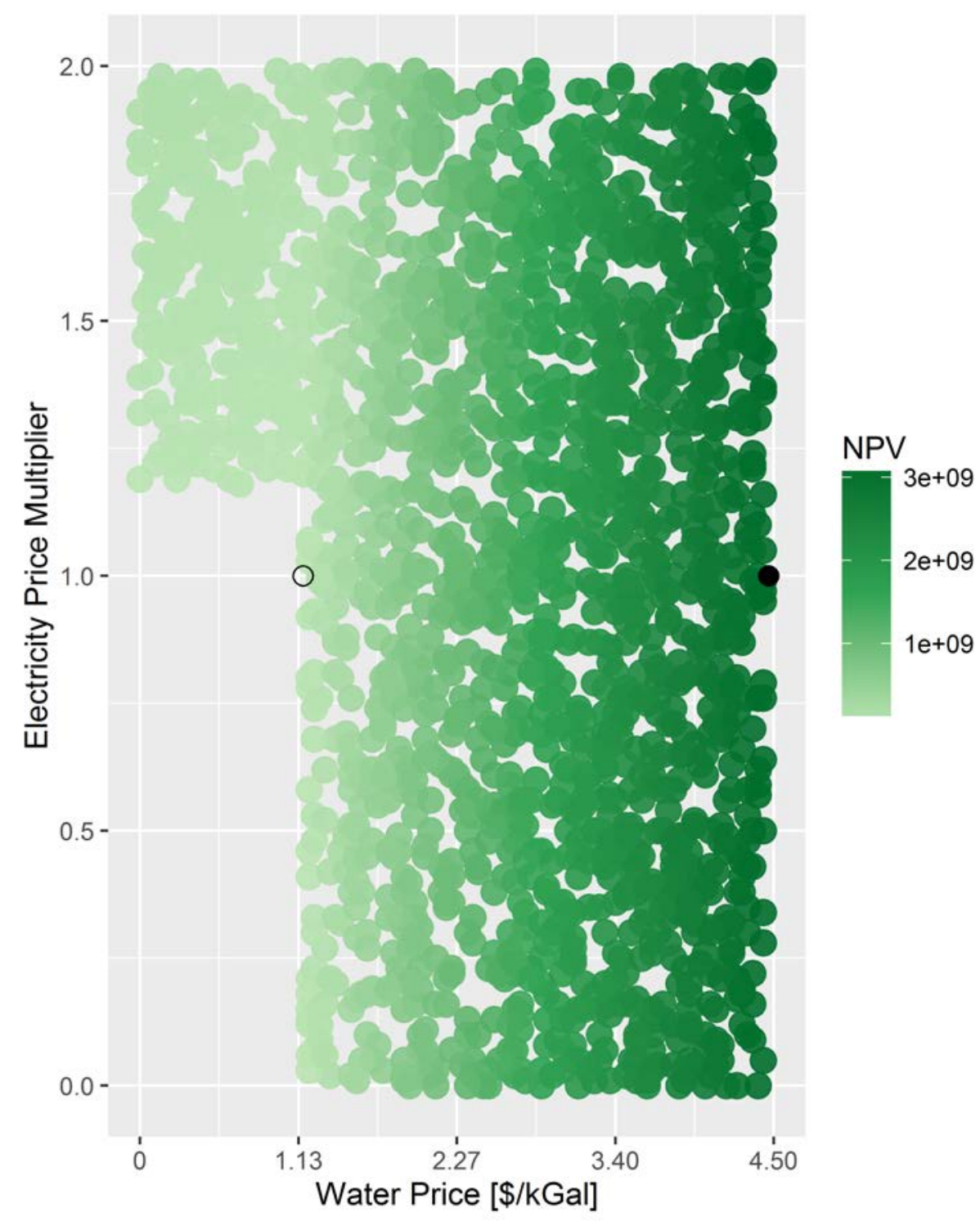

Figure H-35. Arizona-Desalination Scenario NPVs at various water prices and electricity price multipliers based on RPS80 generation mix, AEO low-oil-price case, and \$150/kW-yr capacity payments.

Darker shades indicate higher NPVs.

Solid black dot at electricity price multiplier of 1.0 and $\$ 4.50 /$ thousand gal water price: reference case water price projection; reference-case electricity price vector

Open black dot: minimum water selling price for an $\mathrm{RO}$ desalination plant; reference-case electricity price vector 

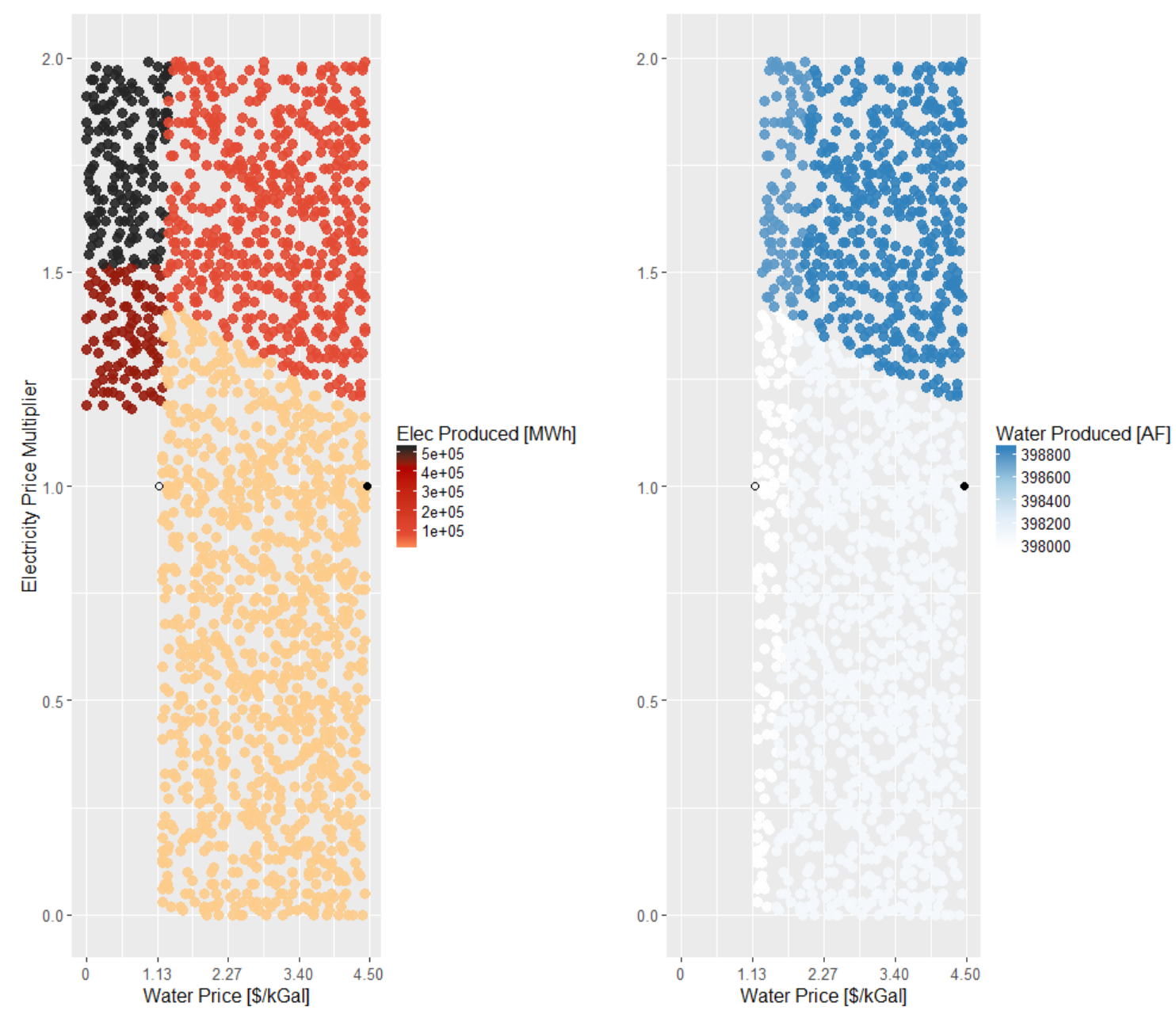

Figure H-36. Optimal annual product generation for Arizona-desalination scenario at various water prices and electricity price multipliers based on RPS80 generation mix, AEO low-oil-price case, and $\$ 150 / \mathrm{kW}$-yr capacity payments.

Electricity is shown on the left with greater generation at the darker color. Water is shown on the right.

Solid black dot at electricity price multiplier of 1.0 and $\$ 4.50 /$ thousand gal water price: reference case water price projection; reference-case electricity price vector

Open black dot: minimum water selling price for an RO desalination plant; reference-case electricity price vector 


\section{H.5 Sensitivities on the Impacts of Electricity and Water Prices}

Based on Electricity Prices Using the RPS80 Generation Mix and the Annual Energy Outlook Reference Case with a Cost of Carbon

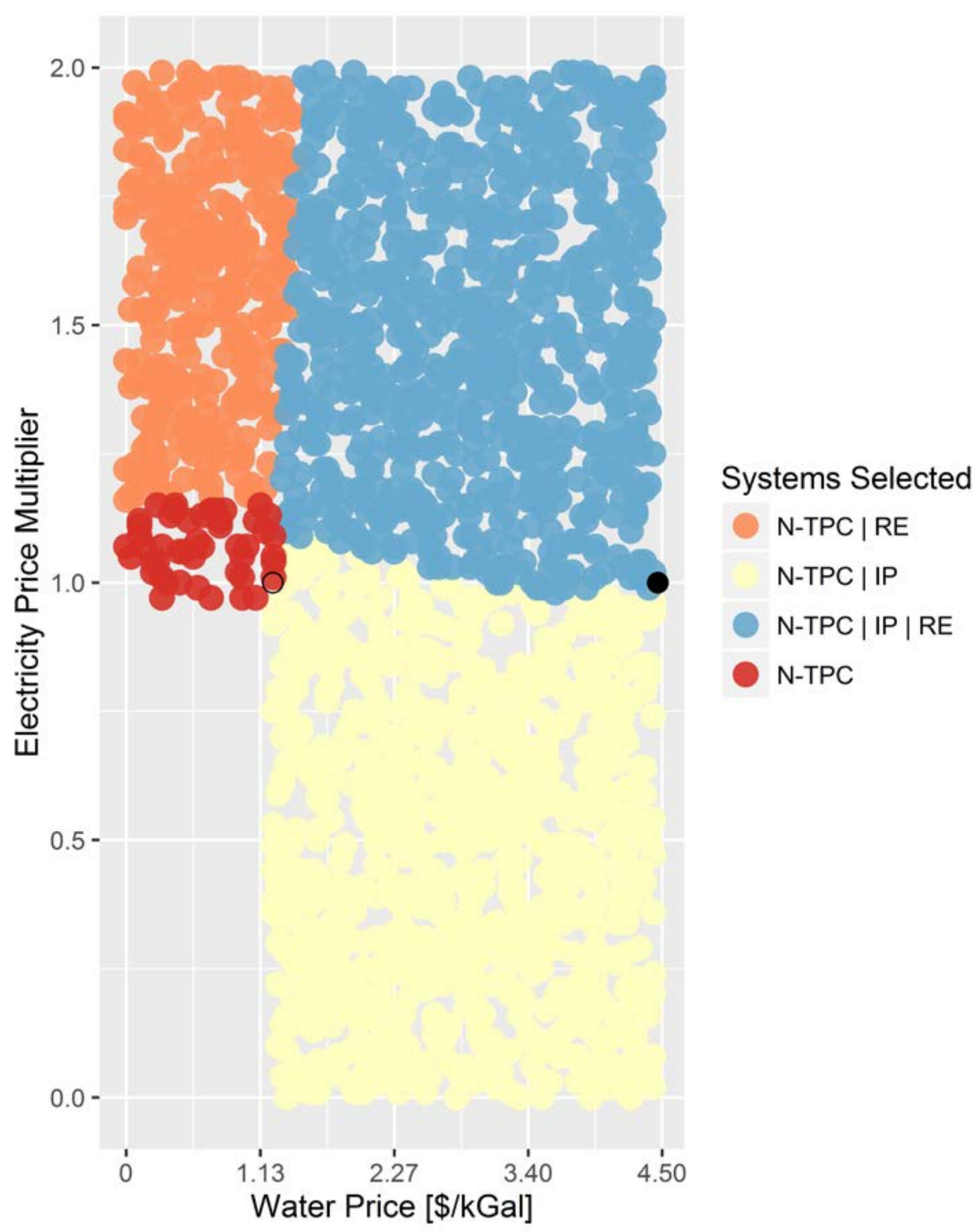

Figure H-37. Optimal configurations for Arizona-desalination scenario at various water prices and electricity price multipliers based on RPS80 generation mix, AEO reference case plus a cost of carbon of $\$ 61 /$ metric ton $\mathrm{CO}_{2}$, and $\$ 50 / \mathrm{kW}$-yr capacity payments

N-TPC: Nuclear reactor and thermal N-IP: Nuclear reactor and industrial process

RE: Renewable electricity generation

Solid black dot at electricity price multiplier of 1.0 and $\$ 4.50 /$ thousand gal water price: reference case water price projection; reference-case electricity price vector

Open black dot: minimum water selling price for an $\mathrm{RO}$ desalination plant; reference-case electricity price vector 


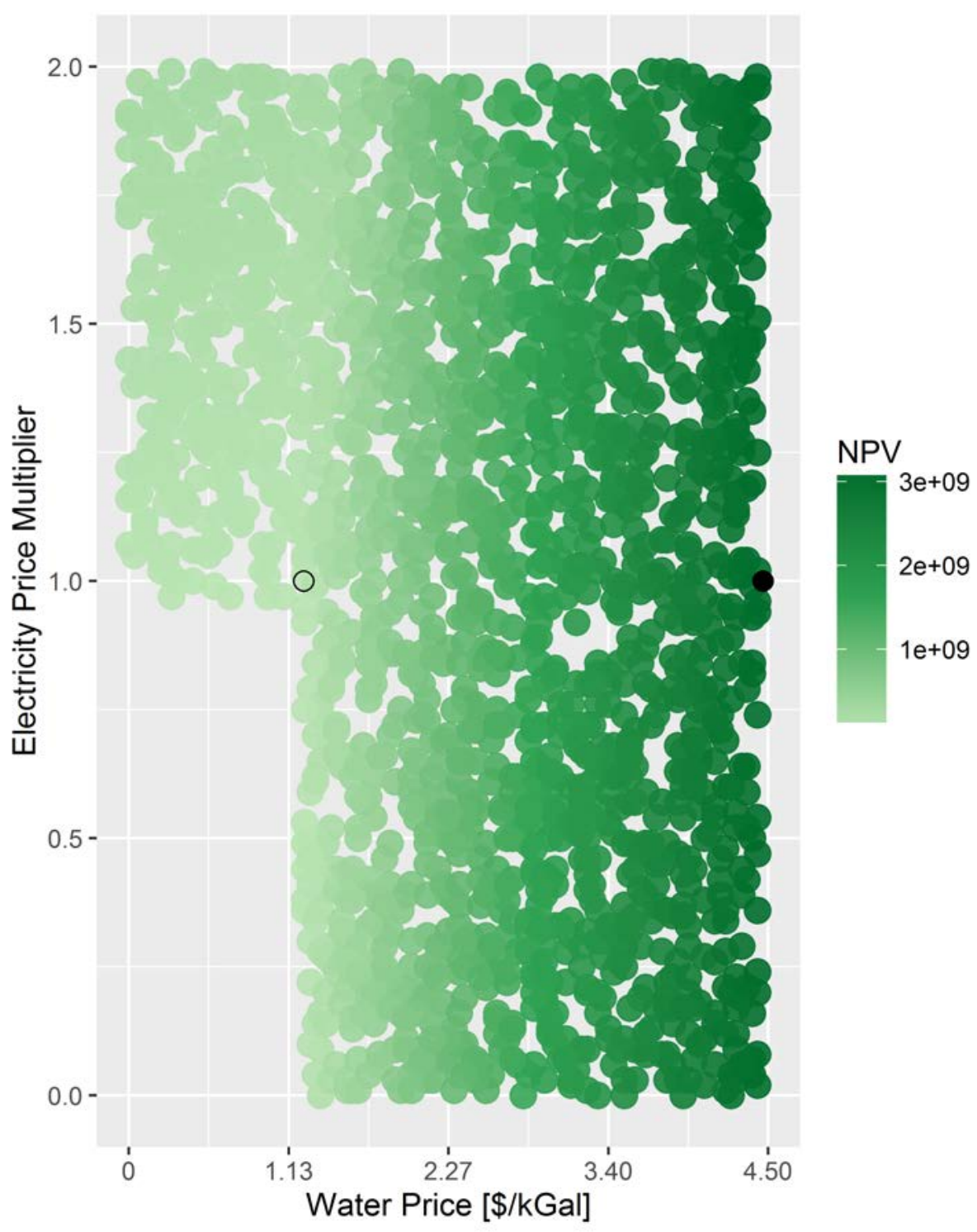

Figure H-38. Arizona-Desalination Scenario NPVs at various water prices and electricity price multipliers based on RPS80 generation mix, AEO reference case plus a cost of carbon of $\$ 61 /$ metric ton $\mathrm{CO}_{2}$, and $\$ 50 / \mathrm{kW}$-yr capacity payments.

Darker shades indicate higher NPVs.

Solid black dot at electricity price multiplier of 1.0 and $\$ 4.50 /$ thousand gal water price: reference case water price projection; reference-case electricity price vector

Open black dot: minimum water selling price for an RO desalination plant; reference-case electricity price vector 

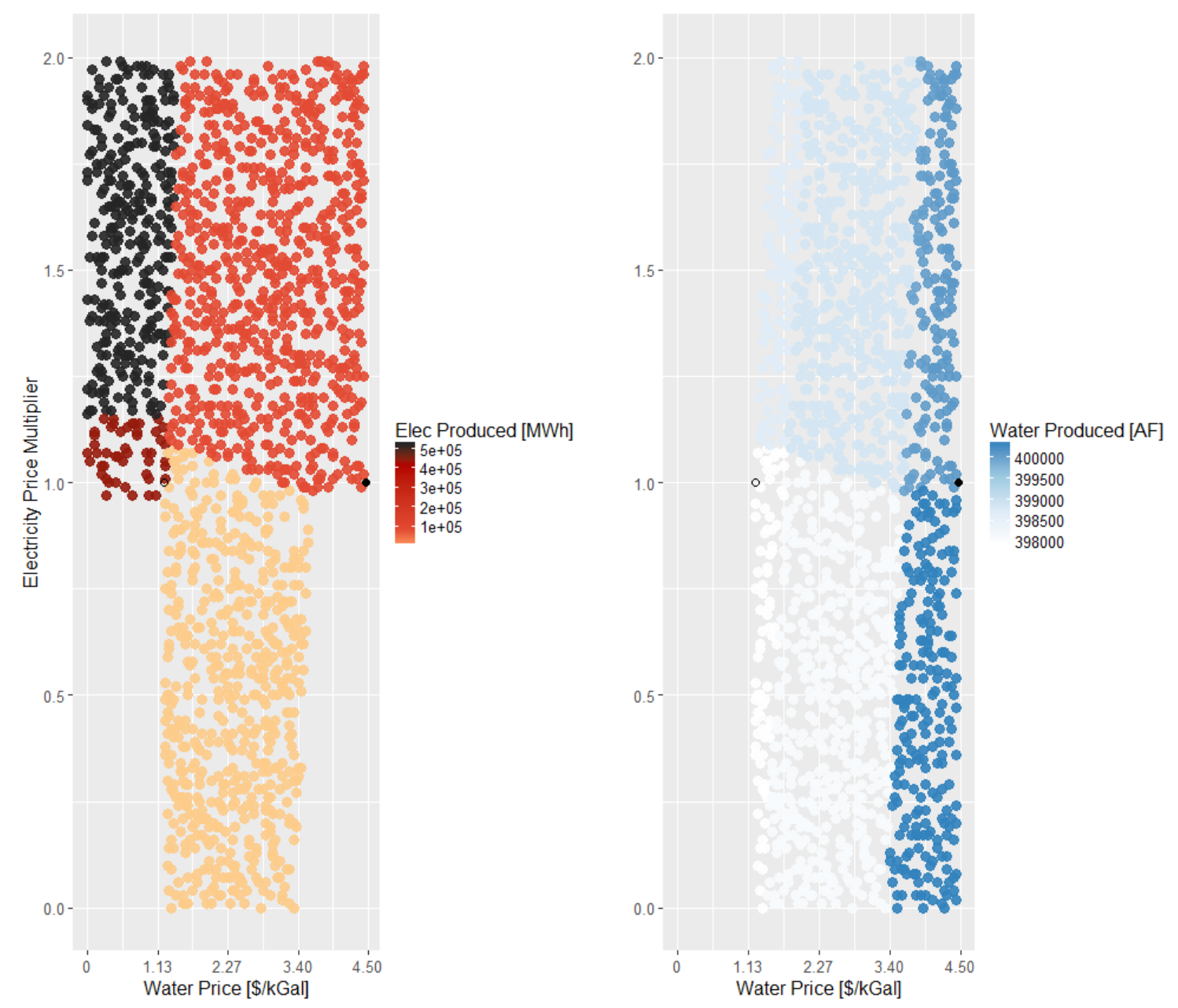

Figure H-39. Optimal annual product generation for Arizona-desalination scenario at various water prices and electricity price multipliers based on RPS80 generation mix, AEO reference case plus a cost of carbon of $\$ 61 /$ metric ton $\mathrm{CO}_{2}$, and $\$ 50 / \mathrm{kW}$-yr capacity payments.

Electricity is shown on the left with greater generation at the darker color. Water is shown on the right.

Solid black dot at electricity price multiplier of 1.0 and $\$ 4.50 /$ thousand gal water price: reference case water price projection; reference-case electricity price vector

Open black dot: minimum water selling price for an RO desalination plant; reference-case electricity price vector 


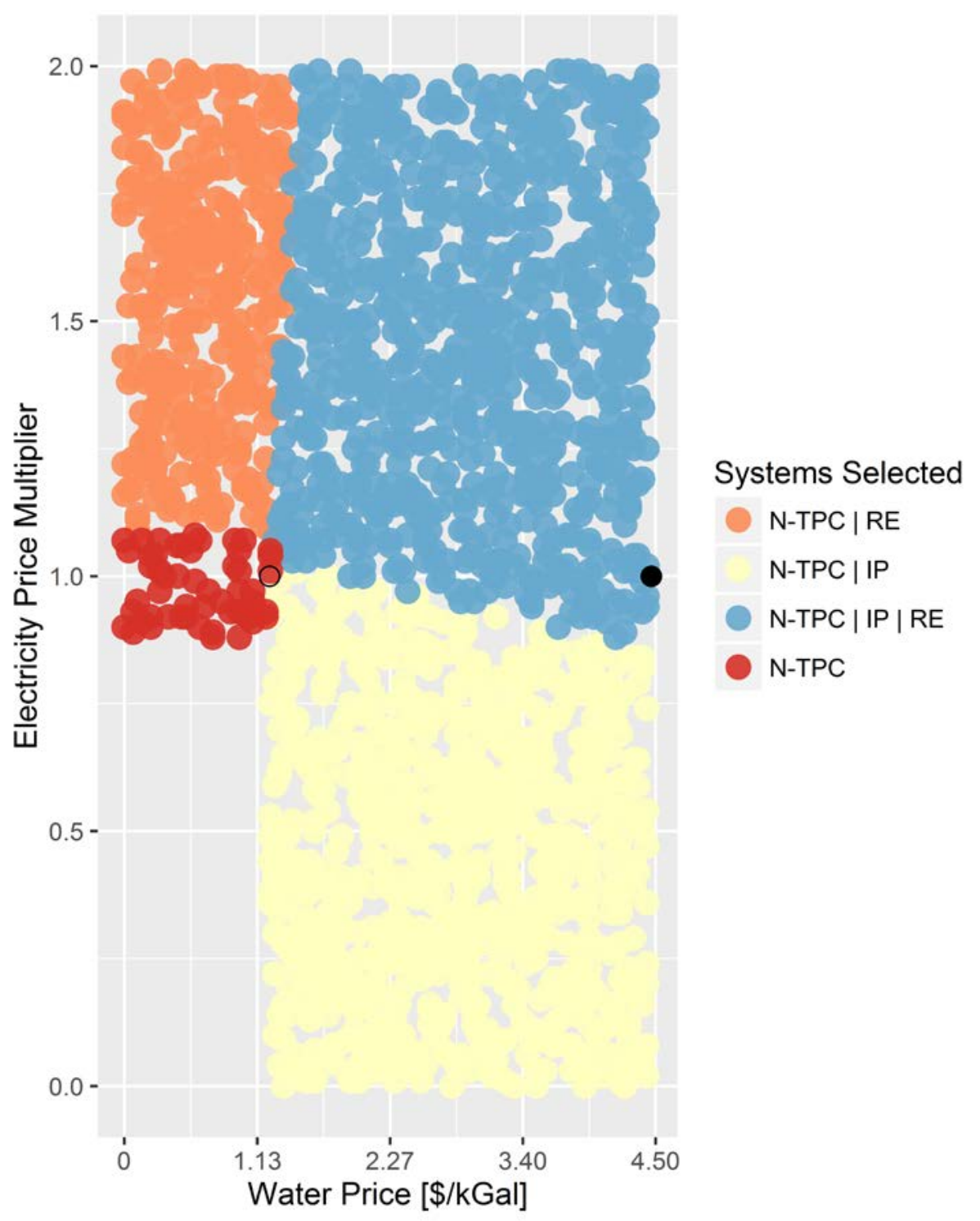

Figure H-40. Optimal configurations for Arizona-desalination scenario at various water prices and electricity price multipliers based on RPS80 generation mix, AEO reference case plus a cost of carbon of $\$ 61 /$ metric ton $\mathrm{CO}_{2}$, and $\$ 100 / \mathrm{kW}$-yr capacity payments.

N-TPC: Nuclear reactor and thermal N-IP: Nuclear reactor and industrial process

RE: Renewable electricity generation

Solid black dot at electricity price multiplier of 1.0 and $\$ 4.50 /$ thousand gal water price: reference case water price projection; reference-case electricity price vector

Open black dot: minimum water selling price for an RO desalination plant; reference-case electricity price vector 


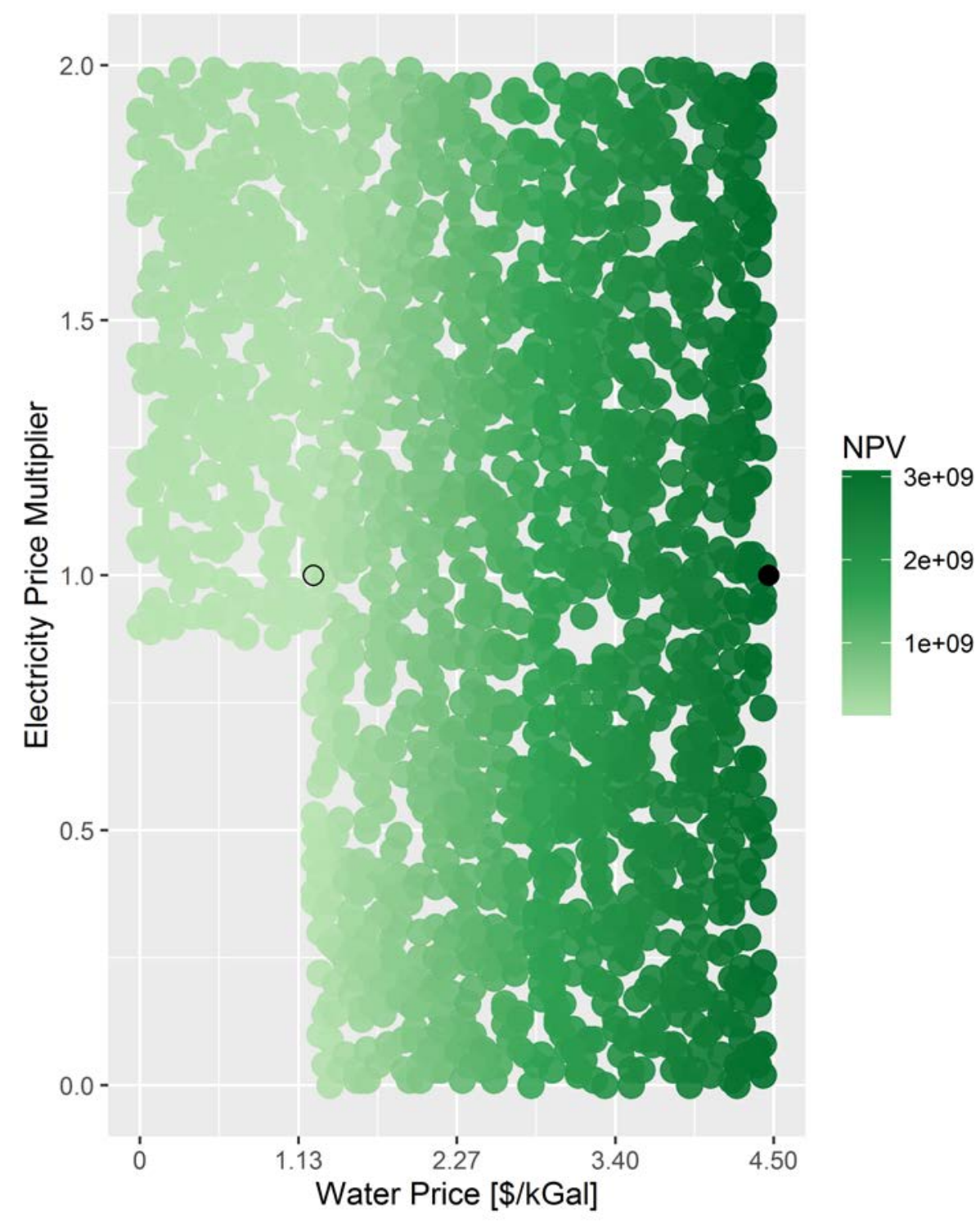

Figure H-41. Arizona-Desalination Scenario NPVs at various water prices and electricity price multipliers based on RPS80 generation mix, AEO reference case plus a cost of carbon of $\$ 61 /$ metric ton $\mathrm{CO}_{2,}$, and $\$ 100 / \mathrm{kW}$-yr capacity payments.

Darker shades indicate higher NPVs.

Solid black dot at electricity price multiplier of 1.0 and $\$ 4.50 /$ thousand gal water price: reference case water price projection; reference-case electricity price vector

Open black dot: minimum water selling price for an RO desalination plant; reference-case electricity price vector 

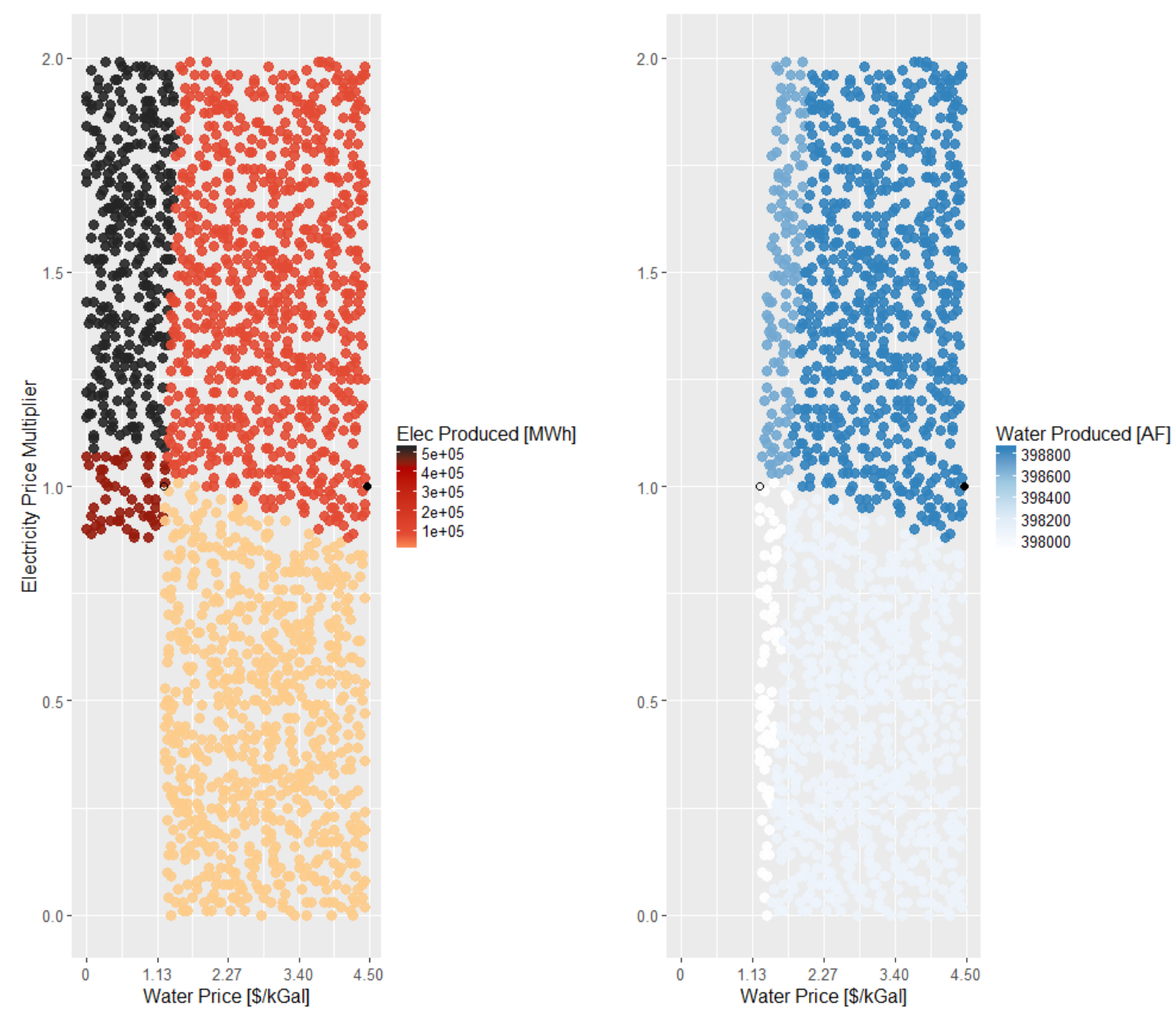

Figure H-42. Optimal annual product generation for Arizona-desalination scenario at various water prices and electricity price multipliers based on RPS80 generation mix, AEO reference case plus a cost of carbon of $\$ 61 /$ metric ton $\mathrm{CO}_{2}$, and $\$ 100 / \mathrm{kW}$-yr capacity payments.

Electricity is shown on the left with greater generation at the darker color. Water is shown on the right.

Solid black dot at electricity price multiplier of 1.0 and $\$ 4.50 /$ thousand gal water price: reference case water price projection; reference-case electricity price vector

Open black dot: minimum water selling price for an RO desalination plant; reference-case electricity price vector 


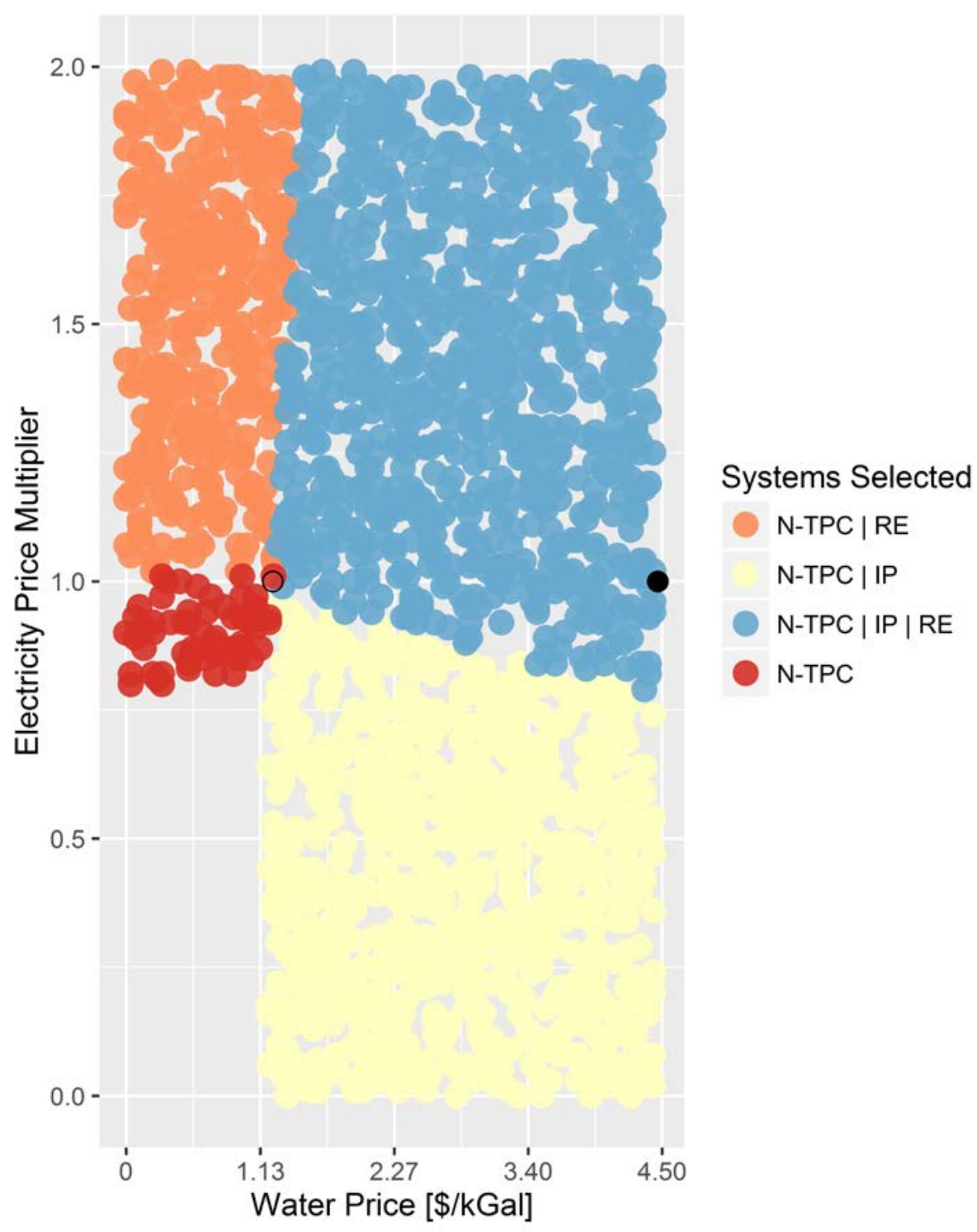

Figure H-43. Optimal configurations for Arizona-desalination scenario at various water prices and electricity price multipliers based on RPS80 generation mix, AEO reference case plus a cost of carbon of $\$ 61 /$ metric ton $\mathrm{CO}_{2}$, and $\$ 150 / \mathrm{kW}$-yr capacity payments

N-TPC: Nuclear reactor and thermal N-IP: Nuclear reactor and industrial process

RE: Renewable electricity generation

Solid black dot at electricity price multiplier of 1.0 and $\$ 4.50 /$ thousand gal water price: reference case water price projection; reference-case electricity price vector

Open black dot: minimum water selling price for an RO desalination plant; reference-case electricity price vector 


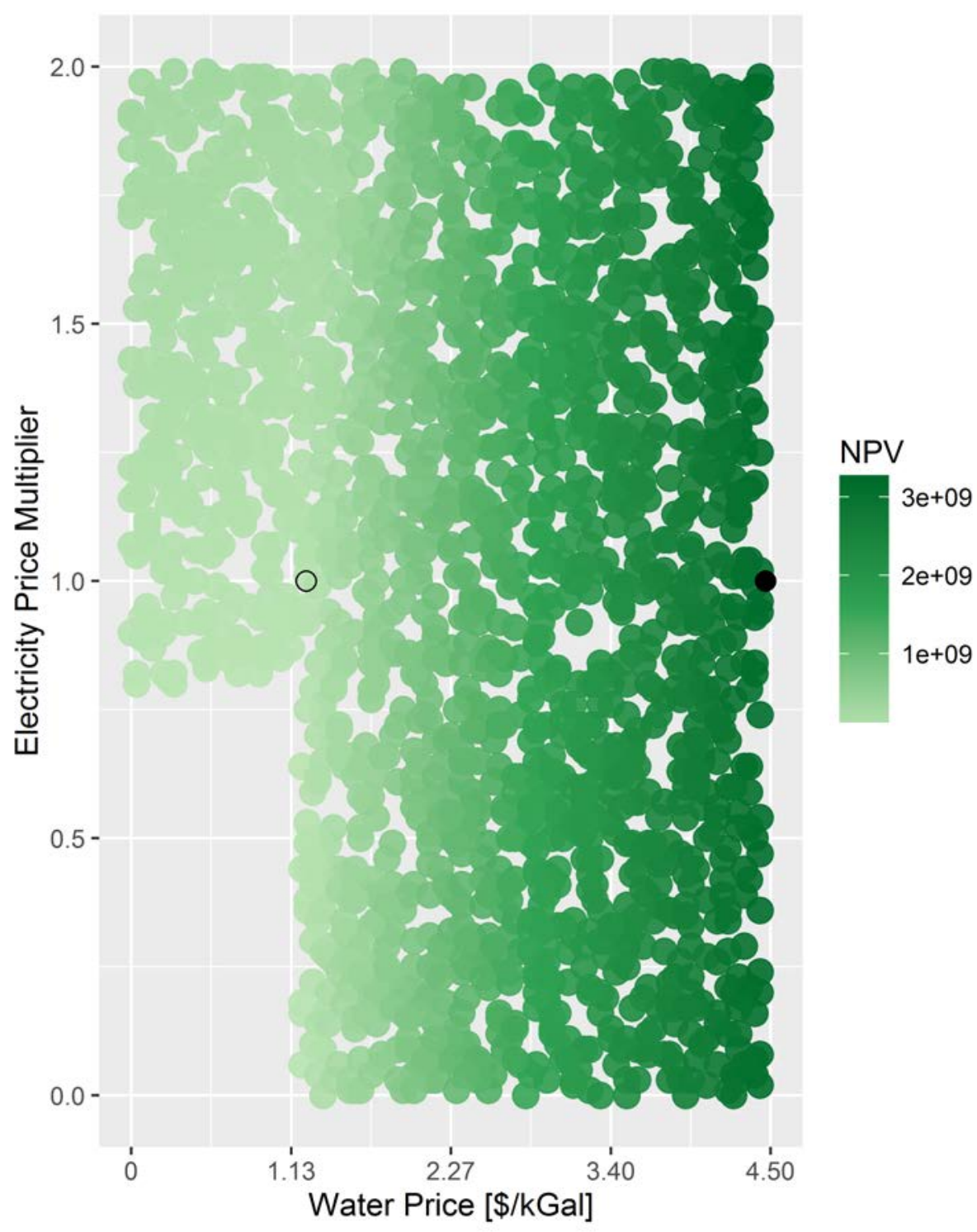

Figure H-44. Arizona-Desalination Scenario NPVs at various water prices and electricity price multipliers based on RPS80 generation mix, AEO reference case plus a cost of carbon of $\$ 61 /$ metric ton $\mathrm{CO}_{2}$, and $\$ 150 / \mathrm{kW}$-yr capacity payments.

Darker shades indicate higher NPVs.

Solid black dot at electricity price multiplier of 1.0 and $\$ 4.50 /$ thousand gal water price: reference case water price projection; reference-case electricity price vector

Open black dot: minimum water selling price for an RO desalination plant; reference-case electricity price vector 

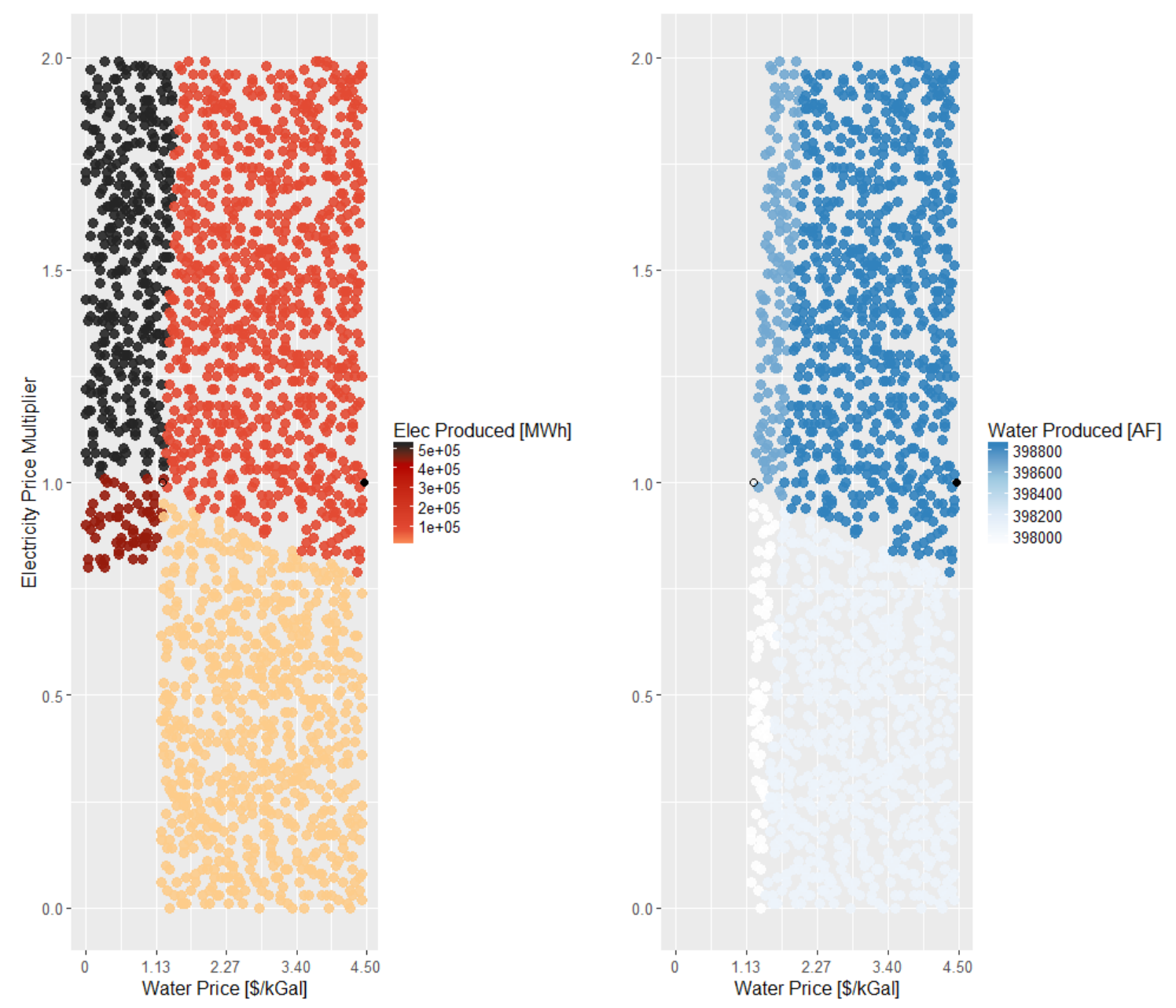

Figure H-45. Optimal annual product generation for Arizona-desalination scenario at various water prices and electricity price multipliers based on RPS80 generation mix, AEO reference case plus a cost of carbon of $\$ 61 /$ metric ton $\mathrm{CO}_{2}$, and $\$ 150 / \mathrm{kW}$-yr capacity payments.

Electricity is shown on the left with greater generation at the darker color. Water is shown on the right.

Solid black dot at electricity price multiplier of 1.0 and $\$ 4.50 /$ thousand gal water price: reference case water price projection; reference-case electricity price vector

Open black dot: minimum water selling price for an RO desalination plant; reference-case electricity price vector 


\section{H.6 Sensitivities on the Impacts of Electricity and Water Prices Based on Electricity Prices Using the Annual Energy Outlook Reference Case with a Nominal Discount Rate of $8.15 \%$}

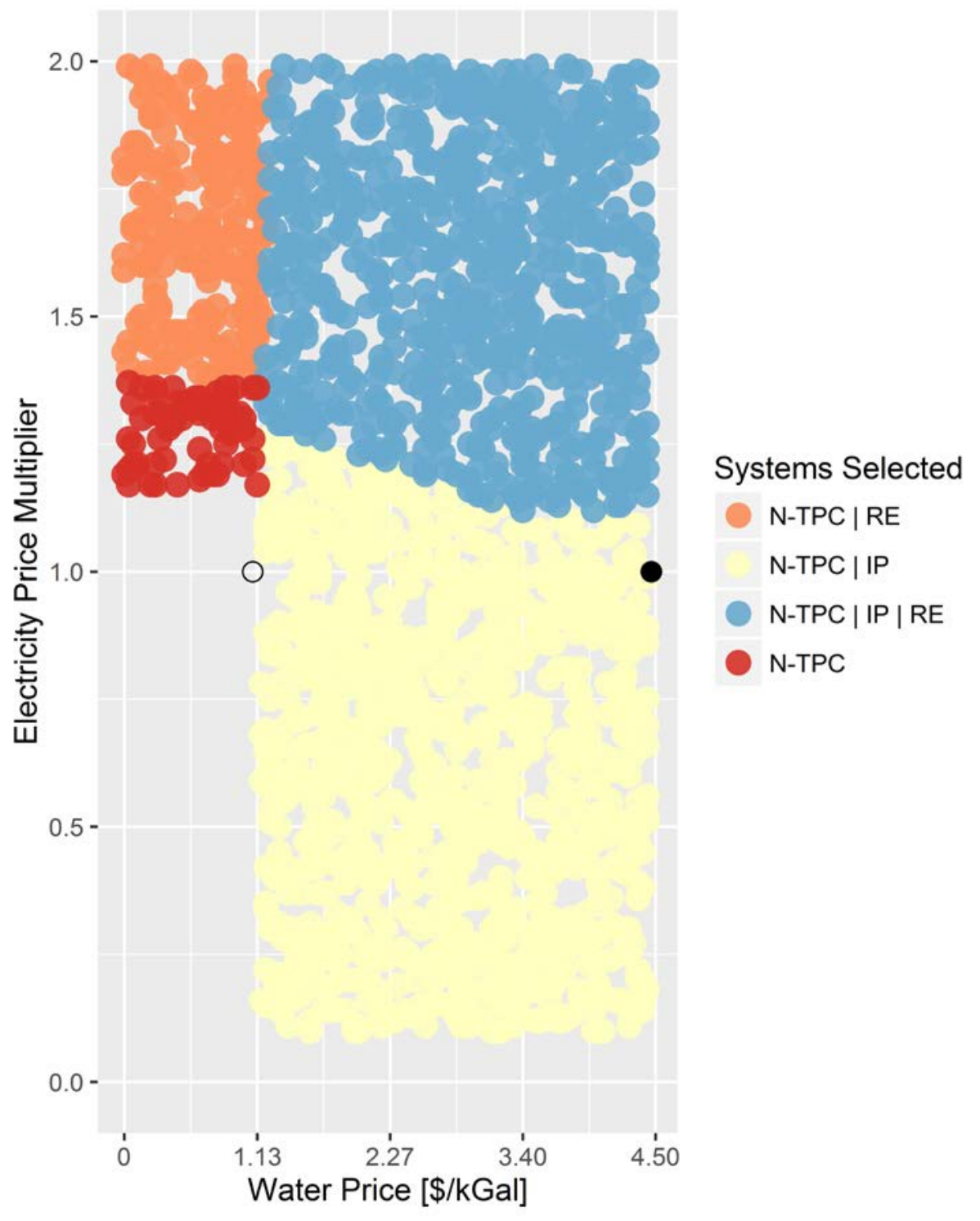

Figure H-46. Optimal configurations for Arizona-desalination scenario at various water prices and electricity price multipliers based on RPS80 generation mix, AEO reference case, nominal discount rate of $8.15 \%$, and $\$ 50 / \mathrm{kW}$-yr capacity payments

N-TPC: Nuclear reactor and thermal

N-IP: Nuclear reactor and industrial process

RE: Renewable electricity generation

Solid black dot at electricity price multiplier of 1.0 and $\$ 4.50 /$ thousand gal water price: reference case water price projection; reference-case electricity price vector

Open black dot: minimum water selling price for an RO desalination plant; reference-case electricity price vector 


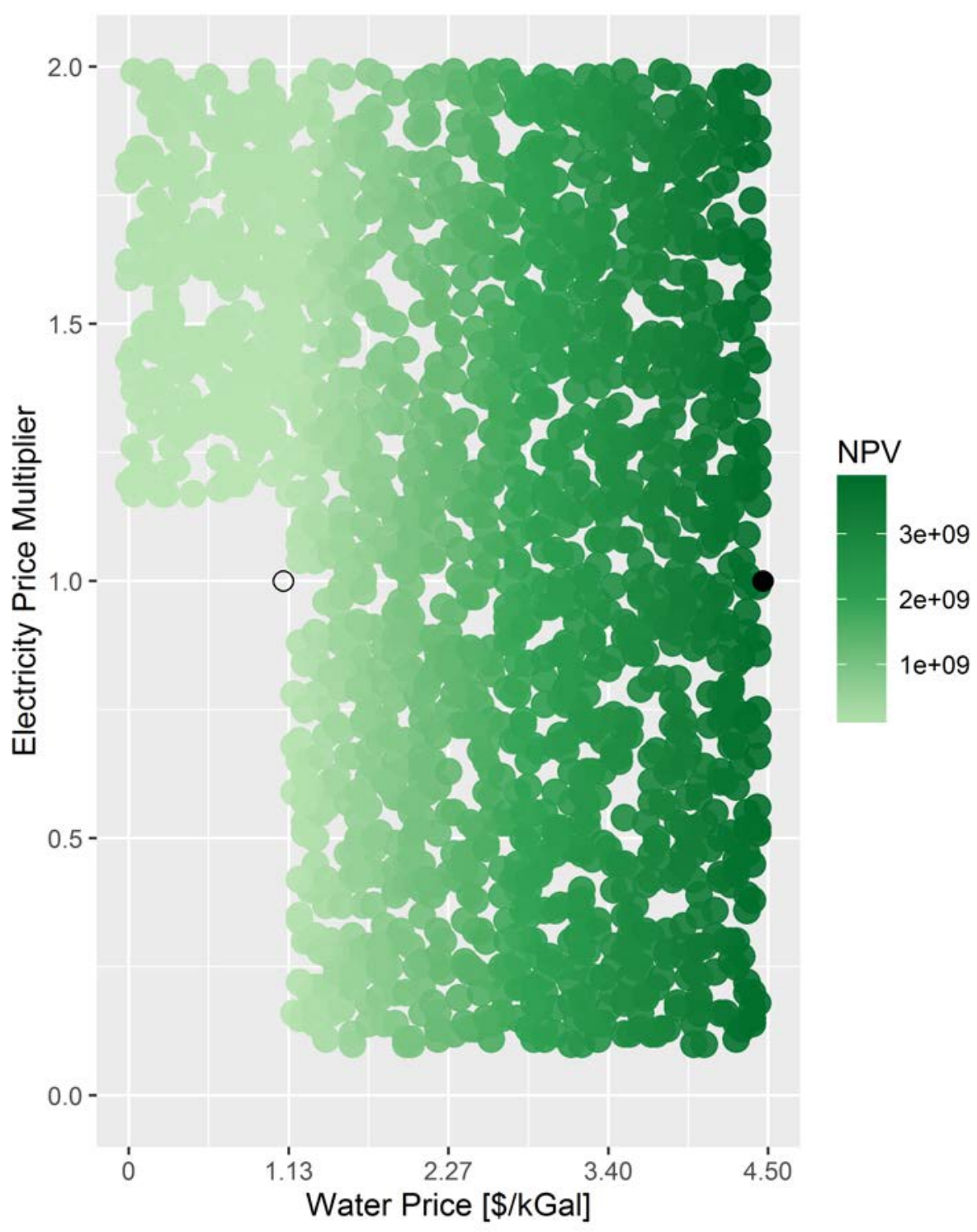

Figure H-47. Arizona-Desalination Scenario NPVs at various water prices and electricity price multipliers based on RPS80 generation mix, AEO reference case, nominal discount rate of $8.15 \%$, and $\$ 50 / k W-y r$ capacity payments.

Darker shades indicate higher NPVs.

Solid black dot at electricity price multiplier of 1.0 and $\$ 4.50 /$ thousand gal water price: reference case water price projection; reference-case electricity price vector

Open black dot: minimum water selling price for an $\mathrm{RO}$ desalination plant; reference-case electricity price vector 

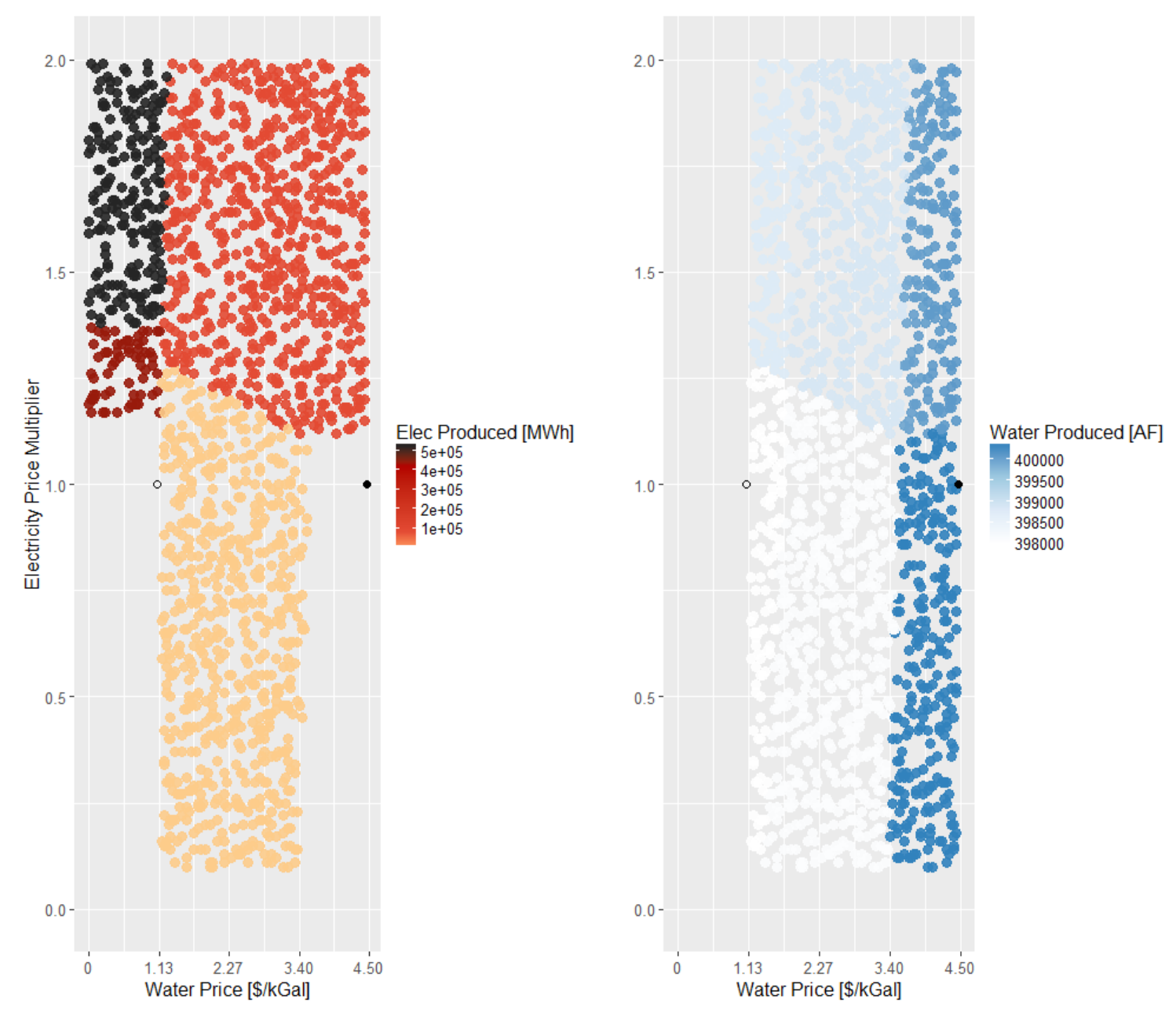

Figure H-48. Optimal annual product generation for Arizona-desalination scenario at various water prices and electricity price multipliers based on RPS80 generation mix, AEO reference case, nominal discount rate of $8.15 \%$, and $\$ 50 / \mathrm{kW}$-yr capacity payments.

Electricity is shown on the left with greater generation at the darker color. Water is shown on the right.

Solid black dot at electricity price multiplier of 1.0 and $\$ 4.50$ /thousand gal water price: reference case water price projection; reference-case electricity price vector

Open black dot: minimum water selling price for an RO desalination plant; reference-case electricity price vector 


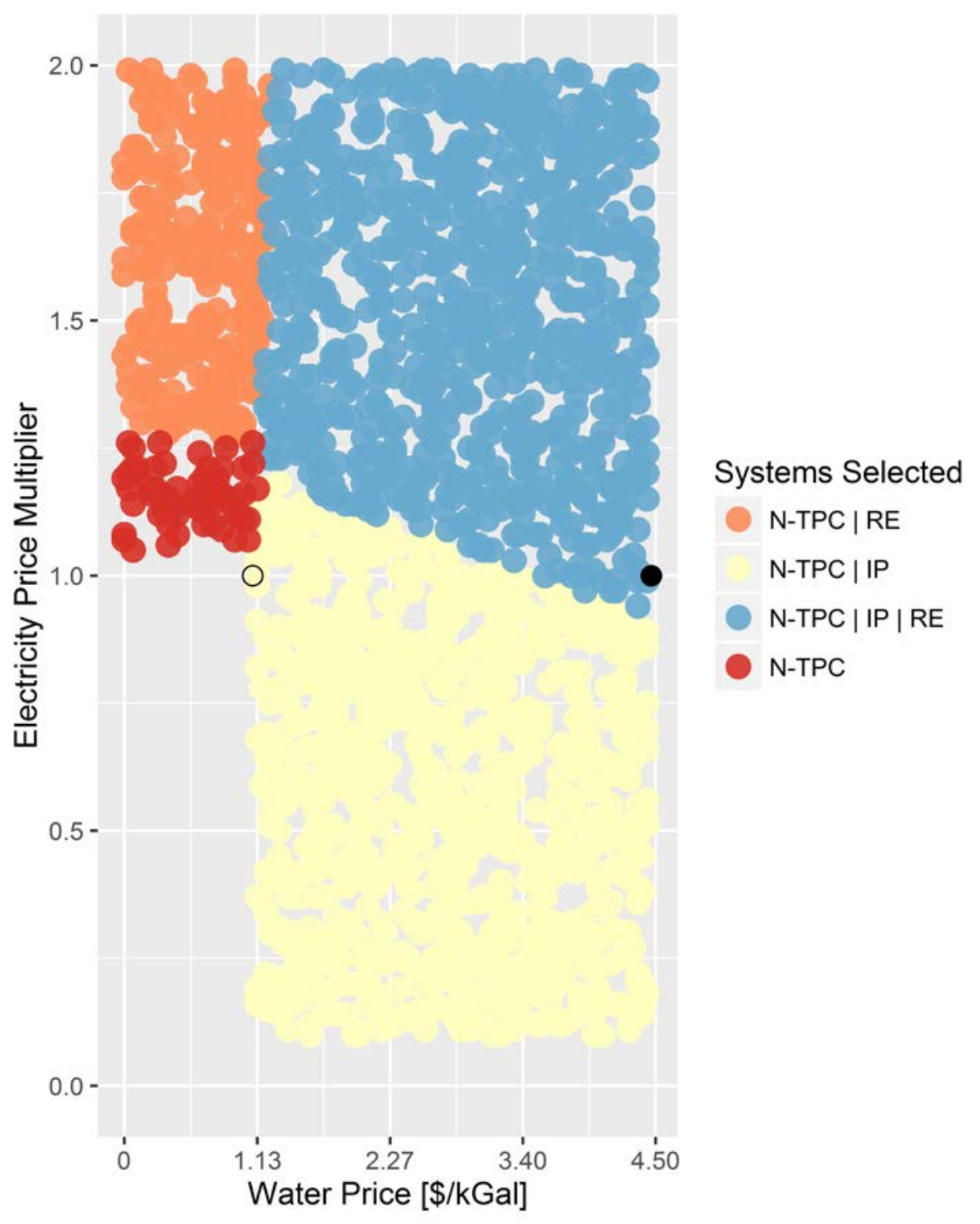

Figure H-49. Optimal configurations for Arizona-desalination scenario at various water prices and electricity price multipliers based on RPS80 generation mix, AEO reference case, nominal discount rate of $8.15 \%$, and $\$ 100 / \mathrm{kW}$-yr capacity payments.

N-TPC: Nuclear reactor and thermal N-IP: Nuclear reactor and industrial process

RE: Renewable electricity generation

Solid black dot at electricity price multiplier of 1.0 and $\$ 4.50 /$ thousand gal water price: reference case water price projection; reference-case electricity price vector

Open black dot: minimum water selling price for an RO desalination plant; reference-case electricity price vector 


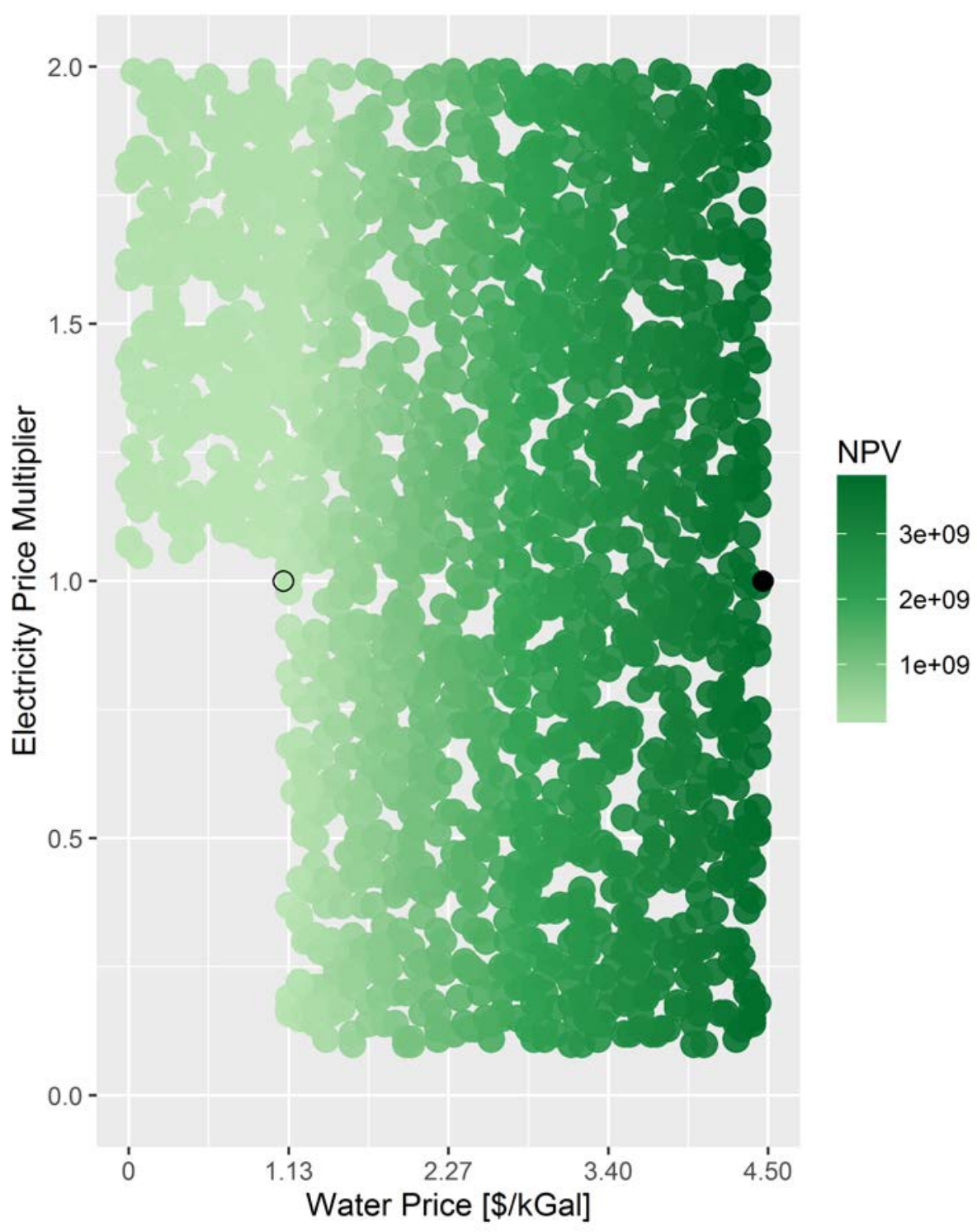

Figure H-50. Arizona-Desalination Scenario NPVs at various water prices and electricity price multipliers based on RPS80 generation mix, AEO reference case, nominal discount rate of $8.15 \%$, and $\$ 100 / \mathrm{kW}$-yr capacity payments.

Darker shades indicate higher NPVs.

Solid black dot at electricity price multiplier of 1.0 and $\$ 4.50 /$ thousand gal water price: reference case water price projection; reference-case electricity price vector

Open black dot: minimum water selling price for an $\mathrm{RO}$ desalination plant; reference-case electricity price vector 

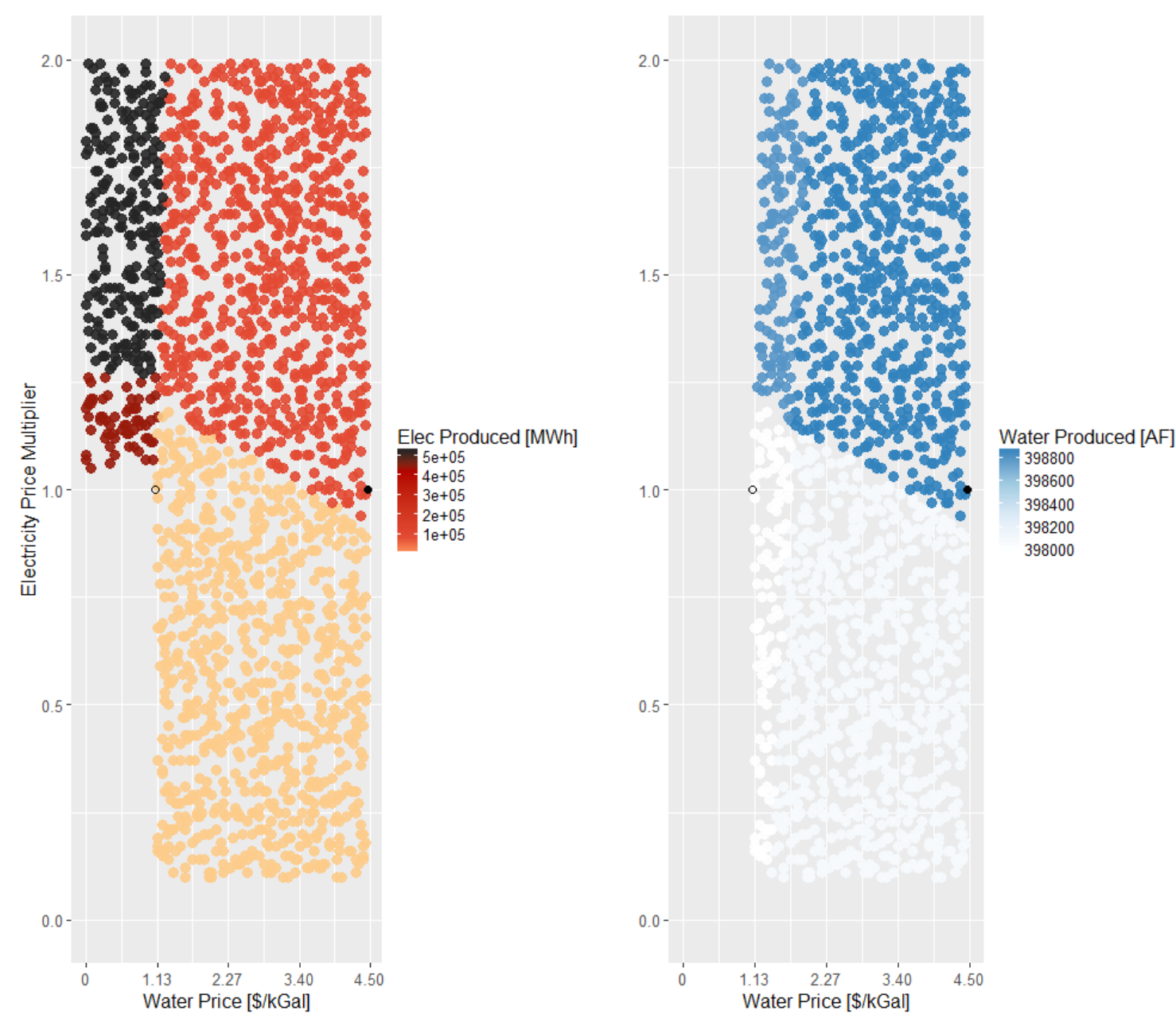

Figure H-51. Optimal annual product generation for Arizona-desalination scenario at various water prices and electricity price multipliers based on RPS80 generation mix, AEO reference case, nominal discount rate of $8.15 \%$, and $\$ 100 / \mathrm{kW}$-yr capacity payments.

Electricity is shown on the left with greater generation at the darker color. Water is shown on the right.

Solid black dot at electricity price multiplier of 1.0 and $\$ 4.50$ /thousand gal water price: reference case water price projection; reference-case electricity price vector

Open black dot: minimum water selling price for an RO desalination plant; reference-case electricity price vector 


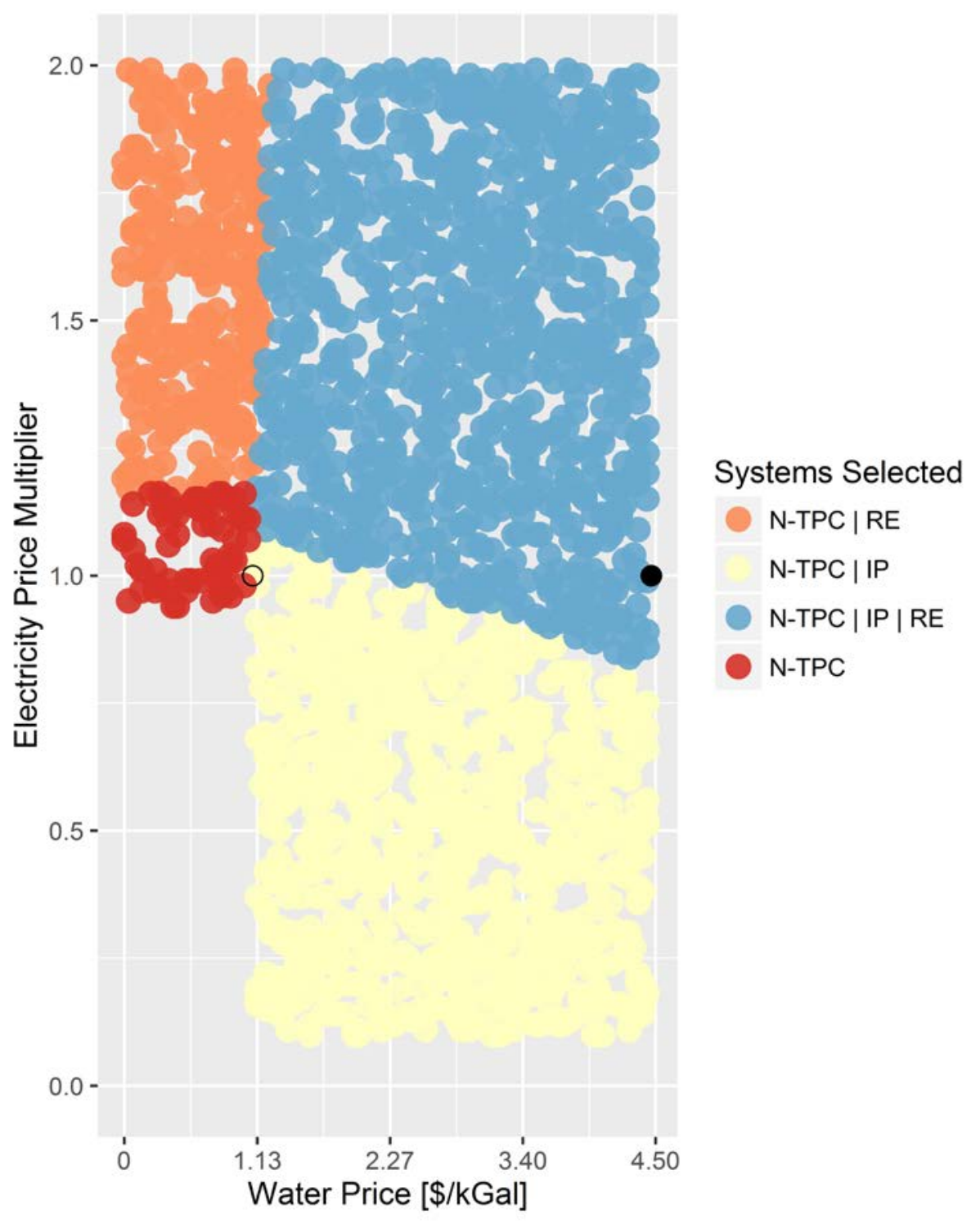

Figure H-52. Optimal configurations for Arizona-desalination scenario at various water prices and electricity price multipliers based on RPS80 generation mix, AEO reference case, nominal discount rate of $8.15 \%$, and $\$ 150 / \mathrm{kW}$-yr capacity payments

N-TPC: Nuclear reactor and thermal

N-IP: Nuclear reactor and industrial process

RE: Renewable electricity generation

Solid black dot at electricity price multiplier of 1.0 and $\$ 4.50 /$ thousand gal water price: reference case water price projection; reference-case electricity price vector

Open black dot: minimum water selling price for an RO desalination plant; reference-case electricity price vector 


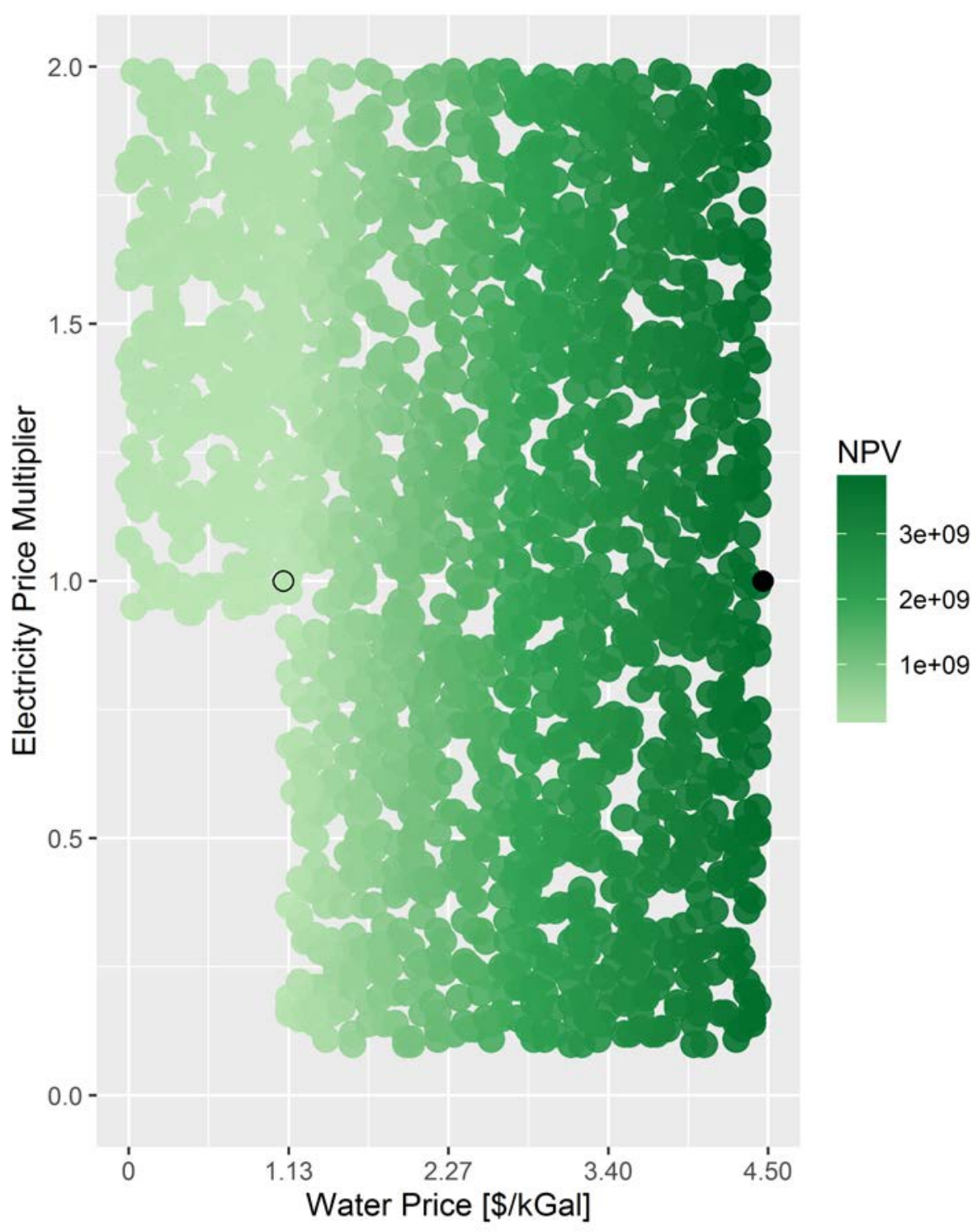

Figure H-53. Arizona-Desalination Scenario NPVs at various water prices and electricity price multipliers based on RPS 80 generation mix, AEO reference case, nominal discount rate of $8.15 \%$, and $\$ 150 / k W$-yr capacity payments.

Darker shades indicate higher NPVs.

Solid black dot at electricity price multiplier of 1.0 and $\$ 4.50 /$ thousand gal water price: reference case water price projection; reference-case electricity price vector

Open black dot: minimum water selling price for an RO desalination plant; reference-case electricity price vector 

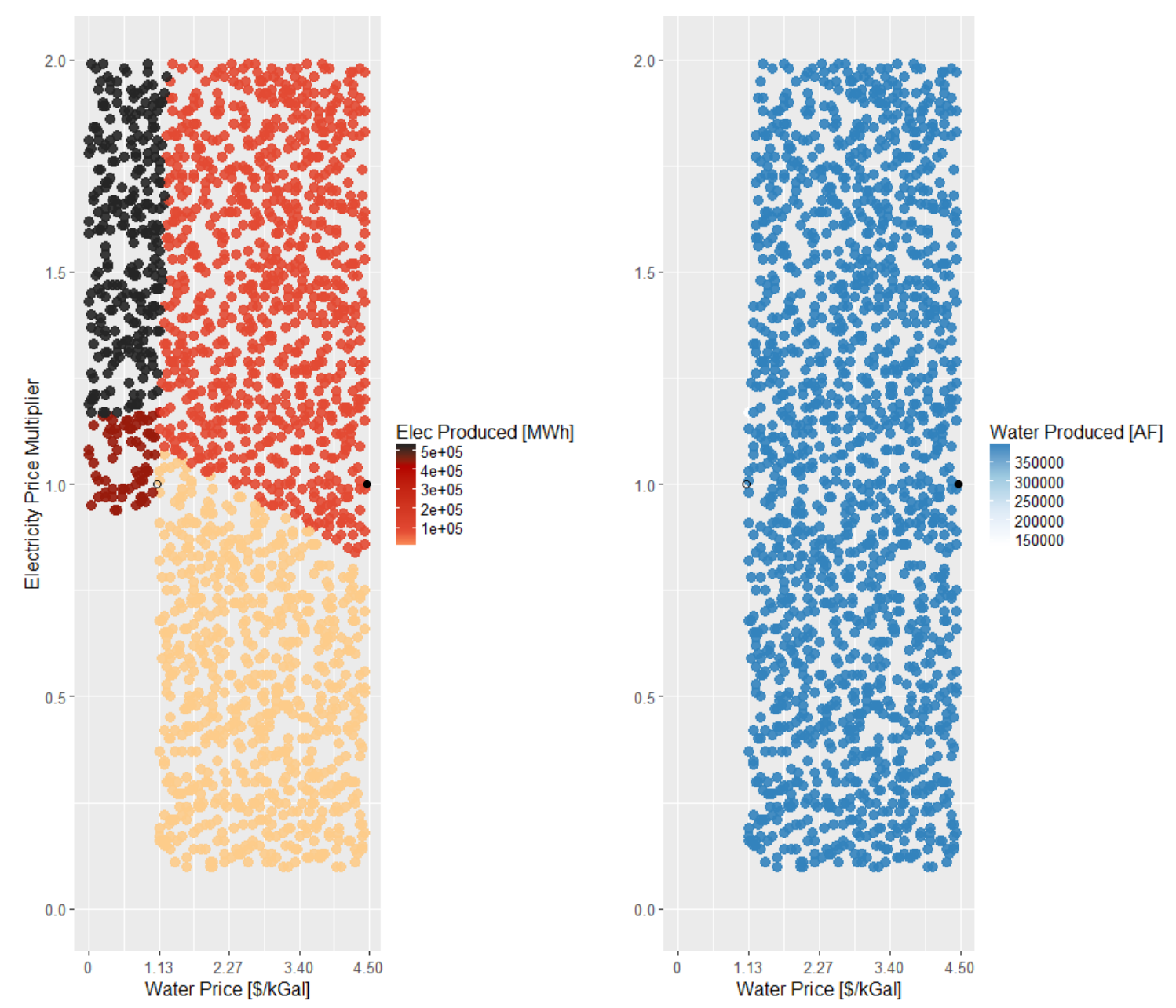

Figure H-54. Optimal annual product generation for Arizona-desalination scenario at various water prices and electricity price multipliers based on RPS80 generation mix, AEO reference case, nominal discount rate of $8.15 \%$, and $\$ 150 / \mathrm{kW}$-yr capacity payments.

Electricity is shown on the left with greater generation at the darker color. Water is shown on the right.

Solid black dot at electricity price multiplier of 1.0 and $\$ 4.50$ /thousand gal water price: reference case water price projection; reference-case electricity price vector

Open black dot: minimum water selling price for an RO desalination plant; reference-case electricity price vector 


\section{H.7 Sensitivities on the Impacts of Electricity and Water Prices Based on a $600 \mathrm{MWt}$ (180MWe) Maximum Capacity of the Nuclear Reactor and Thermal Power Cycle}

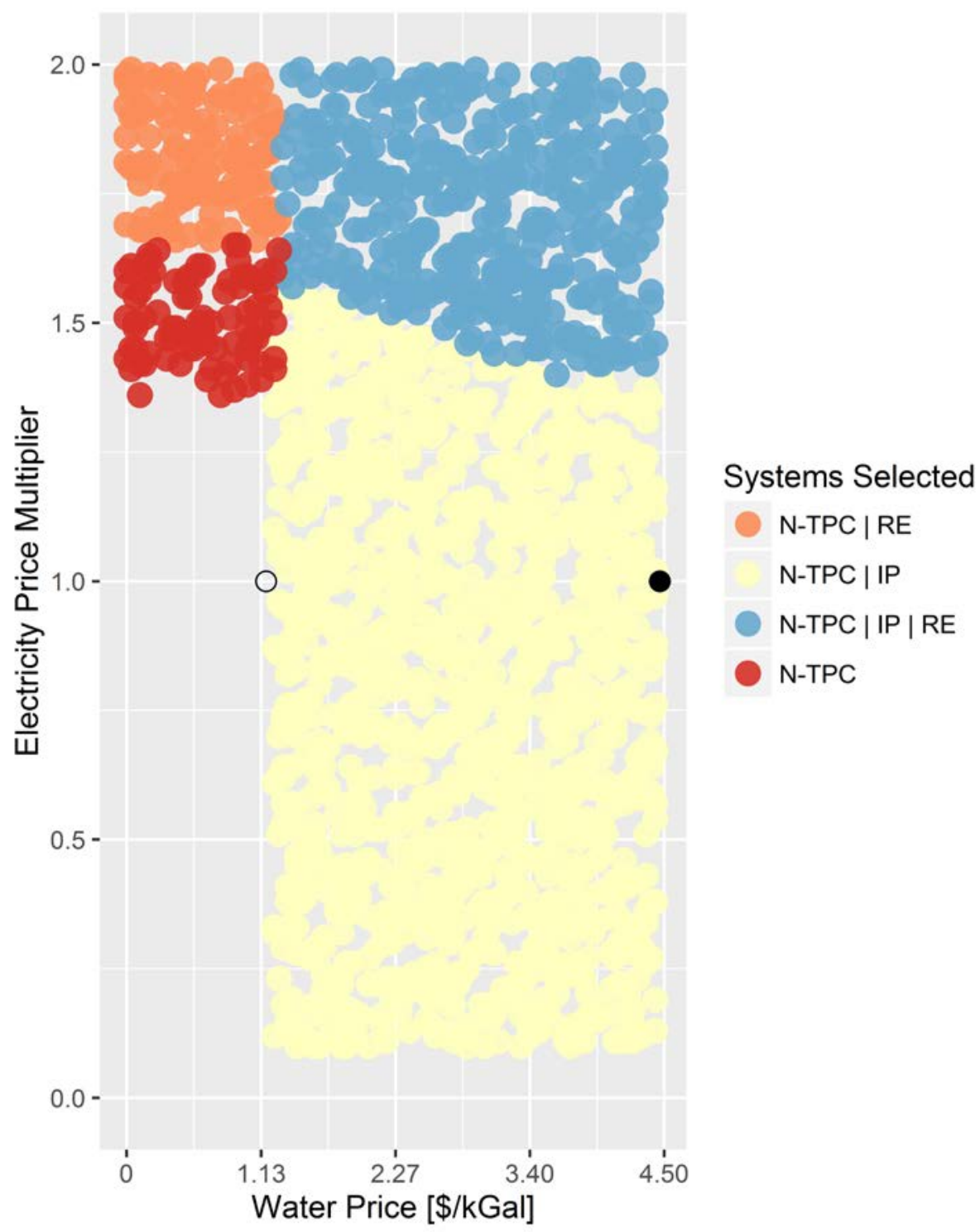

Figure H-55. Optimal configurations for Arizona-desalination scenario at various water prices and electricity price multipliers based on a $600 \mathrm{MWt}(180 \mathrm{MWe})$ maximum capacity of the nuclear reactor and thermal power cycle and $\$ 50 / \mathrm{kW}$-yr capacity payments

N-TPC: Nuclear reactor and thermal

N-IP: Nuclear reactor and industrial process

$\mathrm{RE}$ : Renewable electricity generation

Solid black dot at electricity price multiplier of 1.0 and $\$ 4.50 /$ thousand gal water price: reference case water price projection; reference-case electricity price vector

Open black dot: minimum water selling price for an RO desalination plant; reference-case electricity price vector 


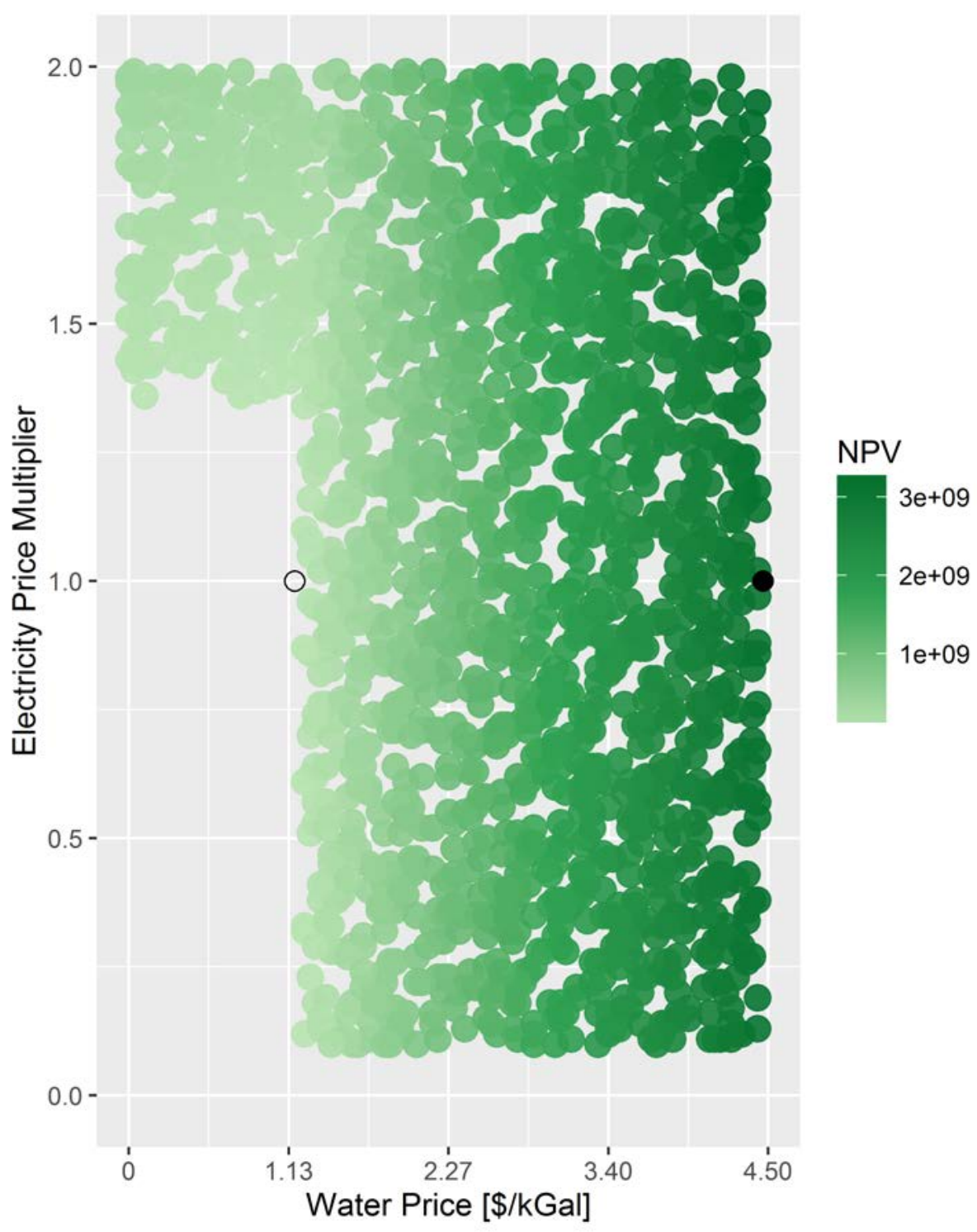

Figure H-56. Arizona-Desalination Scenario NPVs at various water prices and electricity price multipliers based on a $600 \mathrm{MWt}(180 \mathrm{MWe})$ maximum capacity of the nuclear reactor and thermal power cycle and $\$ 50 / \mathbf{k W}$-yr capacity payments.

Darker shades indicate higher NPVs.

Solid black dot at electricity price multiplier of 1.0 and $\$ 4.50 /$ thousand gal water price: reference case water price projection; reference-case electricity price vector

Open black dot: minimum water selling price for an RO desalination plant; reference-case electricity price vector 

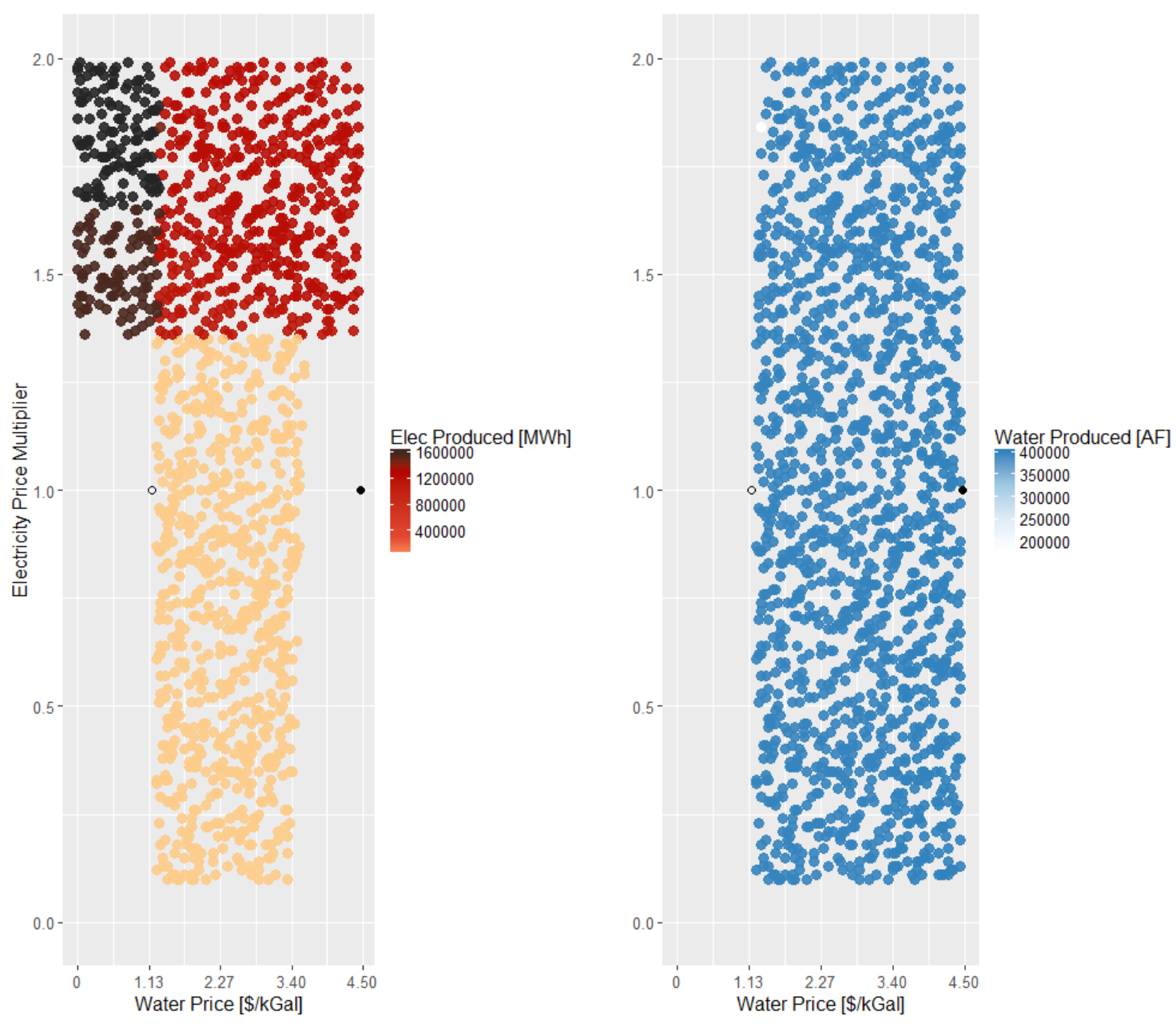

Figure H-57. Optimal annual product generation for Arizona-desalination scenario at various water prices and electricity price multipliers based on a $600 \mathrm{MWt}(180 \mathrm{MWe})$ maximum capacity of the nuclear reactor and thermal power cycle and $\$ 50 / \mathrm{kW}$-yr capacity payments.

Electricity is shown on the left with greater generation at the darker color. Water is shown on the right.

Solid black dot at electricity price multiplier of 1.0 and $\$ 4.50$ /thousand gal water price: reference case water price projection; reference-case electricity price vector

Open black dot: minimum water selling price for an RO desalination plant; reference-case electricity price vector 


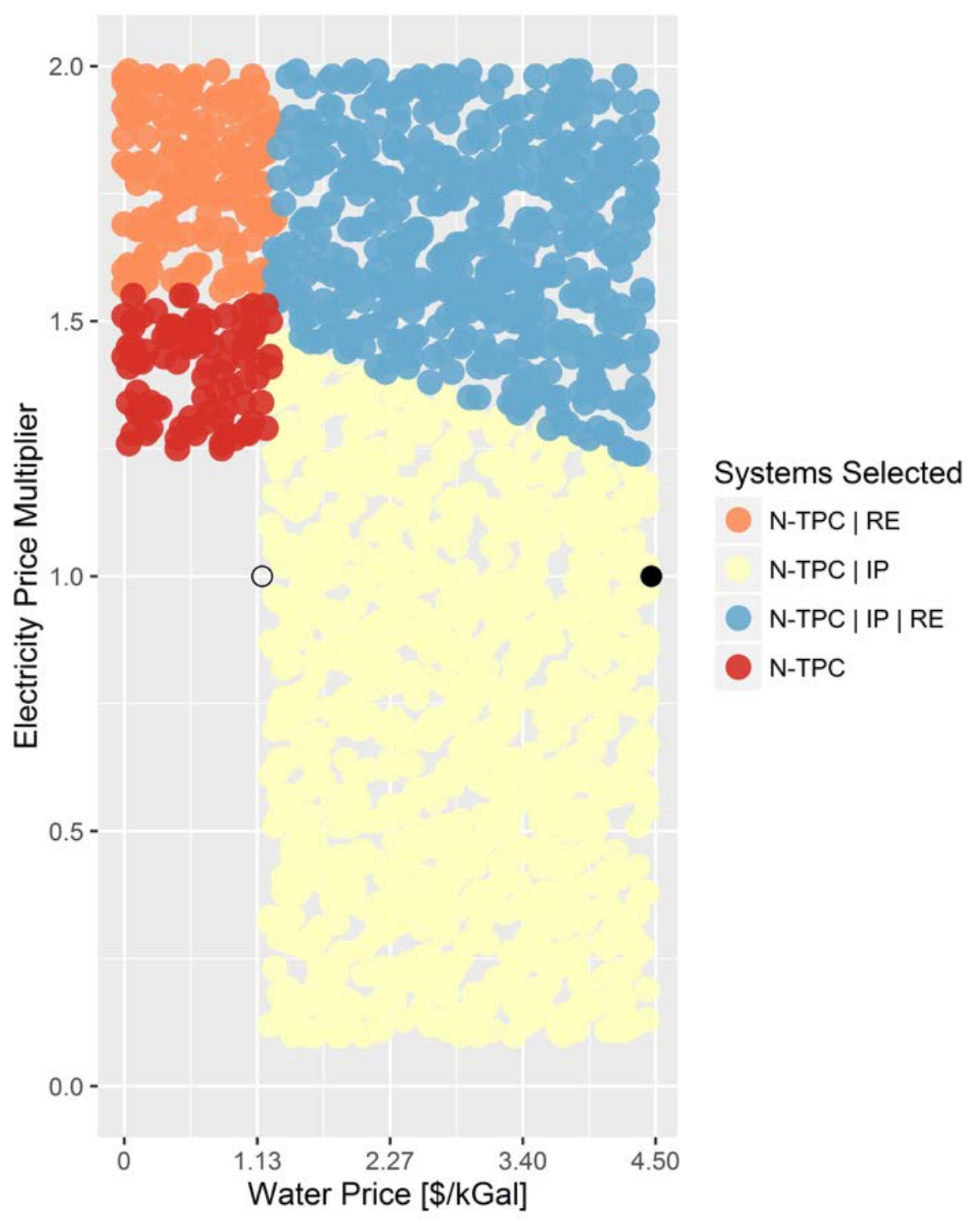

Figure H-58. Optimal configurations for Arizona-desalination scenario at various water prices and electricity price multipliers based on a $600 \mathrm{MWt}(180 \mathrm{MWe})$ maximum capacity of the nuclear reactor and thermal power cycle and $\$ 100 / \mathrm{kW}$-yr capacity payments.

N-TPC: Nuclear reactor and thermal

N-IP: Nuclear reactor and industrial process

$\mathrm{RE}$ : Renewable electricity generation

Solid black dot at electricity price multiplier of 1.0 and $\$ 4.50 /$ thousand gal water price: reference case water price projection; reference-case electricity price vector

Open black dot: minimum water selling price for an RO desalination plant; reference-case electricity price vector 


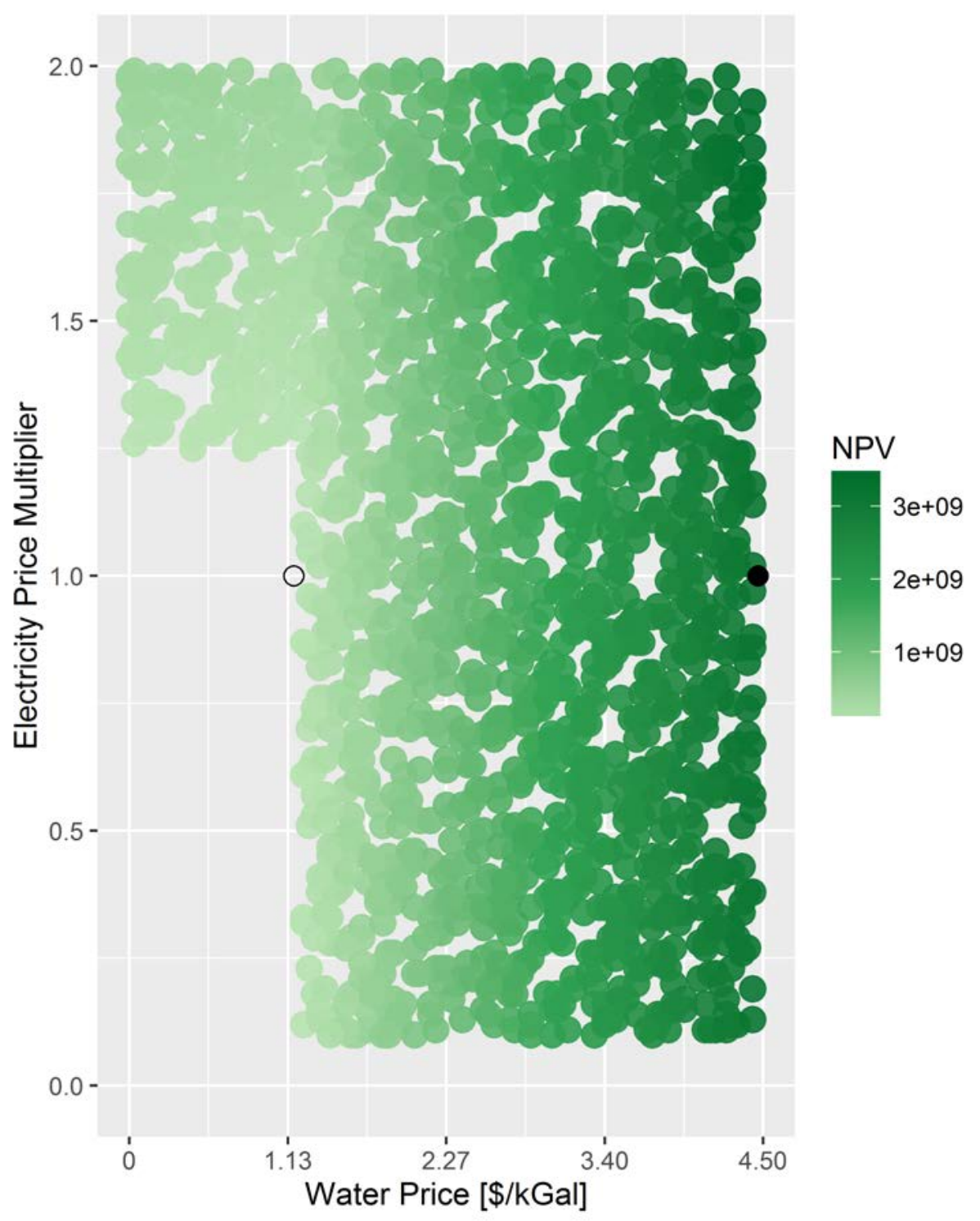

Figure H-59. Arizona-Desalination Scenario NPVs at various water prices and electricity price multipliers based on a $600 \mathrm{MWt}(180 \mathrm{MWe})$ maximum capacity of the nuclear reactor and thermal power cycle and $\$ 100 / \mathrm{kW}$-yr capacity payments.

Darker shades indicate higher NPVs.

Solid black dot at electricity price multiplier of 1.0 and $\$ 4.50 /$ thousand gal water price: reference case water price projection; reference-case electricity price vector

Open black dot: minimum water selling price for an $\mathrm{RO}$ desalination plant; reference-case electricity price vector 

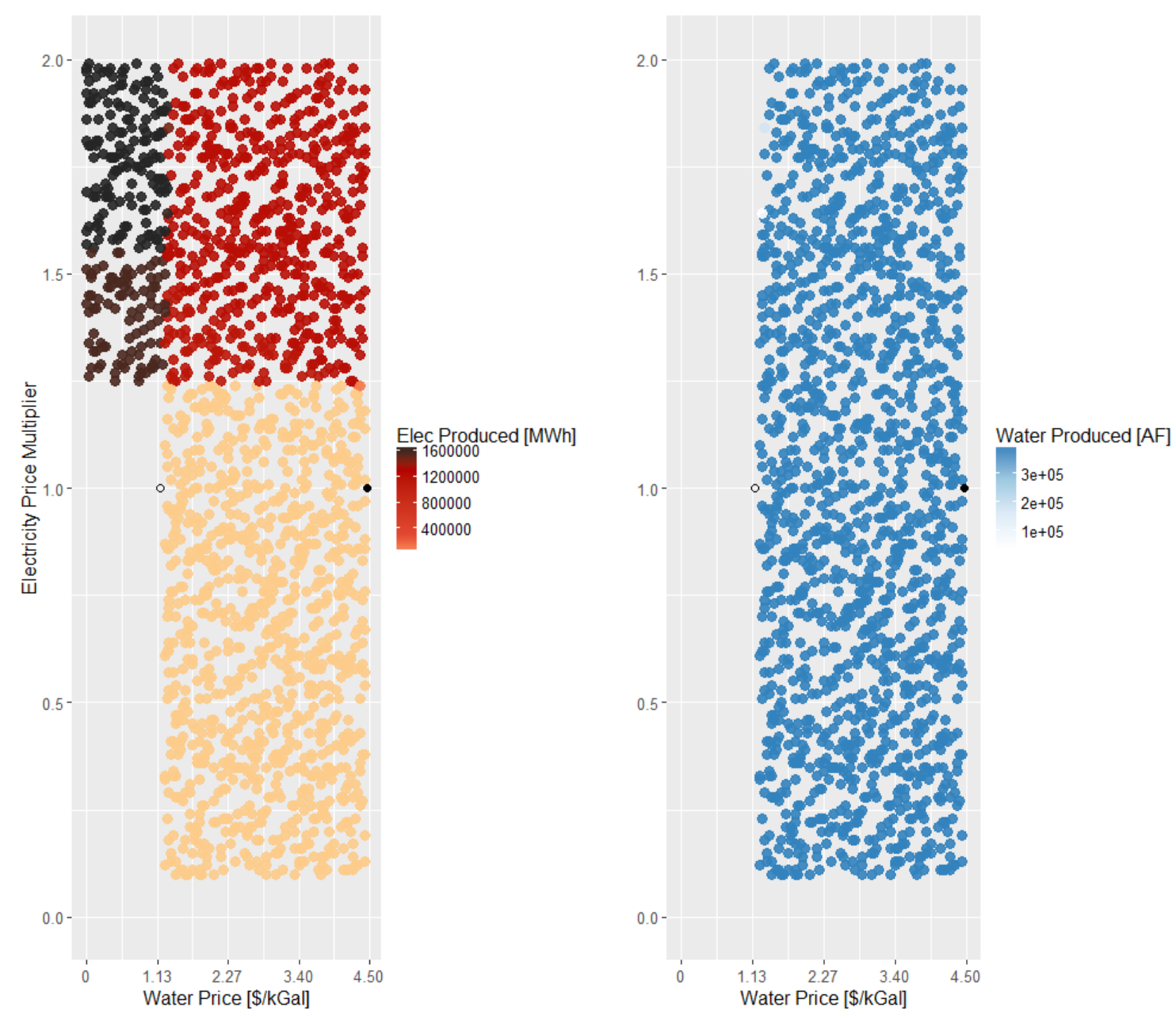

Figure H-60. Optimal annual product generation for Arizona-desalination scenario at various water prices and electricity price multipliers based on a $600 \mathrm{MWt}(180 \mathrm{MWe})$ maximum capacity of the nuclear reactor and thermal power cycle and $\$ 100 / \mathrm{kW}$-yr capacity payments.

Electricity is shown on the left with greater generation at the darker color. Water is shown on the right.

Solid black dot at electricity price multiplier of 1.0 and $\$ 4.50$ /thousand gal water price: reference case water price projection; reference-case electricity price vector

Open black dot: minimum water selling price for an RO desalination plant; reference-case electricity price vector 


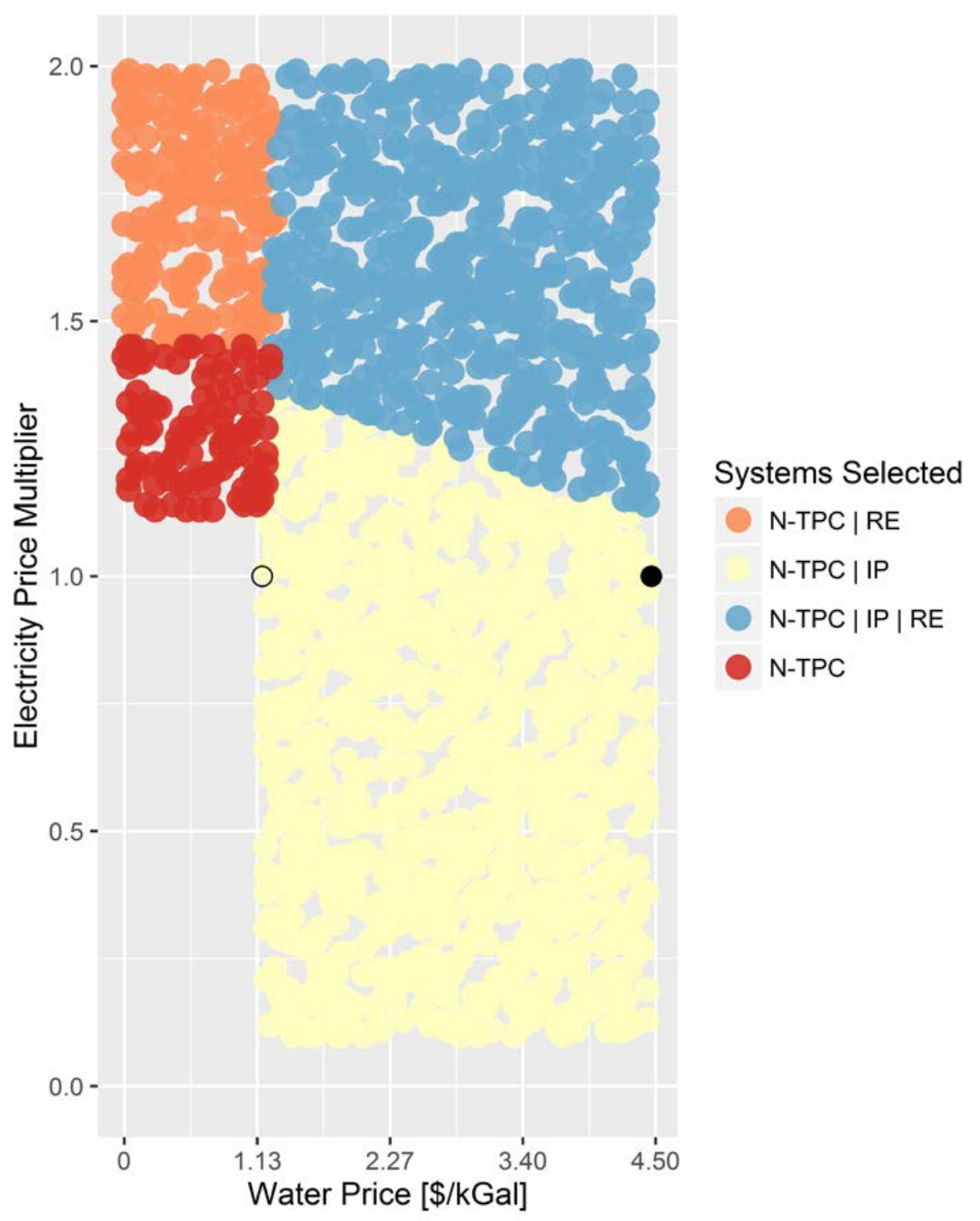

Figure H-61. Optimal configurations for Arizona-desalination scenario at various water prices and electricity price multipliers based on a $600 \mathrm{MWt}(180 \mathrm{MWe})$ maximum capacity of the nuclear reactor and thermal power cycle and $\$ 150 / \mathrm{kW}$-yr capacity payments

N-TPC: Nuclear reactor and thermal N-IP: Nuclear reactor and industrial process

RE: Renewable electricity generation

Solid black dot at electricity price multiplier of 1.0 and $\$ 4.50 /$ thousand gal water price: reference case water price projection; reference-case electricity price vector

Open black dot: minimum water selling price for an RO desalination plant; reference-case electricity price vector 


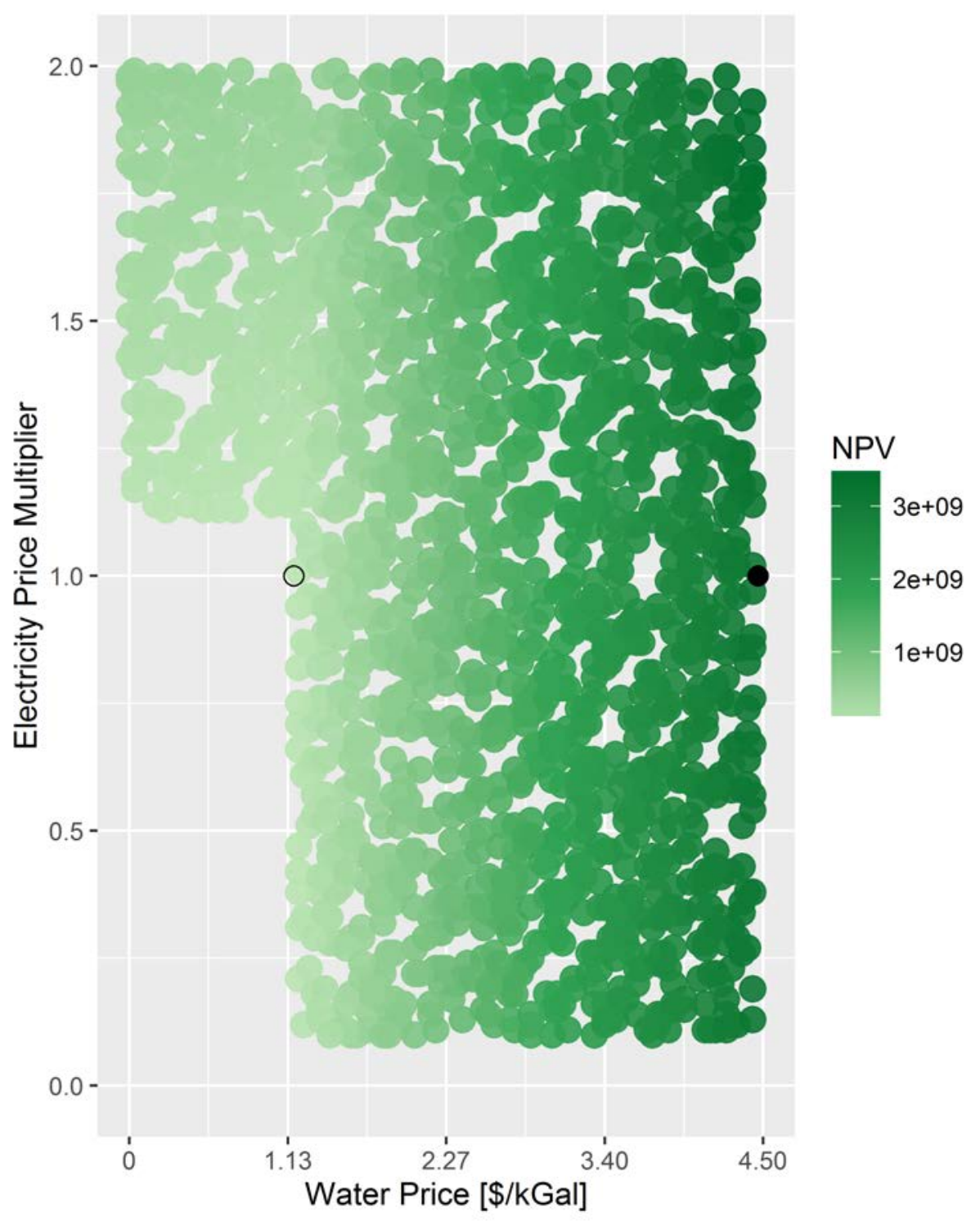

Figure H-62. Arizona-Desalination Scenario NPVs at various water prices and electricity price multipliers based on a $600 \mathrm{MWt}(180 \mathrm{MWe})$ maximum capacity of the nuclear reactor and thermal power cycle and $\$ 150 / \mathrm{kW}$-yr capacity payments.

Darker shades indicate higher NPVs.

Solid black dot at electricity price multiplier of 1.0 and $\$ 4.50 /$ thousand gal water price: reference case water price projection; reference-case electricity price vector

Open black dot: minimum water selling price for an $\mathrm{RO}$ desalination plant; reference-case electricity price vector 

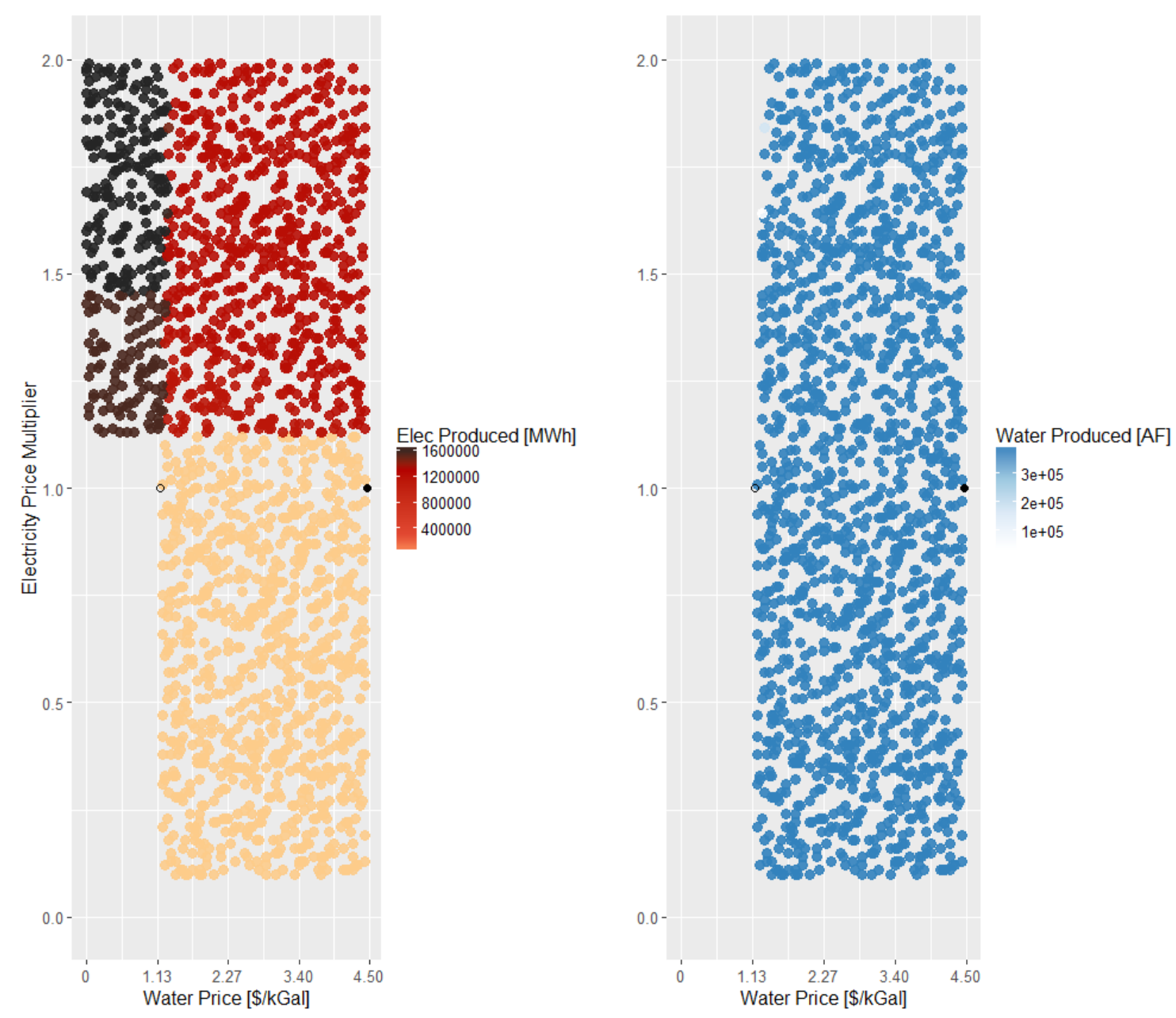

Figure H-63. Optimal annual product generation for Arizona-desalination scenario at various water prices and electricity price multipliers based on a $600 \mathrm{MWt}(180 \mathrm{MWe})$ maximum capacity of the nuclear reactor and thermal power cycle and $\$ 150 / \mathrm{kW}$-yr capacity payments.

Electricity is shown on the left with greater generation at the darker color. Water is shown on the right.

Solid black dot at electricity price multiplier of 1.0 and $\$ 4.50 /$ thousand gal water price: reference case water price projection; reference-case electricity price vector

Open black dot: minimum water selling price for an RO desalination plant; reference-case electricity price vector 


\section{Appendix I Additional Information Comparing NREL's Analysis to INL's Analysis \\ I.1 Comparison between NREL and INL Analysis}

This following section is a discussion of the differences between the Idaho National Laboratory (INL) models and the National Renewable Energy Laboratory (NREL) models.

\section{I.1.1 Synthetic Gasoline N-R HES \\ I.1.1.1 INL Modeling Assumptions and Results}

INL's analysis of the Texas-Synthetic Gasoline scenario consisted of an 180-MWe small modular reactor (SMR) providing industrial heat to a synthetic gasoline plant. The plant makes gasoline (95\%) and liquefied petroleum gas (5\%) from natural gas and methanol using heat from the SMR. The gas plant also has a natural gas-powered 150-MWt auxiliary heat generation unit that provides heat to the gasoline plant when heat from the SMR is diverted to make electricity for the grid. To represent renewable generation, the model uses a wind power plant capable of producing up to $45 \mathrm{MWe}$ coupled with a battery for electrical power smoothing. As with the Arizona model, the thermal power cycle was modeled as a separate subsystem that can be sized independently of the SMR. The SMR was sized to provide $180 \mathrm{MWe}$ to the grid while providing up to $150 \mathrm{MWt}$ to the gas plant. The auxiliary heat generation unit can provide up to $150 \mathrm{MWt}$ to the gas plant, allowing it to run at full capacity continuously. The gas plant was assumed to have an uptime of $95 \%$.

Figure I-1 illustrates the INL model for the Texas case study. 


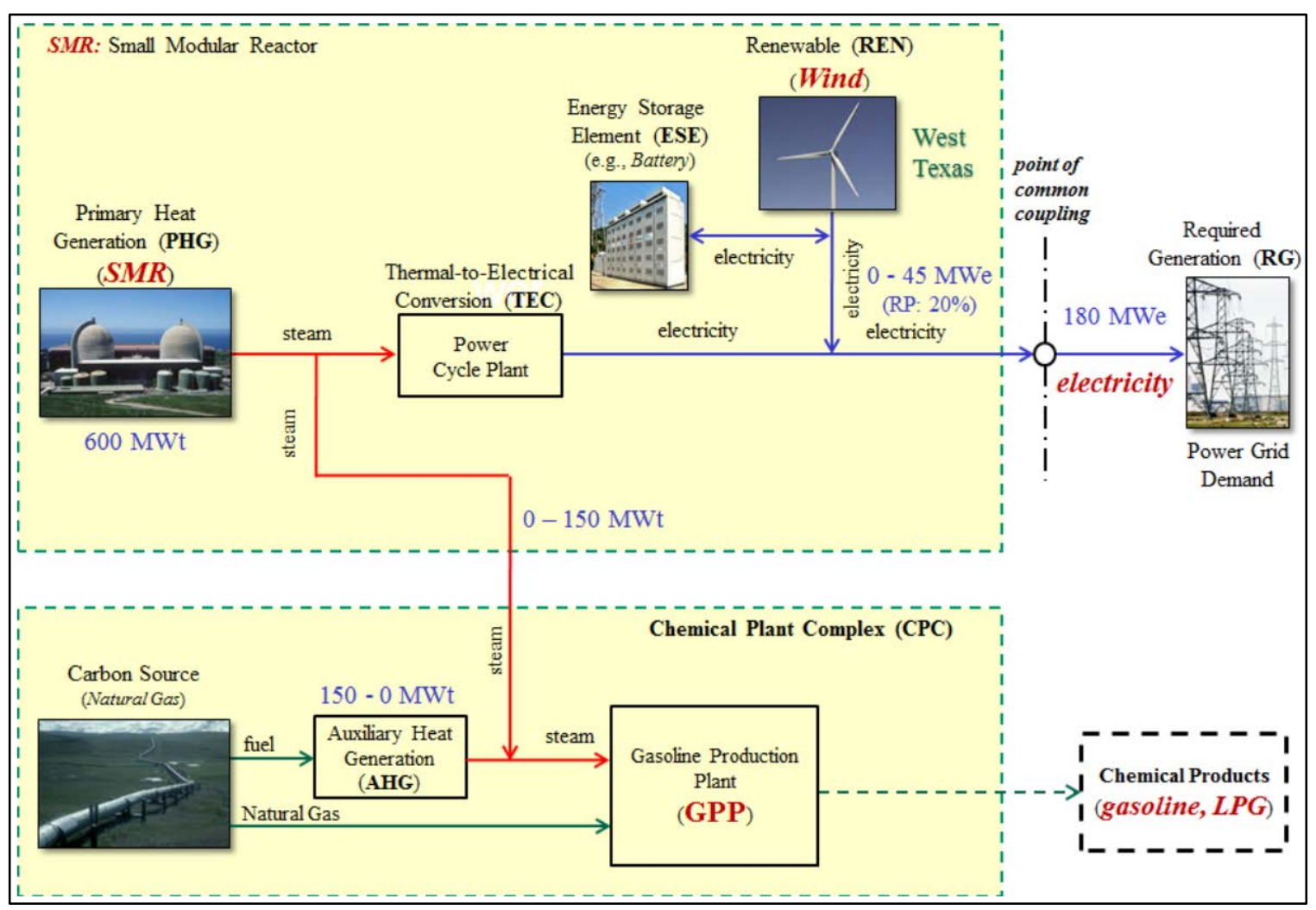

Figure I-1. INL model for the Texas case study

The main results of the INL analysis for the Texas case study were:

- The SMR mainly provides reserves electricity to the grid.

- The economics of the system are favorable when optimizing profit.

- The system has a capital payback of 11 years at a $5 \%$ discount rate.

- The system has an IRR of $11 \%$ for a 20 -year payback, including the penalty for $\mathrm{CO}_{2}$.

- The system pays back in approximately 8.27 and 8.45 years when optimized for net present value (NPV) and when not optimized, respectively. Figure H-2 illustrates the cumulative NPV as a function of time for the optimization of operations assuming that the commodity prices in future years are the same as those for the first year.

- The system economics demonstrate a high sensitivity to the price of gasoline and the cost of natural gas.

- The system is relatively insensitive to changes in electricity prices $( \pm 10 \%)$. 


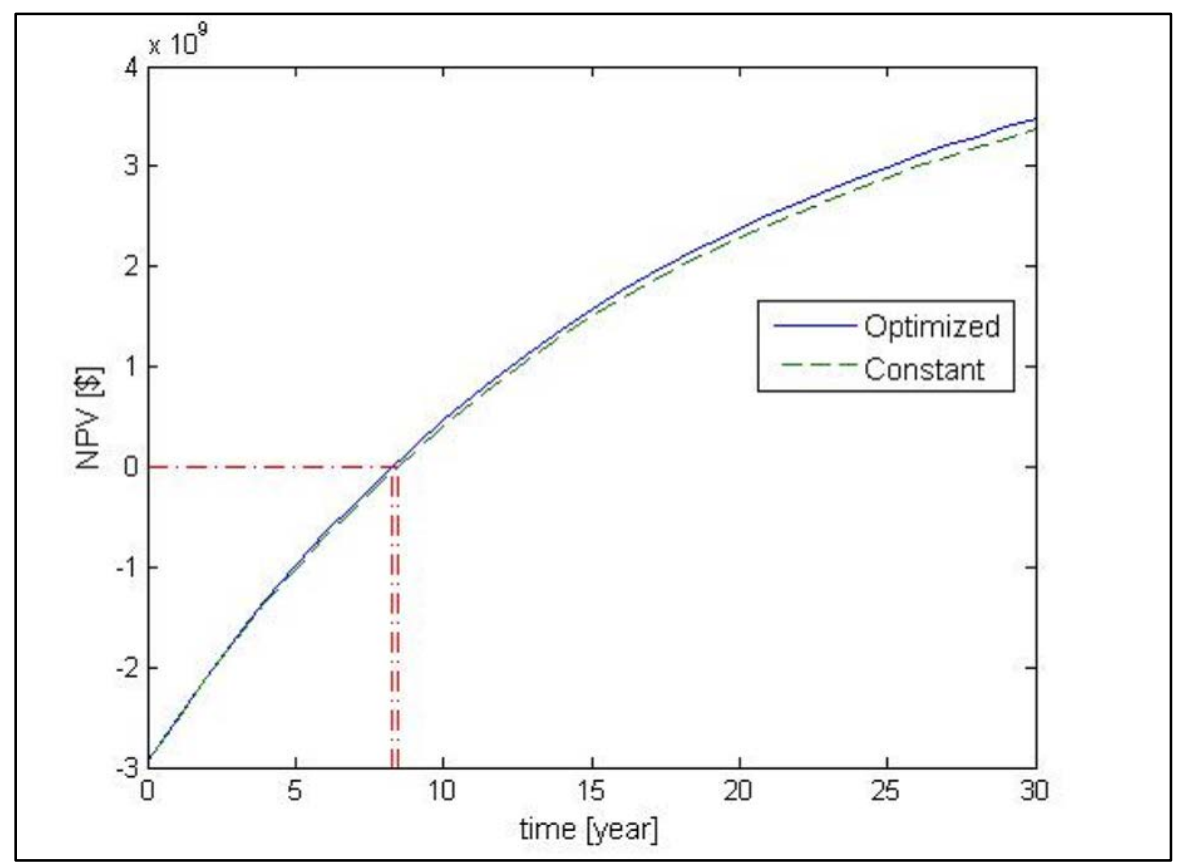

Figure I-2. INL Texas case NPV for optimized and constant electric production

\section{I.1.1.2 Comparison to NREL Modeling Results}

Figure H-3 illustrates the NREL model in REopt, including model parameters and operational boundaries. The parameters used in the INL model are listed in Table H-1.

The NREL model differs from the INL model in the following ways:

1. The NREL model does not include a battery for electrical power smoothing. The battery was removed to the study the inter-dynamics of the system on its own merits.

2. The capital costs of the thermal power cycle ${ }^{32}$ and generation equipment were separated from the capital cost of the SMR in the NREL model. This allowed the reactor and thermal power cycle subsystems to be sized independently from each other, allowing for the optimization of the heat flow for electric generation and the industrial process.

3. In the NREL model, the price projections for water, gasoline, and natural gas were based on data from the U.S. Energy Information Administration Annual Energy Outlook 2015. The INL price data were taken from currently existing commodity prices.

4. The NREL model based electricity prices on the generation mix, which was developed from two of NREL's standard scenarios. ${ }^{33}$ The INL model held the costs fixed and developed load-following requirements.

5. The NREL model did not include a natural gas boiler to enable the gasoline plant to run at a steady state. Instead, the gasoline plant output was allowed to fluctuate as heat from the SMR was diverted to generate more or less electricity.

\footnotetext{
${ }^{32}$ Table 6.6 in [1] served as a reference for thermal power cycle costs as a percentage of direct capital costs for an SMR estimated as $17.05 \%$ of the total direct costs.

${ }^{33}$ Add standard scenario reference
} 
6. The wind resource was taken from wind turbine power curves in the REopt model using a localized data source from AWS Truepower.

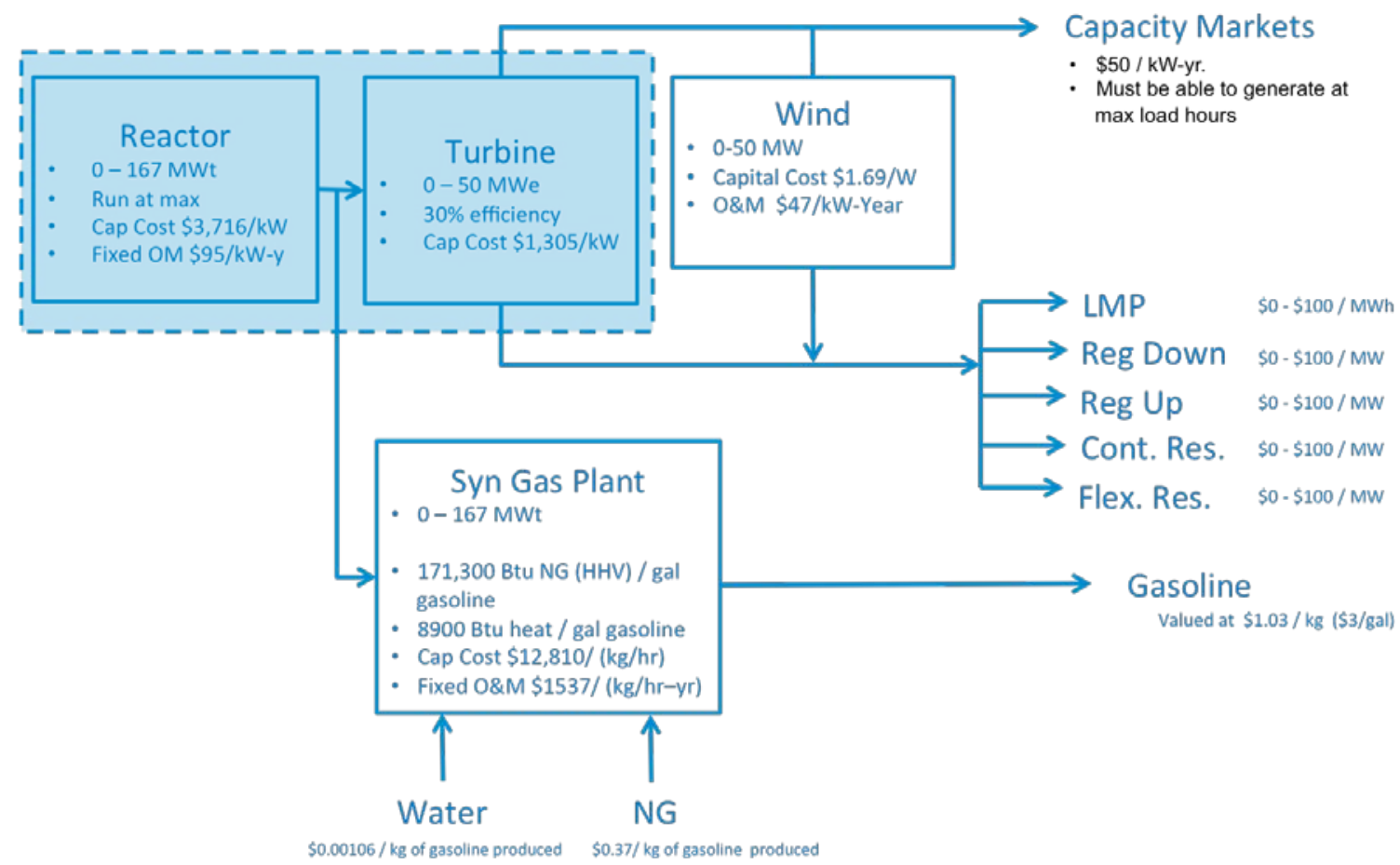

Figure I-3. NREL model for Texas-Synthetic Gasoline system including key model parameters 
Table I-1. INL Parameters for Texas Case Study

\begin{tabular}{|c|c|c|c|c|}
\hline Subsystem & Parameter & Description & Value & Unit \\
\hline \multirow{4}{*}{$\begin{array}{l}\text { Nuclear and } \\
\text { power cycle }\end{array}$} & a_phg & Capital cost per unit of installed capacity & 3,718 & $\$ / \mathrm{kW}$ \\
\hline & $\begin{array}{l}\text { B_phg_f } \\
\text { (annual) }\end{array}$ & Coefficient for fixed O\&M costs & 27.91 & $\$ / M W h$ \\
\hline & B_phg_v & Coefficient for variable O\&M costs & 0 & $\$ / \mathrm{MWh}$ \\
\hline & a_turbine & Capital cost for turbine and generators & 1,000 & $\$ / k W$ \\
\hline \multirow{4}{*}{$\begin{array}{l}\text { Auxiliary heat } \\
\text { generation }\end{array}$} & a_ahg & Capital cost per unit of installed capacity & $1,057.44$ & $\$ / \mathrm{kW}$ \\
\hline & $\begin{array}{l}\text { B_ahg_f } \\
\text { (annual) }\end{array}$ & Coefficient for fixed O\&M costs & 3 & $\%$ \\
\hline & $\beta$ Bahg_v & Coefficient for variable O\&M costs & $\begin{array}{l}\text { NG price } \\
\text { time series }\end{array}$ & $\$ / \mathrm{kg}$ \\
\hline & $\beta \_c$ & & 0.045 & $\$ / \mathrm{kg}$ \\
\hline \multirow{3}{*}{ Wind turbines } & a_ren & Capital cost per unit of installed capacity & $2,339.61$ & $\$ / \mathrm{kW}$ \\
\hline & $\begin{array}{l}\text { B_ren_f } \\
\text { (annual) }\end{array}$ & Coefficient for fixed O\&M costs & 36.91 & $\$ / \mathrm{kW}$ \\
\hline & B_ren_v & ${ }^{*}$ Only fixed O\&M costs are considered & 0 & \\
\hline \multirow{3}{*}{ Battery } & a_ese & Capital cost per unit of installed capacity & 81.42 & $\$ / \mathrm{kWh}$ \\
\hline & $\begin{array}{l}\beta \_ \text {ese_f } \\
\text { (annual) }\end{array}$ & Coefficient for fixed O\&M costs & 3 & $\%$ \\
\hline & $\beta$ _ese_v & ${ }^{*}$ Only fixed O\&M costs are considered & $\mathrm{n} / \mathrm{a}$ & $\$ / \mathrm{kWh}$ \\
\hline \multirow{5}{*}{$\begin{array}{l}\text { Gasoline glant } \\
\text { production }\end{array}$} & a_cp & Capital cost per unit of installed capacity & $42,661,291$ & $\$ \mathrm{~s} / \mathrm{kg}$ \\
\hline & $\begin{array}{l}\beta \_c p \_f \\
\text { (annual) }\end{array}$ & Coefficient for fixed O\&M costs & 12 & $\%$ \\
\hline & $\beta \_c p \_v \_n g$ & $\begin{array}{l}\text { Coefficient for variable O\&M costs } \\
\text { related to } N G^{b} \text { consumption = NG price }\end{array}$ & $\begin{array}{l}\text { NG price } \\
\text { time series }\end{array}$ & $\$ / \mathrm{kg}$ \\
\hline & $\beta \_c p \_v \_w$ & $\begin{array}{l}\text { Coefficient for variable O\&M costs } \\
\text { related to water consumption = water } \\
\text { price }\end{array}$ & $1.06 \mathrm{E}-03$ & $\$ / \mathrm{kg}$ \\
\hline & $\beta \_c p \_v \_g$ & & $\begin{array}{l}\text { Gasoline } \\
\text { price time } \\
\text { series }\end{array}$ & $\$ / \mathrm{kg}$ \\
\hline Inflation rate & $\mathrm{i}$ & & 3 & $\%$ \\
\hline $\begin{array}{l}\text { Discount rate } \\
\text { (WACC) }\end{array}$ & $r_{-} R$ & & 5 & $\%$ \\
\hline $\begin{array}{l}\text { Depreciation } \\
\text { rate }\end{array}$ & $\rho \_d a, k$ & & & $\%$ \\
\hline Tax & $\operatorname{tax}$ & & 35 & $\%$ \\
\hline
\end{tabular}

${ }^{a}$ Operations and maintenance

${ }^{\mathrm{b}}$ Natural gas 


\section{I.1.2 Desalination N-R HES}

\subsubsection{INL Modeling Assumptions and Results}

INL's analysis of the Arizona-Desalination scenario consisted of SMR and a 30-MWe solar photovoltaic (PV) array providing electricity to the grid as well as a reverse osmosis (RO) water plant. The RO plant was capable of using between $15 \mathrm{MWe}$ and $35 \mathrm{MWe}$ of electricity, producing between $6,500 \mathrm{~kg} / \mathrm{s}$ and $15,800 \mathrm{~kg} / \mathrm{s}(102,000 \mathrm{gal} / \mathrm{min}$ and $251,000 \mathrm{gal} / \mathrm{min})$ of freshwater from a brackish water aquifer. The SMR was originally designed to provide a constant $165 \mathrm{MWe}$ to the grid as well as provide the minimum electrical power to the RO plant to make water. A battery bank was included in the original INL model to provide electrical power smoothing for the solar PV system.

Figure I-4 illustrates the INL model for the Arizona case study.

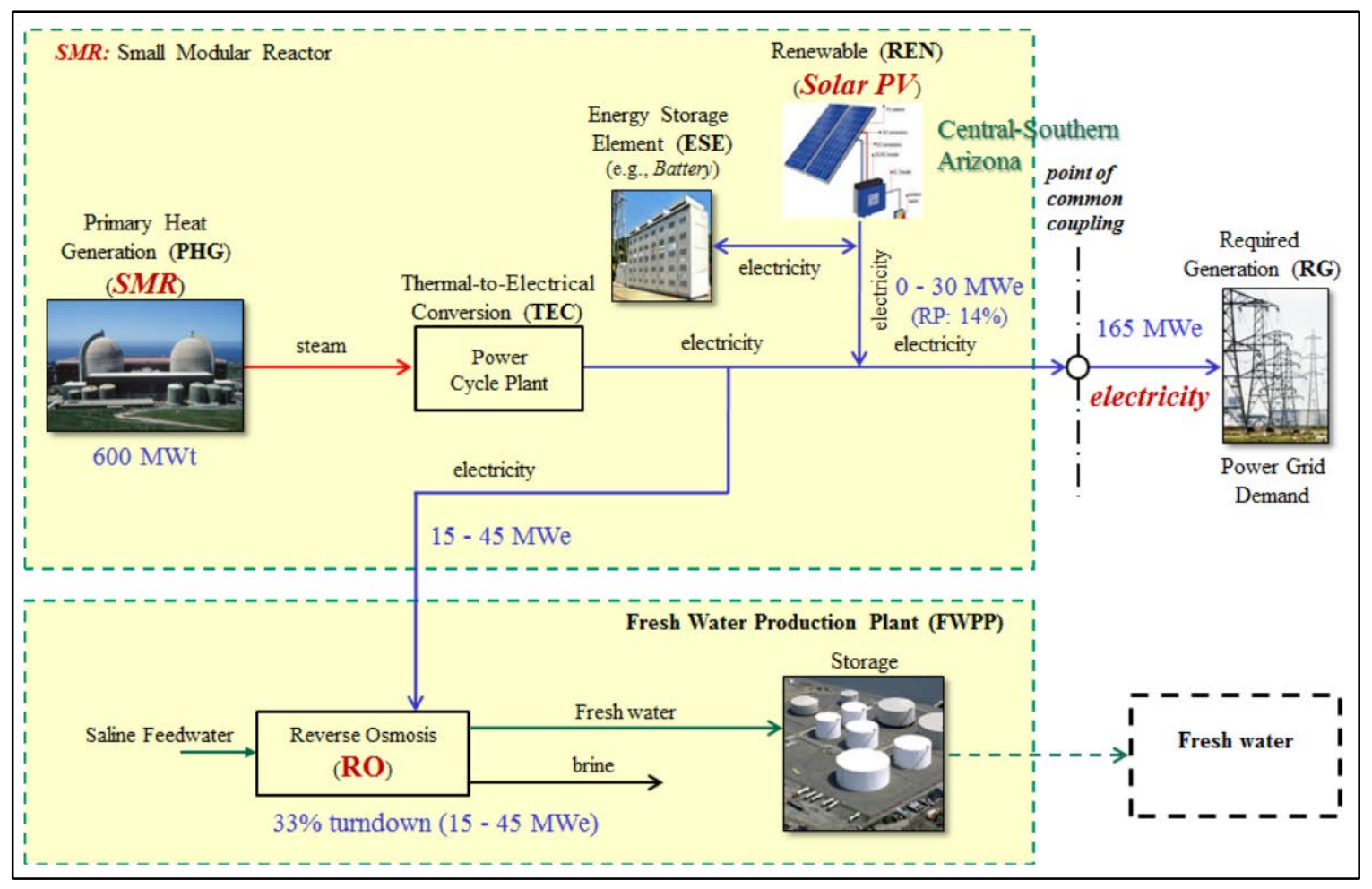

Figure I-4. Layout of INL model for Arizona

The main results of the INL analysis for the Texas case study were:

- As with the Texas case, the SMR mainly provides reserves electricity to the grid.

- The economics of the system are favorable when optimizing profit.

○ The system has a capital payback of 15 years at a $5 \%$ discount rate.

- The system has an IRR of $7 \%$ for a 20 -year payback including the penalty for $\mathrm{CO}_{2}$. 
- Figure I-5 illustrates the cumulative NPV as a function of time for the optimization of operations assuming that the commodity prices in future years are the same as those for the first year.

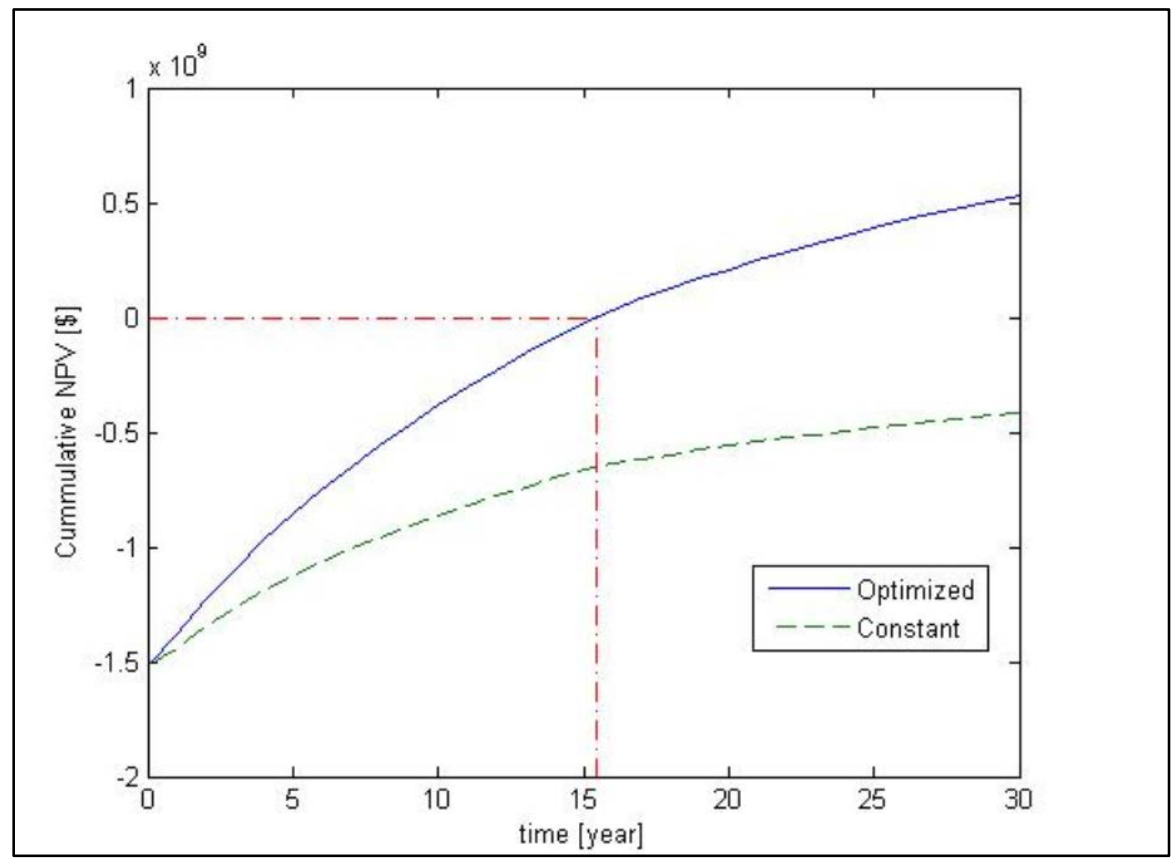

Figure I-5. INL Arizona NPV for optimized and continuous electricity production

\subsubsection{Comparison to NREL Modeling Results}

The NREL model primarily used the same parameter values as the INL model with a few exceptions.

1. The NREL model used solar PV generation information from NREL's PVWatts tool. PVWatts produces hourly generation data for a full year using localized typical meteorological year (TMY) weather data sets. A TMY is an accepted standard in the industry for estimating energy generation from solar PV systems.

2. As with the Texas model, no battery was included in the Arizona model so that the interdynamics of the system could be studied on their own merits.

3. The capital costs of the steam turbine and generation equipment were separated from the capital cost of the SMR in the NREL model. This allowed the reactor and turbine/generator systems to be sized independently from each other, which allowed for the optimization of the heat flow for electric generation and the industrial process and/or prioritizing either the industrial process or electrical grid, depending on their respective financials.

Figure I-6 illustrates the NREL Model for the Arizona case study, including the model parameters and bounds. The INL model parameters are listed in Table I-2. 


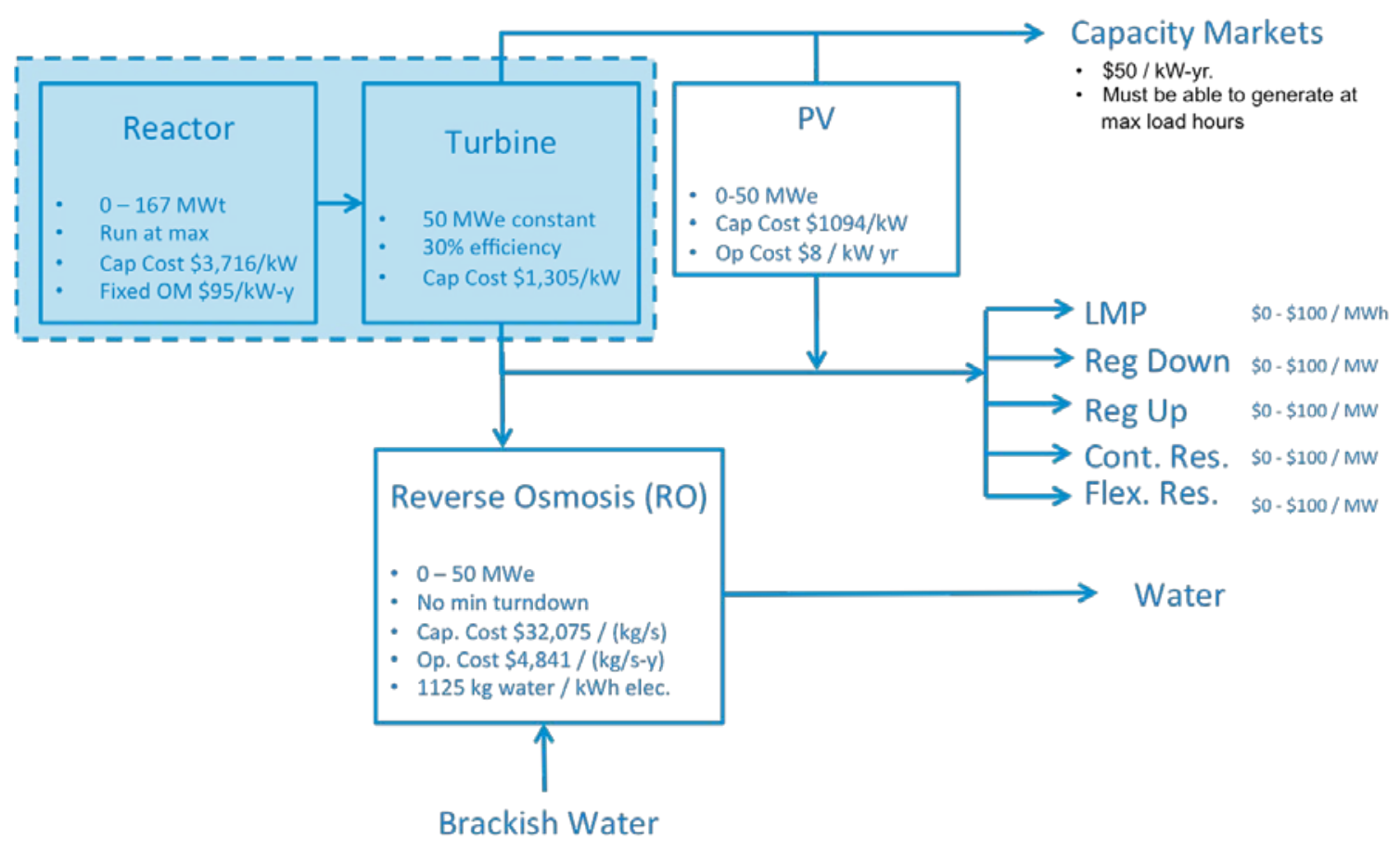

Figure I-6. NREL model for Arizona-Desalination system 
Table I-2. Parameters for the Arizona Model

\begin{tabular}{|c|c|c|c|c|}
\hline Subsystem & Parameter & Description & Value & Unit \\
\hline \multirow{3}{*}{$\begin{array}{l}\text { Nuclear and power } \\
\text { cycle }\end{array}$} & a_phg & $\begin{array}{l}\text { Capital cost per unit of installed } \\
\text { capacity }\end{array}$ & 3,718 & $\$ / \mathrm{kW}$ \\
\hline & $\begin{array}{l}\text { B_phg_f } \\
\text { (annual) }\end{array}$ & Coefficient for fixed O\&M costs & 27.91 & $\$ / M W h$ \\
\hline & $\beta$ Bphg_v & Coefficient for variable O\&M costs & - & $\$ / M W h$ \\
\hline \multirow{3}{*}{ PV station } & a_ren & $\begin{array}{l}\text { Capital cost per unit of installed } \\
\text { capacity }\end{array}$ & $5,386.98$ & $\$ / \mathrm{kW}$ \\
\hline & $\begin{array}{l}\text { B_ren_f } \\
\text { (annual) }\end{array}$ & Coefficient for fixed O\&M costs & 54.28 & $\$ / \mathrm{kW}$ \\
\hline & B_ren_v & Coefficient for variable O\&M costs & - & \\
\hline \multirow{3}{*}{ Battery } & a_ese & $\begin{array}{l}\text { Capital cost per unit of installed } \\
\text { capacity }\end{array}$ & 81.42 & $\$ / \mathrm{kWh}$ \\
\hline & $\begin{array}{l}\text { B_ese_f } \\
\text { (annual) }\end{array}$ & Coefficient for fixed O\&M costs & 3.00 & $\%$ \\
\hline & $\beta$ Bese_v & Coefficient for variable O\&M costs & $\mathrm{n} / \mathrm{a}$ & $\$ / k W h$ \\
\hline \multirow{3}{*}{$\begin{array}{l}\text { RO desalination } \\
\text { plant }\end{array}$} & a_ro & $\begin{array}{l}\text { Capital cost per unit of installed } \\
\text { capacity }\end{array}$ & $\begin{array}{l}32,076.2 \\
1\end{array}$ & $\$ \mathrm{~s} / \mathrm{kg}$ \\
\hline & $\begin{array}{l}\text { B_ro_f } \\
\text { (annual) }\end{array}$ & Coefficient for fixed O\&M costs & $4,841.43$ & $\$ \mathrm{~s} / \mathrm{kg}$ \\
\hline & B_ro_v & Coefficient for variable O\&M costs & 0.00 & $\$ / \mathrm{kg}$ \\
\hline Inflation rate & 1 & & 3.00 & $\%$ \\
\hline $\begin{array}{l}\text { Discount rate } \\
\text { (WACC) }\end{array}$ & $r_{-} R$ & & 5.00 & $\%$ \\
\hline Depreciation rate & $\rho \_d a, k$ & & & $\%$ \\
\hline Tax & $\operatorname{tax}$ & & 40.00 & $\%$ \\
\hline
\end{tabular}

${ }^{\mathrm{a}}$ Operations and maintenance 